\title{
WestVirginiaUniversity
}

THE RESEARCH REPOSITORY @ WVU

Graduate Theses, Dissertations, and Problem Reports

2019

\section{Structural Behavior of Steel Plate Embedded Hybrid GFRP Shapes}

Piyush R. Soti

prsoti@mix.wvu.edu

Follow this and additional works at: https://researchrepository.wvu.edu/etd

Part of the Structural Engineering Commons, and the Structural Materials Commons

\section{Recommended Citation}

Soti, Piyush R., "Structural Behavior of Steel Plate Embedded Hybrid GFRP Shapes" (2019). Graduate Theses, Dissertations, and Problem Reports. 3763.

https://researchrepository.wvu.edu/etd/3763

This Dissertation is protected by copyright and/or related rights. It has been brought to you by the The Research Repository @ WVU with permission from the rights-holder(s). You are free to use this Dissertation in any way that is permitted by the copyright and related rights legislation that applies to your use. For other uses you must obtain permission from the rights-holder(s) directly, unless additional rights are indicated by a Creative Commons license in the record and/ or on the work itself. This Dissertation has been accepted for inclusion in WVU Graduate Theses, Dissertations, and Problem Reports collection by an authorized administrator of The Research Repository @ WVU.

For more information, please contact researchrepository@mail.wvu.edu. 


\title{
STRUCTURAL BEHAVIOR OF STEEL PLATE EMBEDDED HYBRID GFRP SHAPES
}

\author{
Piyush R. Soti
}

Dissertation submitted to the Benjamin M. Statler College of Engineering and Mineral Resources at West Virginia University in partial fulfillment of the requirements

for the degree of

\author{
Doctor of Philosophy \\ in \\ Civil Engineering
}

\author{
P.V. Vijay, Ph.D., P.E., Chair \\ Ever J. Barbero, Ph.D. \\ Udaya B. Halabe, Ph.D., P.E. \\ Hema J. Siriwardane, Ph.D., P.E. \\ Radhey Sharma, Ph.D.
}

Department of Civil and Environmental Engineering

\section{Morgantown, West Virginia \\ 2019}

Keywords: Fiber reinforced polymer, FRP, Glass-FRP, GFRP, GFRP-steel hybrid, finite element modeling, FEM, flexure, shear, fatigue 


\section{Abstract \\ Structural Behavior of Steel Plate Embedded Hybrid GFRP Shapes}

\section{Piyush Soti}

The civil infrastructure industry has been dominated by traditional materials such as steel, timber, and concrete. Although these materials offer great advantages, they have major durability issues in terms of corrosion, decaying, and cracking. Traditional material-based structures deteriorate frequently and require regular-interval repairs with huge expenditures. To resolve these maintenance and durability issues associated with traditional materials, fiber reinforced polymer (FRP) composites have gained some popularity in the past few decades because of their superior mechanical properties and durability. Carbon-FRPs (CFRPs) and glass-FRP (GFRPs) are the most commonly used FRPs in the market. However, in civil engineering applications, CFRPs are less preferred due to their very higher initial costs compared to that of GFRPs, and thus, GFRPs which are relatively cheaper are preferred in civil engineering applications. GFRPs are used extensively in the repair and rehabilitation of older structures; however, in new construction of civil structures, they have not gained momentum since decades due to their major drawbacks in terms of lower stiffness, lower shear capacity, brittle failure, lack of ductility, and connection issues, apart from their higher initial cost compared to traditional construction materials. This research focuses on hybridizing GFRP beams and bridge-deck panels through embedment of steel plates to improve their overall structural properties for their use in new constructions.

As a preliminary study, a $46^{\prime \prime} \times 8.5^{\prime \prime}$ multi-cellular GFRP section was manufactured with two embedded 3" $x 0.375$ " steel plates using a vacuum assisted resin infusion process. The GFRP-steel hybrid panel was tested in a 4-point and 3-point bending setup; the results showed an increase in bending rigidity (EI) of the hybrid section by $66 \%$, resulting in an improvement in serviceability limit with $38 \%$ reduction in deflection. Further, the hybrid section did not show any signs of stiffness or strain energy degradation under fatigue load for 50k cycles. The overall structural performance of the hybrid section was improved with an embedment of two steel plates inside the GFRP composite section.

After successful initial results, the research further focused on steel plates embedded GFRP 6" $\times 6$ " $\times 0.5^{\prime \prime}$ box-beams. The control GFRP and hybrid GFRP-steel box-beam sections were investigated in terms of their bending, shear, and fatigue performance, flexural and shear stiffnesses, bolted connection strengths, failure modes, GFRP-steel interfacial bond behavior, and cost comparison. The $8 \mathrm{ft}$. long box-beams were tested in a 3-point bending setup at different L/D ratios to characterize the beam's bending and shear stiffness. The experimental results showed a gain of $270 \%$ in flexural stiffness of hybrid GFRP-steel sections. Under fatigue, the hybrid beams did not show any signs of stiffness or strain energy degradation even after three million load cycles. The hybridized sections showed bilinear stress-strain behavior with adequate reserve strength within code specified serviceability limits. The bolt-connected GFRP-steel hybrid members showed increased joint strength and stiffness and ductile failure modes due to yielding of steel plates. The research also discusses the modeling of hybrid box-beams in the finite element modeling (FEM) software to characterize the structural behavior and response of hybrid GFRPsteel sections. The finite element analysis results were found to be clearly matching with the experimental and theoretical results. The GFRP-steel specimens cut from the fatigue-tested hybrid beams were observed through scanning electron microscopy (SEM) to study the GFRP- 
steel interface and its bond integrity. The GFRP-steel interface regions were examined in terms of degree of resin cure through digital scanning calorimetry (DSC) tests. The cost comparison between GFRP and hybrid sections showed that the initial cost/stiffness of the hybrid section was only about $23 \%$ of the initial cost of the equivalent non-hybrid GFRP section.

This research has contributed towards the development of cost-effective hybrid GFRP-steel members that can satisfy higher serviceability limits. The outcome of this work will be beneficial to engineers and designers in using hybrid GFRP-steel composite sections as primary structural members in new construction of buildings, highway bridges, pipelines, navigational gates and other pertinent structures. 


\section{Acknowledgements}

I would like to thank my research advisor and my mentor Dr. P.V. Vijay for giving me an opportunity to study and work as a graduate research assistant under his guidance. He has been a very influential person in my academic career and towards my personal growth. His support, guidance, technical contributions, and valuable insights were extremely useful for me to finish my Ph.D. degree. I would always remember him for nurturing me to become a better structural engineer and a better human being.

I am also extremely thankful to Dr. Udaya B. Halabe for providing me an opportunity to start my graduate study at WVU in 2012. He has constantly helped me through his valuable suggestions and feedback during my study at WVU. I also thank him for giving me an opportunity to serve in the executive committee of the Structural Engineering Institute Graduate Student Chapter (SEIGSC) at WVU.

I would also like to appreciate and thank Dr. Hema J. Siriwardane for supporting me with Civil Engineering departmental fellowship and for providing guidance and taking time to serve in my Ph.D. committee. Further, I would also like to thank Dr. Radhey Sharma for supporting me with departmental scholarship and giving his time to serve in my Ph.D. committee and for his guidance and inspirational suggestions throughout my academic journey.

I also want to sincerely thank and show my genuine respect to Dr. Ever J. Barbero for providing his insightful knowledge in fiber composites and finite element modeling. The courses he offered were very helpful to me in learning the skills necessary for completing my Ph.D. research. I also thank him for supporting me in providing recommendations for the SAMPE and CAMX awards.

In addition, I would like to express my sincere appreciation to Mark Skidmore for always being available to help me at times during testing and instrumentation. I would also like to thank Jerry Nestor for helping me in the laboratory during my experimental testing. I am also extremely thankful to my colleagues Praveen Majjigapu, Dr. Jonas Kavi, Amir Houshmandyar for always being there to go for a coffee break or to Buffalo wild wings.

Finally, I thank my parents, my brother, and my sisters for believing in me and inspiring me to pursue this doctorate degree. I would also like to thank all of my friends in Morgantown, the "Dedicated" group members, and the Nepalese community for making me feel at home. Lastly, I would like to thank my wife Irina Badu more than anyone else in this world for loving and supporting me throughout this extensive journey. Without her, I could have never accomplished this degree. I owe this degree to her. 


\section{Table of Contents}

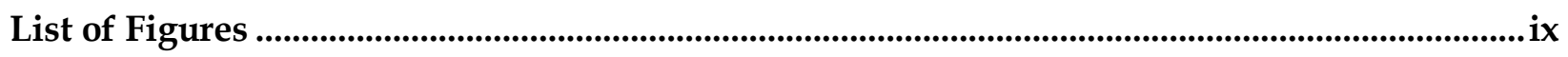

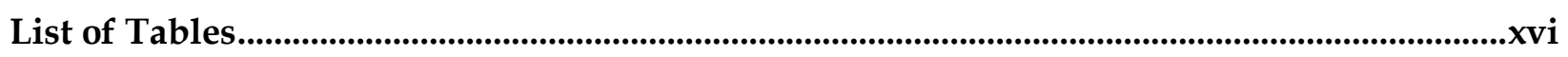

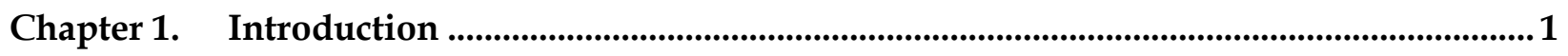

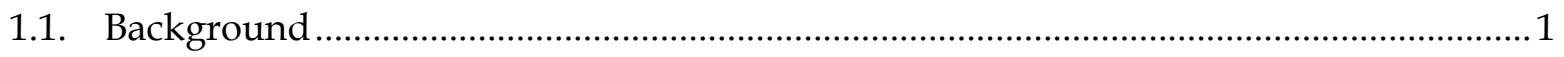

1.2. FRP composites in civil infrastructure and their importance ....................................... 1

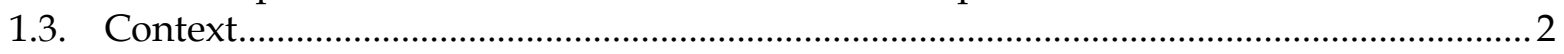

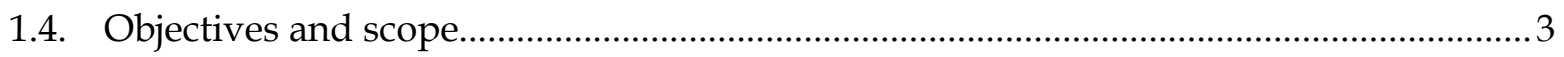

1.5. Organization of the dissertation ...........................................................................

1.6. Research impact and significance ........................................................................... 5

Chapter 2. FRP Composites in Construction ........................................................................................6 6

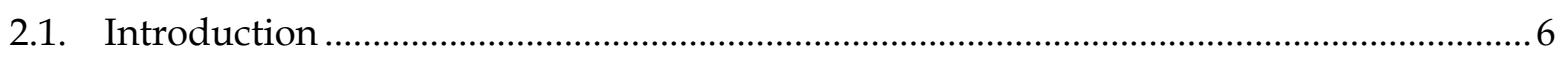

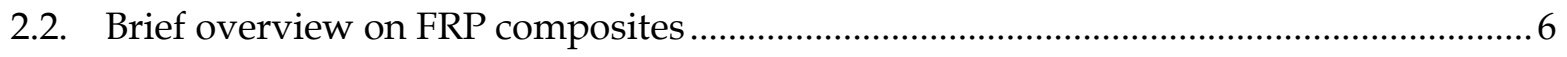

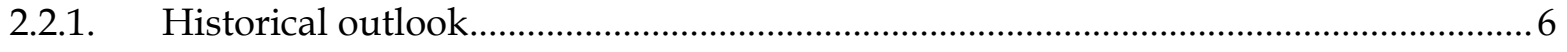

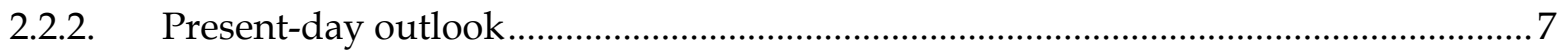

2.2.3. Manufacturing of FRP composites …................................................................. 7

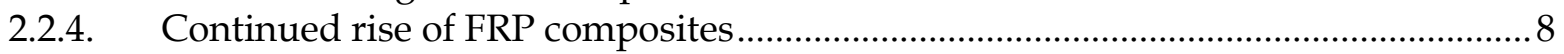

2.3. FRP composites in the construction industry ........................................................... 9

2.3.1. Strengthening and repair of deteriorated structures .............................................. 9

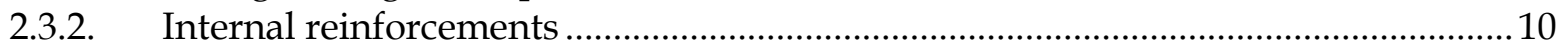

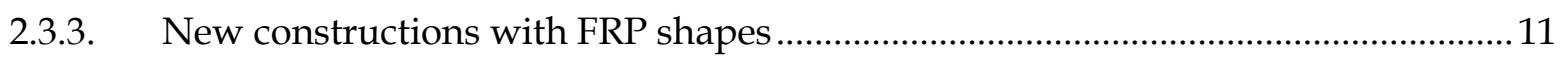

2.4. Limitations of GFRP composites in new constructions ..............................................13

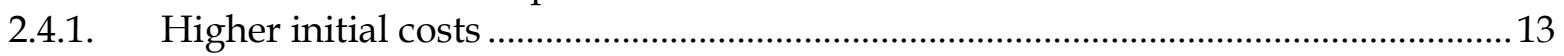

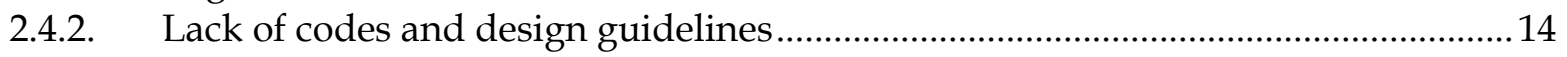

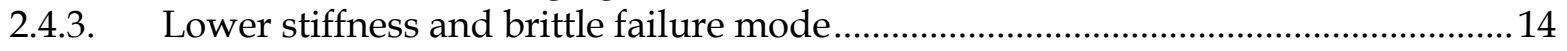

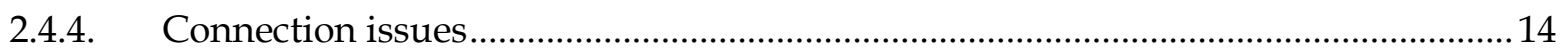

2.4.5. Poor performance under elevated temperatures and fire ....................................... 15

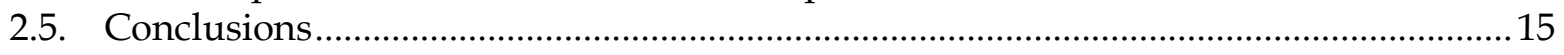

Chapter 3. Hybridization of GFRP Composites.......................................................................16

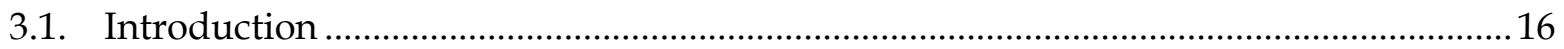

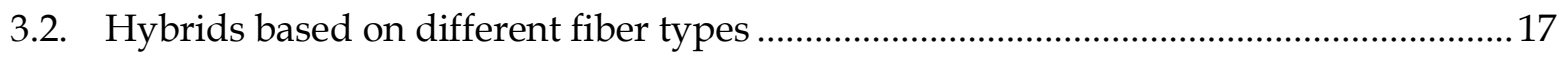

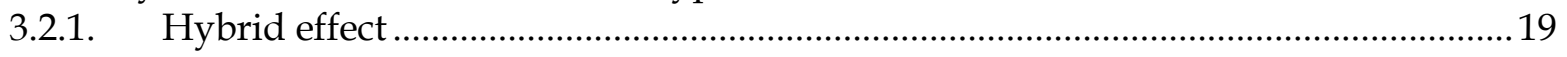

3.2.2. Pseudo-ductility in glass/carbon hybrids .......................................................... 20

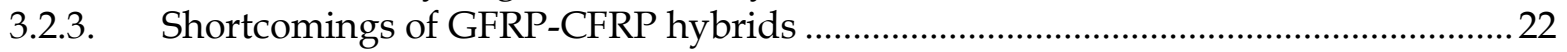

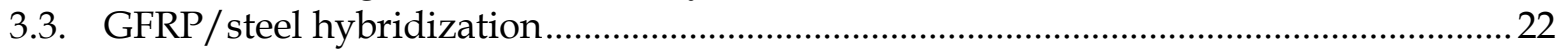

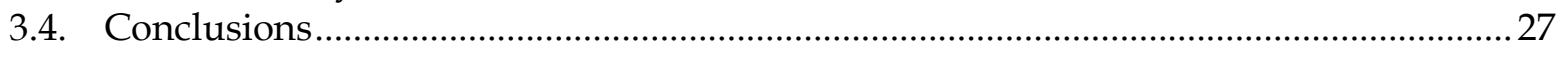

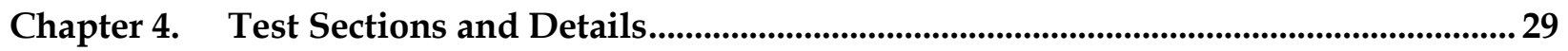

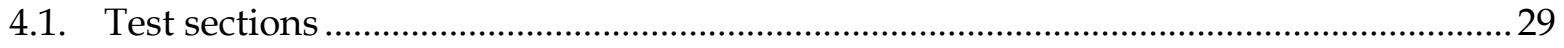

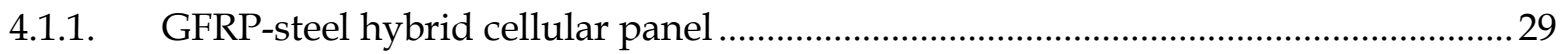

4.1.2. GFRP-steel hybrid box-beam sections................................................................. 30

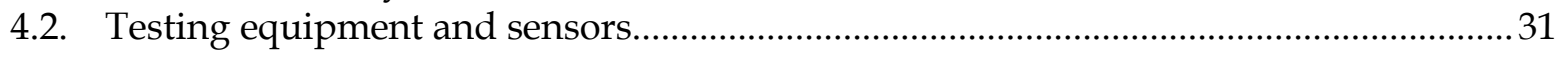

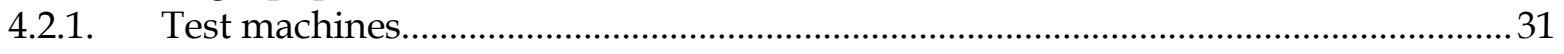

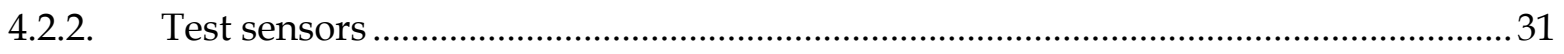




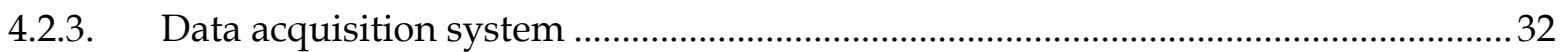

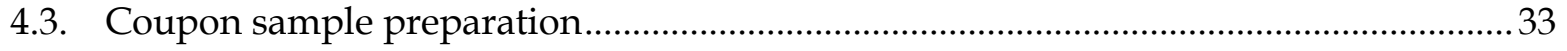

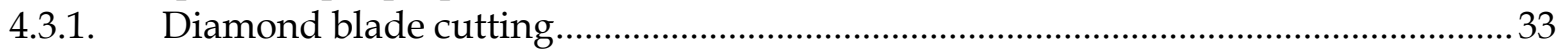

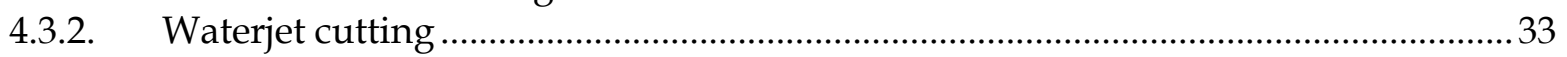

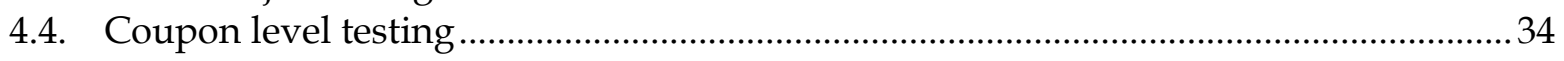

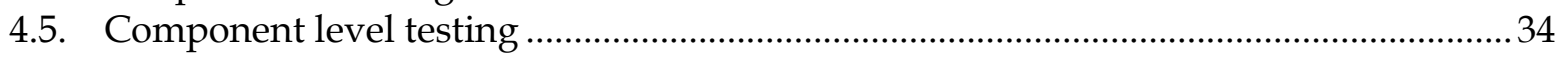

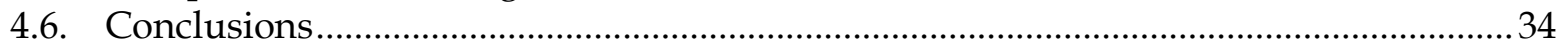

Chapter 5. Hybrid GFRP-Steel Cellular Wicket Gates .........................................................35

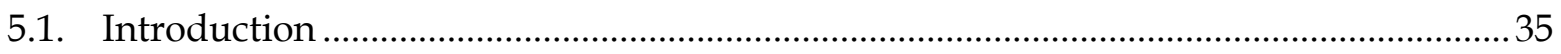

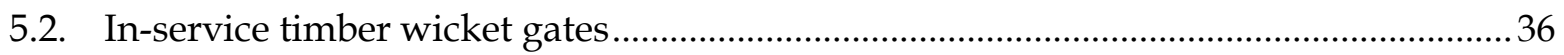

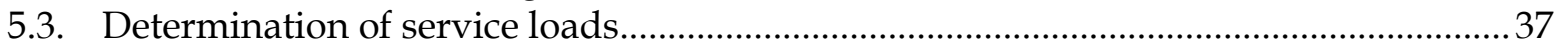

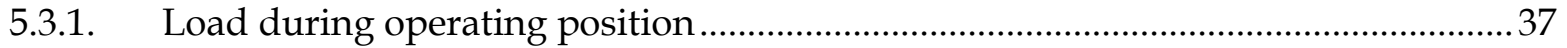

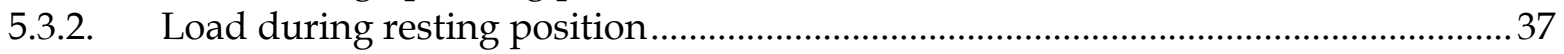

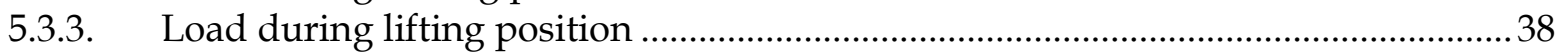

5.3.4. Load due to hydrodynamic effects ......................................................................... 38

5.4. Design of an integrated GFRP-steel wicket gate section ...............................................39

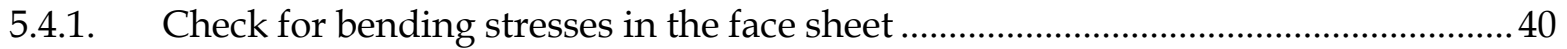

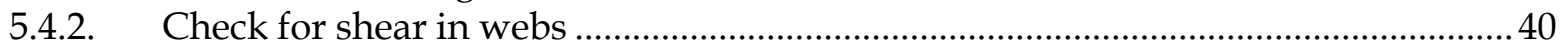

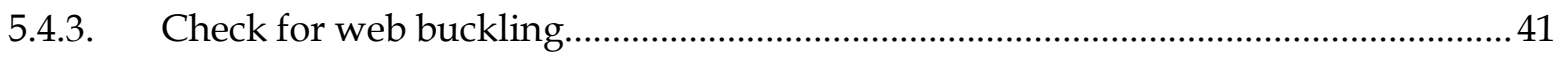

5.5. Theoretical strength and stiffness of hybrid section ................................................... 41

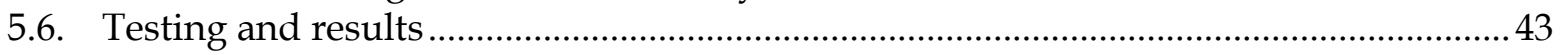

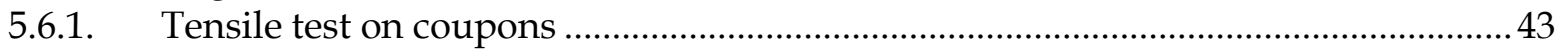

5.6.2. Four point bending on timber and GFRP wicket gate with steel fixtures ...............44

5.6.3. Three point bending on GFRP wicket gate without steel fixtures .......................... 45

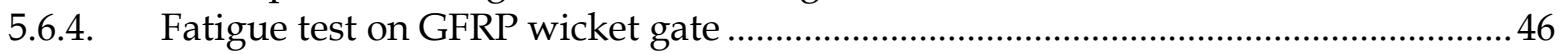

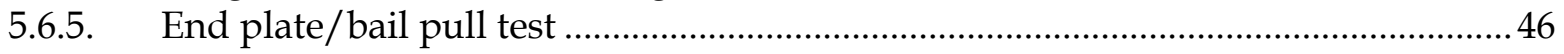

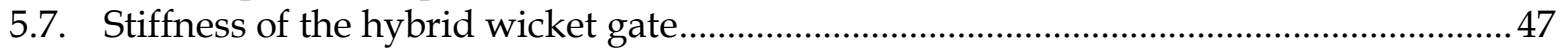

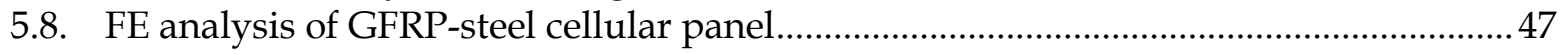

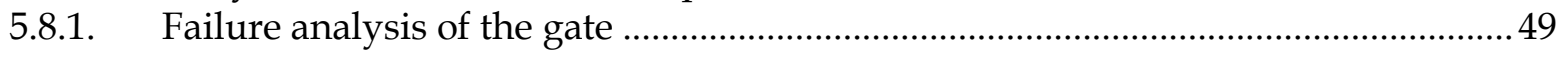

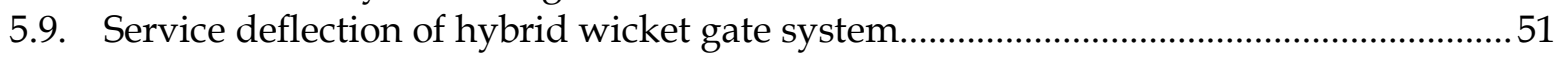

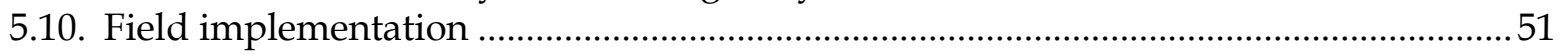

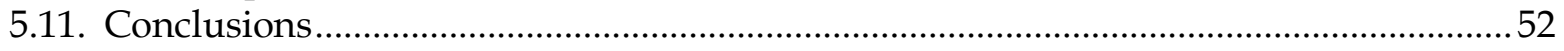

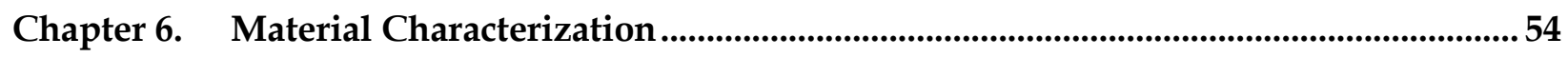

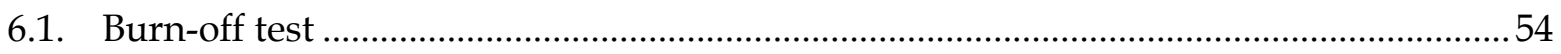

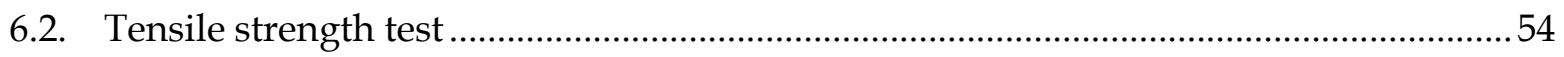

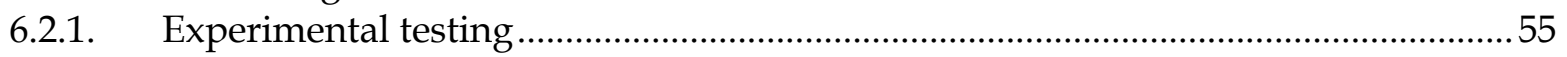

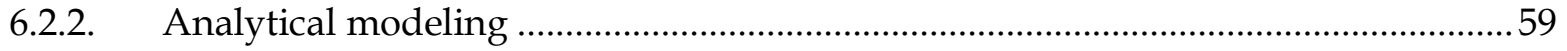

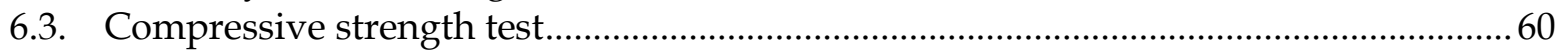

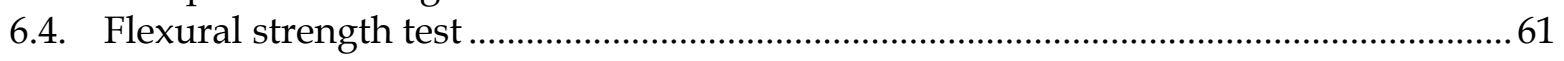

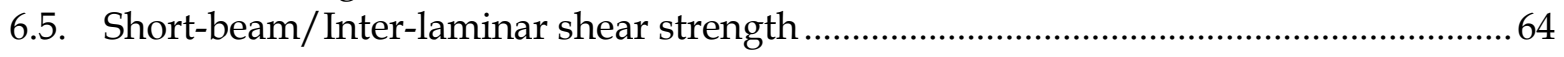

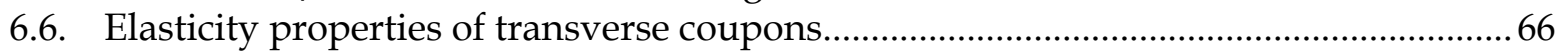

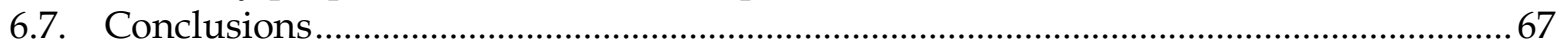

Chapter 7. Bending, Shear, \& Fatigue Behavior of Box-Beam Sections ................................... 69

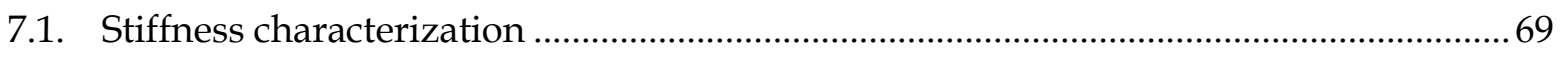

7.1.1. Moment of inertia of box-beam sections.............................................................. 70 
7.1.2. Bending and shear stiffness of box-beam sections …………………………............73

7.2. Fatigue testing on GFRP and hybrid box-beams........................................................

7.2.1. Fatigue test description ....................................................................................

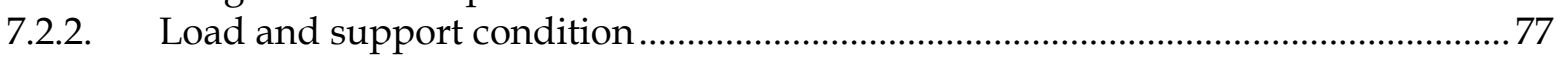

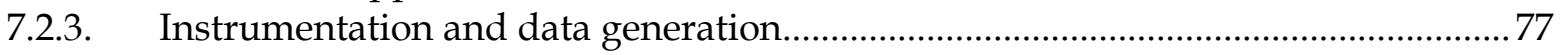

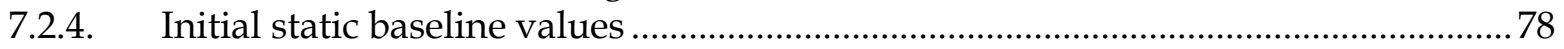

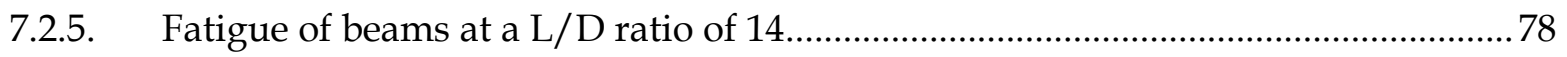

7.2.6. Fatigue of beams at a L/D ratio of 4.5 ................................................................ 90

7.3. Failure of GFRP and hybrid box-beams .................................................................... 91

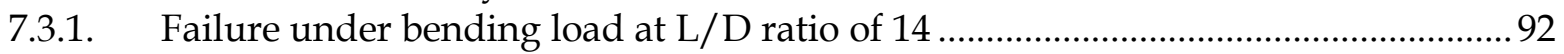

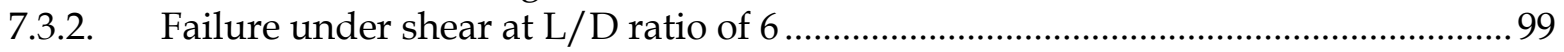

7.3.3. Failure under shear at L/D ratio of 4.5 ................................................................103

7.3.4. Summary of beam failure results .......................................................................... 109

7.3.5. Bending and shear stresses on box-beams at different L/D ratios .........................110

7.3.6. Failure modes on GFRP and hybrid box-beams....................................................111

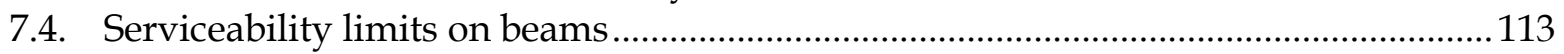

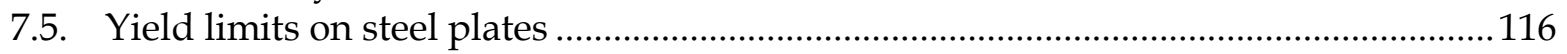

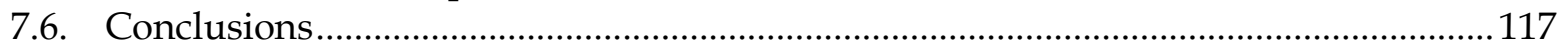

Chapter 8. Theoretical Approach on GFRP-Steel Hybrid Members.........................................118

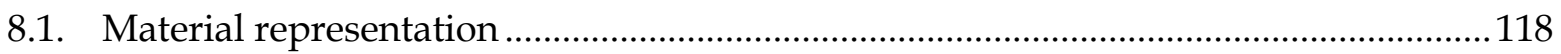

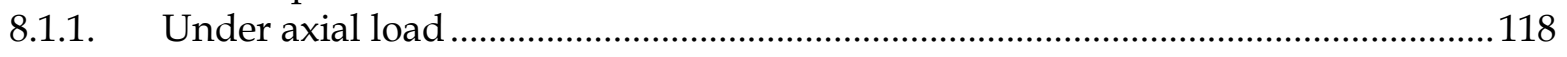

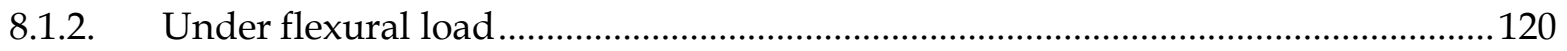

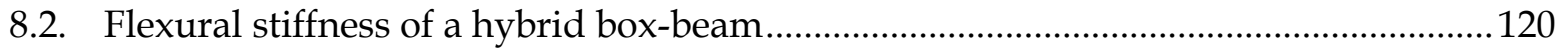

8.3. Load carrying capacity of a hybrid (HAB) beam........................................................... 121

8.4. Design consideration of a GFRP composite beam......................................................... 122

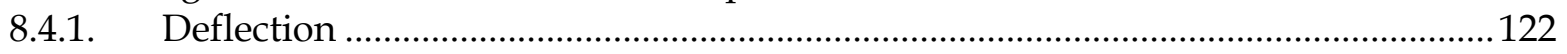

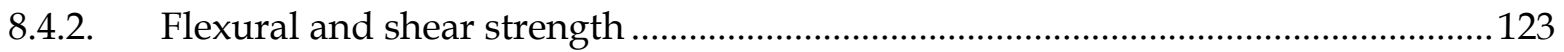

8.4.3. Buckling of the compression flange.......................................................................123

Chapter 9. Finite Element Analysis ...........................................................................................125

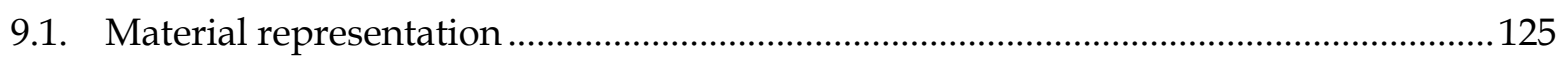

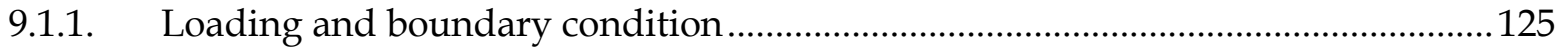

9.1.2. Material properties and orientations......................................................................126

9.1.3. Element and mesh size …………………….....................................................128

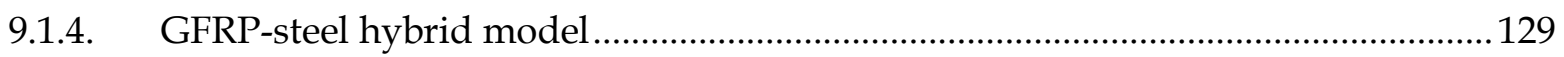

9.2. Validation of FE models with experimental results......................................................130

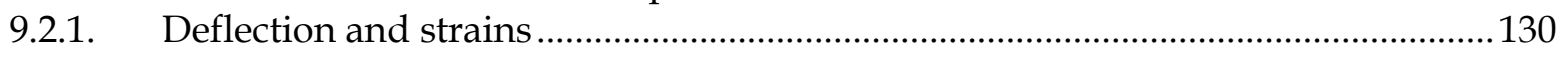

9.2.2. Stress distributions in GFRP and embedded steel plates .......................................131

9.3. Inelastic behavior of hybrid beam models ...................................................................133

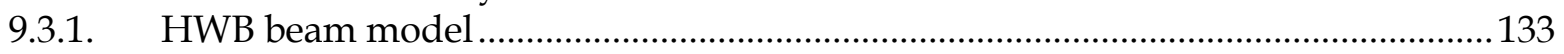

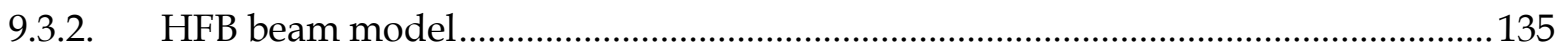

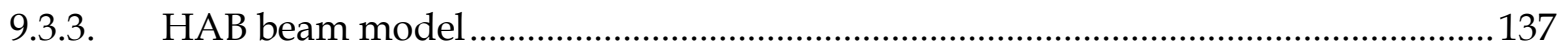

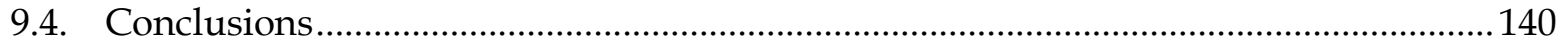

Chapter 10. Bolted Connections on GFRP and Hybrid members .............................................141

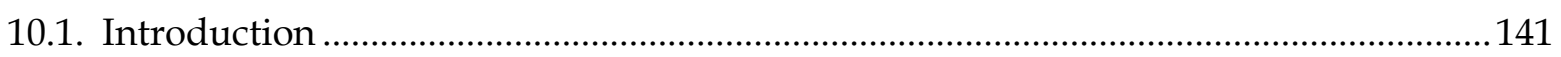

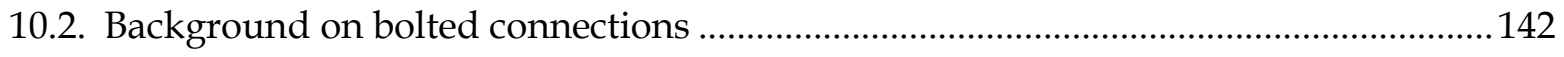


10.3. LRFD Pre-standard Bolted Connection Criteria ......................................................... 143

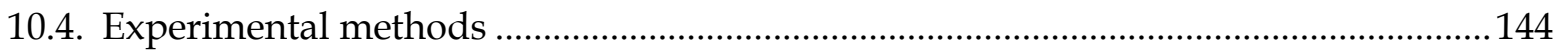

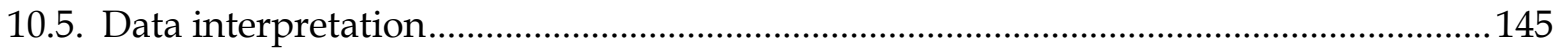

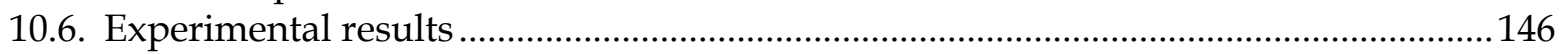

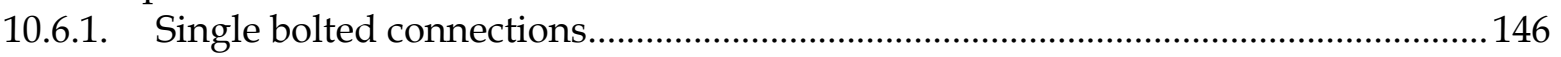

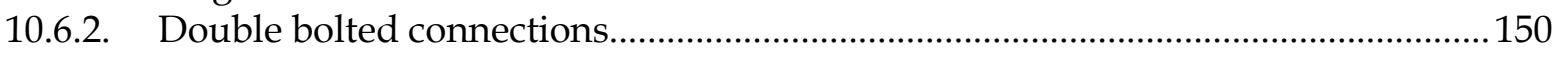

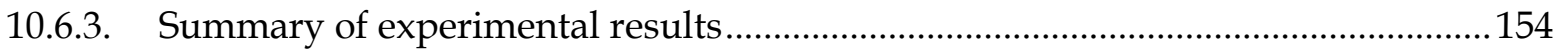

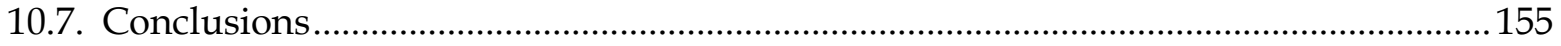

Chapter 11. Conclusions and Recommendations ......................................................................156

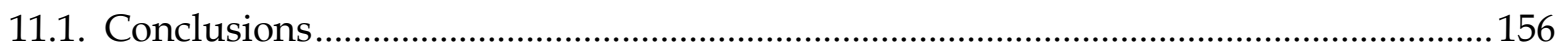

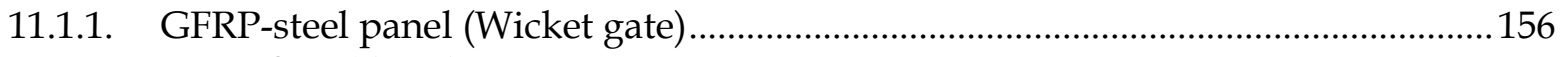

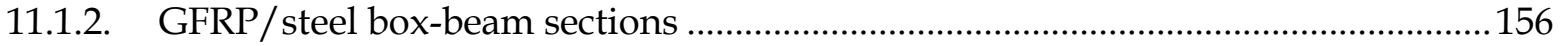

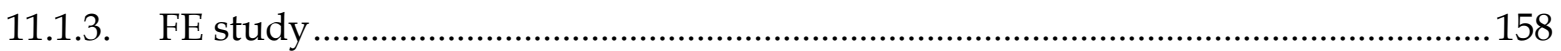

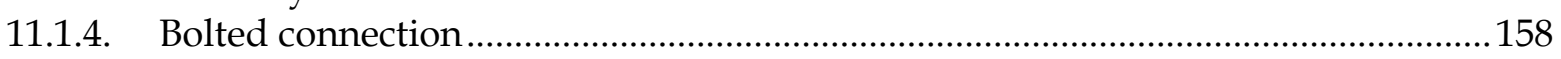

11.1.5. Qualitative/quantitative interface evaluation ..................................................... 159

11.2. New and original contributions to the knowledge base ............................................ 160

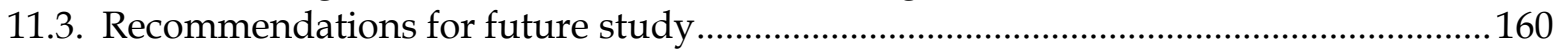

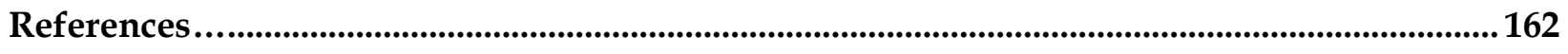

Appendix A. GFRP-steel hybrid panel (wicket gate) supplementary data................................ 169

Appendix B. Non-destructive testing.................................................................................................... 170

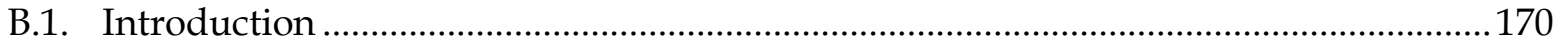

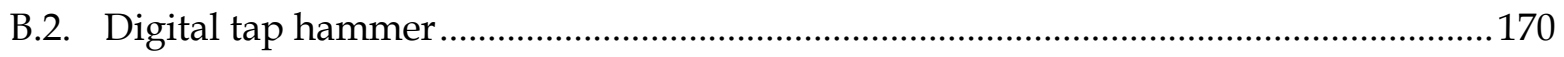

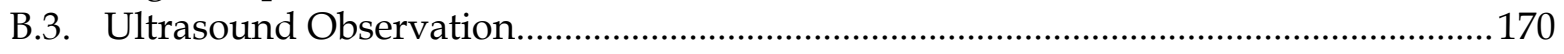

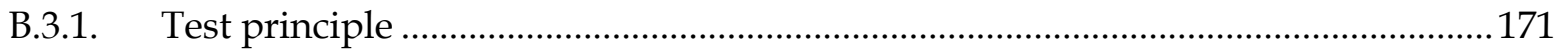

B.3.2. Defect description and test procedure ….......................................................... 171

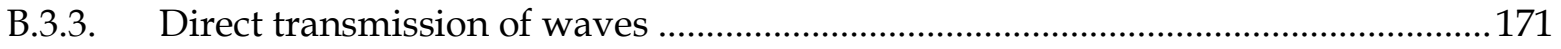

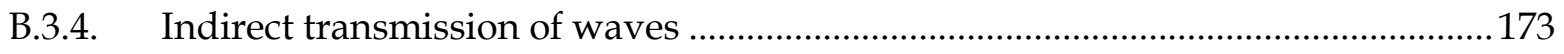

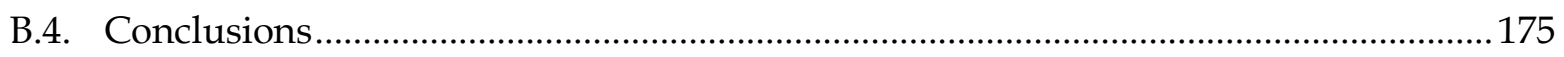

Appendix C. Qualitative observations of GFRP-steel interface ................................................... 176

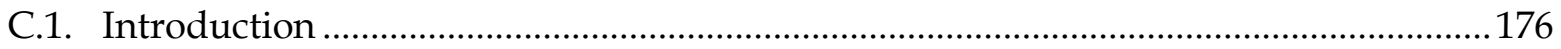

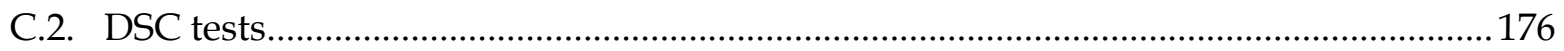

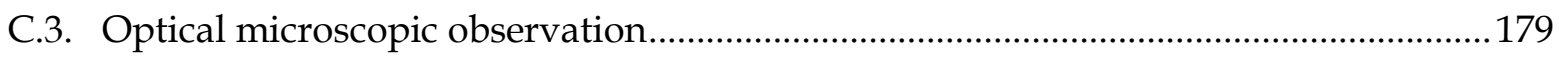

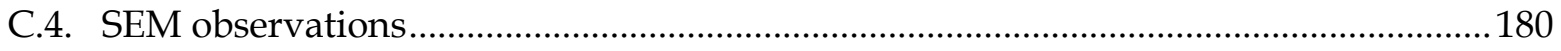

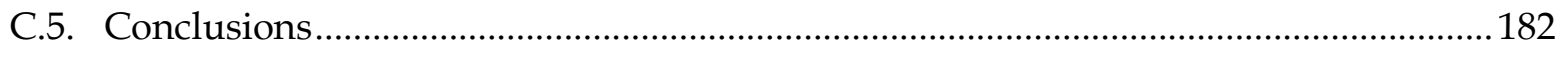

Appendix D. Cost comparison ................................................................................................................183

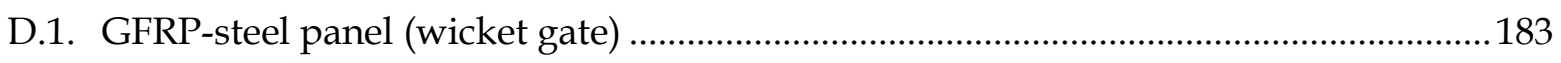

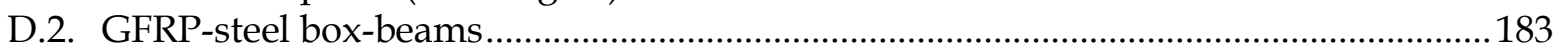

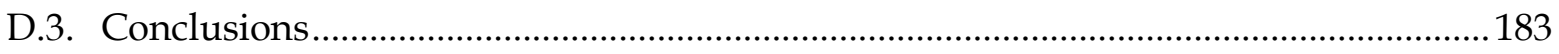




\section{List of Figures}

Figure 2-1. FRP composite laminate (Source: www.aerospaceengineering.blog) ......................... 7

Figure 2-2. Fiber/fabric layup in pultrusion process (Courtesy of Creative pultrusion Inc.) ........ 8

Figure 2-3. Vacuum infusion process (Courtesy of intermasgroup.com) ......................................... 8

Figure 2-4. (a) FRP wrapping on a bridge arch (Sonnenschein et al. 2016), (b) Bridge column repair with FRP wrapping (giatecscientic.com).

Figure 2-5. (a) Fiberline bridge at Kolding, Denmark built in 1997 (Fiberline), (b) Bridge deck installation at Penn State by ZellComp Inc. (ZellComp)

Figure 2-6. (a) One ocean's kinetic façade in South Korea (Soma), (b) GFRP composite sandwich panel facade installed on BBVA bank, Spain (Miguel and Diaz 2015). 12

Figure 2-7. (a) FRP wicket gate in Illinois River, (b) FRP miter gate in Wilhelmina canal (Source: Aliancys)

Figure 3-1. Hybrids: (a) interlayer or interply, (b) intralayer or intraply, (c) intayarn (Swolfs et al. 2014)

Figure 3-2. Load-deflection curve for GFRP-CFRP hybrid beams (Hai et al. 2010) .....................17

Figure 3-3. Tensile stress vs. strains for glass, carbon and hybrids (Pandya et al. 2011)...............18

Figure 3-4. Tensile stress vs. strains for glass, carbon and hybrids (Zhang et al. 2011)................19

Figure 3-5. Hybrid effect, a) enhancement of failure strain of low-elongation (LE) fibers, b)

deviation from rule of mixtures (Swolfs et al. 2014) ..............................................................20

Figure 3-6. Failure modes in 3-layer unidirectional hybrids (Czel \& Wisnom 2013) ................... 21

Figure 3-7. Cross-section of hybrid samples with carbon ratios of a) 0.1, b) 0.2 (Yu et al. 2015).. 21

Figure 3-8. Stress-strain curves of carbon/glass hybrid for different carbon ratio (Yu et al. 2015)

Figure 3-9. Types of hybrid bars and corresponding

Figure 3-9. Types of hybrid bars and corresponding steel area ...................................................23

Figure 3-10. Tensile test results between specimens (Case A to D) ..............................................2

Figure 3-11. Configuration of a continuous fiber/metal/epoxy hybrid composite.......................24

Figure 3-12. (a) Schematic of hybrid FRP-steel sandwich panel, (b) manufactured deck ............ 24

Figure 3-13. (a) Load-deflection curve, (b) load-strain curve (through depth of panel)...............25

Figure 3-14. (a) KSCI cross-section, (b) KSCI plan view..............................................................26

Figure 3-15. (a) Steel honeycomb core, shear stress-strain curves in (b) long-direction, (c) width-

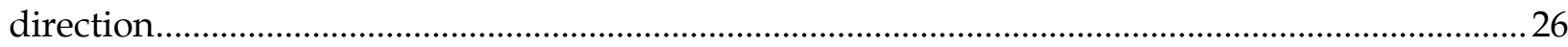

Figure 3-16. Cross-sectional profiles of a hybrid GFRP deck panel ...........................................27

Figure 3-17. (a) Failure modes of a bolt loaded hole, (b) schematic view of a composite bolted joint locally reinforced by metal layer embedding......................................................................2 27

Figure 4-1. Schematic of a GFRP-steel hybrid cellular panel........................................................22

Figure 4-2. (a) Manufacturing of hybrid GFRP panel, (b) GFRP web cores .................................. 30 Figure 4-3. (a) Control GFRP (CB), (b) Hybrid web beam (HWB), (c) Hybrid flange beam (HFB), (d) Hybrid-all beam (HAB) box-beam sections ............................................................................ 30

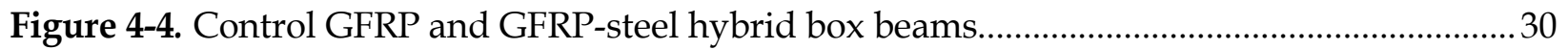

Figure 4-5. Arrangement of GFRP fabrics \& steel plate on control \& hybrid sections ..................31

Figure 4-6. (a) Grinding tool to create bonding surface for strain gages on embedded steel surface, (b) 3-uniaxial strain gages at support to capture strains in three directions... 
Figure 4-7. (a) Uniaxial strain gage, (b) Vishay system 7000 data acquisition, (c) System 8000

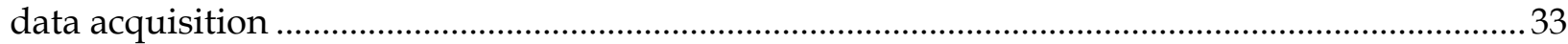

Figure 4-8. (a) Waterjet cutting controller, (b) waterjet cutting through a GFRP sample .............33

Figure 4-9. Three-point bending setup for testing a box-beam .......................................................3

Figure 5-1. a) Timber wicket gates in service, b) deteriorated timber wicket gates .......................36

Figure 5-2. Timber wicket gate: a) upstream face, b) downstream face with a prop-rod..............36

Figure 5-3. Wicket gate in operating position: a) with tail water, b) without tail water ................37

Figure 5-4. Bails on the wicket gate: (a) top bail, (b) bottom bail ..................................................38

Figure 5-5. (a) Three-gate aperture, b) velocity field on upstream side of the gate (Chowdhury et

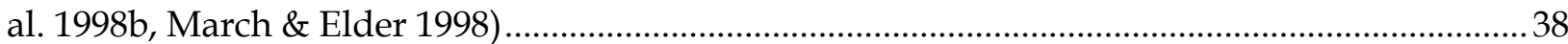

Figure 5-6. Cross-section of FRP composite wicket gate without any steel attachment................40

Figure 5-7. (a) Quarter model of a Cellular FRP panel, (b) cross-section with steel plates ...........41

Figure 5-8. (a) Tensile coupons with/without wrinkle, (b) tensile stress vs. strain plot ...............44

Figure 5-9. Bending tests: (a) on timber wicket gate, (b) on GFRP-steel wicket gate.....................45

Figure 5-10. Three-point bending test of GFRP-steel hybrid wicket gate........................................4 45

Figure 5-11. Pulling test on a top bail of the FRP gate...............................................................46

Figure 5-12. GFRP panel half-length model showing loading location with a red shade.............48

Figure 5-13. Load vs. deflection on GFRP wicket gates under 3-point bending............................48

Figure 5-14. Hashin failure criteria - fiber compression damage at the center of the panel .........50

Figure 5-15. Central failure load vs. failure criteria index .......................................................50

Figure 5-16. Load distribution: a) pressure on 2 sides, b) d/s pressure deducted from $\mathrm{u} / \mathrm{s}$ side 51

Figure 5-17. Hybrid wicket gate: a) steel angle on the sides, b) UHMWPE on the sides ..............52

Figure 5-18. Field installation of wicket gates: a) during installation, b) operation at $65^{\circ}$ position

Figure 6-1. (a) Sample after burning off resin, (b) Chop strand mat and woven fabric ...............54

Figure 6-2. Tensile coupons, (a) steel plate, (b) GFRP laminate, (b) Hybrid GFRP-steel laminate

Figure 6-3. (a) Tensile stress vs. elongation, (b) tensile stress vs. strain for steel ..........................56

Figure 6-4. Tensile failure on, (a) Steel plate, (b) GFRP laminate ...............................................56

Figure 6-5. Tensile stress vs. strain for: (a) longitudinal GFRP laminate, (b) hybrid laminate.....57

Figure 6-6. Tensile failure on hybrid laminate, (a) Fiber fracture, (b) Debonding/delamination57

Figure 6-7. Tensile stress vs. strain for steel plate, and GFRP and hybrid laminates ...................58

Figure 6-8. Young's modulus of elasticity of steel, GFRP, and hybrid material ...........................58

Figure 6-9. (a) Load-elongation curve of a hybrid laminate with 0.125 in-thick steel plate bonded to 0.1875 in-thick GFRP, (b) Failure with debond/fiber fracture, (c) fractured outer GFRP ........59

Figure 6-10. Coupons for compressive strength, (a) GFRP section, (b) Hybrid section ................60

Figure 6-11. Compressive stress vs. strain for a GFRP laminate ....................................................61

Figure 6-12. Failure of GFRP specimen under compressive stress ...........................................61

Figure 6-13. GFRP and hybrid laminate bending coupons with cross-sections .........................62 62

Figure 6-14. Load vs. deflection for bending coupons (a) GFRP section, (b) Hybrid section ....... 62

Figure 6-15. Bending stress-strain curves for (a) GFRP section, (b) Hybrid section ......................63

Figure 6-16. Failure of coupons under bending, (a) GFRP section, (b) hybrid section ..................64

Figure 6-17. ASTM standard on span lengths for testing laminate for short-beam shear strength,

(a) GFRP section, (b) GFRP section with embedded steel plate ...................................................6 64 
Figure 6-18. Inter-laminar shear strength vs. deflection curves for GFRP and hybrid sections... 65 Figure 6-19. Interlaminar shear failure modes on GFRP laminate under short-beam shear test. 65 Figure 6-20. Interlaminar shear failure modes on hybrid laminate under short-beam shear test 66 Figure 6-21. (a) Bending stress-strain, (b) Load-deflection curves for transverse coupons ..........67 Figure 6-22. Failed transverse GFRP laminate under three-point bending...................................67 Figure 7-1. Three-point loading on box-beam sections at a span length of 84 inches....................69 Figure 7-2. Three-point loading on box-beam sections at a span length of 36 inches...................70 Figure 7-3. (a) Rectangular section with a corner radius, (b) Box-beam section with outer and

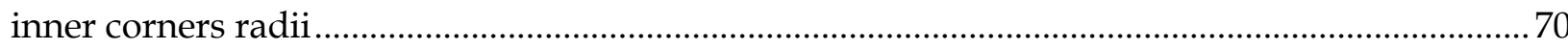

Figure 7-4. Hybrid GFRP-Steel sections: (a) HWB, (b) HFB, (c) HAB .........................................71

Figure 7-5. Moment of inertias of box-beam sections ................................................................ 72

Figure 7-6. Load vs. deflection plots, (a) 84" span (L/D = 14), (b) 36" span (L/D = 6) ...............74

Figure 7-7. Load vs. deflection plots obtained .......................................................................... 75

Figure 7-8. Load vs. strain plots obtained from 3-point load testing: (a) bending strains at 84 "

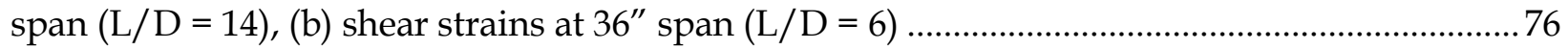

Figure 7-9. Fatigue testing under 3-point loading at a span of $84 \mathrm{in}$.............................................77

Figure 7-10. Strain gage instrumentation on a box-beam ...................................................... 78

Figure 7-11. Load vs. deflection for CB beams before and after fatigue for 1000K cycles: (a) at 1-3 kip, (b) at 2-5 kip .................................................................................................................. 79

Figure 7-12. Load vs. deflection for CB beams before and after fatigue for $1000 \mathrm{~K}$ cycles at 2-5 kip .80

Figure 7-13. Load vs. deflection for CB beams before and after fatigue for $1000 \mathrm{~K}$ cycles at 4-7 kip

Figure 7-14. Load vs. deflection plot for HAB beams before and after fatiguing for 1 million cycles at 1-3-kip load

Figure 7-15. Load vs. deflection plot for $\mathrm{HAB}$ beams before and after fatiguing for 1 million cycles at 4-6.5-kip load @ 0.85 of steel yield strain .....

Figure 7-16. Load vs. deflection plot for HAB beams before and after fatiguing for 1 million

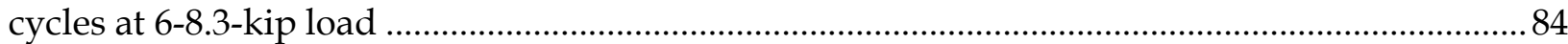

Figure 7-17. Deflection range vs. no. of fatigue cycles during 1 million fatigue cycles .84 Figure 7-18. Residual deflection of around 0.04 inch noticed on a HAB beam after loading it beyond the yield level of embedded steel plates .85

Figure 7-19. Load vs. deflection plot for HAB beams before and after fatiguing for 1 million

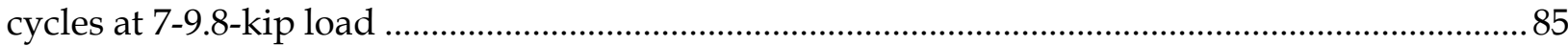

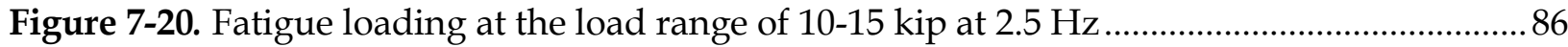
Figure 7-21. Failure of a hybrid HAB beam under fatigue at a load range of 10-15 kip at $2.5 \mathrm{~Hz} 86$ Figure 7-22. Close-up of the failure of a hybrid HAB beam: (a) top view, (b) bottom view ......... 87 Figure 7-23. Load vs. deflection for HFB beam before and after fatigue at 4-6.5 kip...................8 88 Figure 7-24. Load vs. deflection plot for HFB beams before and after fatiguing for 1 million

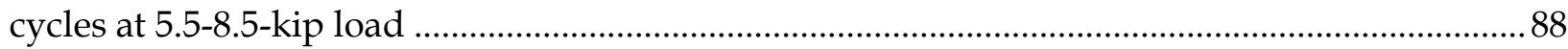
Figure 7-25. Load vs. deflection for HWB beams before and after fatigue for $1000 \mathrm{~K}$ cycles at 5.67.6 kip for 1 million cycle.....

Figure 7-26. Load vs. deflection for CB beams before and after fatigue for $1000 \mathrm{~K}$ cycles at a span length of 27 inches with a load range of 10-18 kips .90 
Figure 7-27. Load vs. deflection for HWB beams before and after fatigue for $1000 \mathrm{~K}$ cycles at a span length of 27 inches with a load range of 10-18 kips .............................................................91

Figure 7-28. Schematic of 3-point load setup during beams failure at L/D ratio of 14 ................92 Figure 7-29. Experimental test setup showing load actuator, LVDT, strain gages during testing

Figure 7-30. (a) Load-deflection, (b) load-strain plots for CB beams during failure

Figure 7-31. (a) Load-shear strain plot for CB beams during failure..............................................93

Figure 7-32. (a) Load-deflection, (b) load-strain plots for CB beams during failure.....................94

Figure 7-33. (a) Failure underneath load point, (b) no failure at supports ...................................94

Figure 7-34. (a) Load-deflection, (b) load-strain plots for HWB beams during failure..................95

Figure 7-35. Load-shear strain plots for gage attached on GFRP and embedded steel plate (Note: strain gage after reaching 18600 lbs. load started giving erroneous values) .................................. 95

Figure 7-36. Failure of HWB, (a) tensile rupture, (b) splitting of webs with intact top flange ..... 95 Figure 7-37. (a) Load-deflection, (b) load-strain plots for CB beams during failure......................96 Figure 7-38. Load-bending strain plot for initial $2000 \mu$ strains on embedded steel plate (tension)

Figure 7-39. Load-strain plots for HFB beams: (a) @ 1 $1^{\text {st }}$ cycle, (b) @ 2nd cycle, (c) @ 3 $3^{\text {rd }}$ cycle ....... 97 Figure 7-40. Load-shear strain plots for HFB beam (gage attached on a GFRP web) ...................97 Figure 7-41. (a) Load-deflection, (b) load-strain plots for HFB beams during failure ...................98 Figure 7-42. (a) Load-deflection, (b) load-strain plots for HAB beams during failure ................. 98 Figure 7-43. Load-shear strain plot for HAB beam (gage attached on a GFRP web) .................... 99 Figure 7-44. (a) Flange-web junction cracking, (b) intact flanges and webs.................................99 Figure 7-45. Three-point loading at L/D ratio of 6, (a) schematic, (b) real beam in laboratory ... 99 Figure 7-46. (a) Load-deflection, (b) load-strain plots for CB beams during failure....................100 Figure 7-47. Load-shear strain plot for CB beam (gage attached on a GFRP web) .....................100 Figure 7-48. Failure on CB beams: (a) web crushing, (b) flange-web junction cracking .............101 Figure 7-49. Failure at the support regions, (a) delamination, (b) delamination and warping...101 Figure 7-50. (a) Load-deflection, (b) load-strain plots for HAB beams during failure ................102 Figure 7-51. Load-shear strain plot for HAB beam (gages attached on GFRP web and steel plate) 102

Figure 7-52. Failure on HAB beams: (a) flange-web junction cracking, (b) punching failure ....102 Figure 7-53. Three-point loading at L/D ratio of 4.5, (a) schematic, (b) real beam in laboratory

Figure 7-54. (a) Load-deflection, (b) load-strain plots for CB beams during failure....................103 Figure 7-55. Load-shear strain plot for CB beam (gage attached on a GFRP web) ..................... 104 Figure 7-56. Failure on CB beams: (a) web crushing, (b) flange-web junction cracking/buckling

Figure 7-57. Bottom flange fracture on CB beams over the support ........................................104 Figure 7-58. (a) Load-deflection, (b) load-strain plots for HWB beams during failure................105 Figure 7-59. Load-shear strain plot for HWB beam (gage attached on GFRP web and steel plate)

Figure 7-60. HWB beam failure: (a) flange-web junction crack, (b) transverse shear failure .....106 Figure 7-61. Transverse shear failure in bottom flange on HWB beam over the support...........106 Figure 7-62. (a) Load-deflection, (b) load-strain plots for HFB beams during failure ................. 107 
Figure 7-63. Load-shear strain plot for HFB beam (gage attached on a GFRP web)...................107 Figure 7-64. Failure in HFB beam, (a) web buckling/splitting, (b) punching shear failure........107 Figure 7-65. Stiffer bottom flange arresting bearing failure over the support on HFB beam ..... 108 Figure 7-66. (a) Load-deflection, (b) load-strain plots for HAB beams during failure ................108 Figure 7-67. Load-shear strain plot for HAB beam (gage attached on GFRP web and steel plate)

Figure 7-68. Failure in HAB beam: (a) flange-web junction crack, (b) transverse shear failure.109 Figure 7-69. Transverse shear failure over supports on HAB beam. 109 Figure 7-70. Load vs. deflection for box-beams up to failure at a span of 84 in., (a) CB and HWB

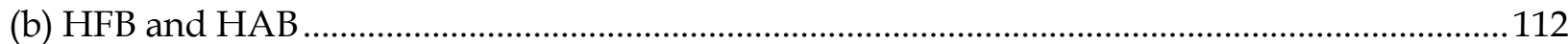

Figure 7-71. Load vs. deflection for box-beams up to failure at a span of $27 \mathrm{in}$. 113 Figure 7-72. Load-deflection plot for GFRP and hybrid box-beams shown until 0.5 " deflection 115

Figure 7-73. Maximum central load for different box-beams to satisfy deflection limits............115 Figure 7-74. Load @ yield strains of steel plates: (a) HFB beam, (b) HAB beam .........................116 Figure 8-1. GFRP-steel representative geometry cut from the flanges and webs of hybrid beams

Figure 8-2. Stress-strain model for GFRP, steel, and GFRP-steel hybrid composite...................118

Figure 8-3. Cross-section of a GFRP-steel hybrid box beam (HAB) ........................................121

Figure 8-3. Cross-section of a hybrid box beam (HAB) and the strain distribution....................121

Figure 9-1. Shaded portion of the beam to be modeled in FE .............................................125

Figure 9-2. Half-length model in the Abaqus with loading and boundary conditions ...............126

Figure 9-3. Material orientation on flanges and webs of box-beams (Gautam \& Matsumoto 2008)

Figure 9-4. (a) Box-beam model with corner radii, (b) material orientation at the corners.........128

Figure 9-5. 20-node quadratic brick element with node numbering ..........................................128

Figure 9-6. Box-beam model meshed with multiple elements within laminate thickness with 20-

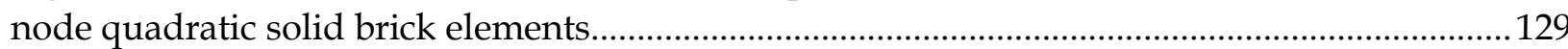

Figure 9-7. Hybrid box-beam models: (a) HWB, (b) HFB, (c) HAB (Note: Red shade = steel)...130 Figure 9-8. Half-length CB beam model showing vertical deflection contours .......................... 130 Figure 9-9. Half-length CB beam with compressive (upper) and tensile strain (bottom) contours

Figure 9-10. Half-length CB beam model showing bending stress contours 131 Figure 9-11. Longitudinal bending stress contours in HWB: (a) GFRP, (b) embedded steel plates 132

Figure 9-12. Longitudinal bending stress contours in HFB: (a) GFRP, (b) embedded steel plates 132

Figure 9-13. Longitudinal bending stress contours in HAB: (a) GFRP, (b) embedded steel plates

Figure 9-14. Load-deflection curves from FE and experiment for HWB beam at failure load...134 Figure 9-15. (a) Longitudinal bending strain, (b) longitudinal bending stress in HWB beam ... 134 Figure 9-16. Transverse bending stress in HWB beam .............................................................134 Figure 9-17. (a) Longitudinal bending stress, (b) shear stress in the embedded steel plates ......135 Figure 9-18. Plastic strain zones in the embedded steel plates in HWB beam............................ 135 
Figure 9-19. Load-deflection curves from FE and experiment for HFB beam at failure load.....136 Figure 9-20. (a) Longitudinal bending strain, (b) longitudinal bending stress in HFB beam .....136 Figure 9-21. Transverse bending stress in HFB beam.............................................................136 Figure 9-22. (a) Longitudinal bending strain, (b) longitudinal bending stress in steel plates ....137 Figure 9-23. Plastic strain zones in the embedded steel plates in HFB beam.............................. 137 Figure 9-24. Load-deflection curves in HAB beam from FE and experiment ............................ 138 Figure 9-25. (a) Longitudinal bending strain, (b) longitudinal bending stress in HAB beam ....138 Figure 9-26. (a) Longitudinal bending strain, (b) longitudinal bending stress in HAB beam .... 138 Figure 9-27. Longitudinal bending-(a) strain, (b) stress in embedded plates in HAB beam ......139 Figure 9-28. (a) Shear strain, (b) shear stress in embedded plates in HAB beam .......................139 Figure 9-29. (a) Longitudinal bending strain, (b) longitudinal bending stress in HWB beam ...139 Figure 10-1. Single-row bolted connections in all-GFRP and hybrid members under tension ..141 Figure 10-2. Double-row bolted connections in all-GFRP and hybrid members under tension 142 Figure 10-3. Failure modes on (a) bolted joints, (b) adhesive joint (Sotiropoulous et al. 1995) ..142 Figure 10-4. Edge, end and pitch distances in bolted connection (ASCE-LRFD, 2010) ..............143 Figure 10-5. (a) Two-inch wide GFRP and steel specimens, (b) drilling a hole in the member .144 Figure 10-6. Location of strain gages and the designed failing member 145 Figure 10-7. Load-slip plots for GFRP and hybrid sections with one 1/2"-dia bolted connection

Figure 10-8. Failure under single-row bolted connection, (a) GFRP member, (b) hybrid member

Figure 10-9. Net-tension failure on: (a) GFRP member, (b) hybrid member (necking on steel).148 Figure 10-10. Load-strain plots for one 0.5"'-dia. bolt connection: (a) GFRP, (b) hybrid section 148 Figure 10-11. Load-slip plots for GFRP and hybrid sections with one 3/8"'-dia bolted connection

Figure 10-12. Failure on GFRP connected member, (a) bearing/shear-out, (b) failure (zoomed)

Figure 10-13. Failure in GFRP-steel hybrid member with single-row bolted connection ...........150 Figure 10-14. Load-strain plots for one $0.375^{\prime \prime}$-dia. bolt connection: (a) GFRP, (b) hybrid section

Figure 10-15. Load-slip plots for GFRP and hybrid sections with two $0.5^{\prime \prime}$-dia bolted connection

Figure 10-16. Net-tension failure on double-bolted connection on: (a) GFRP, (b) hybrid member

Figure 10-17. Net-tension failure on: (a) GFRP member, (b) hybrid member. 152

Figure 10-18. Load-strain plots under two 0.5"-dia. bolt connection: (a) GFRP, (b) hybrid section .153

Figure 10-19. Load-slip plots for GFRP and hybrid sections with two 3/8"-dia bolted connection 153

Figure 10-20. Load-strain plots for two $0.375^{\prime \prime}$-dia. bolt connection: (a) GFRP, (b) hybrid section

Figure 10-21. Net-tension failure on: (a) GFRP members, (b) hybrid members ......................... 154

Figure A-1. Cross-section of GFRP-steel hybrid wicket gate. 169 
Figure B-1. (a) Pundit PL 200 ultrasonic pulse velocity test machine, (b) Direct transmission, (c)

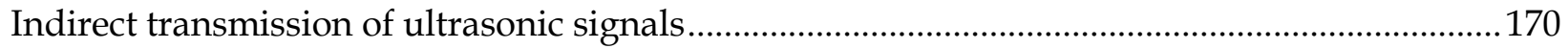

Figure B-2. Ultrasound testing on hybrid GFRP-steel laminate via direct transmission ............171

Figure B-3. Ultrasound waves with $500 \mathrm{kHz}$ transducers under direct transmission for GFRP

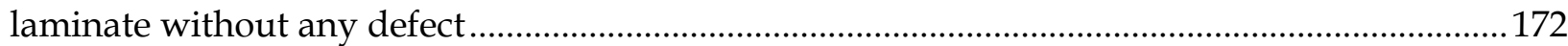

Figure B-4. Ultrasound waves with $54 \mathrm{kHz}$ transducers under direct transmission for GFRP

laminate without any defect. 172

Figure B-5. Ultrasound waves with $500 \mathrm{kHz}$ transducers under direct transmission for GFRP laminate with a defect..... 172

Figure B-6. Ultrasound waves with $54 \mathrm{kHz}$ transducers under direct transmission for GFRP laminate with a defect... 173

Figure B-7. Ultrasound testing on hybrid GFRP-steel laminate via indirect transmission.........173 Figure B-8. Ultrasound waves with $500 \mathrm{kHz}$ transducers under indirect transmission for GFRP laminate without any defect. 173

Figure B-9. Ultrasound waves with $54 \mathrm{kHz}$ transducers under indirect transmission for GFRP

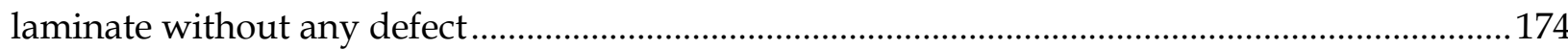

Figure B-10. Ultrasound waves with $500 \mathrm{kHz}$ transducers under indirect transmission for GFRP laminate with a defect. 174

Figure B-11. Ultrasound waves with $54 \mathrm{kHz}$ transducers under indirect transmission for GFRP

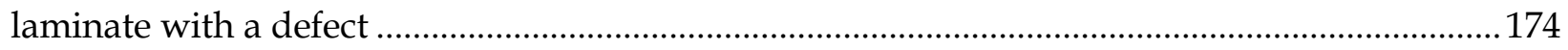

Figure B-12. Ultrasound wave travel under indirect transmission ............................................175

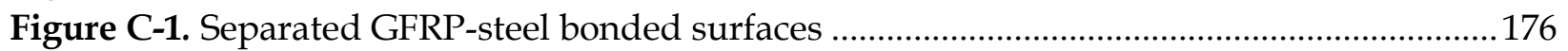

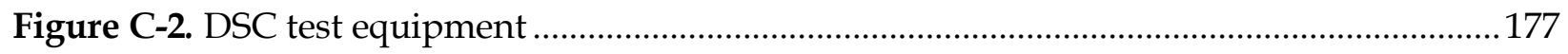

Figure C-3. DSC curve of a sample from surface GFRP layers (first heating cycle)....................177

Figure C-4. DSC curve of a sample from surface GFRP layers (second heating cycle) ...............178

Figure C-5. DSC curve of a sample from GFRP-steel interface (first heating cycle) ....................178

Figure C-6. DSC curve of a sample from GFRP-steel interface (second heating cycle) ...............179

Figure C-7. GFRP-steel interfacial bond failures: (a) sample-1, (b) sample-2 ............................ 180

Figure C-8. (a) Crack observed at the ends of the steel plate, (b) intact bond.............................180

Figure C-9. GFRP-steel interface under SEM, (a) resin-rich interface, (b) surface with debris ...181

Figure C-10. GFRP-steel interface under SEM, (a) sample-1, (b) sample-2 ..............................181

Figure C-11. GFRP surface under SEM: (a) chopped strands, (b) depression marks from fibers

Figure C-12. GFRP surface under SEM: (a) air voids, (b) resin scaling.....................................182 


\section{List of Tables}

Table 3-1. Tensile properties of different materials under loading (Pandya et al. 2011)..............18

Table 3-2. Tensile properties of glass/carbon hybrids (Zhang et al. 2011) ..................................19

Table 3-3. Flexural properties of glass/carbon hybrids (Zhang et al. 2011) ..................................19

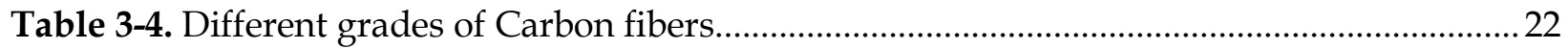

Table 3-5. Tensile strength and elastic modulus of hybrid bars ...................................................2 23

Table 5-1. Summary of forces on wicket gate in different positions ................................................39

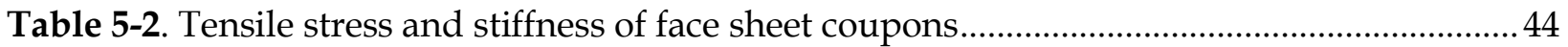

Table 5-3. Four-point bending test results of timber and GFRP-steel gate ....................................45

Table 5-4. Flexural rigidity and Stiffness of the cellular FRP wicket gate ....................................4 47

Table 5-5. Stiffness of the GFRP panel based on FE analysis ....................................................49

Table 6-1. Fiber volume fraction and void content on the GFRP laminate used in box-beams ...54

Table 6-2. Ultimate tensile strength of GFRP, steel, and hybrid specimens ..................................58

Table 6-3. Failure stresses and strains on GFRP and hybrid laminates ......................................... 64

Table 6-4. Inter-laminar shear strength for GFRP and hybrid sections .........................................66

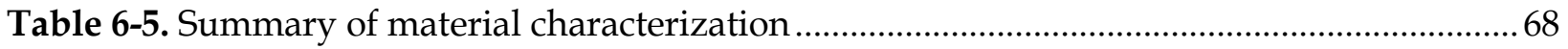

Table 7-1. Moment of inertias of control GFRP and hybrid box-beam sections...........................72

Table 7-2. Moment of inertias of control GFRP and hybrid box-beam sections........................... 72

Table 7-3. Load and deflections on beams under two different L/D ratios..................................73

Table 7-4. Bending and shear stiffness of the box-beams .............................................................74

Table 7-5. Load, strain, and bending and shear stiffness from back calculation method .............75

Table 7-6. Fatigue testing on control GFRP box-beams .................................................................. 78

Table 7-7. Test results before and after fatigue on " $\mathrm{CB}^{\prime}$ " box-beams at a load range of 1-3 kip for

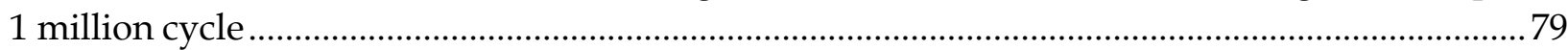

Table 7-8. Test results before and after fatigue on control GFRP box-beams at load range 2-5 kip

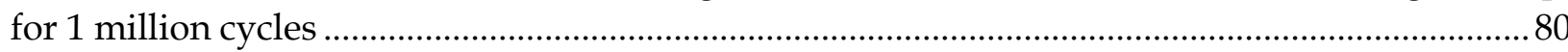

Table 7-9. Test results before and after fatigue on control GFRP box-beams at load range 4-7 kip

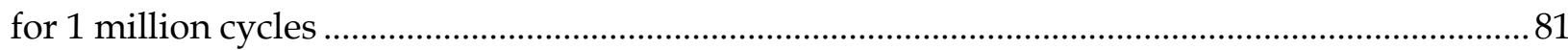

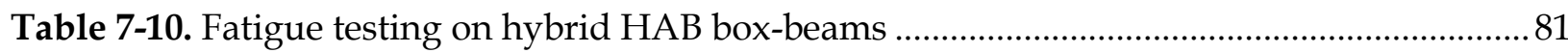

Table 7-11. Static test results obtained at 3-kip load before and after fatigue on HAB box-beams at load range 1-3 kip for 1 million cycles

Table 7-12. Static test results obtained at 6.6-kip load before and after fatigue on HAB boxbeams at load range 4-6.5 kip for 1 million cycles..........................................................................8 83

Table 7-13. Static test results obtained at 8.3-kip load before and after fatigue on HAB box-

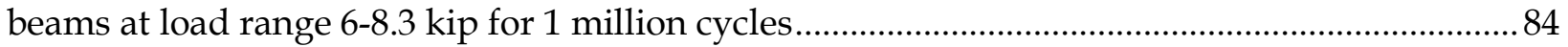

Table 7-14. Static test results obtained at 9.8-kip load before and after fatigue on HAB box-

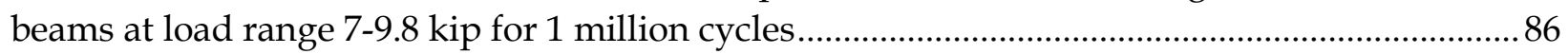

Table 7-15. Deflection and strain values before fatigue and at the time of failure........................8 87

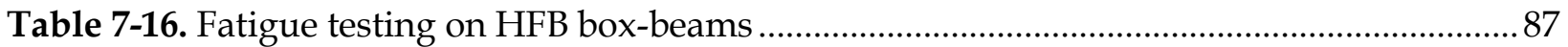

Table 7-17. Static test results obtained at 6.5-kip load before and after fatigue on HFB boxbeams at load range 4-6.5 kip for 1 million cycles 
Table 7-18. Static test results obtained at 8.5-kip load before and after fatigue on HFB boxbeams at load range 5.5-8.5 kip for 1 million cycles

Table 7-19. Test results before and after fatigue on control GFRP box-beams at load range 5.6-

7.6 kip for 1 million cycles

Table 7-20. Test results before and after fatigue on control GFRP box-beams at a span length of

27 inches with a load range of 10-18 kips for 1 million cycles

Table 7-21. Test results before and after fatigue on HWB box-beams at a span of 27 inches with a load range of 10-18 kips for 1 million cycles ..... .91

Table 7-22. Moment of inertias of control GFRP and hybrid box-beam sections. 92

Table 7-23. Ultimate load, deflection and strains on box-beams during failure at a span of 84"

Table 7-24. Ultimate load, deflection and strains on box-beams during failure at a span of 36"

Table 7-25. Ultimate load, deflection and strains on box-beams during failure at a span of 27"

Table 7-26. Bending and shear stresses on the beams at the time of failure ..............................111

Table 7-27. Deflection limits based on IBC, 2018 ........................................................................ 114

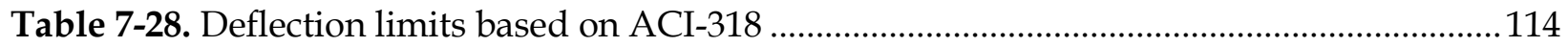

Table 7-29. Maximum central load on GFRP and hybrid beams pertaining to deflection limits

Table 7-30. Maximum central load on GFRP-steel hybrid beams at steel yield strain limits .....116

Table 9-1. Material properties of the GFRP laminate ...............................................................127

Table 9-2. Mesh size and convergence of a result ....................................................................129

Table 9-3. Comparison of deflection and bending strains between FEA and experimental values

Table 9-4. Yield stress-plastic strain data for non-linear analysis

Table 10-1. ASCE-LRFD Pre-standard minimum requirement for bolted connection geometries

Table 10-2. Bolted connection geometries for single-and double-bolted connections 146

Table 10-3. Test results for GFRP and hybrid sections connected with one 0.5 "'-diameter bolt 147

Table 10-4. Test results for GFRP and hybrid sections connected with one 3/8"-diameter bolt149

Table 10-5. Test results for GFRP and hybrid sections connected with two $0.5^{\prime \prime}$-diameter bolts

Table 10-6. Test results for GFRP and hybrid sections connected with two 0.375 "-diameter bolts

Table A-1. Center of gravity of the FRP wicket gate with two embedded steel plates 169

Table A-2. Composite moment of inertia of FRP gate section with two embedded steel plates169 Table D-1. Cost comparison between GFRP and hybrid multi-cellular panel (Chapter-5)........183

Table D-2. Cost comparison between GFRP and hybrid box-beams (Chapter-7) 183 


\section{Chapter 1. Introduction}

\subsection{Background}

Infrastructure serves as the backbone of a country's development. Any nation's significant progress in terms of its economy, lifestyle and public services can only be achieved through a network of robust and efficient infrastructure system. In the earlier twentieth century, western countries made massive investments in infrastructure sector that propelled their pace of urbanization and economic prosperity. However, over the last few decades, these pillars of growth have started showing signs of aging and deterioration, and this has become one of the most serious concerns that plague the developed world including the United States.

The deteriorating infrastructure of the US is set to pose a serious threat to its economy. According to American Society of Civil Engineers'(ASCE) 2017 report card gave a D+ rating to the nation's infrastructure suggesting that a significant portion of our infrastructure is either structurally deficient or functionally obsolete (ASCE, 2017). Consequently, their inadequate maintenance has continued to take a toll on the nation's resources and productivity. The most conventionally used materials such as steel, concrete and timber have weakened severely under increasing loads and environmental exposure, requiring expensive repair and rehabilitation. It is estimated that nearly \$3.6 trillion will be needed to revamp the nation's crippling structures and get to the status of grade $\mathrm{B}$. The department of transportation has allocated $\$ 44$ billion annually to invest in the nation's critical highway and bridge infrastructure (TWH, 2014). The US Army Corps of Engineers, a government body that looks after nation's inland navigation infrastructure, expects to spend about $73 \%$ of their $\$ 4.62$ billion annual budget to upgrade their infrastructure (USACE, 2015). Similarly, Airports Council International spends about 38\% of its $\$ 15$ billion annual budget in updating their existing infrastructure (ACI, 2015). The longer we wait to initiate full scale rehabilitation programs, more time and resources will be spent on negating the impact of aging structures. Thus, it has become time sensitive to revamp every infrastructure domain to guarantee economic progress and stability for the upcoming future generations. There should be focus towards finding out the most effective repair solution in terms of time, money, and performance. Meanwhile, the future structural design should also aim towards achieving stronger, safer, and aesthetically pleasing structures at lower costs by using the most effective and durable materials in the most efficient and optimized geometry.

\subsection{FRP composites in civil infrastructure and their importance}

Fiber reinforced polymer (FRP) composite, the product of combination of fibers and polymers, is one of the most effective and durable materials. This material has many advantageous properties such as lighter weight, corrosion resistance, high strength and stiffness to weight ratios, low thermal expansion, high fatigue and damage tolerance, non-magnetic properties, ease of transportation, tailor-ability, and durability. There is high consensus among the experts that this material is one of the most promising structural materials to have emerged in the last few decades.

In the construction industry, the most commonly used FRPs are: Glass-FRPs (GFRPs) and Carbon-FRPs (CFRPs). The GFRPs are comparatively cheaper and economical and are more 
preferred in the mass civil infrastructure applications. The CFRPs can be 10 to 20 times more expensive than conventional materials and are limited to research-oriented work.

In the civil engineering industry, FRPs are increasingly used as strengthening material for older structures, as internal reinforcements for pavements and slabs, and as all-FRP shapes in new constructions. FRP wraps and laminate are used in strengthening of columns, beams, slabs, and bridge decks and have resulted in tremendous increase in strength, stiffness, durability and other structural properties of deteriorated structures. These light-weight FRPs have become the material of choice in the repair and strengthening sector. However, FRPs have not found similar momentum when it comes to new constructions of structures. Conventional materials such as steel, timber and concrete still continue to be heavily used in new constructions. While these conventional materials offer great advantages and have stood the test of time, they have disadvantages such as corrosion, decaying, cracking, and other deteriorations. These deteriorations result in the reduction of strength, modulus, and load carrying capacity of structures and thus, require frequent maintenance or rehabilitation at regular intervals. In today's competitive economy, it is unproductive to spend such huge costs in just maintaining and repairing these deterioration-prone structures in every few years. Now, infrastructure has even bigger roles to perform and even more forces to withstand; be it from natural calamities or from man-made explosions. With the use of non-corrosive and durable FRP composites, construction of stronger, safer, long-lasting structures that require minimal periodic maintenance during their service life can be a possibility.

\subsection{Context}

FRP material, despite having a great potential, has not been tapped well by designers and builders especially in new construction of buildings and bridges, primarily due to:

- higher initial cost, lack of ready-to-use availability compared to conventional materials;

- lower stiffness requiring uneconomical larger sections to meet deflection limits;

- lack of ductility analogous to steel and brittle failure modes;

- difficulty in joining structural FRP components to form a structural system;

- lack of appropriate design codes and guidelines;

Researchers have been trying to avoid the brittle failure in FRP sections by hybridizing them with different fiber and resin types which have some pseudo-ductility characteristics, but the inherent brittleness of composites could not be avoided. To fill-in the gaps and overcome all these drawbacks associated with FRP composites, this thesis has attempted to provide an innovative solution in the form of hybrid GFRP-steel sections, i.e., by embedding steel members inside flanges and webs of Glass-FRP (GFRP) beam and deck sections. The hybrid GFRP-steel sections will utilize the benefits of steel such as higher stiffness, higher shear strength, higher creep performance, and higher ductility. The ductility of steel will allow redistribution of internal forces, dissipation of energy during impact and seismic forces, warning of structural problems through plastic deformations and thus, increasing safety of a structure. Further, steel embedment inside brittle fibrous and anisotropic FRP material will result in stronger connection schemes, and reduced stress concentration and failure in connection regions. Use of steel sections are also expected to enhance the buckling behavior of compression flanges and web elements by improving force transfer between them. Embedding low-cost steel plates inside GFRP sections will further help to bring down the initial costs of GFRP composites. Also, higher specific 
strength of FRPs reduces the volume and weight of a material to be used in a structure, which inturn reduces the overall weight of the superstructure and the size of the sub-structure. GFRPs and embedded steel plates do not undergo corrosion and last much longer than their counterparts and hence save annual maintenance costs. With all the advantages, it is inevitable that the design codes and guidelines will be developed to ensure widespread usage of these advanced materials in the construction of stronger, safer, and durable civil infrastructure.

\subsection{Objectives and scope}

The following objectives are proposed to be accomplished through this research:

1. Evaluate the feasibility of embedding steel plates at strategic flange and/or web locations of GFRP multi-cellular and box-beam sections during manufacturing through vacuum-assisted resin infusion process.

2. Experimentally evaluate component level GFRP and GFRP-steel hybrid multi-cellular sections and box-beams under static and fatigue loads at different span-to-depth ratios to determine their structural responses in terms of flexural/shear response, stiffness, deflection, and failure modes including the effects of steel component being fatigued beyond yield-strain values. In addition, investigate coupon-level material characterization of hybrids.

3. Develop FE models to predict structural responses of GFRP-steel hybrids and potentially to improve the hybridization schemes.

4. Experimentally evaluate behavior of single- and double-row bolted connections on all-GFRP and GFRP-steel hybrid sections under tensile loads to determine and compare their failure strength and failure modes.

In addition, the GFRP-steel interfacial bond integrity in the hybrid sections subjected to fatigue loads beyond steel yield load levels will be evaluated through scanning electron microscopy (SEM) to observe the formation of any delamination. Manufacturing issues with the use of steel plates due to thermal co-efficient mismatch between GFRP and steel will also be evaluated by performing differential scanning calorimetry (DSC) tests.

This work will be focused on box-beam and multi-cellular panel sections as a representation of beams in buildings and bridge decks in bridges. The GFRP-steel hybrid sections are manufactured with 0.125 " thick steel plates inserted in the flanges and/or webs of the section. The experimental evaluation of all-GFRP box-beams and GFRP-steel hybrid box-beams of crosssections 6" 6 " will be performed under three-point static flexural and shear loads. Similarly, multi-cellular panel of cross-section $46^{\prime \prime} \times 8^{\prime \prime}$ with/without embedded steel plates will be experimentally evaluated under three-point static flexural loads. Fatigue tests will be conducted on all-GFRP and GFRP-steel box-beams at a frequency of $1.0-2.5 \mathrm{~Hz}$ for a minimum of $500 \mathrm{k}-1 \mathrm{M}$ cycles with $40-80 \%$ of failure loads under three-point bending setup. The aspects covering the extensive creep behavior of GFRP-steel hybrid sections, durability and aging of such hybrid systems are out of the scope and can be further investigated. The finite element modeling will be conducted in the commercially available finite element software ABAQUS. 


\subsection{Organization of the dissertation}

The dissertation is divided into twelve chapters to have a proper segregation between topics and to enhance a reading experience for the readers. A brief overview of the organization of this dissertation is as follows:

- Chapter 2: This chapter provides a basic literature review on FRP composites and their use in civil infrastructure sector. It highlights the importance of GFRP composites for civil structures and presents shortcomings of GFRP that are restricting their usage in new construction of civil structures.

- Chapter 3: This chapter provides a literature review on the hybrid FRP composites. The advantages and disadvantages of GFRP-CRRP hybrids and the importance of fiber-metal laminates (GFRP-steel hybrids) to overcome the shortcomings of GFRP composites are also addressed.

- Chapter 4: This chapter focuses on the test sections (multi-cellular section and box-beams) that are manufactured and tested for this research. It presents section details and manufacturing of hybrid sections and summarizes testing equipment and test methods.

- Chapter 5: This chapter exclusively presents the design, analysis, testing and field implementation of GFRP-steel hybrid cellular section (wicket gate), which also serves as a preliminary study prior to further analysis of hybrid GFRP-steel sections.

- Chapter 6: This chapter discusses the material characterization by testing coupon level specimens cut from the hybrid box-sections and provides sectional properties of the beam sections. This chapter also presents the computation of the bending and shear stiffness of the hybrid box-beams based on initial static testing of the hybrid box-beams. In addition, guidelines for hybrid GFRP-steel beams under service loads for civil infrastructure application are also addressed.

- Chapter 7: This chapter provides detailed experimental results, evaluations and discussions associated with GFRP and hybrid beams under static flexural, shear, and fatigue loadings. In addition, failure strength and failure modes are discussed.

- Chapter 8: This chapter provides theoretical equations to predict structural response of hybrid GFRP-steel section under tensile and bending loads. In addition, a design example of a hybrid GFRP-steel box-beam is presented.

- Chapter 9: This chapter discusses the finite element modeling of GFRP and hybrid beams under bending and shear loads including their validation with experimental results. In addition, it provides parametric analysis through placement of steel sections on box-beam corners to investigate the hybrid's structural performance.

- Chapter 10: This chapter provides experimental results and evaluations on bolted connection on GFRP and GFRP-steel hybrid section. In addition, this chapter presents finite element modeling and results on the bolted connections.

- Chapter 11: This chapter summarizes the important findings from the previous chapters and provides conclusions. In addition, it provides recommendations for future research work for further understanding of GFRP-steel hybrid sections. 
- Appendix A: It provides computation for the center of gravity and composite moment of inertia of the hybrid GFRP-steel panel (wicket gate).

- Appendix B: It provides the non-destructive testing on the GFRP-steel hybrid laminates to detect the internal debond between GFRP and embedded steel plates.

- Appendix C: It provides the study on the GFRP-steel interface regions through the use of differential scanning calorimetry and scanning electron microscopy for observing the degree of resin cure and the bond integrity, respectively.

- Appendix D: It provides the cost comparison between non-hybrid GFRP and hybrid GFRPsteel sections (panels and box-beams).

\subsection{Research impact and significance}

- This research will contribute towards the development of hybrid GFRP-steel sections that are superior to all-GFRP sections and has a possibility to change the current state-of-the-art of GFRP manufacturing to develop hybrids for infrastructure application.

- The gaps in GFRP composites in term of higher initial cost, lower stiffness, brittle nature, member connection issues will be abridged by hybridization with steel to develop stronger, safer, and durable structures.

- Outcomes of the research will be beneficial for designing longer-span beams and bridge-decks with hybrid composites with no-compromise on serviceability limits and optimization of the hybrid sections for strength and stiffness as compared to non-hybrid sections.

- Numerous applications that would benefit from this study include structural members in buildings and bridges, pipelines, navigational gates, etc. where serviceability, strength, fatigue resistance, durability, and low-maintenance are of paramount importance. 


\section{Chapter 2. \\ FRP Composites in Construction}

\subsection{Introduction}

This chapter discusses previous researches that focused on the designs and usage of fiber reinforced polymer (FRP) composites with other structural material to achieve better and desirable properties that are needed for any civil infrastructure. In the beginning, the chapter briefly summarizes the historical and present-day outlook of FRP composites, its manufacturing process, associated advantages and the rationale behind the desire of civil engineers to use them in construction industry. Then, it highlights the limitations of FRP composites and the reasons for their minimum usage by designers and builders in the construction of buildings and bridges. After setting up the background, this chapter explores the past research efforts conducted by previous researchers to counter the limitations of FRP composites for their use in construction industry by utilizing concepts of hybridization with different materials. After discussing several hybrid concepts proposed by previous researchers, the chapter establishes a research gap that needs to be explored and highlights the FRP-steel hybrid model concepts and researches published on those concepts. Finally, the chapter summarizes the research gap and its importance to the next-generation civil infrastructure constructions.

\subsection{Brief overview on FRP composites}

\subsubsection{Historical outlook}

Broadly, composites are the combination of two or more materials or constituents. Use of mud and hay straws to build a house in the early years of civilization is a perfect example of a composite. As such, there are many examples of composites since ancient times that can be thoroughly studied in the literature. Our present-day understanding of composites include fiber reinforced polymers or fiber reinforced plastics (FRP), that are made of two different constituents - fibers and polymer. The common fibers are: glass, carbon, aramid, basalt, and natural fibers, and the common polymers are either thermoplastics (acrylic, nylon, polycarbonate, polyethylene, etc.) or thermosets (epoxy, polyester, vinyl ester, etc.). Thermoset resins cannot be reversed once they are cured and have better structural properties than thermoplastics, therefore, they are heavily used for structural purposes. The fibers and the matrix exhibit different physical and chemical properties but nonetheless form a strong material when combined. The first known present-day FRP composite product was a boat hull manufactured in the mid-1930s as part of a manufacturing experiment using a fiberglass fabric and polyester resin (Hensher, 2016, Yazdanbakhsh \& Bank 2010). During the 1940s, the interest shown by U.S. Air Force and Navy on FRP composites, given their lighter weight and corrosion resistance properties, propelled their popularity. After World War II, FRP composites entered enormous sectors such as marine, aerospace, defense and automobiles. During the late 1970's and early 1980's, many applications of composite products were introduced in the restoration of existing structures and construction of new infrastructure in Europe and Asia (Bakis et al. 2002). 


\subsubsection{Present-day outlook}

At present, FRP composites are widely used in marine, aerospace, aircraft, automobiles, civil infrastructure, household appliances, electrical components, consumer and sporting goods, and many other industries. According to a report by Grand View Research, Inc. (GVR 2016), the global fiber reinforced polymer (FRP) composites market size was worth USD 114.13 billion in 2016 and is anticipated to reach USD 282.9 billion by 2025 , according to a report. While automotive segment ranked as the biggest revenue generator for the overall composites market in 2016, construction segment ranked at the second position Moreover, also in the same year, glass fiber reinforced polymer (GFRP) became the most widely FRP composite with over 65\% market share (GVR 2016). Today, FRP composites are built-up from individual plies of continuous, straight, chopped, random fibers/fabrics in a polymer matrix which are laminated layer-by-layer to build the final material/structure as shown in Fig. 2-1.

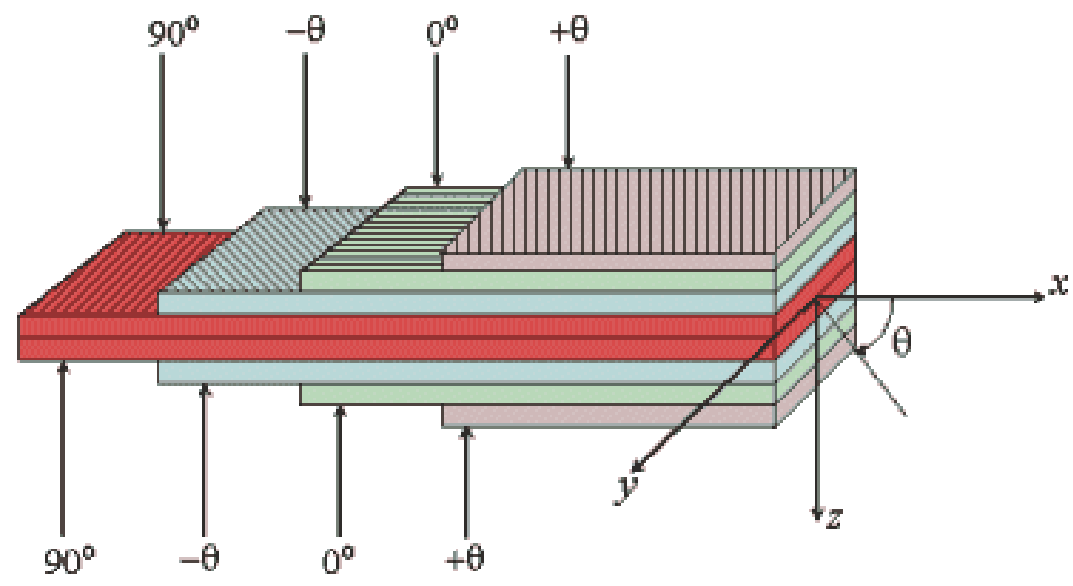

Figure 2-1. FRP composite laminate (Source: www.aerospaceengineering.blog)

\subsubsection{Manufacturing of FRP composites}

FRP composites are manufactured by using different techniques such as pultrusion, vacuum infusion, wet layup, compression molding, extrusion, filament winding, etc. While these processes have their own advantages and limitations, pultrusion and vacuum infusion are the most commonly and widely used manufacturing methods. Pultrusion as shown in Fig. 2-2. is a continuous process where fibers in the form of roving and mat are saturated in resin bath and pulled through a heated die to form structural shapes with constant cross-sections, whereas vacuum infusion process as shown in Fig. 2-3 utilizes fibers in the form of fabrics and mat to be laid into the mold covered with vacuum bagging film where resin is infused via tubing. This infusion process can produce structural shapes of both uniform and non-uniform sections with fibers oriented in any direction at specific and targeted locations. 


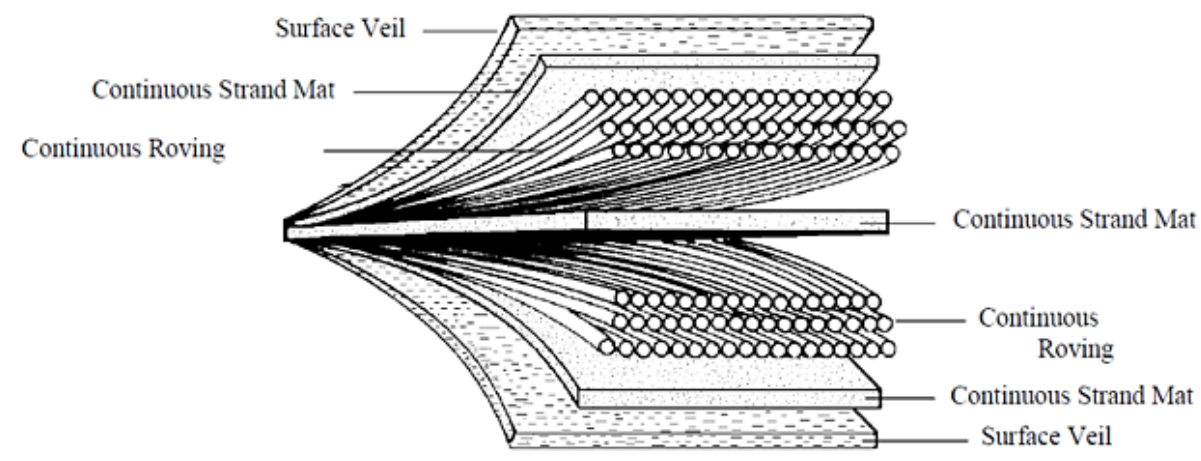

Figure 2-2. Fiber/fabric layup in pultrusion process (Courtesy of Creative pultrusion Inc.)

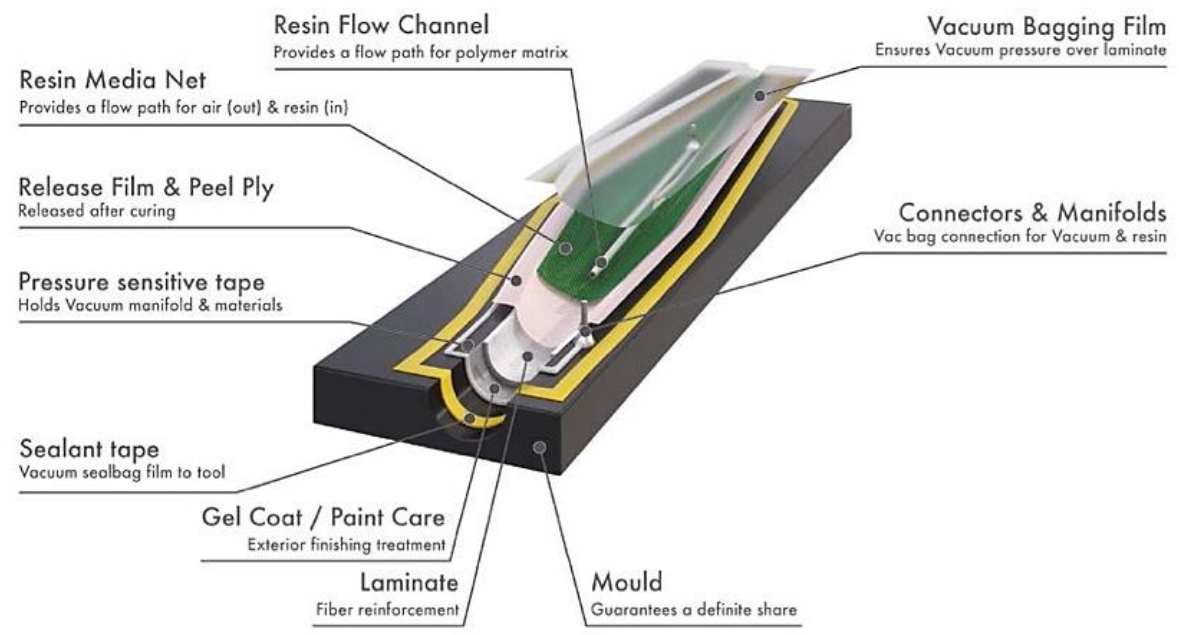

Figure 2-3. Vacuum infusion process (Courtesy of intermasgroup.com)

\subsubsection{Continued rise of FRP composites}

FRP composites are seeing a continued rise with each passing year in almost every sector mentioned above. The reasons for their popularity and continued rise in demand are their unprecedented advantages that they offer, which are highlighted in the following bullets.

- Lightweight

- High strength

- Corrosion resistance

- High-impact strength

- Design flexibility

- Part consolidation

- Nonmagnetic and radar transparent

- Low thermal conductivity

- Durability

These composites are lightweight and have high strength. The lightness or a specific strength is an important requirement in industries such as aircrafts, automobiles, and civil infrastructure construction. The lighter material with higher strength reduces the overall weight of a structure, 
saving huge amount of costs in labor, material use, and other related advantages. For instance, lighter self-weight of an airplane reduces amount of fuel required and increases passenger carrying capacity of a plane. For another instance, lighter self-weight of buildings and superstructure reduces the size of foundation and overall components of the building. These materials are corrosion resistant unlike metals and can stand up to severe weather and environmental conditions. FRP composites can absorb impact and for instance, they are used in bulletproof vests and panels, and to shield airplanes, buildings, and military vehicles from explosions. Composites can be molded into complex shapes more easily than most other materials, which gives designers the freedom to create almost any shape or form and reduces the number of parts in a machine or structure, saving long-term maintenance costs and time. The variety and complexity of shapes and forms that can be achieved from FRP can never be imagined with the use of conventional materials. FRP composites, with exception of carbon composites, are nonmagnetic and radar transparent as they contain no metals and can be used in magnet-sensitive equipment and defense aircrafts that cannot be detected with radar. Composites are good insulators as they do not easily conduct heat or cold and can be used to replace metal parts. FRP composite's inert and corrosion resistant nature make them long lasting and durable. Though FRP composites have been in service for less than 50 years, they have been performing well without significant maintenance.

\subsection{FRP composites in the construction industry}

The research and development of FRP composites for their use in civil engineering has progressed substantially in last few decades. They are largely preferred in the construction industry because of their lighter weight, strength, corrosion resistance, and high durability characteristics-the properties which are sought after in the construction materials. In terms of revenue generated from the usage of FRP composites, construction industry falls in the second place after automotive industries with over $25 \%$ of the total market share (GVR 2016). With increasing need of repair and strengthening of American highways, the use of composites in construction industry is expected to increase substantially over the next few years. Since the cost of carbon fiber composites is too high, the construction industry leans heavily towards glass fiber composites. GFRP composites dominated the industry with over 65\% market share in 2016 (GVR 2016). They have been increasingly used in civil infrastructure from repair and strengthening of old structures to building new structures, which are briefly discussed in this section.

\subsubsection{Strengthening and repair of deteriorated structures}

In the domain of repair and strengthening of deteriorated structures, especially concrete structures, FRP composites have proven themselves as one of the best repair materials and have been dominating this industry (Fig. 2-4). For repair efforts, FRP properties such as lightweight, high strength to weight ratio, durability, ease of transportation, easy installation, less labor etc. have made it stand out among other conventional materials. FRP wraps and laminate have been used in repairing and strengthening of columns, beams, slabs, and bridge decks and have resulted in tremendous increase in strength, stiffness, durability and other structural properties. A deteriorated reinforced concrete beam can be strengthened for flexure by bonding few layers of wrap on the tension side of the beam with fibers running parallel to the beam. Similarly, the beam can be strengthened for shear by bonding FRP wraps on the sides of the beam. Deteriorated reinforced columns are also strengthened for enhancing axial strength and ductility by wrapping 
them with few layers of FRP wraps with fibers principally running in circumferential direction (Fig. 2-4). The traditional use of steel plates to strengthen RC beams and RC columns respectively is labor intensive, cumbersome and prone to debonding problems due to corrosion of steel plates. In addition to strengthening of RC structures, the potential of FRP wraps to increase the flexural and shear strength, stiffness, ductility, and durability of timber beams and/or columns has been demonstrated in various research studies and field applications. In the last few years, use of FRP composites, mainly Carbon-FRPs, to strengthen steel structures has been a common practice. High-stiffness CFRP wrap enhances the mechanical properties of steel beams and columns in addition to being lighter in weight and ease of application (Bakis et al. 2002).

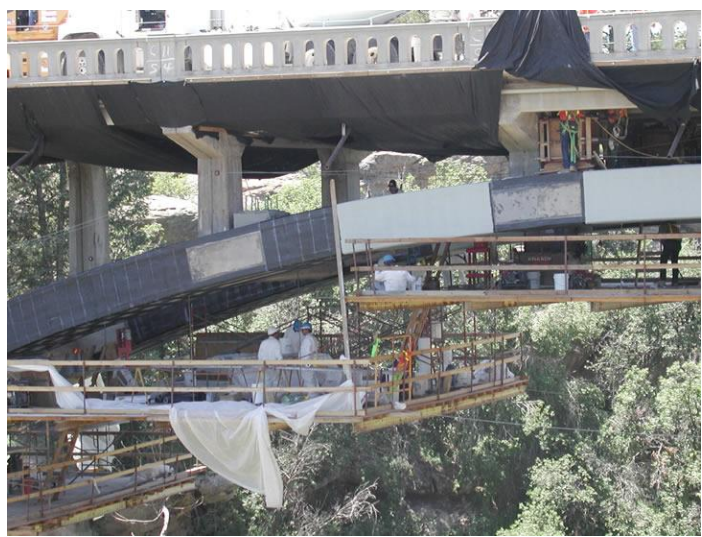

(a)

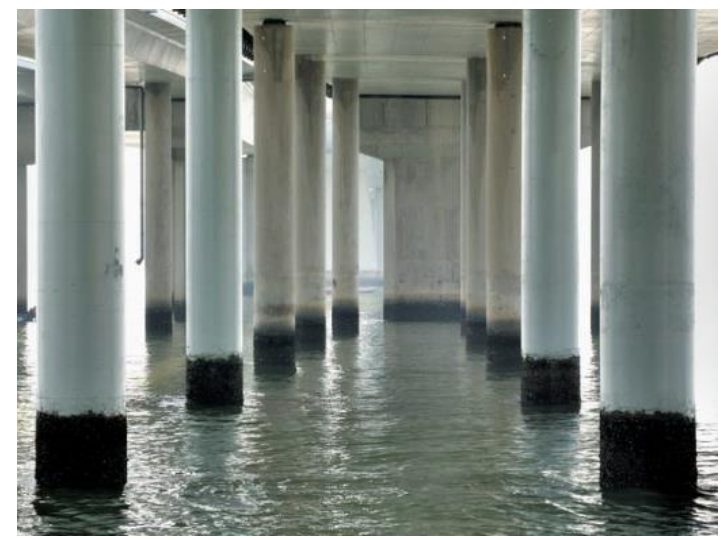

(b)

Figure 2-4. (a) FRP wrapping on a bridge arch (Sonnenschein et al. 2016), (b) Bridge column repair with FRP wrapping (giatecscientic.com)

\subsubsection{Internal reinforcements}

Steel reinforcements are widely used in reinforced and prestressed concrete structures; while they present good strength and ductility to a structure, they are highly susceptible to corrosion. When exposed to deicing salts and marine conditions, concrete becomes vulnerable to chemical attacks, which breaks down the alkaline barrier of cement causing corrosion in the steel reinforcements. Corrosion of steel reinforcement increases the volume of steel causing concrete deterioration such as delamination, spalling, and cracking. It is estimated that more than $30 \%$ of the US bridges need repair because of the corroding reinforcements. FRP composites offer better resistance to environmental agents as well as high stiffness-to-weight and strength-to-weight ratios when compared with conventional construction materials. FRP reinforcing bars have been used in many demonstration projects and field applications, such as bridges, parking garages, watertreatment plants, and concrete pavement and until mow, have not reported significant deterioration or anomaly. Durability studies conducted on FRP reinforcements under saline environment have shown impressive results. The tensile-strength retention of the GFRP bars has been predicted to be roughly $70 \%$ even after a service life of 100 years at a mean annual temperature of $50^{\circ} \mathrm{C}$ (Robert \& Benmokrane 2012). The leftover strength after a complete service life of a structure is still higher than the design tensile strength specified by ACI 440. Studies have shown that fibers are more susceptible to alkali, especially glass fibers. Therefore, resin used in the FRP composite that acts as a load transfer medium between fibers plays an important role in protecting the fibers. The durability of GFRP composite bars depend upon the type of resin used. For instance, GFRP with vinyl ester resin lasts longer than as a bar with a polyester matrix 
(Benmokrane et al 2012). Nevertheless, it can be concluded that FRP composites are more durable than the fibers used in making composites. A study on a life cycle cost analysis on CFRP reinforcements in prestressed concrete bridges over steel reinforcement protected with epoxy coating and cathodic protection found that CFRP reinforcements had lower life cycle cost in a high-traffic volume area, being the least expensive alternative within 23 to 77 years of initial construction (Eamon et al. 2012). In highly aggressive environments exposed to deicing salts, carbon-FRP reinforcing bars can be the most promising alternative to steel. Nonetheless, GFRP reinforcements can provide additional applications in nonmagnetic structures in hospitals and military structures which are undetectable by radar (Micelli \& Nanni 2004).

\subsubsection{New constructions with FRP shapes}

FRP composite materials have been used predominantly for repair and strengthening purposes but have not been seen in new buildings and bridges construction at the same scale. However, since mid-1990's, there has been an uptick in their use in new structures, through pilot projects, as hybrid and all-composite constructions (Hollaway 2010, Keller 2001). FRP shapes and profiles are commonly used as bridge deck slabs, as pedestrian bridges, as claddings, facades, roofing, doors and windows panels in buildings, as structural components in modular housing, as hydraulic lock walls and gates in lock and dam structure, as pipelines, and many other architectural applications. The use of FRP composites in pedestrian and vehicular bridges as deck slabs can be attributed to their lighter weight, high corrosion resistance behavior, low maintenance costs and good durability at aggressive environments (Fig. 2-5). The weight of an FRP deck slab is just $20-25 \%$ of that of comparable concrete deck slab. In addition, the manufacturing of these prefabricated decks brings all the benefits of controlled, industrial off-site fabrication, faster transportation, and rapid on-site assembly, leading to the minimization of traffic disturbance (Mara et al. 2014). The light weight of FRP composites is also beneficial in replacing deteriorated steel or concrete decks, where the load carrying capacity of the structure is improved without significantly adding dead loads to piers and abutments (Smits 2016). Usually, bonded FRP plates, modules, and sandwich panels are used to make bridge deck slabs. The majority of the FRP plates and modules are manufactured by a pultrusion process and are then glued together to make the desired bridge deck panel. Owing to low elastic modulus of GFRP composite, deformations are always the determining design factor, limiting the span lengths are limited and a primary load-carrying structure with several support girders is often required (Keller 2001).

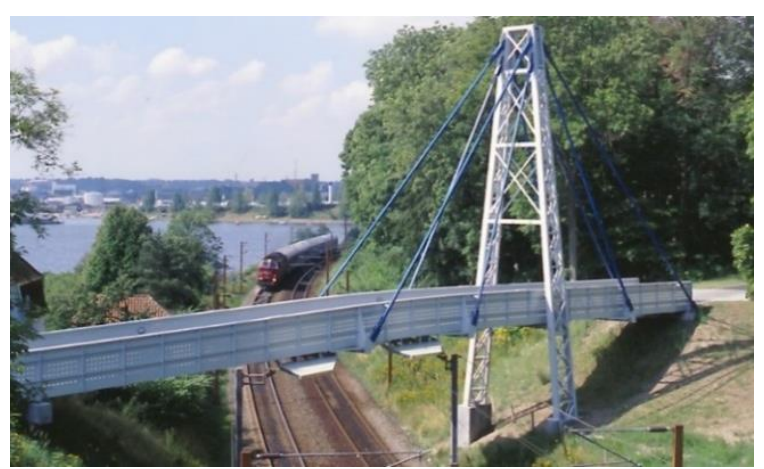

(a)

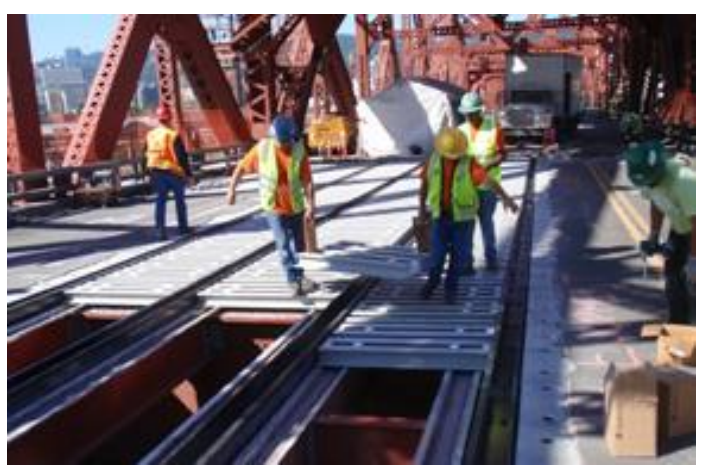

(b)

Figure 2-5. (a) Fiberline bridge at Kolding, Denmark built in 1997 (Fiberline), (b) Bridge deck installation at Penn State by ZellComp Inc. (ZellComp) 
FRP composites are also used in facades and building envelopes. While building facades, the behavior of material and structure against wind load, weather conditions, and sustainability is examined critically (Miguel and Diaz 2015). And because of their strength, lightness, tailorability, and corrosion resistance properties, FRP composites have become an excellent alternative to steel, concrete, and aluminum in building facades and building envelopes. The figures 2-6a and 2-6b show FRP composite façades in the Thematic Pavilion, South Korea and in the BBVA bank, Spain, respectively. The cost of manufacturing GFRP composite façade on this BBVA bank project was cheaper than precast concrete, aluminum honeycomb panel, and stainless-steel by $10 \%, 20 \%$, and $50 \%$, respectively (Miguel and Diaz 2015). Currently, conventional materials and claddings are heavy, therefore with the use of FRP composites, high rise buildings can extract the most advantages. Also, because of the FRP's low thermal conductivity, they provide the opportunity to construct building walls with high thermal performances, thus contributing towards energy efficient building structures (Bedon 2016).

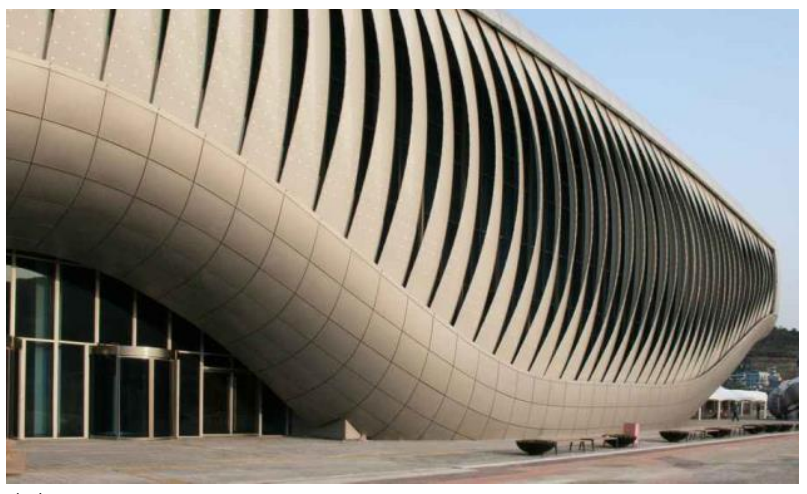

(a)

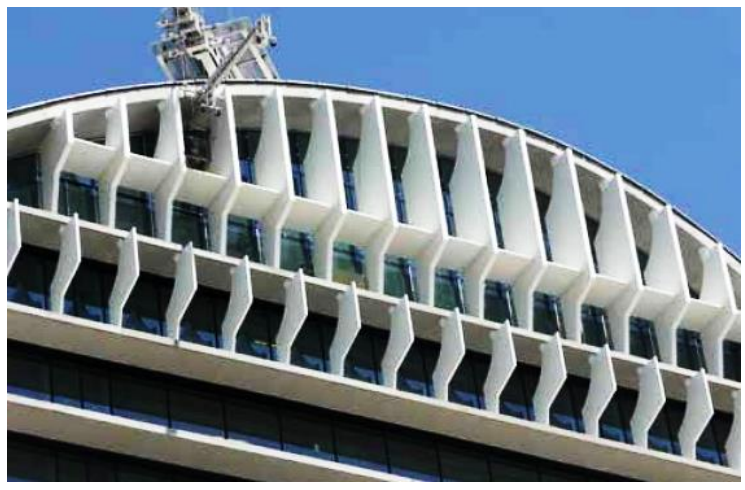

(b)

Figure 2-6. (a) One ocean's kinetic façade in South Korea (Soma), (b) GFRP composite sandwich panel facade installed on BBVA bank, Spain (Miguel and Diaz 2015)

FRP composites have also been used in several demonstration projects for water environments as load bearing piles, fender piles and sheet piles in marine and waterfront environments (Lampo et al. 1998). FRPs have also been used as oil and gas storage tanks, decking for ocean environment and cold-water pipes (Vijay et al. 2016). In Japan, more than four hundred FRP hydraulic gates of different styles of such as slide gate, roller gate, miter gate etc. have been installed since 1960s and are still in a good shape with little or no maintenance (Tomiyami \& Nishizaki 2006). FRPs have also been used in replacing old timber miter gates in Noord Brabant, Netherlands in 2000 with significant cost and weight reductions. Similarly, FRP composite was used to replace steel miter gates in Canal des Voges, France and timber wicket gates (Fig. 2-7a) in the Illinois river (Vijay et al. 2016). The largest FRP lock gate in the world with a of size $10.5 \mathrm{~m} \times 13 \mathrm{~m}$ has been installed in the Wilhelmina canal in Tilburg, France (Fig. 2-7b). 


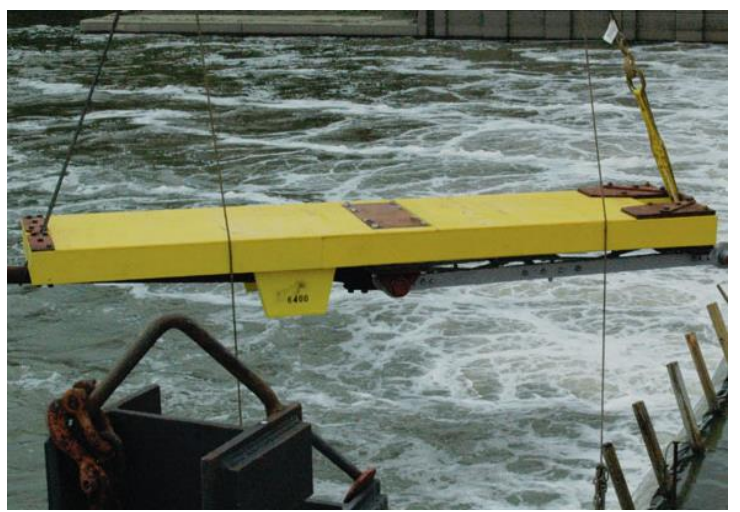

(a)

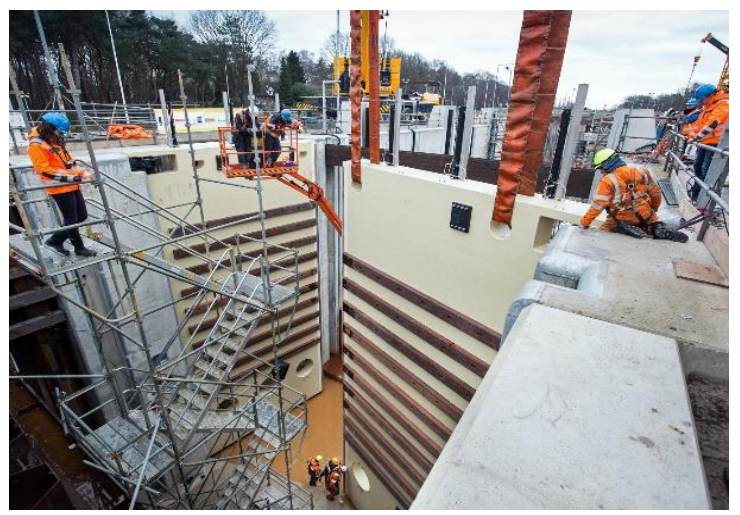

(b)

Figure 2-7. (a) FRP wicket gate in Illinois River, (b) FRP miter gate in Wilhelmina canal (Source: Aliancys)

Components made of FRP composite materials are used in household appliances such as kitchen countertops, shower receptors, bathtubs, enclosure sets, fireplace surrounds, windowsills, wall panels, floor tiles etc. because of their superior properties like corrosion resistance, longer life, low maintenance, ease in workability, fire retardancy etc. Despite tremendous success of FRP composites in new constructions, their application as primary structural members in buildings and bridges has still been slower to gain acceptance as discussed in the next function.

\subsection{Limitations of GFRP composites in new constructions}

Though FRP provides many benefits including a high ultimate strength, light weight, corrosion resistance, easy field and shop application, and formability, there are several drawbacks that restrict their wide usage in the new construction sector such as their relatively low elastic and shear modulus in comparison to steel, brittle failure modes, higher initial cost, and excessive stress concentrations in and around connections, etc. More specifically, the following six limitations are major reasons not letting GFRP composites to be a material of choice among architects and designers in new constructions.

\subsubsection{Higher initial costs}

GFRP components enable rapid installation, rendering a less negative impact on users and society and improving social sustainability (Mara et al. 2014). However, the apparent initial high cost of FRP materials has been a major obstacle for their widespread use in the construction industry. Many proponents of FRP composites often claim that the potential reduction in maintenance costs associated with using noncorrosive GFRPs will eventually outweigh the higher initial cost of construction, as compared to using conventional materials within its service life (Eamon et al. 2012). However, the initial cost is often big enough to dissuade investments of large scale when one considers the time value of money. It is therefore important to reduce the initial cost of GFRPs to make them lucrative and cost-competitive against existing materials. 


\subsubsection{Lack of codes and design guidelines}

Construction industry often expresses a serious concern in the lack of comprehensive design codes, guidelines and specifications around usage of FRPs (Belarbi \& Acun 2013). Lack of official standards and guidelines add to the difficulty associated with creating a base for designs and thus brews skepticism amongst professional engineers and public clients. Consequently, the use of FRPs get restricted to the research community (Zaman et al. 2013). Hence, a strong partnership between scientific research community, manufacturing industry, and private-public sectors is needed to answer technical questions on FRP composites and develop a national standard on the use of FRP composites in new construction (Haghani \& Olsson 2018). While this research does not aim to put forth the codes and design guidelines, respective official bodies can consider studies like these as valuable input when framing the standards.

\subsubsection{Lower stiffness and brittle failure mode}

GFRP composite materials possess inherently high strength-to-weight ratios, but their modulus of elasticity is low relative to common civil engineering (CE) construction materials such as steel and reinforced concrete. Materials with low elastic modulus exhibit large deflections, even at moderate loads. As a result, serviceability (e.g., deflection) issues or limitations constrain GFRP structures (Park et al. 2013, Lombardi \& Liu 2011). Often, vast amount of glass fiber is used to address serviceability limitations, but this is not an economical approach as much of the glass fiber strength remains unused and adds to the high initial cost of GFPRs.

The use of GFRPs can be problematic when large deflections are an issue and where significant creep could be anticipated. The lower effective modulus can be attributed to a lower shear stiffness. In addition to having lower stiffness, GFRP composites are linear to failure and do not display ductility or malleability like those of metals' progressive yielding and strain hardening with detectable warning. The failure is sudden and catastrophic with insufficient warning and low residual load bearing capacity, which is not desired in the design of structures. As glass fibers are brittle, their combination in a component makes them even more hazardous - when one fiber breaks the stresses on the other remaining fibers increases suddenly producing failure earlier than expected (Burgoyne 2009). In ductile structure, loads are redistributed to other elements during failure, whereas in brittle structures, elements just snap during failure (Burgoyne 2009). This unfavorable failure mode results in conservative structural design incorporating cautious limits preventing full exploitation of the outstanding mechanical performance of materials, forcing them to be even more expensive (Czel et al. 2015).

\subsubsection{Connection issues}

Three basic types of connections exist for FRP materials: mechanical, adhesive bonding, and a combination of both. In adhesive bonding, chemical adhesives are used in bonding two GFRP components. A time-consuming degreasing and surface preparation are necessary to obtain high joining strength. The adhesive surface has very high susceptibility towards degradation likely reducing the bonding strength (Matsuzaki et al. 2008). Therefore, construction sector which is used to connecting steel members with mechanical fasteners, does not prefer bonded connections. The common use of mechanical connections in connecting structural members is due to ease of inspection and assembly, tolerance to environmental effects, possibility of part replacement, and minimum surface preparation (Camanho \& Matthews, 2001). However, bolted connection in 
GFRP composites is not very efficient due to high stress concentrations created by the presence of hole in a laminate and random orientation of load-carrying fibers at the region of holes.

A drilling process to fabricate bolt holes breaks reinforcing glass fibers causes peeling of the higher plies at the entry of the hole, resin degradation on the wall of the hole, and delamination of the last plies in the laminate, and thereby initiating crack, decreasing strength of the connection, and producing premature local failure (Matsuzaki et al. 2008, Karbhari et al. 2000, Boscato, 2017). The lack of economical and effective means of connecting individual GFRP composite members prevent standard FRP profile shapes from being used in multistory frame building structures (Bank, 2006). In addition to lower connection strength, the stiffness of the bolted connection is very low due to slip in the FRP bolted connections and lower bearing strength of GFRP composites (Mara et al. 2016). The design of connections in FRP composites is yet to be understood well. However, due to material inhomogeneity, the connections always form the weak link in the overall structural system, leading to premature failure. Due to the anisotropy of GFRP materials, the mechanical behavior of joints is generally more complex than that in conventional isotropic materials. (Boscato, 2017). Consequently, high safety factors are adopted when designing structures with GFRP composites, making them more cost inefficient.

\subsubsection{Poor performance under elevated temperatures and fire}

FRP composites have low fire resistance and there is also a very little knowledge on their loss of strength in fire. The effect of fire in FRP composites leads to a loss in its modulus value. When the temperature of the composite during heating is below the glass transition temperature, the loss in modulus is reversible (Karbhari et al. 2003). But, further increase in temperature results in the degradation of the chemical structure of the resin. In construction sector, most building structures must satisfy the requirements of building codes related to the behavior of structures in a fire, which stipulates minimum time available during a fire event before a structure collapses and the health effect of released combustion products to the buildings' occupants (Hollaway, 2010). It is believed that when the outermost layers of a composite lose their resin due to heat-induced gasification, they act as an insulating layer, slowing heat penetration into the depth of the composite (Karbhari et al. 2003). Due to technological advancement in past few years, fireretardant resins have been developed to slow down the effect of fire. Use of intumescent coatings on the surface of composites can also reduce the effect of fire by charring and producing gases to foam the developing char (Keller et al. 2006). In addition, using construction measures such as use of redundant structural system to slow-down the effect of fire can help mitigate the potential loss during fire.

\subsection{Conclusions}

FRP composites, mainly GFRPs, are one of the most promising materials for civil infrastructure because of their lighter weight, non-corrosiveness, high strength, and durability. Though GFRP composites are used in the repair and strengthening of old structures, they are not quite commonly used in new constructions. Among different limitations discussed within this chapter, the higher initial cost compared to conventional building materials, lower stiffness, brittle failure modes, poor connection issues have restricted the usage of GFRP composites in new constructions. The next chapter discusses different hybridization techniques that can rectify the above-mentioned limitations of GFRP composites. 


\section{Chapter 3. \\ Hybridization of GFRP Composites}

The chapter provides previous research findings on FRP hybrids. Specifically, the chapter highlights on GFRP-CFRP and metal-FRP hybrids and presents the advantages and importance of the latter for overcoming shortcomings of GFRP composites to develop affordable sections for new constructions.

\subsection{Introduction}

FRP composites containing more than one type of fibers are commonly termed as hybrid FRP composites: be it on a small scale (single fiber or a tow) or be it on a large scale such as interlayer, intra-yarn, intra-layer (layers) (Swolfs et al. 2014). Different hybrid types are interlayer (interply) hybrids where alternate layers of different materials are stacked (Fig. 3-1a), intra-layer (intraply) hybrids where two different fibers are present within a single layer (Fig. 3-1b), and intrayarn hybrids where fibers are different materials are bundled in a random manner (Fig. 3-1c). The purpose is to construct a new material that retains the advantages of the constituents but not their disadvantages (Kretsis 1987). But there are many other factors such as cost, weight, failure strain, post-failure behavior, fatigue performance, ductility, and many other mechanical properties enable the use of hybrid FRP composite to meet the exact requirement of the design. These hybrid composites offer a better balance in mechanical properties than non-hybrid composites.

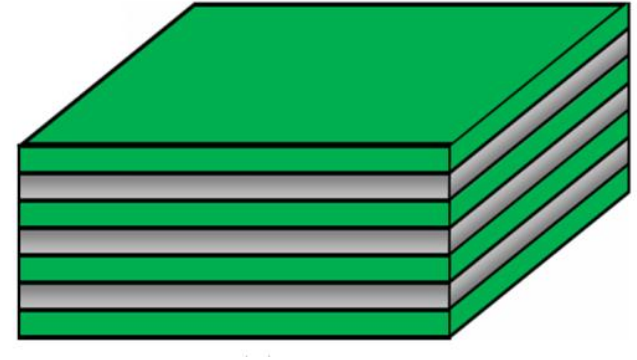

(a)

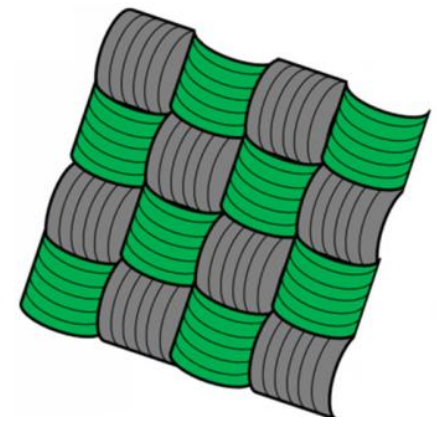

(b)

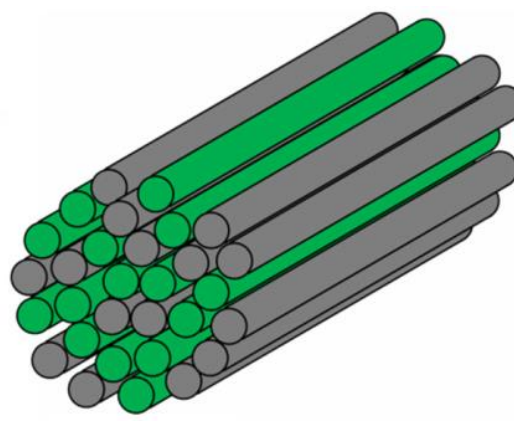

(c)

Figure 3-1. Hybrids: (a) interlayer or interply, (b) intralayer or intraply, (c) intayarn (Swolfs et al. 2014)

The hybrid combinations can be: Carbon/Glass, Carbon/Aramid, Glass/Basalt, and many other combinations. Based upon the design requirement, the hybrid fiber type can be chosen. For example, the incorporation of glass fibers in CFRP appears to improve impact properties and to increase the strain to failure of the carbon fiber in tension. The addition of carbon fibers to the surface of GFRP beams markedly increases the flexural modulus. In Carbon/ Aramid hybrid high impact resistance and tensile strength of aramid fibers combine with high compressive and tensile strength of carbon. On the other hand, in Carbon/Glass hybrid carbon fiber contributes high tensile, compressive strength and stiffness and reduces the density, while glass reduces the cost.

There are also resin hybrid laminate made from combining rigid and flexible resins together. Studies show that resin hybrid composites can increase shear and fracture strengths by more than $50 \%$ over all-flexible or all-rigid resins. Aerospace industries have successfully hybridized aluminum with carbon composites to achieve higher ductility. There are indications that the 
incorporation of both fibers into a single matrix sometimes leads to better properties than would be expected from consideration of the rule of mixtures. This is one of the greatest advantages of hybridization, where designer has complete control over combining required fibers and tailoring the property of the resulting hybrid based on the need of the design. Among all the available hybrids, the most common one or the potential construction-sector competing hybrids is Glass/Carbon hybrid combination, where most of the research has been performed. The next section will focus on reviewing Glass/Carbon hybrids for their use in new construction sector.

\subsection{Hybrids based on different fiber types}

Carbon fibers have high strength and stiffness while glass fibers have moderate strength and low stiffness (Dong \& Davies, 2014). The incorporation of carbon fibers in GFRP composite helps in improving the overall bending stiffness of the section. Designers have difficulty in designing allGFRP structural member due to higher deflection issues and the most common way to overcome the deflection issue is by utilizing carbon FRPs having high strength and stiffness (Hai et al. 2010). The four-point bending experiments on wide flange GFRP beams containing GFRP web and GFRP-CFRP flanges with center-to-center span of $3000 \mathrm{~mm}$ were conducted by Hai et al. 2010.

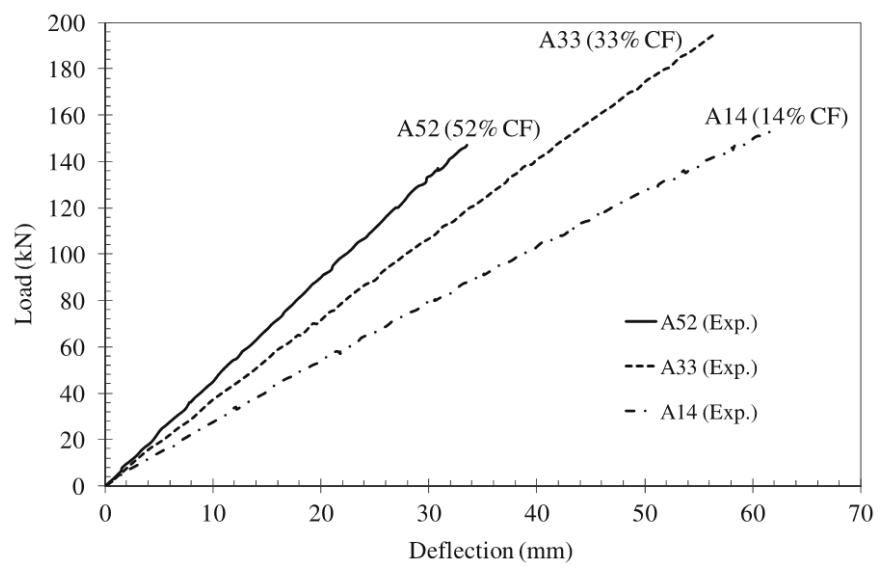

Figure 3-2. Load-deflection curve for GFRP-CFRP hybrid beams (Hai et al. 2010)

The flanges consisted of GFRP laminates oriented in different directions and unidirectional carbon fiber laminates. The CFRP on the flanges were varied in three different percentages $(14 \%$, $33 \%$, and $52 \%$ ) of total flange areas. The $10 \%$ increment in flexural modulus was observed on beams with approximately $20 \%$ of volume content of CFRP added on the flanges (Fig. 3-2). The load carrying capacity of the beams was not found to be proportional to the volume content of CFRP in the flanges. The failure of the hybrid beams was due to crushing of the fibers at the loading point followed by delamination of the compressive flange and buckling of the web.

In another study by Bhagwat et al. 2017, a hybrid FRP composite material was developed by combining $70 \%$ glass fibers and 30\% carbon fibers with an epoxy resin. The typical modulus of elasticity of GFRP used in the manufacturing was $24 \mathrm{MPa}$ and that of CFRP was $113 \mathrm{MPa}$. The tension tests on these hybrid composite specimens showed an overall modulus of elasticity of 51 $\mathrm{MPa}$ in the hybrid composite (Bhagwat et al. 2017). An increase of two-fold in the stiffness value of the hybrids as compared to GFRP composite was obtained. Similarly, Pandya et al. (2011) conducted tensile and compressive tests on two different hybrid specimens made using T300 carbon fabric, E-glass fabric, and epoxy resin. In the first hybrid specimen (H1), glass fabric layers 
were outside of the central carbon layers, while in the second hybrid specimen (H2), carbon fabric layers were outside of glass layers. The tensile test results showed higher ultimate strain to failure for hybrids than that obtained in the carbon FRP (Fig. 3-3, Table 3-1).

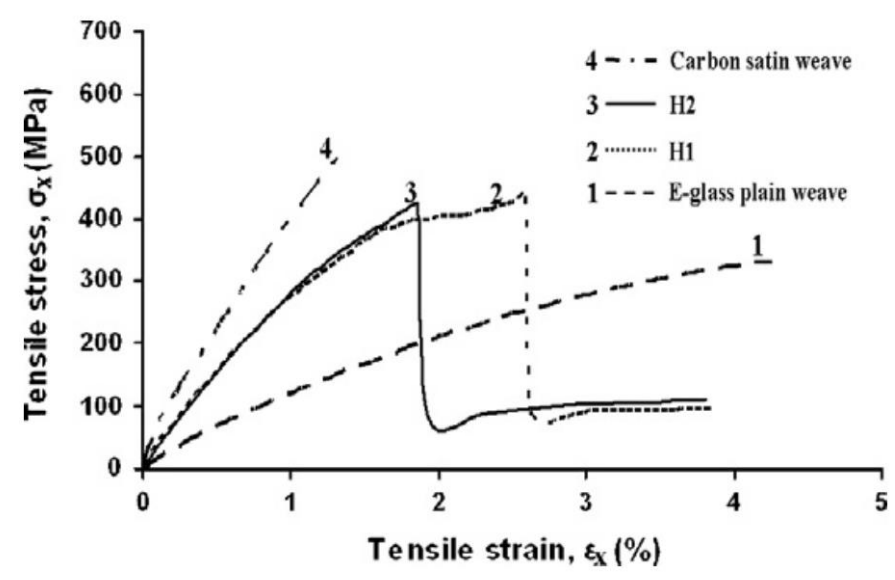

Figure 3-3. Tensile stress vs. strains for glass, carbon and hybrids (Pandya et al. 2011)

Placing glass layers in the outside of the carbon helped in achieving higher strain to failure as ultimate strain of glass fibers is more than that of carbon fibers, possible damage evolution in carbon fibers might have been constrained because of surrounding glass fibers. The study also found that the experimentally obtained tensile strength of hybrids was around $40 \%$ higher than that obtained through the use of rule-of-mixtures. The authors stated the reason for higher properties was due to hybridization effect.

Table 3-1. Tensile properties of different materials under loading (Pandya et al. 2011)

\begin{tabular}{|c|c|c|c|c|}
\hline Material & $\begin{array}{l}\text { Strength, } \\
X_{t}(\mathrm{MPa})\end{array}$ & $\begin{array}{l}\text { Modulus, } \\
E_{x t}(\mathrm{GPa})\end{array}$ & $\begin{array}{l}\text { Ultimate } \\
\text { strain, } \varepsilon_{x t}(\%)\end{array}$ & $\begin{array}{l}\text { Overall fiber } \\
\text { volume } \\
\text { fraction } V_{f}^{o}\end{array}$ \\
\hline $\begin{array}{l}\text { 8H satin weave } \\
\text { T300 } \\
\text { carbon/ } \\
\text { epoxy }\end{array}$ & $\begin{array}{l}511 \\
(-13,+20)\end{array}$ & $\begin{array}{l}39.0 \\
(-1.0,+0.5)\end{array}$ & $\begin{array}{l}1.36 \\
(-0.30,+0.40)\end{array}$ & 0.56 \\
\hline $\mathrm{H} 1\left(V_{c}=0.45\right)$ & $\begin{array}{l}436 \\
(-10,+15)\end{array}$ & $\begin{array}{l}27.0 \\
(-0.6,+1.5)\end{array}$ & $\begin{array}{l}2.59 \\
(-0.49,+0.50)\end{array}$ & 0.52 \\
\hline $\mathrm{H} 2\left(V_{c}=0.45\right)$ & $\begin{array}{l}421 \\
(-12,+18)\end{array}$ & $\begin{array}{l}27.5 \\
(-0.3,+1.2)\end{array}$ & $\begin{array}{l}1.86 \\
(-0.10,+0.35)\end{array}$ & 0.52 \\
\hline $\begin{array}{l}\text { Plain weave E- } \\
\text { glass/epoxy }\end{array}$ & $\begin{array}{l}322 \\
(-08,+16)\end{array}$ & $\begin{array}{l}12.5 \\
(-0.8,+1.9)\end{array}$ & $\begin{array}{l}4.25 \\
(-0.90,+0.60)\end{array}$ & 0.51 \\
\hline
\end{tabular}

The study by Zhang et al. 2011 showed the fabrication of carbon/glass hybrid laminates with five different lay-up sequences with an overall fiber weight fraction of $45 \%$. A significant improvement in the tensile and flexural modulus of the hybrids as compared to glass fiber laminate was found (Fig. 3-4). The realization of full potential of low-elongation carbon fibers was observed giving rise to higher failure strain than that observed in carbon fiber laminate (Tables 3-2 and 3-3). 


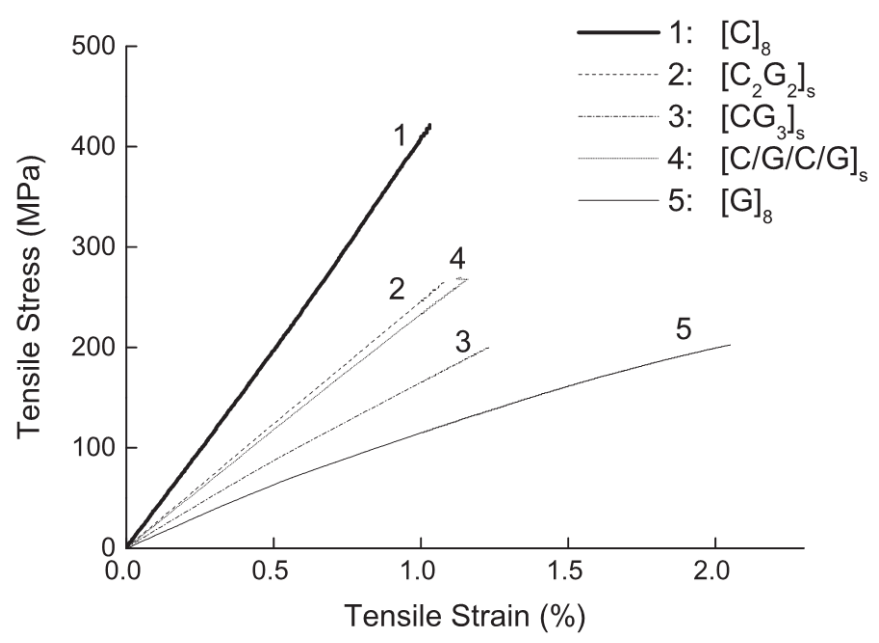

Figure 3-4. Tensile stress vs. strains for glass, carbon and hybrids (Zhang et al. 2011)

Table 3-2. Tensile properties of glass/carbon hybrids (Zhang et al. 2011)

\begin{tabular}{llll}
\hline $\begin{array}{l}\text { Lay-up } \\
\text { scheme }\end{array}$ & $\begin{array}{l}\text { Tensile strength } \\
(\mathrm{MPa})\end{array}$ & $\begin{array}{l}\text { Ultimate tensile } \\
\text { strain }(\%)\end{array}$ & $\begin{array}{l}\text { Young's modulus for } \\
\text { tension }(\mathrm{GPa})\end{array}$ \\
\hline$[\mathrm{C}]_{8}$ & $420( \pm 57)$ & $1.07( \pm 0.13)$ & $38.39( \pm 2.43)$ \\
{$\left[\mathrm{C}_{2} \mathrm{G}_{2}\right]_{s}$} & $260( \pm 7)$ & $1.18( \pm 0.06)$ & $22.04( \pm 1.50)$ \\
{$\left[\mathrm{CG}_{3}\right]_{s}$} & $206( \pm 9)$ & $1.41( \pm 0.14)$ & $18.09( \pm 0.54)$ \\
{$[\mathrm{C} / \mathrm{G} / \mathrm{C} / \mathrm{G}]_{\mathrm{s}}$} & $263( \pm 11)$ & $1.40( \pm 0.38)$ & $22.27( \pm 0.84)$ \\
{$[\mathrm{G}]_{8}$} & $200( \pm 3)$ & $1.87( \pm 0.29)$ & $11.01( \pm 2.11)$ \\
\hline
\end{tabular}

Table 3-3. Flexural properties of glass/carbon hybrids (Zhang et al. 2011)

\begin{tabular}{llll}
\hline $\begin{array}{l}\text { Lay-up } \\
\text { scheme }\end{array}$ & $\begin{array}{l}\text { Flexural strength } \\
(\mathrm{MPa})\end{array}$ & $\begin{array}{l}\text { Ultimate flexural } \\
\text { strain }(\%)\end{array}$ & $\begin{array}{l}\text { Flexural modulus } \\
(\mathrm{GPa})\end{array}$ \\
\hline$[\mathrm{C}]_{8}$ & $455( \pm 35)$ & $1.69( \pm 0.04)$ & $29.03( \pm 2.09)$ \\
{$\left[\mathrm{C}_{2} \mathrm{G}_{2}\right]_{s}$} & $406( \pm 17)$ & $1.68( \pm 0.04)$ & $27.31( \pm 1.19)$ \\
{$\left[\mathrm{CG}_{3}\right]_{s}$} & $339( \pm 15)$ & $1.78( \pm 0.05)$ & $21.98( \pm 0.91)$ \\
{$[\mathrm{C} / \mathrm{G} / \mathrm{C} / \mathrm{G}]_{s}$} & $348( \pm 9)$ & $1.81( \pm 0.08)$ & $22.47( \pm 0.70)$ \\
{$[\mathrm{G}]_{8}$} & $218( \pm 9)$ & $3.00( \pm 0.10)$ & $11.12( \pm 0.46)$ \\
\hline
\end{tabular}

\subsubsection{Hybrid effect}

Hybridization is a trade-off between increases in ultimate strain and impact resistance and decrease in in-plane strengths of hybrid composites compared with high modulus fiber composites (Pandya et al. 2011). The strength of the hybrid composites is always dependent on the failure of the low-elongation fibers within the hybrid, which controls the overall failure of the section. Although the mechanical properties of hybrid laminates can be often modelled on the basis of the volume concentration of their constituents through the general rule of mixtures, many researchers have revealed the existence of a hybrid effect in which the material property 
significantly differ from those predicted by the rule of mixtures as shown in Fig. 3-5 (Dorigato \& Pegoretti 2013).

(a)
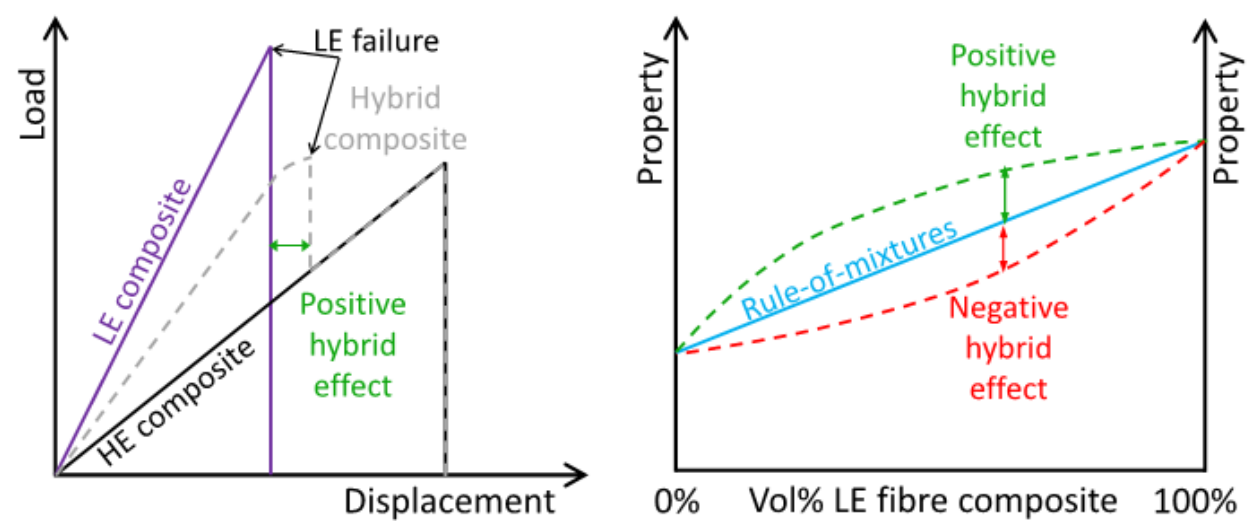

(b)

Figure 3-5. Hybrid effect, a) enhancement of failure strain of low-elongation (LE) fibers, b) deviation from rule of mixtures (Swolfs et al. 2014)

The material property such as stress-strain behavior of glass/carbon hybrid composites depend on the resin used, volume fraction of fibers, and their orientation and lay-up sequences. The tensile strength property of glass/carbon hybrids is generally improved when the low-elongation carbon fiber/fabric layers are in the interior of the laminate and higher-elongation glass fabric layers are in the exterior, which is termed as having a positive hybrid effect (Zhang et al. 2011, Stevanovic \& Stecenko 1992, Pandya et al. 2011). Formation of residual stress while creating a hybrid laminate because of difference in material's thermal expansion coefficient lead to compressive stresses in high-elongation fibers such as glass and tensile stresses in low-elongation fibers such as carbon (Mander \& Bader 1981, Motoc et al. 2013). When such specimen is tested, the failure strain on low-elongation fibers are apparently higher, yielding a positive hybrid effect. A hybrid effect is also observed in hybrid FRP due to a slight change in the failure pattern. Hybrid composites have fibers with different diameters in a bundle; this combination reduces stress concentration effects. Moreover, because high-elongation fibers bridge broken low-elongation fibers, it prevents development of failure and enables increase in failure load of hybrid composites (Kretsis 1987, Zweben 1977, Swolfs et al. 2014).

\subsubsection{Pseudo-ductility in glass/carbon hybrids}

The failure of FRP composites is sudden leading to catastrophic failure without sufficient warning, be it carbon or glass composites, therefore, getting a ductile mode of failure in FRP composites through hybridization has always been the most sought-after quest (Prusty et al. 2015). Czel \& Wisnom introduced the usage of thin-ply hybrid laminates to overcome the inherent brittleness and unstable failure characteristic of conventional high-performance composites. The approach yielded pseudo-ductile failure in specimens with one and two piles of thin carbon while those with three and four piles failed with unstable delamination (Fig. 3-6). In hybrid laminates, stress drops significantly when the low elongation fibers fail and then stress recovers again as the high elongation fibers pick up all the load. In theory, a stable damage process can be achieved in a glass/carbon hybrid by using thin carbon plies. Instead of a sudden drop in stress, a stable transition can be achieved between the stress peaks of the intact hybrid laminate and the delaminated layers, where only the glass plies carry load (Czel \& Wisnom 2013). 

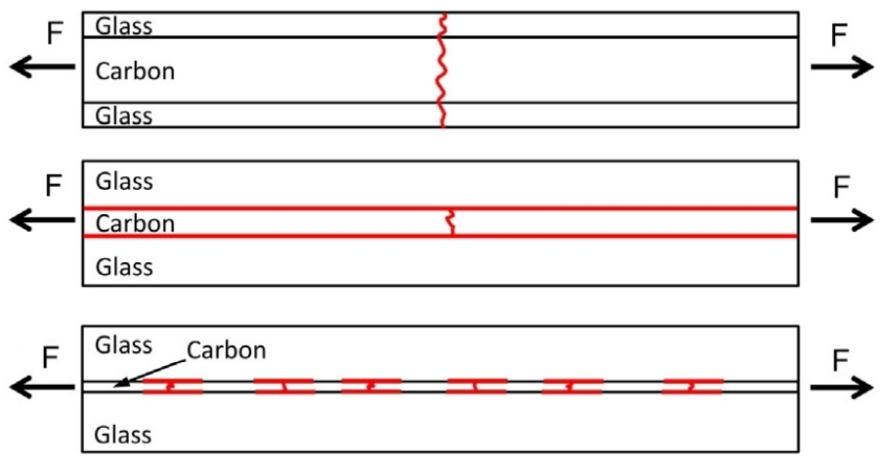

Figure 3-6. Failure modes in 3-layer unidirectional hybrids (Czel \& Wisnom 2013)

Yu et al. 2015 demonstrated positive pseudo-ductile results by using several highly aligned and well dispersed short carbon fibers in glass FRPs. Specimens with lower carbon volume ratios, where carbon fibers were surrounded by glass fibers, showed better pseudo-ductility (Fig. 3-7). During loading, each carbon fiber fragmented individually, resulting in a smooth transition between the elastic and fragmentation plateaus in the stress-strain curve (Fig. 3-8). The apparent failure strain of the low elongation constituent was slightly higher than the nominal failure strain of the high modulus carbon fibers because catastrophic crack propagation is prevented by the intervening glass fibers (high elongation constituent) after the failure of a few carbon fibers. When the carbon volume ratio is increased there is a sharp transition between the elastic region and the fragmentation plateau and the low elongation constituent failure occurs at strains lower than the nominal failure strain of the high modulus carbon fibers.

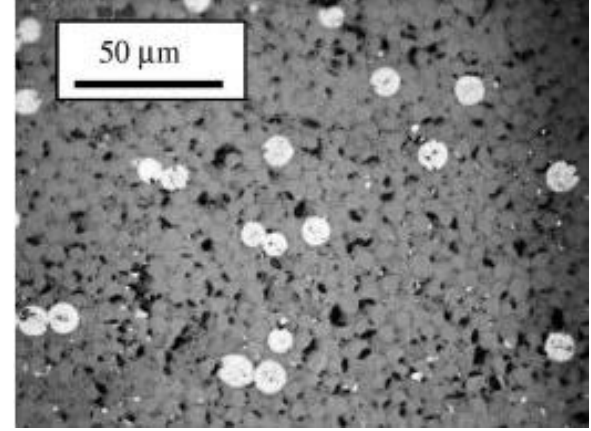

(a)

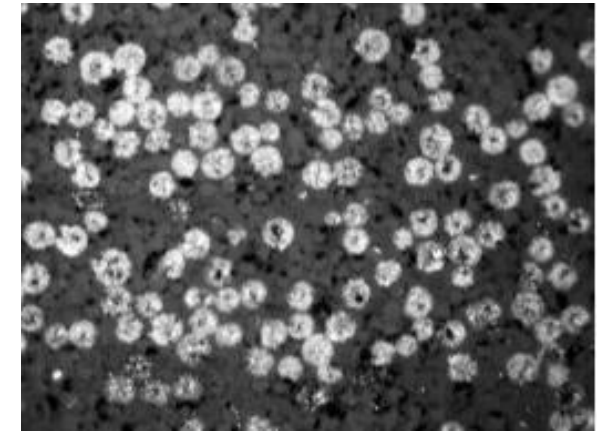

(b)

Figure 3-7. Cross-section of hybrid samples with carbon ratios of a) 0.1, b) 0.2 (Yu et al. 2015)

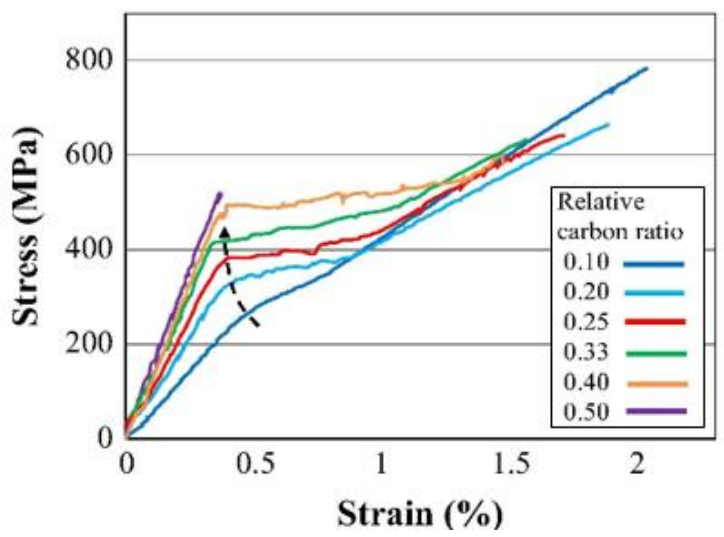

Figure 3-8. Stress-strain curves of carbon/glass hybrid for different carbon ratio (Yu et al. 2015) 
Table 3-4. Different grades of Carbon fibers

\begin{tabular}{|l|c|}
\hline Carbon fiber grades & Modulus of elasticity Range (ksi) \\
\hline Low modulus & $5,800-29,000$ \\
\hline Standard modulus & $29,000-40,000$ \\
\hline Intermediate modulus & $40,000-50,000$ \\
\hline High modulus & $50,000-87,000$ \\
\hline Ultra-High modulus & $87,000-140,000$ \\
\hline
\end{tabular}

\subsubsection{Shortcomings of GFRP-CFRP hybrids}

Hybridizing glass FRPs with carbon FRPs have helped in improving some of the limitations of GFRPs such as low stiffness. However, by introducing few layers of carbon fibers inside a GFRP section, cost of the section have increased signicantly to a point where a hybrid section offers no advantage compared to conventional materials. The different grades of carbon fibers with their modulus of elasticity ranges are shown in Table 3-4. For infrastructure research purposes, usually the low modulus and standard modulus carbon fibers are used because of very high costs associated with other grades of carbon fibers. The modulus of elasticity of carbon fibers that are typically used in construction industry-based research are as comparable to steel, however when mixed with resin, the stiffness of the carbon fiber composite significantly drops down. Carbon FRPs typically have modulus of elasticity of around 12-18 msi, less than that of steel. During hybridization with GFRPs, with 50\% CFRP and 50\% GFRP, the resulting maximum modulus of elasticity that can be achieved in a hybrid section is around 6-9 msi -about three times that of GFRPs. Though, the overall stiffness of GFRP section increased to two times of its original stiffness, the cost of the section increases by almost five to six times. Practically, it is very hard to achieve an economical hybrid section with GFRPs and CFRPs for the construction sector. Engineers and designers hesitate to use glass composites in the structural design because of their brittle failure modes. In case of extreme event, there is a strong probability that structures made from glass composites will collapse suddenly. By adding carbon fibers in glass composite, the inherent ductile nature of these brittle fibers is not going to improve. Researchers have also tried to improve the failure mode of hybrid FRPs. The effort did not yield much successful results, except for some pseudo-ductility failure modes achieved by stacking or dispersing carbon fibers throughout the section of GFRP. However, the stiffness of the hybrid section would not improve much as compared to the GFRP sections due to very low percentage of carbon fibers used within a section. Thus, GFRP-CFRP hybridization does not serve much purpose in construction; however, the same can be desirable for the aerospace and automobile industries. As aerospace and automotive sector can afford carbon FRPs, using few layers of GFRPs within a CFRP section will reduce the overall price of the hybrid CFRP-GFRP section. But, conversely, for civil infrastructure sector, CFRP-GFRP hybrids offer no obvious advantages.

\subsection{GFRP/steel hybridization}

Steel is relatively cheaper material and possesses high elastic modulus, good ductility, high strength utilization rate, good shear strength, and toughness (Li et al. 2014). The elastic modulus of steel is generally 8-9 times that of GFRPs, greater than that of carbon FRPs that are commonly available (Kim et al. 2012). Hybridizing glass fiber composites with highly expensive carbon FRPs increases initial cost of hybrid to an extent where they become uneconomical to use in civil 
infrastructure construction. On the other hand, Steel is inexpensive compared to carbon fibers, and therefore hybridizing GFRPs with steel is a viable solution to achieve cost-effective and better performing hybrid composites.

Amongst others, ductility is one of the most important property of materials. It contributes to robustness of structures by redistributing stresses and allowing a structure to continue carrying load without collapse after a damage. Ductility enables energy dissipation during earthquakes and provides warning of a failure with plastic deformation. Traditionally, steel has been a key source of ductility in civil engineering structures. The following research papers have been selected to review GFRP/steel hybridization.

Park et al. 2013: This study aims to develop a viable hybrid FRP bar for concrete structures by hybridizing GFRP crust with steel to increase the elastic modulus of GFRP bar that are corrosionresistant and low-cost. While GFRP bars are twice as expensive as steel bars, CFRP bars are 10 times expensive. Two types of hybrid FRP bar were studied: GFRP crust with $9.5 \%$ and $47.9 \%$ steel cores (Type B and D) and GFRP bar with dispersed 2 mm-diameter steel wires (30.8\% steel area) (Type C) (Fig. 3-9).

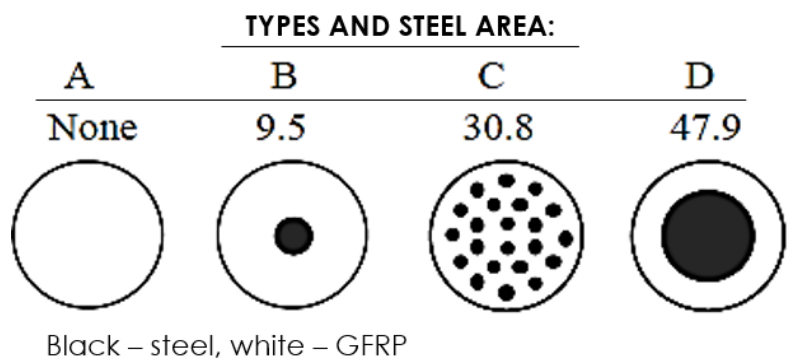

Figure 3-9. Types of hybrid bars and corresponding steel area

Table 3-5. Tensile strength and elastic modulus of hybrid bars

\begin{tabular}{ccccc} 
Type & $\begin{array}{c}\text { Tensile strength } \\
(\mathrm{MPa})\end{array}$ & $\begin{array}{c}\text { Improvements } \\
(\%)\end{array}$ & $\begin{array}{c}\text { Elastic } \\
\text { modulus } \\
(\mathrm{GPa})\end{array}$ & $\begin{array}{c}\text { Improvements } \\
(\%)\end{array}$ \\
\hline $\mathrm{A}$ & 1035.9 & 1.00 & 49.6 & 1.00 \\
$\mathrm{~B}$ & 970.4 & 0.94 & 53.7 & 1.08 \\
$\mathrm{C}$ & 876.2 & 0.85 & 98.3 & 1.98 \\
$\mathrm{D}$ & 956.1 & 0.92 & 129.2 & 2.60 \\
\hline
\end{tabular}

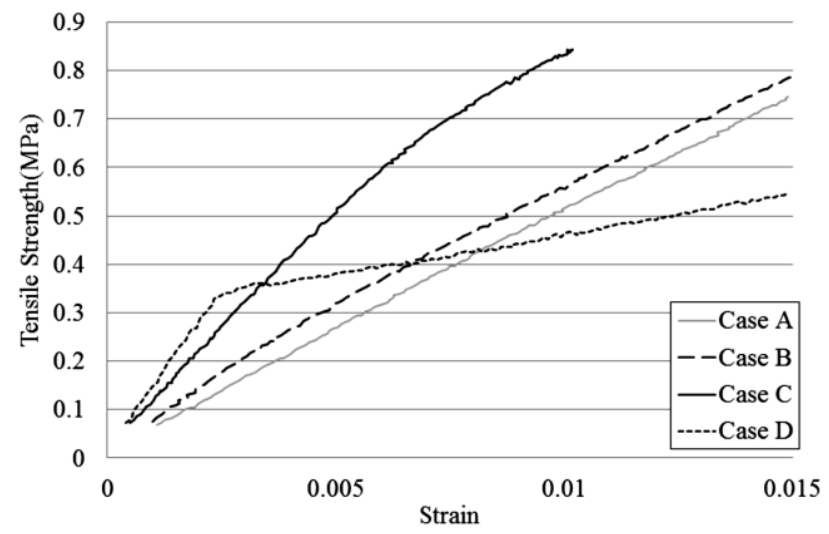

Figure 3-10. Tensile test results between specimens (Case A to D) 
In comparison with GFRP bar without hybridization (Type A), as the steel volume fractions increased from $9.5 \%$ to $47.9 \%$, tensile strengths decreased from $6 \%$ to $15 \%$ but elastic modulus increased from $8 \%$ to $160 \%$ (Table 3-4). Though the minimum tensile strength was $876.2 \mathrm{MPa}$, this value was higher than tensile strength of general steel rebar. And the elastic modulus of Type D was $63 \%$ of steel rebar's elastic modulus (Fig. 3-10). Therefore, Type C and D can be applied to concrete structures exposed to aggressive environments effectively than GFRP without hybridization.

Botelho et al. 2006: The development of a lightweight Fiber/Metal Laminate (FML) as shown in Fig. 3-11 to reduce weight and improve damage tolerance characteristics for the aerospace and aeronautical industry has been discussed. The aluminum and carbon/glass polymer composite laminates were combined to create a synergistic effect on many properties.

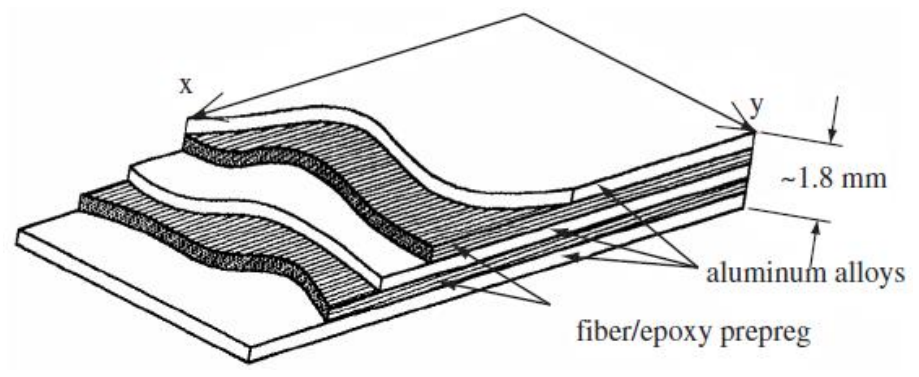

Figure 3-11. Configuration of a continuous fiber/metal/epoxy hybrid composite

The combination of high stiffness and strength of the carbon composite layer with good impact property from aluminum was achieved through carbon/aluminum laminates for aerospace applications, in fuselage and wing structures of airplanes. Meanwhile, higher fatigue and impact damage was achieved through glass/aluminum laminates. The tensile stress/strain behavior of FML exhibits well defined elastic response and load bearing capability, and toughness due to aluminum stress/strain plastic region. The study highlights the important role of interface bond between the composite laminate and the aluminum in the transfer of stresses in the hybrid composite.

Ji et al. 2011: A cost-effective hybrid FRP-steel sandwich panel for bridge decks was developed to improve bending stiffness and buckling response compared to all GFRP decks. The hybrid deck consisted of GFRP grid and multiple steel box cells with upper, central, and lower GFRP face-sheet layers, designated by UFL, CFL, and LFL, respectively, in Fig. 3.12.

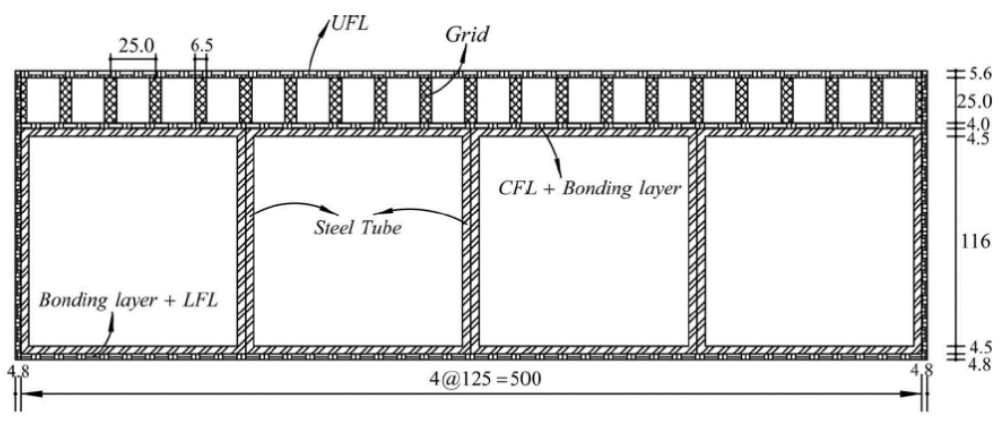

(a)

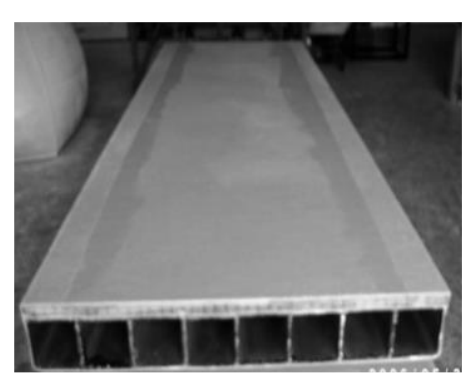

(b)

Figure 3-12. (a) Schematic of hybrid FRP-steel sandwich panel, (b) manufactured deck 
The displacement at the mid-span of the specimen was $5.65 \mathrm{~mm}(0.21 \mathrm{in}$.) at the service load of $122.3 \mathrm{kN}$ (27.4 kip) applied through a $580 \mathrm{~mm} \times 230 \mathrm{~mm}$ (23 in. $\times 9$ in.) loading patch to represent a design truck wheel loading for a span of $2.7 \mathrm{~m}(8.87 \mathrm{ft})$. The deflection was about $\mathrm{L} / 478 \mathrm{for}$ the span of which satisfied the deflection limit of L/425. The panel exhibited a linear behavior up to the service load besides some audible noises, with a maximum bending strain of 800 micro-strains recorded on the top and bottom faces. No reduction in stiffness or strength was found after 2 million cycles of fatigue load in the service load condition based upon the load-deflection and load-strain responses from the static tests after $0,0.5,1.0,1.5$ and 2.0 million cycles. The panel exhibited non-linear behavior beyond $400 \mathrm{kN}$ (89.7 kip) and failed at the ultimate load of 632.5 $\mathrm{kN}$ (141.7 kip), with a very strong and loud noise due to delamination of GFRP laminates from the wrapped GFRP grid and the steel tube core. This failure mode was different from the local punching failure mode or other local damages of the cellular all-FRP panels around the loading patch. Yielding of the steel tube core created the desired ductility in the hybrid sandwich panel. The proposed concept showed sufficient load capacity with reduced weight compared to all-steel option and was also cost efficient compared to all-GFRP decks but had a manufacturing difficulty.

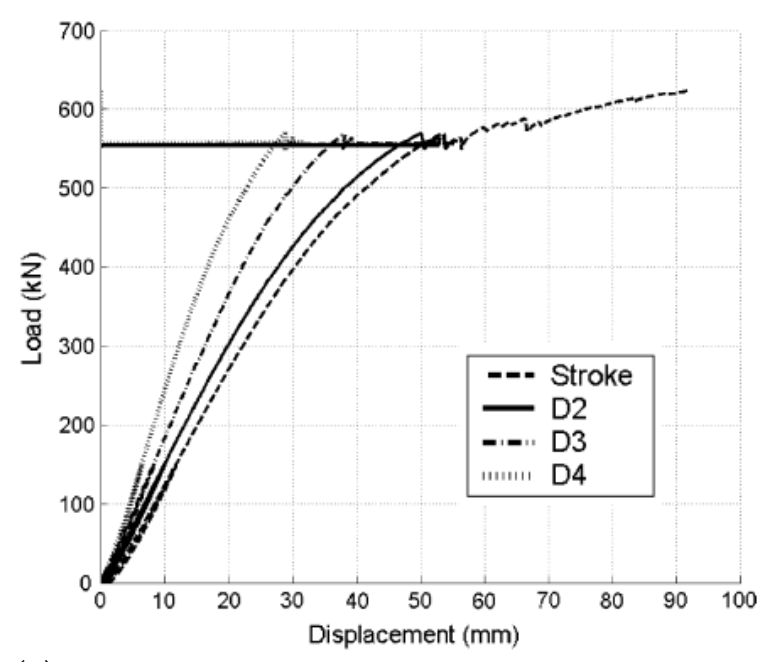

(a)

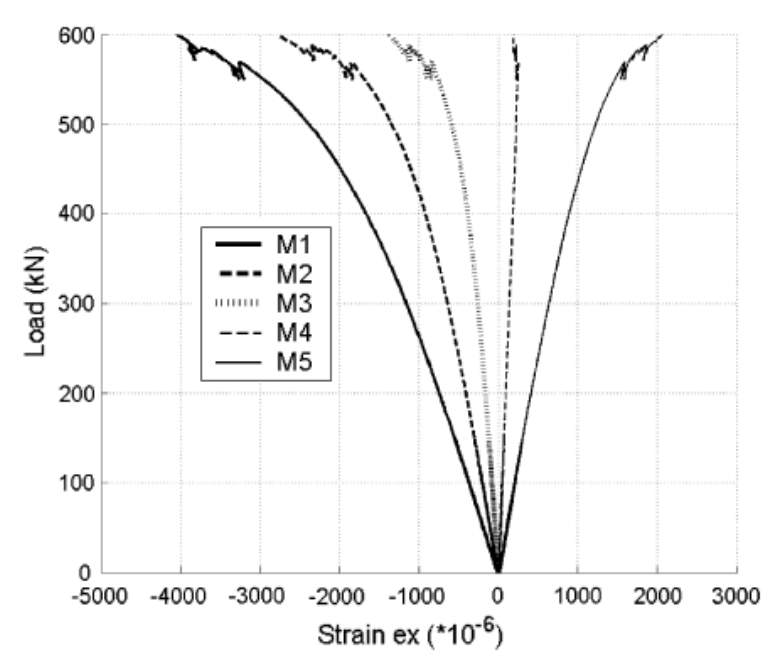

(b)

Figure 3-13. (a) Load-deflection curve, (b) load-strain curve (through depth of panel)

Lombardi et al. 2011: The objective of the study was to increase the stiffness of a commercial GFRP honeycomb sandwich panel through the inclusion of steel within the cross section. The KSCI honeycomb GFRP deck (Fig. 3-14) produced by Kansas Structural Composites, Inc. through the hand layup technique did not satisfy the AASHTO deflection criteria on an overhang portion of the bridge deck to be designed, as a result, the use of steel deck hexagonal honeycomb core with GFRP face-sheets was chosen as the final hybrid concept and was investigated experimentally and was found to increase the flexural and shear stiffness of the deck in both long and transverse directions. 


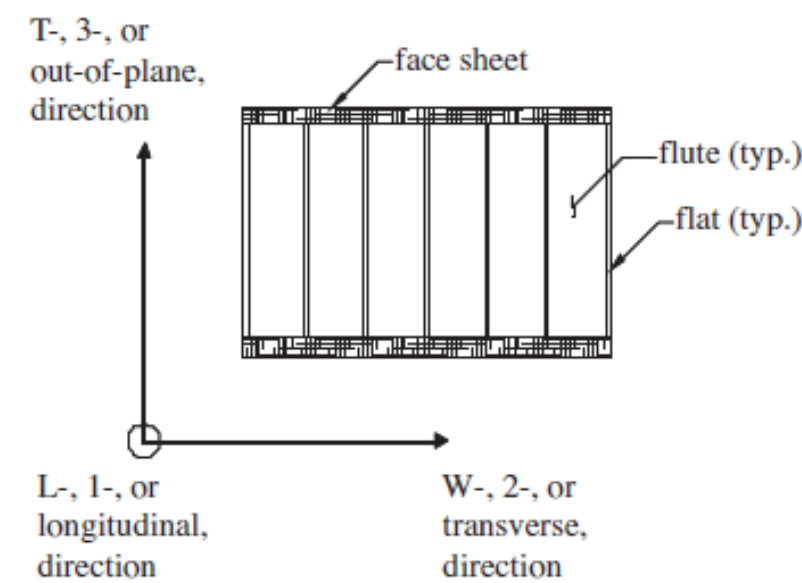

(a)

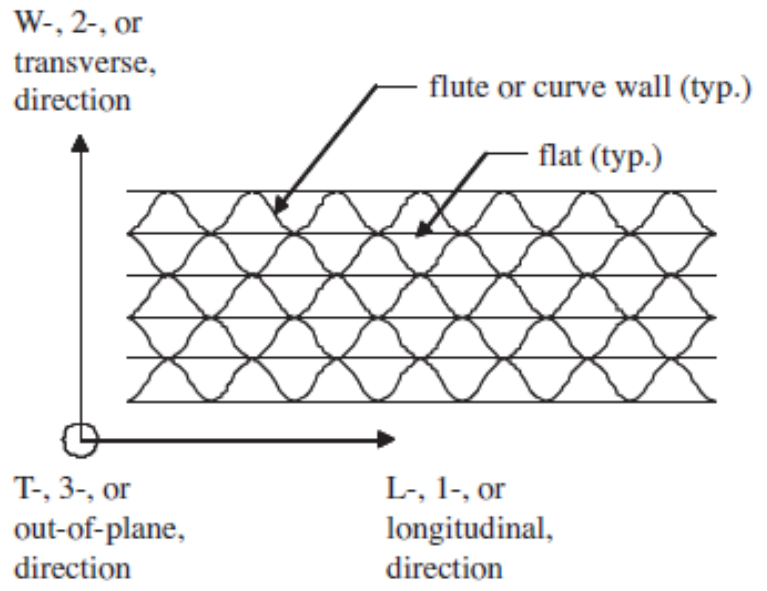

(b)

Figure 3-14. (a) KSCI cross-section, (b) KSCI plan view

The hybrid beams were $298 \%$ stiffer in terms of shear modulus as compared with the KSCI specimen in long-direction (Fig. 3-14). Similarly, in transverse direction, the hybrid beams were $458 \%$ stiffer in terms of shear modulus as compared with the KSCI specimen (Fig. 3-14). The author highlighted that steel cores in the section would possibly give an advantage over an allsteel deck in terms of corrosion, however, the use of galvanized steel was considered.

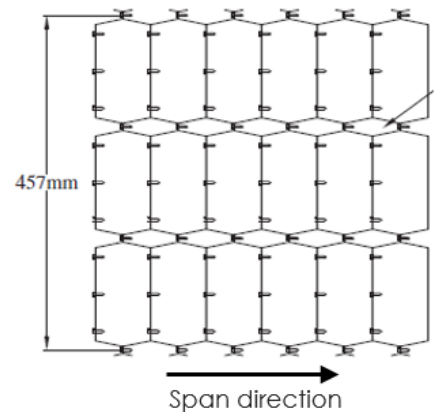

(a)

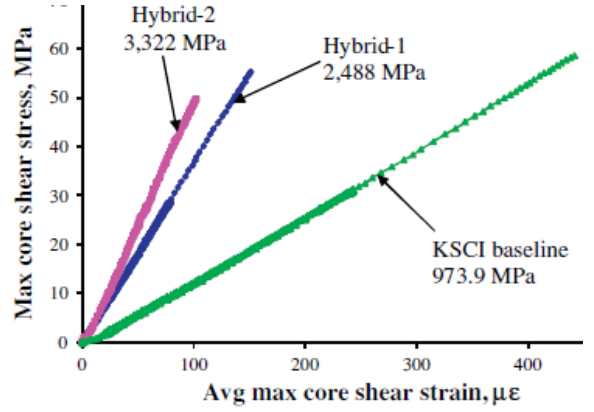

(b)

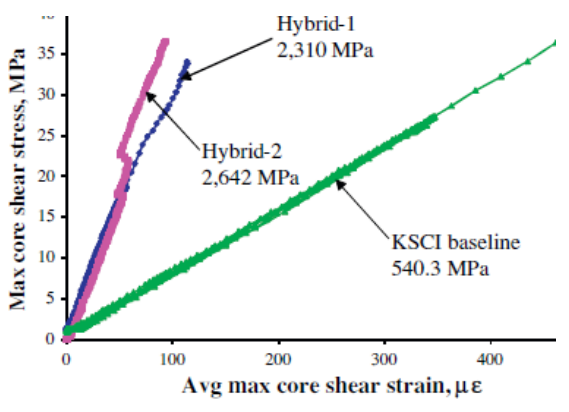

(c)

Figure 3-15. (a) Steel honeycomb core, shear stress-strain curves in (b) long-direction, (c) widthdirection

Kim et al. 2012: This paper presents the design and analysis of a steel-reinforced hybrid GFRP deck panel (Fig. 3-16). The top and bottom flanges are reinforced with uniformly spaced steel wires with a yield strength of $500 \mathrm{MPa} .2 .5 \mathrm{~m}$-long deck panel with a clear span length of 2190 $\mathrm{mm}$ was tested in bending and a deflection limit of span/400 was assumed to reduce the vibration of the deck panel under a live load.

Based upon a finite element analysis, with a steel reinforcement ratio of $2.5 \%$, the flexural stiffness of the hybrid deck panel was about $114 \%$ greater than that of the non-hybrid deck panel. The results of the FE analysis further indicate that the stresses induced in the hybrid deck panel was within $24 \%$ of the design tensile strength of the GFRP composite, whereas the stresses induced in the steel wire were within $85 \%$ of the allowable stress of the steel wire. The results confirmed that the flexural stiffness of the GFRP deck panel could be effectively increased by the proposed method of hybridization. 


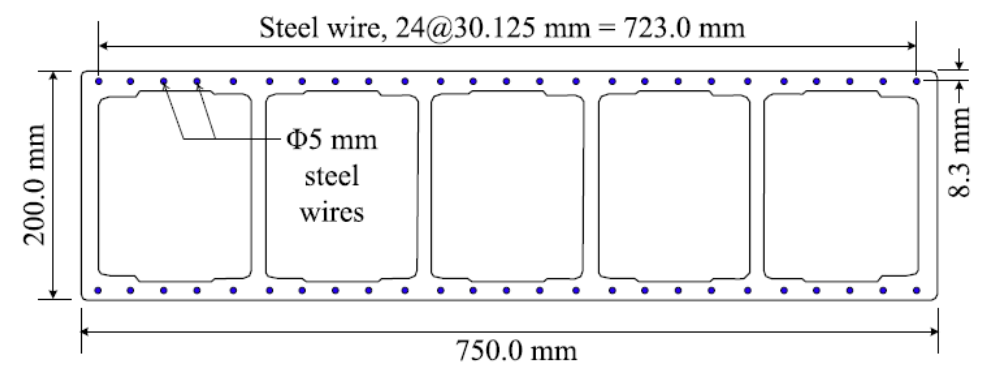

Figure 3-16. Cross-sectional profiles of a hybrid GFRP deck panel

Kolesnikov et al. 2008: The presence of complex stress mechanics at bolt loaded holes and the variety of potential failure modes decreases the efficiency of bolted joints in composites. To improve the efficiency, use of additional \pm 45 -plies, laminate tailoring techniques or insertion of metal are prevalent. The use of thin metal plates in the form of layers within the FRP has been studied (Fig. 3-17).

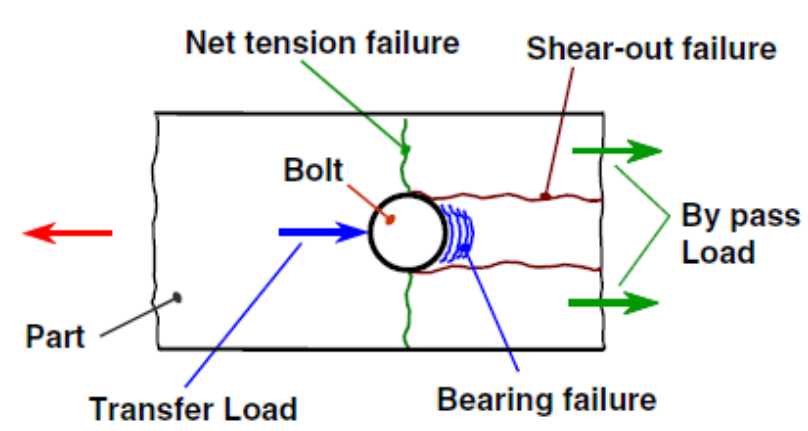

(a)

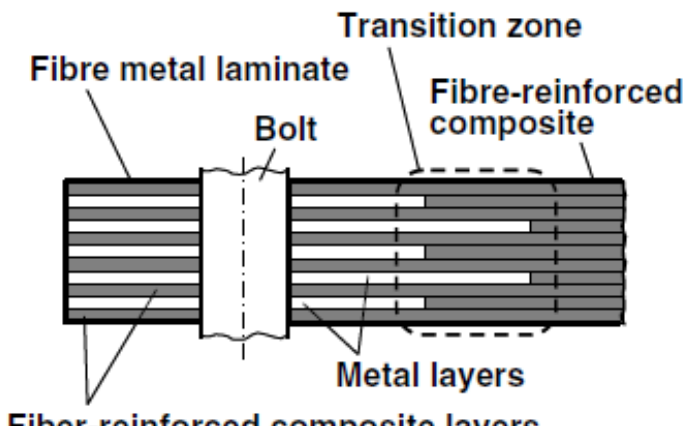

Fiber-reinforced composite layers

Figure 3-17. (a) Failure modes of a bolt loaded hole, (b) schematic view of a composite bolted joint locally reinforced by metal layer embedding.

A maximum strength gains of $191 \%$ was determined for a single-row bolted joint in the case of $90^{\circ}$ off-axis loading. The hybrid specimens showed bearing capabilities as comparable as those of pure titanium alloy at a relatively low titanium content of about $50 \%$. The load capability of composite bolted joints strongly depends on the laminate configuration. The reliability of local hybrid materials depends upon the adhesion quality between the metal and FRP-layers, the impact sensitivity as well as the load capability of the transition region from the pure composite laminate to the hybridized region.

\subsection{Conclusions}

The design and construction of building and bridge structures require high strength and serviceability requirements. GFRP composites are strong, lightweight, non-corrosive and durable - a material that is desired in the civil engineering industry, but their lower stiffness, lower ductility, brittle failure modes, and connection issues are not wanted. GFRP composite has a low material stiffness of about $10-20 \%$ of steel, which results in failure to meet serviceability limit state criteria. In addition, GFRP exhibits low shear strength and material anisotropy, introducing challenges to design connections. The brittle nature of GFRP results in sudden catastrophic failure without warning. Therefore, it is required to improve these properties either 
by material hybridization. By introducing concepts of hybridization, researchers have tried combining carbon fibers into glass FRP sections to improve its stiffness. GFRP-CFRP hybridization has shown the overall increase in stiffness of hybrid section upto two times of its original stiffness, however, the cost of the section becomes more as compared to the original section. In essence, it is very hard to achieve an economical hybrid section with GFRPs and CFRPs for the construction sector. Furthermore, the brittle failure mode in FRP composites does not improve with CFRP-GFRP hybridization.

Aerospace industries have been successfully hybridizing aluminum with carbon composites to achieve higher performing hybrids. Similarly, in construction industry, cheaper steel material has been used to improve GFRP composite's structural properties. It has been observed that GFRPsteel hybridization produced a low-cost and stiffer hybrid material. Alongside stiffness, ductility performance was achieved with the use of steel inside GFRP section. Further, GFRP-steel hybrids have shown reduction in stress concentrations leading to stronger connection. However, attempts to embed thin steel plates into GFRP sections have not been exploited fully. The bending and shear performance of steel plate embedded GFRP beam and bridge deck sections, their fatigue performance, their reduction in stiffness after certain number of load-cycles, the GFRP-steel interface study and its bond degradation, bolted connections in steel-plate embedded hybrid sections, and cost analysis have not been fully studied. Thus, this dissertation provides a comprehensive study on the structural and functional performance of steel plate embedded GFRP sections. 


\section{Chapter 4. \\ Test Sections and Details}

This chapter explains different types of sections that were tested in this experimental program and their manufacturing processes. This chapter also lists out the coupon level testing and component level testing on control GFRP and hybrid beam and cellular sections along with experimental details. The instrumentation and data collection processes performed during the testing are also explained. In addition, methods and details during qualitative observation of samples are presented within this chapter.

\subsection{Test sections}

\subsubsection{GFRP-steel hybrid cellular panel}

The preliminary section that was tested in the beginning of the research presented in this dissertation is GFRP cellular panel with two steel plates embedded inside the section as shown in Fig. 4-1. The panel had a cross-section of 8.5" $x 46$ " and consisted 0.523 " thick top and bottom flanges and fourteen $0.4^{\prime \prime}$ thick webs. In addition, two embedded steel plates of size 3 " $x 0.375^{\prime \prime}$ ran for an entire length of the section inside the top flange as shown in the Fig. 4-1. The GFRP section was manufactured by using vacuum assisted resin infusion process by Composite Advantage, Inc. for a length of $16.5 \mathrm{ft}$. (Fig. 4-2). The reinforcement in the face-sheet skins and webs were Eglass fibers running primarily in the $0^{\circ}$ direction along the length for resisting bending loads and tri-axial fabrics with fibers in the $\pm 45^{\circ}, 90^{\circ}$ directions for resisting in-plane shear and transverse forces. The section consisted of thirteen closed cells with water-resistant web cores as shown in Fig. 4-2. Web cores reinforced with $\pm 45^{\circ}$ fabrics were infused with resin to form strong and stiff shear webs for the sandwich cross-section to provide good crushing resistance against concentrated loads. The closely spaced webs helped in reducing local skin deflections. The fiber/fabric layup of the composite top and bottom face sheets from outside to inside were $0.75 \mathrm{oz}$ CFM (non-structural), $55 \mathrm{oz}$ unidirectional $\left(0^{\circ}\right), 40 \mathrm{oz}$ triaxial $\left(90^{\circ}\right), 40 \mathrm{oz}$ triaxial $\left(0^{\circ}\right), 55 \mathrm{oz}$ unidirectional $\left(0^{\circ}\right), 40 \mathrm{oz}$ triaxial $\left(90^{\circ}\right), 40 \mathrm{oz}$ triaxial $\left(0^{\circ}\right), 55 \mathrm{oz}$ unidirectional $\left(0^{\circ}\right), 40 \mathrm{oz}$ triaxial $\left(90^{\circ}\right)$, $40 \mathrm{oz}$ triaxial $\left(0^{\circ}\right)$, and $55 \mathrm{oz}$ unidirectional $\left(0^{\circ}\right)$ fabrics. The background, test results, and field implementation of this section is presented in Chapter 5.

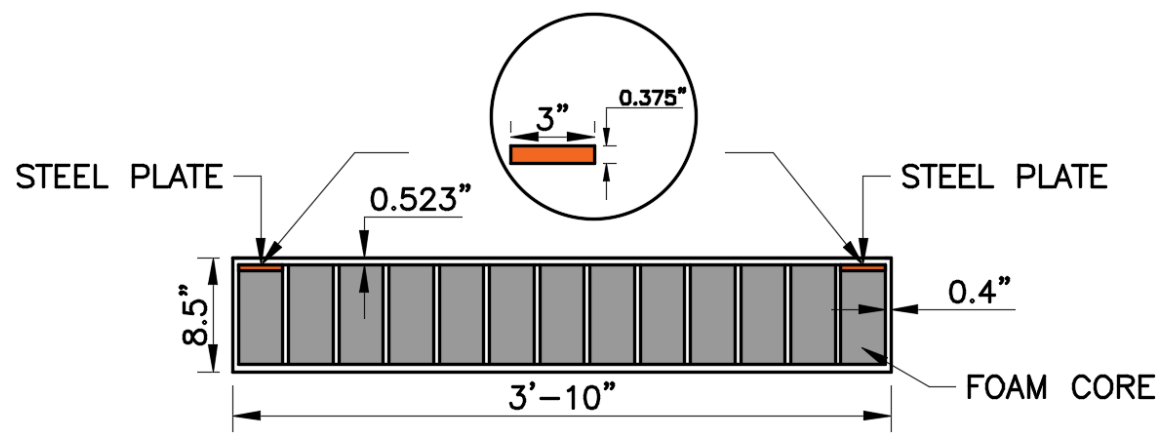

Figure 4-1. Schematic of a GFRP-steel hybrid cellular panel 


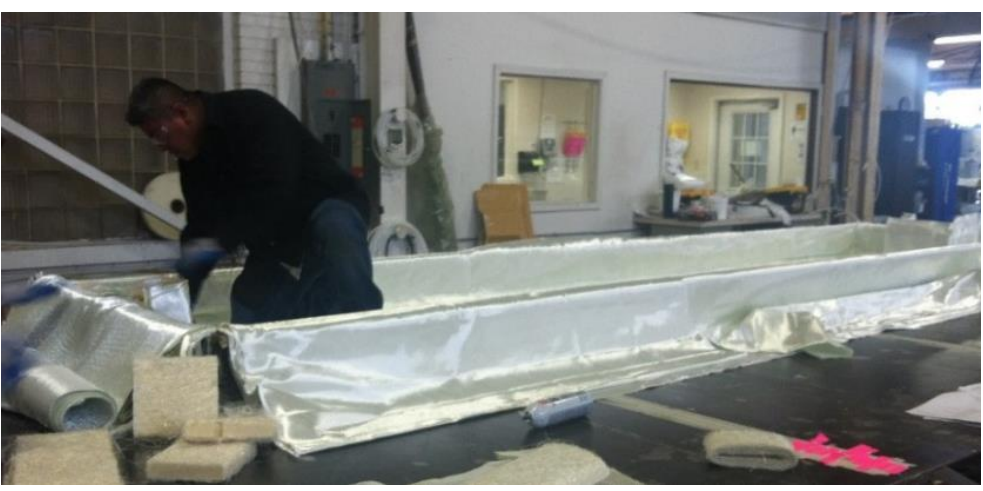

(a)

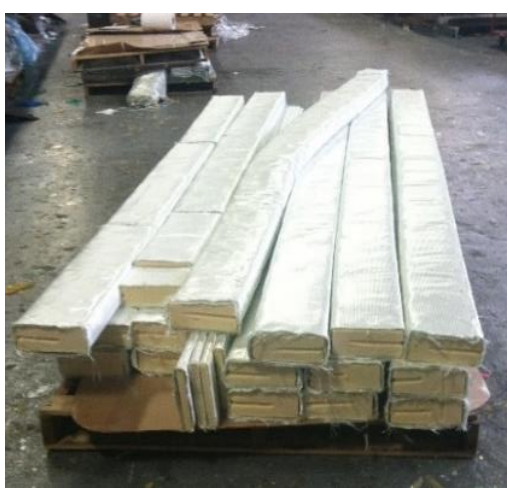

(b)

Figure 4-2. (a) Manufacturing of hybrid GFRP panel, (b) GFRP web cores

\subsubsection{GFRP-steel hybrid box-beam sections}

After obtaining successful results with the hybrid GFRP cellular panel as introduced in section 4.1.1, the GFRP and hybrid GFRP-steel box-beams were manufactured for further testing and analysis. The box-beam sections as a representative of beams in buildings and bridges (designated by $\mathrm{CB}, \mathrm{HWB}, \mathrm{HFB}$, and $\mathrm{HAB}$ ) were manufactured for a cross-section of 6 " $\times 66^{\prime \prime}$ and a length of $8 \mathrm{ft}$. (Figs. 4-3, 4-4). In addition, the sections consisted $4 " \times 1 / 8^{\prime \prime}$ steel plates embedded inside the flanges and/or webs throughout the length but 1 " shorter on both ends of a beam (Fig. 4-3).

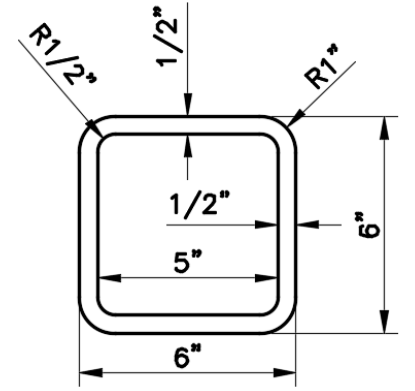

(a)

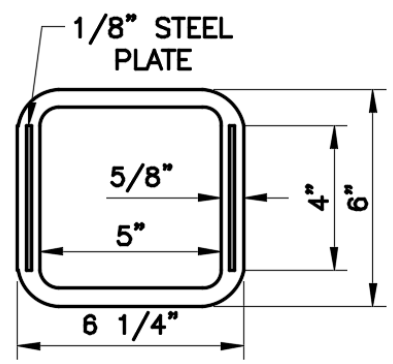

(b)

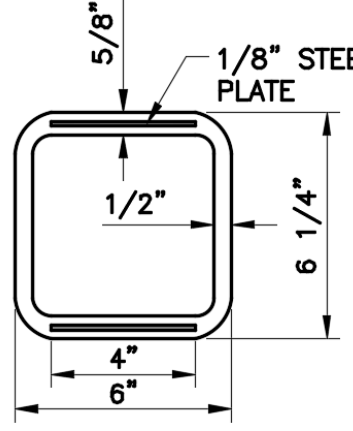

(c)

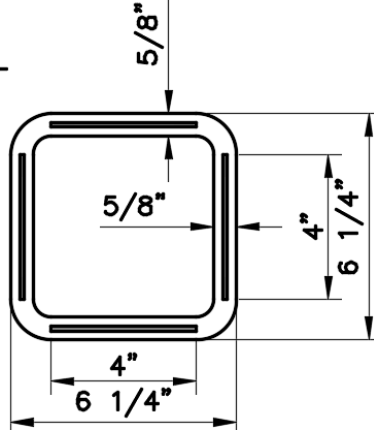

(d)

Figure 4-3. (a) Control GFRP (CB), (b) Hybrid web beam (HWB), (c) Hybrid flange beam (HFB), (d) Hybrid-all beam (HAB) box-beam sections

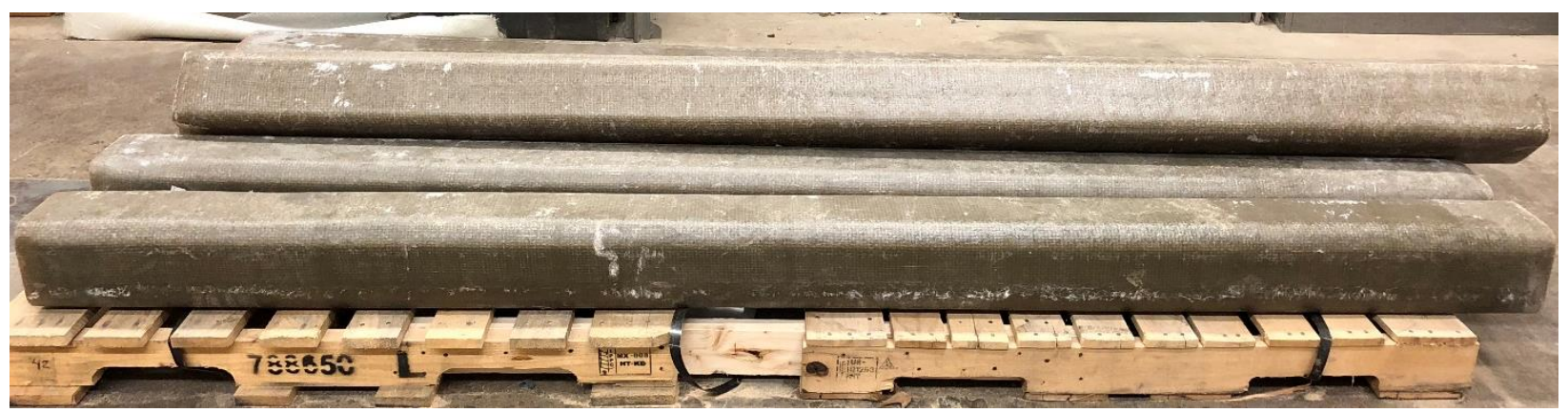

Figure 4-4. Control GFRP and GFRP-steel hybrid box beams 
Box-beams were manufactured using vacuum assisted resin infusion process. The glass fabrics that were used to form the flange and web thicknesses of the GFRP box-beam were 1.5 oz./ $\mathrm{ft}^{2}$ chop strand mat and $24 \mathrm{oz} . / \mathrm{ft}^{2}$ woven roving and are shown in Fig. $4-5$. The fiberglass roving laid down along the axis of the beam were responsible for providing the longitudinal mechanical properties, while the chop strand mat provided the transverse properties of the beams. For GFRP-steel hybrid beams, steel plates that were embedded inside GFRP sections were A35 steel plates with an average yield strength $36 \mathrm{ksi}$. Before placing the steel plates inside the GFRP section, the surfaces of those plates were sanded with a 36-grit sandpaper and no any special primer was applied on them. A resin-compatible putty was applied on the edges of the plate to make a smooth transition into fabric layups.

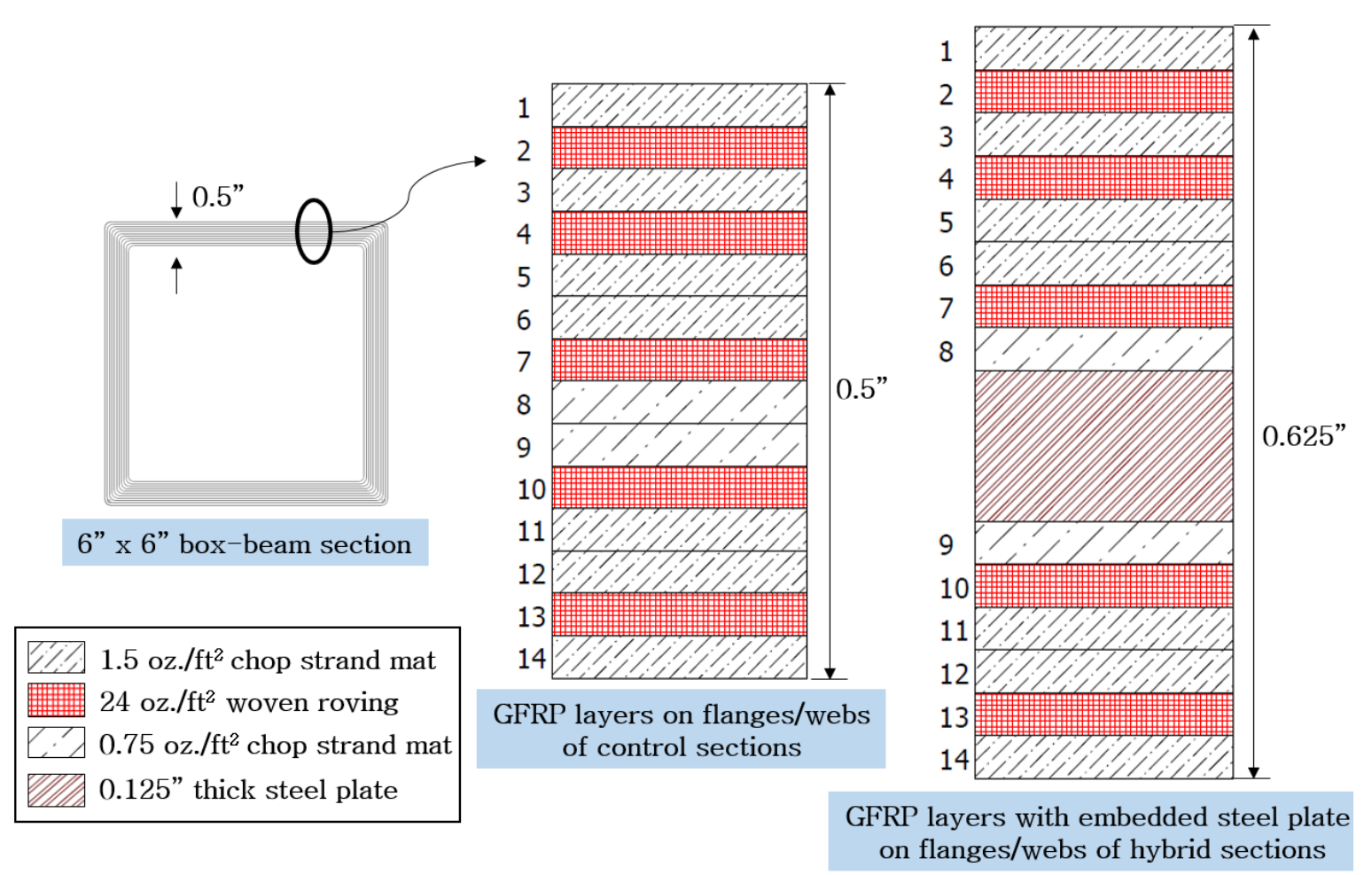

Figure 4-5. Arrangement of GFRP fabrics \& steel plate on control \& hybrid sections

\subsection{Testing equipment and sensors}

\subsubsection{Test machines}

The coupon level testing under bending, tension, shear, and compression loads were performed in Instron 1000HDX having a maximum capacity of 224 kips. In addition, the testing of bolted connection on GFRP and hybrid samples were performed in the same Instron 1000HDX. The component level bending, shear and fatigue tests on beams and cellular sections were performed using MTS controlled hydraulic controlled actuator with a maximum capacity of 110 kips.

\subsubsection{Test sensors}

The test sensors that were used during the experimental testing were uniaxial strain gages, linear variable differential transducer (LVDTs), and strain-gage based load transducers (load cell). 
During each testing, several strain gages were bonded to the surfaces to capture the behavior (tensile and compressive local deformation) of the material under loading. In addition, LVDTs were placed at the center and one-third of the span to measure global deflections on the member. The load cell was placed under the actuator to record load levels during testing. Determining the level of strain on a material surface and global deformation of a structure during experimental testing is one of the most necessary steps that helps in understanding the response of a structure under loading. The set of procedure shown below was followed while bonding a strain gage on a surface of the test component.

- Abrasion - The bonding area on a surface of a structural component was abraded with a fine 150 or 200-grit silicon-carbide sand paper to remove the outer material surface layer and expose a clean and virgin bonding surface.

- Surface conditioning, and neutralizing - The bonding area was thoroughly cleaned with an acid as a conditioner and ammonia as a neutralizer using a cotton paper.

- Strain gage bonding - The bonding surface of a strain gage was cleaned with an alcohol and the gage was bonded to the surface with an M-Bond 200.

- Soldering - Lead wires were soldered to the tabs and the connection was checked with a strain indicator to ensure its desired resistance value was obtained.

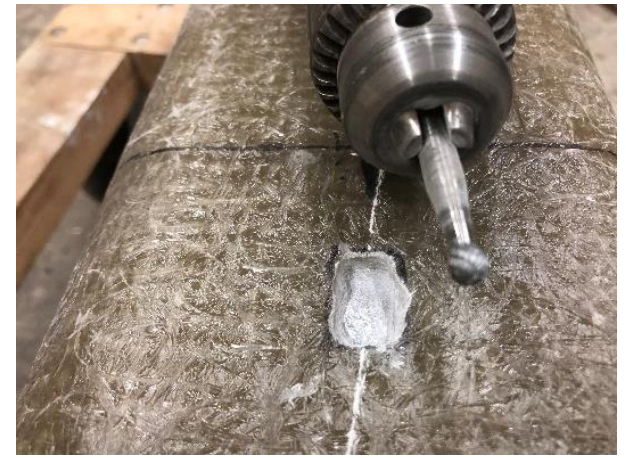

(a)

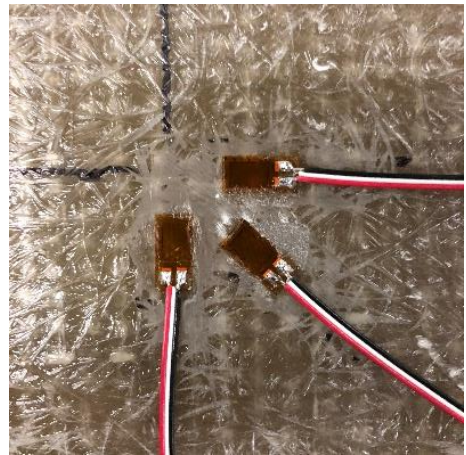

(b)

Figure 4-6. (a) Grinding tool to create bonding surface for strain gages on embedded steel surface, (b) 3-uniaxial strain gages at support to capture strains in three directions

\subsubsection{Data acquisition system}

The data from different sensors such as strain gages, strain gage-based transducers (Load cell) and high-level voltage signal (LVDT) were collected using Vishay Strain Smart 7000 and 8000 data acquisition system. These data acquisition system acquire data from the measurements, store them and reduces the data to meaningful units and presents the reduced data for viewing. During testing, recorded load-deflection and strain data were used to determine the flexural and shear strength as well as stiffness of the test sample. 


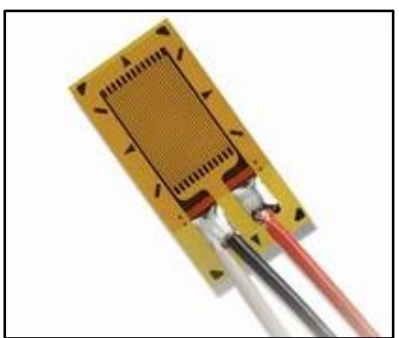

(a)

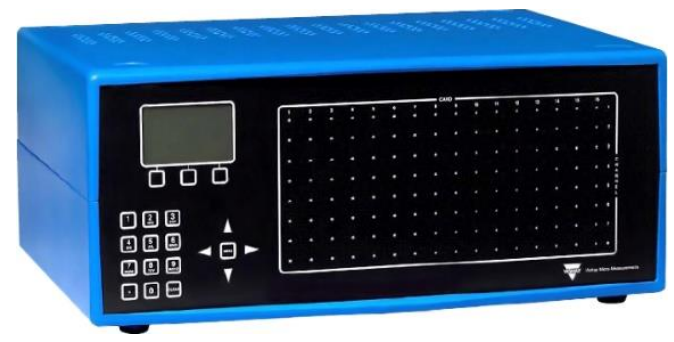

(b)

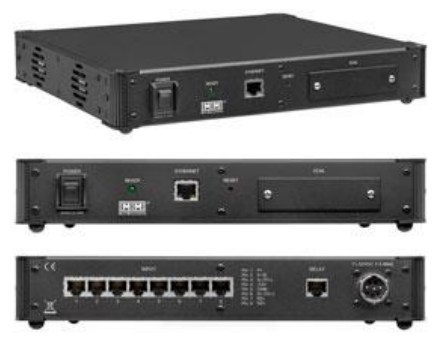

(c)

Figure 4-7. (a) Uniaxial strain gage, (b) Vishay system 7000 data acquisition, (c) System 8000 data acquisition

\subsection{Coupon sample preparation}

\subsubsection{Diamond blade cutting}

The control GFRP laminates were cut into coupon specimens for tensile, bending, shear testing as well as for bolted connection testing using a table saw with a diamond blade.

\subsubsection{Waterjet cutting}

The GFRP laminates with embedded steel plates were cut using a pressurized water jet cutter, also known as a waterjet to produce different coupon level specimens. The waterjet cutter was connected to a high-pressure water pump to pressurize the water up to $55 \mathrm{ksi}$. The pressurized water was then ejected out of the nozzle, cutting through the material placed on a water bath by bombarding it with the stream of high-speed water. Additives in the form of suspended grit (80 grit sand) was added to assist in the cutting process. The main advantages of waterjet cutting of GFRP or steel were that it didn't produce any hazardous dust or any heat in the material.

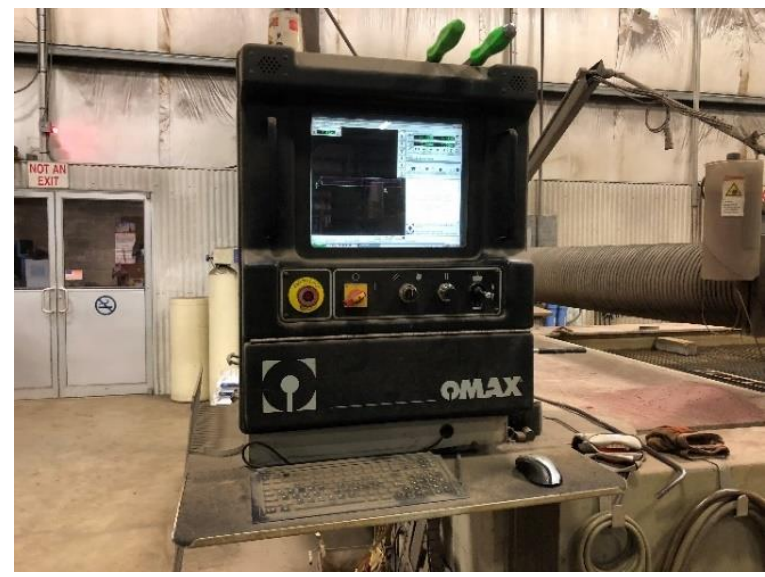

(a)

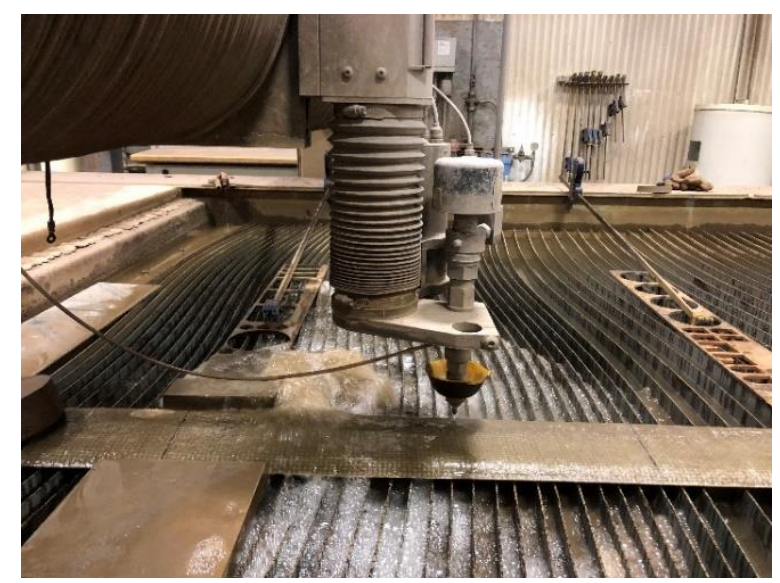

(b)

Figure 4-8. (a) Waterjet cutting controller, (b) waterjet cutting through a GFRP sample 


\subsection{Coupon level testing}

The steel plate, GFRP and GFRP-steel hybrid coupons cut from the original GFRP-steel hybrid cellular panel and box-beams were tested during the research. The coupons obtained from the cellular panel were tested in tension as per ASTM standard for determining the coupon-level strength of the section and the test results are discussed in Chapter 6. Similarly, coupons obtained from the control GFRP and hybrid box-beams were tested as per ASTM standards for determining tension, compression, shear, inter-laminar shear, and bending strength and the test results are discussed in Chapter 6.

\subsection{Component level testing}

The cellular panel and box-beam sections were tested under static bending, shear and fatigue loads. An MTS controller with a maximum load capacity of 110 kips was used to control the applied load of the hydraulic actuator. Load, deflection, and strain signals were continuously recorded during testing using the high-speed data acquisition system. To assure uniform load application and to prevent slippage of the beam from supports, 0.5 -inch thick neoprene pads were placed on the load contact area and also placed between the roller supports and the bottom surface of the samples. During each testing, data acquisition was started, and the load crosshead of an actuator was lowered until contact was made with the beam. The load actuator was controlled manually and was loaded at a rate of 100-200 pounds per second making sure that there was no impact on the beam during initial contact of the load crosshead. The load was increased until a significant drop in load was noticed indicating a failure.

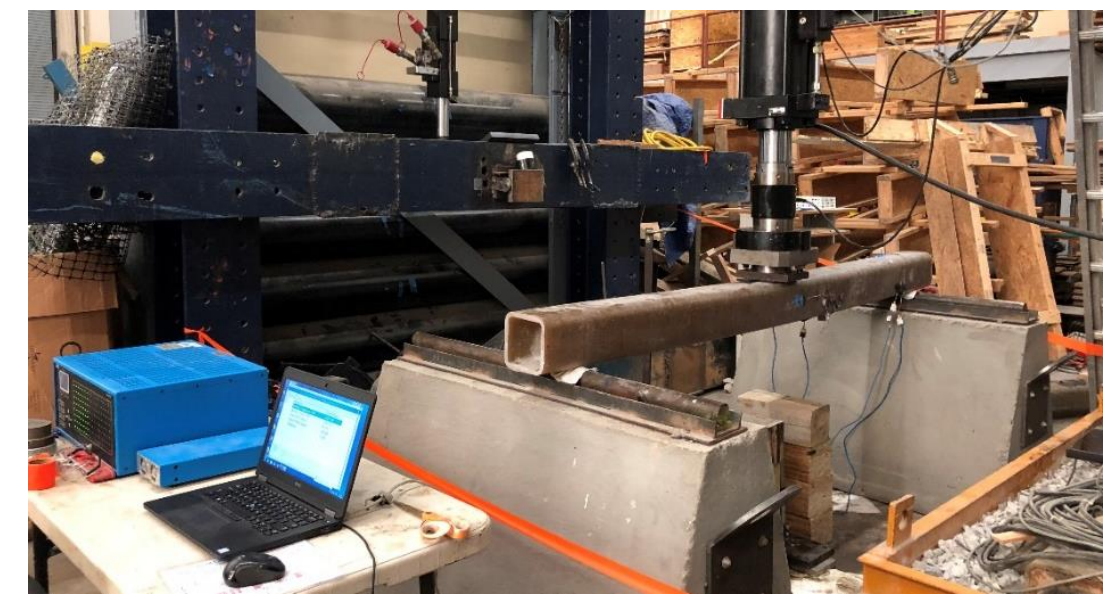

Figure 4-9. Three-point bending setup for testing a box-beam

\subsection{Conclusions}

This chapter presented the test sections and test methods and procedures followed within this research. The coupon-level testing of GFRP and hybrid section will be discussed in Chapter 6 . Whereas, the component-level testing on sections discussed within this chapter will be exclusively discussed in Chapters 5 and 7. 


\section{Chapter 5. Hybrid GFRP-Steel Cellular Wicket Gates}

The background, test details and results, structural and finite element analysis, and field implementation of GFRP cellular panel consisting of embedded steel plates are presented within this chapter. The inception of this work presented in this chapter took place during the design of the GFRP-steel hybrid cellular section as wicket gates. These wicket gates were designed as replacement hydraulic gates in place of existing timber and steel gates in the Mississippi River. The necessity of light-weight, corrosion-resistant, maintenance-free, and durable gates were hard to obtain by using conventional materials like steel and timber, thus GFRP sections were chosen and in order to increase the bending rigidity of the section, two steel plates were embedded inside the GFRP section that helped in reducing gate deflections and fluttering under water loading.

\subsection{Introduction}

The U.S. Army corps of Engineers (USACE) owns, operates and maintains an extensive infrastructure of navigational, flood control and waterfront structures over a length of 19,000 km $(12,000$ miles $)$ in the United States. Most of these structures are made up of traditional materials such as steel, concrete and timber which are now exhibiting significant amount of corrosion, decaying and aging (Lampo et al. 2001). According to USACE, more than $\$ 13$ billion is required to maintain existing levels of inland waterways without exacerbating further by 2020 (ASCE 2012). Almost $73 \%$ of the budget is allocated to the rehabilitation of current lock and dam facilities. Due to expensive regular maintenance and replacement costs of these structures, USACE decided to utilize FRP composites to manufacture and install few test-run gates to minimize maintenance costs and to observe how they are going to perform under field conditions.

A wicket gate is a movable dam that is raised in times of low water and lowered when the water level is adequate for navigation (Fig. 5-1). These gates have been utilized for navigation dams for over 100 years (Chowdhury \& Davis 2001). These gates are hinged individually just below their center to the river bottom with a help of horse framing. These gates are placed across a navigation channel with $50 \mathrm{~mm}$ to $100 \mathrm{~mm}$ gap in-between and oriented at an angle of $65^{\circ}$ to form a dam (Fig. 5-1). These gates are hoisted into position manually with a gantry operated crane or winch cable and are held in an upward position with a prop-rod that slides into a hurter. GFRP composites were previously used to manufacture wicket gates for replacing old timber wickets in Olmsted locks and dam in Ohio River in 1993 but were not field implemented for some undisclosed reasons (GangaRao \& Vijay 2010, Chowdhury et al. 1998a). A single prototype wicket gate using FRP composite and steel was manufactured for Olmsted lock and dam and tested in the field for short duration. The testing showed larger deflections in the GFRP gates while sides were damaged due to debris getting caught between adjacent gates (Chowdhury et al. 1998b). The study on a scaled model of the FRP wicket gate showed some peeling off on both edges due to high velocity of water flow between the panels. The study suggested the use of local steel plates to minimize out of plane loading during lifting and addition of steel angles on the side panels to increase the durability (Chowdhury \& Davis 2001). 


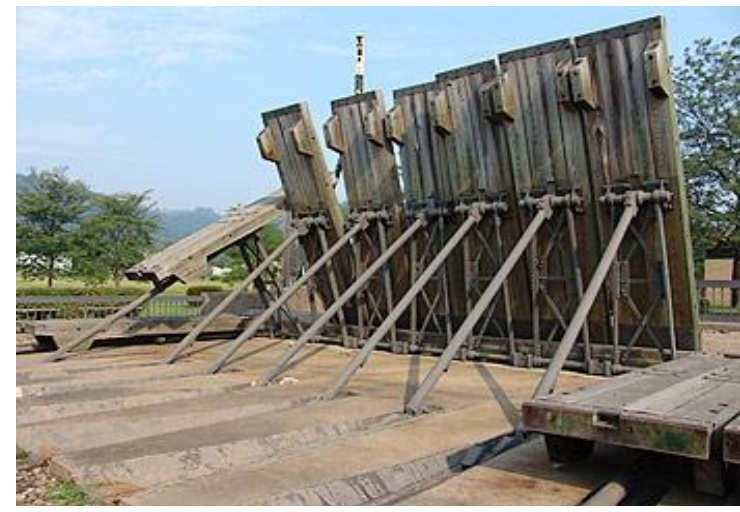

(a)

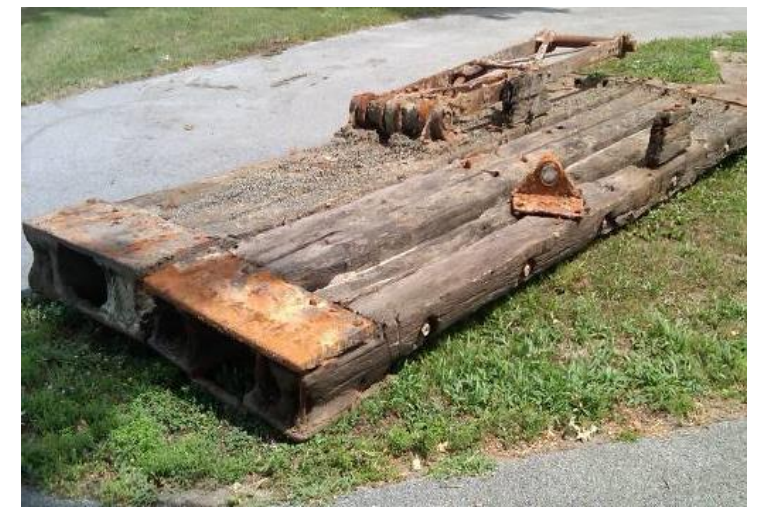

(b)

Figure 5-1. a) Timber wicket gates in service, b) deteriorated timber wicket gates

\subsection{In-service timber wicket gates}

Wicket gates, currently in service at Rock Island lock and dam, IL, were constructed with white oak timber sections enclosed in steel or iron framing (Fig. 5-2). The length and width of the wicket gate was $5.03 \mathrm{~m}(16.5 \mathrm{ft}$.) and $1.17 \mathrm{~m}(3.83 \mathrm{ft}$.), respectively. The gate was made of four individual timber beams with a maximum depth of $305 \mathrm{~mm} \mathrm{(12")}$ at nearly one-third height from the bottom end. Peripheral steel angles $\left(3.5^{\prime \prime} \times 3.5^{\prime \prime} \times 0.25^{\prime \prime}\right)$ were bolted to the edges of upstream face of the timber gate. Half-inch thick steel plates were bolted on both upstream and downstream faces of the gate at the top and bottom, respectively (Fig. 5-2a). The downstream face of the gate consisted two steel plates that were connected by a shaft to which a 6-inch diameter prop-rod was connected (Fig. 5-2b).

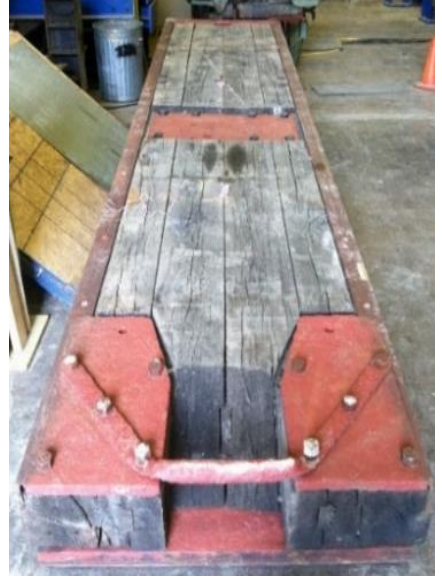

(a)

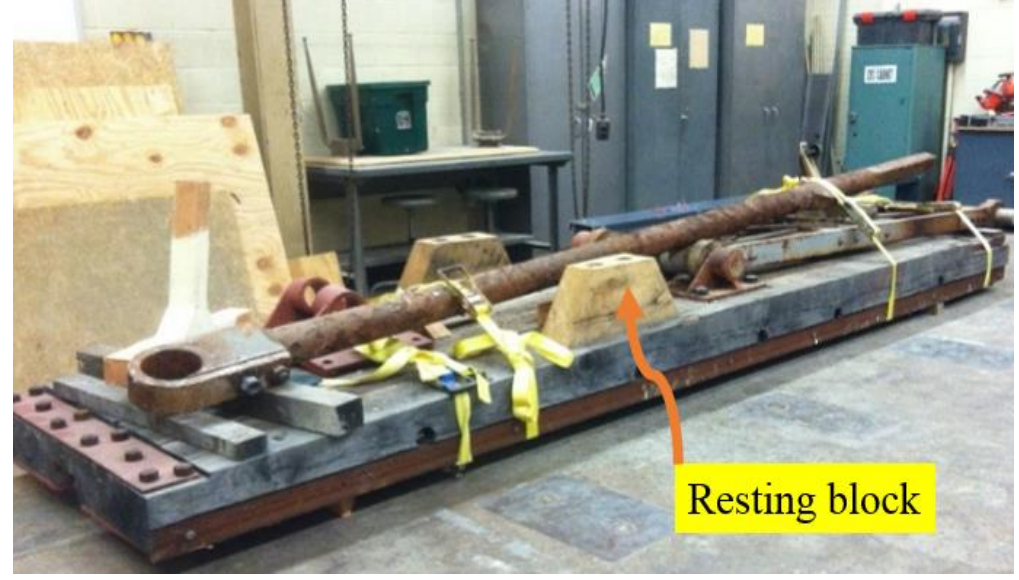

(b)

Figure 5-2. Timber wicket gate: a) upstream face, b) downstream face with a prop-rod

The timber used in the gate had a design bending strength of 1300 psi, shear strength of 205 psi, compressive strength perpendicular to grain of $800 \mathrm{psi}$ and the modulus of elasticity of $1.78 \mathrm{msi}$ as per NDS supplement for wood construction (AWC 2005). The allowable calculated shear force resisted by the gate was 75-kip, allowable punching shear through steel plates was 295 kip, and allowable bending moment of a solid timber gate was $119 \mathrm{kip}-\mathrm{ft}$. These reverse engineered values were used as a basis to design the FRP wicket gate. 


\subsection{Determination of service loads}

The length and width of the gate are $5.03 \mathrm{~m}(16.5 \mathrm{ft}$.$) and 1.17 \mathrm{~m}(3.83 \mathrm{ft}$.$) , respectively and a prop-$ rod is connected to the middle portion (top hinge) of the gate as shown in Fig. 5-3. The location of the top hinge from the bottom of the gate is $2.44 \mathrm{~m}(8 \mathrm{ft}$.) along the gate length (Fig. 5-3). For analysis, four loading scenarios were considered.

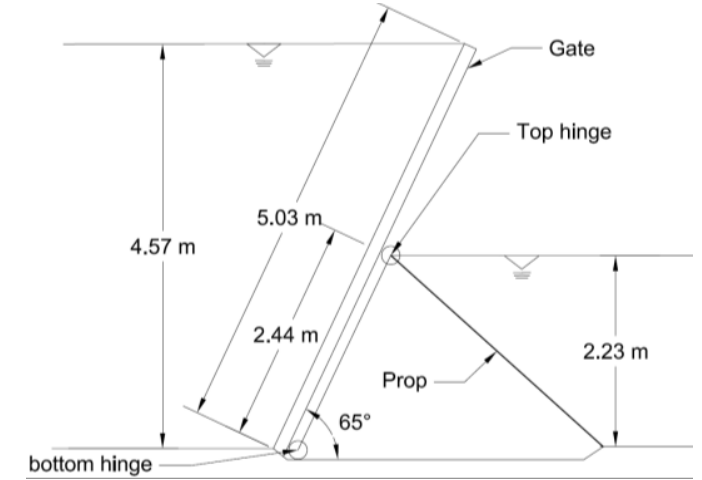

(a)

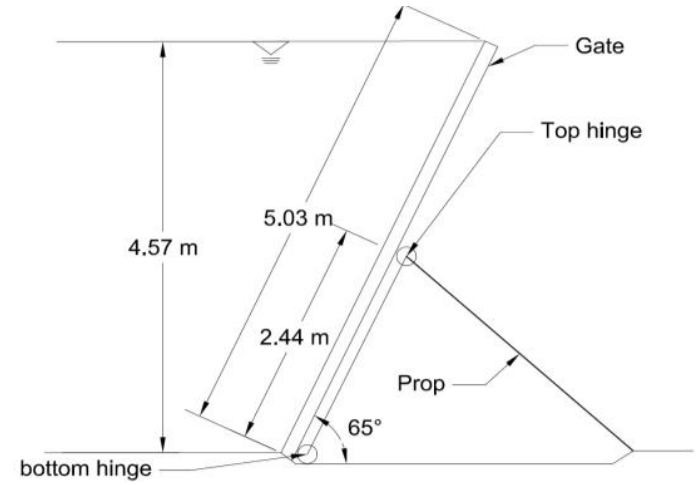

(b)

Figure 5-3. Wicket gate in operating position: a) with tail water, b) without tail water

\subsubsection{Load during operating position}

During operating position (Fig. 5-3), the maximum angle between the gate and the ground is $65^{\circ}$. The calculation of forces including self-weight and hydraulic pressure are based on two scenarios:

i) Presence of full height of water, i.e. (15 ft.) on upstream side (head water) and up to the height of the top hinge on downstream side (tail water), i.e., (7.3. ft.)

ii) Presence of full height of water, i.e. (15 ft.) on upstream side and absence of water on downstream side

The self-weight of the FRP gate system is assumed as $26.7 \mathrm{kN}$ (6 kip) and considered to be acting through the center of the gate for the ease of calculation. The average water pressure and hydrostatic force on the gate surface were calculated by Eqns. (5-1) and (5-2). Equating moment of forces about bottom hinge (Fig. 5-3), forces in the prop and gate section were calculated as shown in Table 5-1.

Average water pressure on upstream side $=\frac{\gamma \mathrm{h}}{2}=\frac{9.81 * 4.57}{2}=44.8 \frac{\mathrm{kN}}{\mathrm{m}^{2}}$

Hydrostatic force on upstream side $=44.8 \frac{\mathrm{kN}}{\mathrm{m}^{2}} \times 5.03 \mathrm{~m} \times 1.17 \mathrm{~m}=263.65 \mathrm{kN}$

\subsubsection{Load during resting position}

During resting position on the river bed, the wicket gate stays on two support points, i) solid block and ii) bottom hinge. The maximum height of water above the resting gate is $15 \mathrm{ft}$. and the space underneath the gate is filled with water. Thus, equal pressure is exerted on both sides of the gate assuming the depth of the gate is insignificant. Therefore, wicket gate will have practically negligible loads during resting position and their negative buoyancy should be ascertained. 


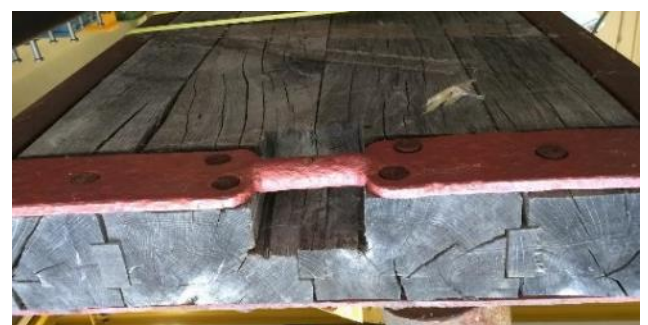

(a)

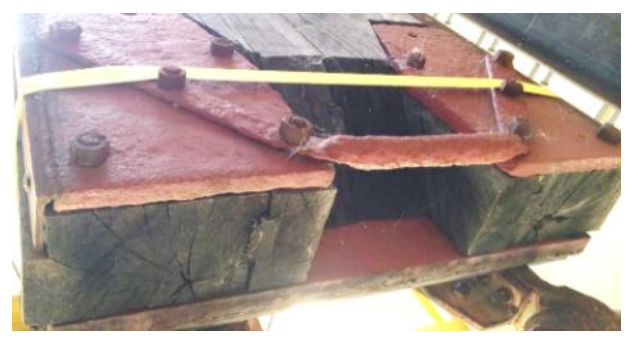

(b)

Figure 5-4. Bails on the wicket gate: (a) top bail, (b) bottom bail

\subsubsection{Load during lifting position}

During lifting, a winch cable is tied to either top or bottom bail (Fig. 5-4). In order to achieve higher safety factor and design for the worst possible scenario, the gate is assumed to act like a simply supported beam with the two ends hinged. The full height of water above the gate is assumed to be $15 \mathrm{ft}$. just when the lifting is started from the rest position. It is also assumed that no pressure is exerted from the downstream side of the gate during lifting and the gate resists the entire column of water over its surface. Computed maximum shear force and maximum bending moment are shown in Table 5-1.

\subsubsection{Load due to hydrodynamic effects}

The presence of turbulent flow of water around the gate can create a scenario where each gate can be subjected to forces that can locally compound the mean induced stresses (March \& Elder 1992). Researchers in the past have conducted mathematical modeling to determine hydrodynamic forces on the gate based on the results obtained from the experimental analysis on 1:25-scale physical model of the gate at the U.S. Army Engineer Waterways Experiment Station (Bejar \& Hall 1998). The largest hydraulic force acted on the closed central gate when adjacent gates on both sides of the test-gate were opened. This configuration (Fig. 5-5) was identified from experiments as one of the critical conditions to be considered in the gate design (March \& Elder 1992). The study conducted by Bejar and Hall, 1997 showed the resultant hydrodynamic force acting on the vertical projection of the gate and the vertical distance $(z)$ at which it acts from the bottom of the gate based on Eqns. (5-3) and (5-4).

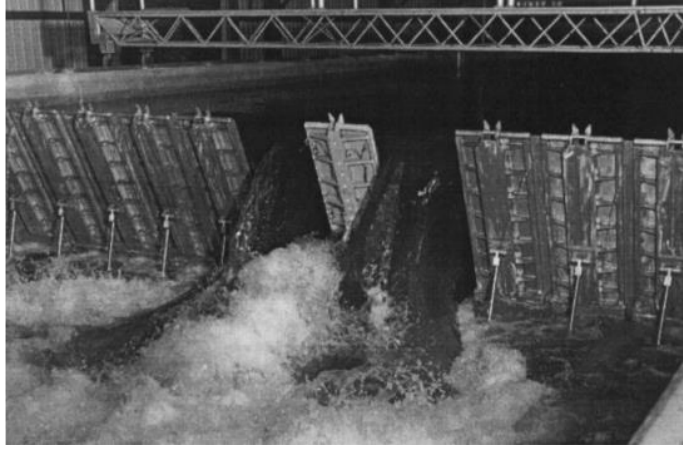

(a)

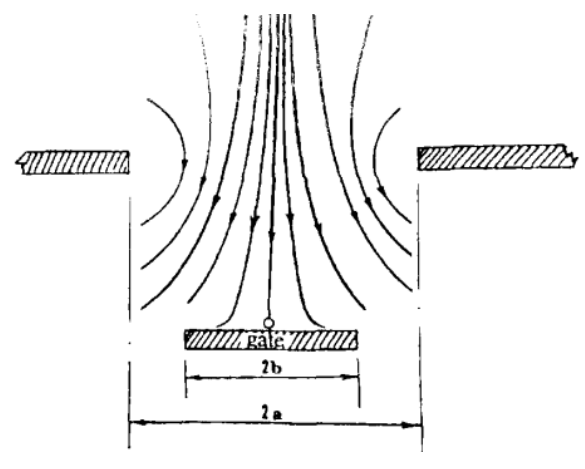

(b)

Figure 5-5. (a) Three-gate aperture, b) velocity field on upstream side of the gate (Chowdhury et al. 1998b, March \& Elder 1998) 


$$
\begin{aligned}
& F_{H}=\rho k_{d}^{2} * \frac{\pi}{2}\left(\frac{\pi}{2}+1\right) * \frac{A_{g}}{(2 a)^{2}} * \chi(\Delta \beta) * \sin \theta \\
& Z=0.58 h
\end{aligned}
$$

Where, $\rho$ is the density of water, $k_{d}$ is the coefficient of actual flow (length $2 /$ time) obtained during experiment on the physical model, $A_{g}$ is the area of the upstream face of the gate, $2 a$ is the width of the test-gate including aperture on both sides, $h$ is the height of the vertical projection of the gate, $\Delta \beta$ is the hydrodynamic pressure distribution and $\theta$ is the inclination of the gate. $\chi(\Delta \beta)$ is the equivalent normalized distance of the gate as defined by Eqn. (5-5).

$$
\chi(\Delta \beta)=\frac{8(1-\Delta \beta)-1}{1+(1-\Delta \beta)}-\ln \left(\frac{2}{\Delta \beta}-1\right)=0.62
$$

For calculating the hydrodynamic resultant force for the wicket gate discussed in this paper, $k_{d}$ is taken as $0.0372 \mathrm{~m}^{2} / \mathrm{s}$ (March \& Elder 1992). The area of the upstream face $\left(A_{g}\right)$ and the width $(2 a)$ of the gate including 2 " aperture on both sides for 1:25 scale model is taken as $0.009398 \mathrm{~m}^{2}$ and $0.0508 \mathrm{~m}$. Likewise, the hydrodynamic pressure distribution $(\Delta \beta)$ and $\chi(\Delta \beta)$ are taken as 0.15 and 0.62 , respectively. The inclination of the gate during the operating position is $65^{0}$. Therefore, the hydrodynamic resultant force for a 1:25 scale wicket gate model is provided by Eqns. (5-6) and (5-7) with appropriate scaling factor.

$$
\begin{aligned}
& F_{H}=1000 * 0.0372^{2} * \frac{\pi}{2}\left(\frac{\pi}{2}+1\right) * \frac{0.009398}{(0.0508)^{2}} * 0.62 * \sin 65=11.39 \mathrm{~N} \\
& F_{H}=25^{3} * 11.39 \mathrm{~N}=178 \mathrm{kN}(40 \mathrm{kip})
\end{aligned}
$$

Hydrodynamic force of $178 \mathrm{kN}$ (40 kip) applied on the gate at a vertical height of $z=0.58 \mathrm{~h}$ for a height of $h=4.57 \mathrm{~m}$ (15 ft.) will result in a prop compressive force of $191.3 \mathrm{kN}$ (43 kip). Based on the analysis of above four scenarios, the design of FRP wicket gate is governed by the shear, compression and bending forces induced during lifting of the gate. Table 5-1 shows the summary of forces acting on the gate and governing forces which are accounted for with sufficient safety factors as discussed in section 5.4.

Table 5-1. Summary of forces on wicket gate in different positions

\begin{tabular}{|l|l|c|c|c|}
\hline \multicolumn{2}{|l|}{ Loading scenarios } & $\begin{array}{c}\text { Prop force } \\
\text { (kip) }\end{array}$ & $\begin{array}{c}\text { Shear force } \\
\text { (kip) }\end{array}$ & $\begin{array}{c}\text { Bending moment } \\
\text { (kip-ft) }\end{array}$ \\
\hline \multirow{2}{*}{1} & Operating (with tail water) & 20.6 & 11.5 & 27.7 \\
\cline { 2 - 5 } & Operating (without tail water) & 23.0 & 9.2 & 20.4 \\
\hline 2 & Resting & 0 & 0 & 0 \\
\hline 3 & Lifting & 0 & 29.6 & 122.0 \\
\hline 4 & Hydrodynamic effects & 43.0 & 23.7 & 57.7 \\
\hline
\end{tabular}

\subsection{Design of an integrated GFRP-steel wicket gate section}

In contrast to timber wicket gates consisting of four individual timber sections connected through bolts, FRP wicket gate was designed as a single sandwich section by integrating face sheets, webs and foam core. In addition, two steel plates were embedded inside face sheets which helped to enhance the moment of inertia of the section, reduce deflection and buoyancy and facilitate 
connectivity with existing horse and prop systems. Resting blocks (Fig. 5-2) were also integrated into the section which resulted in easier and stable assembly. Bolted steel angles on the sides of the wicket gate were replaced with the bonded ultra-high molecular weight polyethylene (UHMWPE) which helped reduce the use of steel and promised superior impact and abrasion performance. Negative buoyancy of the integrated FRP wicket gate was ensured through design and placement of embedded steel plates, core material and additional steel fixtures.

The cross-section of $215.5 \mathrm{~mm}\left(8.5^{\prime \prime}\right)$ deep wicket gate designed through this research is shown in Fig. 5-6. There are 14 webs across the $1.17 \mathrm{~m} \mathrm{(46")}$ wide section wicket gate with top and bottom flange thickness of $13.28 \mathrm{~mm}\left(0.523^{\prime \prime}\right)$ each and web thickness of $10.16 \mathrm{~mm}\left(0.4^{\prime \prime}\right)$ each. Moment of inertia of a single FRP wicket gate module without steel attachments is $39,250.6 \mathrm{~cm}^{4}\left(943 \mathrm{in}^{4}\right)$. Timber wicket gates have additional steel attachments on top and bottom of the gate along with edge steel angles as shown in Figs. 5-2 and 5-4, which contribute to the overall strength and stiffness of the gate. In this section, design checks have been performed on only GFRP module without considering the contributions from external steel attachments.

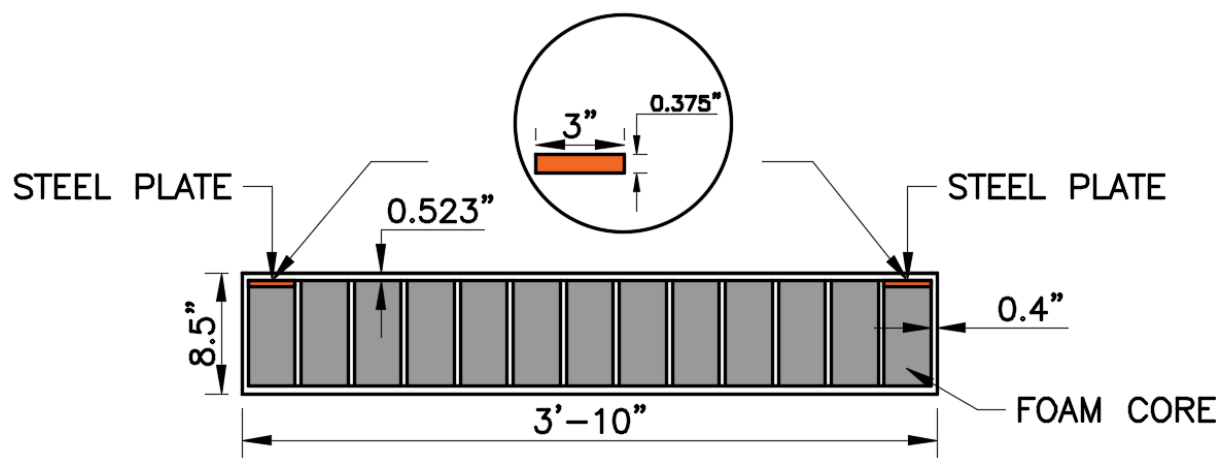

Figure 5-6. Cross-section of FRP composite wicket gate without any steel attachment

\subsubsection{Check for bending stresses in the face sheet}

$$
\text { Bending stress in face-sheet }(\sigma)=\frac{\mathrm{Md}}{2 \mathrm{I}}=\frac{165.4 \mathrm{kNm} \times 215.5 \mathrm{~mm}}{2 \times 39250.6 \mathrm{~cm}^{4}}=45.5 \mathrm{MPa}(6.6 \mathrm{ksi})
$$

where, $\mathrm{d}$ is the depth of the section. Eqn. (5-8) gives a maximum bending stress of $45.5 \mathrm{MPa}(6.6$ $\mathrm{ksi}$ ) for the gate section. The failure bending stress of the FRP panel without any steel attachment is $196.5 \mathrm{MPa}(28.5 \mathrm{ksi})$, which is discussed in section 5.6.1. Based on this bending stress, total resisting bending moment of the selected FRP wicket gate is $696.6 \mathrm{kN}-\mathrm{m}$ (513.8 kip-ft.). Thus, a factor of safety of 4.3 against bending failure (196.5/45.5) is obtained. After considering a live load factor of 1.6, factor of safety against bending failure is 2.7 .

\subsubsection{Check for shear in webs}

Shear stress in webs $(\tau)=\frac{1.5 \mathrm{~V}}{\mathrm{n}_{\mathrm{w}} \mathrm{t}_{\mathrm{w}} \mathrm{h}}=\frac{1.5 \times 132 \mathrm{kN}}{14 \times 10.16 \mathrm{~mm} \times 202.2 \mathrm{~mm}}=6.88 \mathrm{MPa}(0.99 \mathrm{ksi})$

where, $n_{w}$ and $t_{w}$ are the number of webs and thickness of single web, respectively and $h$ is the height of webs between mid-planes of face sheets. Eqn. (5-9) gives a shear stress of 6.88 $\mathrm{MPa}(0.99$ ksi) across the wicket gate section. The in-plane failure shear strength of the FRP webs is established to be $113.1 \mathrm{MPa}(16.4 \mathrm{ksi})$ from manufacturer's test results. Based on this stress, factor of safety against shear failure is $16.4(113.1 / 6.88)$. 


\subsubsection{Check for web buckling}

Total prop force of $102.3 \mathrm{kN}$ ( $23 \mathrm{kip}$ ) is distributed to the gate through two plates of sizes $330 \mathrm{~mm}$ x $432 \mathrm{~mm}\left(13^{\prime \prime} \times 17^{\prime \prime}\right)$. In each of this area, there are 4 webs of $10.16 \mathrm{~mm}\left(0.4^{\prime \prime}\right)$ thickness. Conservatively, considering total prop force coming to only one steel plate, each web is subjected to $26.7 \mathrm{kN}$ (6 kip). For an inch length of the web, moment of inertia about its minor axis is 2,218.5 $\mathrm{mm}^{4}\left(0.00533 \mathrm{in}^{4}\right)$. Considering the modulus of elasticity of the FRP webs to be of $24131.66 \mathrm{MPa}$ (3.5 msi), the buckling load for $25.4 \mathrm{~mm}\left(1^{\prime \prime}\right)$ length of the web is given by Eqn. (5-10).

$$
\mathrm{P}_{\mathrm{cr}}=\frac{\pi^{2} \mathrm{EI}}{\mathrm{h}^{2}}=\frac{\pi^{2} \times 24131.66 \times 2218.5}{202.2^{2}}=12.9 \mathrm{kN} \text { (2.9 kip) }
$$

The buckling load for a single web of length $432 \mathrm{~mm}\left(17^{\prime \prime}\right)$ underneath the steel plate is $219.3 \mathrm{kN}$ (49.3 kip), which gives a factor of safety of $8.2(219.3 / 26.7)$ for the webs against buckling. However, the factor of safety of FRP webs against buckling is more than 8.2 due to higher buckling load value of webs than $12.9 \mathrm{kN}$ (2.9 kip). Fixity of the webs near top and bottom face sheets will halve their effective height which will result in quadrupling of the buckling resistance.

\subsection{Theoretical strength and stiffness of hybrid section}

The designed cellular GFRP-steel hybrid sandwich panel consists of face sheets, primary and secondary webs, core material and embedded steel as shown in Fig. 5-7. In this section, the elastic analysis of sandwich cellular FRP deck with two embedded steel plates has been conducted. This analysis can be used to evaluate stresses in the face sheets, webs and core and also to calculate the flexural rigidity of the deck. The sandwich panel has a total width of $b$ and the depth of $d$. The face sheets, primary webs and secondary webs have thicknesses $t_{f}, t_{p w}$ and $t_{s w}$, respectively. The core material has a thickness $c$ and two embedded steel plates have width $b_{s}$ and thickness $t_{s}$, as shown in Fig. 5-7.

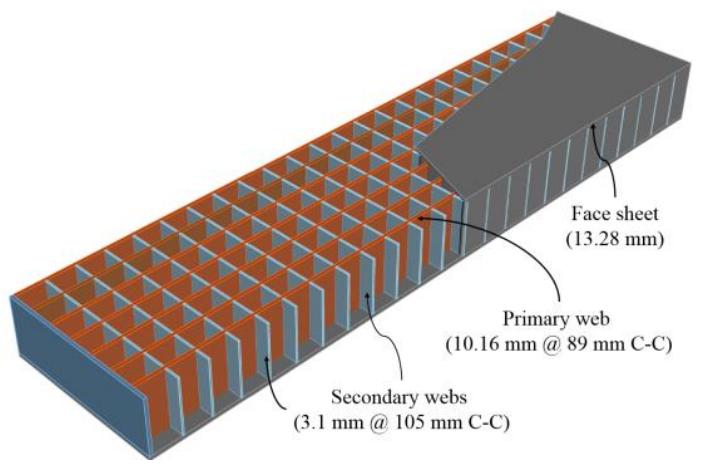

(a)

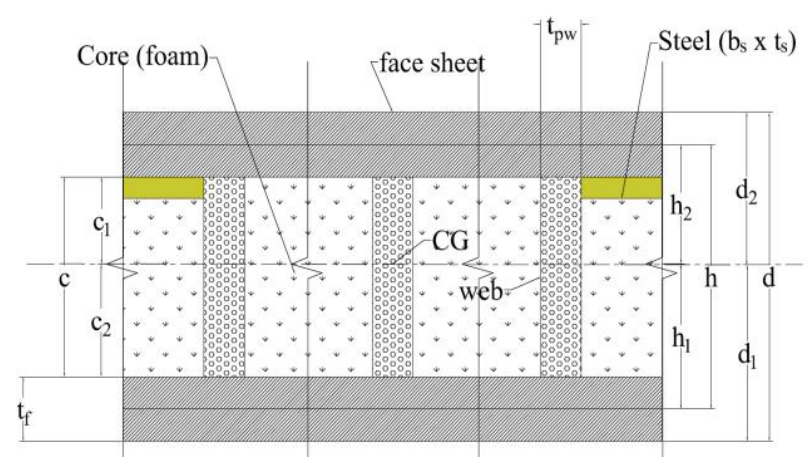

(b)

Figure 5-7. (a) Quarter model of a Cellular FRP panel, (b) cross-section with steel plates

During bending, it is assumed that the face sheets remain bonded to the core and the section bends with no curvature in the YZ-plane and the cross-section of the panel remains perpendicular to the longitudinal axis. The flexural rigidity "D" of the sandwich cellular FRP panel section in the longitudinal direction is given by the algebraic summation of longitudinal stiffnesses of face sheets, primary webs, core and embedded steel plates as shown in Eqns. (5-11) to (5-14). The 
contribution of secondary webs to the flexural rigidity in the longitudinal direction is less and can be neglected.

$$
\begin{aligned}
& D_{\text {face sheets }}=\frac{E_{f x} b_{f}{ }^{3}}{6}+E_{f x} b t_{f}\left(h_{1}{ }^{2}+h_{2}{ }^{2}\right) \\
& D_{\text {primary webs }}=\frac{n_{p w} E_{p w x} t_{p w}\left(h_{1}+h_{2}\right)^{3}}{12}+n_{p w} E_{w x} t_{p w}\left(h_{1}+h_{2}\right)\left(d_{1}-\frac{d}{2}\right)^{2} \\
& D_{\text {core }}=\frac{E_{c x}\left(b-n_{p w} t_{w}\right) c^{3}}{12}+E_{c x}\left(b-n_{p w} t_{w}\right) c\left(c_{1}-\frac{c}{2}\right)^{2} \\
& D_{\text {embedded steel }}=\frac{E_{s} b_{s} t_{s}{ }^{3}}{12}+E_{s} b_{s} t_{s}\left(d_{2}-t_{f}-\frac{t_{s}}{2}\right)^{2}
\end{aligned}
$$

Where, $h_{1}$ and $h_{2}$ are distances between center of gravity (CG) of the panel and the mid-planes of upper and bottom face sheets, respectively. $d_{1}$ and $d_{2}$ are distances between CG of the panel and the bottom and top of the face sheets, respectively and $c_{1}$ and $c_{2}$ are distances between CG of the panel and the bottom and top of the foam core as shown in Fig. 5-7. Likewise, $\mathrm{n}_{\mathrm{pw}}$ denotes the number of primary webs in the section. $\mathrm{E}_{\mathrm{fx}}, \mathrm{E}_{\mathrm{pwx}}, \mathrm{E}_{\mathrm{cx}}$ and $\mathrm{E}_{\mathrm{s}}$ are the in-plane young's moduli of the face sheet, primary webs, core and steel respectively along the longitudinal axis of the panel. The first terms of Eqns. (5-11 to 5-14) corresponds to the bending of the respective sections about their own centroid axes, while the second term corresponds to the bending about the centroid axes of the whole panel section. When the modulus of elasticity of the core material is very less compared to that of the panel, its contribution to the flexural rigidity of the entire panel section can be neglected. The contributions from the first terms of Eqns. (5-11), (5-14) and second term of Eqn. (5-12) are also negligible. Thus, the flexural rigidity or the bending stiffness of the sandwich cellular FRP panel with embedded steel plates can be simplified as shown by Eqn. (5-15).

$$
\mathrm{D}_{\mathrm{x}}=\mathrm{E}_{\mathrm{fx}} \mathrm{bt}_{\mathrm{f}}\left(\mathrm{h}_{1}{ }^{2}+\mathrm{h}_{2}{ }^{2}\right)+\frac{\mathrm{n}_{\mathrm{w}} \mathrm{E}_{\mathrm{wx}} \mathrm{t}_{\mathrm{pw}}\left(\mathrm{h}_{1}+\mathrm{h}_{2}\right)^{3}}{12}+\mathrm{E}_{\mathrm{s}} \mathrm{b}_{\mathrm{s}} \mathrm{t}_{\mathrm{s}}\left(\mathrm{d}_{2}-\mathrm{t}_{\mathrm{f}}-\frac{\mathrm{t}_{\mathrm{s}}}{2}\right)^{2}
$$

The out-of-plane shear stiffness of the cellular FRP sandwich deck in the longitudinal direction $\left(F_{x}\right)$ is expressed as shown in Eqn. (5-16):

$$
\mathrm{F}_{\mathrm{x}}=\mathrm{n}_{\mathrm{pw}} \mathrm{G}_{\mathrm{pxy}} \mathrm{t}_{\mathrm{pw}} \mathrm{h}
$$

Where, $G_{p x y}$ is the in-plane shear modulus of primary webs and $h$ is the depth of the web between the mid-planes of face sheets. The transverse bending stiffness of the cellular GFRP sandwich deck is mainly achieved from the bending stiffnesses of the face sheets and the secondary webs as shown by Eqn. (5-17). The effects of primary webs and second moment of area of face sheets about their own centroids are neglected.

$$
D_{y}=E_{y} l_{f}\left(h_{1}{ }^{2}+h_{2}^{2}\right)+\frac{n_{s w} E_{s w x} t_{s w}\left(h_{1}+h_{2}\right)^{3}}{12}
$$

Where, $\mathrm{E}_{\mathrm{y}}$ is the modulus of elasticity of the panel in y-direction, $\mathrm{l}$ is the length of the panel in longitudinal direction, $\mathrm{n}_{\mathrm{sw}}$ and $\mathrm{t}_{\mathrm{sw}}$ are the number and thickness of secondary webs in the section and $\mathrm{E}_{\mathrm{swx}}$ is the in-plane young's modulus of the secondary webs. Similarly, the transverse shear stiffness $\left(\mathrm{F}_{\mathrm{y}}\right)$ for the cellular FRP sandwich section can be obtained by considering the structure as a vierendeel frame in the transverse direction as shown in Eqn. (5-18). 


$$
F_{y}=n_{s w} G_{s x y} t_{s w} h+\frac{12 E_{y}}{b\left(\frac{h}{I_{w}}+\frac{b}{2 I_{f}}\right)}
$$

Where, $G_{\text {sxy }}$ is the in-plane shear modulus of secondary webs and the moment of inertias are defined as shown in Eqn. (5-19).

$$
I_{f}=\frac{l_{t}{ }^{3}}{12} ; I_{w}=\frac{1 t_{w}{ }^{3}}{12}
$$

The theoretical bending and shear stiffness of cellular FRP sandwich deck panel were verified with experimental results obtained from 3-point and 4-point bending tests of the panel in later sections. The central deflection of the deck can be computed from their corresponding bending and shear stiffness as shown in Eqns. (5-20) and (5-21).

$$
\begin{aligned}
& \delta=\frac{\mathrm{PL}^{3}}{48 \mathrm{D}_{\mathrm{x} \text { or } \mathrm{y}}}+\frac{\mathrm{PL}}{4 \kappa \mathrm{F}_{\mathrm{x} \text { or } \mathrm{y}}}(3 \text {-point bending }) \\
& \delta=\frac{23 \mathrm{PL}^{3}}{1296 \mathrm{D}_{\mathrm{x} \text { or } \mathrm{y}}}+\frac{\mathrm{PL}}{6 \kappa \mathrm{F}_{\mathrm{x} \text { or } \mathrm{y}}}(4 \text {-point bending })
\end{aligned}
$$

Where, $\mathrm{P}$ is the total load applied, $\mathrm{L}$ is the length of the span, $\mathrm{\kappa}$ is the shear correction factor (assumed as 1.0) and D, F are the bending and shear stiffness in either longitudinal or transverse direction based on loading and support conditions.

\subsection{Testing and results}

Laboratory tests were performed on FRP coupon specimens, timber and FRP wicket gates. Loading levels were within $40 \%$ of the ultimate loads. Bending and shear strains were measured both on the upstream and downstream sides of the gate at the center of the panel and hinge and prop locations. Deflections were measured through LVDTs. Shear gages were instrumented on side walls. During reverse engineering analysis, it was found that the bending loads were more critical as compared to shear. Following tests were performed in the laboratory:
A. Tensile test on FRP wicket gate coupon specimens
B. Four point bending on timber and FRP wicket gate with steel fixtures
C. Three-point bending test on FRP wicket gate after removing steel fixtures
D. Fatigue test on FRP wicket gate
E. End plate/bail pull test

\subsubsection{Tensile test on coupons}

Tensile tests were conducted on GFRP coupons representing face sheet of the GFRP wicket gate to obtain modulus of elasticity (E) of the FRP laminate. These face sheet coupons were selected to represent smooth and potential wrinkling near the outer surfaces or edges (Fig. 5-8a). Samples with dimensions of $1067 \mathrm{~mm} \times 50.8 \mathrm{~mm} \times 10.9 \mathrm{~mm}$ in the longitudinal and transverse directions were prepared and tested in tension. The strain gages were located at the mid-height region of the sample. Table 5-2 shows the test results and Fig. 5-8b shows the stress vs. strain plot for specimens with and without wrinkling in the longitudinal direction. The modulus of elasticity for both types of specimens was identified and found to be $30.34 \mathrm{GPa}$ (4.4 msi). 


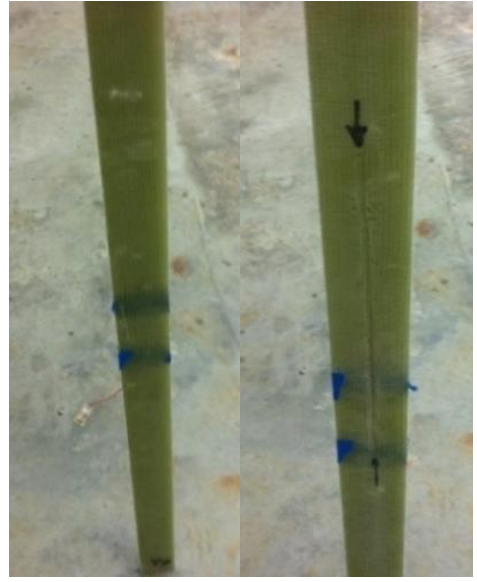

(a)

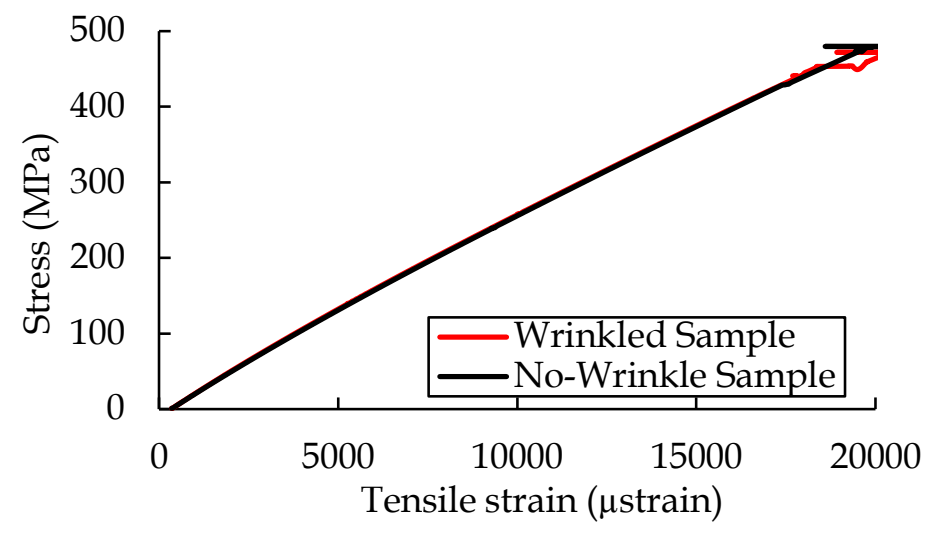

(b)

Figure 5-8. (a) Tensile coupons with/without wrinkle, (b) tensile stress vs. strain plot

Table 5-2. Tensile stress and stiffness of face sheet coupons

\begin{tabular}{|c|c|c|c|c|c|}
\hline Sample & $\begin{array}{l}\text { Width } \\
\text { mm (in) }\end{array}$ & $\begin{array}{c}\text { Thickness } \\
\text { mm (in) }\end{array}$ & $\begin{array}{l}\text { C/S area } \\
\mathrm{mm}^{2}\left(\text { in }^{2}\right)\end{array}$ & $\begin{array}{c}\text { Failure stress } \\
\mathrm{MPa}(\mathrm{ksi})\end{array}$ & $\begin{array}{c}\text { Stiffness } \\
\text { GPa (msi) }\end{array}$ \\
\hline \multirow{2}{*}{ Longitudinal } & \multirow{4}{*}{$50.8(2)$} & \multirow{4}{*}{$10.9(0.43)$} & \multirow{4}{*}{$\begin{array}{l}555.5 \\
(0.86)\end{array}$} & 490.9 (71.2) & $30.34(4.4)$ \\
\hline & & & & $490.2(71.1)$ & $30.34(4.4)$ \\
\hline \multirow{2}{*}{ Transverse } & & & & $250.3(36.3)$ & - \\
\hline & & & & $239.9(34.8)$ & - \\
\hline
\end{tabular}

The tensile strain to failure for the coupon specimens is 18,000 micro-strain as seen in Fig. 10. Bending failure stress of the entire panel was obtained by applying a knock-down factor of 0.6 and a stress concentration factor of 0.6 which leads to the bending strain to failure of the gate as 6,480 micro-strains. Thus, stress to failure for bending is given by Eqn. (5-22).

Bending stress to failure $=30.34 \mathrm{GPa} * 6480 \times 10^{-6}=196.5 \mathrm{MPa}(28.5 \mathrm{ksi})$

\subsubsection{Four point bending on timber and GFRP wicket gate with steel fixtures}

Four-point bending loads were applied at L/3 distance from both ends of the FRP gate without removing external steel fixtures (Fig. 5-9). These fixtures such as steel edge angles and connecting plates (top and bottom) enhance flexural rigidity and provide abrasion resistance. Five shear strain gages and 15 axial strain gages were bonded at different locations of the gate and LVDTs were used to measure deflections. Load of $267 \mathrm{kN}$ (60 kip) each was applied with two MTS hydraulic actuators at L/3 distance for FRP wicket gate and similar load of $155.7 \mathrm{kN}$ (35 kip) each was applied to the timber wicket gate. Table 5-3 shows the results of the testing. The maximum bending strains at L/2 (center) and L/3 distances were 3352 micro-strains and 2001 micro-strains, respectively. Maximum shear strain of 2230 micro-strains was measured at a distance ' $d$ ' from the support, where ' $d$ ' is the gate depth. Strains during bending failure in FRP shapes is noted to be in the range of 10,000 to 15,000 micro-strains and in the range of 8000 to 10,000 micro-strains during shear failure. These induced strains are about $1 / 4^{\text {th }}$ to $1 / 3^{\text {rd }}$ of the failure strains but may vary based on the fiber-fabric architecture, L/d ratio, and local failure modes. 


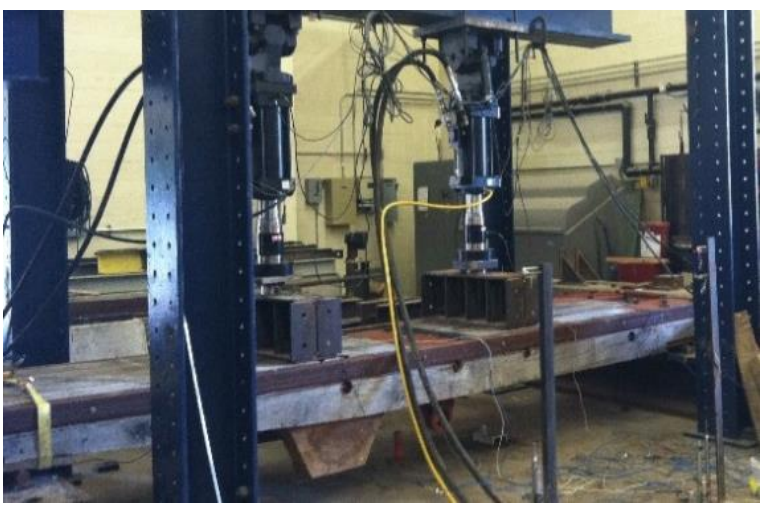

(a)

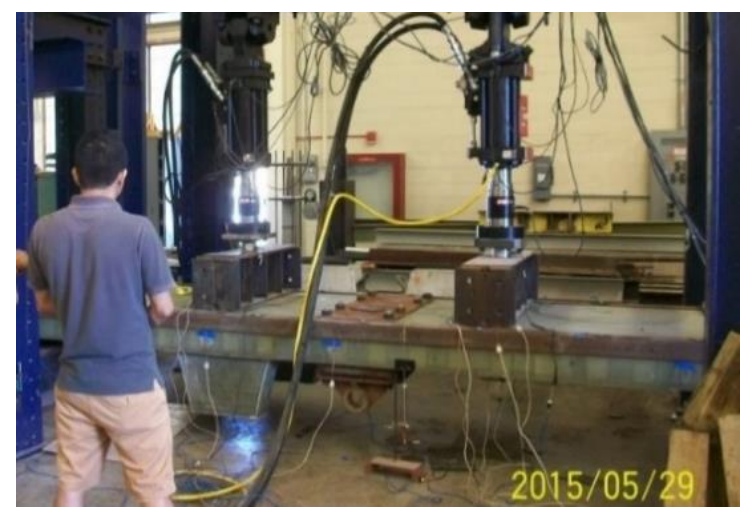

(b)

Figure 5-9. Bending tests: (a) on timber wicket gate, (b) on GFRP-steel wicket gate

Table 5-3. Four-point bending test results of timber and GFRP-steel gate

\begin{tabular}{|l|c|c|}
\hline \multicolumn{1}{|c|}{ Items } & Timber gate & GFRP gate \\
\hline Test span, m (ft.) & $4.57(15)$ & $4.57(15)$ \\
\hline Load distance from supports, m (ft.) & $1.52(5)$ & $1.52(5)$ \\
\hline Total load, kN (kip) & $311.4(70)$ & $534(120)$ \\
\hline Maximum moment, kN-m (k-ft) & $237.3(175)$ & $406.7(300)$ \\
\hline Maximum bending strain at center $(\mu \mathrm{s})$ & 1312 & 3352 \\
\hline Maximum shear strain $(\mu \mathrm{s})$ & 129 & 2230 \\
\hline Deflection at center $(\mathrm{L} / 2), \mathrm{mm}($ inch) & $26.42(1.04)$ & $58.75(2.3)$ \\
\hline Deflection at L/3, mm (inch) & $24.13(0.95)$ & $51.8(2.04)$ \\
\hline
\end{tabular}

\subsubsection{Three point bending on GFRP wicket gate without steel fixtures}

After removing steel fixtures, GFRP wicket gate was loaded in 3-points for a span of $4.57 \mathrm{~m}$ (15 $\mathrm{ft}$.) with a load of $89 \mathrm{kN}$ (20 kip) as shown in Fig. 5-10. Strains were measured at different locations of the gate and the vertical displacements were measured at the center and one-third distance. At the maximum load of $89 \mathrm{kN}$, the maximum deflection obtained at the center and one-third of the span was $14.81 \mathrm{~mm}\left(0.583^{\prime \prime}\right)$ and $12.78 \mathrm{~mm}\left(0.503^{\prime \prime}\right)$, respectively.

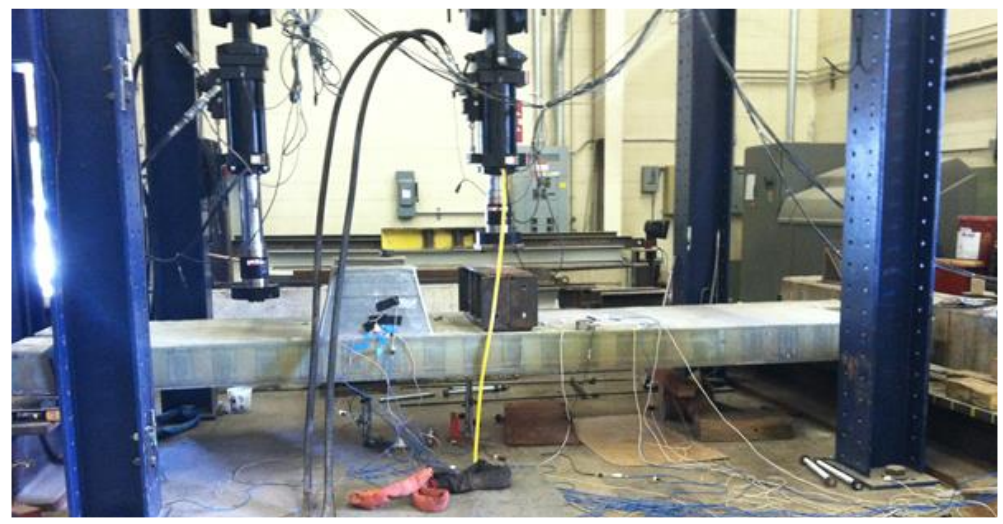

Figure 5-10. Three-point bending test of GFRP-steel hybrid wicket gate 


\subsubsection{Fatigue test on GFRP wicket gate}

GFRP wicket gate, without any external steel fixtures, was tested in fatigue with a load-range of 53.4 to $106.8 \mathrm{kN}(12-24 \mathrm{kip})$ at a frequency of $1 \mathrm{~Hz}$ in a three-point bending setup with a span of $4.57 \mathrm{~m}$ ( $15 \mathrm{ft}$.) for 50,000 cycles. As obtained from USACE, the gate operating sequences are based on seasonal variations of water level and are highly unlikely to exceed 5,000 cycles in a 100-year life cycle. For a typical FRP material, applied stress (S) vs. number of cycles (N), i.e., S-N curve can be expressed in a linear manner as shown in Eqn. (23), when the number of cycles is less than one million cycles (Kelkar 2001, Mathieson \& Fam 2011).

$$
\frac{\sigma_{\text {applied }}}{\sigma_{\text {static }}}=\mathrm{A}+\mathrm{B} \log \mathrm{N}
$$

where, $\sigma_{\text {applied }}$ is the applied stress or stress range, and $\sigma_{\text {static }}$ is the ultimate static strength. A and $\mathrm{B}$ are material constants. At a very low stress range, the S-N curve gets flattened indicating the infinite life of the material (Kelkar 2001). For the FRP wicket gate designed in this research, the maximum load that gets transferred to the gate through prop rod via prop connecting steel plates during operating position is $91.8 \mathrm{kN}$ (20.6 kip) (Table 5-1), therefore the load applied on the gate was in the range of 53.4 to $106.8 \mathrm{kN}$ (12-24 kip), where the maximum stress applied to the gate is just $17 \%$ of its ultimate strength. Generally, this limit of stress falls below the endurance limit for FRP composites and at this stress, the fatigue life of the FRP material is considered to be infinite (Kelkar 2001, Mathieson \& Fam 2011). In addition, after 50,000 cycles of loading, three-point static bending test was performed on the gate with the central load of $178 \mathrm{kN}$ (40 kip). The maximum tensile strain obtained at the center of the gate was 975 micro-strains compared to 978 microstrains before fatigue. The strain levels indicated that the stiffness and strain energy absorption capacity of the gate was not reduced due to fatigue loading and will not be affected during its service life.

\subsubsection{End plate/bail pull test}

FRP wicket gate was placed horizontally on two end supports with top of the gate fixed against horizontal movement. A chain was attached to the top bail (weaker than the bottom bail) and pulled horizontally with a force of $84.1 \mathrm{kN}$ (18.9 kip) (Fig. 5-11). The pulling force on the bail is transferred to the FRP face sheets through the bolt attachments. Few strain gages bonded to the FRP surface below the bail recorded a maximum strain of 104 micro-strains. These low strains indicate that the gate can safely withstand the bail pullout forces with a high factor of safety.

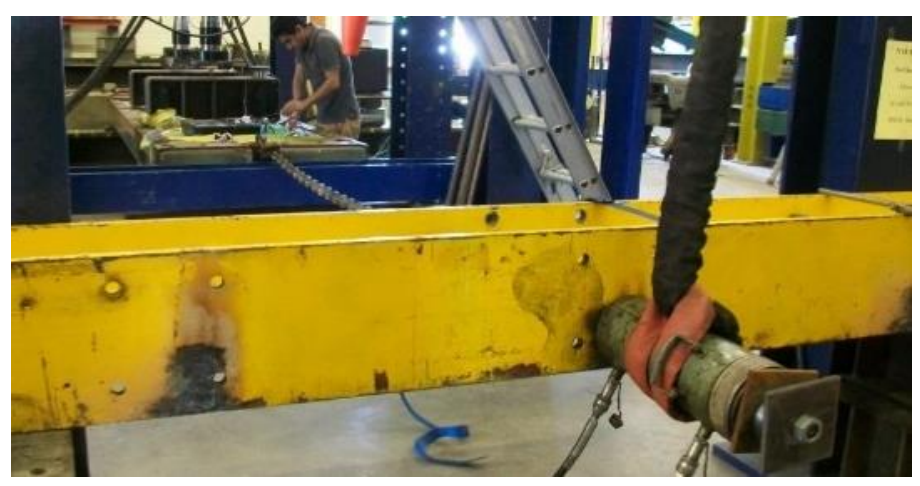

Figure 5-11. Pulling test on a top bail of the FRP gate 


\subsection{Stiffness of the hybrid wicket gate}

In this section, the stiffness of the FRP wicket gate is experimentally evaluated and compared with the theoretical value. Center of gravity (c.g.) of the wicket gate with two embedded steel plates is calculated as shown in Table A1 (Appendix A). Low stiffness of the core material (foam) is ignored in the calculations. Two embedded steel plates act compositely with the FRP section. Using a stiffness (E) value of $28.3 \mathrm{GPa}(4.1 \mathrm{msi})$ for face sheets and primary webs, a modular ratio of 7.1 was obtained for steel plates embedded in the integrated FRP wicket gate. The density of steel plates is $7861 \mathrm{~kg} / \mathrm{m}^{3}\left(0.284 \mathrm{lbf} / \mathrm{in}^{3}\right)$ as compared to $996.5 \mathrm{~kg} / \mathrm{m}^{3}\left(0.036 \mathrm{lbf} / \mathrm{in}^{3}\right)$ for FRP composites. It is necessary to compute composite moment of inertia of the FRP cellular deck including embedded steel attachment in order to find the overall stiffness of the FRP gate. The composite moment of inertia has been computed and shown in Table A2 of Appendix A.

The center of gravity of the cellular FRP section with embedded steel plates is located at distance of $134.1 \mathrm{~mm}$ (5.28") from the bottom surface marked as X-X in Fig. A1 and the total moment of inertia is $481.1 \times 10^{6} \mathrm{~mm}^{4}\left(1155.8 \mathrm{in}^{4}\right)$ (Appendix A). From 3-point bending tests on the FRP wicket gate (section 5.6.3) without steel fixtures, the total deflection of $14.81 \mathrm{~mm}(0.583$ ") was obtained for a span of $4.57 \mathrm{~m}(15 \mathrm{ft}$.) and a central load of $89 \mathrm{kN}$ (20 kip). By using Eqn. (5-20), the total deflection is separated into bending and shear deflections. With a shear modulus of 3.1 GPa (447 ksi) for FRP primary webs, the shear stiffness of the cellular FRP gate in the longitudinal direction is obtained as $88822.1 \mathrm{kN}\left(1.997 \times 10^{7} \mathrm{lbs}\right.$.) based on Eqn. (5-16). After accounting for shear related deflection, the experimental bending rigidity is $1.31 \times 10^{13} \mathrm{~N} \cdot \mathrm{mm}^{2}\left(4.55 \times 10^{9} \mathrm{lbf}\right.$. in $\left.{ }^{2}\right)$, which correlates well with the theoretical bending rigidity calculated using Eqn. (5-15) (Table 5-4). Addition of steel fixtures (edge angles and connecting plates) increased the flexural rigidity to $1.67 \times 10^{13}$ N.mm² $\left(5.82 \times 10^{9} \mathrm{lbf}^{2}{ }^{2}\right)$ which resulted in a $28 \%$ gain.

Table 5-4. Flexural rigidity and Stiffness of the cellular FRP wicket gate

\begin{tabular}{|c|c|c|c|c|c|c|c|}
\hline \multirow{2}{*}{$\begin{array}{l}\text { Bending } \\
\text { test }\end{array}$} & \multirow{2}{*}{$\begin{array}{c}\text { Central } \\
\text { load } \\
\text { kN (kip) }\end{array}$} & \multirow{2}{*}{$\begin{array}{c}\text { Central } \\
\text { deflection } \\
\text { mm (in) }\end{array}$} & \multicolumn{2}{|c|}{$\begin{array}{l}\text { Flexural rigidity (D) } \\
\left.\text { N.mm² (lbf.in }{ }^{2}\right)\end{array}$} & \multicolumn{2}{|c|}{$\begin{array}{c}\text { Stiffness (E) } \\
\text { GPa (msi) }\end{array}$} & \multirow{2}{*}{$\begin{array}{l}\text { Diff. } \\
(\%)\end{array}$} \\
\hline & & & Exptl. & Theo. & Exptl. & Theo. & \\
\hline $\begin{array}{l}\text { 3-point } \\
\text { (Sect. 5.3) }\end{array}$ & $\begin{array}{c}89 \\
(20)\end{array}$ & $\begin{array}{l}14.81 \\
(0.583)\end{array}$ & $\begin{array}{l}1.31 \times 10^{13} \\
\left(4.55 \times 10^{9}\right)\end{array}$ & $\begin{array}{l}1.29 \times 10^{13} \\
\left(4.49 \times 10^{9}\right)\end{array}$ & $\begin{array}{c}27.2 \\
(3.94)\end{array}$ & $\begin{array}{c}26.8 \\
(3.89)\end{array}$ & 1.3 \\
\hline
\end{tabular}

\subsection{FE analysis of GFRP-steel cellular panel}

Half length of the FRP wicket gate was modeled using the commercial finite element method (FEM) software Abaqus. The half-length modeling was performed with symmetric boundary condition in the longitudinal direction (Fig. 5-12). The gate was modeled by creating three different parts, i) face-sheet, ii) primary webs and iii) secondary webs as 3D-deformable shell elements with orthotropic properties and later assembled together. The analysis was performed for two scenarios, i) FRP wicket gate without steel plate embedment and ii) FRP wicket gate with steel plate embedment. Steel plate was selected as a 3D-deformable solid element with isotropic

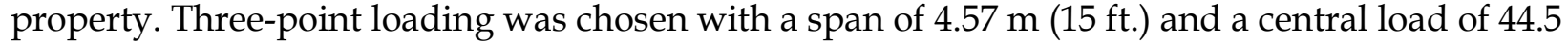
kN (20 kip) load was applied on a width of $114 \mathrm{~mm}\left(4.5^{\prime \prime}\right)$ to represent laboratory loading conditions. 


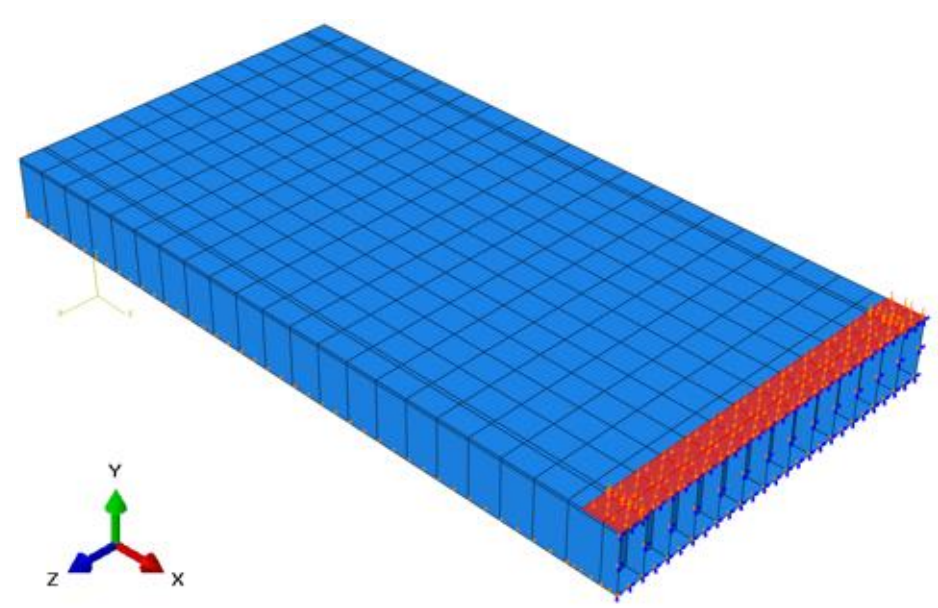

Figure 5-12. GFRP panel half-length model showing loading location with a red shade

The vertical deflection obtained for the wicket gate with embedded steel plates was $14.71 \mathrm{~mm}$ $\left(0.579^{\prime \prime}\right)$. Experimentally, the deflection value obtained for the same gate was $14.81 \mathrm{~mm}\left(0.583^{\prime \prime}\right)$. The deflection values obtained from FE analysis was in excellent correlation with values obtained from laboratory tests with an error percenatge of just $0.6 \%$. In order to know the contribution of those two embedded steel plates to the overall stiffness of the gate, similar model was created without embedded steel plates. For a similar span length and loading, the deflection obtained for wicket gate without steel plate embedment was $23.69 \mathrm{~mm}\left(0.933^{\prime \prime}\right)$. Thus, absence of two embedded steel plates increased the overall deflection of the FRP gate by $61 \%$ (Table 5-5).

Due to addition of two embedded steel plates, the center of gravity of the section changed by $26.35 \mathrm{~mm}\left(1.04^{\prime \prime}\right)$ from the previous center of gravity of the panel. Composite moment of inertia of the section increased to $4.81 \times 108 \mathrm{~mm} 4$ (1156 in4) from the previous value of $3.93 \times 108 \mathrm{~mm} 4$ (943 in4). The load versus deflection plots for FRP wicket gate obtained from experiments and finite element analysis has been shown in Fig. 5-13. It is clear from the graph that the overall stiffness of the FRP gate is higher when two steel plates were embedded in the section. The load vs. deflection graphs obtained for FRP gate with embedded steel plates from both FE and experiments are correlating excellently.

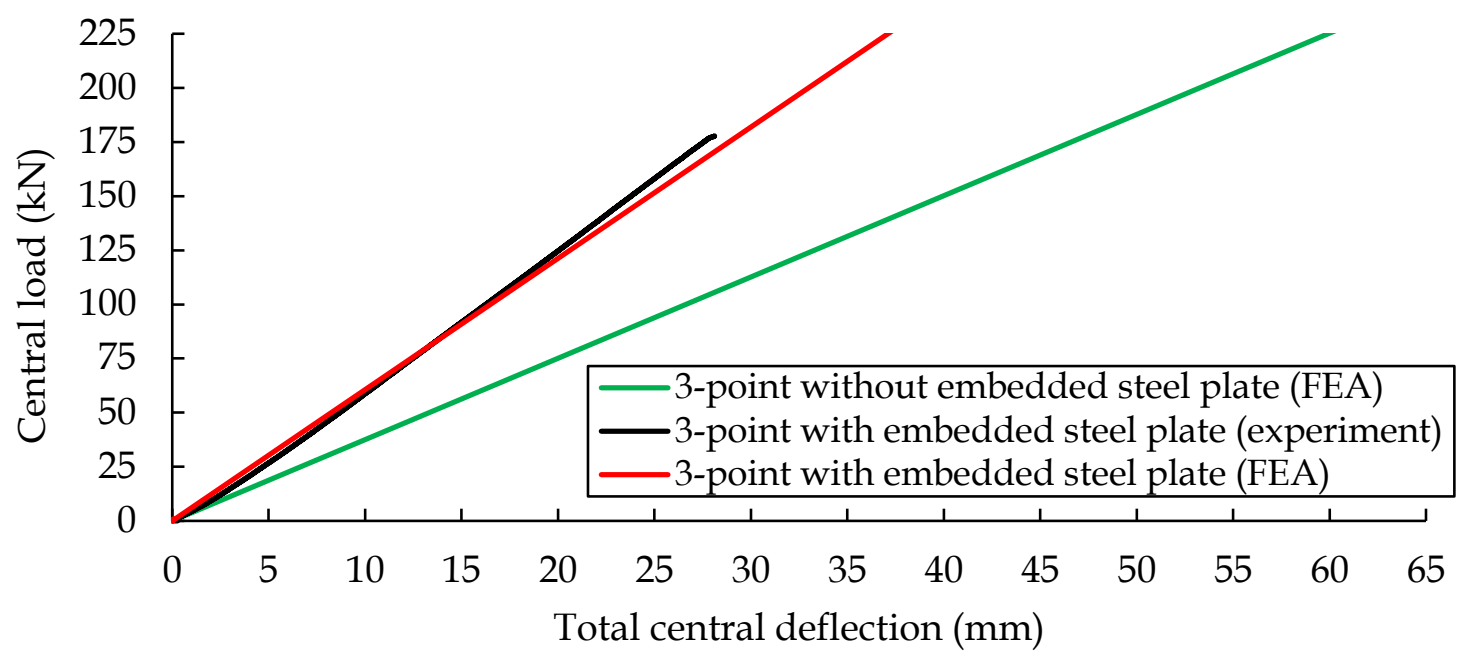

Figure 5-13. Load vs. deflection on GFRP wicket gates under 3-point bending 
The modulus of elasticity (stiffness) for FRP wicket gates with and without embedded steel plate was computed by subtracting shear deflections from total deflections (Table 5-5). Experimentally, the modulus of elasticity for FRP gate with two embedded steel plates was found to be 27.2 GPa (3.94 msi) and the value obtained from the finite element analysis matched in an excellent manner. The embeddement of two steel plates inside the upstream-side face-sheet of the wicket gate increased the modulus of elasticity of the gate by 36\% from $19.99 \mathrm{GPa}$ to $27.17 \mathrm{GPa}$. As both modulus of elasticity (E) and moment of inertia (I) has been increased for FRP section by adding two embedded steel plates, there was a significant decrease in deflection value as deflection is a funtion of EI with inverse relationship.

Table 5-5. Stiffness of the GFRP panel based on FE analysis

\begin{tabular}{|l|c|c|c|}
\hline \multicolumn{1}{|c|}{ GFRP panel } & $\begin{array}{c}\text { Deflection } \\
\text { mm (in) }\end{array}$ & $\begin{array}{c}\text { Moment of inertia (I) } \\
\mathrm{mm}^{4}\left(\mathrm{in}^{4}\right)\end{array}$ & $\begin{array}{c}\text { Stiffness (E) } \\
\text { GPa (msi) }\end{array}$ \\
\hline Without embedded steel plate & $23.69(0.933)$ & $3.93 \times 10^{8}(943)$ & $19.99(2.9)$ \\
\hline With embedded steel plate & $14.71(0.579)$ & $481.1 \times 10^{6}(1156)$ & $27.17(3.94)$ \\
\hline
\end{tabular}

\subsubsection{Failure analysis of the gate}

The failure analysis was performed with Hashin and Tsai-Wu failure criteria with the central load starting from unit and increased slowly until failure in a three-point bending of a FRP wicket gate with and without embedded steel plate for a span of $4.57 \mathrm{~m}$. Hashin criteria takes into account four different failure modes: fiber tension (HSNFTCRT), fiber compression (HSNFCCRT), matrix tension (HSNMTCRT) and matrix compression (HSNMCCRT). However, in this model as fabrics run in both directions, the matrix failure is not considered. Eqns. (5-24) and (5-25) define Hashin fiber failure criteria.

$$
\begin{aligned}
& \text { HSNFTCRT }=\left(\frac{\sigma_{11}}{X_{T}}\right)^{2}+\frac{\sigma_{12}^{2}+\sigma_{13}^{2}}{S_{12}^{2}} \geq 1=\text { failure } \\
& \text { HSNFCCRT }=\left(\frac{\sigma_{11}}{X_{C}}\right)^{2} \geq 1=\text { failure }
\end{aligned}
$$

where, $\sigma_{11}, \sigma_{12}, \sigma_{13}$ are the stresses in 1,2,3 axis direction. $S_{12}$ is the shear in the plane. $X_{t}, X_{c}$ are tensile and compressive strengths in 1-direction and $Y_{t}, Y_{c}$ are tensile and compressive strengths in 2-direction, respectively. Similarly, Tsai- $\mathrm{Wu}$ failure failure criterion index (IF) is defined as shown in Eqn. (5-26).

$$
\mathrm{IF}=\left(\frac{1}{X_{t}}-\frac{1}{X_{c}}\right) \sigma_{1}+\left(\frac{1}{Y_{t}}-\frac{1}{Y_{c}}\right) \sigma_{2}+\frac{1}{X_{t} X_{c}} \sigma_{1}^{2}+\frac{1}{Y_{t} Y_{c}} \sigma_{2}^{2}+\frac{-1}{\sqrt{X_{t} X_{c} Y_{t} Y_{c}}} \sigma_{1} \sigma_{2}+\frac{1}{S_{12}^{2}} \sigma_{12}^{2} \geq 1=\text { failure }
$$

where, $\sigma_{1}, \sigma_{2}$ are stresses in 1-and-2-direction and $\sigma_{12}$ is the shear stress in the plane. $X_{t}, X_{c}$ are tensile and compressive strengths in 1-direction and $Y_{t}, Y_{c}$ are the tensile and compressive strengths in 2-direction, whereas $S_{12}$ is the shear strength in the plane.

For FRP wicket gate with embedded steel plate, both failure criteria predicted the failure of the FRP gate at the central loaded region with fiber compression damage as shown in Fig. 5-14. Fig. 5-15 shows the plot of failure load vs. failure index for Hashin's fiber compression damage criteria and Tsai-Wu criteria. When the failure index is equal to 1 , the load at that moment is considered as the failure load for the given loading and boundary condition of the section. For three-point bending, the central failure load predicted by Hashin criteria was 1,064 kN with a bending 
moment of 1,215 kN-m (897 kip-ft) and a maximum tensile bending strain of 12,670 micro-strains. Similarly, the failure load predicted by Tsai-Wu criteria was $988 \mathrm{kN}$ with a bending moment of $1,129 \mathrm{kN}-\mathrm{m}$ (832.5 kip-ft) and a maximum tensile bending strain of 11,770 micro-strains. The failure load predicted by Hashin criterion was $7.7 \%$ higher than the failure load predicted by Tsai-Wu criterion.

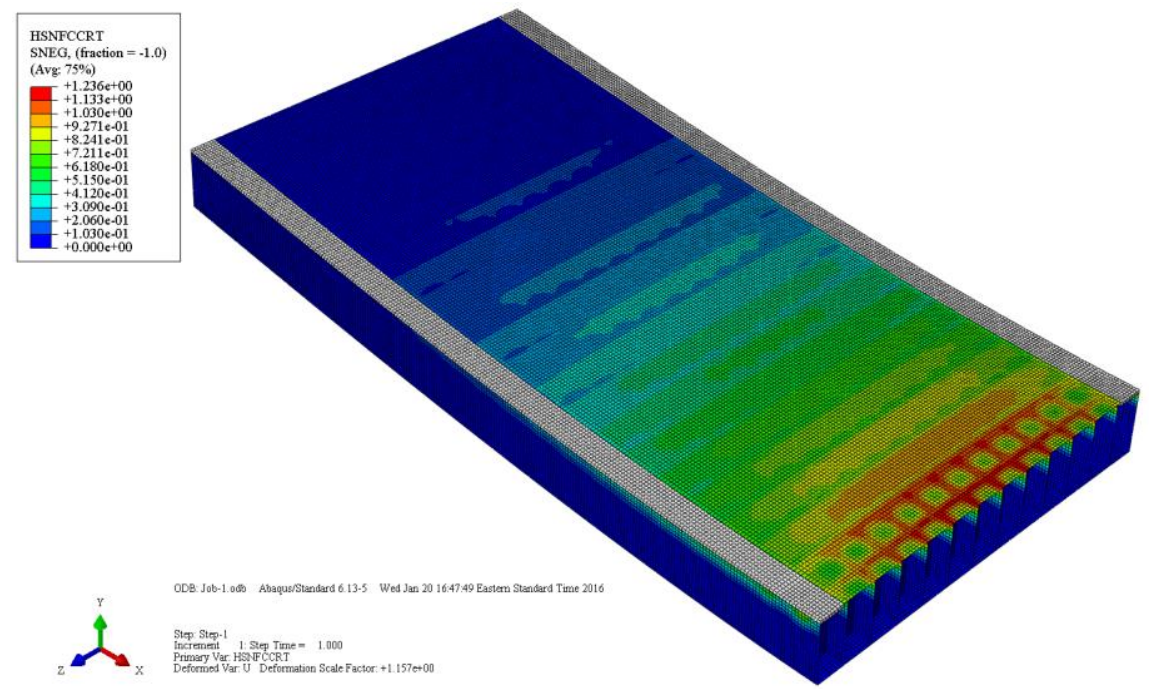

Figure 5-14. Hashin failure criteria - fiber compression damage at the center of the panel

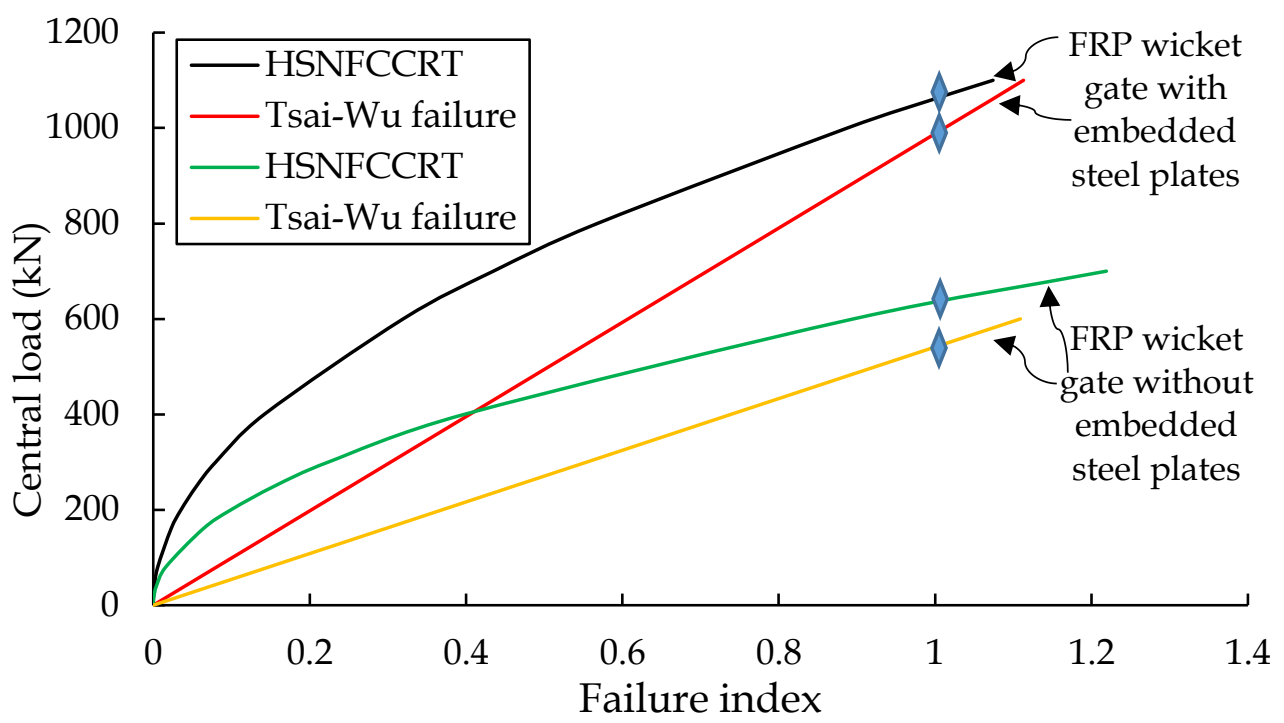

Figure 5-15. Central failure load vs. failure criteria index

Similarly, the failure analysis was performed in FRP wicket gate without embedded steel plate. In this case, failure occurred at corners in the junction of primary webs and top face-sheet. The failure load predicted by Hashin criteria was $635 \mathrm{kN}$ with a bending moment of $726 \mathrm{kN}-\mathrm{m}$ (536 kip-ft) and a maximum tensile bending strain of 10,460 micro-strains, whereas Tsai-Wu predicted the failure load as $541 \mathrm{kN}$ with a bending moment of $618 \mathrm{kN}-\mathrm{m}$ (456 kip-ft) and a maximum tensile strain of 9,057 micro-strains. However, if the corner stresses were ignored, the load resisted by the gate was much higher. 


\subsection{Service deflection of hybrid wicket gate system}

Figure 15 shows the distribution of hydrostatic pressure on the upstream $(\mathrm{u} / \mathrm{s})$ and downstream $(\mathrm{d} / \mathrm{s})$ side of the gate during operating position. The maximum deflection at the tip of the gate (free end) occurs when there is full level of water on upstream side and only up to the level of the top hinge (prop location) on the downstream side. After deducting the hydrostatic pressure of the $\mathrm{d} / \mathrm{s}$ side from the $\mathrm{u} / \mathrm{s}$ side, the distribution of load is obtained as shown in Fig. 5-16. For the given load distribution and hinge boundary conditions at $\mathrm{A}$ and $\mathrm{B}$, the deflection at the tip (free end) can be obtained from Eqn. (5-27), obtained from virtual work principles.

Deflection at the tip (free end) $(\delta)=\frac{w L_{1}^{3} L_{2}}{24 \mathrm{EI}}-\frac{w L_{2}^{4}}{30 \mathrm{EI}}-\frac{w L_{2}^{3} \mathrm{~L}_{1}}{18 \mathrm{EI}}$

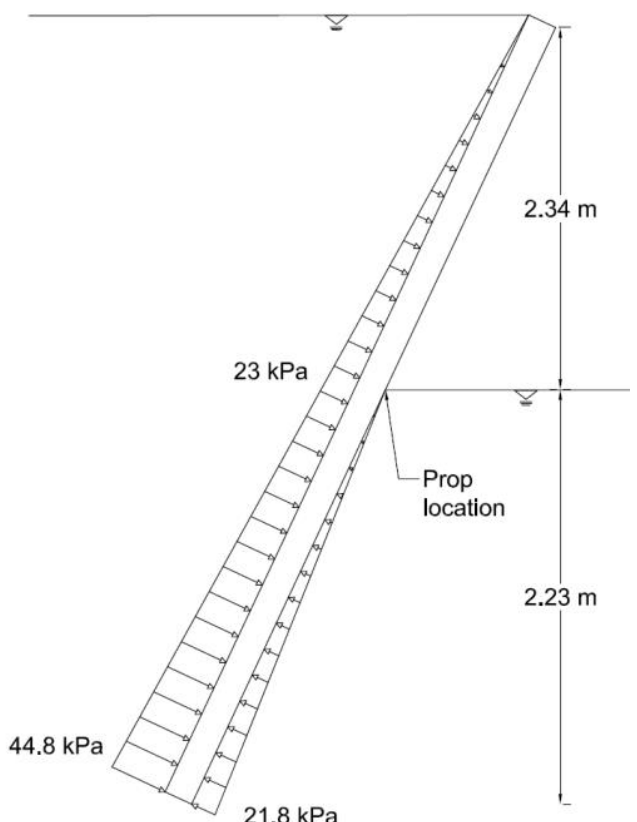

(a)

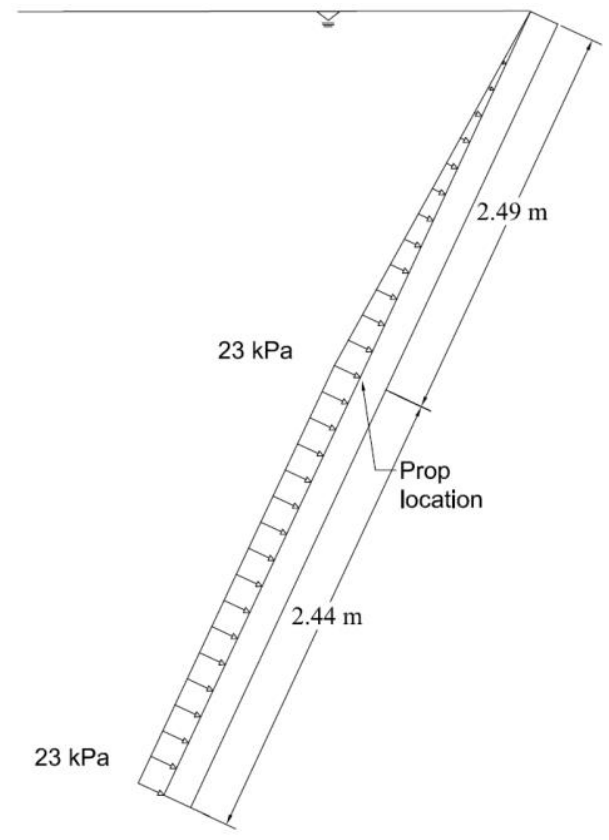

(b)

Figure 5-16. Load distribution: a) pressure on 2 sides, b) d/s pressure deducted from $u / s$ side

The deflection obtained from Eqn. (5-27) is $3 \mathrm{~mm}\left(0.12^{\prime \prime}\right)$ which correlates well with the deflection of $3.11 \mathrm{~mm}\left(0.122^{\prime \prime}\right)$ obtained from commercial structural analysis software. The deflection at the free end of the gate is equivalent to the ratio of (L/660) for the cantilevered portion of $2.49 \mathrm{~m}$ and is acceptable for field implementation.

\subsection{Field implementation}

The prop connection zone, shear pins and connecting devices at the base are the most susceptible components in the wicket gate assembly through which loads are transferred from one part to another. At present, connections of the GFRP-steel hybrid wicket gate at prop location, horse assembly utilize existing steel fixtures. However, it is intended in the future to develop and replace the entire assembly with FRP composites. Four FRP wicket gates were manufactured for 
field installation. One of these gates had all the existing steel attachments, while the other three gates had no steel angles on the edges of the gate, instead UHMWPE (Ultra high molecular weight polyethylene) plate was bonded on the upstream face and sides of the gates in order to minimize the use of steel attachments and also to monitor the effectiveness of UHMWPE plate on resisting abrasion and barge impacts in comparison to the steel. Fig. 5-17 (a) shows the existing steel angle on the sides of the gate while Fig. 5-17(b) shows UHMWPE plate on the sides covering the entire depth. All of the four gates have been installed in Mississippi River at Rock Island lock and dam, IL in August 2015 as shown in Fig. 5-18. The monitoring of the gate will be done periodically to establish the relationship between strength and durability.

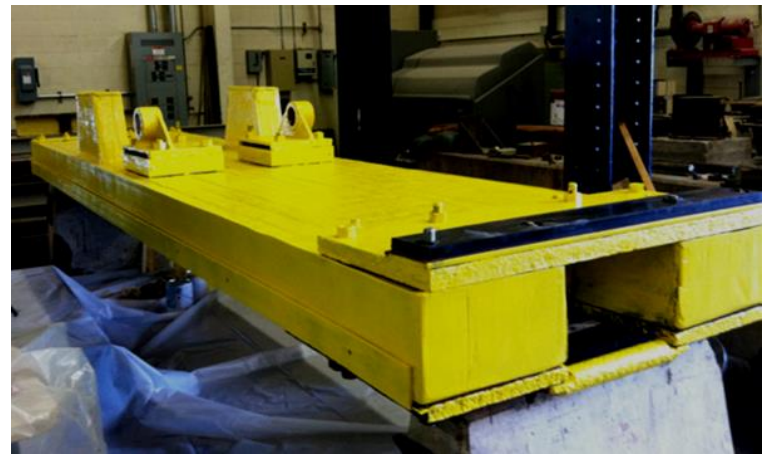

(a)

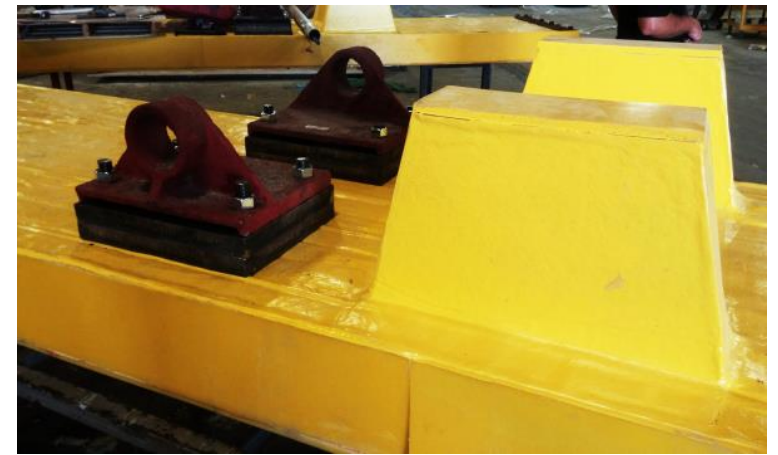

(b)

Figure 5-17. Hybrid wicket gate: a) steel angle on the sides, b) UHMWPE on the sides

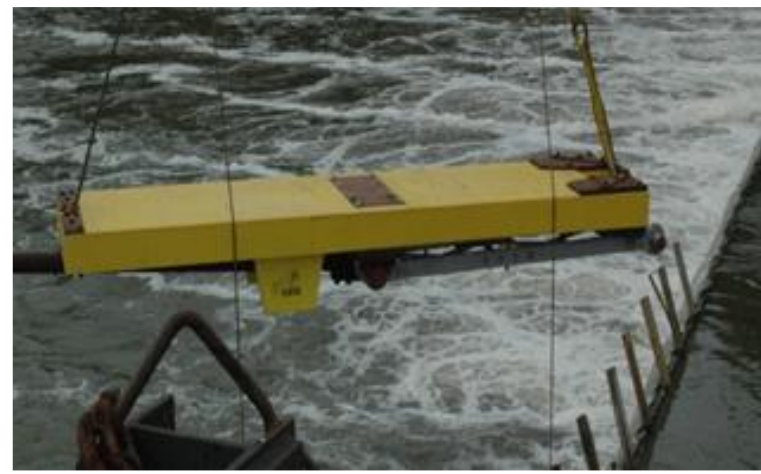

(a)

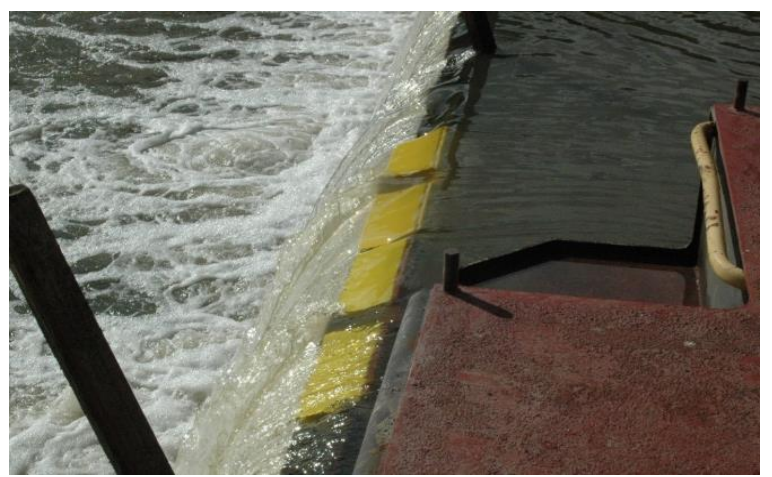

(b)

Figure 5-18. Field installation of wicket gates: a) during installation, b) operation at $65^{\circ}$ position

\subsection{Conclusions}

Based on the literature review, reverse engineering of current timber wicket gates, and applying the basic principles of composite mechanics and structural analysis, GFRP-steel hybrid composite wicket gates are designed to satisfy field requirement. Following conclusions are drawn from this study.

1. Integrated GFRP-Steel hybrid wicket gate panel was successfully developed as a replacement to the existing timber wicket gate consisting of an assembly of several timber leaves and support blocks held together by an assortment of steel plates and angles that are fastened with numerous bolts and welds. 
2. Based on the non-destructive bending load tests, GFRP-steel gate resisted an applied (desired) bending moment of $406.7 \mathrm{kN}-\mathrm{m}$ (300 k-ft.) with maximum induced bending and shear strains of 3352 and 2230 micro-strains, respectively. These induced strains are about $1 / 4^{\text {th }}$ to $1 / 3^{\text {rd }}$ of the failure strains. The design factors of safety for the GFRP-steel wicket gate in bending, shear, and buckling are in the range of 4.3 to 16.4 .

3. The experimental and theoretical stiffness values (E) of the full-scale cellular hybrid wicket gate were found to be $27.2 \mathrm{GPa}(3.94 \mathrm{msi})$ and $26.8 \mathrm{GPa}(3.89 \mathrm{msi})$, respectively, showing an excellent correlation. The finite element analysis of the section also showed similar stiffness value within $1 \%$.

4. Based on the FE analysis, the addition of two steel plates within the GFRP section enhances the bending rigidity (EI) by $66 \%$ and reduces the deflection ( $\delta$ ) by $38 \%$.

5. Maximum theoretical deflection of the GFRP-steel hybrid wicket gate during operating position is $3 \mathrm{~mm}\left(0.12^{\prime \prime}\right)$ at the tip of the gate and corresponds to an acceptable ratio of L/660 for the cantilevered portion.

6. The failure bending moments for GFRP-steel hybrid wicket gate under 3-point bending setup from Hashin and Tsai-Wu failure criteria were 1,215 kN-m (897 kip-ft) and 1,129 kN-m (832.5 kip-ft), respectively.

7. The field implementation of the GFRP-steel hybrid wicket gates was successfully performed. These gates are monitored periodically to further evaluate their performance under actual field conditions consisting of turbulent water flow. 


\section{Chapter 6. \\ Material Characterization}

This chapter presents all the experimental and theoretical work to determine strength of materials that were used in creating flanges and webs of the control GFRP and hybrid GFRP-steel boxbeams. The coupons obtained from the box-beams were tested in different loading scenarios as per the respective ASTM guidelines. In addition to experimental work, theoretical work has been performed to validate and substantiate the experimental results.

\subsection{Burn-off test}

Burn-off test was carried out on GFRP coupons as per ASTM D3171 to determine the volume fraction of fibers and percentage of void content (Fig. 6-1). Three cubic samples of rough size $1^{\prime \prime} \times 1$ " $x 0.5^{\prime \prime}$ were cut from the flanges and webs of the box-beams and were heated to $565^{\circ} \mathrm{C}$ for around six hours to ensure complete loss of resin through oxidation process. The densities of Ashland Derakane 510C - 350 epoxy vinyl ester resin and E-glass fibers used in the manufacturing of GFRP box-beams were 1.14 and 2.57 grams per cubic centimeter, respectively. The average fiber volume percentage of the GFRP laminate was found to be $22.15 \%$, whereas the void content was less than $1 \%$ by volume (Table $6-1$ ). They were calculated based on the fiber and resin density data along with measured dimensions of the samples.

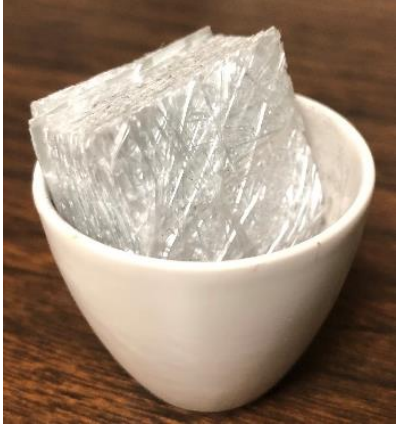

(a)

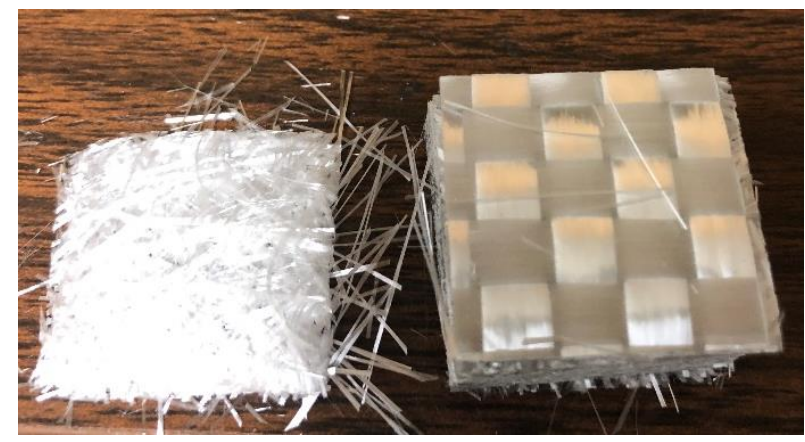

(b)

Figure 6-1. (a) Sample after burning off resin, (b) Chop strand mat and woven fabric

Table 6-1. Fiber volume fraction and void content on the GFRP laminate used in box-beams

\begin{tabular}{|c|c|c|c|c|c|}
\hline $\begin{array}{c}\text { Sample size } \\
\left(\mathrm{cm}^{3}\right)\end{array}$ & $\begin{array}{c}\text { Initial sample wt. } \\
(\mathrm{gm})\end{array}$ & $\begin{array}{c}\text { Final sample wt. } \\
(\mathrm{gm})\end{array}$ & \multicolumn{2}{|c|}{ Fiber content $(\%)$} & Void \\
\cline { 4 - 5 } & & Wt. & Volume & $(\%)$ \\
\hline $2.54 \times 2.54 \times 1.42$ & 13.305 & 5.198 & 39.07 & 22.15 & 0.7 \\
\hline $2.54 \times 2.54 \times 1.42$ & 13.406 & 5.245 & 39.12 & 22.18 & 0.1 \\
\hline $2.54 \times 2.54 \times 1.42$ & 13.358 & 5.215 & 39.04 & 22.12 & 0.2 \\
\hline
\end{tabular}

\subsection{Tensile strength test}

The tensile coupons were cut from the flanges and webs of the GFRP and hybrid box-beams using diamond saw and water-jet cutting tool, respectively as discussed in Chapter 4 . The longitudinal coupons from the box-beam could be cut in a length that was good for the tensile testing based on the guidelines of ASTM D3039. Whereas, the transverse coupons were too small in length, that 
there was no enough length for gripping the sample, and therefore, transverse coupons were only tested in bending which are discussed later in this chapter. The embedded $1 / 8$ in-thick steel plate inside the section was taken out to cut tensile coupons for steel. The tensile strength test was carried on the GFRP laminate, steel plate, and GFRP-steel hybrid laminate as shown in Fig. 6-2.

Based on ASTM standard for tensile coupon testing, the length of the coupons must be long enough to minimize or avoid bending stresses caused by minor grip eccentricities. The specimens had a grip length of $6 \mathrm{in}$. on both ends and a central gage length of 12 inches. All tensile tests were conducted in the Instron 1000HDX, where tabs were not necessary on the coupons. The grip length of 6 inches was good to let specimens not slip and to produce recommended failure in the gage length, as per ASTM guidelines. The thicknesses of the control GFRP, steel plate, and hybrid laminates were 0.5 in., 0.125 in., and 0.625 in., respectively. The width the steel plate was 1.5 in., and that of GFRP and hybrid laminates was 2 inches. A constant head displacement rate of 0.05 $\mathrm{in} / \mathrm{min}$ was used to load the tensile coupons. A uniaxial strain gage was attached on the side of a steel coupons to measure axial strains until failure. For hybrid laminate, two strain gages were used, one on the embedded steel plate and the other on the outer GFRP skin.

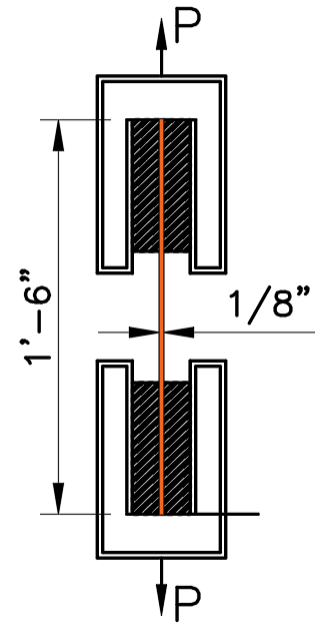

(a)

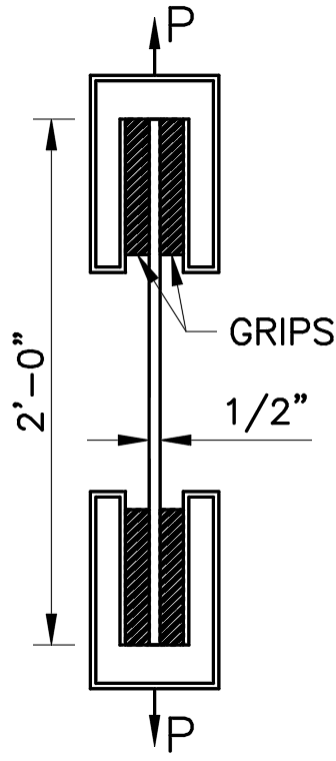

(b)

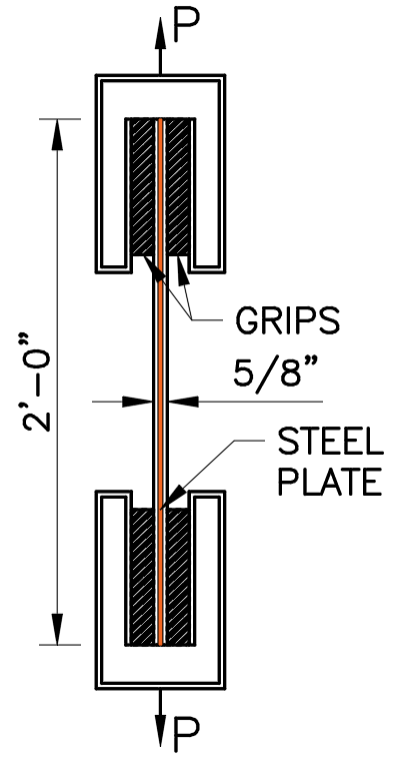

(c)

Figure 6-2. Tensile coupons, (a) steel plate, (b) GFRP laminate, (b) Hybrid GFRP-steel laminate

\subsubsection{Experimental testing}

The purpose of the experimental test was to determine tensile strength and young's modulus of elasticity of a steel and longitudinal tensile and longitudinal modulus of elasticity of orthotropic GFRP laminate. The tensile stress vs. elongation and tensile stress vs. strain for steel coupons are shown in Fig. 6-3a and 6-3b, respectively. The applied load produced necking of the steel plate cross-section at the mid-point of the gage length, leading to the fracture of the sample as shown in Fig 6-4a. The yield strength and maximum tensile strength of steel was obtained as $33 \mathrm{ksi}$ and $47.3 \mathrm{ksi}$, respectively (Table 6-1). 

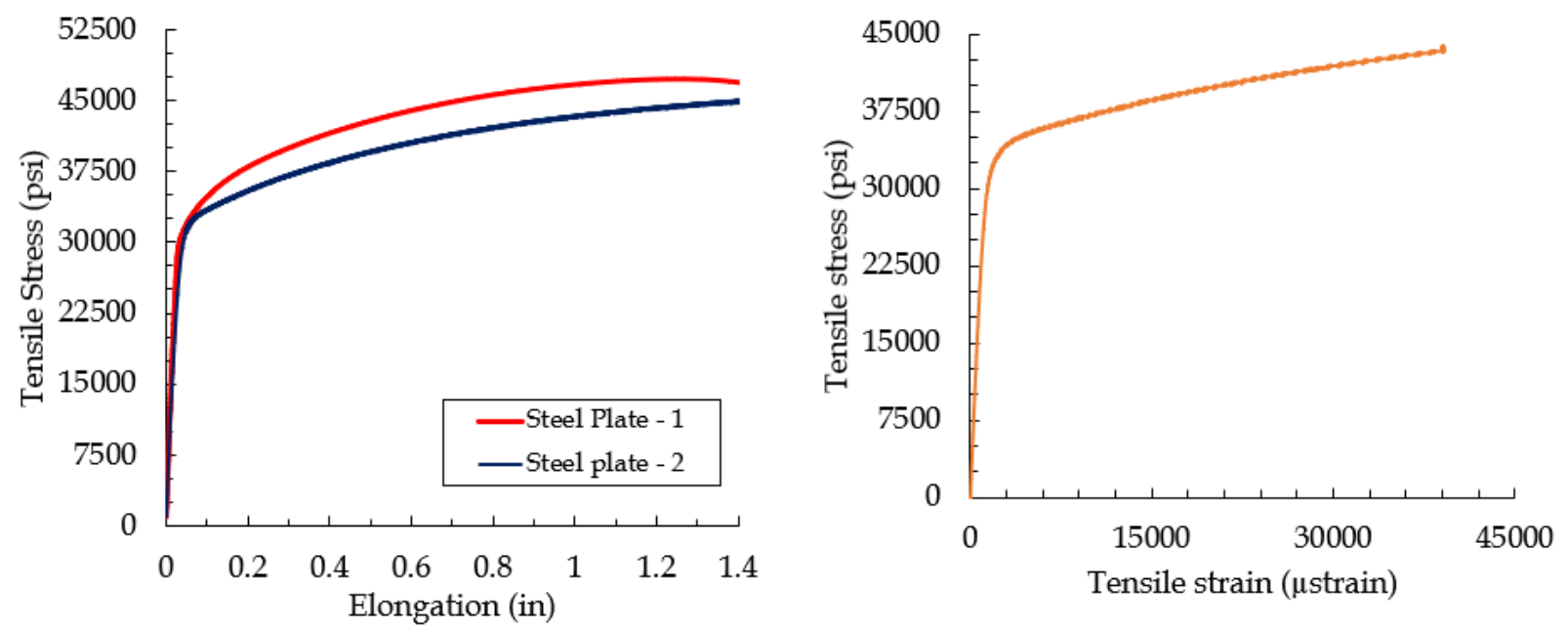

(a)

(b)

Figure 6-3. (a) Tensile stress vs. elongation, (b) tensile stress vs. strain for steel

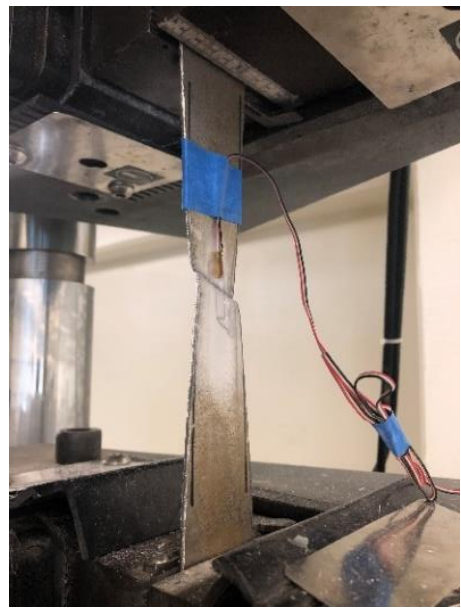

(a)

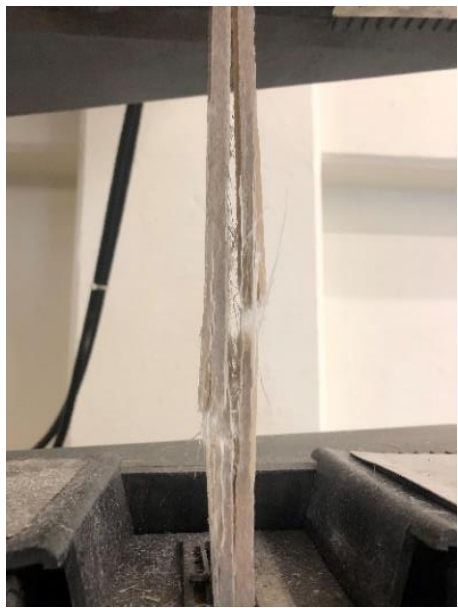

(b)

Figure 6-4. Tensile failure on, (a) Steel plate, (b) GFRP laminate

The tensile stress-strain curve for the GFRP laminate is shown in Fig. 6-5a and is practically linear until failure. The failure occurred due to fiber/matrix interface debonding and fiber fracture as shown in Fig. 6-4b. The average failure strength of GFRP laminate in tension obtained from three test results was $28.3 \mathrm{ksi}$ and the ultimate tensile strain at failure was around 17,000 micro-strains. The tensile stress-strain curve for the hybrid laminate is shown in Fig. 6-5b. The strains were recorded at the outer GFRP skin and at the inside steel surface; which are practically same, displaying perfect strain compatibility due to bonding between steel and GFRP. The stress-strain curve was linear until the yielding of the steel plate started at around 1250 micro-strains. 


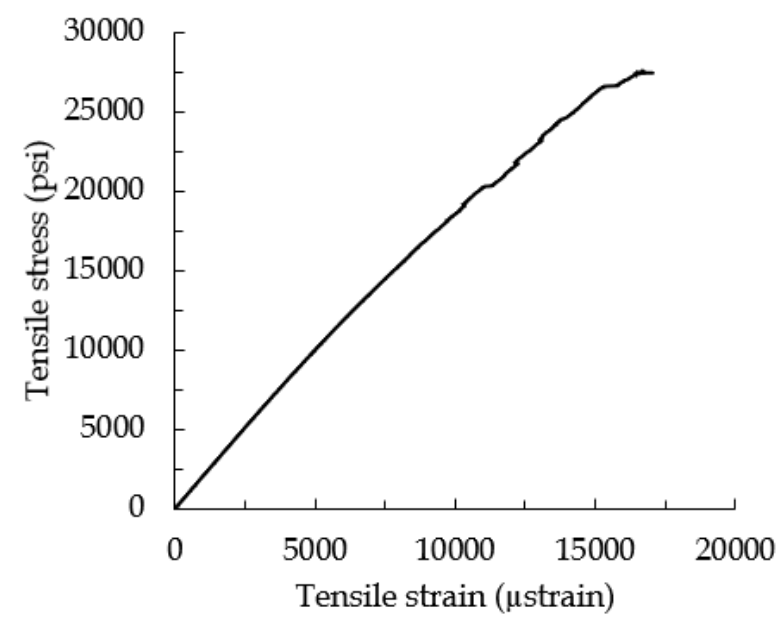

(a)

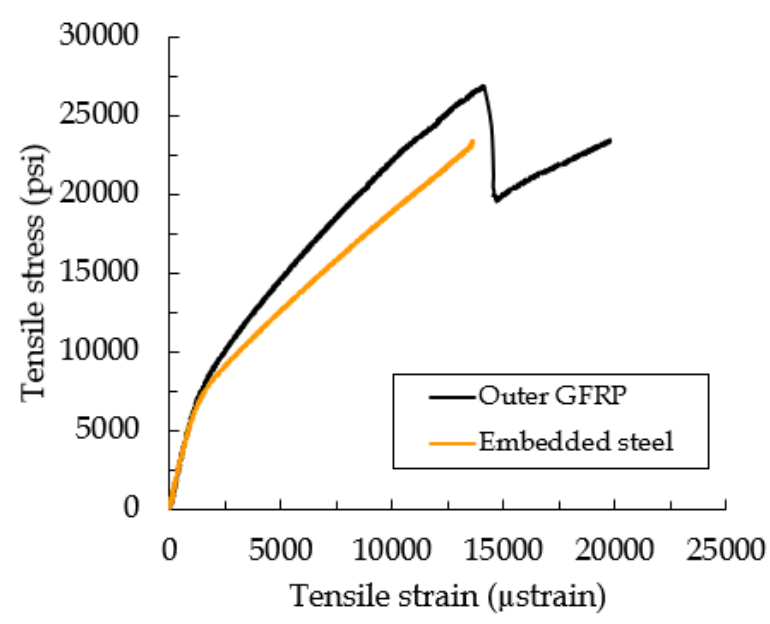

(b)

Figure 6-5. Tensile stress vs. strain for: (a) longitudinal GFRP laminate, (b) hybrid laminate

The hybrid laminate showed a nonlinear behavior, which came mainly from the plastic deformation of steel plate. During the tensile loading of the hybrid laminate, the outer GFRP failed first because of its low strain to failure compared to inner steel plate. The stress-strain curve of the hybrid specimen was bilinear prior to the fracture of the outer GFRP. The post yield stiffness after the yielding of the central steel plate is stable. The tensile strength and strain at which outer GFRP failed were $27.0 \mathrm{ksi}$ and 14,050 micro-strains, respectively. The outer GFRP failed through various failure mechanism such as fiber/matrix interface debonding, fiber fracture, and pullout. After the outer GFRP failure, the load was taken by the inner steel plate as can be noticed from the Fig. 6-5b. The strain gage got detached and the testing was stopped. The final failure of the hybrid laminate would be through fracture of steel plate. The Fig. 6-7 shows the plots for tensile stress-strain for steel, GFRP, and hybrid laminates plotted together.

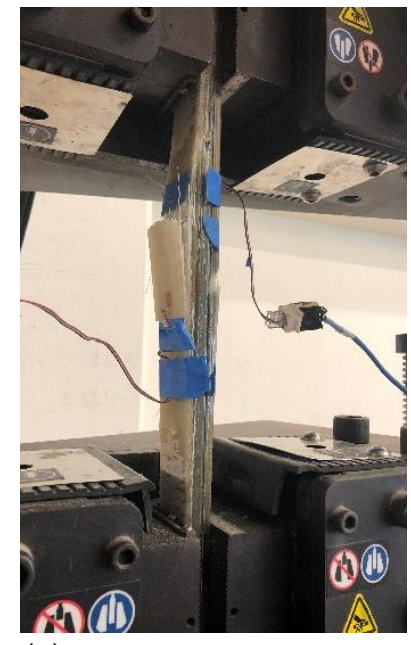

(a)

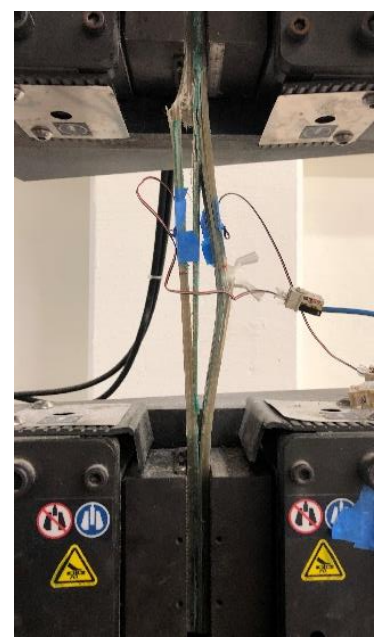

(b)

Figure 6-6. Tensile failure on hybrid laminate, (a) Fiber fracture, (b) Debonding/delamination 


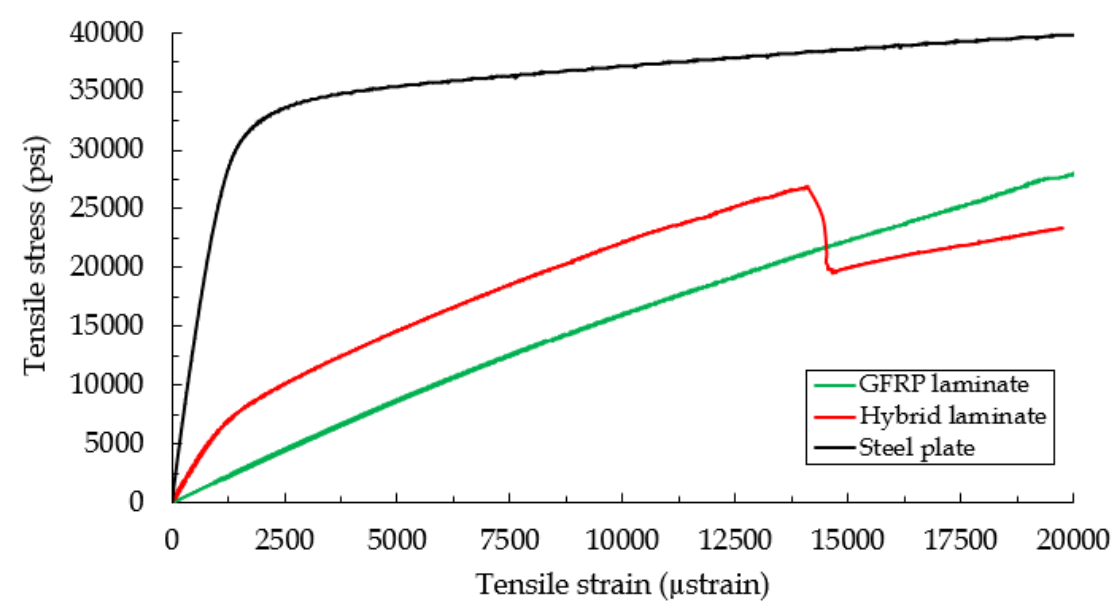

Figure 6-7. Tensile stress vs. strain for steel plate, and GFRP and hybrid laminates

The young's modulus of elasticity for steel, GFRP, and hybrid laminate were obtained from the slope of tensile stress-strain curves at the initial strain levels, as shown in Fig. 6-8. The values are shown in the Fig. 6-5 and Table 6-1. With insertion of 0.125 in-thick steel inside the GFRP laminate, the modulus of elasticity of hybrid laminates was significantly improved by $219 \%$ as compared to GFRP laminates.

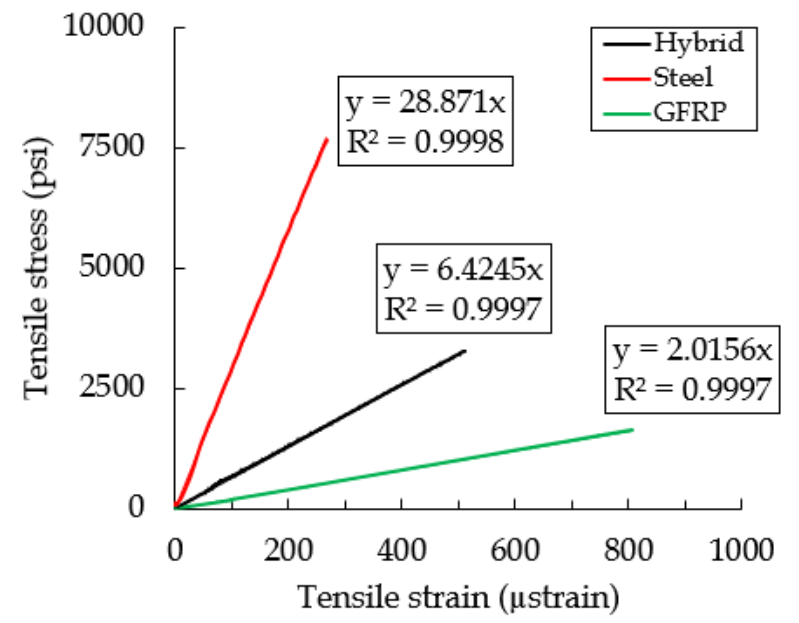

Figure 6-8. Young's modulus of elasticity of steel, GFRP, and hybrid material

Table 6-2. Ultimate tensile strength of GFRP, steel, and hybrid specimens

\begin{tabular}{|c|c|c|c|c|c|}
\hline Specimen & Dimension & Failure load (lbs) & Failure stress (ksi) & SD (ksi) & E (msi) \\
\hline Steel plate & $1.5^{\prime \prime} \times 0.125^{\prime \prime} \times 18^{\prime \prime}$ & 9,230 & 47.3 & - & 28.9 \\
\hline GFRP & 2"x0.5"x24" & 28,310 & 28.3 & 0.99 & 2.02 \\
\hline Hybrid & 2"x0.625"x24" & 33,750 & 27.0 & 1.32 & 6.42 \\
\hline
\end{tabular}

Further, a hybrid laminate with 0.125 in-thick steel plate attached on one side, and 0.1875 in-thick GFRP on the other side as shown in Fig. 6-9 was tested in tension to observe the load-deflection behavior of thin hybrids. The load-elongation curve is shown in Fig. 6-9a. The behavior is nonlinear with GFRP and steel sharing load before the yielding of steel plate, then the GFRP takes up the load and fails at the ultimate strain. After the failure of GFRP, the steel plate sustains the load 
at its yield strength level and continues to carry load until its failure. The plastic deformation of steel plates provided tremendous ductility to a structure and a slow ductile failure is observed in the hybrid laminate.

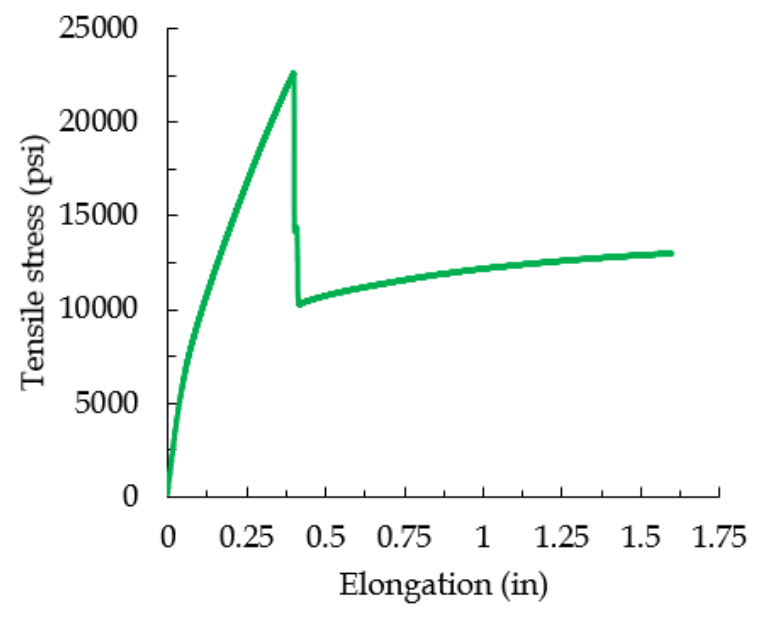

(a)

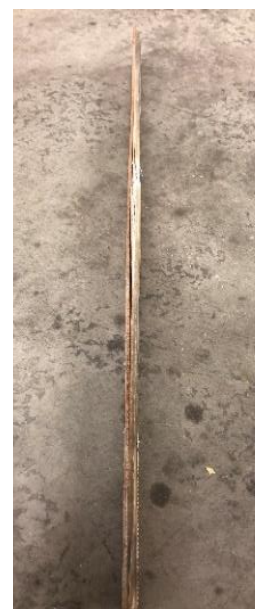

(b)

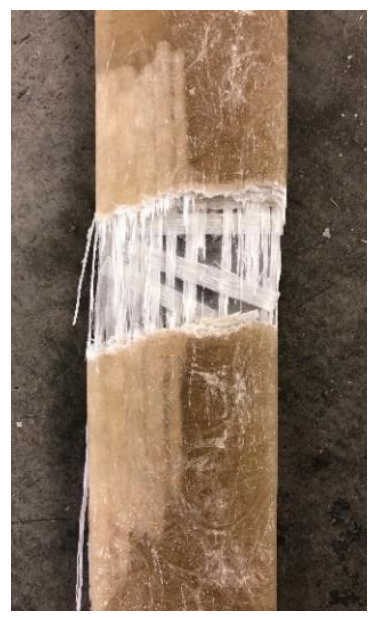

(c)

Figure 6-9. (a) Load-elongation curve of a hybrid laminate with 0.125 in-thick steel plate bonded to 0.1875 in-thick GFRP, (b) Failure with debond/fiber fracture, (c) fractured outer GFRP

\subsubsection{Analytical modeling}

For hybrid GFRP-steel laminate, when the perfect bonding between these dissimilar materials is assumed, linear elastic and bilinear elastic-plastic models can be adopted to characterize the mechanical properties of GFRP and steel, respectively. During the initial elastic region, before the steel yielding takes place, both GFRP and steel are elastic in nature and the young's modulus of elasticity of the hybrid laminate $\left(\mathrm{E}_{\mathrm{HE}}\right)$ can be obtained using rule of mixture theorem as shown in Eqns. (6-1 \& 6-2). Similarly, the tensile stress $\left(\sigma_{\mathrm{HE}}\right)$ in the hybrid laminate at a strain level of $\epsilon_{\mathrm{HE}}$ is shown in Eqn. (6-3)

$$
\begin{aligned}
& \mathrm{E}_{\mathrm{HE}}=\mathrm{E}_{\mathrm{S}} \mathrm{V}_{\mathrm{S}}+\mathrm{E}_{\mathrm{G}} \mathrm{V}_{\mathrm{G}} \\
& \mathrm{E}_{\mathrm{HE}}=\frac{\mathrm{E}_{\mathrm{S}} \mathrm{t}_{\mathrm{S}}+\mathrm{E}_{\mathrm{G}} \mathrm{t}_{\mathrm{G}}}{\left(\mathrm{t}_{\mathrm{S}}+\mathrm{t}_{\mathrm{G}}\right)} \\
& \sigma_{\mathrm{HE}}=\mathrm{E}_{\mathrm{HE}} \epsilon_{\mathrm{HE}}
\end{aligned}
$$

where $E_{S}, V_{S}$, and $t_{S}$ are young's modulus of elasticity, volume fraction, and thickness of steel, respectively, and $E_{G}, V_{G}$, and $t_{G}$ are the modulus of elasticity, volume fraction, and thickness of GFRP in the hybrid laminate. In the post-elastic region, the modulus of elasticity of hybrid laminate $\left(\mathrm{E}_{\mathrm{HP}}\right)$ and the tensile stress $\left(\sigma_{\mathrm{HP}}\right)$ at a strain level of $\epsilon_{\mathrm{HP}}$ can be obtained as shown in Eqn. (6-4).

$$
\begin{aligned}
E_{H P} & =\frac{E_{G} t_{G}}{\left(t_{S}+t_{G}\right)} \\
\sigma_{H P} & =E_{H E} \epsilon_{Y}+E_{H P}\left(\epsilon_{H P}-\epsilon_{Y}\right)
\end{aligned}
$$


where $\epsilon_{Y}$ is the yield strength of the embedded steel. After the rupture strain of GFRP is reached, the failure of the outer GFRP takes place, and the young's modulus of elasticity is going to be zero, with the stress being constant at the yiled strength of steel, as shown in Eqn. (6-6).

$$
\sigma_{\mathrm{HF}}=\mathrm{E}_{\mathrm{HE}} \epsilon_{\mathrm{Y}}
$$

The theoretical and experimental modulus of elasticity are compared in Table 6-2 for the hybrid laminate tested in the experimental analysis. The thickness of steel plate and GFRP are 0.125 inches and 0.52 inches, respectively.

Table 6-2. Comparison between theoretical and experimental (E) values for hybrid laminate

\begin{tabular}{|c|c|c|c|c|c|}
\hline Parameters & $\mathrm{E}_{\mathrm{S}}$ & $\mathrm{E}_{\mathrm{G}}$ & Theoretical (E) & Experimental (E) & Difference \\
\cline { 1 - 4 } $\mathrm{E}_{\mathrm{HE}}$ & \multirow{2}{*}{28.9} & \multirow{2}{*}{2.02} & $7.23 \mathrm{msi}$ & $6.42 \mathrm{msi}$ & $11.2 \%$ \\
\cline { 1 - 4 } & & & $1.62 \mathrm{msi}$ & $1.65 \mathrm{msi}$ & $1.8 \%$ \\
\hline
\end{tabular}

The differences in theoretical and experimental modulus of elasticity values for hybrid laminates in the initial elastic region were mainly due to presence of unaccounted voids in the adhesive layer and slight incompatibility between GFRP and steel noticed during the experimental testing. The strains carried by embedded steel were slightly higher than that on outer GFRP. However, after the yielding of steel, the theoretical and experimental values were in good match.

\subsection{Compressive strength test}

The compressive strength of GFRP longitudinal coupons cut from the flanges and webs of boxbeams was evaluated based on ASTM D695. According to this standard, the GFRP specimens were cut in rectangular prism shape with a width of an inch and the length of 2 inches as shown in Fig. 6-10 to prevent weak-axis buckling. Specimens were placed between two compressive plates in Instron 1000HDX and were loaded in compression at a crosshead rate of $0.05 \mathrm{in} / \mathrm{min}$. The compressive strength was calculated as the maximum compressive load divided by the original cross-sectional area and the modulus of elasticity was calculated as the slope of the line tangent to the initial linear portion of the load-strain curve divided by the cross-sectional area. At least three specimens were tested for each case and the results were averaged. The strains were recorded from the strain gage attached at the mid-height of the specimen.

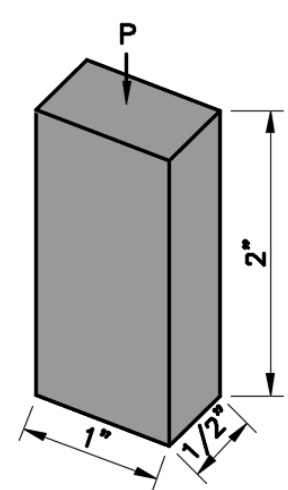

(a)

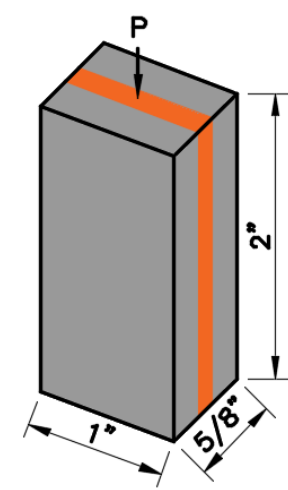

(b)

Figure 6-10. Coupons for compressive strength, (a) GFRP section, (b) Hybrid section 
The typical compressive stress-strain curve is shown in Fig. 6-11. The average compressive strength of the GFRP obtained from the failure of three samples was $29 \mathrm{ksi}$. The maximum strain to failure recorded was around 14,000 micro-strains. The modulus of elasticity in compression obtained from the slope of the stress-strain curve is $1.6 \mathrm{msi}$. The typical stress-strain curve in compression is slightly non-linear with positive curvature due to imperfect interface bonding between fibers and matrix and inefficiency in matrix to support fibers against micro buckling (Torabizadeh et al. 2012).

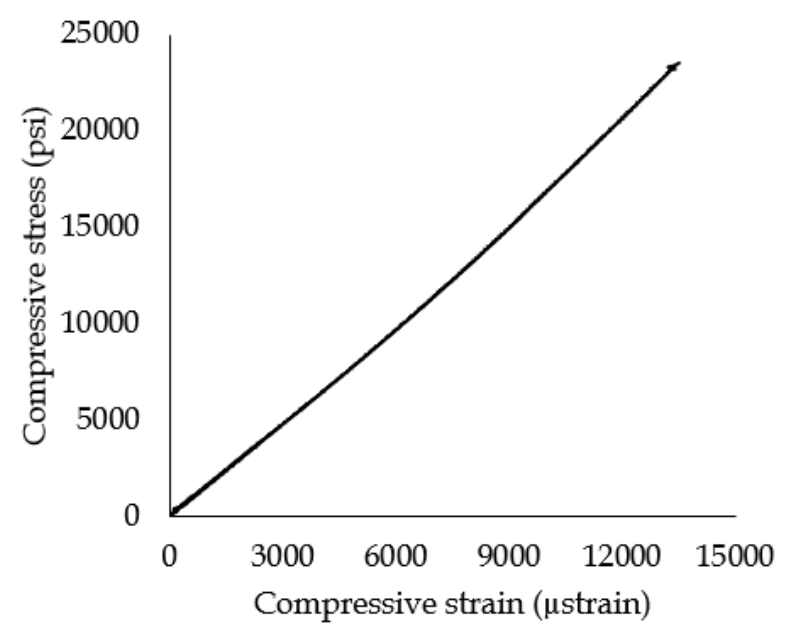

Figure 6-11. Compressive stress vs. strain for a GFRP laminate

The GFRP coupons failed catastrophically under compressive stress with delamination of GFRP layers and fiber buckling within the layers were observed as shown in Fig. 6-12. Similarly, the hybrid laminate failed with debonding of steel plate and outer GFRP laminate and microbuckling of fibers within the laminate.

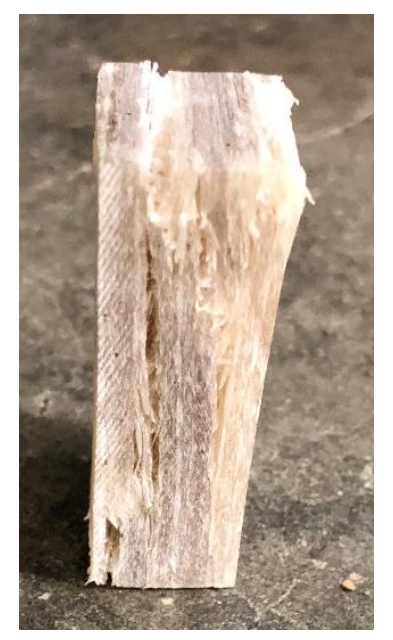

Figure 6-12. Failure of GFRP specimen under compressive stress

\subsection{Flexural strength test}

Flexural tests were conducted on an Instron 1000HDX with a 3-point bending fixture installed as shown in Fig. 6-13. The testing procedures as described in ASTM D790 were used as guidelines 
for the test sample preparation and loading. For highly orthotropic laminates, it is recommended to have a span-to-depth ratios of 32:1 or 40:1 for the test specimens. As thicknesses of the control GFRP and hybrid laminates were 0.5 in. and 0.625 in., respectively, the support span length of 20 inches was chosen for the testing to provide span-to-depth ratios of 40:1 and 32:1, respectively. The width of GFRP laminate was 1 inch, while the width of the hybrid laminate was 2 inches. As per the ASTM guidelines, it is recommended to have at least $10 \%$ of the support span length as an overhang on each end. Thus, 2 in. overhang was provided on both control GFRP and hybrid specimens, which resulted on a specimen length of 24 inches as shown in the Fig. The testing was conducted at a crosshead speed of around $0.1 \mathrm{in} / \mathrm{min}$ for both samples. A minimum of three tests were conducted on each type and the results were averaged. The load-deflection data were collected through the Instron's built-in load cell and LVDT and the strain gages at the bottom of the coupon specimens recorded the bending strain until failure.

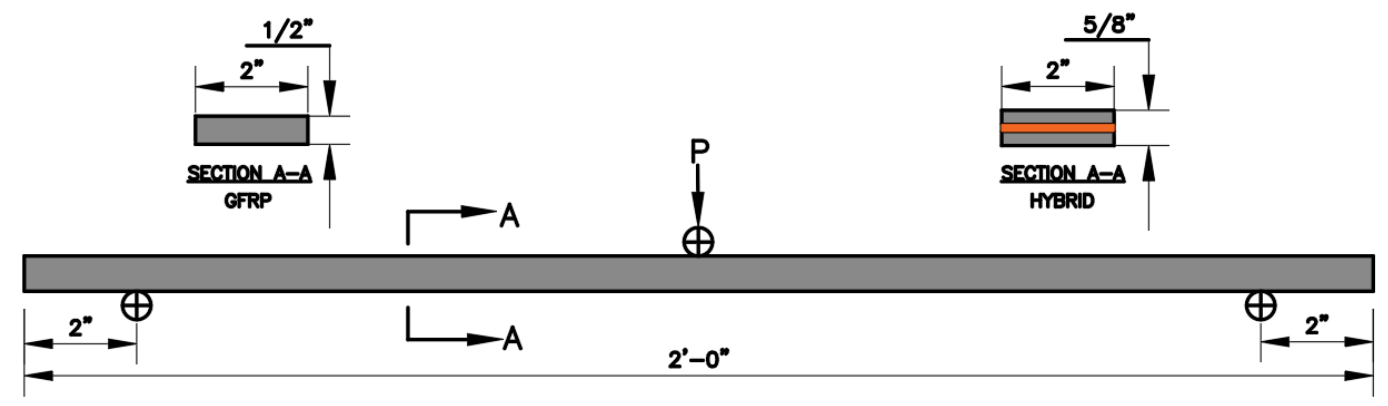

Figure 6-13. GFRP and hybrid laminate bending coupons with cross-sections

The load-deflection curves for both GFRP and hybrid laminate were linear (Fig. 6-14). The nonlinear behavior on steel-embedded GFRP laminate was not noticed due to the reason that the steel plate was at the middle of the section, which is the least stressed region within the given section. However, slight non-linearity due to plastic yielding of steel plate was noticed in later phases, when the strain level in steel plate reached beyond its yield strain.

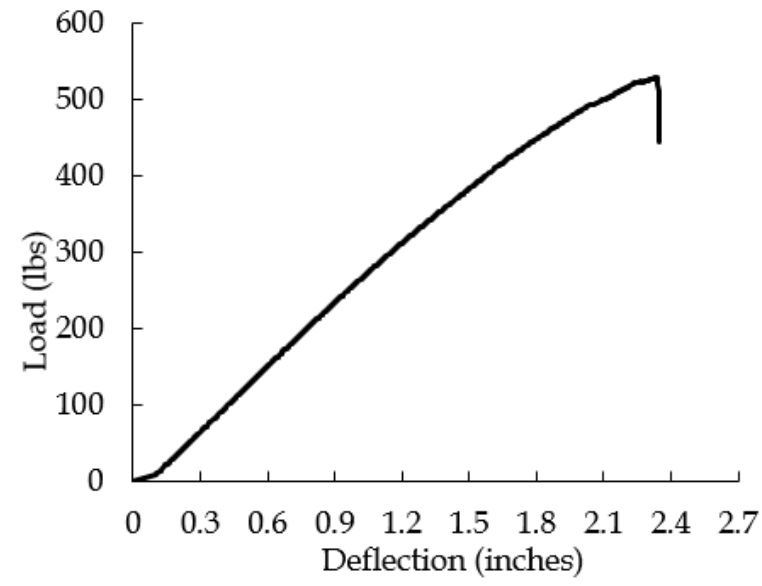

(a)

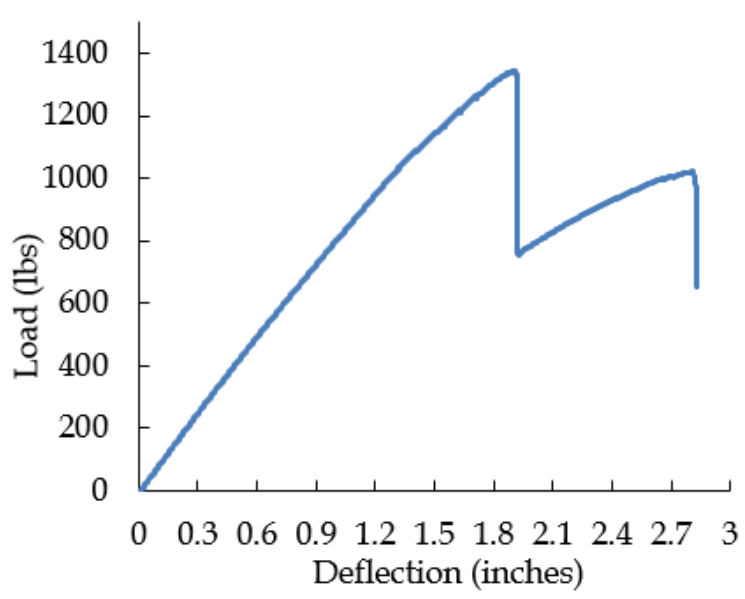

(b)

Figure 6-14. Load vs. deflection for bending coupons (a) GFRP section, (b) Hybrid section

The bending stress-strain curves for GFRP and hybrid laminate are shown in Fig. 6-15. The maximum bending strain recorded on the strain gage which was bonded at the bottom of the GFRP laminate under 3-point bending was around 19,650 micro-strains (Table 6-3). Whereas for hybrid laminate, the bending strains were recorded more for the outermost GFRP, while steel 
plate inside the section did not show higher strains since plate being in the mid-height of the section. The max. strain on outer GFRP was around 11,900 micro-strains, after which the strain gage debonded and the max. strain recorded on the embedded steel was around 3000 microstrains. The ultimate flexural strengths $\left(\sigma_{\mathrm{b}}\right)$ of the sections were calculated using Eqn. (6-7).

$$
\sigma_{\mathrm{b}}=\frac{3 \mathrm{P}_{\max } \mathrm{L}}{2 \mathrm{Bd}^{2}}
$$

where $\mathrm{P}_{\max }, \mathrm{L}, \mathrm{B}$, and $\mathrm{d}$ are the maximum three-pint load, span length, width of the sample, and thickness of the sample, respectively. The average ultimate bending strength for the GFRP laminate from three testes was caluclated to be around $37.6 \mathrm{ksi}$, while that for the hybrid laminate was around $36.5 \mathrm{ksi}$ (Table 6-3). To obtain the modulus of elasticity under bending, the slope of the load-deflection curves were obtained experimentally and were used in the Eqn. (6-8). As the samples were tested in span-to-depth ratios of 32:1 and 40:1, the effect of shear in the recorded defelection $(\Delta)$ is negligible and cane be neglectred as per the ASTM standard.

$$
\mathrm{E}=\left(\frac{\mathrm{P}}{\Delta}\right) \frac{\mathrm{L}^{3}}{4 \mathrm{Bd}^{3}}
$$

where $(\mathrm{P} / \Delta)$ is the slope of the initial portion of the load-deflection graph. The effective modulus of elasticity (E) of the section with embedded steel plate was $47 \%$ more, compared to the GFRP section from $2.15 \mathrm{msi}$ to $3.15 \mathrm{msi}$ (Table 6-3). As the steel plate was at the middle of the section, the moment of inertia of the overall section was not improved. The calculated moment of inertia for the hybrid section was 0.045 in ${ }^{4}$ compared to equivalent GFRP section's 0.041 in 4 . Usually, by distributing stiffer material away from the neutral axis of the section, more gain in the stiffness values is noticed. That is where, adding plates on the flanges of the box or I-sections is more effective in providing more stiffness to the overall section
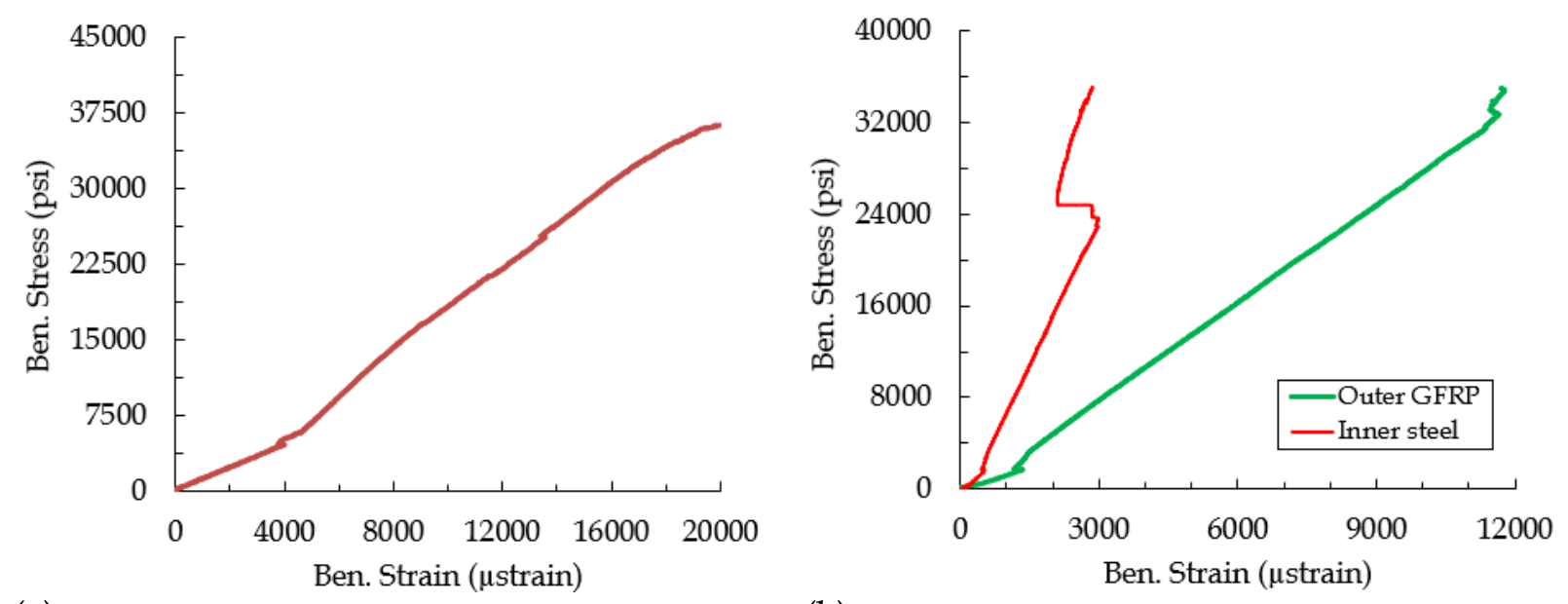

(a)

(b)

Figure 6-15. Bending stress-strain curves for (a) GFRP section, (b) Hybrid section

The GFRP laminate failed due to fracture of fibers at the bottom of the section just underneath the load application point (Fig. 6-16). The hybrid laminate also failed due to fracture of fibers at the bottommost layer of the section. After the fiber fracture, the steel plate and the bottom GFRP 
laminate got separated as can be noticed in the Fig. 6-16. In the flexural testing of hybrid, the steel and GFRP were not equally stressed. The contribution of the steel plate was not much compared to the contribution from the outer GFRP, which is different in behavior compared to tensile test wherein both steel plate and GFRP were equally stressed. However, if the steel plate sections are distributed away from the neutral axis as in the box-beam sections, the contribution of the steel plates will be more predominant.

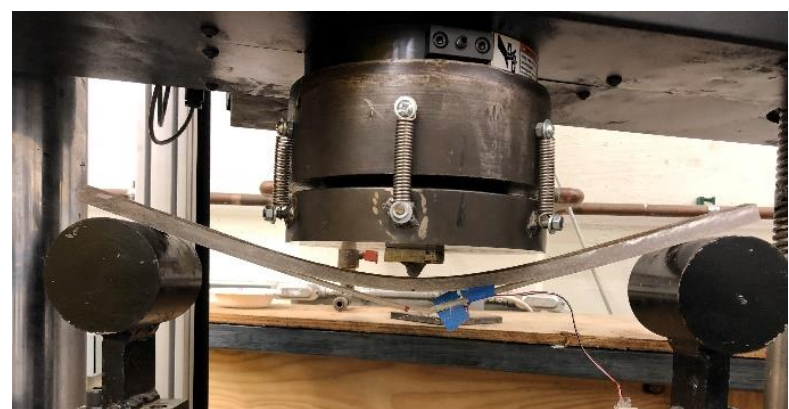

(a)

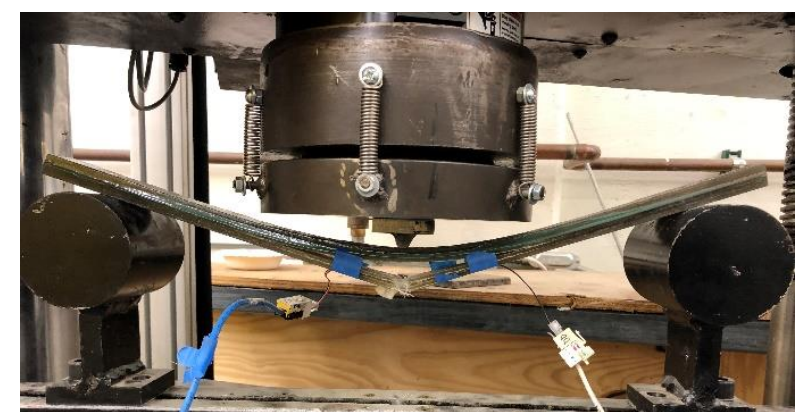

(b)

Figure 6-16. Failure of coupons under bending, (a) GFRP section, (b) hybrid section

Table 6-3. Failure stresses and strains on GFRP and hybrid laminates

\begin{tabular}{|c|c|c|c|c|c|c|}
\hline \multirow{2}{*}{ Section } & \multirow{2}{*}{$\mathrm{C} / \mathrm{S}$} & \multirow{2}{*}{$\begin{array}{c}\text { Span } \\
\text { (in) }\end{array}$} & \multicolumn{2}{|c|}{ Ultimate (Avg.) } & Ultimate & $\begin{array}{c}\text { Effective modulus } \\
\text { of elasticity (E) }\end{array}$ \\
\hline GFRP & $1^{\prime \prime} \times 0.5^{\prime \prime}$ & 20 & $460 \mathrm{lbs}$ & $37.6 \mathrm{ksi}$ & $19,650 \mu \mathrm{s}$ & $2.15 \mathrm{msi}$ \\
\hline Hybrid & $2^{\prime \prime} \times 0.625^{\prime \prime}$ & 20 & $1405 \mathrm{lbs}$ & $36.5 \mathrm{ksi}$ & $11,900 \mu \mathrm{s}$ & $3.15 \mathrm{msi}$ \\
\hline
\end{tabular}

\subsection{Short-beam/Inter-laminar shear strength}

The specimen preparation and the testing of the prepared specimens are governed by ASTM D2344. The specimens having a minimum thickness of $0.08 \mathrm{in}$. and which are center-loaded loaded at a span-to-depth ratio of 4.0, generally produces inter-laminar failure at the mid-plane of the specimen. At the peak load, the horizontal shear stress calculated for the given laminate is defined as short-beam strength or the inter-laminar shear strength of the laminate. The thickness of the laminate cut from the flange and web regions of the control GFRP and hybrid box-sections were $0.5 \mathrm{in}$. and $0.625 \mathrm{in}$., respectively. Therefore, the specimen length of the short-beam test laminates were 3 in. and 3.75 in., respectively, with span lengths of 2 in. and 2.5 in., respectively as shown in Fig. 6-17. The specimen widths were 1 inch for both GFRP and hybrid laminates.

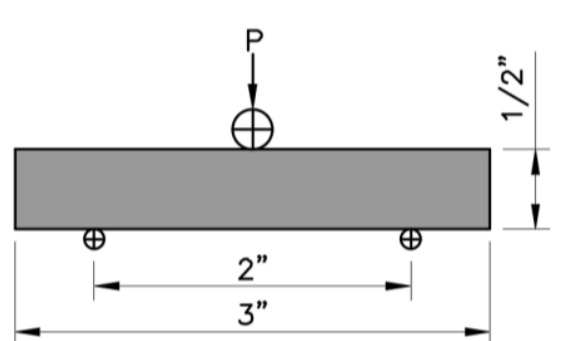

(a)

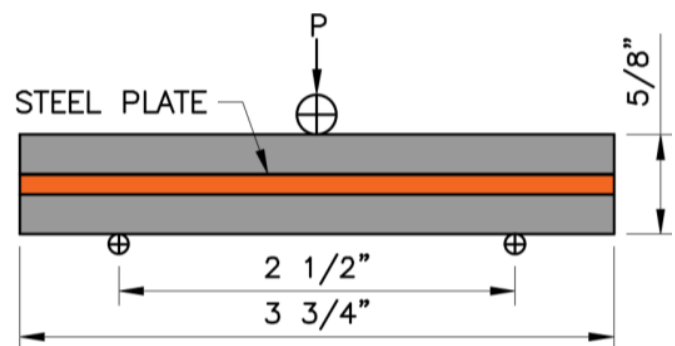

(b)

Figure 6-17. ASTM standard on span lengths for testing laminate for short-beam shear strength, (a) GFRP section, (b) GFRP section with embedded steel plate 
The inter-laminar shear strength vs. deflection curves for both samples are shown in Fig. 6-18. The inter-laminar shear strength of the section was calculated using Eqn. (6-9).

$$
\sigma_{\mathrm{b}}=\frac{3 \mathrm{P}_{\max }}{4 \mathrm{Bd}}
$$

where $\mathrm{P}_{\max }, \mathrm{B}$, and $\mathrm{d}$ are the maximum load at the crack, width of the sample, and thickness of the sample, respectively. The first drop in the curve corresponds to the first appearance of an interlaminar crack within the section. The first inter-laminar crack for GFRP laminate was observed at the interlaminar shear stress of around 5,900 psi due to delamination within GFRP layers, while for the hybrid laminate, the first crack appeared at the interlaminar shear stress of around 3,320 psi, due to debonding between steel plate and GFRP. The point to be noted before concluding the behavior is that there was no surface preparation of steel plates while creating a hybrid laminate beside cleaning. The bonding of sand-blasted steel plate within the section would have helped in increasing the interlaminar shear strength value. The study by Kulkarni et al. (2008) have founded that the sand-blasting of aluminum plates helped in increasing the surface roughness and in turn improved the inter-laminar shear strength values of fiber metal laminate.

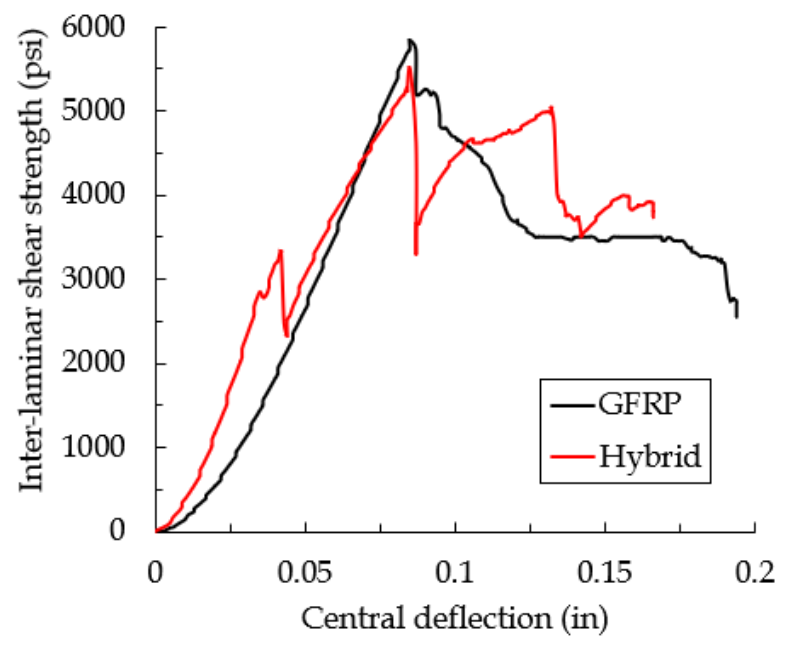

Figure 6-18. Inter-laminar shear strength vs. deflection curves for GFRP and hybrid sections

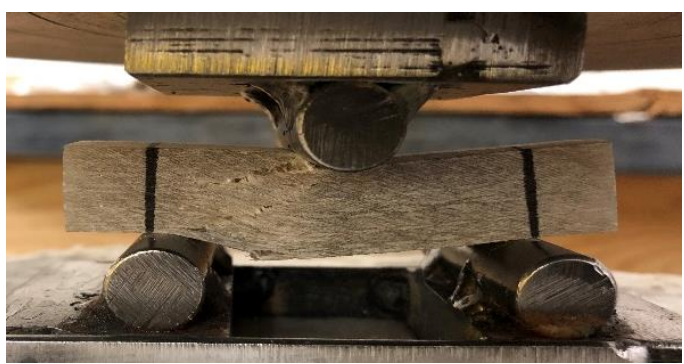

(a)

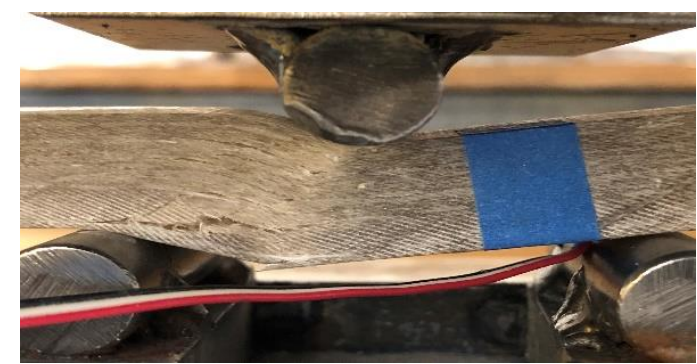

(b)

Figure 6-19. Interlaminar shear failure modes on GFRP laminate under short-beam shear test 


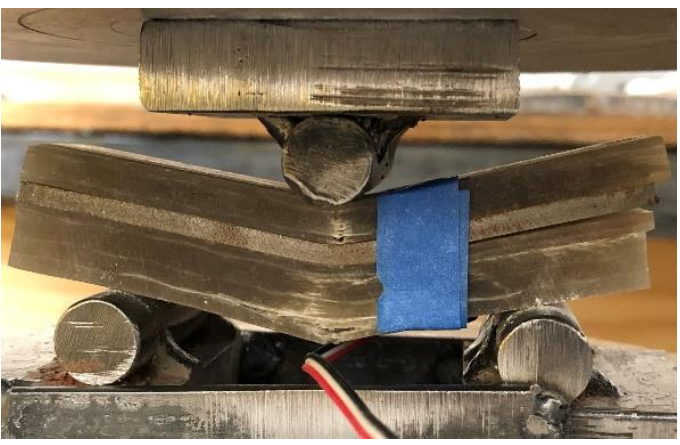

(a)

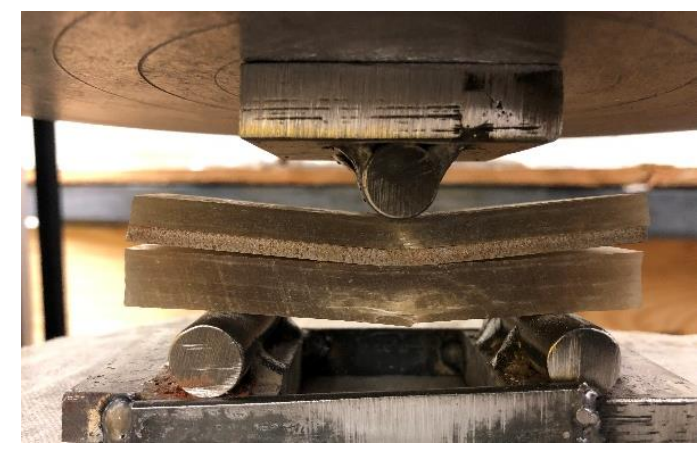

(b)

Figure 6-20. Interlaminar shear failure modes on hybrid laminate under short-beam shear test

Table 6-4. Inter-laminar shear strength for GFRP and hybrid sections

\begin{tabular}{|c|c|c|c|c|}
\hline \multirow{2}{*}{ Section } & \multirow{2}{*}{ C/S } & \multirow{2}{*}{$\begin{array}{c}\text { Span } \\
\text { (in) }\end{array}$} & \multicolumn{2}{|c|}{ Inter-laminar shear strength (ksi) } \\
\cline { 4 - 5 } & & Debonding @ Interface & Delamination @ GFRP layers \\
\hline GFRP & $1^{\prime \prime} \times 0.5^{\prime \prime}$ & 2 & - & 5.9 \\
\hline Hybrid & $1^{\prime \prime} \times 0.625^{\prime \prime}$ & 2.5 & 3.3 & 5.7 \\
\hline
\end{tabular}

The short-beam strength can only be attributed to a shear property if the failure produced in the laminate is by inter-laminar failure in the mid-plane, which was the failure modes obtained during the experimental testing. The short beam tests showed failure of the GFRP and hybrid laminates due to delamination and debonding, respectively as shown in Fig. 6-20.

\subsection{Elasticity properties of transverse coupons}

As the box-beams were 6" $66^{\prime \prime} \times 0.5^{\prime \prime}$ in cross-section with corner radius, the maximum length of transverse coupons cut from the flanges and webs of the beams was 3.75 inches. The tensile testing of the transverse coupons was difficult due to lack of length for gripping. Therefore, it was decided to test transverse coupons in three-point bending and obtain their modulus of elasticity using classical beam deflection equation as shown in Eqn. (6-10). The modulus of rigidity or shear modulus (G) was used as obtained from the experimental testing as discussed previously. The width and depth of the transverse coupon specimens was $0.4375^{\prime \prime}$ and 0.5 " respectively and were tested in a span of 2.5" as shown in Fig. 6-22.

$$
\Delta=\frac{\mathrm{PL}^{3}}{48 \mathrm{EI}}+\frac{\mathrm{PL}}{4 \mathrm{kGA}}
$$

Where, P, L, I, and A are the load, span length, moment of inertia, and cross-sectional area of the coupon section, respectively. The shear modulus $(\mathrm{G})$ of the section was previously obtained to be $0.4 \mathrm{msi}$. The shear correction factor $(\mathrm{k})$ is assumed as unity for the rectangular coupon crosssection. The bending stress-strain curve and the load-deflection curve obtained for the transverse coupons under three-point bending are shown in Fig. 6-21. The ultimate bending strength obtained from the experiment was around $46 \mathrm{ksi}$, higher than that obtained from the longitudinal bending coupon testing (Fig. 6-21a). The high bending stress is also validated by the high strain readings of almost 24,000 micro-strains. The deflection obtained experimentally contained both bending and shear deflections, and thus, to obtain the modulus of elasticity (E) of the section, the shear deflection part must be removed from the total deflection. 


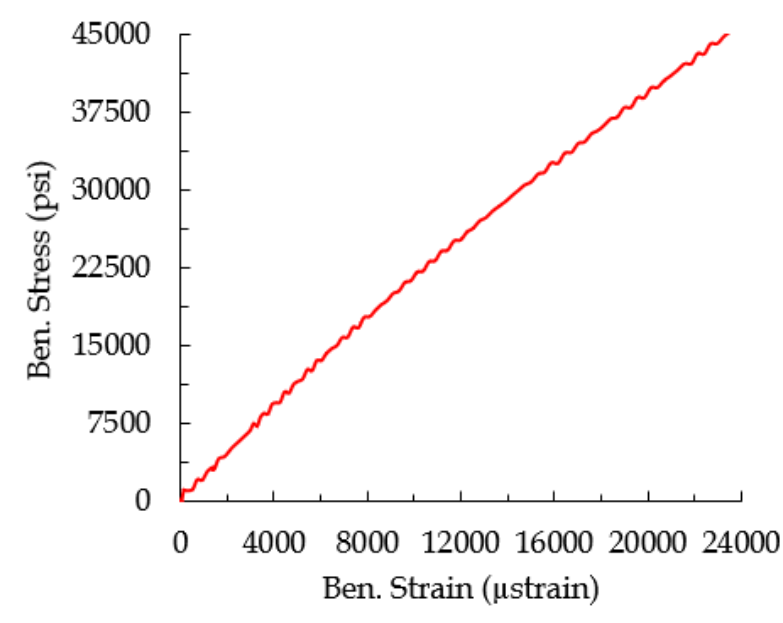

(a)

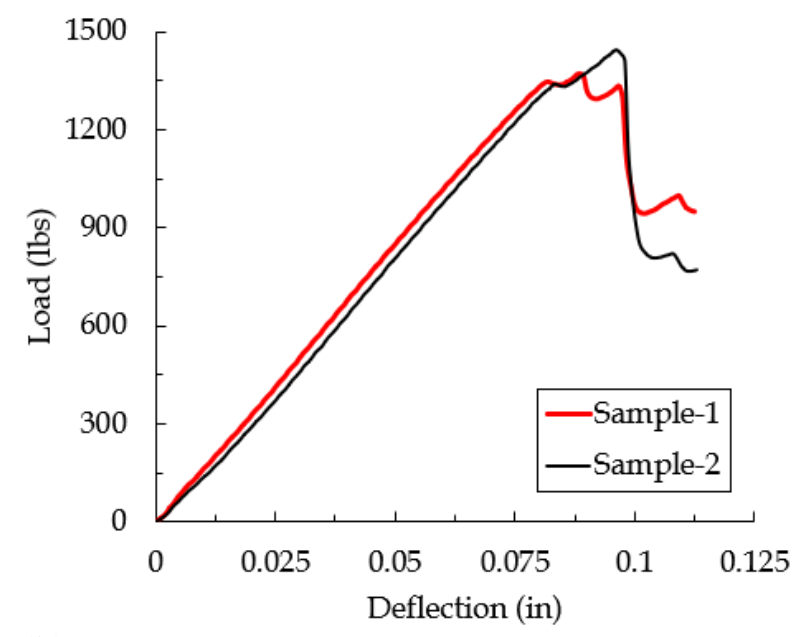

(b)

Figure 6-21. (a) Bending stress-strain, (b) Load-deflection curves for transverse coupons

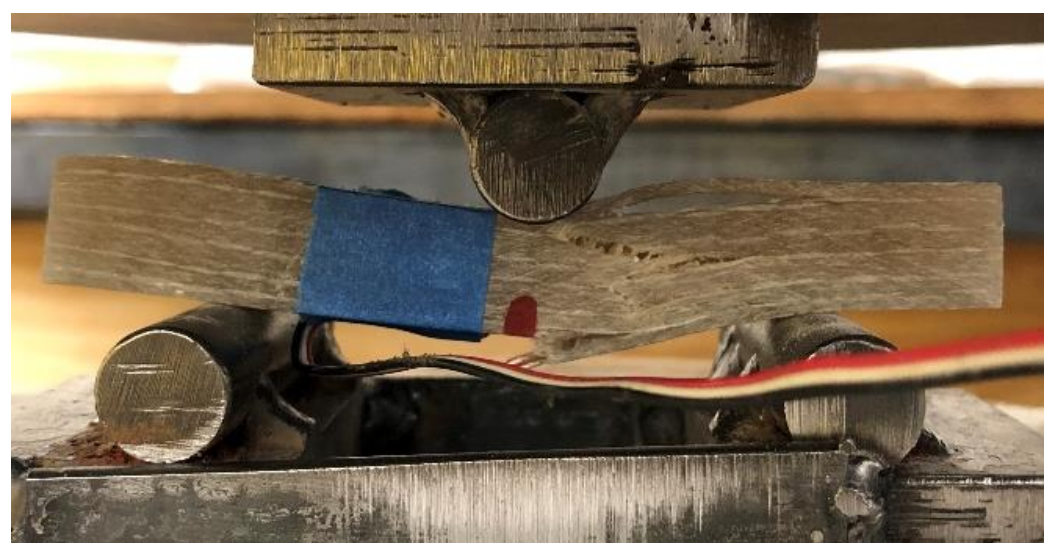

Figure 6-22. Failed transverse GFRP laminate under three-point bending

The transverse coupons under three-point bending failed in fiber fracture at the bottom most GFRP layers. After deducting the shear deflection from the total deflection using Eqn. (6-10), the computed modulus of elasticity for the transverse coupons was found to be $2.15 \mathrm{msi}$, similar to the value obtained for longitudinal bending coupons. Therefore, it can be concluded that the fiber volume fraction in the lamina that were used to construct the flanges and webs of box-beams were equal in both directions.

\subsection{Conclusions}

The coupon-level strength and modulus were successfully obtained for the GFRP and hybrid laminates through various testing as discussed within this chapter. The strength and stiffness values are summarized in Table 6-5. The material strengths of GFRP, steel, and hybrids in terms of tension, compression, bending, shear, and inter-laminar shear will be used in the analytical and FE modeling as discussed in Chapters 8 and 9. 
Table 6-5. Summary of material characterization

\begin{tabular}{|l|c|c|}
\hline Properties & GFRP & Hybrid \\
\hline Tensile strength (ksi) & 28.3 & 27.0 \\
\hline Tensile modulus (msi) & 2.02 & 6.42 \\
\hline Compressive strength (ksi) & 29.0 & - \\
\hline Compressive modulus (msi) & 1.6 & - \\
\hline Bending strength (ksi) & 46.4 & 51.5 \\
\hline Bending modulus (msi) & 2.15 & 3.15 \\
\hline Interlaminar shear strength (ksi) & 5.9 & 3.3 \\
\hline
\end{tabular}

The box-beams were manufactured with chopped strand mat and bi-axial woven roving with equal volume fraction in both directions. Therefore, the mechanical properties of the GFRP flange and web laminates in both longitudinal and transverse direction were identical. The steel plates embedded inside the box-beams were tested in tension and it was found to be A36 steel with a yield strength of $36 \mathrm{ksi}$, ultimate strength of $47.3 \mathrm{ksi}$ and a modulus of elasticity of $29 \mathrm{msi}$. 


\section{Chapter 7. Bending, Shear, \& Fatigue Behavior of Box-Beam Sections}

This chapter explains the experimental testing on box-beams under bending, shear, and fatigue loads to characterize the flexural and shear stiffness of the GFRP and hybrid GFRP-steel boxbeams. The computation of sectional properties of box-beam sections and the increases in their stiffness values due to embedment of steel plates are also discussed. After beam characterization, the chapter discusses the ultimate failure loads, load-deflection, load-strain, and failure modes on these box-beams. This chapter also discusses serviceability and yield limits on the embedded steel plates under service loads.

\subsection{Stiffness characterization}

As an initial testing to characterize stiffness properties of the GFRP and hybrid box-beam sections, as discussed previously in Chapter 4, they were tested under three-point bending with span lengths of 84 in. and 36 in. as shown in Fig. 7-1. and 7-2, respectively. An MTS controller was used to control hydraulic actuator with a maximum load capacity of 110 kips during the application of load on the beams. The 84-inch span length gives an L/D ratio of 14, while span length of 36 inch gives an L/D ratio of 6 . Usually, for L/D ratios greater than 9 , beams are predominantly under pure bending and for L/D ratios smaller than 6, beams are predominantly under the effect of shear. For beams tested on span lengths (L) of 84 in. and 36 in., the maximum central load (P) applied were $3000 \mathrm{lbs}$. and $6500 \mathrm{lbs}$., respectively. These box-beam specimens were tested to approximately $15 \%$ of the failure load to ensure that the beams are still in the elastic range. The recommended load level during characterization of elastic properties based on ASTM D7250 is $20 \%$ of the failure load. It is generally not recommended to compute stiffness properties at a load level where the specimen exhibits non-linear response due to excessive local deflection.

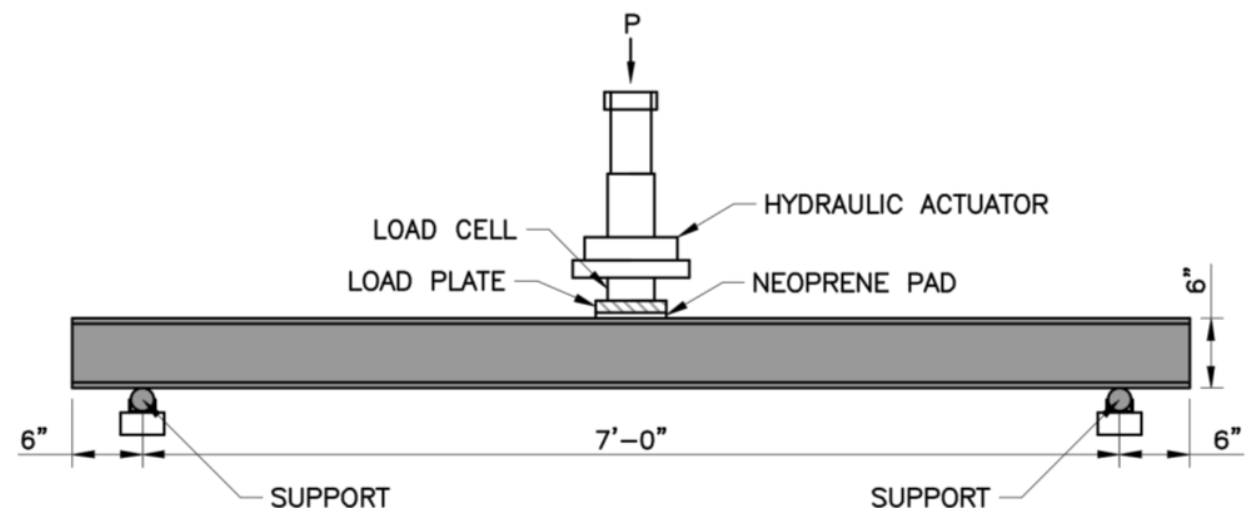

Figure 7-1. Three-point loading on box-beam sections at a span length of 84 inches

During testing, load, deflection, and strains were continuously recorded during testing using the high-speed data acquisition system. To assure uniform load application and to prevent slippage of the beam from supports, 0.5-inch-thick neoprene pads were placed on the load contact area and between the roller supports and the bottom surface of the samples. During each testing, data acquisition was started, and the load crosshead of an actuator was lowered until contact was made with the beam. The load actuator was controlled manually and was loaded at a rate of 100- 
200 pounds per second making sure that there was no impact on the beam during initial contact of the load crosshead.

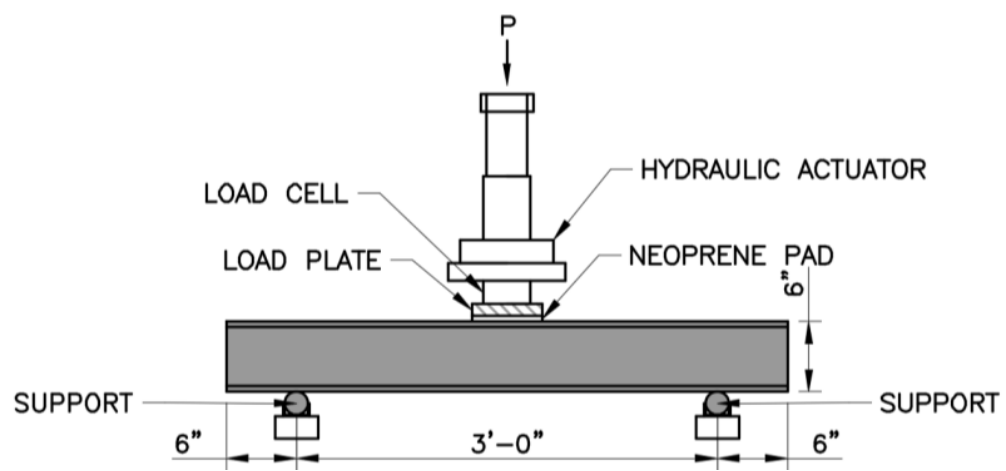

Figure 7-2. Three-point loading on box-beam sections at a span length of 36 inches

\subsubsection{Moment of inertia of box-beam sections}

The moment of inertia of any rectangular section having a width of dimension " $\mathrm{B}$ " and a depth of dimension " $\mathrm{D}$ " about its neutral axis is given by an Eqn. (7-1).

$$
\mathrm{I}=\frac{\mathrm{B} \mathrm{D}^{3}}{12}
$$

But when a rectangular section is chamfered at the ends with a certain radius, the moment of inertia of the section will be lower than that of a similar sized rectangular section depending upon a radius of the chamfer. The moment of inertia provided by the corners as shown in the figure must be subtracted from the overall sectional moment of inertia to compute moment of inertia value for the curve-shaped box-beam.
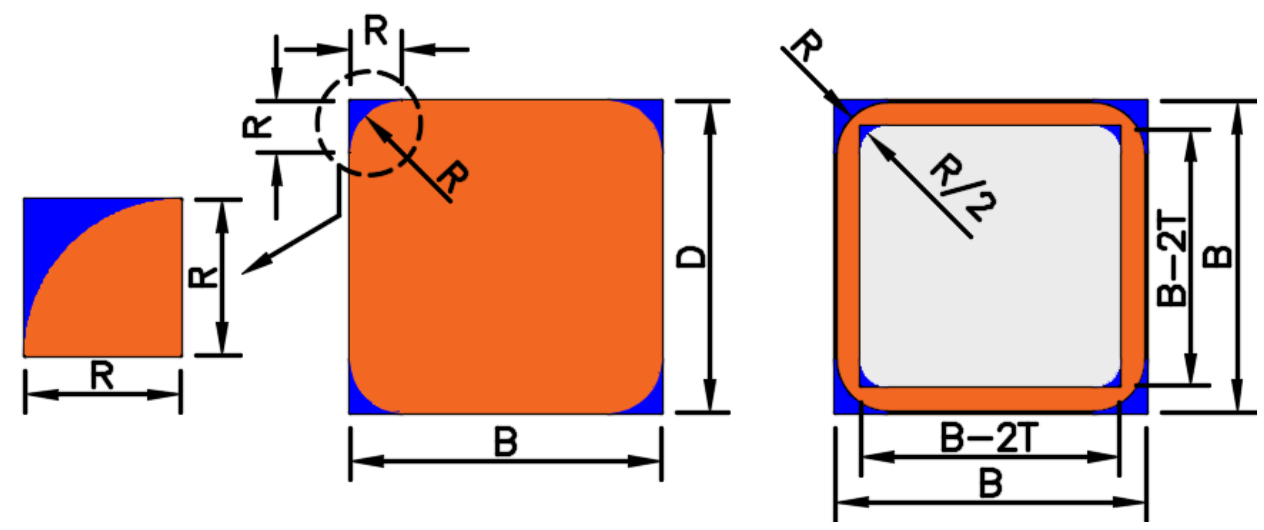

Figure 7-3. (a) Rectangular section with a corner radius, (b) Box-beam section with outer and inner corners radii

A corner of a box-beam can be represented as a square with a side equal to a radius of a chamfer, and as can be visualized in Fig. 7-3, the moment of inertia of a corner (represented by a blue region) can be obtained by subtracting the MI of a quarter circle from a MI of a square as shown in the Eqn. (7-2). 


$$
I_{\text {corner }}=I_{\text {square }}-I_{\text {qt-circle }}
$$

The moment of inertia of those corner squares as shown in the Fig. 7-3 from the neutral axis of the box-section can be calculated as shown in Eqn. (7-3). Similarly, the moment of inertia of the quarter circle present inside of the corner squares from the neutral axis of the box-section can be calculated as shown in Eqn. (7-4).

$$
\begin{aligned}
& I_{\text {square }}=\frac{R^{4}}{12}-R^{2}(0.5 D-0.5 R)^{2} \\
& I_{\text {qt-circle }}=\frac{\pi R^{4}}{16}-\frac{4 R^{4}}{9 \pi}+\left(0.5 D-R+\frac{4 R}{3 \pi}\right)^{2}
\end{aligned}
$$

Finally, the moment of inertia of a box-section having corner radius can be calculated by subtracting the difference of Eqn. (7-3) and Eqn. (7-4) from Eqn. (7-1) and is given by Eqns. (7-5) and (7-6). For square box-sections, the depth " $\mathrm{D}$ " and width " $\mathrm{B}$ " are equal.

$$
\begin{aligned}
& I_{\text {box }}=\frac{B D^{3}}{12}-4\left(I_{\text {square }}-I_{\text {qt-circle }}\right) \\
& I_{\text {box }}=\frac{B D^{3}}{12}-\frac{R^{4}}{3}-R^{2}(D-R)^{2}+\frac{\pi R^{4}}{4}-\frac{16 R^{4}}{9 \pi}+\pi R^{2}\left(0.5 D-R+\frac{4 R}{3 \pi}\right)^{2}
\end{aligned}
$$

For box-beam sections which were tested in this research, the section can be divided into outer and inner box-section areas, where moment of inertia of each area can be calculated by using Eqn. (7-6). The difference in the two moment of inertias is the resulting moment of inertia of the boxsections and the values are shown in Table 7-1. The steel plates that were embedded inside the flanges and webs of GFRP sections to obtain three different varieties of hybrid sections as shown in Fig. 7-4, were found to have a yield strength of $36 \mathrm{ksi}$ and a modulus of elasticity of 29,000 ksi.

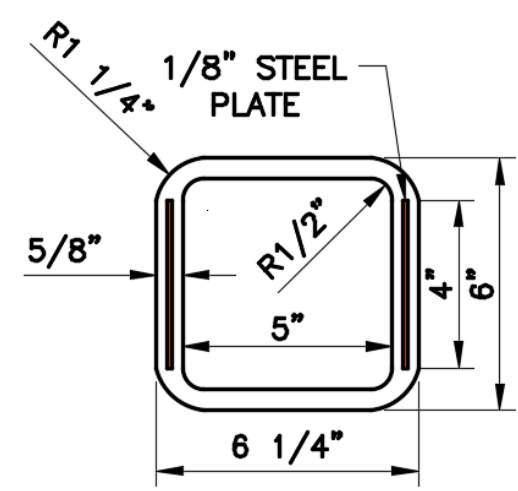

(a)

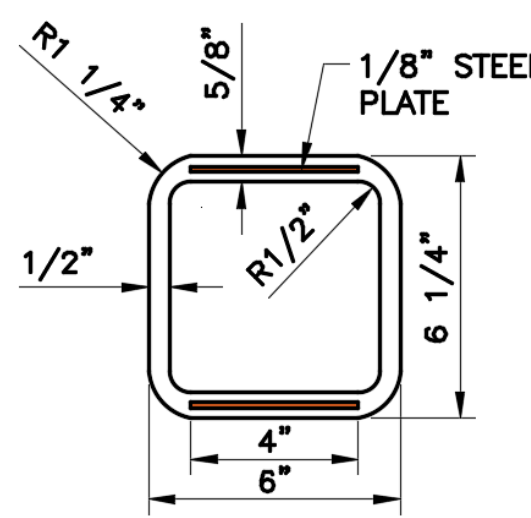

(b)

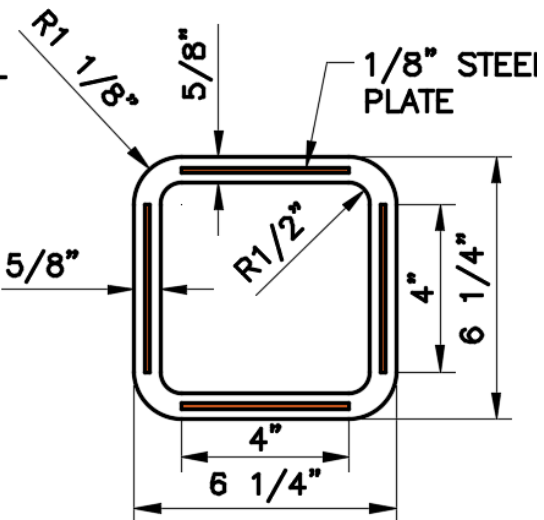

(c)

Figure 7-4. Hybrid GFRP-Steel sections: (a) HWB, (b) HFB, (c) HAB

The modulus of elasticity of GFRP sections as found from the tensile testing of coupons obtained from flanges and webs of these sections were $2.02 \mathrm{msi}$. Since, steel plates and GFRP material have different moduli of elasticity, the composite moment of inertias for hybrid sections were computed by transforming the area of steel to an equivalent GFRP area by using a modular ratio 
(n), which is the ratio of modulus of elasticity of steel to that of GFRP, which in this case was 14.3. The area moment of inertias (I) of a GFRP box-beam sections have been obtained by two ways, one ignoring the corner radii on the box-beams and the other by accounting for the corner radii. The differences in the moment of inertia values obtained between these methods are also tabulated in Table 7-1.

Table 7-1. Moment of inertias of control GFRP and hybrid box-beam sections

\begin{tabular}{|l|c|c|}
\hline \multirow{2}{*}{\multicolumn{1}{|c|}{ Sections }} & \multicolumn{2}{c|}{ Moment of inertia $\left(\mathrm{in}^{4}\right)$} \\
\cline { 2 - 3 } & Ignoring corners & Accounting corners \\
\hline Control GFRP box-beam (CB) & 55.92 & 50.49 \\
\hline Hybrid Web Beam (HWB) & 78.15 & 69.37 \\
\hline Hybrid Flange Beam (HFB) & 180.44 & 170.73 \\
\hline Hybrid All Beam (HAB) & 203.26 & 195.47 \\
\hline
\end{tabular}

The moment of inertia values that will be used in the calculation and discussion throughout this chapter will be the ones obtained after accounting for the corner radii, and the values are represented in a bar-chart diagram for better readability purpose (Fig. 7-5). The increases in the moment of inertia values due to embedment of the steel plates in the web and flange regions significantly improved the sectional properties of those hybrid sections and the increases in MI values are tabulated in Table 7-2.

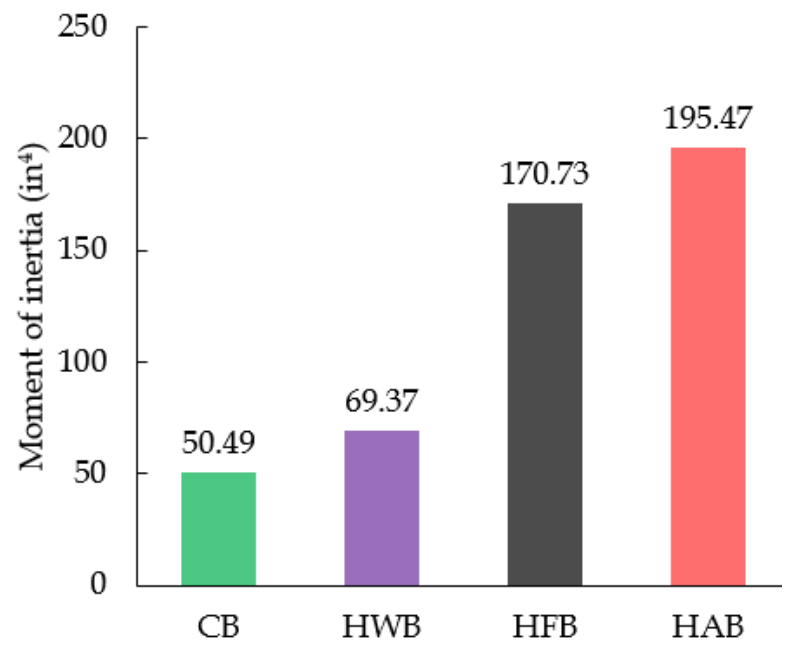

Figure 7-5. Moment of inertias of box-beam sections

Table 7-2. Moment of inertias of control GFRP and hybrid box-beam sections

\begin{tabular}{|l|c|c|}
\hline \multicolumn{1}{|c|}{ Sections } & Moment of inertia $\left(\mathrm{in}^{4}\right)$ & Increases (\%) \\
\hline Control GFRP box-beam (CB) & 50.49 & - \\
\hline Hybrid Web Beam (HWB) & 69.37 & 37.4 \\
\hline Hybrid Flange Beam (HFB) & 170.73 & 238.1 \\
\hline Hybrid All Beam (HAB) & 195.47 & 287.1 \\
\hline
\end{tabular}




\subsubsection{Bending and shear stiffness of box-beam sections}

The bending and shear stiffness of the box-beam sections have been determined by using two different techniques, simultaneous and back-calculation methods. In simultaneous method, the beam is experimentally tested at two different span lengths and values are plugged into Timoshenko beam theory as shown in Eqn. (7-7) to compute bending and shear stiffness. Whereas, in back calculation method, Bernoulli's equation as shown in Eqn. (7-10) is used to calculate bending stiffness (EI) based on experimental outermost bending strain reading, and which is back-plugged into Eqn. (7-7) to compute shear stiffness (kGA).

\subsubsection{Simultaneous method}

As box-beams were tested at two different L/D ratios, as discussed before, the maximum load and corresponding deflection were recorded during the test and are shown in Table 7-3. The total central deflection $(\Delta)$ on a beam is divided into bending deflection and shear components as shown in Eqn. 7-7.

$$
\Delta=\frac{\mathrm{PL}^{3}}{48 \mathrm{EI}}+\frac{\mathrm{PL}}{4 \mathrm{kGA}_{\mathrm{w}}}
$$

Where,

$\mathrm{P}=$ point load at the center of the beam

$\mathrm{I}=$ moment of inertia $\left(\mathrm{in}^{4}\right)$

$\mathrm{E}=$ modulus of elasticity (psi)

$\mathrm{G}=$ modulus of rigidity or shear modulus (psi)

$\mathrm{A}_{\mathrm{w}}=$ shear area of a profile $\left(\mathrm{in}^{2}\right)$

$\mathrm{k}=$ shear coefficient

$\mathrm{L}=$ length of a span (in)

Table 7-3. Load and deflections on beams under two different L/D ratios

\begin{tabular}{|c|c|c|c|c|c|c|}
\hline \multirow{2}{*}{ Beam } & \multicolumn{3}{|l|}{$\mathrm{L} / \mathrm{D}=14$} & \multicolumn{3}{|l|}{$\mathrm{L} / \mathrm{D}=6$} \\
\hline & Load (lbs.) & Def. (in) & Reduction (\%) & Load (lbs.) & Def. (in) & Reduction (\%) \\
\hline $\mathrm{CB}$ & \multirow{4}{*}{3000} & 0.432 & - & \multirow{4}{*}{6500} & 0.115 & - \\
\hline HWB & & 0.339 & 21.5 & & 0.094 & 18.3 \\
\hline HFB & & 0.177 & 59.0 & & 0.075 & 34.8 \\
\hline HAB & & 0.149 & 65.5 & & 0.061 & 46.9 \\
\hline
\end{tabular}

The load vs. deflection plots for beams tested under three-point bending at L/D ratios of 14 and 6 are shown in Figs. 7-6a and 7-6b, respectively. As can be noticed from Table 7-3 and Fig. 7-6, the deflections on hybrid beams were significantly lower compared to that on the control beam for beams tested in both $\mathrm{L} / \mathrm{D}$ ratios. The central deflection got reduced by $21.5 \%, 59.0 \%$ and $65.5 \%$ for hybrid beams HWB, HFB and $\mathrm{HAB}$, respectively tested at L/D ratio of 14 . Whereas, the central deflection got reduced by $18.3 \%, 34.8 \%$ and $46.9 \%$ for hybrid beams HWB, HFB and HAB, respectively tested at $\mathrm{L} / \mathrm{D}$ ratio of 6 . Since, the addition of steel plates on flanges improved the bending stiffness (EI) of the hybrid section, the bending deflection was more improved than the 
shear deflection, therefore, higher L/D ratio-tested beams showed greater improvement in deflection values.
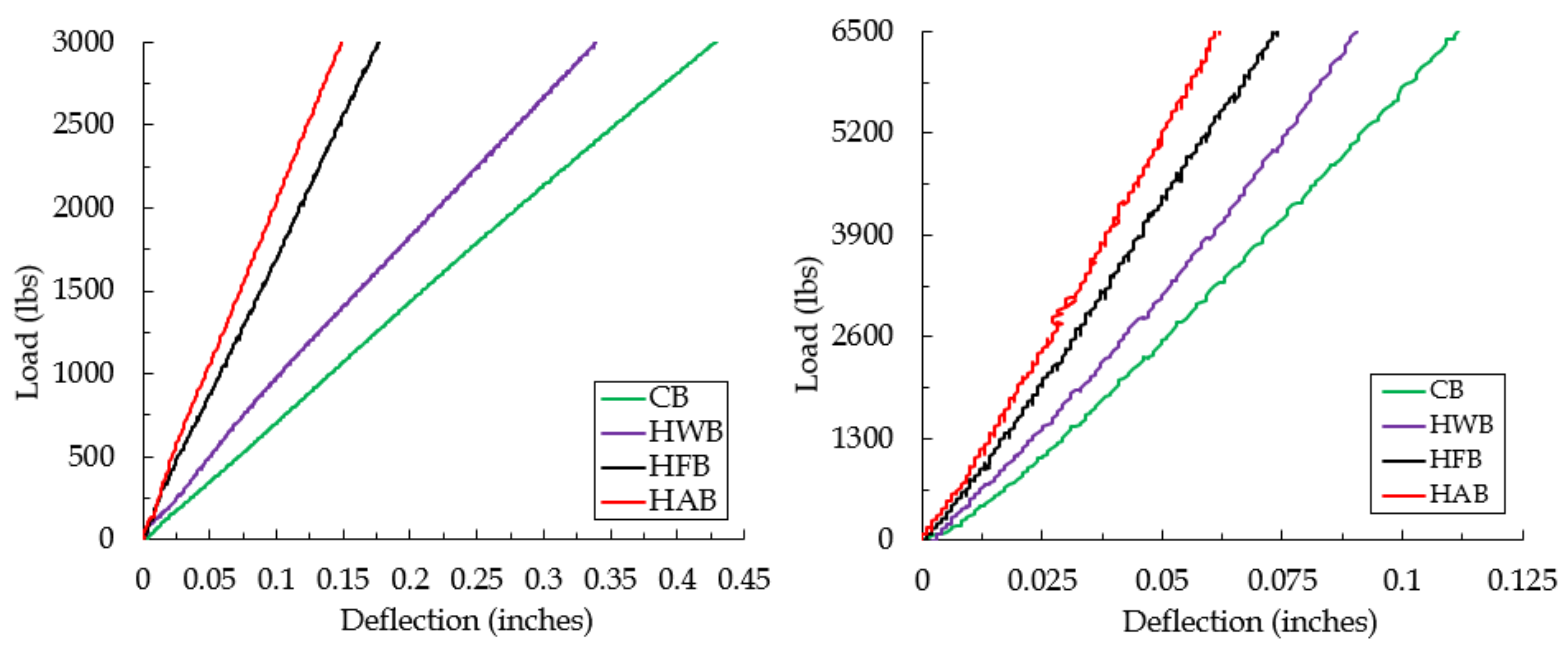

Figure 7-6. Load vs. deflection plots, (a) 84" $\operatorname{span}(\mathrm{L} / \mathrm{D}=14)$, (b) 36" $\operatorname{span}(\mathrm{L} / \mathrm{D}=6)$

Using deflection and load values obtained from experimental testing of box-beams at two different span lengths, Eqn. (7-7) was used to calculate the bending stiffness (EI) and the shear stiffness (GA) for all the beams and are shown in Table 7-4. The calculation for computing stiffnesses for control GFRP box-beam section based on deflections obtained during experimental testing is shown below in Eqns. (7-8) and (7-9). The shear correction factor " $k$ " is assumed as unity for the beams for easier comparisons.

$$
\begin{aligned}
& 0.432 "=\frac{3000 \times 84^{3}}{48 \times E I}+\frac{3000 \times 84}{4 \times \mathrm{kxGA}}\{3 \text {-point load @ 84" span }\} \\
& 0.114^{\prime \prime}=\frac{3000 \times 36^{3}}{48 \times E I}+\frac{3000 \times 36}{4 \times \mathrm{kxGA}}\{3 \text {-point load @ 36" span }\}
\end{aligned}
$$

Solving these above Eqns. (7-8) and (7-9), the values for EI and GA can be obtained for the control GFRP box-beam. Similarly, stiffness values were obtained for remaining hybrid box-sections and are tabulated in Table 7-4. The bending stiffness of hybrid sections were improved significantly compared to the control GFRP section. The bending stiffness values for hybrid sections HWB, $\mathrm{HFB}$, and $\mathrm{HAB}$ were increased by $29.6 \%, 220.2 \%$ and $269.9 \%$, respectively compared to the control GFRP box-section. As shear loads are only carried by the vertical webs of the section, the increase in shear stiffness value was maximum for the hybrid beams (HWB) and (HAB), where steel plates were embedded in the shear dominated webs of the box-beam section.

Table 7-4. Bending and shear stiffness of the box-beams

\begin{tabular}{|l|c|c|c|c|}
\hline Beam & Bending stiffness, EI (lb.in 2$)$ & Increase & Shear stiffness, kGA (lb.) & Increase \\
\hline CB & $0.98 \times 10^{8}$ & - & $1.16 \times 10^{6}$ & - \\
\hline HWB & $1.27 \times 10^{8}$ & $29.6 \%$ & $1.32 \times 10^{6}$ & $14.2 \%$ \\
\hline HFB & $3.14 \times 10^{8}$ & $220.2 \%$ & $1.07 \times 10^{6}$ & $-7.8 \%$ \\
\hline HAB & $3.63 \times 10^{8}$ & $269.9 \%$ & $1.34 \times 10^{6}$ & $16.1 \%$ \\
\hline
\end{tabular}




\subsubsection{Back-calculation method}

The flexural and shear modulus are also determined using back calculation method. The beams tested at 84 inches had a maximum bending moment of 63,000 lb-in at the mid-length and the bending strain at that location was recorded in the outermost region in the tension side and are shown in Table 7-5. The load-bending strain plot for the beam is shown in Fig. 7-8a. Eqn. (7-10) is used to calculate bending stiffness (EI) of the beam and are shown in Table 7-5. Further, the EI values were back-plugged into Eqn. (7-8) to determine shear stiffness of the beam and are also shown in Table 7-5.

$$
\mathrm{EI}=\frac{\mathrm{Mc}}{\varepsilon}
$$

Where, $\mathrm{c}$ is the distance from the neutral axis to the outermost fiber and $\mathrm{M}$ is the bending moment for the corresponding load.

Table 7-5. Load, strain, and bending and shear stiffness from back calculation method

\begin{tabular}{|c|c|c|c|c|c|}
\hline Beam & Bend. moment (lb-in) & NA depth (in) & Strain $(\mu \mathrm{s})$ & $\mathrm{EI}\left(\mathrm{lb} . \mathrm{in}^{2}\right)$ & kGA (lb.) \\
\hline \multicolumn{6}{|c|}{3000 lbs. load at a span of 84 inches } \\
\hline $\mathrm{CB}$ & \multirow{4}{*}{63,000} & 3.0 & 1868 & $1.01 \times 10^{8}$ & $0.97 \times 10^{6}$ \\
\hline HWB & & 3.0 & 1458 & $1.30 \times 10^{8}$ & $1.17 \times 10^{6}$ \\
\hline HFB & & 3.125 & 662 & $2.97 \times 10^{8}$ & $1.21 \times 10^{6}$ \\
\hline HAB & & 3.125 & 565 & $3.48 \times 10^{8}$ & $1.48 \times 10^{6}$ \\
\hline
\end{tabular}

The bending stiffness of the beams predicted by two methods were within $10 \%$, whereas shear stiffness for the beams were within $17 \%$. The shear correction factor $(\mathrm{k})$ is the ratio of the average shear strain on a section to the shear strain at the centroid and is typically taken as 0.42 for thinwalled box-beams and can also be estimated by using Eqn. (7-11) (Barbero, 2017, Bank, 2006).

$$
\mathrm{k}=\frac{80}{192+(v+\mathrm{G} / \mathrm{E})(-12)}
$$

The shear strain on the beams were measured at a distance equal to the depth of the beam " $\mathrm{d}$ " and " $\mathrm{d} / 2$ " from the support using a rectangular rosette formation, i.e., three strain gages at 45 degrees to each other to measure three normal strains as shown in Fig. 7-7. The shear strain based on three recorded normal strains $\left(\varepsilon_{\mathrm{A}}, \varepsilon_{\mathrm{B}}\right.$, and $\left.\varepsilon_{\mathrm{C}}\right)$ can be computed using Eqn. (7-12).

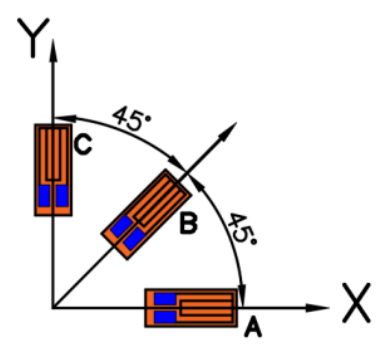

Figure 7-7. Load vs. deflection plots obtained

Shear strain, $\gamma_{\mathrm{XY}}=2 \varepsilon_{\mathrm{B}}-\left(\varepsilon_{\mathrm{A}}+\varepsilon_{\mathrm{C}}\right)$ 
Since, the shear recorded at a distance of " $\mathrm{d}$ " was slightly larger than the one recorded at " $\mathrm{d} / 2$ ", the shear strain discussed afterwards represent strains recorded at a distance " $\mathrm{d}$ ". The load vs. shear strain recorded for GFRP and hybrid beams while testing at a span of 36 inches is shown in Fig. 7-8b.

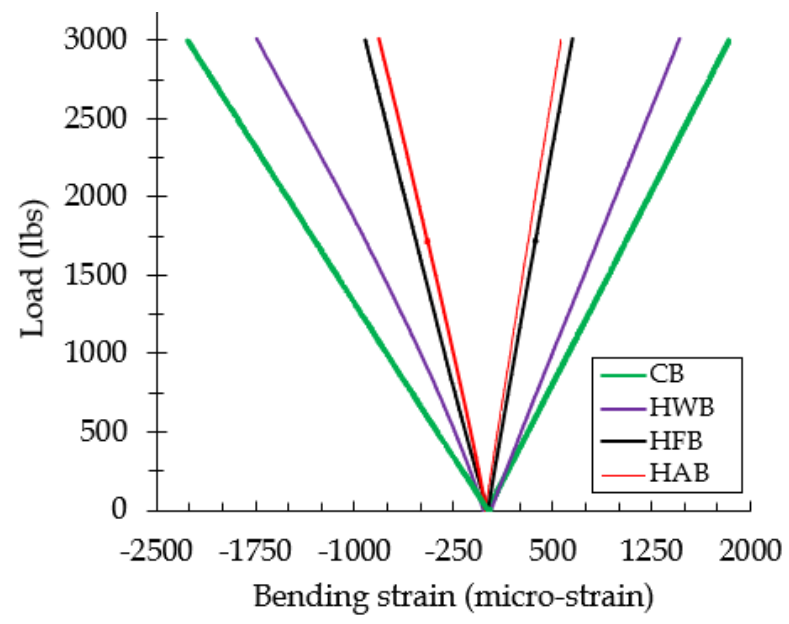

(a)

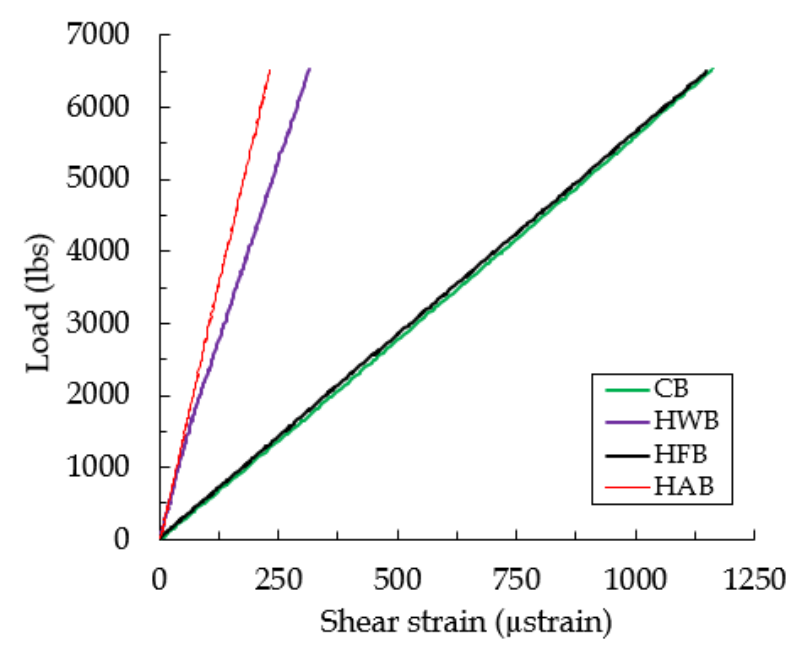

(b)

Figure 7-8. Load vs. strain plots obtained from 3-point load testing: (a) bending strains at 84" $\operatorname{span}(\mathrm{L} / \mathrm{D}=14),(\mathrm{b})$ shear strains at 36" $\operatorname{span}(\mathrm{L} / \mathrm{D}=6)$

\subsection{Fatigue testing on GFRP and hybrid box-beams}

After performing stiffness characterization of the GFRP and hybrid box-beams as discussed before, the box-beams were tested under fatigue loads. The fatigue is a repetitive loading on a structure. The constant repetition of load cycles even within a linear elastic limit of a structure can result in the degradation of the material properties and even causing failure, due to damage accumulation. The material properties degrade more with increasing load values and increasing fatigue cycles. Thus, it is very important to study fatigue behavior to establish fatigue limits of structures to safeguard the safety of a structure under service loads.

This section will discuss fatigue test methods and procedures that were followed during fatigue testing. The purpose of the testing was to quantify any progressive accumulation of damage such as cracks in matrix and fiber/matrix interface, GFRP/steel interface that would adversely affect the material property. The loss in stiffness values of beams after undergoing certain number of repetitive load cycles are quantified and the effect of fatigue on structural properties of GFRP box-beam sections are presented. After fatigue test, the loading and unloading path of the specimen was studied to find out any damage, hysteresis, loss in strain energy, and any residual deflection.

\subsubsection{Fatigue test description}

The box-beams were fatigued at a frequency of $2.5 \mathrm{~Hz}$ with a load controlled constant amplitude sinusoidal loading function under normal laboratory conditions. Since the tests were conducted under load-control, a constant stress-range was maintained, regardless of any damage or relaxation within the material. Fatigue tests were conducted at different levels of cyclic loads, which will be discussed within this section. Tests were programed to automatically shut down 
when reaching a predetermined run-out limit of one million cycles, or when the beam failed, after a precipitous drop in deflection, stiffness loss, or fracture.

\subsubsection{Load and support condition}

The fatigue tests on control GFRP and hybrid GFRP-steel box-beams were conducted under a three-point loading setup in an MTS universal testing machine having a maximum load and deflection capacity of 110 kips and 12 inches, respectively at normal laboratory conditions for a minimum of 1 million cycles. The initial fatigue load was also chosen to be within linear elastic limit of the beams to not complicate the overall behavior of the beam with the plastic behavior of embedded steel plates. The loads were in between service load levels of L/180 to L/500. However, at later stages, the load levels were beyond the elastic limits of the steel plate which will be discussed later.

The beams were placed on two steel rollers which were fixed on the concrete supports which acted as a simply supported condition for the beams as shown in Fig. 7-9. The ratio of minimum to maximum load applied during fatigue (R-ratio) was around 0.33 to 0.5 , which keeps the loading actuator always in contact with the specimens that eliminate impact on beams during the fatigue test. The parameters for fatigue test such as maximum load, minimum load, frequency, sine waveform was controlled using station manager software of the MTS controller. The loading was applied at the center of the beams with a 6 inches wide steel plate, which was 1-inch thick and covered the entire width of the beam. The neoprene pads were used in between the beams and the loading plate to make sure the loading gets distributed uniformly across the area. The box-beams were placed on roller supports on both ends and beams had an overhang of 6 inches beyond the supports at each end. This overhang was enough to prevent the specimen from slipping through the supports when broken.

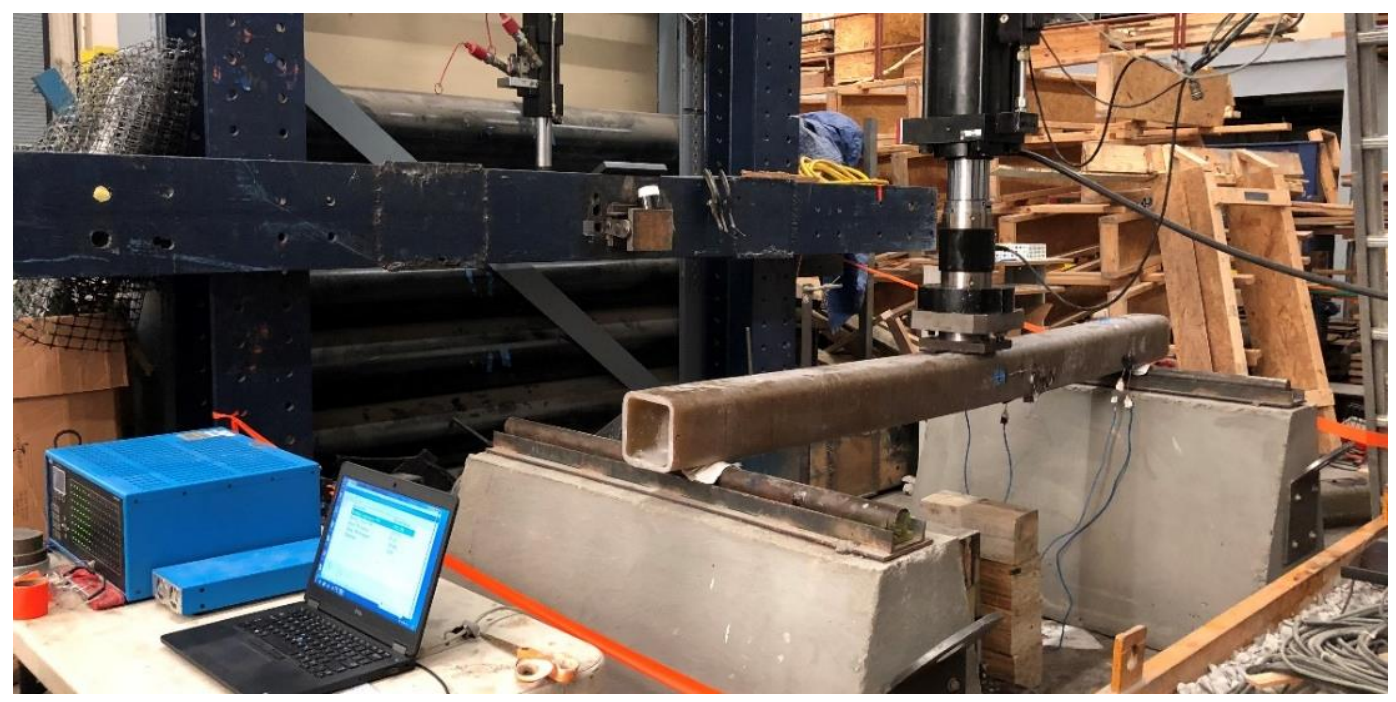

Figure 7-9. Fatigue testing under 3-point loading at a span of $84 \mathrm{in.}$

\subsubsection{Instrumentation and data generation}

Axial strain gages were placed to determine the bending and shear strains under load. The strain gages were mounted at the center of the span on both the tension and compression flanges of the 
beam. In addition, the axial gage was mounted on one of the webs of the beams at a distance of " $d$ " equal to the depth of the beam, from the support to record shear strains. The strain gage arrangement for the beam is illustrated in Figure 7-10. One LVDT was used to record deflection of the beams at the center of the span. The central deflection and strains were continuously monitored and recorded using a data acquisition system and sometimes also by conducting a static test in between by interrupting the fatigue test. A thorough visual inspection of the test sample was taken at every 200 thousand cycles to detect any fracture or delamination.

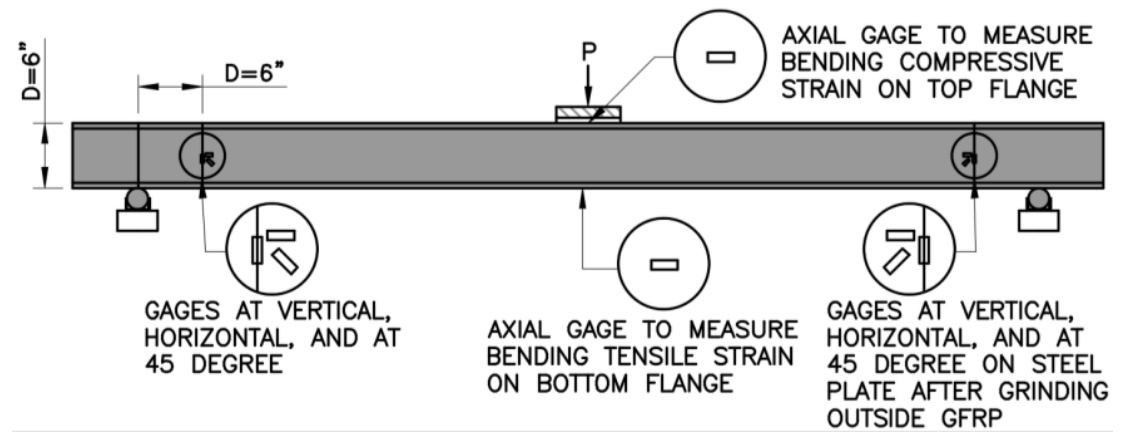

Figure 7-10. Strain gage instrumentation on a box-beam

\subsubsection{Initial static baseline values}

As discussed previously, the control GFRP and hybrid box-beams were initially tested for a load up to 3 kips and 6.5 kips at span lengths of 84 inches and 36 inches, respectively to establish baseline strength and stiffness values before undergoing fatigue tests. Further, whenever the boxbeam was fatigued at higher loads, an initial static testing was conducted to record baseline values before starting fatigue cycles.

\subsubsection{Fatigue of beams at a $\mathrm{L} / \mathrm{D}$ ratio of $\mathbf{1 4}$}

As the span length governs the behavior of the beams, the section is segregated for testing under two different span lengths. This section discusses the results of fatigue test performed on control GFRP and hybrid GFRP-steel box beams at a span of 84 inches, (L/D =14) with a frequency of 2.5 $\mathrm{Hz}$. The sub-sections are populated based on the experimental testing sequence conducted in the laboratory.

\subsubsection{Control GFRP box-beam (CB)}

The fatigue tests conducted on the control GFRP box-beam with test parameters, minimum and maximum load levels, and percentage of ultimate failure strength and service deflection limits are shown in Table 7-6.

Table 7-6. Fatigue testing on control GFRP box-beams

\begin{tabular}{|l|c|c|c|c|c|}
\hline $\begin{array}{c}\text { Fatigue } \\
\text { cycles }\end{array}$ & $\begin{array}{c}\text { Load range } \\
\text { (kip) }\end{array}$ & $\begin{array}{c}\text { Ultimate strength } \\
\text { limit }\end{array}$ & $\begin{array}{c}\text { Deflection } \\
\text { limit }\end{array}$ & $\begin{array}{c}\text { Max. strain } \\
\text { level }\end{array}$ & Notes \\
\hline 1st million & $1-3$ & $14 \%$ of failure & $\mathrm{L} / 180$ & 2290 & No failure \\
\hline 2nd million & $2-5$ & $23 \%$ of failure & $\mathrm{L} / 115$ & 3927 & No failure \\
\hline 3rd million & $4-7$ & $33 \%$ of failure & $\mathrm{L} / 80$ & 5774 & No failure \\
\hline
\end{tabular}


The first fatigue test on control GFRP box-beam was performed at a load range with a lower limit of $F_{\min }=1 \mathrm{kip}$ and an upper limit of $F_{\max }=3 \mathrm{kip}$ for the first million cycles at a frequency of 2.5 $\mathrm{Hz}$. The maximum load level was selected in such a way that the deflection produced at that level was within the service deflection limit of $\mathrm{L} / 180$, as the permissible maximum deflection limits by ACI, IBC, and AASHTO codes are L/180 in building structures.

The fatigue test on deflection limits less than L/180 such as (L/360, L/400) was not practical as the load level would be too negligible compared to the failure load of the beam, which would not produce any fatigue damage. On the other hand, the maximum loading on the GFRP box-beam under its service life is capped by the minimum permissible service limit of L/180, and the maximum load will not experience more than 3-kip load level. The damage or any significant change in the stiffness was not observed over the entire course of one million fatigue cycles, as indicated by the Fig. 7-11, which shows load vs. deflection for the beam taken before and after fatigue for 1 million cycles. This is not too surprising as the maximum bending strain level observed at the load of 3 kips was around 2200 micro-strains, whereas, the failure strain of the section under three-point bending at the tested span is more than 13,000 micro-strains, which will be discussed later.

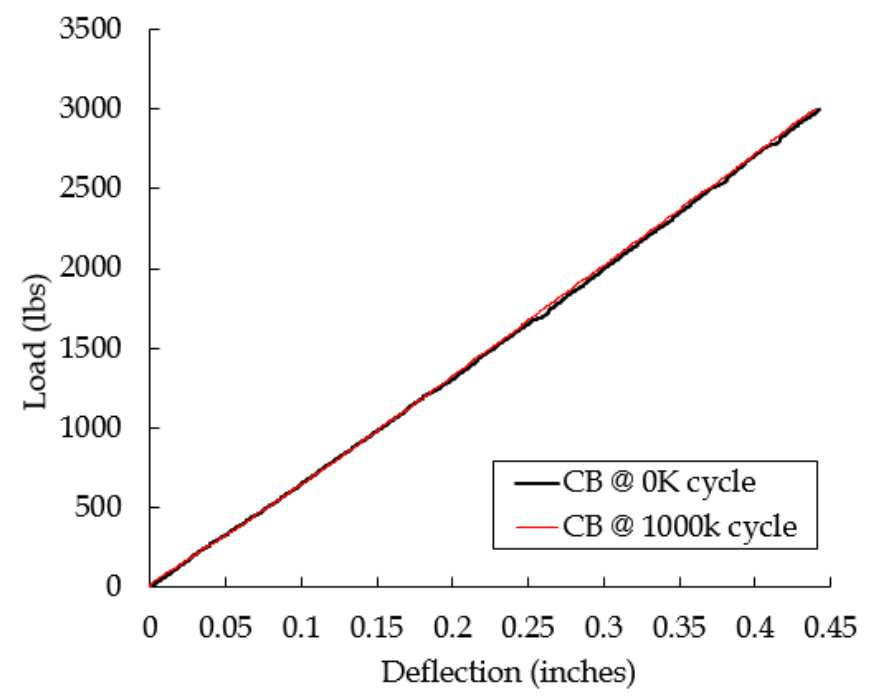

Figure 7-11. Load vs. deflection for CB beams before and after fatigue for $1000 \mathrm{~K}$ cycles: (a) at 1-3 kip, (b) at 2-5 kip

Table 7-7. Test results before and after fatigue on " $\mathrm{CB}$ " box-beams at a load range of 1-3 kip for 1 million cycle

\begin{tabular}{|c|c|c|c|c|c|c|}
\hline $\begin{array}{c}\text { Fatigue } \\
\text { cycles }\end{array}$ & $\begin{array}{c}\text { Load } \\
(\text { lbs. })\end{array}$ & $\begin{array}{c}\text { Def. } \\
(\text { in. })\end{array}$ & $\begin{array}{c}\text { Comp. } \\
\text { strain }(\mu \varepsilon)\end{array}$ & $\begin{array}{c}\text { Tensile } \\
\text { strain }(\mu \varepsilon)\end{array}$ & $\begin{array}{c}\text { Shear } \\
\left(90^{\circ}\right)(\mu \varepsilon)\end{array}$ & $\begin{array}{c}\text { Shear } \\
\left(45^{\circ}\right)(\mu \varepsilon)\end{array}$ \\
\hline $0 \mathrm{k}$ & 3000 & 0.432 & 2291 & 1868 & 44 & 275 \\
\hline $1000 \mathrm{k}$ & 3000 & 0.433 & 2339 & 1869 & 47 & 279 \\
\hline
\end{tabular}

After completing the first million cycles and not observing any reduction in beam's effective modulus of elasticity, the beam was fatigued for another 1 million cycles at similar conditions but at a higher load range of 3 kips, with minimum load value of 2 kips and maximum load value of 5 kips. The upper load on the load-range was around $23 \%$ of the failure load of the beam. 
Practically, the beam is never going to experience such load in its normal service life as the deflection is more than any permissible limit by any building code standards. However, the purpose here was to understand the behavior of the control GFRP box-beam under fatigue loads. The deflection at the load level of 5 kips after the fatigue cycle completion was increased by $1.3 \%$ than the value taken before fatigue. The change in effective modulus of elasticity strain values were within $1 \%$.

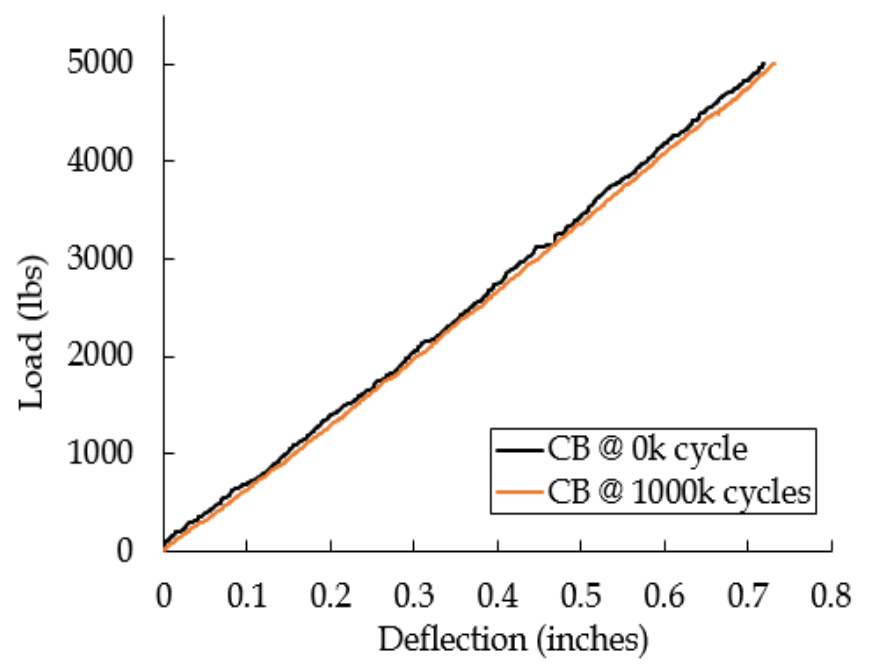

Figure 7-12. Load vs. deflection for CB beams before and after fatigue for $1000 \mathrm{~K}$ cycles at 2-5 kip

Table 7-8. Test results before and after fatigue on control GFRP box-beams at load range 2-5 kip for 1 million cycles

\begin{tabular}{|c|c|c|c|c|c|c|}
\hline $\begin{array}{c}\text { Fatigue } \\
\text { cycles }\end{array}$ & $\begin{array}{c}\text { Load } \\
(\text { lbs. })\end{array}$ & $\begin{array}{c}\text { Def. } \\
(\text { in. })\end{array}$ & $\begin{array}{c}\text { Comp. } \\
\text { strain }(\mu \varepsilon)\end{array}$ & $\begin{array}{c}\text { Tensile } \\
\text { strain }(\mu \varepsilon)\end{array}$ & $\begin{array}{c}\text { Shear } \\
\left(90^{\circ}\right)(\mu \varepsilon)\end{array}$ & $\begin{array}{c}\text { Shear } \\
\left(45^{\circ}\right)(\mu \varepsilon)\end{array}$ \\
\hline $0 \mathrm{k}$ & 5000 & 0.719 & 3927 & 3134 & 92 & 434 \\
\hline $1000 \mathrm{k}$ & 5000 & 0.728 & 4016 & 3112 & 82 & 428 \\
\hline
\end{tabular}

After completing two million cycles and not observing significant reduction in beam's effective modulus of elasticity, the beam was fatigued for another 1 million cycles at similar conditions with similar load range of (5-2 =7-4=3 kip), but at a lower load limit of $F_{\min }=4 \mathrm{kip}$ and an upper limit of $F_{\max }=7 \mathrm{kips}$. The upper load on the load-range was around 33\% of the failure load of the beam. The load vs. deflection plot for the beam before and after fatigue and strain values are shown in Fig. 7-x and Table 7-3. The effective stiffness of the box-beam and strain values were slightly reduced but within negligible $1 \%$. 


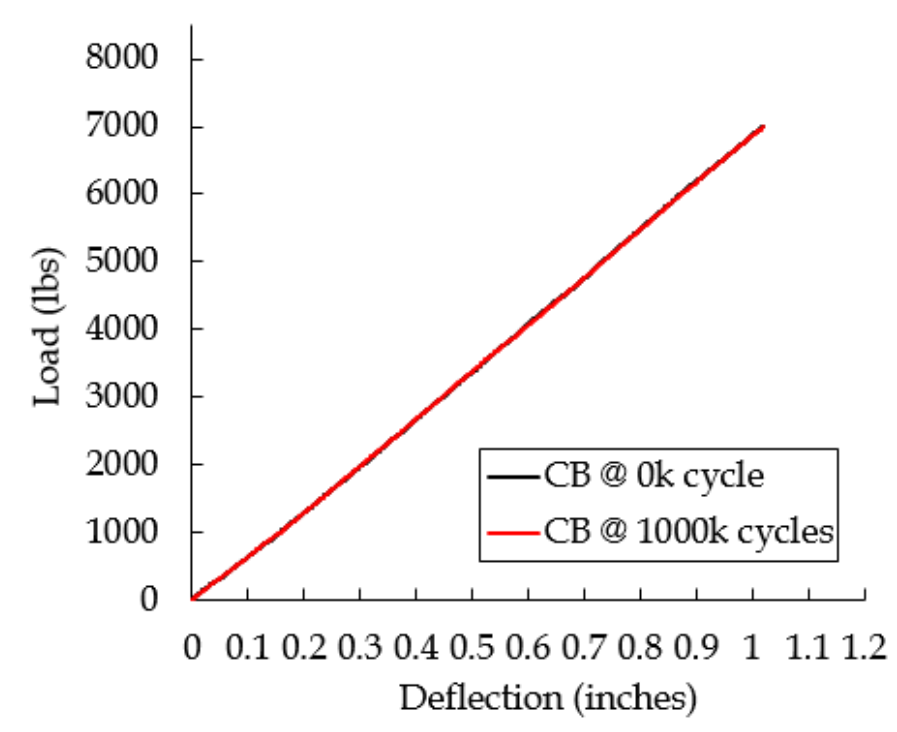

Figure 7-13. Load vs. deflection for CB beams before and after fatigue for $1000 \mathrm{~K}$ cycles at 4-7 kip

Table 7-9. Test results before and after fatigue on control GFRP box-beams at load range 4-7 kip for 1 million cycles

\begin{tabular}{|c|c|c|c|c|c|c|}
\hline $\begin{array}{c}\text { Fatigue } \\
\text { cycles }\end{array}$ & $\begin{array}{c}\text { Load } \\
(\text { lbs. })\end{array}$ & $\begin{array}{c}\text { Def. } \\
(\text { in. })\end{array}$ & $\begin{array}{c}\text { Comp. } \\
\text { strain }(\mu \varepsilon)\end{array}$ & $\begin{array}{c}\text { Tensile } \\
\text { strain }(\mu \varepsilon)\end{array}$ & $\begin{array}{c}\text { Shear } \\
\left(90^{\circ}\right)(\mu \varepsilon)\end{array}$ & $\begin{array}{c}\text { Shear } \\
\left(45^{\circ}\right)(\mu \varepsilon)\end{array}$ \\
\hline $0 \mathrm{k}$ & 7000 & 1.019 & 5774 & 4399 & 113 & 606 \\
\hline $1000 \mathrm{k}$ & 7000 & 1.021 & 5733 & 4410 & 119 & 606 \\
\hline
\end{tabular}

\subsubsection{Hybrid All Box-Beam (HAB)}

After the completion of fatigue testing on control box-beam (CB), the hybrid-all-box-beam (HAB) was tested under fatigue in a 3-point bending setup at a span of 84 inches with a frequency of 2.5 $\mathrm{Hz}$ as discussed before. The fatigue testing load levels, and percentage of ultimate failure strength and service deflection limits are shown in Table 7-10.

Table 7-10. Fatigue testing on hybrid HAB box-beams

\begin{tabular}{|l|c|c|c|c|c|}
\hline $\begin{array}{c}\text { Fatigue } \\
\text { cycles }\end{array}$ & $\begin{array}{c}\text { Load range } \\
\text { (kip) }\end{array}$ & $\begin{array}{c}\text { Ultimate strength } \\
\text { limit }\end{array}$ & $\begin{array}{c}\text { Deflection } \\
\text { limit }\end{array}$ & $\begin{array}{c}\text { Max. strain } \\
\text { level in steel }\end{array}$ & Notes \\
\hline 1st million & $1-3$ & $16 \%$ of failure & $\mathrm{L} / 490$ & $670 \mu \varepsilon$ & No failure \\
\hline 2nd million & $4-6.5$ & $35 \%$ of failure & $\mathrm{L} / 220$ & $1710 \mu \varepsilon$ & No failure \\
\hline 3rd million & $6-8.3$ & $45 \%$ of failure & $\mathrm{L} / 180$ & $2133 \mu \varepsilon$ & No failure \\
\hline 4th million & $7-9.8$ & $54 \%$ of failure & $\mathrm{L} / 150$ & $2575 \mu \varepsilon$ & No failure \\
\hline 5th million & $10-15$ & $80 \%$ of failure & $\mathrm{L} / 90$ & $5770 \mu \varepsilon$ & Failure \\
\hline
\end{tabular}

The first fatigue test on HAB box-beam was performed at a load range of 2 kips, with a lower limit of $F_{\min }=1 \mathrm{kip}$ and an upper limit of $F_{\max }=3 \mathrm{kip}$, like other beams, for the first one million cycles. The maximum load in the load range was about $16 \%$ of the failure load of the beam and the deflection limit was about L/49. At this fatigue range, there was no any change in the stiffness and strain values (Fig. 7-14, Table 7-11). The deflection obtained before and after the fatigue test was practically same, indicating no damages or property degradation. However, compressive 
bending strain was slightly reduced after 1 million cycles of fatigue. This might have occurred due to stretching of fibers in the load application point due to repetitive loading and the better distribution of stresses at that region afterwards.

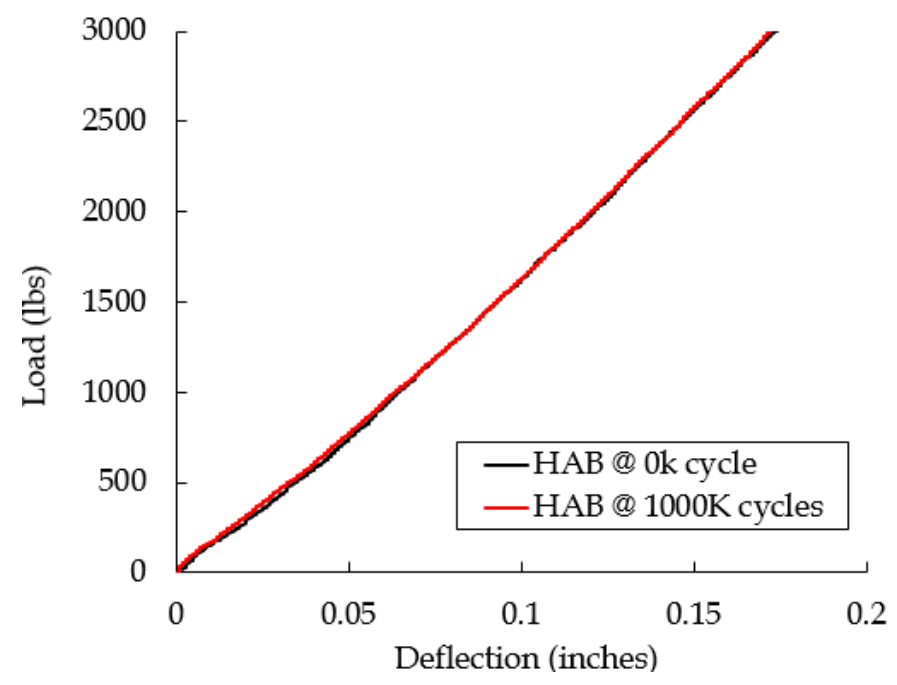

Figure 7-14. Load vs. deflection plot for HAB beams before and after fatiguing for 1 million cycles at 1-3-kip load

Table 7-11. Static test results obtained at 3-kip load before and after fatigue on HAB box-beams at load range 1-3 kip for 1 million cycles

\begin{tabular}{|c|c|c|c|c|c|c|c|c|}
\hline Fatigue & Load & Def. & \multicolumn{2}{|c|}{ Comp. strain $(\mu \varepsilon)$} & \multicolumn{2}{|c|}{ Ten. strain $(\mu \varepsilon)$} & \multicolumn{2}{|c|}{ Shear strain $(\mu \varepsilon)$} \\
\cline { 4 - 9 } cycles & $($ lbs. $)$ & (in.) & GFRP & Steel & GFRP & Steel & $90^{\circ}$ & $45^{\circ}$ \\
\hline $0 \mathrm{k}$ & 3000 & 0.172 & 910 & 670 & 565 & 573 & 37 & 52 \\
\hline $1000 \mathrm{k}$ & 3000 & 0.174 & 850 & 682 & 570 & 578 & 20 & 80 \\
\hline
\end{tabular}

After the first one million fatigue cycles, the hybrid beam was subjected to another round of 1 million cycles at higher load range of $2.5 \mathrm{kips}$, with a lower limit of $\mathrm{F}_{\min }=4 \mathrm{kip}$ and an upper limit of $F_{\max }=6.6 \mathrm{kip}$. Before starting the fatigue test, the beam was tested under static load of $6.5 \mathrm{kip}$ to obtain the baseline values. The static testing conducted after the completion of 1 million fatigue cycles showed no significant changes in deflection, stiffness, and strain values compared to the ones obtained before the fatigue (Fig. 7-15, Table 7-12). 


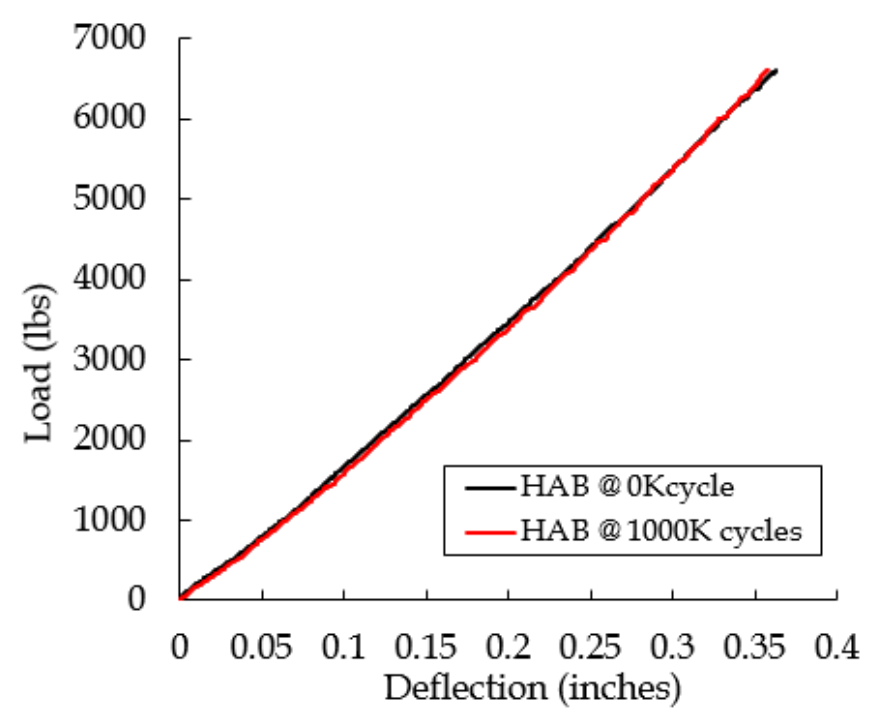

Figure 7-15. Load vs. deflection plot for HAB beams before and after fatiguing for 1 million cycles at 4-6.5-kip load @ 0.85 of steel yield strain

Table 7-12. Static test results obtained at 6.6-kip load before and after fatigue on HAB boxbeams at load range 4-6.5 kip for 1 million cycles

\begin{tabular}{|c|c|c|c|c|c|c|c|c|}
\hline Fatigue & Load & Def. & \multicolumn{2}{|c|}{ Comp. strain $(\mu \varepsilon)$} & \multicolumn{2}{|c|}{ Ten. strain $(\mu \varepsilon)$} & \multicolumn{2}{|c|}{ Shear strain $(\mu \varepsilon)$} \\
\cline { 4 - 10 } cycles & $($ lbs. $)$ & $($ in. $)$ & GFRP & Steel & GFRP & Steel & $@ 90^{\circ}$ & $@ 45^{\circ}$ \\
\hline $0 \mathrm{k}$ & 6600 & 0.402 & 2330 & 1710 & 1580 & 1670 & 49 & 138 \\
\hline $1000 \mathrm{k}$ & 6600 & 0.398 & 2300 & 1680 & 1545 & 1652 & 54 & 140 \\
\hline
\end{tabular}

After subjecting the beam for 2 million cycles as discussed above, the beam was further fatigued at higher load that produced strains on embedded steel plates more than 2000 micro-strains. The hybrid beam was subjected to another round of 1 million cycles at a load range of $2.3 \mathrm{kips}$, with a lower limit of $F_{\min }=6 \mathrm{kip}$ and an upper limit of $\mathrm{F}_{\max }=8.3 \mathrm{kip}$. Before starting the fatigue test, the beam was tested under static load of 8.3 kip to obtain the baseline values. During the loading process, at load values greater than 8 kips, slight yielding of steel plates occurred as evidenced by the load-deflection plot in Fig. 7-16. The static test performed after the fatigue showed no yield plateau at the same load level beyond 8 kips, which might have occurred due to strain hardening effects. The residual deflection of around 0.04" was noticed in the beam as can be seen in Fig. 717 and 7-18, however, the elastic modulus of the beam was not reduced, as evidenced by the slope of load-deflection curve. 


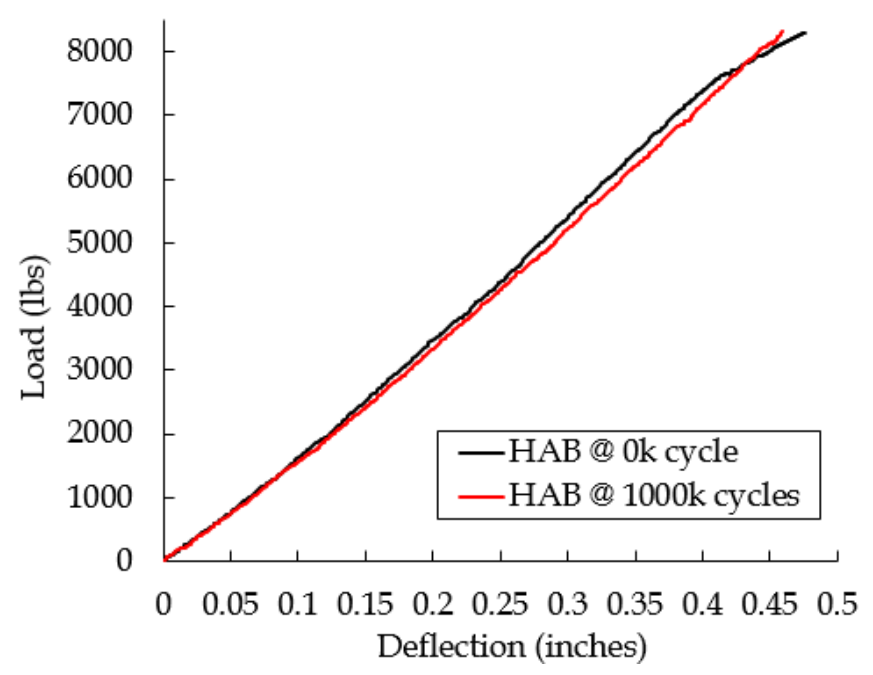

Figure 7-16. Load vs. deflection plot for $\mathrm{HAB}$ beams before and after fatiguing for 1 million cycles at 6-8.3-kip load

Table 7-13. Static test results obtained at 8.3-kip load before and after fatigue on HAB boxbeams at load range 6-8.3 kip for 1 million cycles

\begin{tabular}{|c|c|c|c|c|c|c|c|c|}
\hline \multirow{2}{*}{$\begin{array}{l}\text { Fatigue } \\
\text { cycles }\end{array}$} & \multirow{2}{*}{$\begin{array}{l}\text { Load } \\
\text { (lbs.) }\end{array}$} & \multirow{2}{*}{$\begin{array}{l}\text { Def. } \\
\text { (in.) }\end{array}$} & \multicolumn{2}{|c|}{ Comp. strain $(\mu \varepsilon)$} & \multicolumn{2}{|c|}{ Ten. strain $(\mu \varepsilon)$} & \multicolumn{2}{|c|}{ Shear strain $(\mu \varepsilon)$} \\
\hline & & & GFRP & Steel & GFRP & Steel & (a) $90^{\circ}$ & @ $45^{\circ}$ \\
\hline 0k & 8300 & 0.476 & 2974 & 21 & 19 & 20 & 91 & 157 \\
\hline $1000 \mathrm{k}$ & 8300 & 0.463 & 3182 & 1895 & 1809 & 1792 & 86 & 139 \\
\hline
\end{tabular}

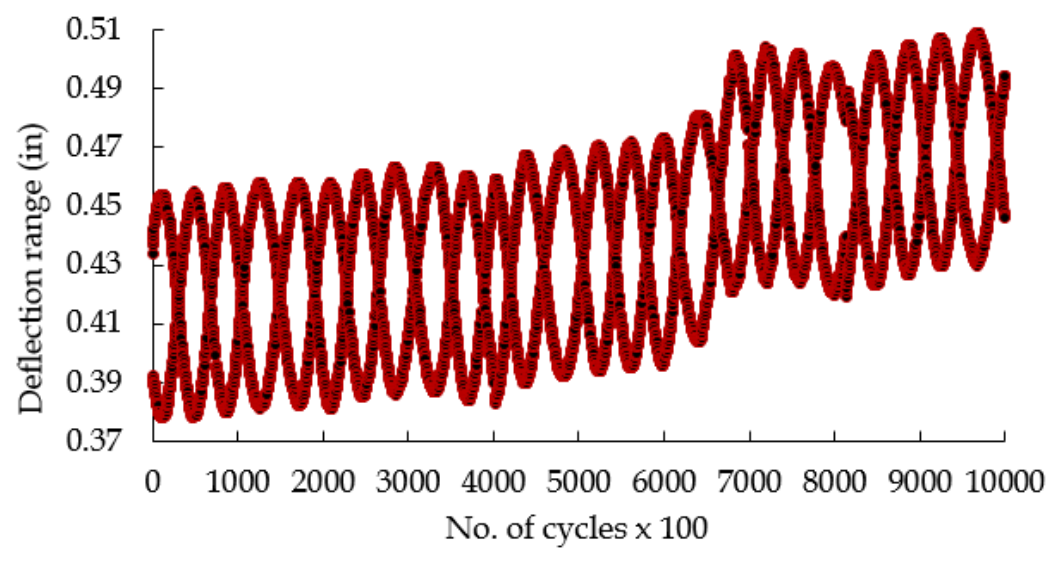

Figure 7-17. Deflection range vs. no. of fatigue cycles during 1 million fatigue cycles 


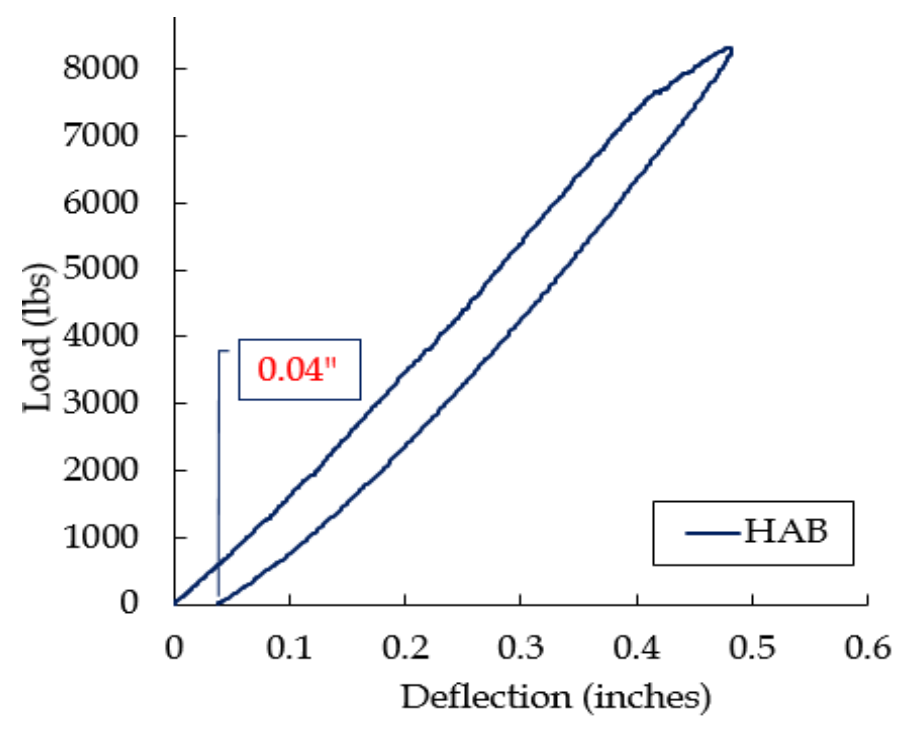

Figure 7-18. Residual deflection of around 0.04 inch noticed on a HAB beam after loading it beyond the yield level of embedded steel plates

Next, HAB beams were fatigued at higher load that would produce bending strains of 2500 microstrains on embedded steel plates. The corresponding load value was $9.8 \mathrm{kip}$. The hybrid beam was fatigued for another round of 1 million cycles, with a lower load limit of 7 kips and a higher load limit of $9.8 \mathrm{kips}$, with a load range of $2.8 \mathrm{kips}$. The static test before and after the fatigue showed no change in stiffness, however, the strain readings got reduced by around $5 \%$ and the permanent deflection of around 0.03" was observed in the beam (Fig. 7-19 and Table 7-14). The loss in strain energy, hysteresis loss, and strain hardening effect were the reasons for higher strain readings at similar load levels.

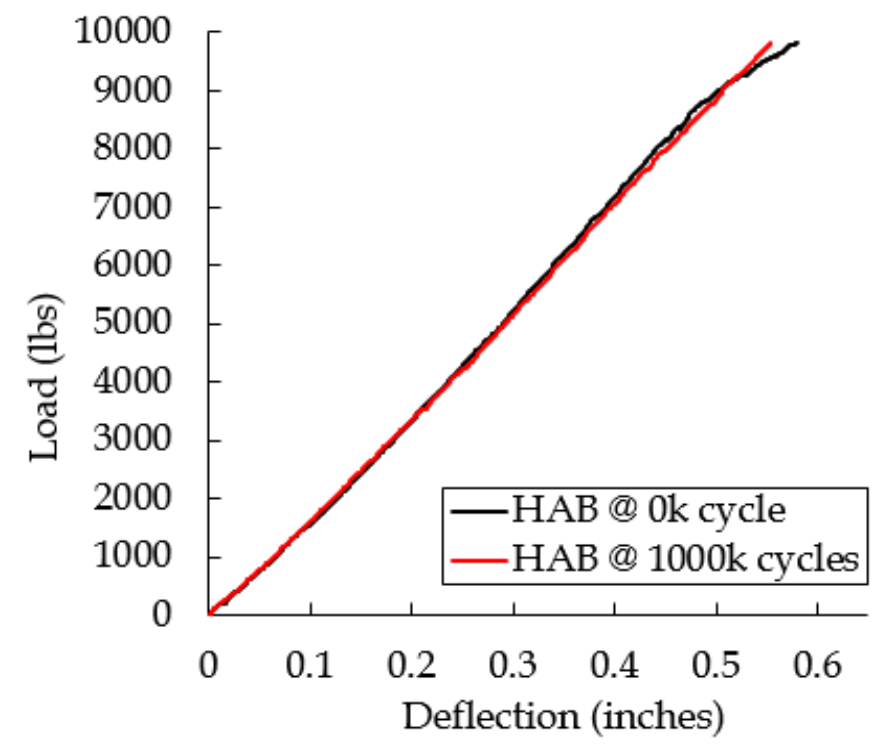

Figure 7-19. Load vs. deflection plot for HAB beams before and after fatiguing for 1 million cycles at 7-9.8-kip load 
Table 7-14. Static test results obtained at 9.8-kip load before and after fatigue on HAB boxbeams at load range 7-9.8 kip for 1 million cycles

\begin{tabular}{|c|c|c|c|c|c|c|c|c|}
\hline Fatigue & Load & \multirow{2}{*}{$\begin{array}{c}\text { Def. } \\
\text { cycles }\end{array}$} & \multicolumn{2}{c|}{ Comp. strain $(\mu \varepsilon)$} & \multicolumn{2}{|c|}{ Ten. strain $(\mu \varepsilon)$} & \multicolumn{2}{|c|}{ Shear strain $(\mu \varepsilon)$} \\
\cline { 4 - 10 }$($ lbs. & (in.) & GFRP & Steel & GFRP & Steel & $@ 90^{\circ}$ & $@ 45^{\circ}$ \\
\hline $0 \mathrm{k}$ & 9800 & 0.580 & 4120 & 2508 & 2466 & 2575 & 99 & 161 \\
\hline $1000 \mathrm{k}$ & 9800 & 0.554 & 3695 & 2377 & 2286 & 2370 & 96 & 99 \\
\hline
\end{tabular}

Further, the fatigue load level was increased to a load which would produce strain on embedded steel plate more than 5000 micro-strains. The corresponding load level was $15 \mathrm{kips}$. The beam was fatigued at a load range of 5 kips, with a lower limit of 10 kips and an upper limit of 15 kips (Fig. 7-20). The beam failed with an excessive deflection and creep at 625,000 cycles (Fig. 7-21 and 722). The excessive yielding of steel plates was observed at the time of failure. The deflection and strain readings at the time of failure are shown in Table 7-15. Since the fatigue setting was load controlled, the actuator tries to push down on the beams to achieve the load level set in the program. The bending strains on the embedded steel plate on tension side reached to 9797 microstrains, while the strains on steel plate on compressive side reached 6533 micro-strains.

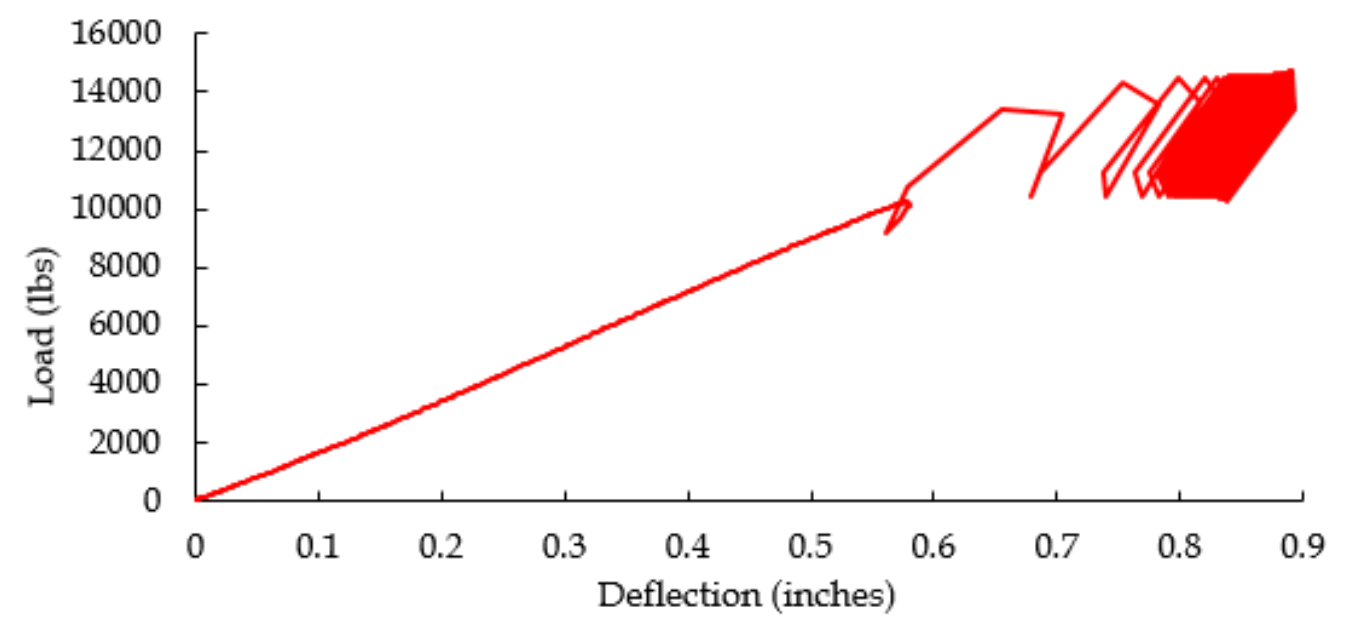

Figure 7-20. Fatigue loading at the load range of 10-15 kip at $2.5 \mathrm{~Hz}$

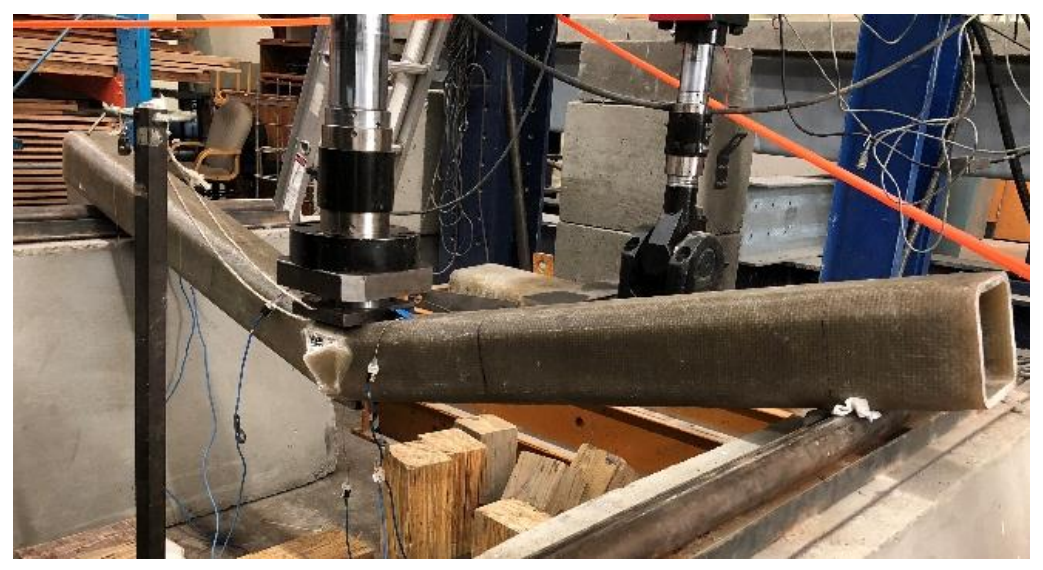

Figure 7-21. Failure of a hybrid $\mathrm{HAB}$ beam under fatigue at a load range of 10-15 kip at $2.5 \mathrm{~Hz}$ 


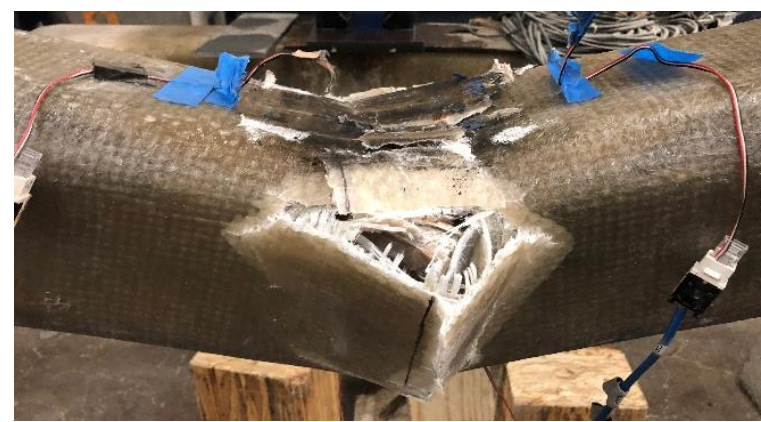

(a)

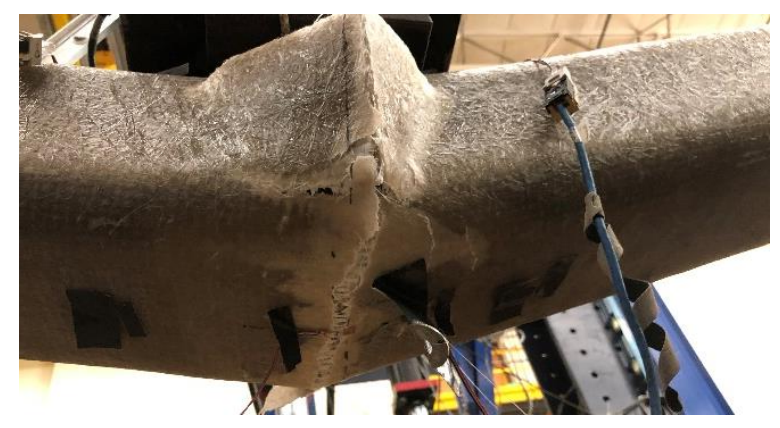

(b)

Figure 7-22. Close-up of the failure of a hybrid HAB beam: (a) top view, (b) bottom view

Table 7-15. Deflection and strain values before fatigue and at the time of failure

\begin{tabular}{|c|c|c|c|c|c|c|c|c|}
\hline Fatigue & Load & Def. & \multicolumn{2}{c|}{ Comp. strain $(\mu \varepsilon)$} & \multicolumn{2}{|c|}{ Ten. strain $(\mu \varepsilon)$} & \multicolumn{2}{|c|}{ Shear strain $(\mu \varepsilon)$} \\
\cline { 4 - 9 } cycles & $($ lbs. $)$ & (in.) & GFRP & Steel & GFRP & Steel & @ 90 & @ $45^{\circ}$ \\
\hline $0 \mathrm{k}$ & 15000 & 0.893 & 6747 & 4645 & 4598 & 5771 & 109 & 207 \\
\hline $625 \mathrm{k}$ & 15000 & 2.225 & 12912 & 6533 & 7069 & 9797 & 90 & 1148 \\
\hline
\end{tabular}

\subsubsection{Hybrid Flange Box-Beam (HFB)}

After completing fatigue test on control beam (CB) and hybrid all-beam (HAB), the hybrid flange box-beam (HFB) was tested under fatigue in a 3-point bending setup at a span of 84 inches with a frequency of $2.5 \mathrm{~Hz}$ as discussed before, and the fatigue load levels, and percentage of ultimate failure strength and service deflection limits are shown in Table 7-16.

Table 7-16. Fatigue testing on HFB box-beams

\begin{tabular}{|l|c|c|c|c|c|}
\hline $\begin{array}{c}\text { Fatigue } \\
\text { cycles }\end{array}$ & $\begin{array}{c}\text { Load range } \\
\text { (kip) }\end{array}$ & $\begin{array}{c}\text { Ultimate strength } \\
\text { limit }\end{array}$ & $\begin{array}{c}\text { Deflection } \\
\text { limit }\end{array}$ & $\begin{array}{c}\text { Max. strain } \\
\text { level in steel }\end{array}$ & Notes \\
\hline 1st million & $4-6.5$ & $38 \%$ of failure & $\mathrm{L} / 180$ & $2046 \mu \varepsilon$ & No failure \\
\hline 2nd million & $5.5-8.5$ & $50 \%$ of failure & $\mathrm{L} / 140$ & $2527 \mu \varepsilon$ & No failure \\
\hline
\end{tabular}

The first fatigue test on HFB box-beam was performed at a load range of $2.5 \mathrm{kips}$, with a lower limit of $F_{\min }=4$ kips and an upper limit of $F_{\max }=6.5 \mathrm{kips}$ for one million cycles at a frequency of $2.5 \mathrm{~Hz}$. While taking an HFB beam for a static loading up to $6.5 \mathrm{kip}$, the steel plate inside the beam yielded slightly, as evidenced by the load-deflection curve in Fig. 7-23 and also by the strain values shown in Table 7-17. The static test after fatigue showed less deflection on the beam at 6.5 kips due to presence of residual strains and deflection, as compared to values before fatigue. However, the beam suffered no damage and the effective modulus of elasticity of the hybrid section seems unaffected, as evidenced by the slope of the curve.

Table 7-17. Static test results obtained at 6.5-kip load before and after fatigue on HFB boxbeams at load range 4-6.5 kip for 1 million cycles

\begin{tabular}{|c|c|c|c|c|c|c|c|c|}
\hline Fatigue & Load & Deflection & \multicolumn{2}{c|}{ Comp. strain $(\mu \varepsilon)$} & \multicolumn{2}{|c|}{ Ten. strain $(\mu \varepsilon)$} & \multicolumn{2}{c|}{ GFRP shear strain } \\
\cline { 4 - 9 } cycles & $($ lbs. $)$ & (in.) & GFRP & Steel & GFRP & Steel & $90^{\circ}(\mu \varepsilon)$ & $45^{\circ}(\mu \varepsilon)$ \\
\hline $0 \mathrm{k}$ & 6500 & 0.476 & 2432 & 1897 & 1913 & 2046 & 67 & 545 \\
\hline $1000 \mathrm{k}$ & 6500 & 0.400 & 1960 & 1511 & 1441 & 1350 & 53 & 537 \\
\hline
\end{tabular}




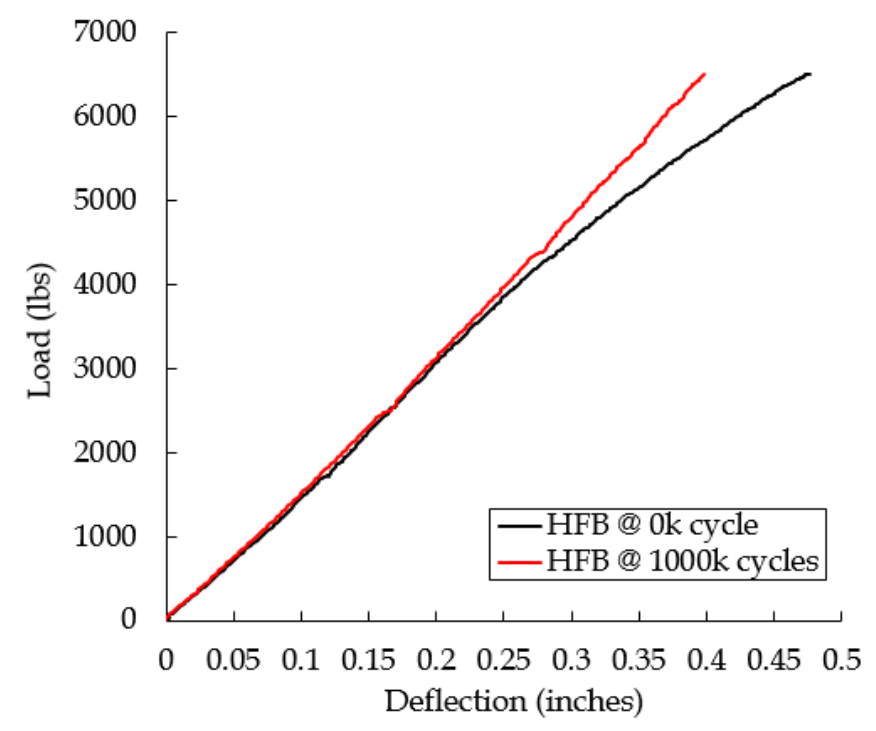

Figure 7-23. Load vs. deflection for HFB beam before and after fatigue at 4-6.5 kip

Further, the beam was fatigued at a load range of 5.5-8.5 kip, which is about $50 \%$ of the failure load, at similar conditions. The static load testing before fatigue at the load level of 8.5 kips showed the bending strain on embedded steel plate about 2500 micro-strains, which is more than the yield strain of steel. The cracking, debonding, delamination, or any other damages were not noticed in the beam during the fatigue cycles. The static testing after fatigue showed an unchanged bending stiffness of the beam (Fig. 7-24 and Table 7-18). However, the strain values recorded were lower than the values obtained before fatigue. The residual effects and strain hardening effect of steel might have played a role in lower deflection and strain readings.

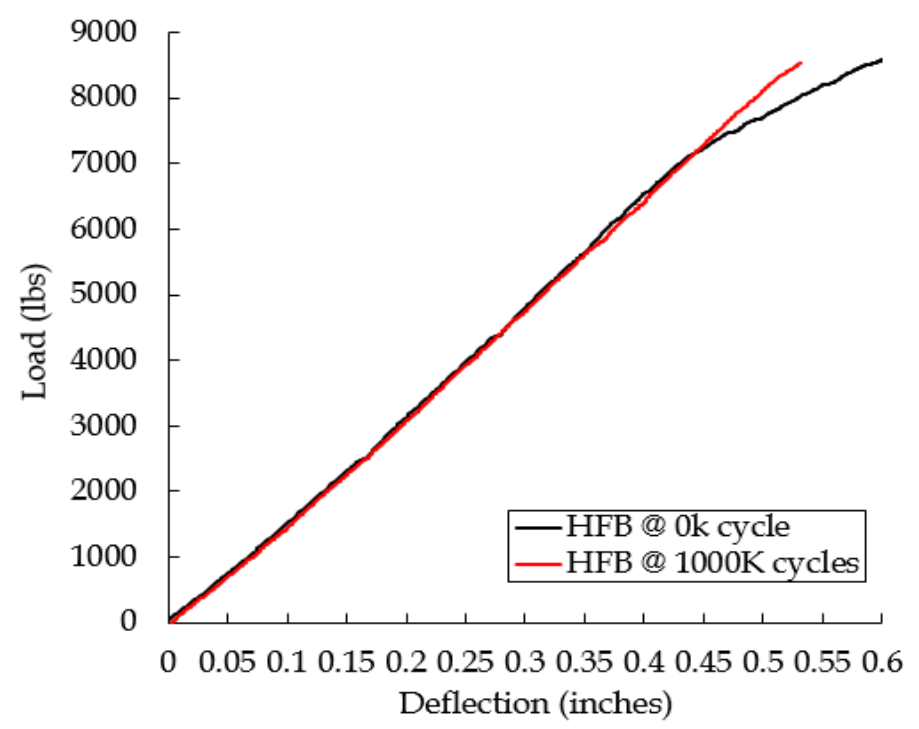

Figure 7-24. Load vs. deflection plot for HFB beams before and after fatiguing for 1 million cycles at 5.5-8.5-kip load 
Table 7-18. Static test results obtained at 8.5-kip load before and after fatigue on HFB boxbeams at load range 5.5-8.5 kip for 1 million cycles

\begin{tabular}{|c|c|c|c|c|c|c|c|c|}
\hline Fatigue & Load & Def. & \multicolumn{2}{c|}{ Comp. strain $(\mu \varepsilon)$} & \multicolumn{2}{c|}{ Ten. strain $(\mu \varepsilon)$} & \multicolumn{2}{c|}{ GFRP shear strain } \\
\cline { 4 - 9 } cycles & $($ lbs. $)$ & (in.) & GFRP & Steel & GFRP & Steel & $90^{\circ}(\mu \varepsilon)$ & $45^{\circ}(\mu \varepsilon)$ \\
\hline $0 \mathrm{k}$ & 8550 & 0.600 & 3112 & 2476 & 2453 & 2527 & 75 & 721 \\
\hline $1000 \mathrm{k}$ & 8550 & 0.532 & 3010 & 2247 & 2063 & 2008 & 74 & 737 \\
\hline
\end{tabular}

\subsubsection{Hybrid Web Box-Beam (HWB)}

The hybrid web box-beam (HWB) was tested for a million cycle under 3-point bending setup at a span of 84 inches with a frequency of $2.5 \mathrm{~Hz}$ at a load range of 5.6-7.6 kip. The upper load value was around $33 \%$ of the failure load and the deflection produced at that load was within the service limit of L/90. The load-deflection plot for the beam before and after the fatigue test is shown in Fig. 7-25. The strain values are shown in Table 7-19. The deflection and recorded strains after the fatigue test were lower compared to the values obtained before. The deflection might have been lower due to presence of residual deflection on the fatigued beam and some regions of the steel plate in the webs might have yielded during the fatigue test and the strain hardening effect of the steel plates might have made the beam stiffer, thus reduction deflection and strain values.

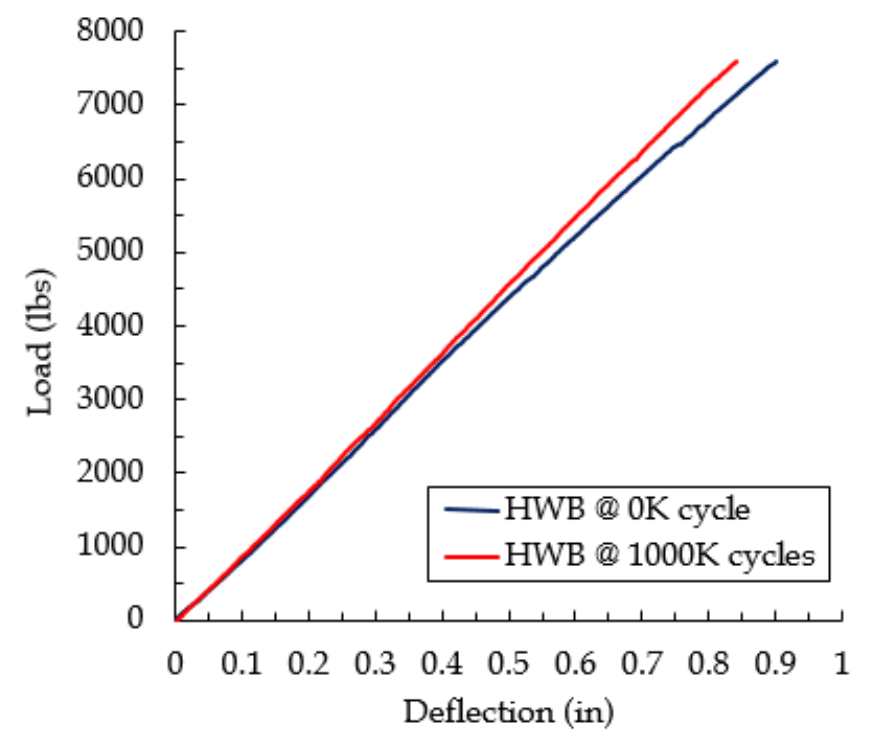

Figure 7-25. Load vs. deflection for HWB beams before and after fatigue for $1000 \mathrm{~K}$ cycles at 5.67.6 kip for 1 million cycle

Table 7-19. Test results before and after fatigue on control GFRP box-beams at load range 5.67.6 kip for 1 million cycles

\begin{tabular}{|c|c|c|c|c|c|c|c|c|}
\hline Fatigue & Load & Def. & Comp. & Ten. & \multicolumn{3}{|c|}{ GFRP shear $(\mu \varepsilon)$} & \multicolumn{3}{|c|}{ Steel shear $(\mu \varepsilon)$} \\
\cline { 5 - 9 } cycles & $($ lbs. $)$ & (in.) & strain $(\mu \varepsilon)$ & strain $(\mu \varepsilon)$ & $90^{\circ}$ & $45^{\circ}$ & $90^{\circ}$ & $45^{\circ}$ \\
\hline 0 & 7600 & 0.902 & 5006 & 4212 & 14 & 147 & 97 & 305 \\
\hline $1 \mathrm{M}$ & 7600 & 0.846 & 4882 & 3923 & 10 & 157 & 80 & 185 \\
\hline
\end{tabular}




\subsubsection{Fatigue of beams at a $\mathrm{L} / \mathrm{D}$ ratio of 4.5}

This section discusses the results of fatigue test performed on control GFRP and hybrid GFRPsteel box beam at a span of 27 inches, giving a span to depth ratio (L/D) of 4.5. At this span length, the behavior is more governed by the shear stresses. The sub-sections are populated based on the experimental testing sequence performed in the laboratory.

\subsubsection{Control GFRP Box-Beam (CB)}

The control GFRP box-beam was tested under fatigue in a 3-point bending setup at a span length of 27 inches to understand how fatigue load cycles affect the mechanical properties of GFRP boxbeams at lower span which is dominated by shear stress. The beam was fatigued at a load range of 8 kips, with a lower limit of 10 kips and an upper limit of 18 kips. The upper load limit was around $42 \%$ of the failure load. During the fatigue test, few micro-cracks were observed in the bottom tension flange near the support regions, which opened during load application. However, the cracks did not grow during the entire course of the fatigue cycles. The beam before and after fatigue showed no reduction in the stiffness values. The strain values are also within $1 \%$ difference. The deflection was reduced slightly for the beam tested after fatigue (Table 7-20). The reason was a minor depression at the GFRP bottom flange at the support locations, during initial testing which is also evident through load-deflection curve in the Fig. 7-26.

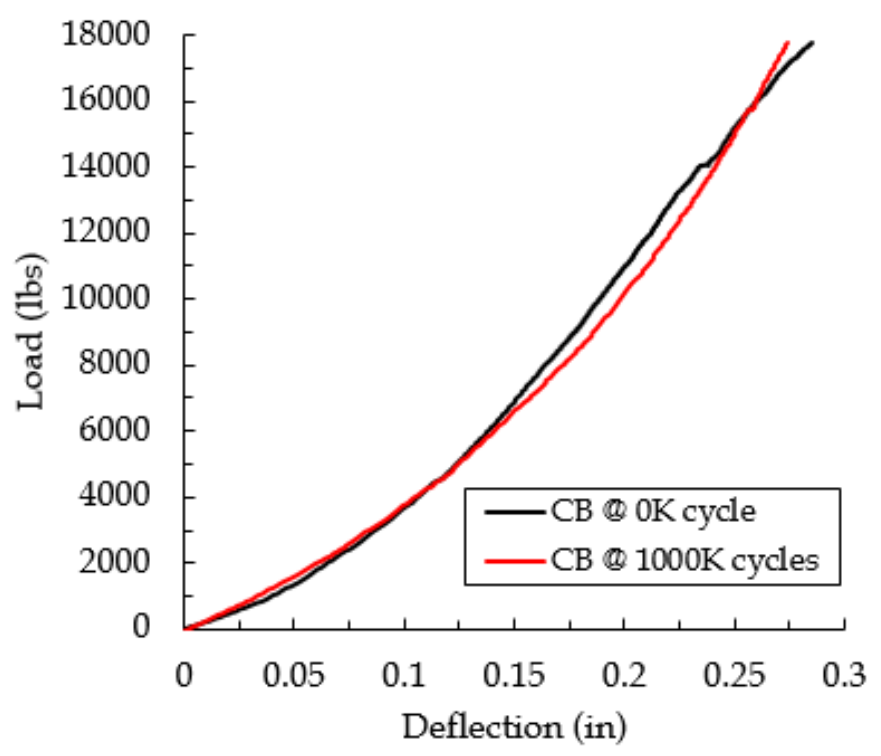

Figure 7-26. Load vs. deflection for CB beams before and after fatigue for $1000 \mathrm{~K}$ cycles at a span length of 27 inches with a load range of 10-18 kips

Table 7-20. Test results before and after fatigue on control GFRP box-beams at a span length of 27 inches with a load range of 10-18 kips for 1 million cycles

\begin{tabular}{|c|c|c|c|c|c|c|}
\hline $\begin{array}{c}\text { Fatigue } \\
\text { cycles }\end{array}$ & $\begin{array}{c}\text { Load } \\
(\text { lbs. })\end{array}$ & $\begin{array}{c}\text { Def. } \\
(\text { in. })\end{array}$ & $\begin{array}{c}\text { Comp. } \\
\text { strain }(\mu \varepsilon)\end{array}$ & $\begin{array}{c}\text { Tensile } \\
\text { strain }(\mu \varepsilon)\end{array}$ & $\begin{array}{c}\text { Shear } \\
\left(90^{\circ}\right)(\mu \varepsilon)\end{array}$ & $\begin{array}{c}\text { Shear } \\
\left(45^{\circ}\right)(\mu \varepsilon)\end{array}$ \\
\hline $0 \mathrm{~K}$ & 18000 & 0.285 & 5041 & 2928 & 1012 & -1392 \\
\hline $1000 \mathrm{~K}$ & 18000 & 0.277 & 5139 & 2905 & 798 & -1369 \\
\hline
\end{tabular}




\subsubsection{Hybrid web box-beam (HWB)}

After completing fatigue cycles on control beam at a span of 27 inches, the hybrid GFRP boxbeam (HWB) was tested under fatigue in a 3-point bending setup at a span length of 27 inches with a load range of 10-18 kips. The upper limit of the load range was about $42 \%$ of the failure load. The static testing before and after the test did not reveal any significant changes in the strain values (Fig. 7-27, Table 7-21). The deflection varied slightly because of the similar reason as mentioned for the control beam (CB), due to slight depression caused at the bottom flange over the roller support causing a slight kink in the curve. The load-deflection curve for the beam after the fatigue test looks slightly steeper than that obtained before fatigue, which might have been caused due to slight residual effects or strain hardening on the embedded steel plates. The fatigue testing of other hybrid beams at lower span was not performed as the purpose here was not to fail the beams under fatigue loads, therefore, further testing was thought to be redundant in terms of understanding the fatigue behavior.

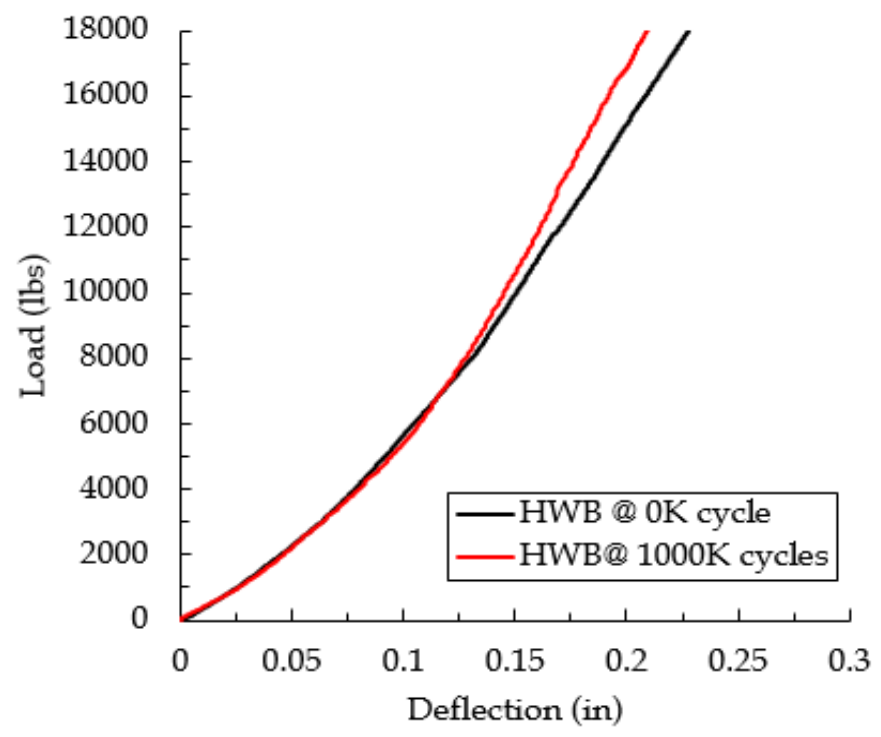

Figure 7-27. Load vs. deflection for HWB beams before and after fatigue for $1000 \mathrm{~K}$ cycles at a span length of 27 inches with a load range of 10-18 kips

Table 7-21. Test results before and after fatigue on HWB box-beams at a span of 27 inches with a load range of 10-18 kips for 1 million cycles

\begin{tabular}{|c|c|c|c|c|c|c|}
\hline $\begin{array}{c}\text { Fatigue } \\
\text { cycles }\end{array}$ & $\begin{array}{c}\text { Load } \\
(\text { lbs. })\end{array}$ & $\begin{array}{c}\text { Def. } \\
(\text { in. })\end{array}$ & $\begin{array}{c}\text { Comp. strain } \\
(\mu \varepsilon)\end{array}$ & $\begin{array}{c}\text { Tensile strain } \\
(\mu \varepsilon)\end{array}$ & $\begin{array}{c}\text { Shear steel } \\
\left(90^{\circ}\right)(\mu \varepsilon)\end{array}$ & $\begin{array}{c}\text { Shear steel } \\
\left(45^{\circ}\right)(\mu \varepsilon)\end{array}$ \\
\hline $0 \mathrm{~K}$ & 18000 & 0.228 & 4368 & 1090 & 203 & 269 \\
\hline $1000 \mathrm{~K}$ & 18000 & 0.219 & 4323 & 1026 & 197 & 258 \\
\hline
\end{tabular}

\subsection{Failure of GFRP and hybrid box-beams}

The GFRP and hybrid GFRP-steel box-beams (CB, HWB, HFB, and HAB) were tested to failure in a three-point loading configuration with simply supported boundary conditions at three different span lengths of 84,36 , and 27 inches. These span lengths were chosen to obtain flexural and shear behavior for different L/D ratios, as bending behavior is more pronounced in higher 
$\mathrm{L} / \mathrm{D}$ ratios and shear behavior is more pronounced in lower $\mathrm{L} / \mathrm{D}$ ratios (Table 7-22). The load was applied in a displacement control mode to achieve controlled elastic response with no sudden damage to the beams. As the failure modes are dependent on the span-to-depth ratios, the subsections are populated based on a span-to-depth ratio.

Table 7-22. Moment of inertias of control GFRP and hybrid box-beam sections

\begin{tabular}{|l|c|c|c|}
\hline \multicolumn{1}{|c|}{ Failed sections } & Span length (in) & L/D ratios & Note \\
\hline CB, HWB, HFB, HAB & 84 & 14.0 & Bending dominated \\
\hline CB, HAB & 36 & 6.0 & \multirow{2}{*}{ Shear dominated } \\
\hline CB, HWB, HFB, HAB & 27 & 4.5 & \\
\hline
\end{tabular}

\subsubsection{Failure under bending load at L/D ratio of 14}

The GFRP and hybrid box-beams that were failed at L/D ratio of 14 (Figs. 7-28, 7-29) are discussed within this section. The sub-sections are divided to presents results and discussions for each individual beam.

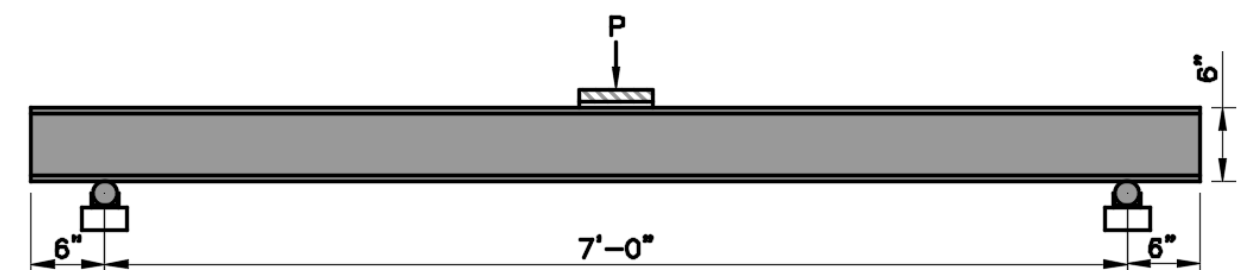

Figure 7-28. Schematic of 3-point load setup during beams failure at L/D ratio of 14

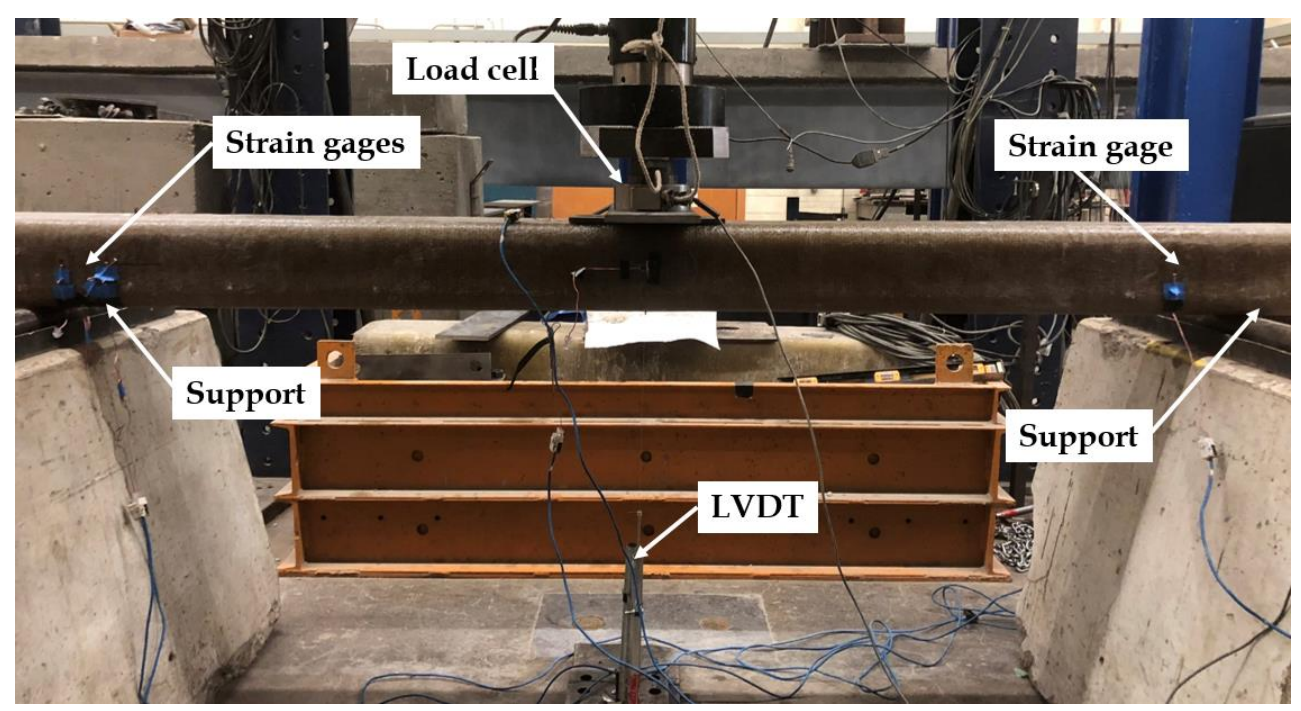

Figure 7-29. Experimental test setup showing load actuator, LVDT, strain gages during testing

\subsubsection{Control GFRP box-beam (CB)}

The control GFRP box-beams under three-point loading showed a linear load-deflection behavior until its failure at a maximum central load of $21.7 \mathrm{kip}$. The load-deflection and load-bending compressive and bending tensile strains are shown in Fig. 7-30. The shear strain computed from 
shear rosette attached at a distance of "depth of beam" from support is plotted against load values as shown in Fig. 7-31.
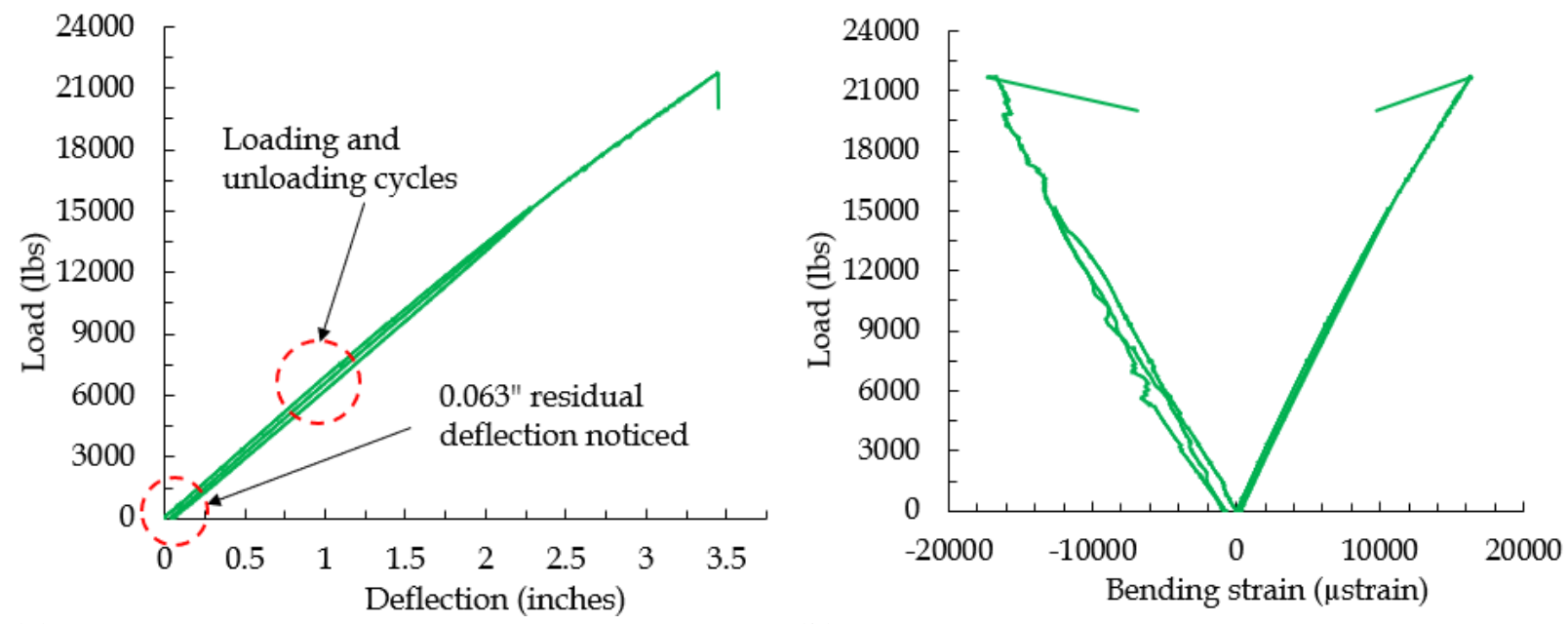

(a)

(b)

Figure 7-30. (a) Load-deflection, (b) load-strain plots for CB beams during failure

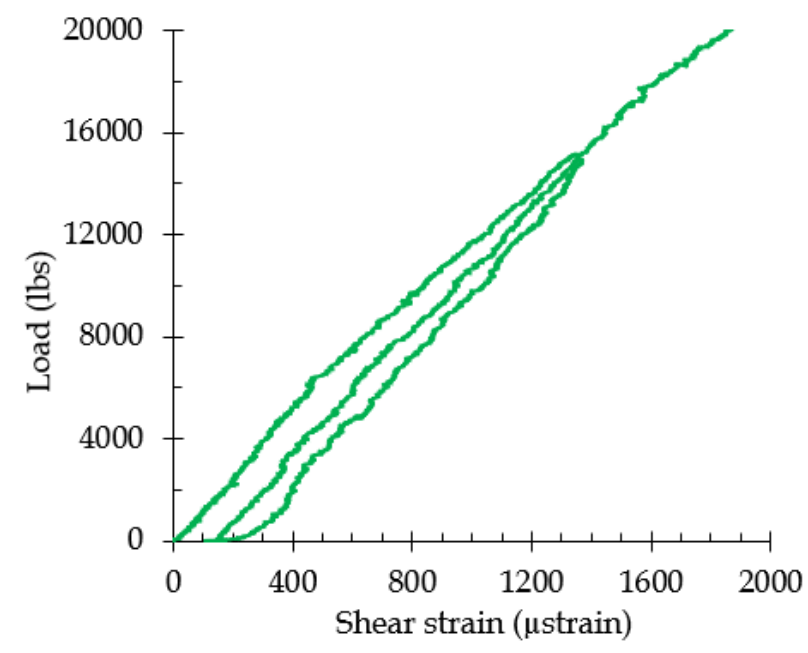

Figure 7-31. (a) Load-shear strain plot for CB beams during failure

The failure occurred in the compression flanges beneath the load point with crushing of compression flange and web buckling/crushing, followed by delamination and shear failure of the flange (Fig. 7-32a). The bottom flange of the beam had no failure and looked intact, suggesting bending stresses were higher in compression flange than that in tension flange due to local effects. The GFRP pultruded beams showed a brittle failure mode. The failure happened without any reduction in the slope of the load-deflection behavior. The load-deflection and load-strain plots were linear showing elastic failure of the beams (Fig. 7-30). 


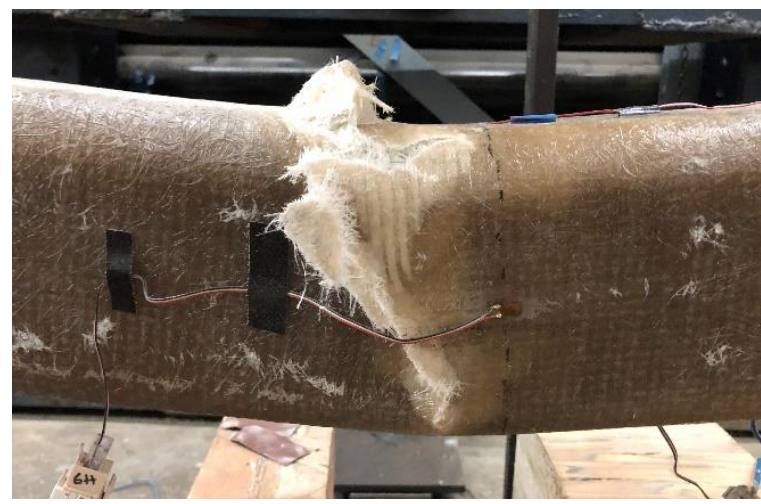

(a)

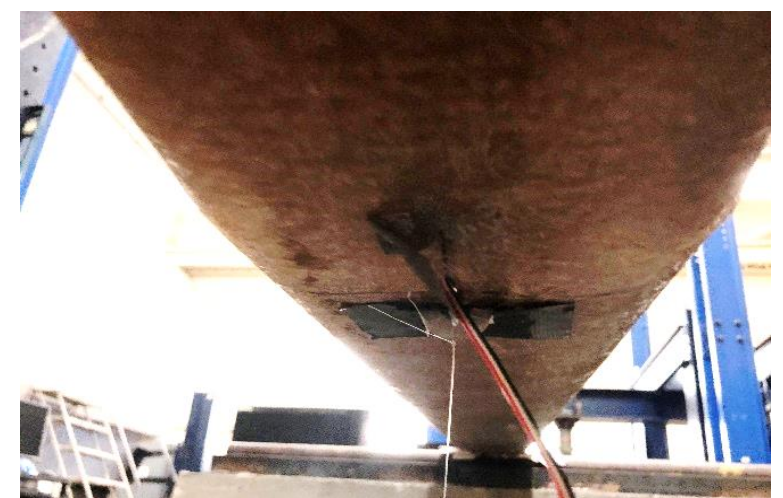

(b)

Figure 7-32. (a) Load-deflection, (b) load-strain plots for CB beams during failure

The delamination between GFRP layers in the compression flange of the beam is clearly visible in Fig. 7-33a. The beams near the support regions were not stressed enough to cause any cracking or fracture and looked intact as shown in Fig. 7-33b.

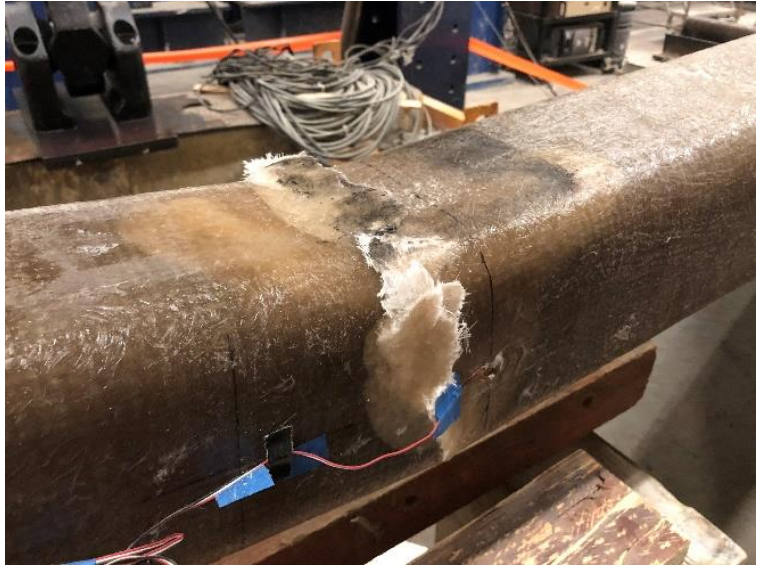

(a)

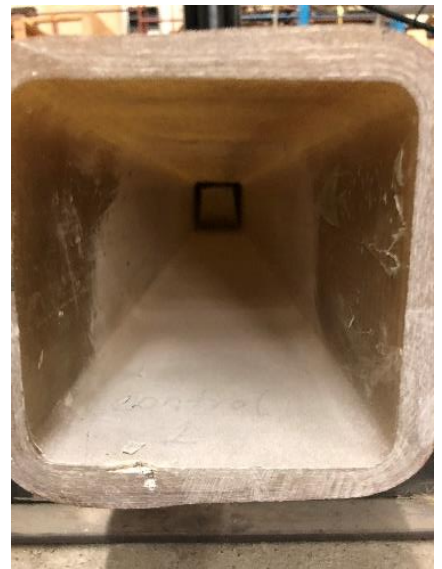

(b)

Figure 7-33. (a) Failure underneath load point, (b) no failure at supports

\subsubsection{Hybrid web box-beam (HWB)}

The hybrid web box-beam (HWB) with embedded steel plates in the webs also showed almost linear load-deflection and load-strain curve, with a slight non-linear response beyond 18,000 lbs. of central load, just before the failure, as can be noticed in the Fig. 7-34. The failure occurred at a load of 23.9 kips, with a classic bending tensile flange rupture as can be observed in Fig. 7-36. The fracture of fibers lead to matrix cracking and splitting of webs as the fracture started moving from the bottom flange towards the compression flange. The embedment of steel plates in the webs helped in distributing stresses more evenly, with no local failures observed. 


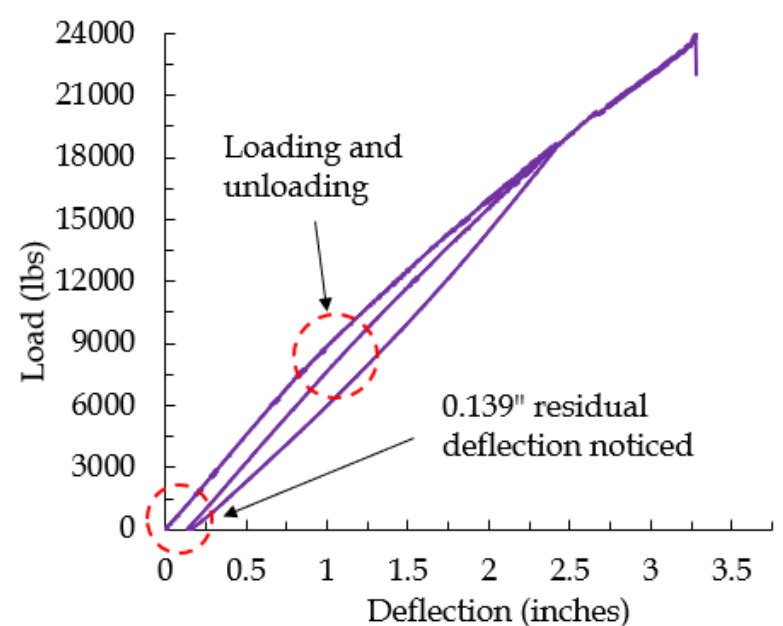

(a)

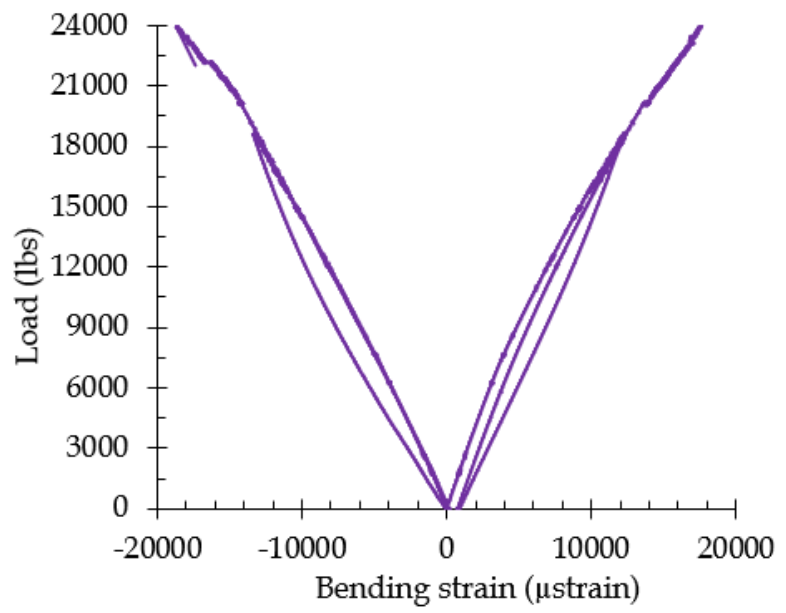

(b)

Figure 7-34. (a) Load-deflection, (b) load-strain plots for HWB beams during failure

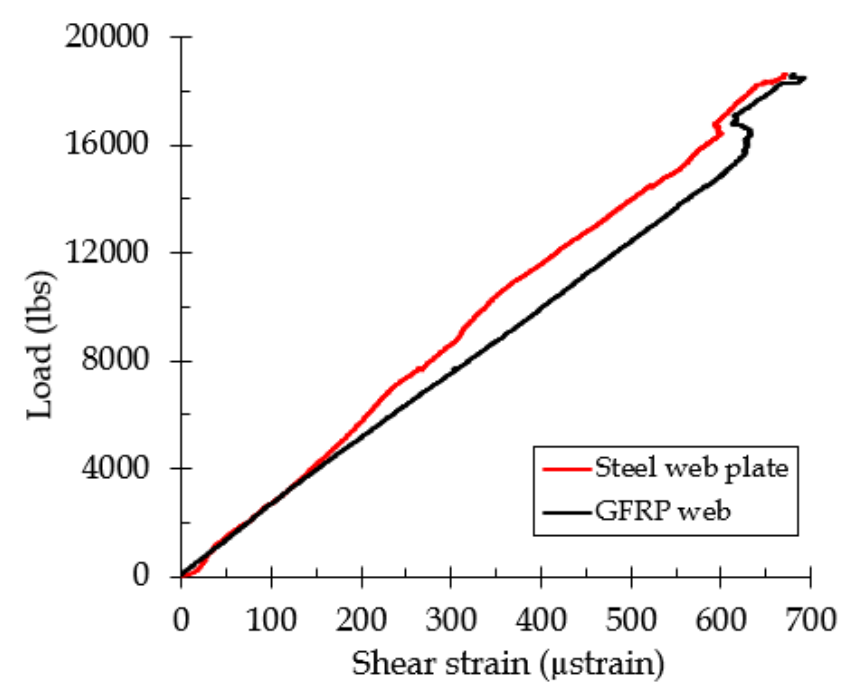

Figure 7-35. Load-shear strain plots for gage attached on GFRP and embedded steel plate (Note: strain gage after reaching 18600 lbs. load started giving erroneous values)

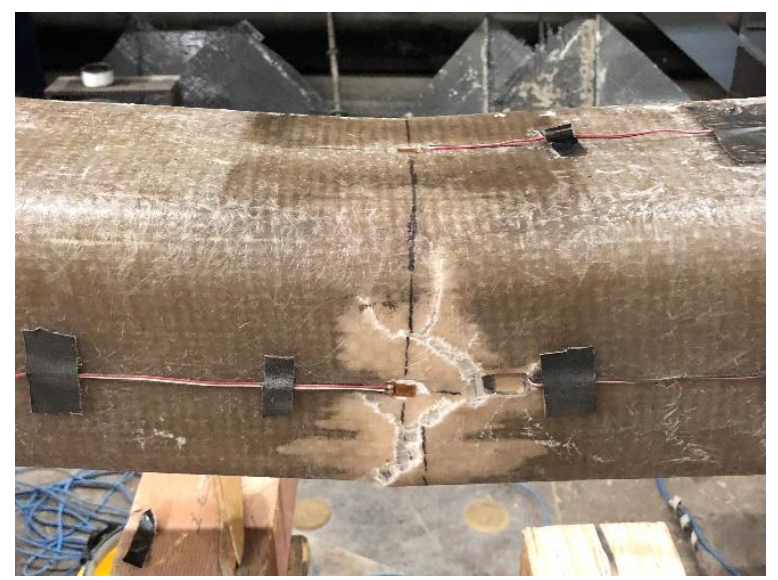

(a)

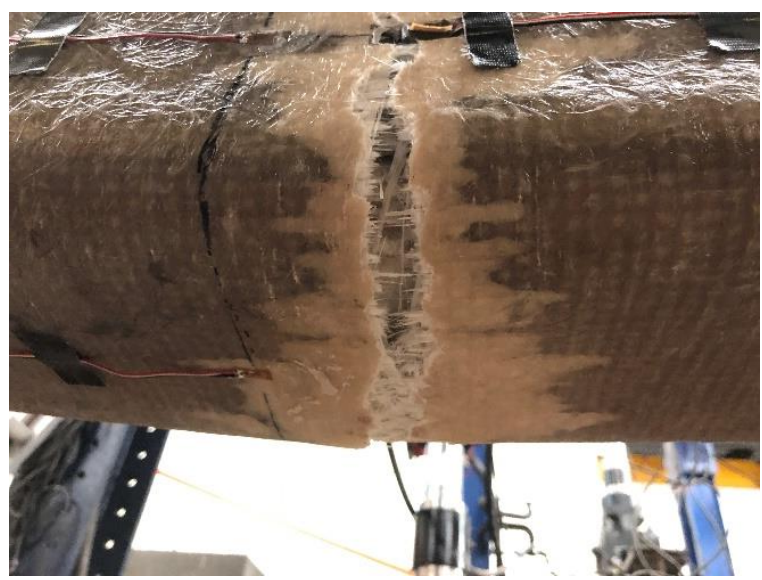

(b)

Figure 7-36. Failure of HWB, (a) tensile rupture, (b) splitting of webs with intact top flange 


\subsubsection{Hybrid flange box-beam (HFB)}

The hybrid flange box-beam (HFB) with embedded steel plates in the flanges showed a non-linear load-deflection and load-strain behavior as can be observed in Fig. 7-37. The non-linear response is due to the yielding of the embedded steel plates in compression and tension flanges. From the load-deflection plot, the behavior is linear almost up to a load value of 9000 lbs. (Fig. 7-37a). Though, steel used in the beam is A36, which typically yields at a strain of 1250 micro-strains, the load-deflection plot does not reveal yielding of plates until about the load value of $9000 \mathrm{lbs}$. However, when the load-bending strain plot was zoomed below the strain level of $2000 \mu$ strain as shown in Fig. 7-38, the curve slightly starts showing up the non-linear behavior from the yielding of steel plates at a load value of $6000 \mathrm{lbs}$.

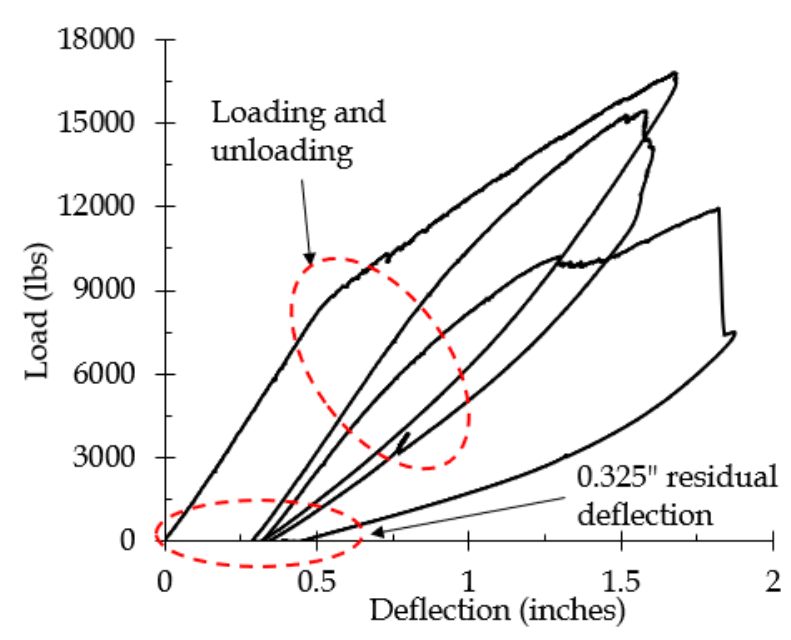

(a)

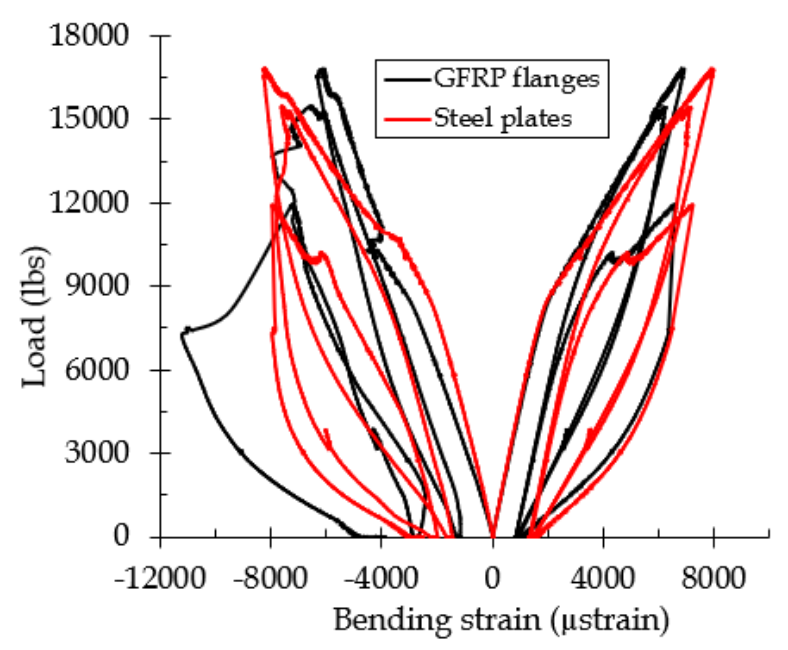

(b)

Figure 7-37. (a) Load-deflection, (b) load-strain plots for CB beams during failure

The beams were taken to multiple loading and unloading cycles before taking to failure to observe the residual strains and residual deflection. The beams showed a residual deflection of nearly $0.325^{\prime \prime}$ and a residual bending strain of about 1200 micro-strains due to plastic deformation on the steel plates. However, when the residual strains were removed from each loading and unloading curve, the load-strain curves exactly show the same stiffness and the strain levels on the outer GFRP flanges and inner embedded steel plates perfectly match with each other as can be seen in Fig. 7-39, suggesting, the existence of strain compatibility even when the beams are taken to such higher loads with strains on steel plates more than 7000 micro-strains. Similarly, the load-shear strain curve is shown in Fig. 7-40, which was linear up to failure.

The HFB beams failed at a load of 16.8 kips with a local failure that started from a compression flange buckling with punching shear failure as can be noticed in Fig. 7-41a. The compression flange-web junction at the location of loading point fractured with web buckling and web fracture (Fig. 7-41b). However, the failure was not sudden and catastrophic. The load-strain and loaddeflection data shows that the beam came back to its original position after the load was removed with some residual deflection and strains, unlike CB and HWB beams, which failed and did not come back to its original position. 


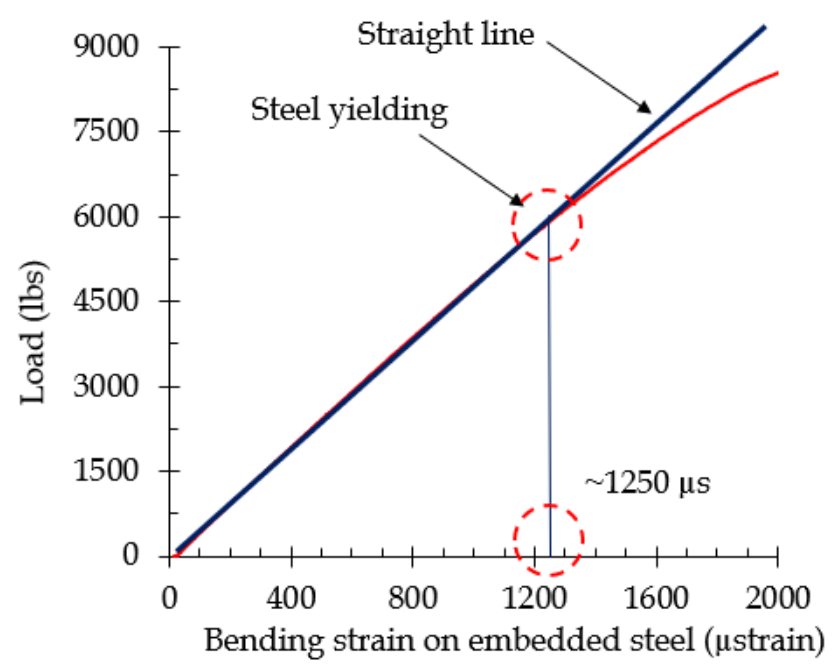

Figure 7-38. Load-bending strain plot for initial $2000 \mu$ strains on embedded steel plate (tension)

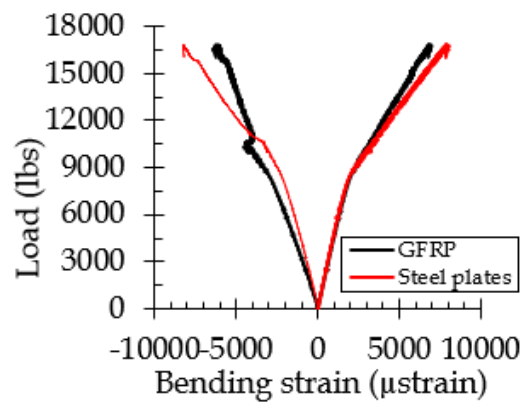

(a)

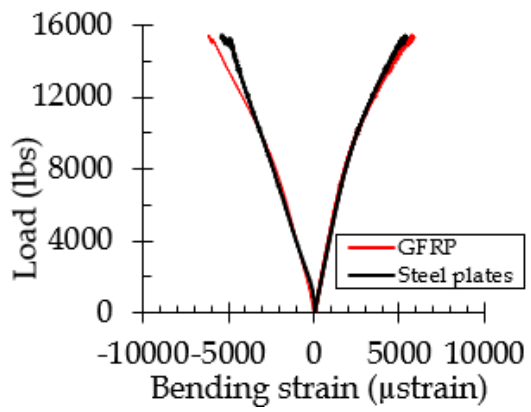

(b)

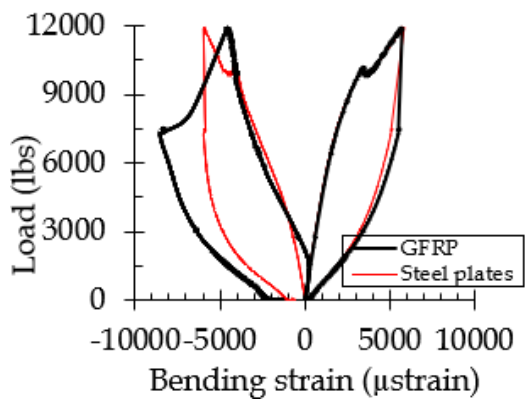

(c)

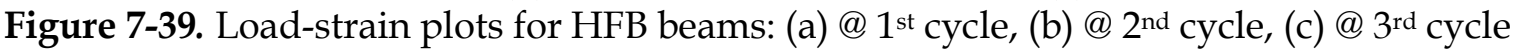

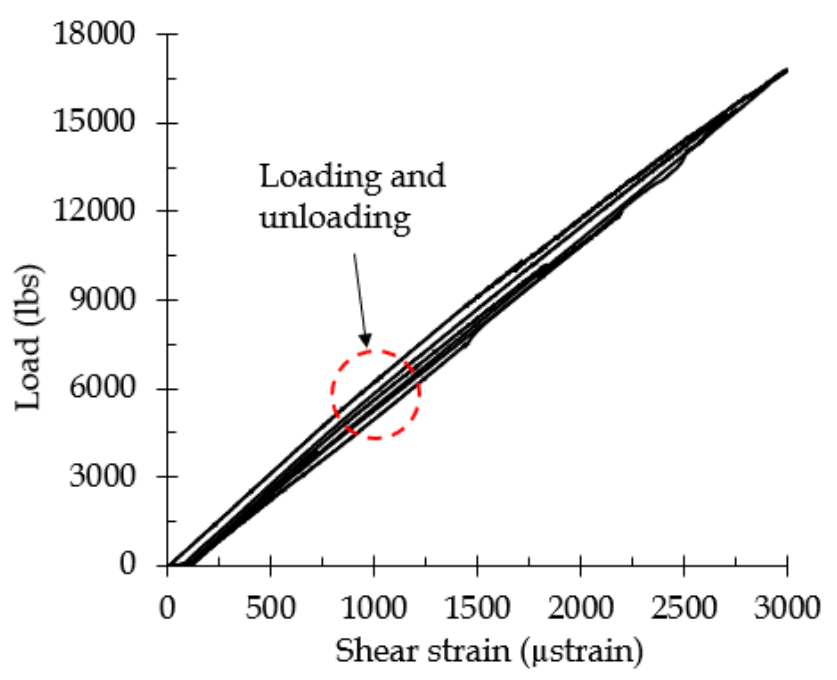

Figure 7-40. Load-shear strain plots for HFB beam (gage attached on a GFRP web) 


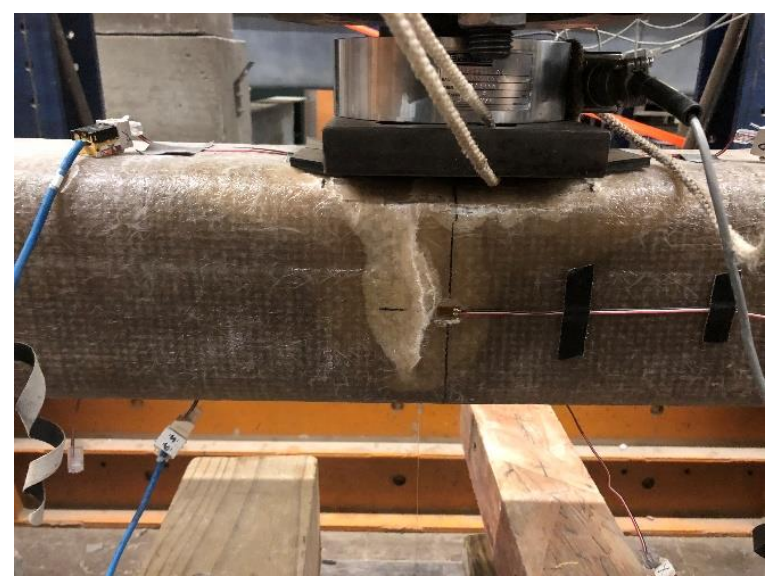

(a)

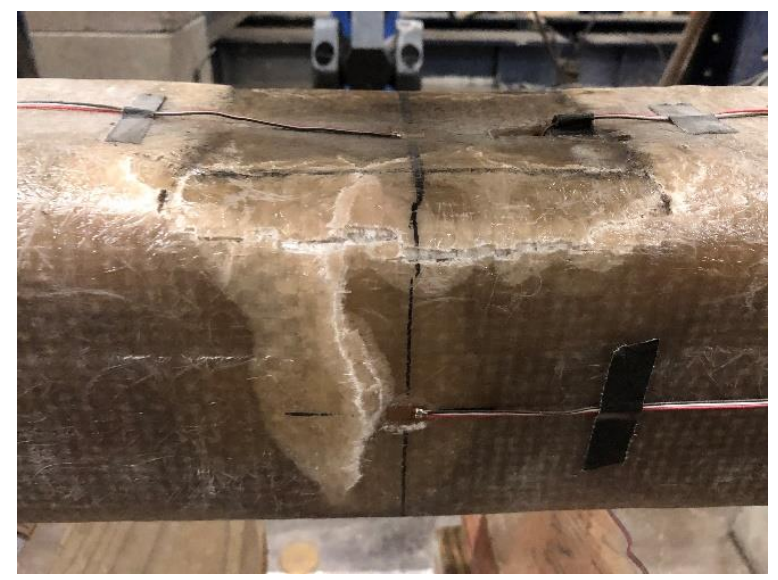

(b)

Figure 7-41. (a) Load-deflection, (b) load-strain plots for HFB beams during failure

\subsubsection{Hybrid all box-beam (HAB)}

The hybrid all-box-beam (HAB) which had embedded steel plates in the flanges and webs also showed a clear non-linear behavior when yield levels on steel plates were reached. The loaddeflection and load-bending strain plots are shown in Fig. 7-42. The beams were taken to multiple loading and unloading cycles before it failed. At each loading and unloading cycle, there was a clear residual deflection and strains, that can be observed in the Fig. 7-42. The load-shear strain plot, however, did not show non-linear response and was linear up to a failure of the beam.

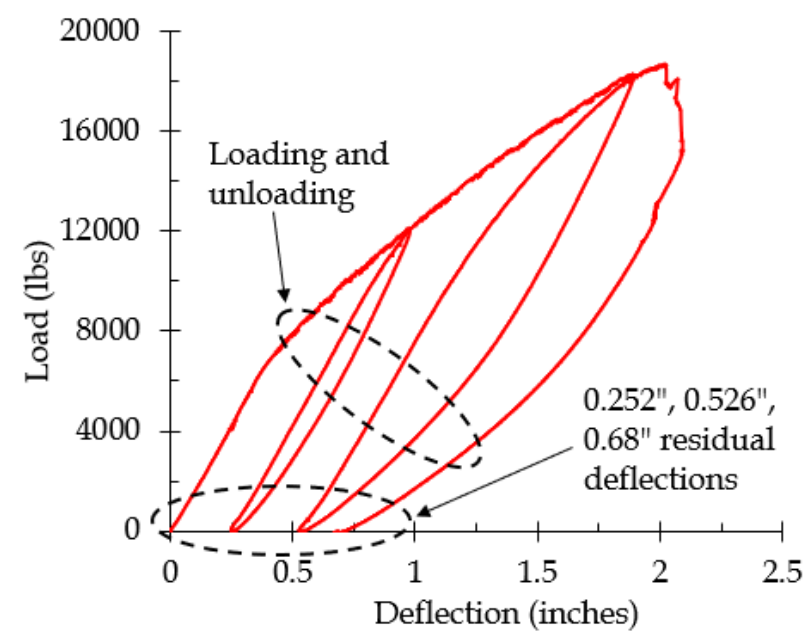

(a)

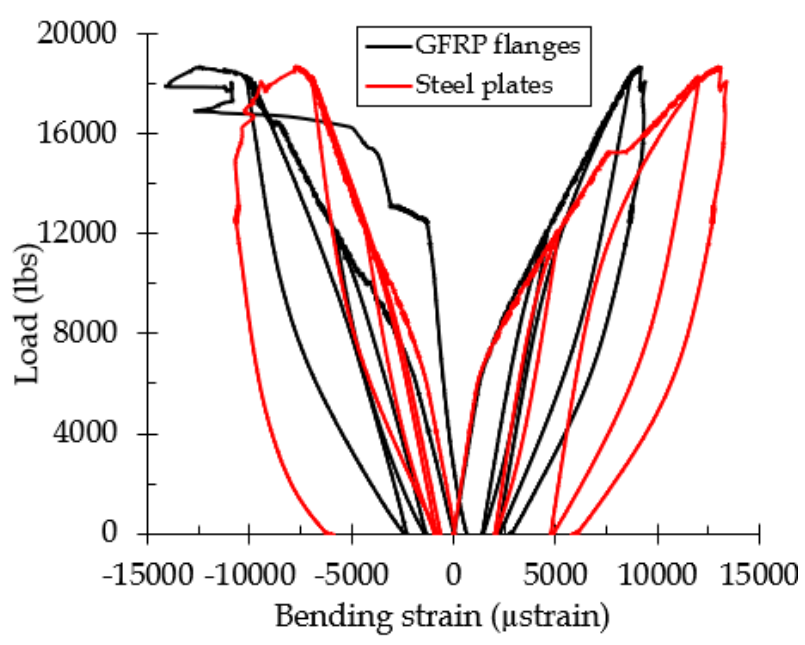

(b)

Figure 7-42. (a) Load-deflection, (b) load-strain plots for HAB beams during failure

The HAB beam failed at a load of around $17.5 \mathrm{kips}$, with a rupture in the compression flange-web junction as can be seen in the Fig. 7-44. The compression flange and tension flange were stiff and evenly distributed the stresses throughout, however, the junction of flange-web, which had no internal steel plate, was a weaker point from where the cracking started. However, the failure was not catastrophic, but a local failure and the beam came back to a straight position with a residual deflection of 0.68 " after the removal of a load. 


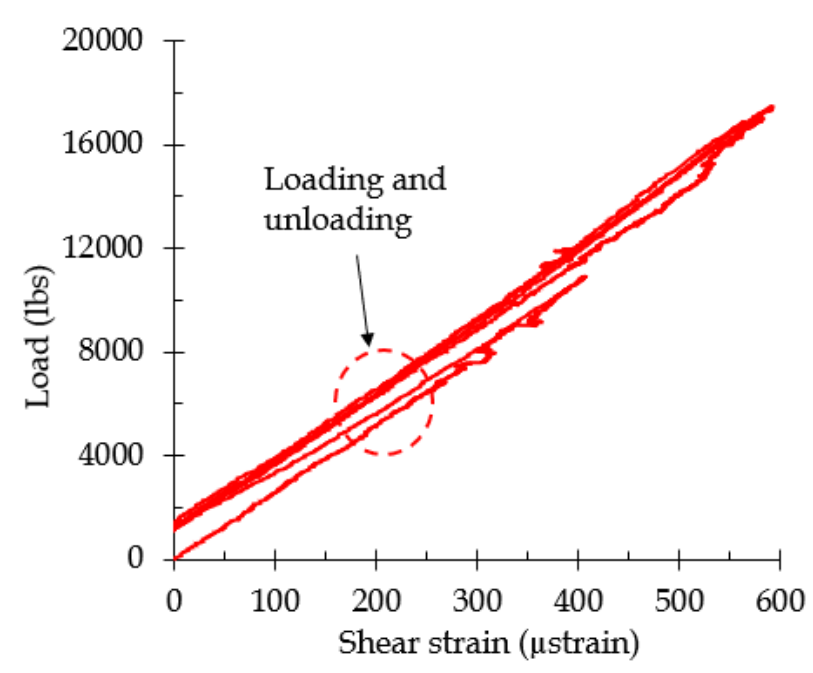

Figure 7-43. Load-shear strain plot for HAB beam (gage attached on a GFRP web)

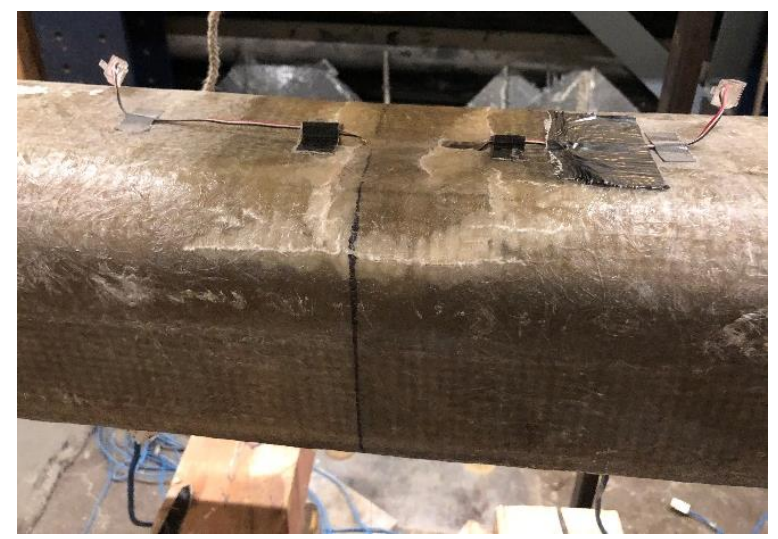

(a)

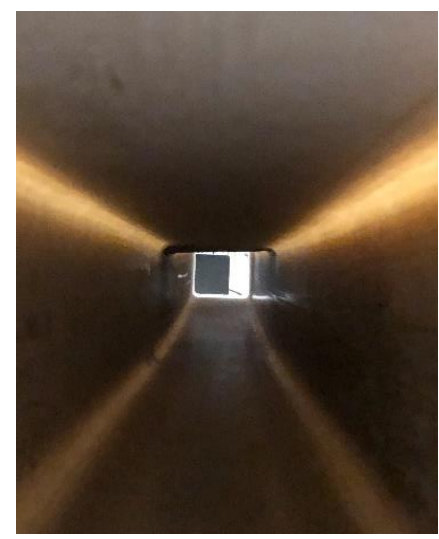

(b)

Figure 7-44. (a) Flange-web junction cracking, (b) intact flanges and webs

\subsubsection{Failure under shear at $\mathrm{L} / \mathrm{D}$ ratio of 6}

This section presents test results and discussions related to a failure of the box-beams at a shorter span length of 36 inches, giving a L/D ratio of 6 . Only two beams, CB and HAB were tested at this span length. It was anticipated that the failure under shear dominated loading would be a classic shear failure near supports, but since two of the beam categories did not result in the shear failure, it was decided to fail other beams at a lower span length of 27 inches, which will be discussed in the next section.

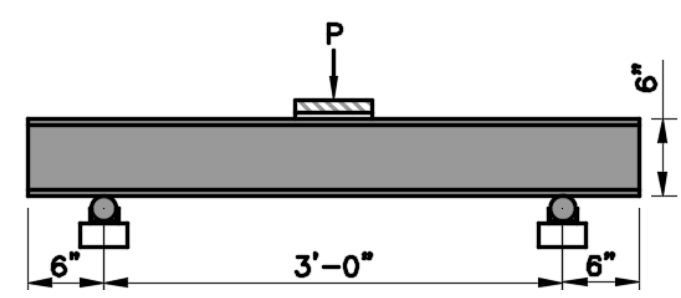

(a)

Figure 7-45. Three-point loading at L/D ratio of 6, (a) schematic, (b) real beam in laboratory

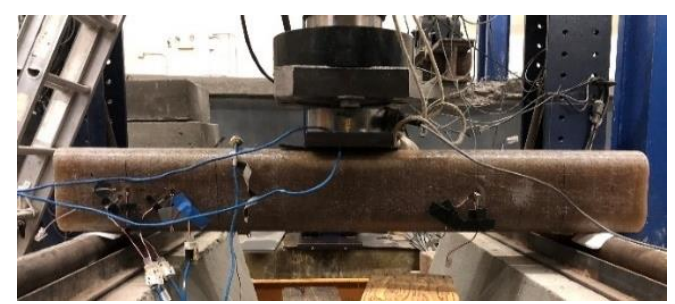

(b) 


\subsubsection{Control GFRP box-beam (CB)}

The control GFRP box-beam at a span of 36 inches failed at a central load of 33 kips. The beam displayed progressive damage accumulation, indicated by the drops in the load-deflection curves, with increasing applied load (Fig. 7-46a). The load-deflection, load-bending strain, and load-shear strain plots are shown in Fig. 7-46 and 7-47.
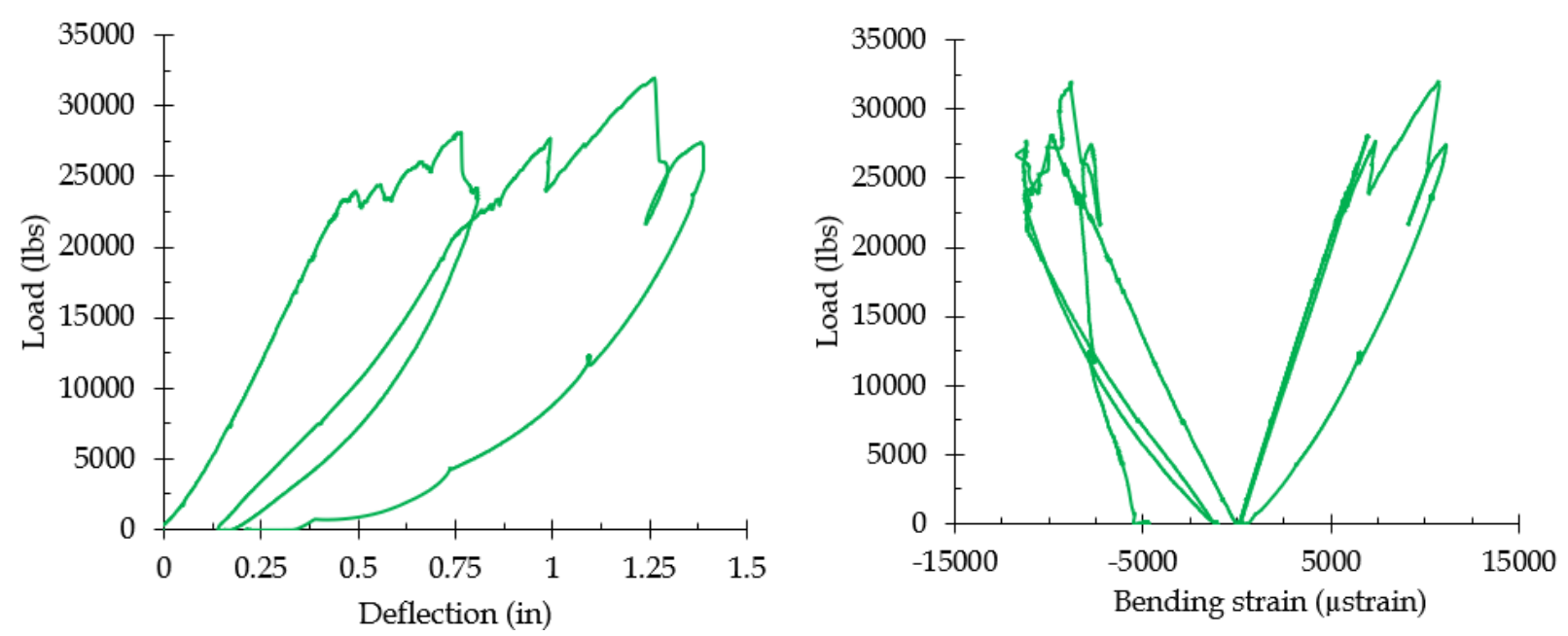

(b)

Figure 7-46. (a) Load-deflection, (b) load-strain plots for CB beams during failure

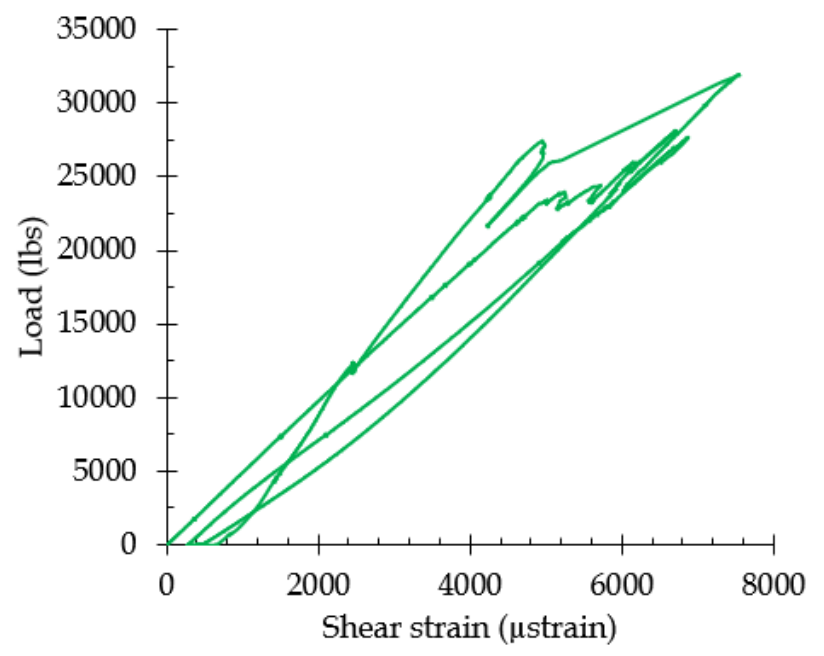

Figure 7-47. Load-shear strain plot for CB beam (gage attached on a GFRP web)

The failure occurred at the points of loading and distinct cracks developed on the top surface and at the compression flange-web junction, resulting from local buckling in the compression flange and due to higher stress concentration in the junctions (Fig. 7-48). The local cracking lead to web buckling and web crushing as can be observed in Fig. 7-48. 


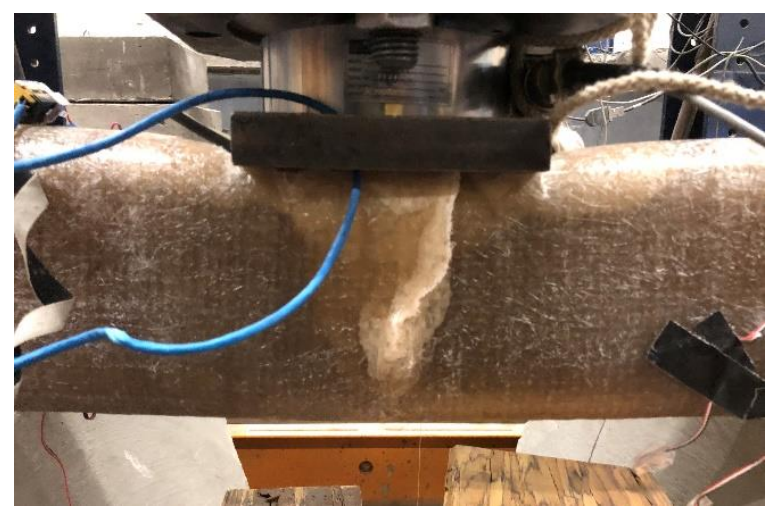

(a)

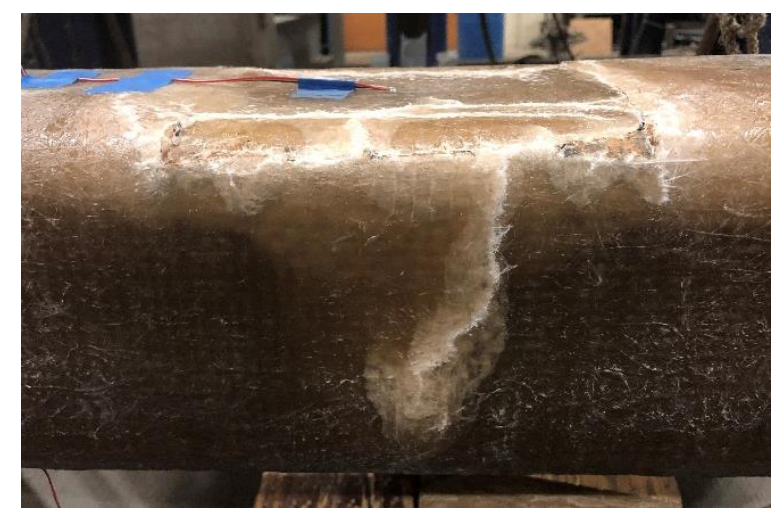

(b)

Figure 7-48. Failure on CB beams: (a) web crushing, (b) flange-web junction cracking

In addition to the failure in the compression flange, the failure also occurred at the support regions due to high bearing and shear stresses. The delamination between the GFRP layers and warping in the bottom flange were observed as can be seen in the Fig. 7-49.

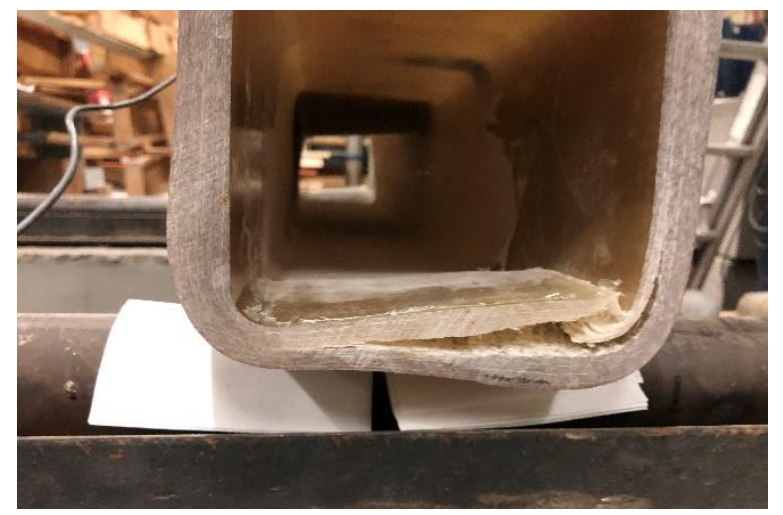

(a)

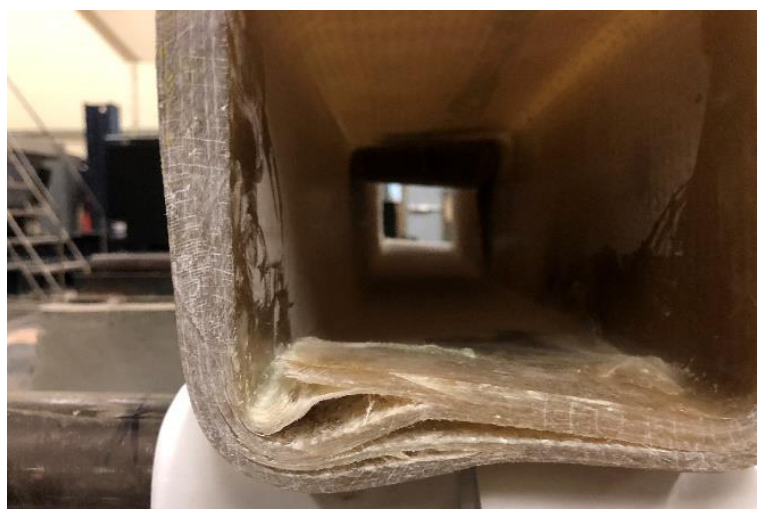

(b)

Figure 7-49. Failure at the support regions, (a) delamination, (b) delamination and warping

\subsubsection{Hybrid all-box-beam (HAB)}

The hybrid beam also displayed progressive failure as can be seen from the Fig. 7-50a. The loaddeflection, load-bending strain, and load-shear strain plots are shown in Figs. 7-50 and 7-51, respectively. The beam failed at a load of 29 kips with a maximum recorded bending strain of around $7000 \mu$ strains. The high concentrated load at the center caused the local punching failure or transverse shear failure of the compression flange, which started from the cracking in the flange-web junction and with transverse shear failure on the compression flange. The local crushing of the compression flange and flange-web junction lead to a web buckling, web cracking and web crushing. 


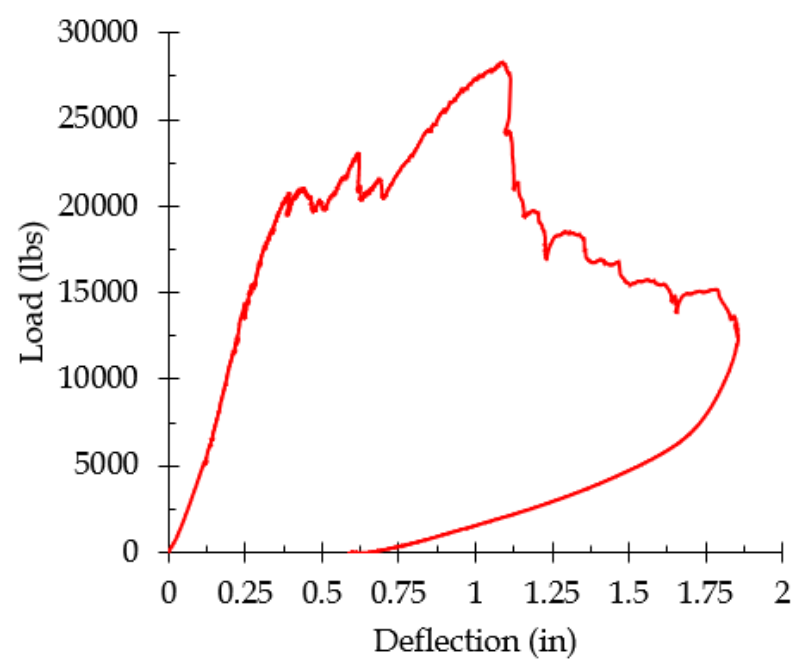

(a)

Figure 7-50. (a) Load-deflection, (b) load-strain plots for HAB beams during failure

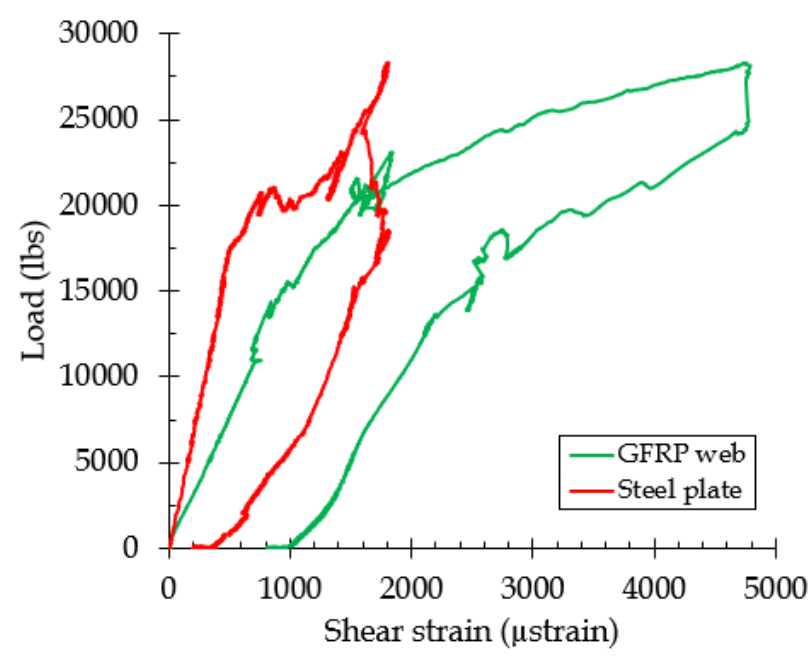

Figure 7-51. Load-shear strain plot for HAB beam (gages attached on GFRP web and steel plate)

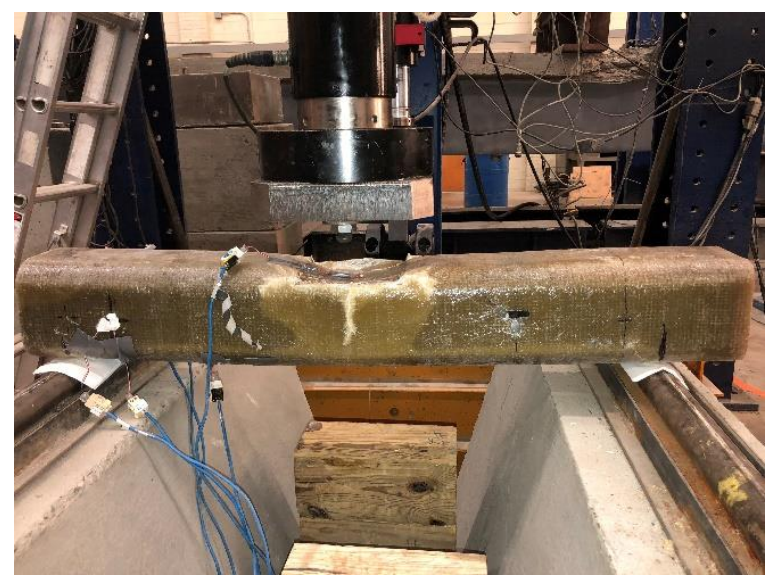

(a)

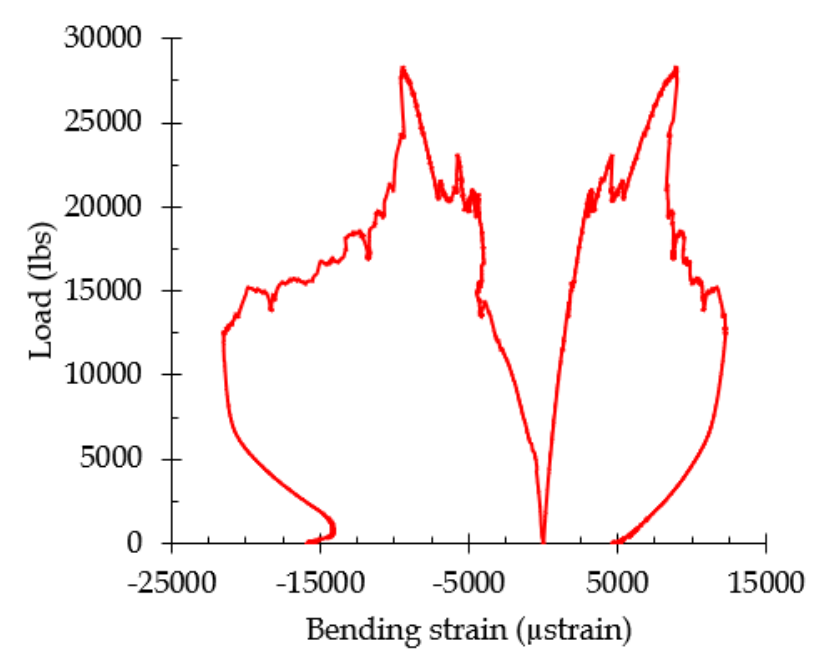

(b) 


\subsubsection{Failure under shear at $\mathrm{L} / \mathrm{D}$ ratio of 4.5}

This section presents test results and discussions related to a failure of the box-beams at a shorter span length of 27 inches, giving a L/D ratio of 4.5 as shown in Fig. 7-53, where the behavior of the beam is more dominated by shear.

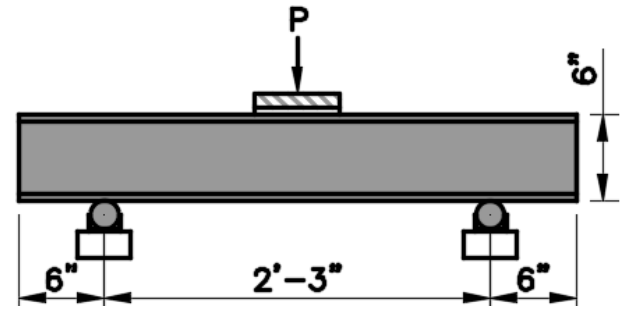

(a)

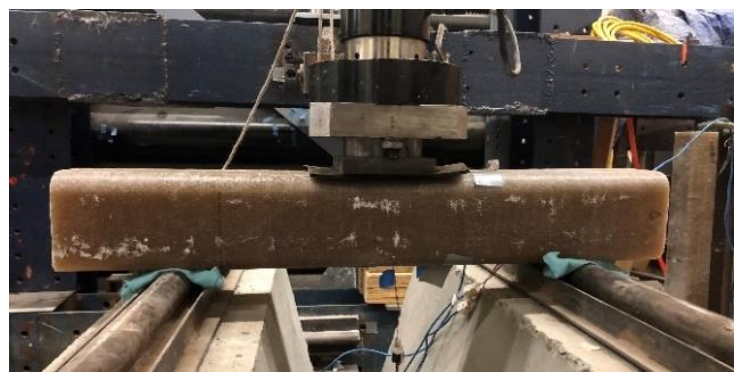

(b)

Figure 7-53. Three-point loading at L/D ratio of 4.5, (a) schematic, (b) real beam in laboratory

\subsubsection{Control GFRP box-beam (CB)}

The control GFRP beam tested at a span of 27 inches failed at a central load of 42 kips with a maximum recorded bending strain of $11,000 \mu$ strains in the compression flange. The loaddeflection, load-bending strain, and load-shear strain plots are shown in Fig. 7-54 and 7-55, respectively. The failure was similar to the beam failure tested at a span of 36 inches, with a progressive damage occurrence as can be evidenced from the load-deflection plot, where drops in the curve is visible with increasing load.

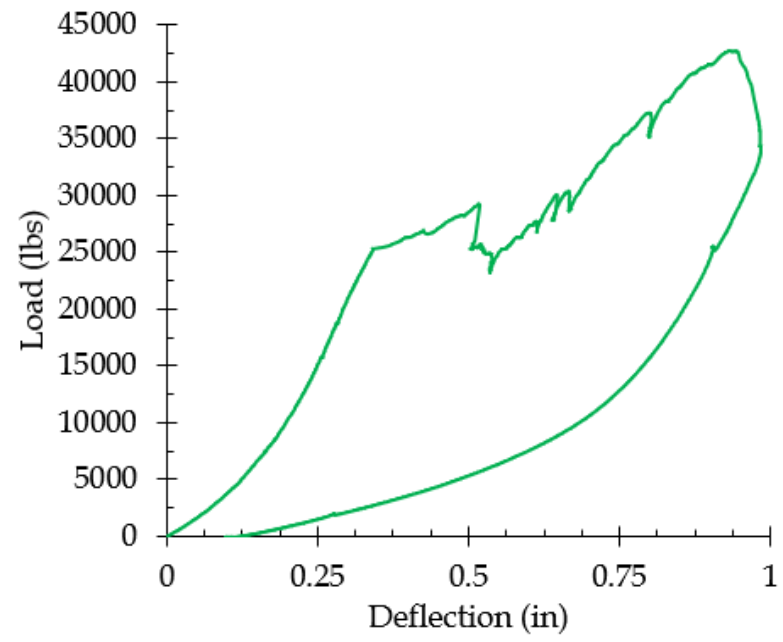

(a)

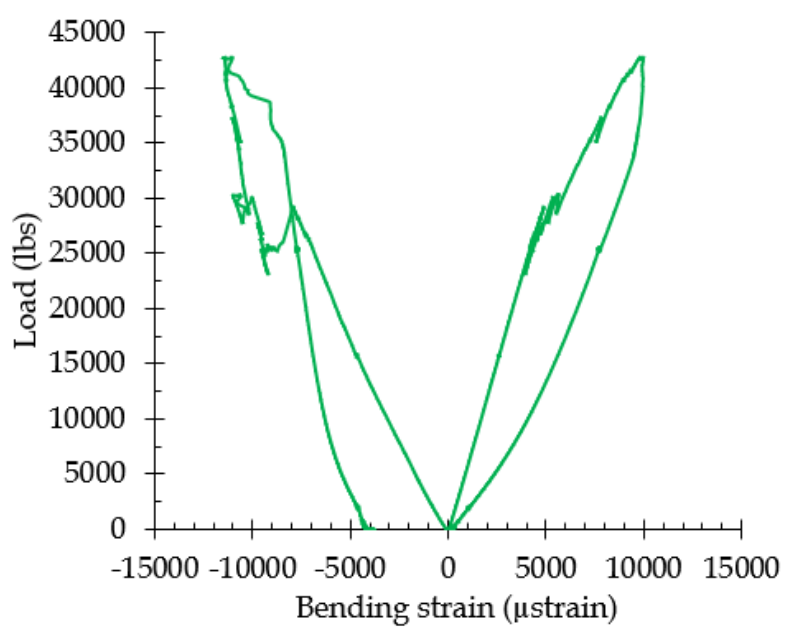

(b)

Figure 7-54. (a) Load-deflection, (b) load-strain plots for CB beams during failure 


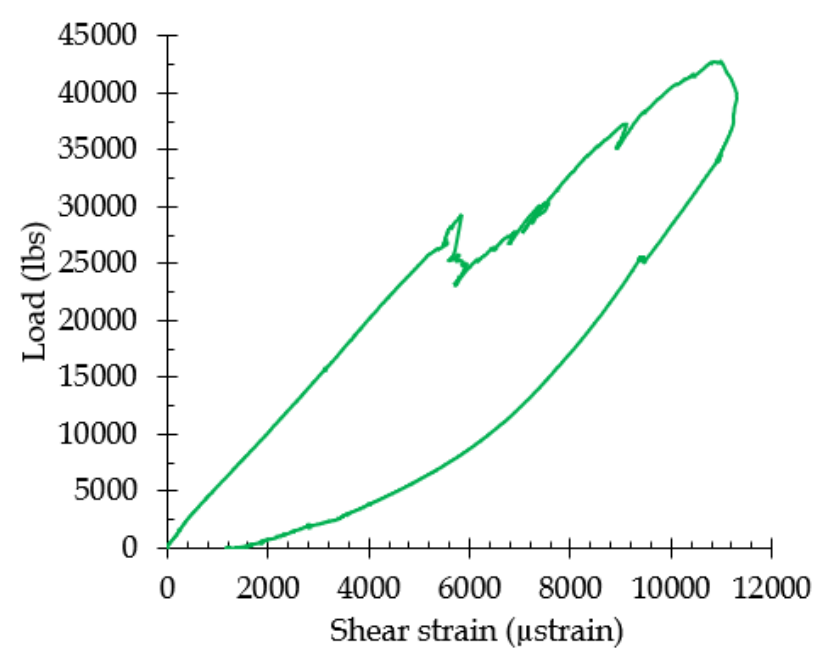

Figure 7-55. Load-shear strain plot for CB beam (gage attached on a GFRP web)

The beam failed with flange-web junction fracture leading to a punching failure/transverse shear failure of the compression flange under the load plates. The crack from the flange-web junction lead to the web buckling and web crushing (Fig. 7-56). In addition, the tension flange just at the support cracked due to high bearing compressive stress (Fig. 7-57).

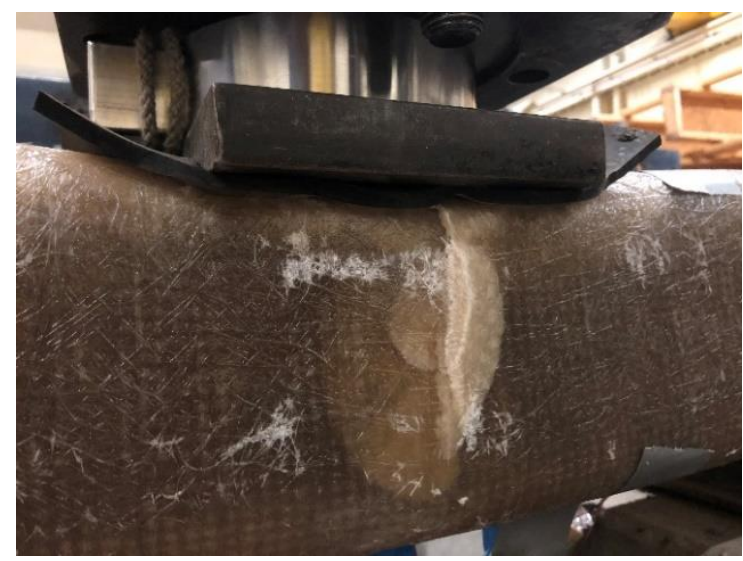

(a)

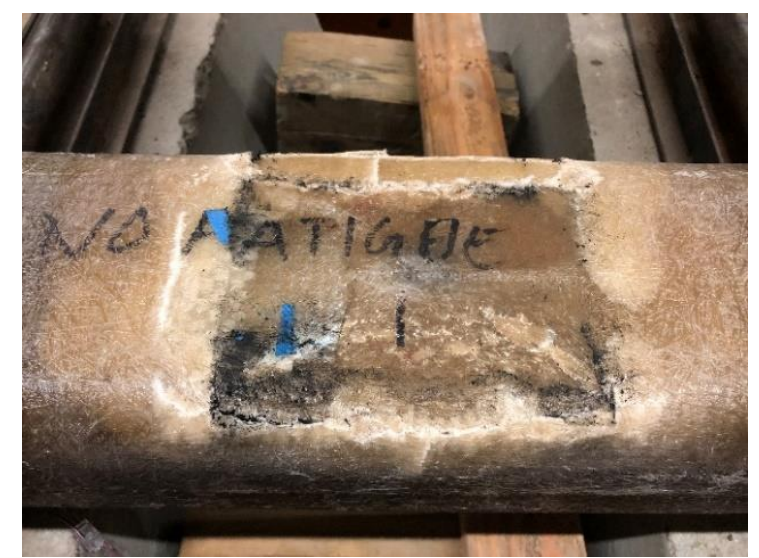

(b)

Figure 7-56. Failure on CB beams: (a) web crushing, (b) flange-web junction cracking/buckling

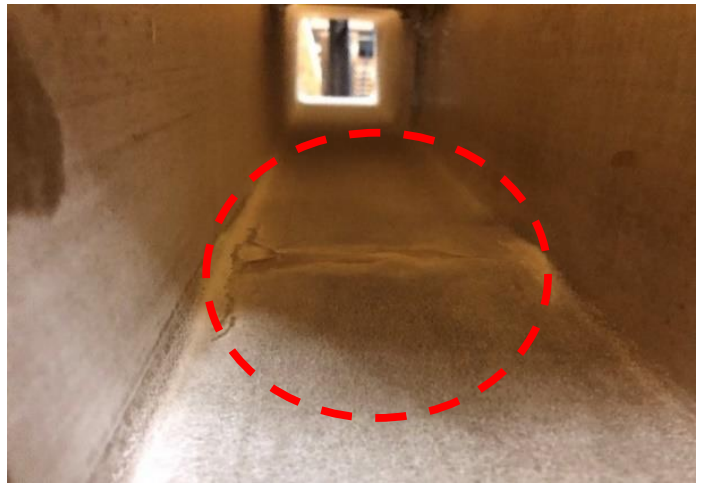

Figure 7-57. Bottom flange fracture on CB beams over the support 


\subsubsection{Hybrid web box-beam (HWB)}

The HWB tested at a span of 27 inches failed at a central load of $45 \mathrm{kips}$ with a maximum recorded bending strain of $8,000 \mu$ strains in the compression flange. The load-deflection, load-bending strain, and load-shear strain plots are shown in Fig. 7-58a, 7-58b, and 7-59y, respectively.
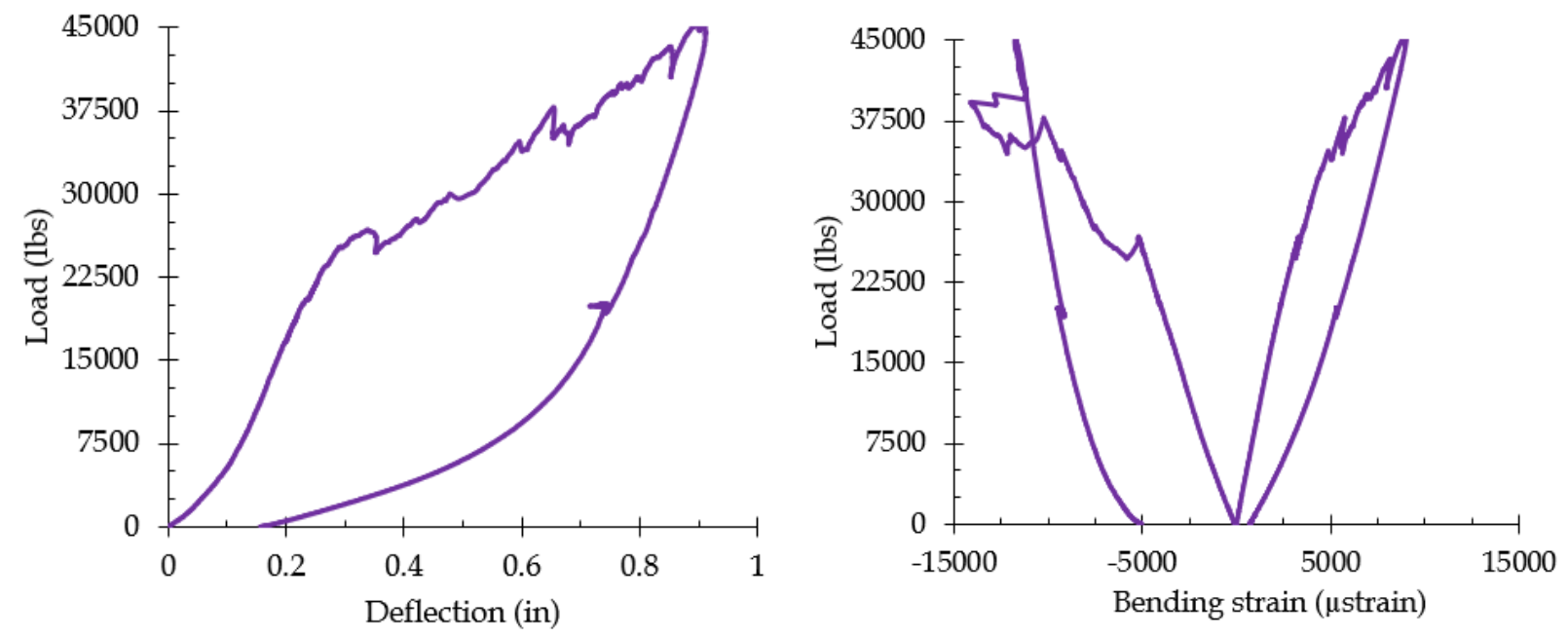

(a)

(b)

Figure 7-58. (a) Load-deflection, (b) load-strain plots for HWB beams during failure

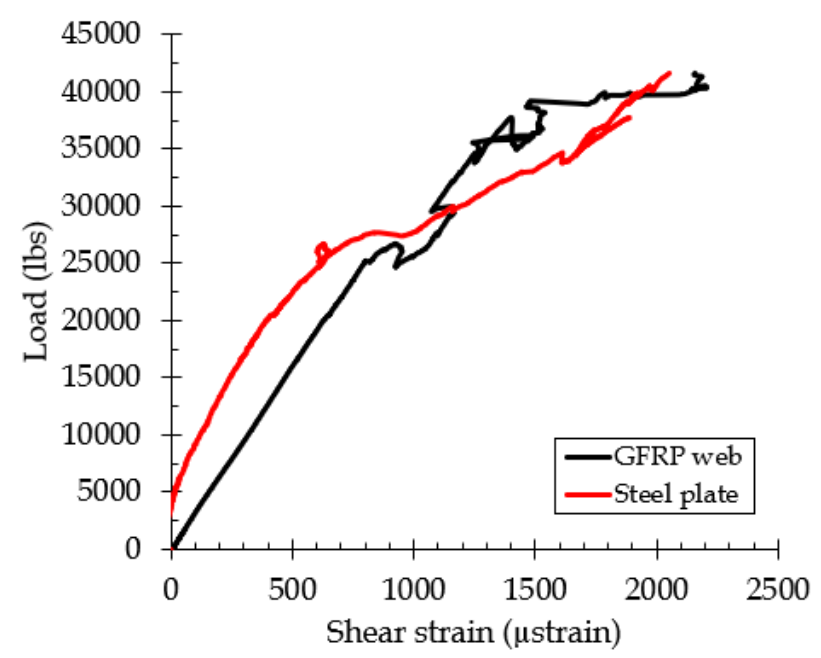

Figure 7-59. Load-shear strain plot for HWB beam (gage attached on GFRP web and steel plate)

The hybrid HWB beam failed with the compression flange-web junction failure. However, due to embedded steel plates in the web regions, the failure did not propagate into webs as can be seen in the Fig. 7-60. The webs are intact with no failure unlike the failure observed in control GFRP beams. The compression flange started showing local flange buckling due to transverse shear failure and in addition to that, the tension flange just above the support cracked and fractured due to punching shear effect (Fig. 7-61). 


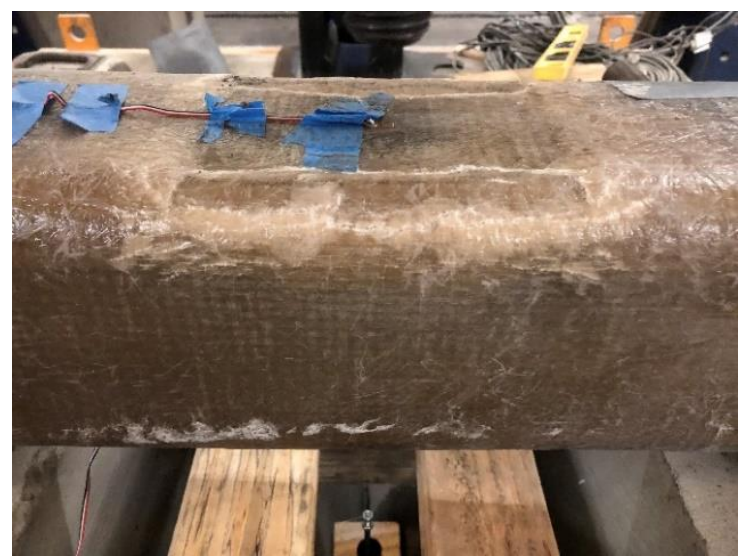

(a)

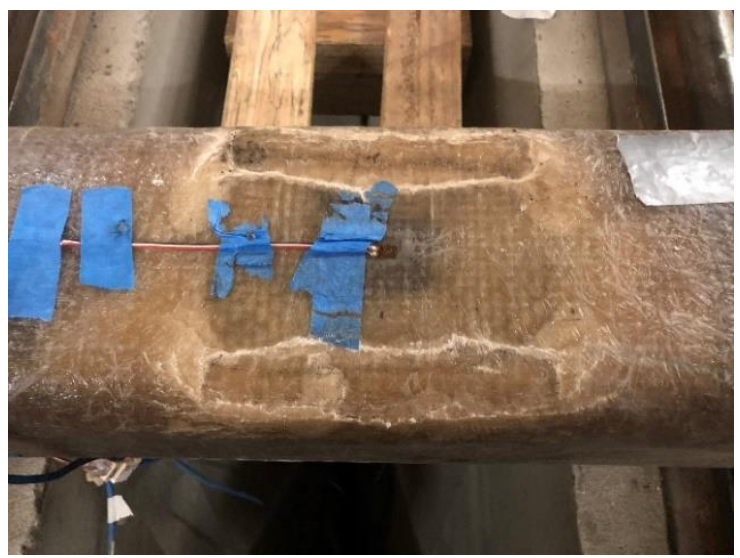

(b)

Figure 7-60. HWB beam failure: (a) flange-web junction crack, (b) transverse shear failure

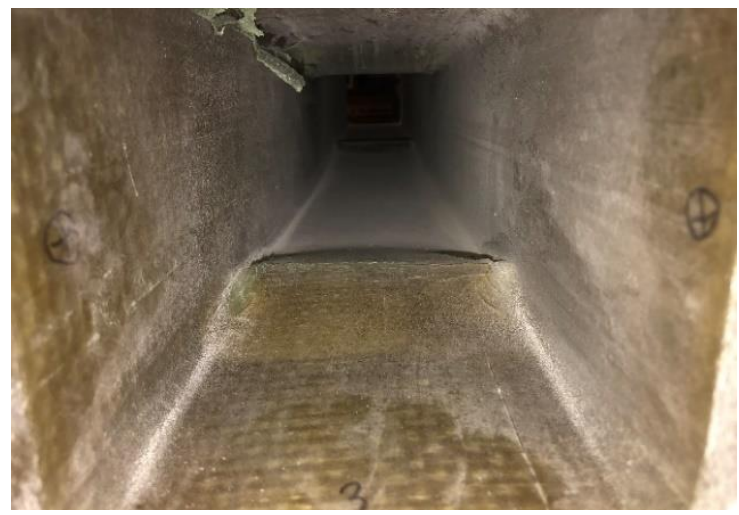

Figure 7-61. Transverse shear failure in bottom flange on HWB beam over the support

\subsubsection{Hybrid flange box-beam (HFB)}

The hybrid HFB tested at a span of 27 inches failed at a central load of 30 kips with a maximum recorded bending strain of around 5,000 $\mu$ strains in the compression flange. The load-deflection, load-bending strain, and load-shear strain plots are shown in Fig. 7-62a, 7-62b, and 7-63, respectively. The HFB beam failed with the compression flange-web junction failure, leading to transverse shear failure in the compression flange locally underneath the load plate. The junction failure also resulted in the web buckling and web cracking (Fig. 7-64). However, due to embedded steel plates in the flanges, the bottom tension flange did not show pronounced bearing failure over supports like those seen in CB and HWB beam failures previously (Fig. 7-65). 


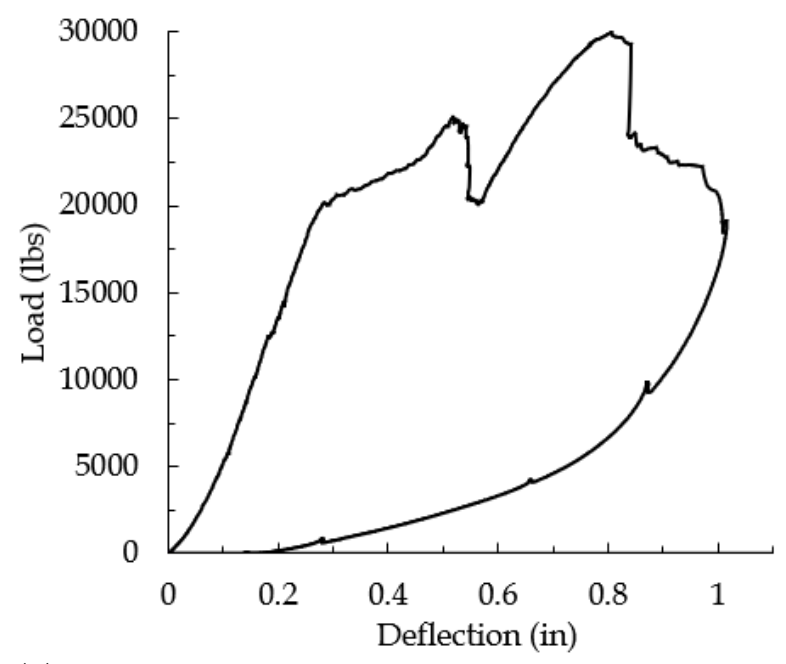

(a)

Figure 7-62. (a) Load-deflection, (b) load-strain plots for HFB beams during failure

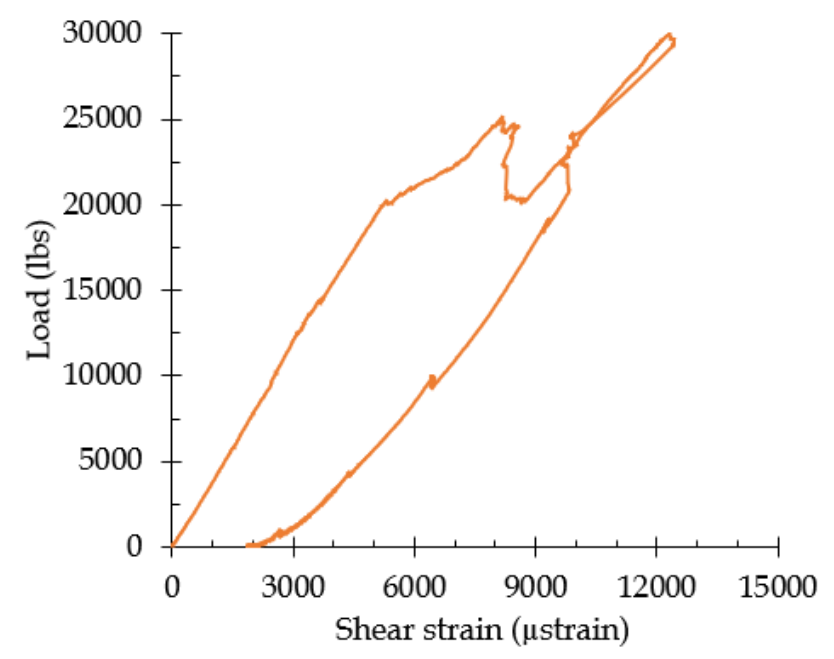

Figure 7-63. Load-shear strain plot for HFB beam (gage attached on a GFRP web)

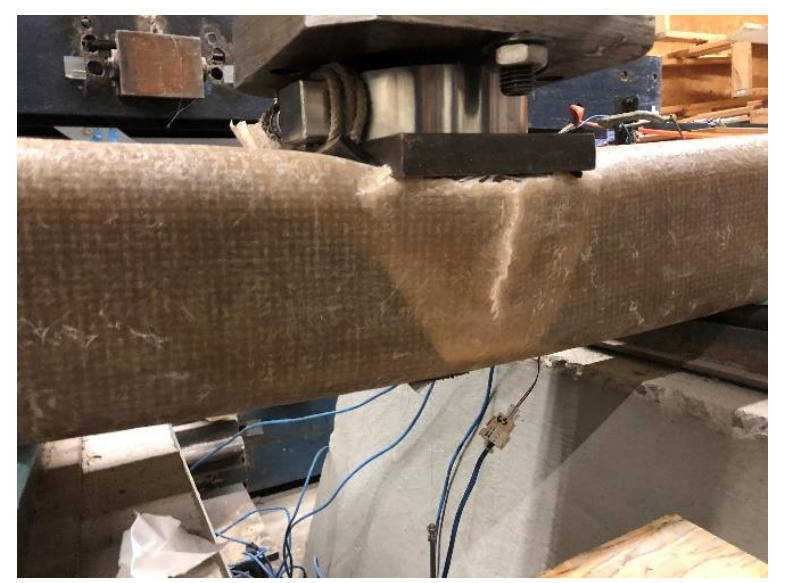

(a)

Figure 7-64. Failure in HFB beam, (a) web buckling/splitting, (b) punching shear failure

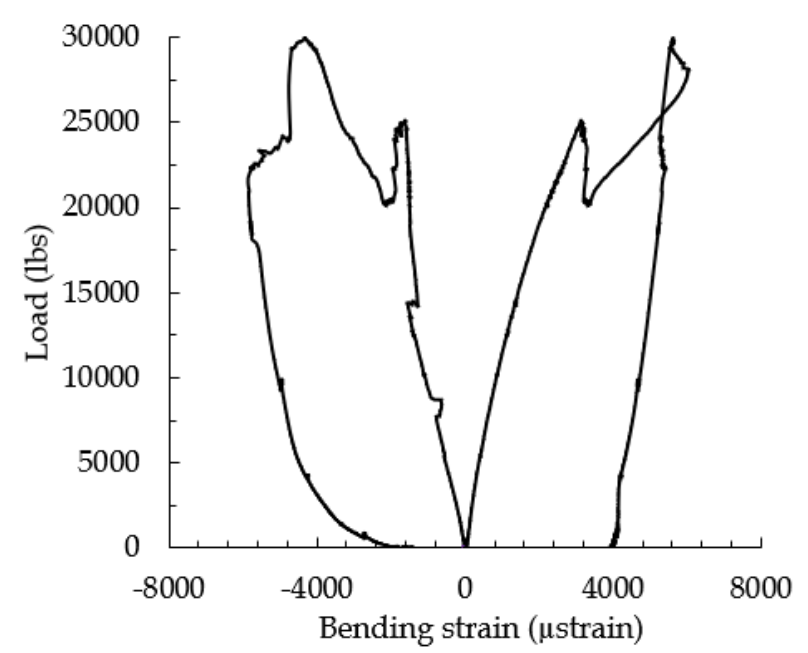

(b) 


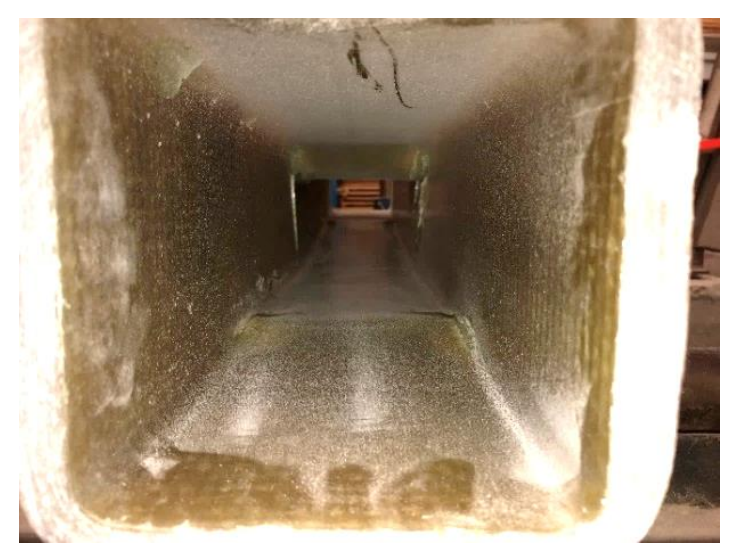

Figure 7-65. Stiffer bottom flange arresting bearing failure over the support on HFB beam

\subsubsection{Hybrid all box-beam (HAB)}

The HAB tested at a span of 27 inches failed at a central load of 42 kips with a maximum recorded bending strain of $8,000 \mu$ strains in the compression flange. The load-deflection, load-bending strain, and load-shear strain plots are shown in Fig. 7-66a, 7-66b, and 7-67, respectively

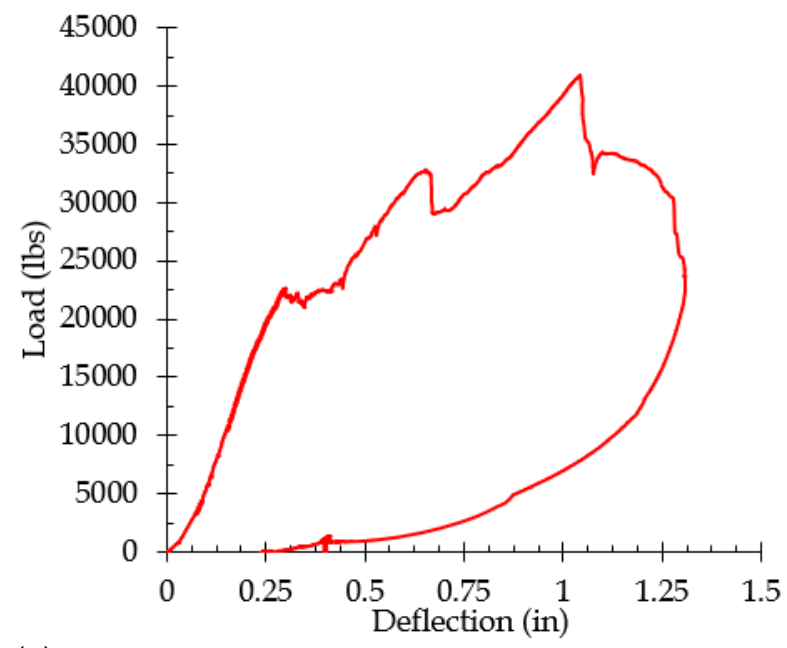

(a)

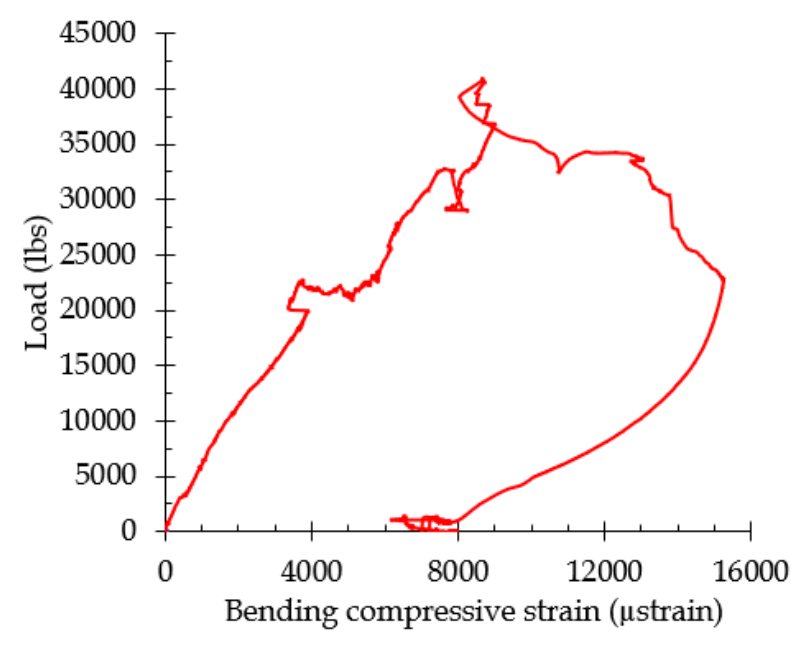

(b)

Figure 7-66. (a) Load-deflection, (b) load-strain plots for HAB beams during failure

The similar failure mode was observed in the HAB beam as it was seen in the HFB beam. It failed with the compression flange-web junction failure, leading to transverse shear failure in the compression flange and web buckling/web crushing (Fig. 7-68). The bottom flange over the supports showed cracking similar to that observed in HFB beam, but less pronounced than those observed in CB and HWB beams with no embedded steel plate in the flanges (Fig. 7-69). 


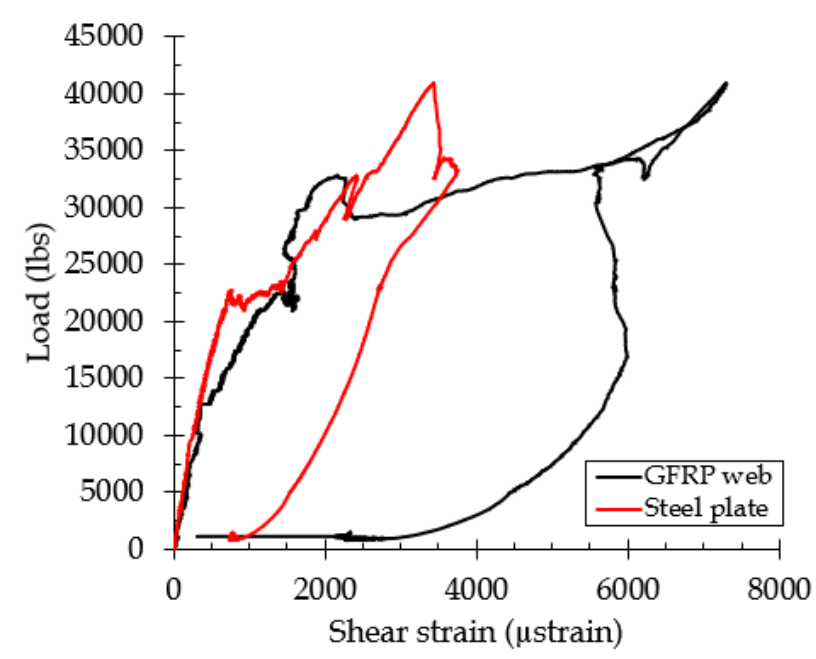

Figure 7-67. Load-shear strain plot for HAB beam (gage attached on GFRP web and steel plate)

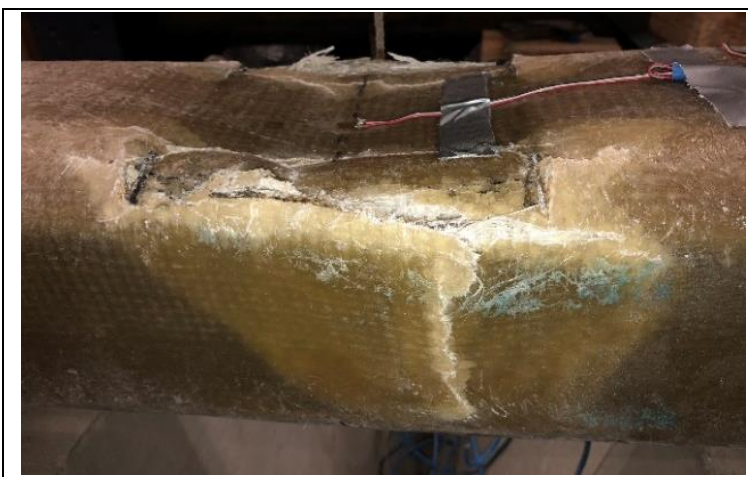

(a)

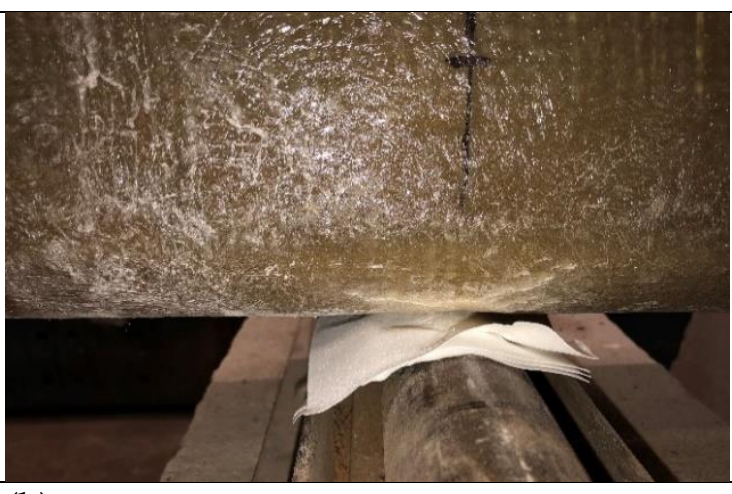

(b)

Figure 7-68. Failure in HAB beam: (a) flange-web junction crack, (b) transverse shear failure

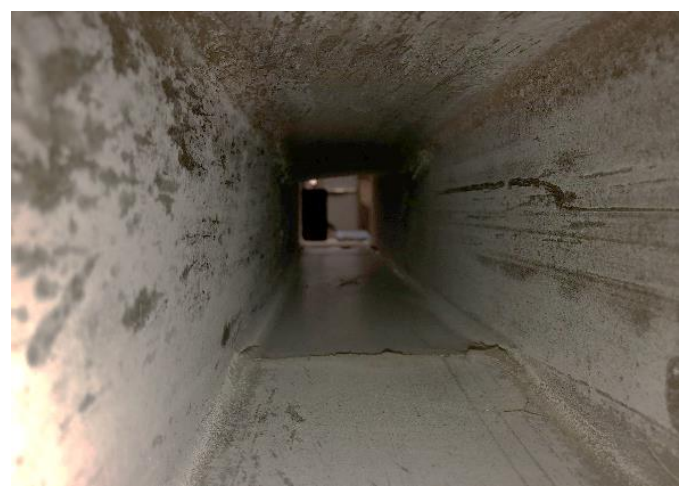

Figure 7-69. Transverse shear failure over supports on HAB beam

\subsubsection{Summary of beam failure results}

The Tables 7-23, 7-24, and 7-25 show test results from the experimental testing of GFRP and hybrid box-beams under three-point loading at three different spans as discussed before. 
Table 7-23. Ultimate load, deflection and strains on box-beams during failure at a span of $84^{\prime \prime}$

\begin{tabular}{|c|c|c|c|c|c|c|c|c|}
\hline \multirow[t]{2}{*}{ Beam } & \multirow{2}{*}{$\begin{array}{c}\text { Failure } \\
\text { load } \\
\text { (kip) }\end{array}$} & \multirow{2}{*}{$\begin{array}{c}\text { Max. } \\
\Delta \\
\text { (in) }\end{array}$} & \multicolumn{2}{|c|}{$\begin{array}{l}\text { Max. bending strain } \\
(\text { GFRP })(\mu \varepsilon)\end{array}$} & \multicolumn{2}{|c|}{$\begin{array}{l}\text { Max. bending strain } \\
\text { (steel) }(\mu \varepsilon)\end{array}$} & \multicolumn{2}{|c|}{$\begin{array}{c}\text { Shear strain } \\
(\mu \varepsilon)\end{array}$} \\
\hline & & & Compressive & Tensile & Compressive & Tensile & GFRP & Steel \\
\hline $\mathrm{CB}$ & 21.7 & 3.44 & 17,320 & 16,340 & - & - & 1,870 & - \\
\hline HWB & 23.9 & 3.14 & 18,450 & 17,570 & - & - & 892 & 892 \\
\hline HFB & 16.8 & 1.68 & 7,880 & 6,890 & 8,200 & 7,950 & 2,990 & - \\
\hline HAB & 18.6 & 1.50 & 8,220 & 8,120 & 7,670 & 8,270 & 592 & - \\
\hline
\end{tabular}

Table 7-24. Ultimate load, deflection and strains on box-beams during failure at a span of 36"

\begin{tabular}{|l|c|c|c|c|c|c|}
\hline \multirow{2}{*}{ Beam } & Failure load & Max. $\Delta$ & \multicolumn{2}{|c|}{ Max. bending strain (GFRP) $(\mu \varepsilon)$} & Shear on & Shear on \\
\cline { 4 - 5 } & (kip) & (in) & Compressive & Tensile & GFRP $(\mu \varepsilon)$ & steel $(\mu \varepsilon)$ \\
\hline CB & 31.9 & 1.12 & 12,000 & 11,100 & 7,500 & - \\
\hline HAB & 28.2 & 1.10 & 9,340 & 9,000 & 2,200 & 1,810 \\
\hline
\end{tabular}

Table 7-25. Ultimate load, deflection and strains on box-beams during failure at a span of 27"

\begin{tabular}{|l|c|c|c|c|c|c|}
\hline \multirow{2}{*}{ Beam } & Failure load & Max. $\Delta$ & \multicolumn{2}{|c|}{ Max. bending strain (GFRP) $(\mu \varepsilon)$} & Shear on & Shear on \\
\cline { 4 - 5 } & (kip) & $($ in) & Compressive & Tensile & GFRP $(\mu \varepsilon)$ & steel $(\mu \varepsilon)$ \\
\hline CB & 42.7 & 0.96 & 11,220 & 9,960 & 11,000 & - \\
\hline HWB & 45.1 & 0.91 & 11,660 & 8,980 & 2,300 & 2,150 \\
\hline HFB & 29.8 & 0.82 & 4,550 & 5,630 & 12,000 & - \\
\hline HAB & 40.9 & 1.03 & 8,500 & - & 5,600 & 3,400 \\
\hline
\end{tabular}

\subsubsection{Bending and shear stresses on box-beams at different L/D ratios}

The flexural behavior of the GFRP and hybrid box-beams were studied by computing bending stress $(\sigma)$ during the time of failure at different L/D ratios, using the Eqn. (7-13).

$$
\sigma=\frac{\mathrm{Mc}}{\mathrm{I}}=\frac{\mathrm{P}_{\max } L \mathrm{c}}{4 \mathrm{I}}
$$

Where, $\mathrm{P}_{\max }$, and $\mathrm{L}$ are the ultimate failure load at the time of failure, and span length, respectively. And, $\mathrm{c}$ and I are the depth of neutral axis and the moment of inertias of the testsections, which has been computed during stiffness characterization of the beams. Similarly, the maximum shear stress experienced by the beams at the time of failure at different span lengths is computed by using Eqn. (7-14).

$$
\tau=\frac{\mathrm{VQ}}{\mathrm{It}}=\frac{\mathrm{P}_{\mathrm{max}} \mathrm{Q}}{2 \mathrm{It}}
$$

Where, $\mathrm{V}$ is the shear force on the beam, equal to half of the failure load $\left(\mathrm{P}_{\max }\right), \mathrm{Q}$ is the first moment of area above or below the neutral axis, I is the moment of inertia of the section and $t$ is the total thickness of the webs. The bending and shear stresses experienced by the box-beams at the time of failure are shown in Table 7-26. For hybrid beams, the steel plate area was converted into equivalent GFRP area while computing their first moment of areas and moment of inertias. 
Table 7-26. Bending and shear stresses on the beams at the time of failure

\begin{tabular}{|c|c|c|c|c|c|c|}
\hline Beam & $Q\left(\mathrm{in}^{3}\right)$ & I $\left(\mathrm{in}^{4}\right)$ & Span length (in) & $P_{\max }(k i p)$ & Flexural stress (ksi) & Shear stress (ksi) \\
\hline & & & & & & \\
\hline \multirow{3}{*}{ CB } & \multirow{3}{*}{10.35} & \multirow{3}{*}{50.5} & 84 & 21.7 & 27.1 & 2.2 \\
\hline & & & 36 & 31.9 & 17.1 & 3.3 \\
\hline & & & 27 & 42.7 & 17.1 & 4.4 \\
\hline & & & & & & \\
\hline \multirow{2}{*}{ HWB } & \multirow{2}{*}{14.82} & \multirow{2}{*}{69.4} & 84 & 23.9 & 21.7 & 2.0 \\
\hline & & & 27 & 45.1 & 13.2 & 3.9 \\
\hline \multirow{3}{*}{ HFB } & \multirow{3}{*}{20.73} & \multirow{3}{*}{170.7} & & 160 & & \\
\hline & & & 84 & 16.8 & 6.5 & 1.0 \\
\hline & & & 27 & 29.8 & 3.7 & 1.8 \\
\hline \multirow{3}{*}{$\mathrm{HAB}$} & \multirow{3}{*}{25.43} & \multirow{3}{*}{195.5} & 84 & 18.6 & 6.2 & 1.0 \\
\hline & & & 36 & 28.2 & 4.1 & 1.5 \\
\hline & & & 27 & 40.9 & 4.4 & 2.1 \\
\hline
\end{tabular}

The results showed that beams tested at longer span lengths experience higher bending stresses and lower shear stresses. The shorter span beams can be subjected to higher failure load resulting in higher shear stresses. The bending stress obtained for control GFRP (CB) beam at the time of failure was $27.1 \mathrm{ksi}$. The experimental coupon level tensile and compressive strength of the GFRP laminate was $28.3 \mathrm{ksi}$ and $29.0 \mathrm{ksi}$, respectively. The control beam failed at around that stress level. The beam under bending loads not only experience flexural stress but also shear stress, and the combination of these stresses usually cause the failure. However, previous studies have found that the shear strength of the flange-web junction are much lower, and the failure of the section typically starts from the shear failure of the junctions (Muttashar et al. 2016, Turvey and Zhang 2005). For hybrid beams, the flexural and shear stresses are much lower as compared to control box-beams. This is true and also proved by the lower bending strains recorded during experimental testing. The hybrid beams experienced much lower stresses globally, however, the failure occurred due to local effects under the loading point. If the load is distributed on the top surface of the hybrid beam, they will be able to take much higher load than the control box-beams, which will be investigated during finite element analysis.

\subsubsection{Failure modes on GFRP and hybrid box-beams}

The failure modes of the GFRP and hybrid box-beams are discussed in this section by segregating failure modes on beams tested at longer and shorter span lengths.

\subsubsection{Failure at a span of 84 inches}

The control GFRP (CB) box-beams tested at a span length of 84 inches showed a brittle failure mode without showing any change in the slope of the load-deflection behavior. The loaddeflection curve was linear until the failure of the beam. The failure occurred in the compression flange beneath the load point with crushing leading to web buckling/crushing, followed by delamination and shear failure of the flange. 
The failure of hybrid (HWB) beams occurred in a bending failure with rupture/fracture of the bottom tension flange. The fracture of fibers lead to matrix cracking and crack started moving from the bottom tension flange towards the compression flange causing splitting of webs. The embedment of steel plates in the webs helped in distributing stresses more evenly, with no local failures observed. The failures of hybrid box-beams (HFB and HAB) were not sudden and catastrophic and showed a distinct bilinear load-deflection and load-strain behavior, as compared to (CB and HWB) beams as can be observed in the Figs. 7-70a and 7-70b. The HWB beam with steel plates in the webs also showed very negligible non-linearity near the failure of the beam.

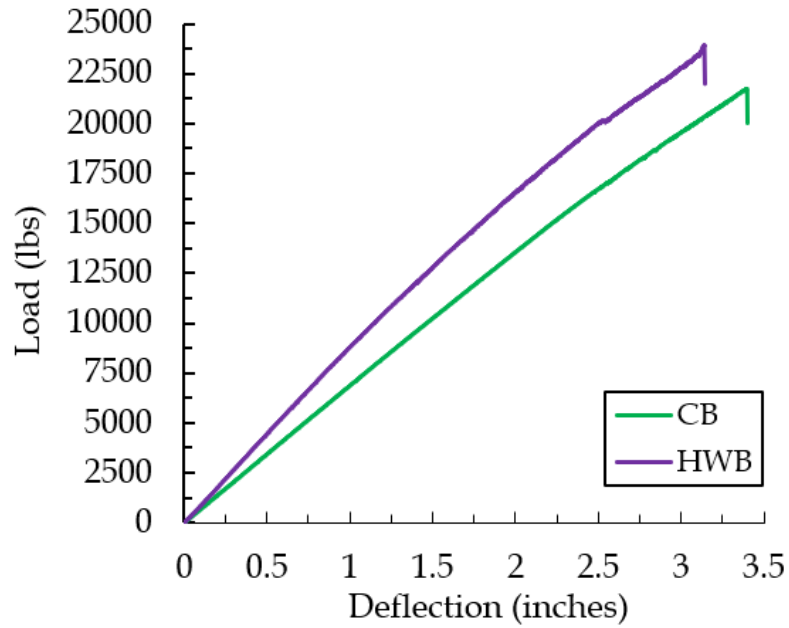

(a)

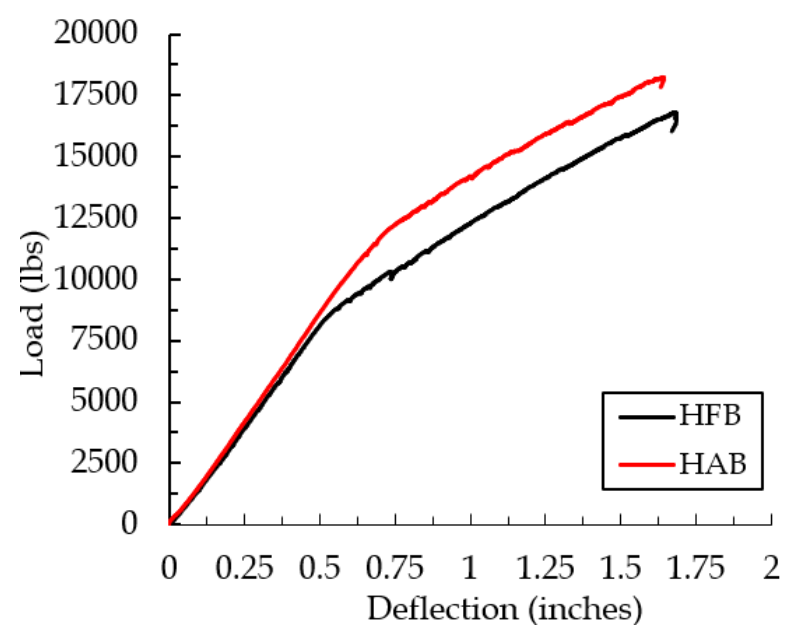

(b)

Figure 7-70. Load vs. deflection for box-beams up to failure at a span of 84 in., (a) CB and HWB (b) HFB and HAB

The HFB beams failed with a compression flange-web junction crack at the loading point causing local transverse shear failure of the compression flange, leading to local web buckling/web fracture. However, the HAB beam did not show any other failure modes except a rupture in the compression flange-web junction. The addition of steel plates inside the section definitely helped in distributing stresses in larger areas away from the loading point.

\subsubsection{Failure at a span of 36 and 27 inches}

The failures on both GFRP and hybrid beams tested at lower span lengths of 36 and 27 inches were progressive in nature where beams showed non-linear load-deflection behavior due to crushing of the web-flange corners at the loading points, resulting a load transfer to webs, which continued to carry the load until the final failure of the beam. The failures of control beams (CB) at both span lengths of 36 and 27 inches were similar. The failure occurred at the loading points that started with a flange-web junction fracture leading to a punching shear failure/transverse shear failure of the compression flange under the load plates. The cracking lead to web buckling/web crushing. In addition, the failure occurred at the support regions due to high bearing and shear stresses. The delamination between the GFRP layers and warping in the bottom flange were also observed.

The hybrid HWB beam failed with the compression flange-web junction failure, but the cracking did not propagate into webs as was observed in control beams. However, the compression flange at the loading point showed local transverse shear failure. In addition, the bottom flange just 
above the support cracked/fractured due to high bearing stresses. On HFB and HAB beams, the similar failure modes were observed. The hybrid beams failed with a compression flange-web junction failure, leading to transverse shear failure in the compression flange and web buckling/ crushing. The bottom flange over the supports on both beams showed transverse shear failure due to high bearing stresses, however, the fracture on HFB beam was more pronounced than that appeared on HAB beam. In conclusion, the failure on all beams (GFRP and hybrids) at a span length of 27 inches, were similar in nature. The failures were progressive in nature with several drops in load-deflection curve after a point when local failures in compression flange were observed (Fig. 7-71).

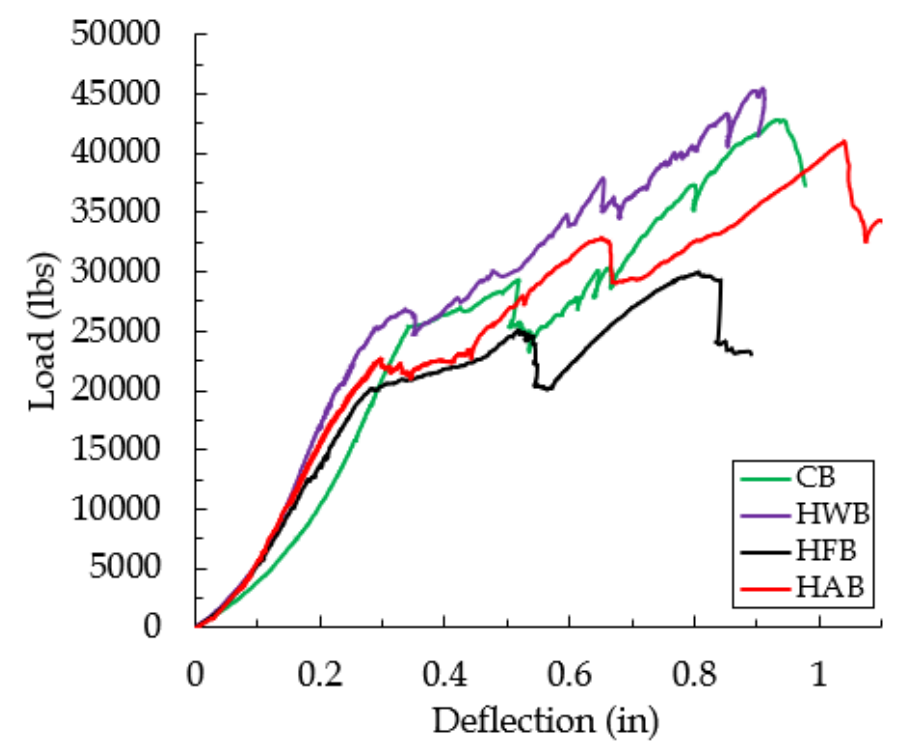

Figure 7-71. Load vs. deflection for box-beams up to failure at a span of 27 in.

\subsection{Serviceability limits on beams}

In the design of building and bridge structures, there are two limit states to check, one strength limit state which controls the safety of the structure and the other is serviceability limit states which defines the functional performance of the structure (AISC, 2017). The serviceability limit states are due to excessive deformations or deflections that affect the appearance or use of the structure. This limit states may also include excessive vibrations or local damage (i.e. buckling, cracking).

According to International Building Code, it stipulates that the structural system and member should have adequate stiffness to limit deflections and lateral drift. The deflection of structural members in the buildings as per International Building Code (IBC) and American Concrete Institute (ACI) shall not exceed the values shown in the Table 7-27 and 7-28, respectively.

Similarly, American Association of State Highway and Transportation Officials (ASHTO) has a maximum live load deflection limit of L/360 for the bridge structural members carrying only pedestrian loads, while the maximum deflection limit of L/1000 is more common for bridges carrying both vehicles and pedestrian loads. In general, bridge structural members should satisfy the live load deflection limit of L/800. 
Table 7-27. Deflection limits based on IBC, 2018

\begin{tabular}{|l|c|c|}
\hline \multicolumn{1}{|c|}{ CONSTRUCTION } & $L$ & Sor $w^{f}$ \\
\hline Roof members: $^{\text {e }}$ & & \\
$\quad$ Supporting plaster ceiling & $1 / 360$ & $1 / 360$ \\
Supporting nonplaster ceiling & $1 / 240$ & $1 / 240$ \\
Not supporting ceiling & $1 / 180$ & $1 / 180$ \\
\hline Floor members & $1 / 360$ & - \\
\hline Exterior walls and interior partitions: & & \\
With brittle finishes & - & $1 / 240$ \\
With flexible finishes & - & $1 / 120$ \\
\hline
\end{tabular}

Table 7-28. Deflection limits based on ACI-318

\begin{tabular}{|l|l|c|}
\hline Type of member & Deflection to be considered & Deflection limit \\
\hline $\begin{array}{l}\text { Flat roofs not supporting or attached to } \\
\text { nonstructural elements likely to be damaged by } \\
\text { large deflection }\end{array}$ & Immediate deflection due to live load (L) & $\ell / 180$ \\
\hline $\begin{array}{l}\text { Floors not supporting or attached to } \\
\text { nonstructural elements likely to be damaged by } \\
\text { large deflections }\end{array}$ & Immediate deflection due to live load (L) & $\ell / 360$ \\
\hline $\begin{array}{l}\text { Roof or floor construction supporting or } \\
\text { attached to nonstructural elements likely to be } \\
\text { damaged by large deflections }\end{array}$ & $\begin{array}{l}\text { That part of the total deflection occurring } \\
\text { after attachment of nonstructural } \\
\text { elements (sum of long-term deflection } \\
\text { due to all sustained loads and the } \\
\text { immediate deflection due to any } \\
\text { additional live load) }\end{array}$ & $\ell / 480$ \\
\cline { 1 - 3 } $\begin{array}{l}\text { Roof or floor construction supporting or } \\
\text { be damaged to nonstructural elements not likely to }\end{array}$ & $\ell / 240$ \\
\hline
\end{tabular}

For the design of pultruded FRP structures, American Society of Civil Engineers (ASCE) has published an LRFD Pre-standard for FRP composite members which stipulates that the structural systems and components to be designed to accommodate long-term deflections under sustained load given as in Eqn. (7-15).

$$
\Delta=\Delta_{\mathrm{st}} \mathrm{K}_{\mathrm{cr}}(\mathrm{t})
$$

Where, $\Delta_{\text {st }}$ is the short-term deflection due to loads from load combination, $\mathrm{K}_{\mathrm{cr}}(\mathrm{t})$ is a deflection amplification factor defined as in Eqn. (7-16), where $(\mathrm{t})$ is service period of structure in years.

$$
\mathrm{K}_{\mathrm{cr}}(\mathrm{t})=1+\mathrm{t}^{1 / 4} / 6
$$

For example, if a structure is designed for 50 years, the structure should be stiff enough to resist 1.44 times the short-term deflection for service loads to not impair the serviceability of the structure. Based on the experimental testing of GFRP and hybrid GFRP-steel box-beams, the maximum central load for satisfying the deflection limits stipulated in major building design codes can be computed from the load-deflection plot for the beams as shown in Fig. 7-72. The maximum central load values are shown in Table 7-29 and are also shown in Fig. 7-73 for better readability and comparison purposes. 


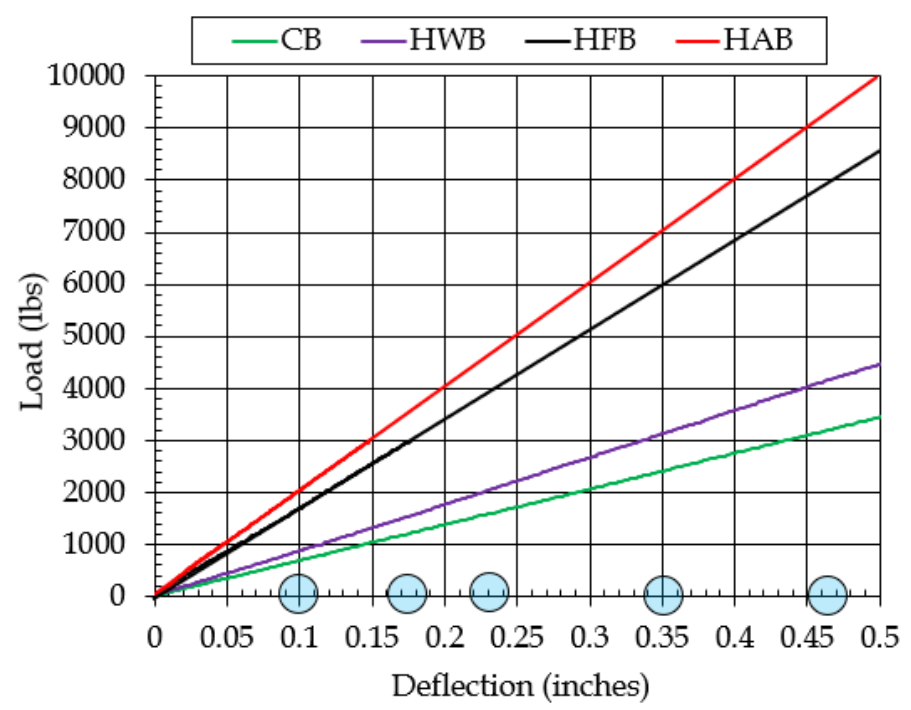

Figure 7-72. Load-deflection plot for GFRP and hybrid box-beams shown until $0.5^{\prime \prime}$ deflection

The maximum central load for hybrid GFRP-steel box beams were higher than that for control GFRP box-beams. The load values obtained for HAB beams were almost 2.8-3.0 times of the load values obtained for the control box-beam.

Table 7-29. Maximum central load on GFRP and hybrid beams pertaining to deflection limits

\begin{tabular}{|l|c|c|c|c|c|}
\hline \multirow{2}{*}{$\begin{array}{l}\text { Deflection } \\
\text { limit }\end{array}$} & Deflection & \multicolumn{5}{|c|}{ Central load at a 3-point loading setup (lb.) } \\
\cline { 3 - 6 } @ L=84" (in) & CB & HWB & HFB & HAB \\
\hline L/180 & 0.467 & 3,250 & 4,200 & 7,850 & 9,200 \\
\hline $\mathrm{L} / 240$ & 0.350 & 2,400 & 3,150 & 6,000 & 7,050 \\
\hline $\mathrm{L} / 360$ & 0.233 & 1,600 & 2,100 & 4,000 & 4,700 \\
\hline $\mathrm{L} / 480$ & 0.175 & 1,200 & 1,550 & 3,000 & 3,600 \\
\hline $\mathrm{L} / 800$ & 0.105 & 750 & 975 & 1,800 & 2,175 \\
\hline
\end{tabular}

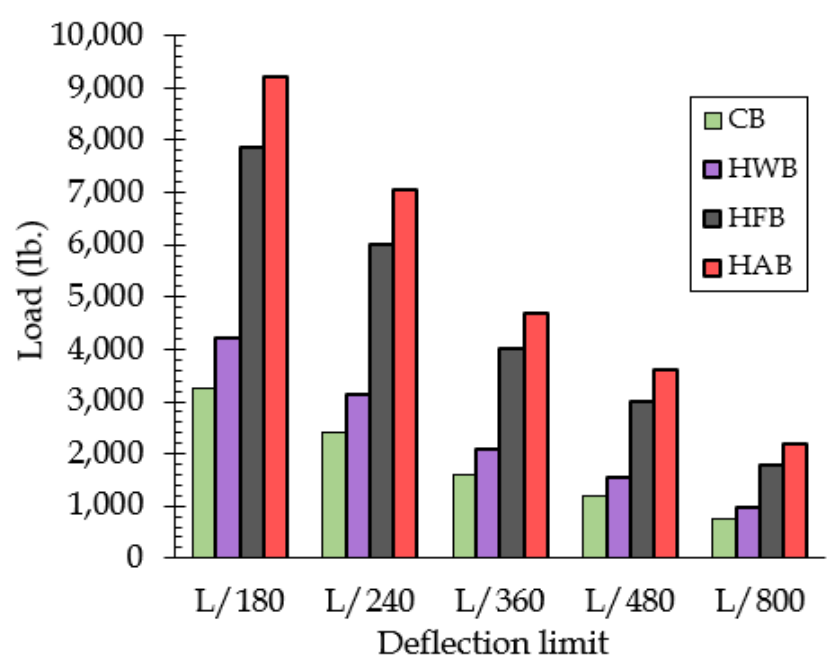

Figure 7-73. Maximum central load for different box-beams to satisfy deflection limits 


\subsection{Yield limits on steel plates}

During the service life of a GFRP beam with embedded steel plates, if the stresses on the embedded steel plate exceeds its yield strength values, structure will start seeing some plastic deformation, which is not intended for a normal functioning of a structure. When a beam is loaded beyond its elastic limit, it starts accumulating some residual strain at each loading and unloading cycle, which might ultimately cause a failure of the structure. Therefore, the design load on the GFRP-steel hybrid beam shall be capped by the yield limits of the steel used in the beam. For hybrid beams with steel plates embedded in the flanges of the GFRP beams, will undergo bending strains under loading. Therefore, when a maximum design strain limit on the steel plates is capped at a strain of $(\varepsilon=\sigma / E)$, based on the type of steel plates used, the corresponding maximum central loads in a three-point bending setup at a span of 84 inches for HFB and HAB hybrid beams can be obtained from the experimental load-strain plots as shown in Fig. 7-74.

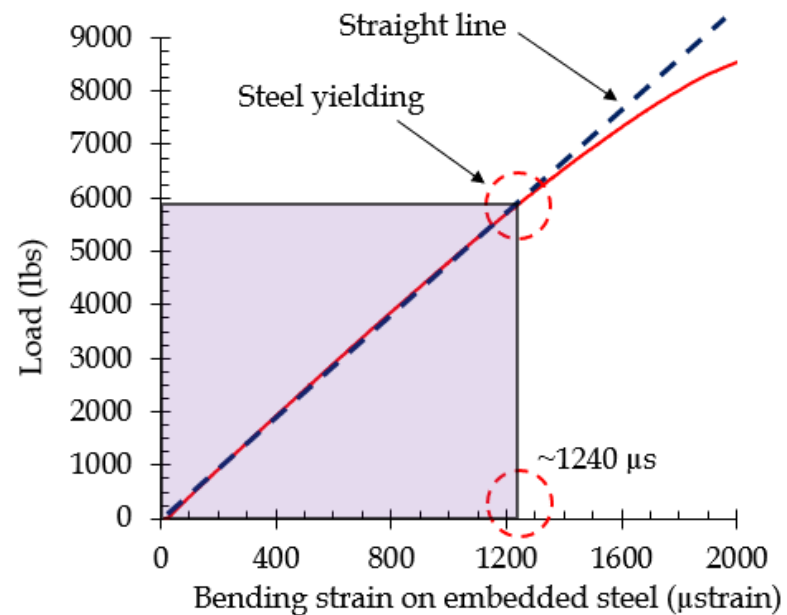

(a)

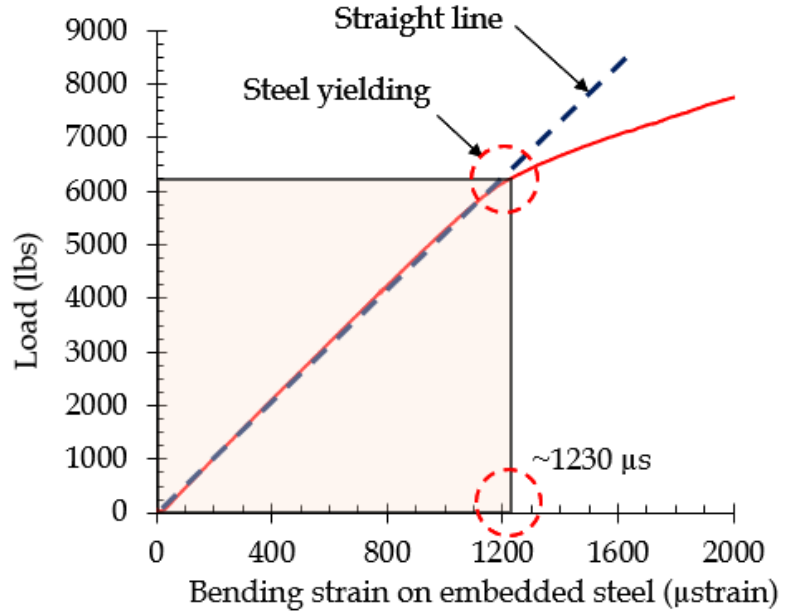

(b)

Figure 7-74. Load @ yield strains of steel plates: (a) HFB beam, (b) HAB beam

The maximum load values are shown in Table 3-1. In addition, the table also shows load values that the beams can carry if A572, grade 60 steel is used instead of A36 steel. The maximum load that a hybrid box-beam could carry within an elastic zone before yielding of internal plates takes place, is much higher with the use of Grade 60 steel plates, as compared to A36 steel which was used in the experiment.

Table 7-30. Maximum central load on GFRP-steel hybrid beams at steel yield strain limits

\begin{tabular}{|l|c|c|c|}
\hline \multirow{2}{*}{ Steel type } & \multirow{2}{*}{ Yield strain limit } & \multicolumn{2}{|c|}{ Max. central load within permissible limit } \\
\cline { 3 - 4 } & & HFB & HAB \\
\hline A36 & $1240 \mu \varepsilon$ & $5,875 \mathrm{lbs}$. & $6,250 \mathrm{lbs}$. \\
\hline A572 - Grade 60 & $2000 \mu \varepsilon$ & $9,500 \mathrm{lbs}$. & $10,700 \mathrm{lbs}$. \\
\hline
\end{tabular}




\subsection{Conclusions}

The conclusions that can be obtained from the research discussed within this chapter are follows.

1. The bending and shear stiffnesses of control GFRP and hybrid box-beams were obtained through experimental testing and classical beam-deflection equations. Due to thin steel plate embedment around the web and flange locations, the bending stiffness values for hybrid sections (HWB, HFB, and $\mathrm{HAB}$ ) were increased by $29.6 \%, 220.2 \%$ and $269.9 \%$, respectively compared to control GFRP (CB) box-beams, whereas, shear stiffness values were only improved for the hybrids with steel plate insertion in the webs (HWB, HAB).

2. The fatigue testing on the hybrid beams within serviceability limits of L/180 (for a span of $84^{\prime \prime}$ ) or up to $54 \%$ of the failure load for 2 to 4 million cycles could not produce damages or reduction in stiffness values in hybrid box-beams. However, when fatigue load levels were increased beyond the yield-strain of steel plates, residual deflection and strains were observed to be as high as $10 \%$ for hybrid beams. The hybrid beam (HAB) fatigued at a load range of about 55-80\% (i.e., lower and upper limit beyond steel yielding) of ultimate load produced a failure consisting of GFRP fracture at $0.625 \times 10^{6}$ load cycles. A permanent deflection of about $5 \%$ was noticed in hybrid beams fatigued at higher loads at lower span of 27 inches.

3. At a span length of 84 in., the control (CB) box-beams showed brittle failure modes, with linear load-deflection curves until failure. On contrary, hybrid beams (HFB and HAB) showed nonlinear responses with distinct bilinear load-deflection and stress-strain curves. At lower spans of $27^{\prime \prime}$ and 36 ", all beams exhibited progressive failure with drops in $\mathrm{p}-\delta$ curves.

4. The local failure modes such as compression-flange junction cracking, compression flange buckling, transverse shear failure, and web-buckling/web-crushing were noticed in the hybrid beams for both longer (84") and shorter spans (36" and 27"). In addition to the above failure modes, the beams with shorter spans (36" and 27") exhibited transverse shear failure caused by high bearing and shear stresses over the roller supports.

5. The bending strains recorded in the hybrid beams during failure were lower by as much as $150 \%$ when compared to those recorded in the control GFRP beam, indicating tremendous reserve capacity in the section, provided the failure mode could be shifted from local to global modes by increasing the dimensions of vulnerable locations.

6. The design of GFRP composite structure is often governed by the serviceability deflection limits. For a given deflection limit, the maximum central load for hybrid (HAB) box-beam was 2.8-3.0 times higher than that obtained for the control GFRP (CB) box-beam. The addition of steel plates on flanges provided the most improvement in the bending stiffness (EI) of the hybrid section, resulting in greatest reduction in deflection values.

7. By limiting the strain on the embedded A36 steel plates within the elastic zone, the maximum central loads obtained for hybrid beams HFB and HAB with a span of 84 " were 5.88 kips and $6.25 \mathrm{kips}$, respectively. These values would increase to $9.5 \mathrm{kips}$ and $10.7 \mathrm{kips}$, respectively if A572 Grade 60 steel plates were to be used.

8. The minimum surface preparation of a steel plate before embedding it in GFRP section was able to produce a good bond with $\sim 95 \%$ effectiveness. GFRP-steel hybrids helped overcome some of the major limitations of GFRP in terms of serviceability and energy-absorption related performance, thus providing a better and affordable alternative for new constructions. 


\section{Chapter 8. \\ Theoretical Approach on GFRP-Steel Hybrid Members}

This chapter discusses the analytical models and approaches that can be used to define the behavior of hybrid GFRP-steel composite material. The theoretical models will be used to compute the structural behavior of the hybrids and will be compared with the experimental values obtained within this research.

\subsection{Material representation}

To represent a steel plate embedded hybrid GFRP box-beams, the model can be represented with a steel plate of thickness $\left(t_{s}\right)$ with bonded GFRP laminate of thickness $\left(t_{G}=t_{G 1}+t_{G 2}\right)$ on both sides of the steel plate as shown in Fig. 8-1. The total width and depth of the hybrid model is $b_{\mathrm{H}}$ and $\mathrm{d}_{\mathrm{H}}$, respectively. In order for a hybrid to work, it is assumed that the bonding between these two dissimilar materials is perfect and remains intact at all times (strain-compatibility). The material model (stress-strain) that is assumed for a GFRP-steel hybrid laminate is shown in Fig. 8-2.

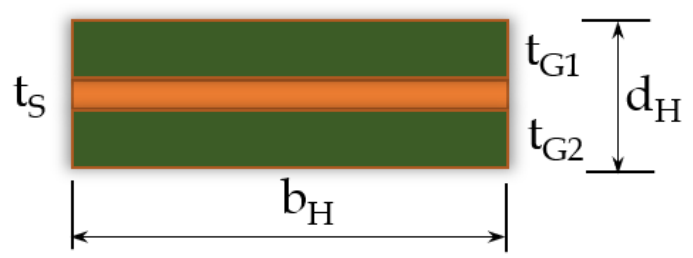

Figure 8-1. GFRP-steel representative geometry cut from the flanges and webs of hybrid beams

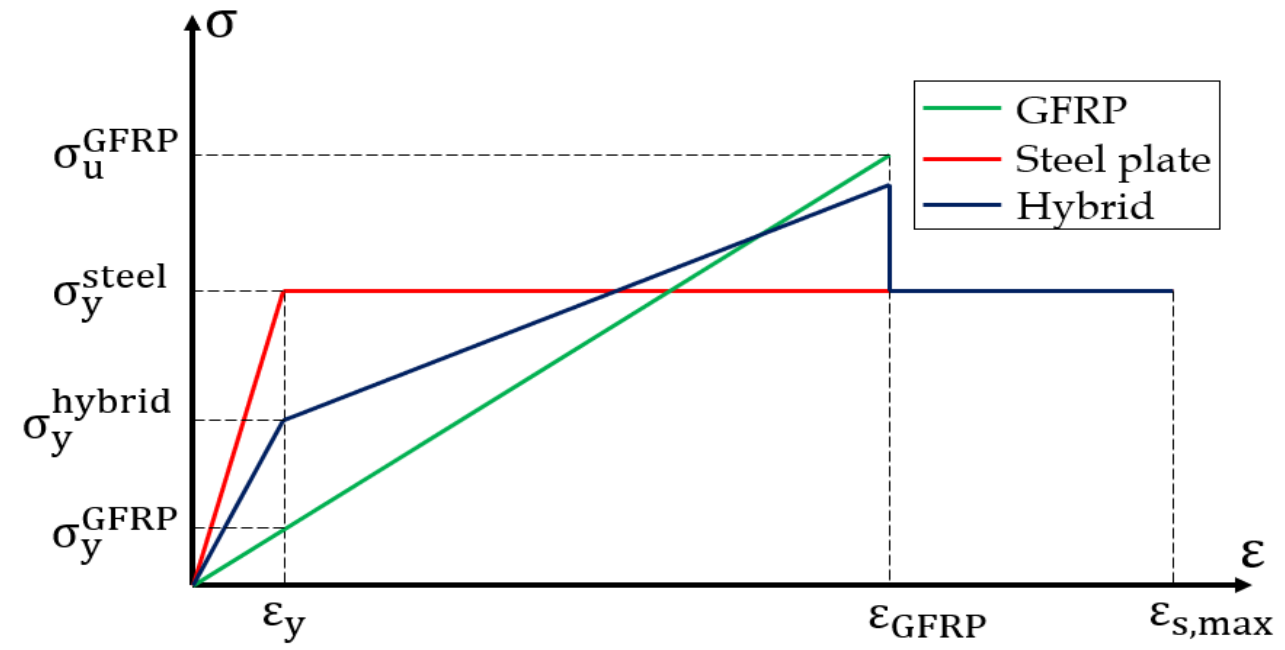

Figure 8-2. Stress-strain model for GFRP, steel, and GFRP-steel hybrid composite

\subsubsection{Under axial load}

The stress-strain behavior of GFRP-steel hybrid under uniaxial tensile loading will have distinct three stages. Under uniaxial tensile loading, the hybrid GFRP-steel laminate will start to elongate at a certain stiffness which is the first slope shown in the Fig. 8-2. The stiffness or the slope of the first curve is dependent on the material properties of GFRP and steel and their geometrical 
dimension. The hybrid laminate will elongate until the strain reaches the yield strain of an internal steel plate. As the strain is increased more, the GFRP laminates on both sides of the steel plate will start to take the load as steel plate will be yielding. At this stage, the yielding inner steel plate is unable to withstand any more load. The stiffness is defined as the post-yield stiffness and is represented on the stress-strain curve by a straight line with a lower slope than the first stage. This second slope is dependent on the material properties of the GFRP laminate and also some hardening behavior of steel might play some role in adding stiffness.

When the strain is further increased, the GFRP laminate fractures at its ultimate strain value and the load will be sustained at the yield strength level of the steel plate, until steel plate fractures.

The classical mixture rule can be used to predict the first stage elastic modulus of the hybrid (Kulkarni et al. 2008, Wu et al. 2010, Lu et al. 2015, Li et al. 2014). The equations for the elastic modulus $\left(\mathrm{E}_{\mathrm{I}}\right)$, and corresponding stress $\left(\sigma_{\mathrm{I}}{ }^{\mathrm{H}}\right)$ and load $\left(\mathrm{P}_{\mathrm{I}}{ }^{\mathrm{H}}\right)$ are shown in Eqns. (8-1), (8-3) and (83), respectively.

$$
\begin{aligned}
& 0 \leq \epsilon_{\mathrm{H}} \leq \epsilon_{\mathrm{Y}} \quad \mathrm{E}_{\mathrm{I}}=\mathrm{E}_{\mathrm{S}} \mathrm{V}_{\mathrm{S}}+\mathrm{E}_{\mathrm{G}} \mathrm{V}_{\mathrm{G}}=\frac{\mathrm{E}_{\mathrm{S}} \mathrm{A}_{\mathrm{S}}+\mathrm{E}_{\mathrm{G}} \mathrm{A}_{\mathrm{G}}}{\mathrm{A}_{\mathrm{H}}}=\frac{\mathrm{E}_{\mathrm{S}} \mathrm{t}_{\mathrm{S}}+\mathrm{E}_{\mathrm{G}} \mathrm{t}_{\mathrm{G}}}{\left(\mathrm{t}_{\mathrm{S}}+\mathrm{t}_{\mathrm{G}}\right)} \\
& \sigma_{\mathrm{I}}^{\mathrm{H}}=\mathrm{E}_{\mathrm{I}} \epsilon_{\mathrm{H}} \\
& \mathrm{P}_{\mathrm{I}}^{\mathrm{H}}=\left[\mathrm{E}_{\mathrm{I}} \epsilon_{\mathrm{H}}\right]\left(\mathrm{A}_{\mathrm{H}}\right)
\end{aligned}
$$

where $E_{S}, V_{S}, A_{S}$, and $t_{S}$ are young's modulus of elasticity, volume fraction, cross-sectional area and thickness of steel, respectively, and $\mathrm{E}_{\mathrm{G}}, \mathrm{V}_{\mathrm{G}}, \mathrm{A}_{\mathrm{G}}$, and $\mathrm{t}_{\mathrm{G}}$ are the modulus of elasticity, volume fraction, cross-sectional area and total thickness of GFRP laminate in the hybrid GFRP-steel composite with a total area of $\mathrm{A}_{\mathrm{H}}$.

In the post-elastic region, the modulus of elasticity of hybrid laminate $\left(\mathrm{E}_{\mathrm{II}}\right)$, tensile stress $\left(\sigma_{\mathrm{HP}}\right)$, and tensile load $\left(\mathrm{P}_{\mathrm{II}}{ }^{\mathrm{H}}\right)$ at a strain level of $\epsilon_{\mathrm{H}}$, below the ultimate rupture strain of GFRP laminate $\left(\epsilon_{\mathrm{GU}}\right)$ can be obtained as shown in Eqns. (8-4), (8-5), and (8-6), respectively.

$$
\begin{aligned}
\epsilon_{\mathrm{Y}} \leq \epsilon_{\mathrm{H}} \leq \epsilon_{\mathrm{GU}} & \mathrm{E}_{\mathrm{II}}=\frac{\mathrm{E}_{\mathrm{G}} \mathrm{t}_{\mathrm{G}}}{\left(\mathrm{t}_{\mathrm{S}}+\mathrm{t}_{\mathrm{G}}\right)} \\
& \sigma_{\mathrm{II}}^{\mathrm{H}}=\mathrm{E}_{\mathrm{I}} \epsilon_{\mathrm{Y}}+\mathrm{E}_{\mathrm{II}}\left(\epsilon_{\mathrm{H}}-\epsilon_{\mathrm{Y}}\right) \\
& \mathrm{P}_{\mathrm{II}}{ }^{\mathrm{H}}=\left[\mathrm{E}_{\mathrm{I}} \epsilon_{\mathrm{Y}}+\mathrm{E}_{\mathrm{II}}\left(\epsilon_{\mathrm{H}}-\epsilon_{\mathrm{Y}}\right)\right]\left(\mathrm{A}_{\mathrm{H}}\right)
\end{aligned}
$$

After the rupture of GFRP, the tensile modus $\left(\mathrm{E}_{\mathrm{II}}\right)$ is zero when strain-hardening or stiffening effect of steel is ignored, with the load $\left(\mathrm{P}_{\mathrm{III}}{ }^{\mathrm{H}}\right)$ being constant at the yield load of steel, until the steel fractures at a strain of $\epsilon_{\mathrm{SU}}$. The equations to compute stress $\left(\sigma_{\text {III }}{ }^{\mathrm{H}}\right)$ and load $\left(\mathrm{P}_{\mathrm{III}}{ }^{\mathrm{H}}\right)$ are shown in Eqns. (8-7) and (8-8), respectively.

$$
\begin{aligned}
\epsilon_{\mathrm{GU}} \leq \epsilon_{\mathrm{H}} \leq \epsilon_{\mathrm{SU}} & \mathrm{E}_{\mathrm{III}}=0 \\
& \sigma_{\mathrm{III}}{ }^{\mathrm{H}}=\mathrm{E}_{\mathrm{I}} \epsilon_{\mathrm{Y}} \\
& \mathrm{P}_{\mathrm{III}}{ }^{\mathrm{H}}=\left[\mathrm{E}_{\mathrm{I}} \epsilon_{\mathrm{Y}}\right]\left(\mathrm{A}_{\mathrm{S}}\right)
\end{aligned}
$$




\subsubsection{Under flexural load}

When a hybrid laminate $\left(b_{H} \times d_{H}\right)$ as shown in Fig. 8-1 is loaded under flexural 3-point load, it is assumed that the steel plates and outer GFRP laminates remain bonded and the cross-section of the hybrid remains perpendicular to the longitudinal axis along the test-span. The flexural rigidity (D) of the hybrid section is given by the algebraic summation of longitudinal stiffnesses of two outer GFRP laminates with thickness $\left(t_{\mathrm{G} 1}\right)$ and $\left(t_{\mathrm{G} 2}\right)$ and the longitudinal stiffness of the inner steel plates with thickness $\left(t_{\mathrm{S}}\right)$ as given by Eqns. (8-9) and (8-10).

$$
\begin{gathered}
\mathrm{D}_{\mathrm{GFRP}}=\frac{\mathrm{E}_{\mathrm{G}} \mathrm{b}_{\mathrm{H}}\left(\mathrm{t}_{\mathrm{G} 1}{ }^{3}+\mathrm{t}_{\mathrm{G} 2}{ }^{3}\right)}{12}+\mathrm{E}_{\mathrm{G}} \mathrm{b}_{\mathrm{H}}\left(\mathrm{t}_{\mathrm{G} 1} \mathrm{~h}_{\mathrm{G} 1}{ }^{2}+\mathrm{t}_{\mathrm{G} 2} \mathrm{~h}_{\mathrm{G} 2}{ }^{2}\right) \\
\mathrm{D}_{\text {Steel }}=\frac{\mathrm{E}_{\mathrm{S}} \mathrm{b}_{\mathrm{H}} \mathrm{t}_{\mathrm{s}}{ }^{3}}{12}
\end{gathered}
$$

Where, $\mathrm{h}_{\mathrm{G} 1}$ and $\mathrm{h}_{\mathrm{G} 2}$ are the distances to the center of gravity (CG) of the outer GFRP laminates from the mid-plane of the hybrid section. When the steel plate is at the mid-plane of the hybrid section, the contribution of its stiffness property in the overall bending rigidity of the hybrid is negligible. However, in the box-beam sections, steel plates are away from the mid-plane of the beam and the contribution of those steel plates in the overall bending rigidity of the section is higher and will be discussed in the next section. The maximum bending strain at the outer GFRP laminate when inner steel plate reaches its yield strain value is given by Eqn. (8-11).

$$
\varepsilon_{\mathrm{G}}=\frac{\mathrm{d}_{\mathrm{H}}}{\mathrm{t}_{\mathrm{S}}} \varepsilon_{\mathrm{y}}
$$

\subsection{Flexural stiffness of a hybrid box-beam}

The hybrid GFRP-steel box-beam (HAB) has been simplified by removing the corners as shown in Fig. 8-3. The beam consists of embedded steel plates of size $\left(b_{S} \times t_{S}\right)$ in both flanges and webs. The bending rigidity (D) of the hybrid section is obtained from the algebraic summation of longitudinal stiffnesses of GFRP section and embedded steel plates with reference to the midplane of the hybrid section as shown in Eqns. (8-12) and (8-13).

$$
\begin{gathered}
D_{G F R P}=E_{G}\left[\frac{b d^{3}}{12}-\frac{\left(b-2 t_{w}\right)\left(d-2 t_{f}\right)^{3}}{12}-2 b_{s} t_{s}\left(\frac{d}{2}-\frac{t_{f}}{2}\right)^{2}-\frac{t_{s} b_{s}{ }^{3}}{6}\right] \\
D_{\text {Steel }}=\frac{E_{S} b_{S} t_{s}{ }^{3}}{6}+2 E_{S} b_{S} t_{S}\left(\frac{d}{2}-\frac{t_{f}}{2}\right)^{2}+\frac{E_{S} t_{s} b_{S}{ }^{3}}{6}
\end{gathered}
$$

Since the bending moment capacity of a section is directly proportional to its moment of inertia, the increase in moment of inertia of the hybrid section due to addition of those steel plates is significantly going to increase the bending moment capacity of a beam. 


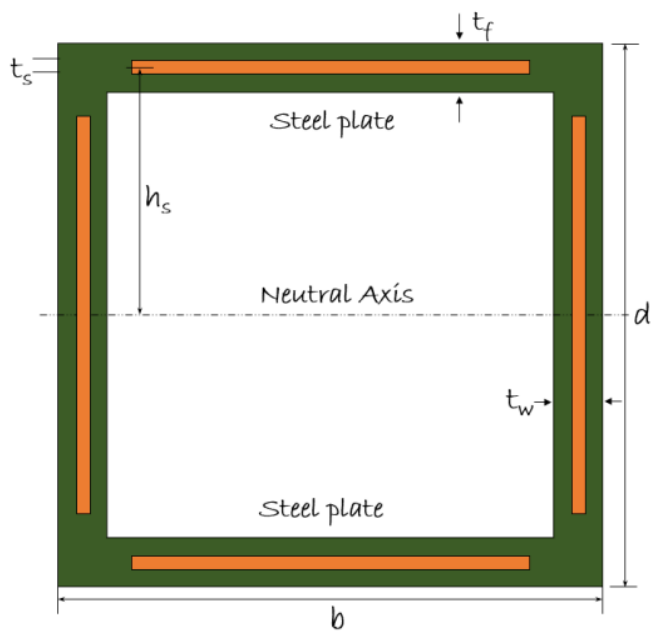

Figure 8-3. Cross-section of a GFRP-steel hybrid box beam (HAB)

\subsection{Load carrying capacity of a hybrid (HAB) beam}

The hybrid beam maintains the strain compatibility between GFRP and steel plates and distribute the applied load to both GFRP and steel members until failure.

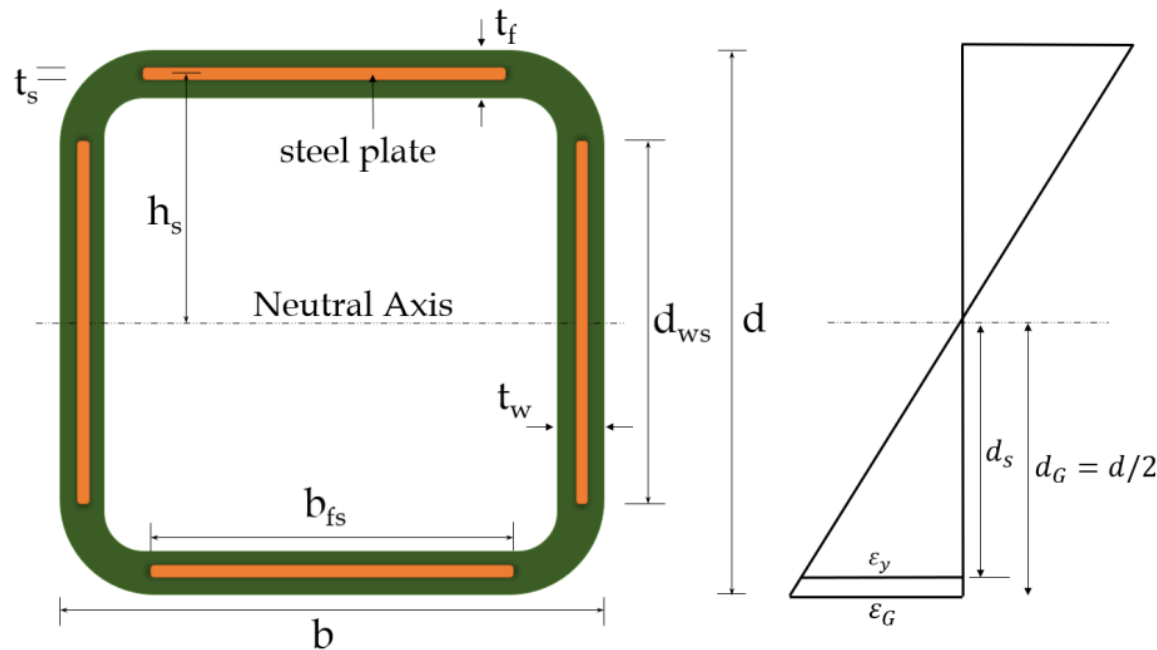

Figure 8-4. Cross-section of a hybrid box beam (HAB) and the strain distribution

During bending, the bending tensile strain at the extreme GFRP lamina in the bottom flange $\left(\varepsilon_{\mathrm{G}}\right)$ when bottom embedded steel plate in the bottom flange reaches its yield strain limit $\left(\varepsilon_{\mathrm{y}}\right)$ is given by Eqn. (8-14).

$$
\varepsilon_{\mathrm{G}}=\frac{\mathrm{d}_{\mathrm{G}}}{\mathrm{d}_{\mathrm{s}}} \varepsilon_{\mathrm{y}}
$$

The corresponding stress at the outer GFRP at a strain level of $\left(\varepsilon_{\mathrm{G}}\right)$ is equal to the product of strain and its modulus of elasticity $\left(\mathrm{E}_{\mathrm{G}}\right)$ as shown by Eqn. (8-15). 


$$
\sigma_{\mathrm{G}}=\mathrm{E}_{\mathrm{G}} \varepsilon_{\mathrm{G}}=\mathrm{E}_{\mathrm{G}} \frac{\mathrm{d}_{\mathrm{G}}}{\mathrm{d}_{\mathrm{s}}} \varepsilon_{\mathrm{y}}
$$

The maximum central point load and a uniformly distributed load that can be applied within the elastic limit of the beam before the yielding of internal steel plates are given by Eqns. (8-16) and (8-17), respectively.

$$
\begin{gathered}
\mathrm{P}_{\max }=\frac{8 \sigma_{G} \mathrm{I}_{H}}{\mathrm{Ld}}=\frac{8 \mathrm{E}_{\mathrm{G}} \mathrm{I}_{\mathrm{H}} \mathrm{d}_{\mathrm{G}}}{\mathrm{Ldd}_{\mathrm{s}}} \varepsilon_{\mathrm{y}} \\
\mathrm{W}_{\max }=\frac{16 \sigma_{\mathrm{G}} \mathrm{I}_{\mathrm{H}}}{\mathrm{L}^{2} \mathrm{~d}}=\frac{16 \mathrm{E}_{\mathrm{G}} \mathrm{I}_{\mathrm{H}} \mathrm{d}_{\mathrm{G}}}{\mathrm{L}^{2} \mathrm{dd}_{\mathrm{s}}} \varepsilon_{\mathrm{y}}
\end{gathered}
$$

\subsection{Design consideration of a GFRP composite beam}

The design of a GFRP composite flexural member is carried out for deflection, shear strength, flexural strength, and buckling of compression flanges or lateral torsional buckling depending upon the shape, size, and length of members. The common failure mode on a long-span flexural member is typically local buckling of the compressive flange while on short spans, failure is dominated by shear strength. In most cases, the design of a GFRP composite flexural member is governed by a deflection limit.

\subsubsection{Deflection}

Fiber reinforced composite beams exhibit both flexural and shear deflections. At shorter spans, significant percentage of the total deflection is comprised by shear deflections. Shear deflections are apparent at spans to depth ratios of less than 20. Therefore, shear deflection should never be neglected while designing with composites. The typical deflection on a simply supported beam with uniformly distributed load (w) per unit length is given by Eqn. (8-18) and with central point load (P) is given by Eqn. (8-19). During the design process, it is required to check the maximum allowable deflection limits specified by the client or building and bridge codes, such as (L/180) or $(\mathrm{L} / 360)$. The overall deflection on a structural member with given loading must be smaller than the allowable deflection limit.

$$
\begin{aligned}
& \Delta=\frac{5 \mathrm{wL}^{4}}{384 \mathrm{EI}}+\frac{\mathrm{wL}^{2}}{8 \mathrm{kGA}_{\mathrm{w}}} \\
& \Delta=\frac{\mathrm{PL}^{3}}{48 \mathrm{EI}}+\frac{\mathrm{PL}}{4 \mathrm{kGA}_{\mathrm{w}}}
\end{aligned}
$$

Where,

$\mathrm{w}=$ uniformly distributed load on the beam (lbs./in)

$\mathrm{P}=$ point load at the center of the beam

$\mathrm{I}=$ moment of inertia $\left(\mathrm{in}^{4}\right)$

$\mathrm{E}=$ modulus of elasticity (psi)

$\mathrm{G}=$ modulus of rigidity or shear modulus (psi) 
$\mathrm{A}_{\mathrm{w}}=$ shear area of a profile $\left(\mathrm{in}^{2}\right)$

$\mathrm{k}=$ shear coefficient

$\mathrm{L}=$ length of a span (in)

\subsubsection{Flexural and shear strength}

When a GFRP composite box-beam section of cross-section $(b \times d)$ with a flange thickness of $\left(t_{f}\right)$ and the web thickness of $\left(t_{w}\right)$ is simply supported for a span length (L) with a central point load $(\mathrm{P})$, the maximum bending moment $(\mathrm{M})$ and shear force $(\mathrm{V})$ that occur on the beam are given by Eqn. (8-20). Similarly, when the same beam is loaded with uniformly distributed load (w) per unit length, the maximum bending moment (M) and shear force (V) are given by Eqn. (8-21).

$$
\begin{gathered}
\mathrm{M}=\frac{\mathrm{PL}}{4} ; \mathrm{V}=\frac{\mathrm{P}}{2} \\
\mathrm{M}=\frac{\mathrm{wL}^{2}}{8} ; \mathrm{V}=\frac{\mathrm{wL}}{2}
\end{gathered}
$$

The moment of inertia of a given section can be calculated by using Eqn. (8-22).

$$
I=\frac{b d^{3}}{12}-\frac{\left(b-2 t_{w}\right)\left(d-2 t_{f}\right)^{3}}{12}
$$

Thus, the maximum bending stress $\left(f_{b}\right)$ and shear stress $\left(f_{v}\right)$ that occur on a simply supported beam with a central point load and a uniformly distributed load are given by Eqns. (8-23) and (824), respectively.

$$
\begin{gathered}
f_{b}=\frac{P L d}{8 I} ; f_{v}=\frac{P}{2 A_{w}} \\
f_{b}=\frac{w L^{2} d}{16 I} ; f_{v}=\frac{w L}{2 A_{w}}
\end{gathered}
$$

The stresses under factored design load of a GFRP section must be lower than the bending and shear strength after accounting for factor of safety. The ultimate bending failure load and the ultimate shear failure load of the given box-beam on a simply supported span with a central point load and uniformly distributed load are given by Eqns. (8-25) and (8-26), respectively.

$$
\begin{gathered}
\mathrm{P}_{\mathrm{b}, \text { fail }}=\frac{8 \mathrm{~F}_{\mathrm{b}} \mathrm{I}}{\mathrm{Ld}} ; \mathrm{P}_{\mathrm{v}, \text { fail }}=2 \mathrm{~F}_{\mathrm{v}} A_{\mathrm{w}} \\
\mathrm{w}_{\mathrm{b}, \text { fail }}=\frac{16 \mathrm{~F}_{\mathrm{b}} \mathrm{I}}{\mathrm{L}^{2} \mathrm{~d}} ; \mathrm{w}_{\mathrm{v}, \text { fail }}=\frac{2 \mathrm{~F}_{\mathrm{v}} A_{\mathrm{w}}}{\mathrm{L}}
\end{gathered}
$$

\subsubsection{Buckling of the compression flange}

The local buckling strength of the compression flange for I-sections and box-sections can be computed by Eqn. (8-27) (Pultex manual). 


$$
\sigma_{x}^{c r}=\frac{\pi^{2}}{12}\left(\frac{t_{f}}{b}\right)^{2}\left[\sqrt{q}\left(2 \sqrt{E_{x f} E_{y f}}\right)+p\left\{E_{y f} v_{x y f}+2 G_{x y f}\right\}\right]
$$

Where,

$\sigma_{\mathrm{x}}^{\mathrm{cr}}=$ critical stress for local buckling of compression flange

$\mathrm{p}, \mathrm{q}=$ constants defined by coefficient of restraint ( $\zeta)$ as given in Eqn. 8-28

$\mathrm{t}_{\mathrm{f}}=$ thickness of a compression flange (in)

$\mathrm{b}=\mathrm{b}_{\mathrm{f}}$ for box-sections, and $\left(\mathrm{b}_{\mathrm{f}} / 2\right)$ for wide flange and I-sections (in)

$b_{\mathrm{f}}=$ width of the compression flange (in)

$\mathrm{d}=$ height of the section (in)

$\mathrm{E}_{\mathrm{xf}}=$ longitudinal modulus of elasticity of flanges (psi)

$\mathrm{E}_{\mathrm{yf}}=$ transverse modulus of elasticity of flanges (psi)

$\mathrm{E}_{\mathrm{yw}}=$ transverse modulus of elasticity of webs (psi)

$v_{\mathrm{xyf}}=$ poison's ratio of flanges

$\mathrm{G}_{\mathrm{xyf}}=$ Modulus of rigidity or shear modulus (psi)

For box-sections, constants $\mathrm{p}$ and $\mathrm{q}$ are defined by Eqn. (8-28).

$$
\mathrm{p}=2+\left(\frac{0.002}{\zeta-1.3}\right) ; \mathrm{q}=1+\left(\frac{0.08}{\zeta+0.2}\right) ; \zeta=\frac{\mathrm{dE}_{\mathrm{yf}}}{\mathrm{b}_{\mathrm{f}} \mathrm{E}_{\mathrm{yw}}}
$$

For a beam of span length $(\mathrm{L})$, the critical local buckling load $\left(\mathrm{P}_{\mathrm{cr}}\right)$ for beams under a central point load and the critical local buckling load $\left(\mathrm{w}_{\mathrm{cr}}\right)$ for beams under a uniformly distributed load can be obtained in terms of critical local buckling strength and beam properties by using Eqn. (8-29).

$$
\mathrm{P}_{\mathrm{cr}}=\frac{8 \mathrm{EI} \sigma_{\mathrm{x}}^{\mathrm{cr}}}{\mathrm{E}_{\mathrm{xf}} \mathrm{dL}} ; \mathrm{w}_{\mathrm{cr}}=\frac{16 \mathrm{EI} \sigma_{\mathrm{x}}^{\mathrm{cr}}}{\mathrm{E}_{\mathrm{xf}} \mathrm{dL}^{2}}
$$

The load that satisfies the service deflection limit and strength limits based on bending strength and compression flange buckling strength should be the design load on the GFRP box-beam after accounting for the code-based or client-based factor of safety. 


\section{Chapter 9. \\ Finite Element Analysis}

This chapter discusses the finite element modeling and analysis of GFRP and hybrid box-beams with variable configurations such as geometry, fiber material, and steel plate layout using commercially available finite element modeling software ABAQUS. The chapter discusses the modeling efforts and the results for different assemblies are presented. Finally, the results obtained from ABAQUS are compared with the experimental and analytical studies and experiments.

\subsection{Material representation}

The 3-D finite element analysis was conducted using commercial software ABAQUS/CAE 6.135 . The finite element model (FEM) of a representative section of the experimentally tested beams as shown in Fig. 9.1 was developed to predict its structural behavior. Due to symmetry, only half of the section representing the finite element mesh and boundary conditions was modeled and analyzed as shown in Fig. 9.2 to save computation time and effort. By analyzing half portion of the beam with $1 / 2$ of the total load at the center, the deflection and stresses for the full-length beam under the total load could be obtained with good approximation.

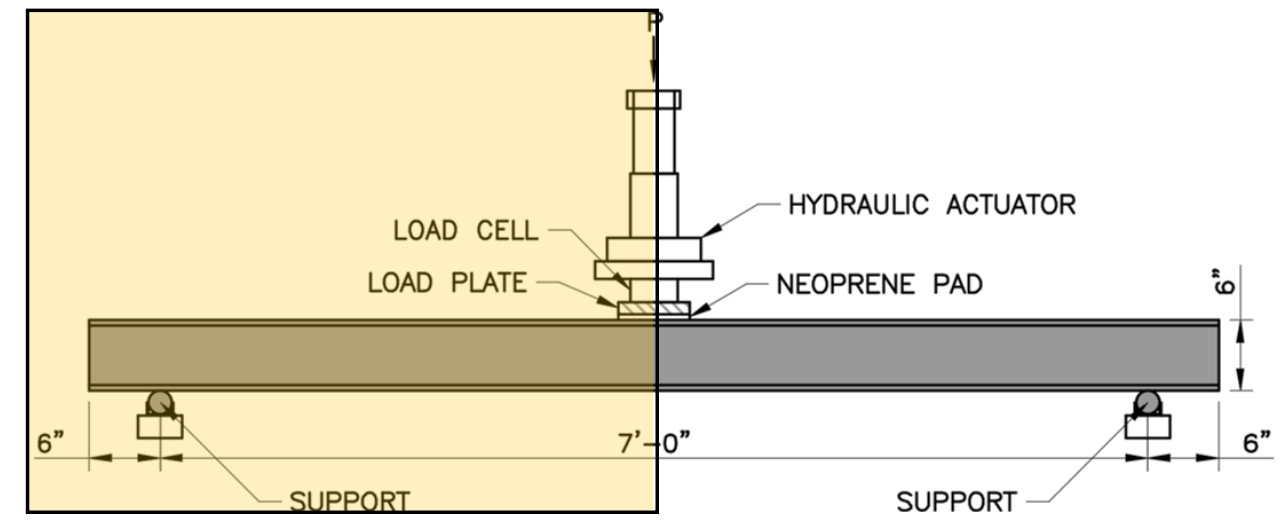

Figure 9-1. Shaded portion of the beam to be modeled in FE

\subsubsection{Loading and boundary condition}

During experimental investigation, the load was applied centrally with a 6 in.-wide steel plate on the top flange of the beam. Similarly, in the FE mode, the load is applied at the half-length model on the top flange on 3 "'-wide area due to symmetry boundary condition present at the center as shown in Fig. 9-2. The 0.5"'-wide area across the beam was fixed in translation in vertical (Y) and horizontal $(\mathrm{X})$ directions but free in $(\mathrm{Z})$ direction to mimic the laboratory conditions, where $2^{\prime \prime}$ diameter steel rollers were used as supports. 


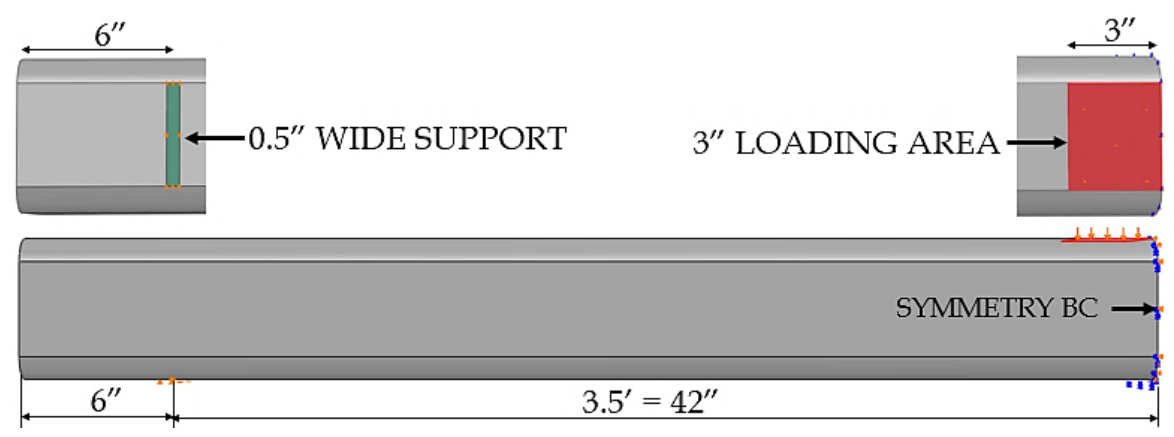

Figure 9-2. Half-length model in the Abaqus with loading and boundary conditions

\subsubsection{Material properties and orientations}

GFRP laminate of the box-beams was modeled as a 3D-deformable orthotropic material with linearly elastic constitutive relationship. The advantage of using 3D orthotropic material is that through-thickness normal stress and interlaminar shear stresses are directly involved in the beam response (Gautam \& Matsumoto 2008). The nine different engineering constants needed to define the orthotropic laminate were obtained through experimental investigation or through micromechanical models as shown in this section. The modulus of elasticity in longitudinal and transverse directions were obtained through experimental testing as discussed in Chapter 6 . The in-plane Poisson's ratio of the lamina can be estimated using Eqn. (9-1) through the use of rule of mixtures (Barbero, 2017).

$$
v_{12}=v_{\mathrm{f}} \mathrm{V}_{\mathrm{f}}+v_{\mathrm{m}} \mathrm{V}_{\mathrm{m}}
$$

The volume fraction of fibers and matrix (resin) were obtained experimentally. Using Eqn. (8-1), the in-plane Poisson's ration was obtained as 0.34. But, since the laminate of the box-beam consisted of few layers of woven fabric with plain fabric architecture, the actual Poisson's ratio is much less than the value obtained from the micromechanical analysis valid for unidirectional composites (UD). However, from studies (Akkerman, 2004, Aly et al. 2010), it was found that the $v_{13}$ and $v_{23}$ are equal but higher than $v_{12}$, for woven fabric (WF). The in-plane Poisson's ration obtained from Eqn. (9-2) is 0.28 and will be used in this study. The $v_{13}$ and $v_{23}$ are equal and can be used as 0.34, as was estimated by the UD micromechanical approach.

$$
\left(\frac{4}{\mathrm{E}_{1}} \frac{v_{12} \mathrm{E}_{2}\left(\mathrm{E}_{1}-v_{12}{ }^{2} \mathrm{E}_{2}\right.}{\mathrm{E}_{1}\left(\mathrm{E}_{1}+2 \mathrm{E}_{2}\right)+\left(1+2 v_{12}{ }^{2}\right) \mathrm{E}_{2}^{2}}\right)^{\mathrm{UD}}=\left(\frac{v_{12}}{\mathrm{E}_{1}}\right)^{\mathrm{WF}}
$$

The shear modulus of the E-glass fiber and Vinyl Ester resin, which are isotropic materials, were computed based on their Young's modulus of elasticity and Poisson's ratios supplied by the manufacturer as shown in Eqn. (9-1).

$$
G=\frac{E}{2(1+v)}
$$

The in-plane shear modulus can be estimated by using the inverse rule of mixtures of the micromechanical theory as given by Eqn. (9-4). However, as inverse rule of mixture gives simple approximation but not accurate prediction, the cylindrical assemblage model as shown in Eqn. (9-5) is used to better predict the shear modulus (Barbero, 2017). 


$$
\begin{aligned}
G_{12} & =\frac{V_{m}}{V_{m}+V_{f} G_{m} / G_{f}} \\
G_{12} & =G_{m}\left[\frac{\left(1+V_{f}\right)+\left(1-V_{f}\right) G_{m} / G_{f}}{\left(1-V_{f}\right)+\left(1+V_{f}\right) G_{m} / G_{f}}\right]
\end{aligned}
$$

The in-plane shear modulus obtained through Eqn. (9-4) was $216 \mathrm{ksi}$ and through Eqn. (9-5) was $260 \mathrm{ksi}$. The latter will be used in this study. Based on the study (Akkerman, 2004), the $\mathrm{G}_{13}$ and $\mathrm{G}_{23}$ are found to be equal for woven fabric and is estimated by using Eqn. (9-6). The value obtained was $378 \mathrm{ksi}$ and was found to be higher than in-plane shear modulus.

$$
\left(\frac{1+v_{23}}{E_{2}}+\frac{1}{2 G_{12}}\right)^{\mathrm{UD}}=\left(\frac{1}{\mathrm{G}_{13}}\right)^{\mathrm{WF}}
$$

The experimentally obtained and estimated values for the engineering properties of the laminate is summarized in Table 9-1 and will be used in this FE study. In addition, the table also shows the modulus of elasticity and Poisson's ratio for steel, which is also used in the hybrid GFRP-steel box-beams.

Table 9-1. Material properties of the GFRP laminate

\begin{tabular}{|c|c|c|c|c|c|c|c|c|c|}
\hline Material & $\mathrm{E}_{1}$ & $\mathrm{E}_{2}$ & $\mathrm{E}_{3}$ & $\mathrm{G}_{12}$ & $\mathrm{G}_{13}$ & $\mathrm{G}_{23}$ & $v_{12}$ & $v_{13}$ & $v_{23}$ \\
\hline GFRP & $1.9 \mathrm{E} 6$ & $1.9 \mathrm{E} 6$ & $1.2 \mathrm{E} 6$ & $0.26 \mathrm{E} 6$ & $0.37 \mathrm{E} 6$ & $0.37 \mathrm{E} 6$ & 0.28 & 0.34 & 0.34 \\
\hline Steel & $\mathrm{E}=29 \mathrm{E} 6, \mathrm{v}=0.26$ \\
\hline
\end{tabular}

The orientation of material axis system (1-2-3) to the global loading axis system $(x-y-z)$ is different at different locations of a box beam. Thus, GFRP material properties were entered with proper orientations for flange and web locations of a beam as shown in Fig. 9-3.

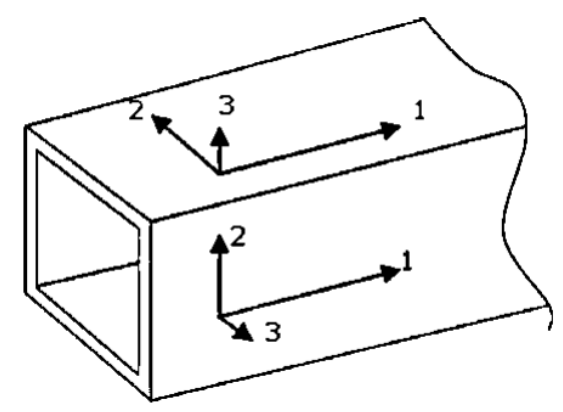

Figure 9-3. Material orientation on flanges and webs of box-beams (Gautam \& Matsumoto 2008)

The box-beams tested in the experimental investigation have corner radii, therefore, to represent accurate behavior in the mode, the corners were provided with actual fillet radii as shown in Fig. 9-4a. But, when a fiber passes across the corner of a box beam, it changes its orientation from horizontal ( $\mathrm{z}$ ) axis in the flange region to vertical (y) axis in the web region. The fiber bends gradually from 0 to 90 degrees with respect to the z-axis. A proper material orientation was required; therefore, cylindrical local coordinate system was created. In cylindrical coordinate system, the R, $\theta$, and Z-axes are interpreted as the 1-, 2-, and 3-axes, respectively. Accordingly, the orientation of material properties in four corner regions of the box-beams were selected based on cylindrical coordinate system as shown in Fig. 9-4b. 


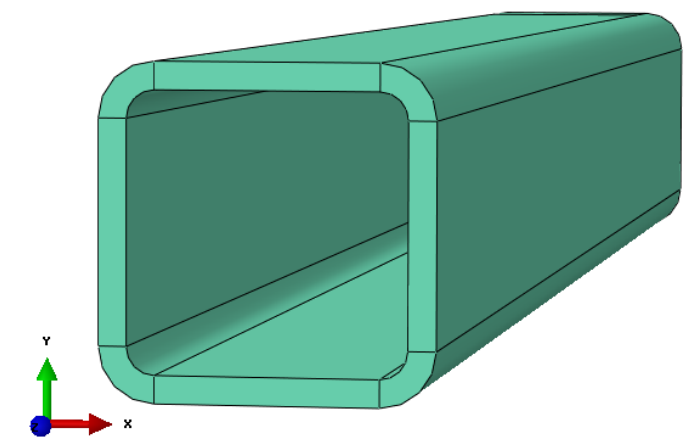

(a)

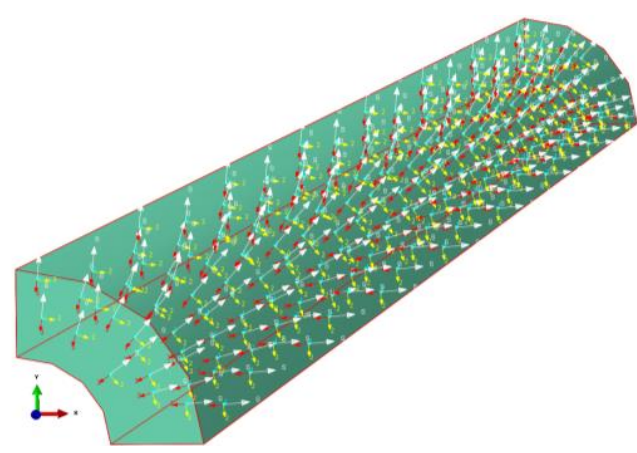

(b)

Figure 9-4. (a) Box-beam model with corner radii, (b) material orientation at the corners

\subsubsection{Element and mesh size}

The FE model developed for linear analysis was discretized with C3D20 elements, which is a general-purpose quadratic brick element ( $3 \times 3 \times 3$ integration points). The node numbering follows the convention as shown in Fig. 9-5. This is an excellent element for linear elastic calculations (Abaqus manual). Due to the location of the integration points, stress concentrations at the surface of a structure are well captured. However, for nonlinear calculations the elements due to the full integration, the element will behave badly for isochoric material behavior, i.e. for high values of Poisson's coefficient or plastic behavior, but much better than 8-noded brick element. The element tends to be too stiff in bending, e.g. for slender beams or thin plates under bending, but for thick laminates of $0.5 \mathrm{in}$. and more, this element is good.

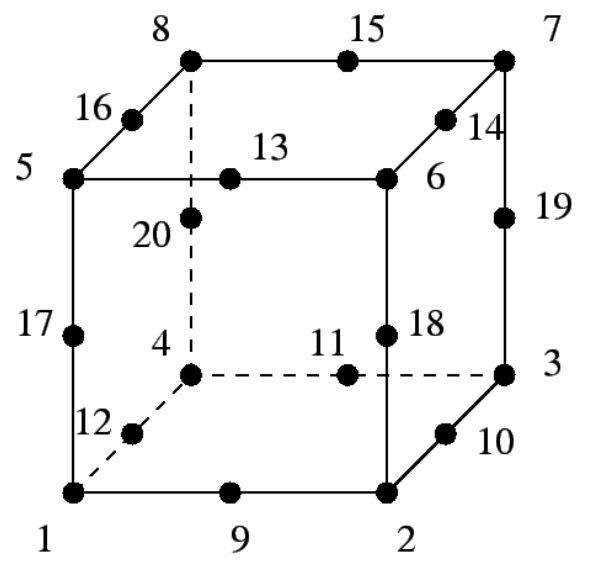

Figure 9-5. 20-node quadratic brick element with node numbering

For studying non-linear behavior of the hybrid beams, the FE model was discretized with C3D20R elements, which is also a general-purpose quadratic brick element but with reduced integration $(2 \times 2 \times 2$ integration points). The node numbering follows the convention similar to C3D20 element as shown in Fig. 9-5. The element behaves very well and is excellent for isochoric material behavior and in bending and rarely exhibits hour glassing despite the reduced integration. Before starting to analyze stresses and strains on the models, it was necessary to find the optimum element size and number of elements in a model that would provide convergence of the result. The mesh convergence for both C3D20 and C3D20R elements was obtained with element size of 0.25 " with 29,952 elements within a half-length model as shown in Table 9-2. 
Table 9-2. Mesh size and convergence of a result

\begin{tabular}{|l|l|c|c|}
\hline $\begin{array}{l}\text { Element size } \\
\text { (in) }\end{array}$ & \multirow{2}{*}{$\begin{array}{c}\text { Total mesh elements } \\
\text { (No.) }\end{array}$} & \multicolumn{2}{|c|}{ Deflection @ 3-kip load (in) } \\
\cline { 3 - 4 } & 60 & C3D20 & C3D20R \\
\hline 5 & 120 & 0.315 & 0.311 \\
\hline 5 & 320 & 0.395 & 0.393 \\
\hline 2.5 & 780 & 0.404 & 0.398 \\
\hline 1.25 & 1820 & 0.417 & 0.425 \\
\hline 0.75 & 7168 & 0.428 & 0.430 \\
\hline 0.375 & $\mathbf{2 9 9 5 2}$ & 0.431 & 0.432 \\
\hline $\mathbf{0 . 2 5}$ & & $\mathbf{0 . 4 3 3}$ & $\mathbf{0 . 4 3 4}$ \\
\hline
\end{tabular}

It was decided to have multiple elements within a laminate thickness of a beam to have better distribution of strains, therefore element size across the thickness was reduced to $0.125^{\prime \prime}$. But, the element size along the length of the beam was increased to $0.5^{\prime \prime}$ as shown in Fig. 9-6. However, the total number of elements on a half-length model was 31,040, more than that needed for mesh convergence as shown in Table 9-2. The deflection at 3-kip loading was checked, which was obtained as 0.433 " similar to that obtained with 0.25 " element size.

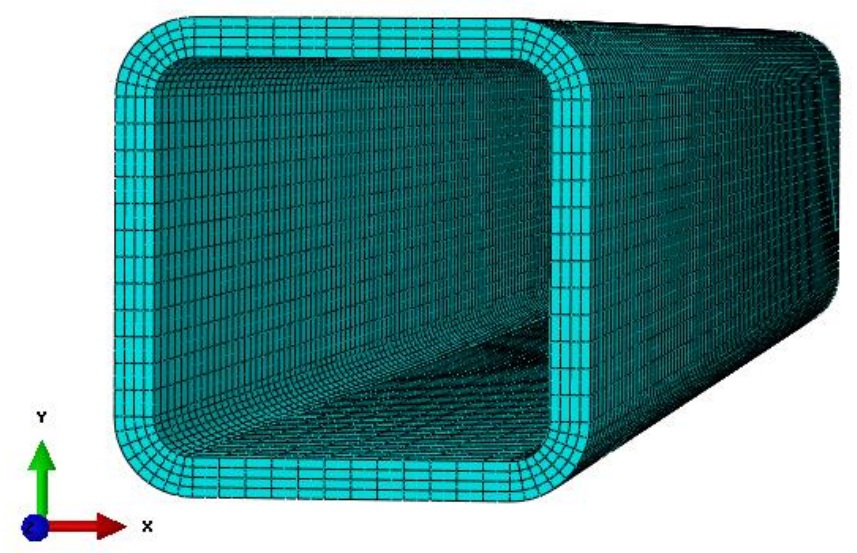

Figure 9-6. Box-beam model meshed with multiple elements within laminate thickness with 20node quadratic solid brick elements

\subsubsection{GFRP-steel hybrid model}

The steel plates were 4 " $x 0.125^{\prime \prime}$ and were created as 3D-deformable homogeneous section. Initially, the GFRP section was created with an extrusion of 4 " $x 0.125^{\prime \prime}$ area in the web or flange regions. Later, the plates were assembled into the open grooves of GFRP section as shown in Fig. 9-7. The steel plates and GFRP section was tied together with surface-based tie constraints. A surface-based tie constraint is generally used to make the translational and rotational motion as well as all other active degrees of freedom equal for a pair of surfaces and this constraint ties two surfaces together for the duration of a simulation (Abaqus manual). As strain compatibility was obtained between embedded steel plates and outer GFRP laminate during the experimental testing until the failure of the beams, it is reasonable to have a surface-to-surface tie constraint in the analysis. The surface-to-surface formulation generally avoids stress noise at tied interfaces and has fewer surface restriction compared to node-to-surface formulation. 


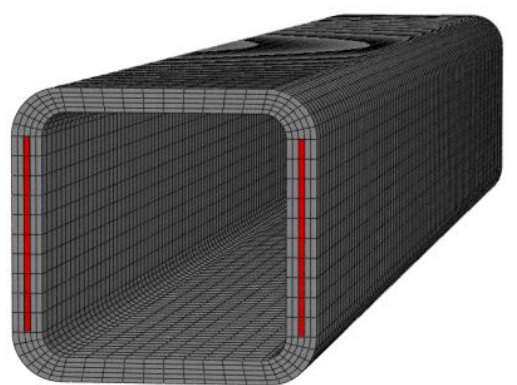

(a)

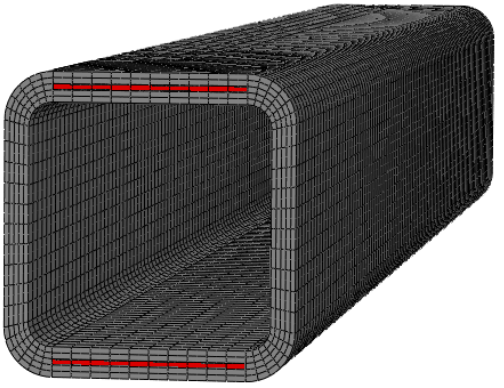

(b)

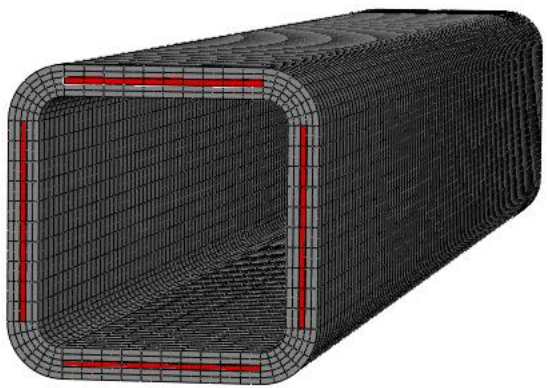

(c)

Figure 9-7. Hybrid box-beam models: (a) HWB, (b) HFB, (c) HAB (Note: Red shade = steel)

\subsection{Validation of FE models with experimental results}

The GFRP and hybrid beams were experimentally tested under service loads of 3,000 lbs. and 6,500 lbs. under three-point bending at span lengths of 84 and 36 inches, respectively to perform beam stiffness characterization, which is discussed in Chapter 7. These load levels are within service load levels and do not produce any non-linear response on the beams. Similarly, the FE models created for GFRP and hybrid beams were subjected to these load levels to validate the accuracy of the model by comparing deflection and strain values.

\subsubsection{Deflection and strains}

The Fig. 9-8 shows the mid-span deflection contour for control GFRP (CB) beams obtained through FEA. The result from FEA was in excellent correlation with experimentally obtained value. Similarly, Fig. 9-9 and 9-10 show bending strain and bending stress contours, respectively. The FE model showed higher compressive stresses and strains on the top flange compared to the tensile stresses and strains at the bottom flange. The higher compressive stresses and strains at the top flange possibly be due to loading applied on the compressive flange.

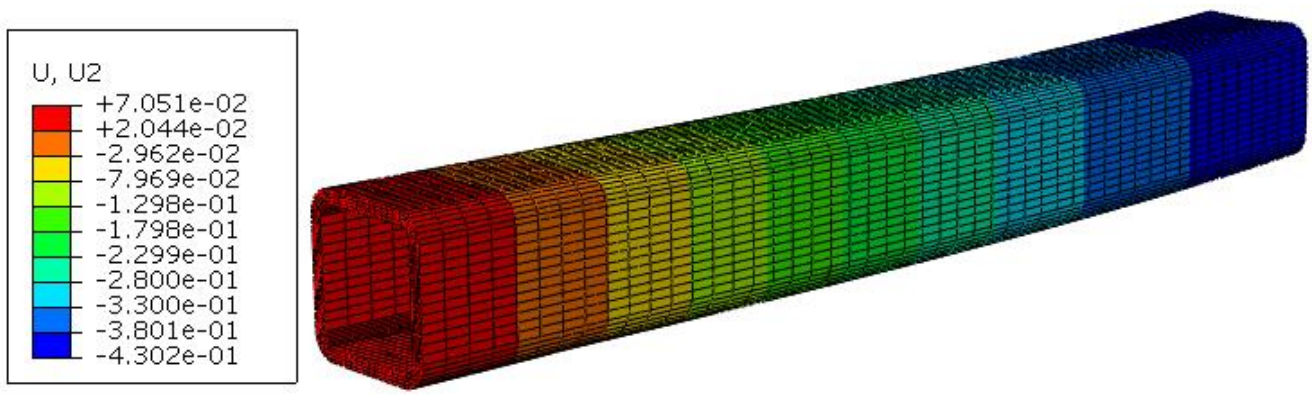

Figure 9-8. Half-length CB beam model showing vertical deflection contours 

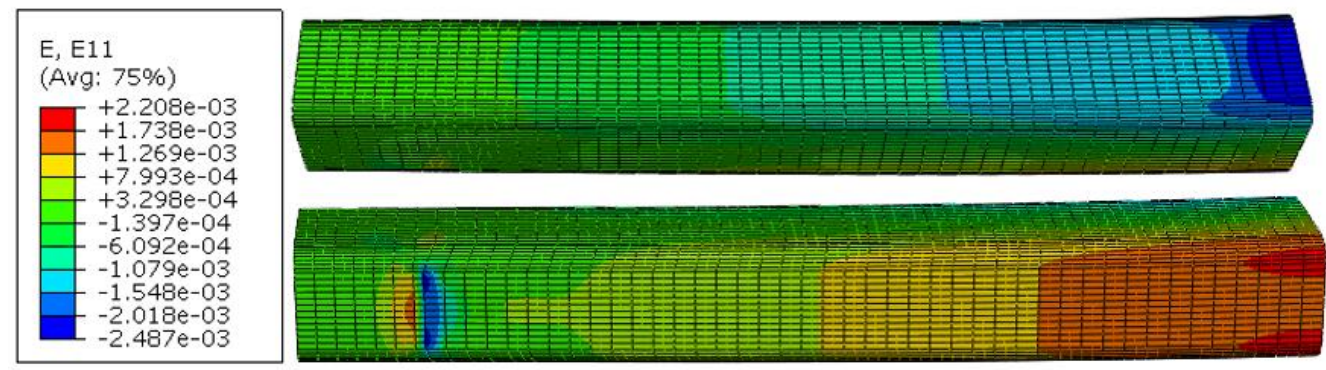

Figure 9-9. Half-length CB beam with compressive (upper) and tensile strain (bottom) contours

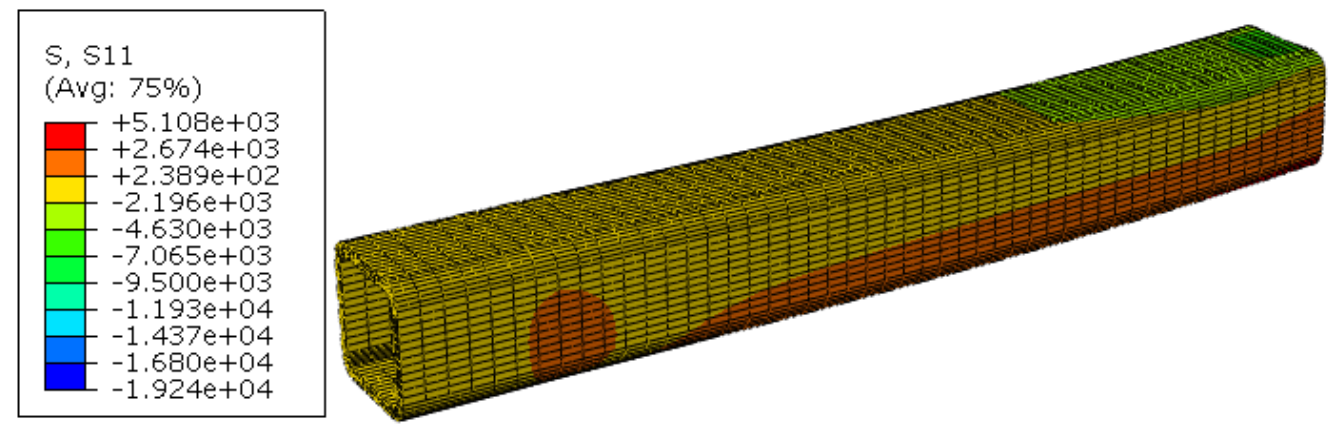

Figure 9-10. Half-length CB beam model showing bending stress contours

The Table 9-3 shows the comparison between FE results and experimental values for GFRP and hybrid beams. The results matched mostly within 10\% variation. However, for HWB and HAB beams, the results were differing by $12 \%$, which may be due to assumption of a perfect bonding between steel plates and GFRP in the FE model with tie-constraints, and that may not be the case during experimental testing. The reason is also highlighted due to lower deflection and strains observed in the FE model compared to experimental values.

Table 9-3. Comparison of deflection and bending strains between FEA and experimental values

\begin{tabular}{|c|c|c|c|c|c|c|c|}
\hline \multirow{2}{*}{ Beam } & \multirow{2}{*}{ 3-point load } & \multicolumn{2}{|c|}{ Deflection (in.) } & \multicolumn{2}{|c|}{ Compressive strain $(\mu \varepsilon)$} & \multicolumn{2}{|c|}{ Tensile strain $(\mu \varepsilon)$} \\
\hline & & FEA & Expt. & FEA & Expt. & FEA & Expt. \\
\hline $\mathrm{CB}$ & \multirow{4}{*}{$\begin{array}{c}\text { 3,000 lbs. } \\
@ \\
84 \text { in-span }\end{array}$} & 0.430 & 0.433 & 2487 & 2520 & 1830 & 1868 \\
\hline HWB & & 0.296 & 0.337 & 1617 & 1730 & 1330 & 1460 \\
\hline HFB & & 0.168 & 0.175 & 887 & 920 & 614 & 652 \\
\hline HAB & & 0.133 & 0.148 & 803 & 816 & 492 & 565 \\
\hline
\end{tabular}

\subsubsection{Stress distributions in GFRP and embedded steel plates}

The longitudinal bending stress contours obtained at a 3-kip central load at a span of 84 inches are shown in the Figs. 9-11, 9-12, and 9-13 for hybrid box-beams HWB, HFB, and HAB, respectively. The longitudinal stress in GFRP is denoted by S11 (stress along the longitudinal-axis of fibers) and the longitudinal stress in steel plates is denoted by S33 (stress along the beam global axis). For better visibility of stress contours, the only one-inch length at the mid-span of the beam is shown. The stresses observed in the embedded steel plates were higher than the surrounding GFRP section, possibly due to higher stiffness of steel plates compared to GFRP as the load is attracted more towards the stiff member in the composite section. In HWB beams (Fig. 9-11), the 
longitudinal bending stress in steel plates $(\sim 26 \mathrm{ksi})$ is almost 8-10 times more than the stress observed in the same surrounding area in GFRP ( 2.5-3 ksi)

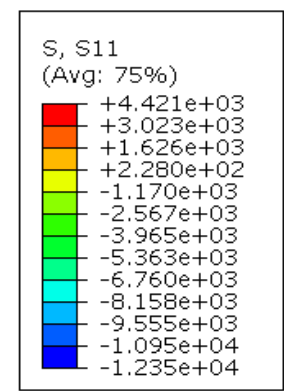

(a)

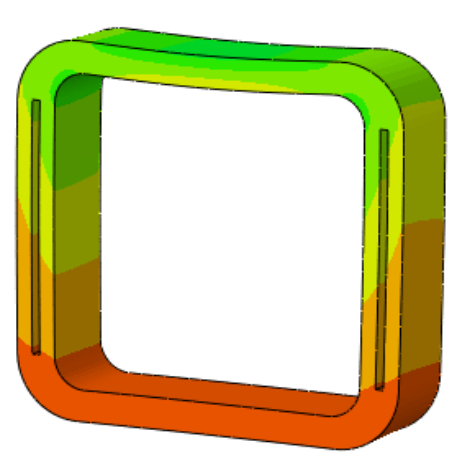

(a)

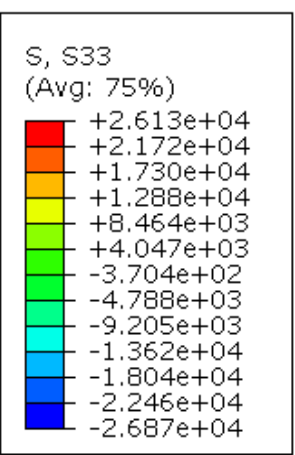

(b)
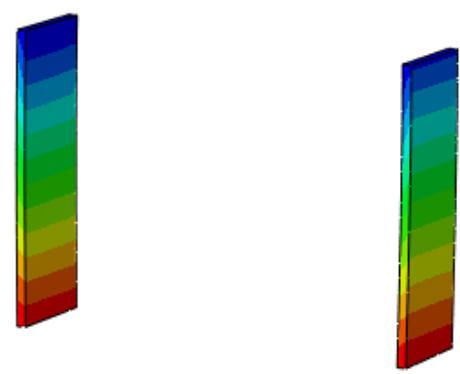

Figure 9-11. Longitudinal bending stress contours in HWB: (a) GFRP, (b) embedded steel plates

The stresses in GFRP section in HFB (Fig. 9-12a) and HAB beams (Fig. 9-13a) are less compared to HWB beam (Fig. 9-11a) possibly due to higher bending capacity of the box-beams with steel plates embedded in the flanges, achieved from higher moment of inertias.

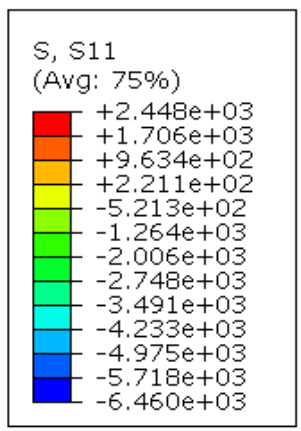

(a)

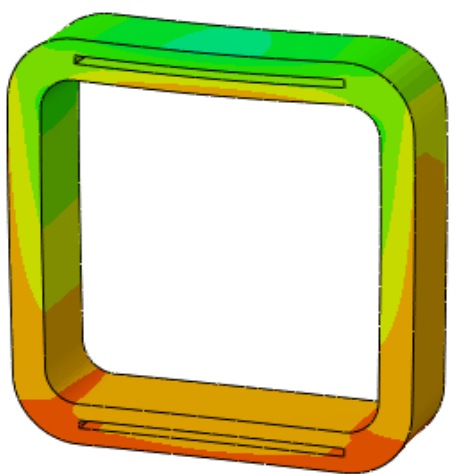

(b)

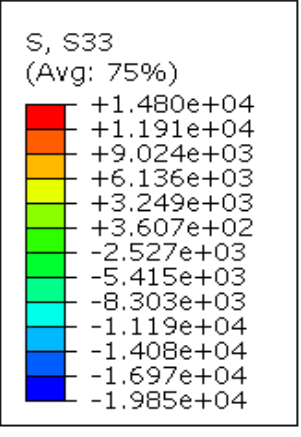

Figure 9-12. Longitudinal bending stress contours in HFB: (a) GFRP, (b) embedded steel plates

In HAB beams (Fig. 9-13), since there are four steel plates inside the section, the load is better distributed to all four plates as can be noticed from the stress values in plates in HAB beam (Fig. 9-13b) compared to stress values in plates in HFB beams (Fig. 9-12b) and HWB beams (Fig. 9-11b).

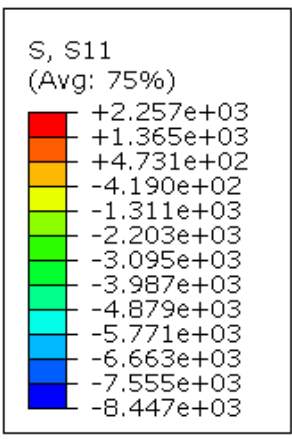

(a)

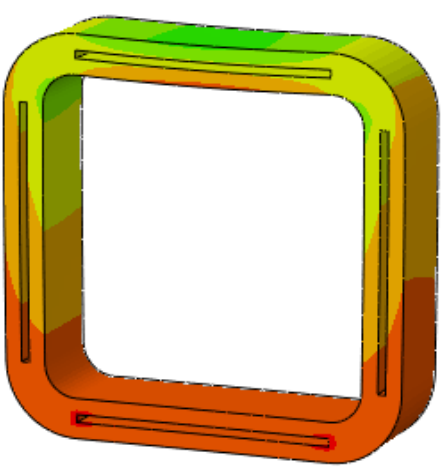

(b)
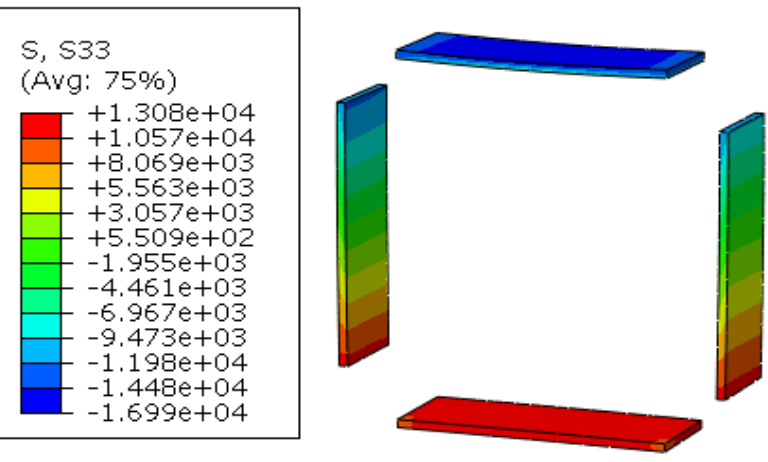

Figure 9-13. Longitudinal bending stress contours in HAB: (a) GFRP, (b) embedded steel plates 


\subsection{Inelastic behavior of hybrid beam models}

The stress vs. plastic strain data for the steel plate embedded inside the box-beam was obtained through experimental testing. The plastic strain is computed by subtracting elastic strain $\left(\varepsilon^{e l}\right)$ from the experimental strain values as shown in Eqn. (9-7).

$$
\varepsilon^{\mathrm{pl}}=\varepsilon^{\mathrm{total}}-\varepsilon^{\mathrm{el}}=\varepsilon^{\mathrm{total}}-\sigma / \mathrm{E}
$$

The stress-strain data obtained from the tensile testing of steel coupons as discussed in Chapter 6 was used to compute plastic strains for the steel and are shown in Table 9-4. The data shows that the steel undergoes hardening effect after yielding.

Table 9-4. Yield stress-plastic strain data for non-linear analysis

\begin{tabular}{|l|l|}
\hline Yield stress & Plastic strain \\
\hline 36,000 & 0 \\
\hline 40,000 & 0.0195 \\
\hline 44,000 & 0.0375 \\
\hline 48,000 & 0.0575 \\
\hline
\end{tabular}

The failure loads for the hybrid box-beams obtained through experimental testing was applied in the model to observe the maximum strains and stresses in the beams along with plastic strains in the embedded steel plates at the time of failure. At the experimentally obtained failure load level, the beams showed non-linear response with yielding of embedded steel plates. The loaddeflection plot, stress-strain distribution, and corresponding plastic strains in steel plates are discussed in following sub-sections.

\subsubsection{HWB beam model}

The hybrid box-beam model with steel plates in the webs was loaded centrally with a 23.9-kip load (failure load obtained experimentally). The load-deflection curve obtained from the model matched with the experimentally obtained curve with a maximum error of $6.5 \%$. The non-linear response was not distinct possibly due to lesser regions of steel plates under plastic yielding (top and bottom part in mid-span are under high stresses). Also, stiffer load-deflection curve obtained from the FE analysis is possibly due to an assumption of a perfect bond between steel plates and GFRP during simulation. 


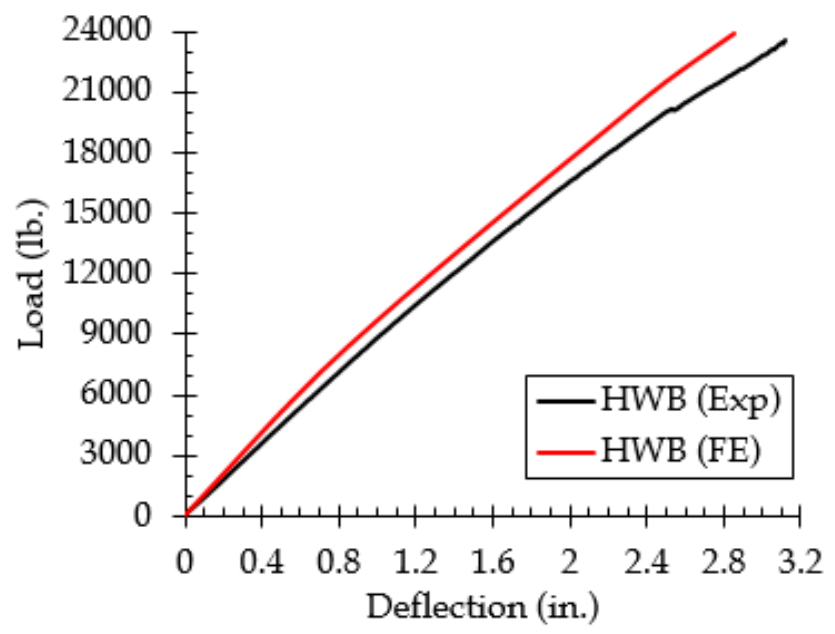

Figure 9-14. Load-deflection curves from FE and experiment for HWB beam at failure load

The maximum longitudinal bending strain and longitudinal bending stress are shown in Figs. 915(a) and (b), respectively. The maximum stress was observed in the compressive flange and was around $36.4 \mathrm{ksi}$, which is beyond the compressive strength of GFRP laminate which was obtained from coupon testing discussed in Chapter 6. Similarly, the transverse stress in the beam at the mid-span was around $35.5 \mathrm{ksi}$ (Fig. 9-16). The compressive stress values indicate that the beam is stressed beyond its compressive strength value, indicating a failure.

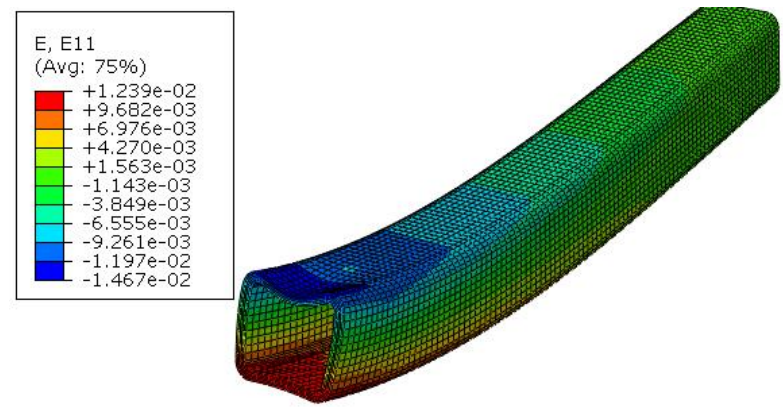

(a)

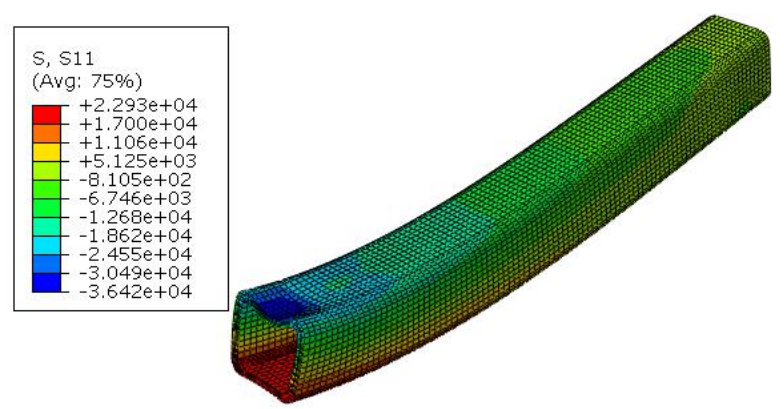

(b)

Figure 9-15. (a) Longitudinal bending strain, (b) longitudinal bending stress in HWB beam

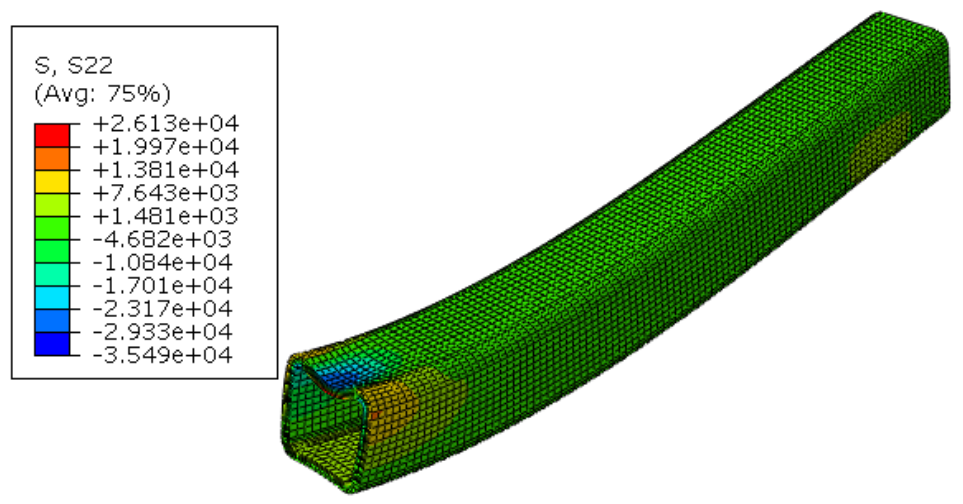

Figure 9-16. Transverse bending stress in HWB beam 
The bending and shear stresses were observed in the embedded steel plates in the HWB beam model as shown in Fig. 9-17a and 9-17b, respectively. The bending stress was around 43-45 ksi, which is beyond the yield strength of the steel plates. Similarly, the shear stress was obtained as around $11.4 \mathrm{ksi}$. The shear stress contours started from the support and moved along the length to meet the applied load (Fig. 9-17b).

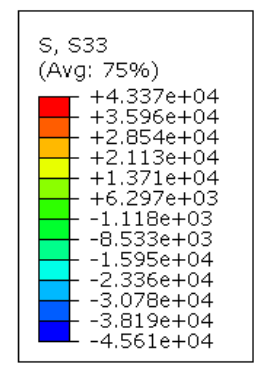

(a)

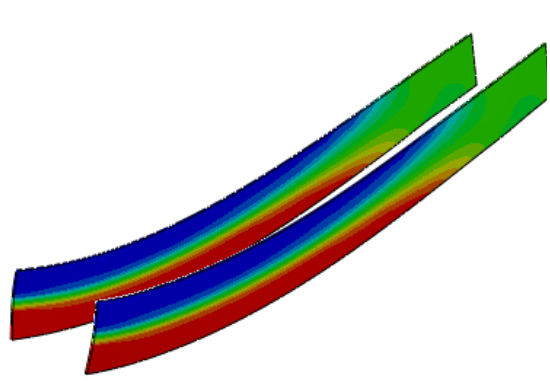

(b)

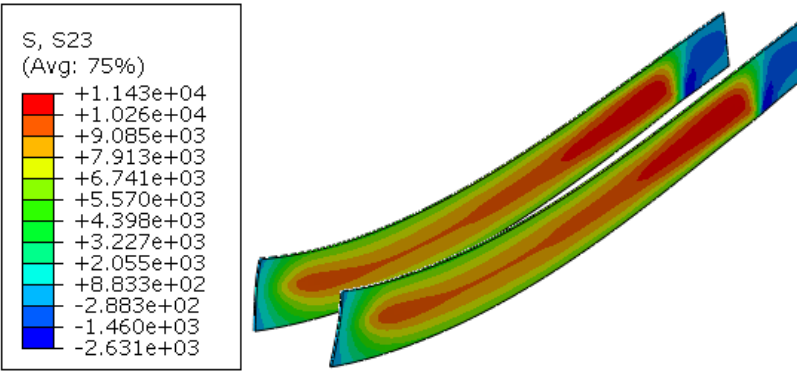

Figure 9-17. (a) Longitudinal bending stress, (b) shear stress in the embedded steel plates

The Fig. 9-18 shows the equivalent plastic strain in the embedded steel plates at the failure load. The high plastic regions were very small at the top and bottom of the plates near the mid-span (Note: the model is half-beam model). The lesser plastic regions in this beam might be the reason to not obtain distinct non-linear or bilinear load-deflection curve (Fig. 9-14)

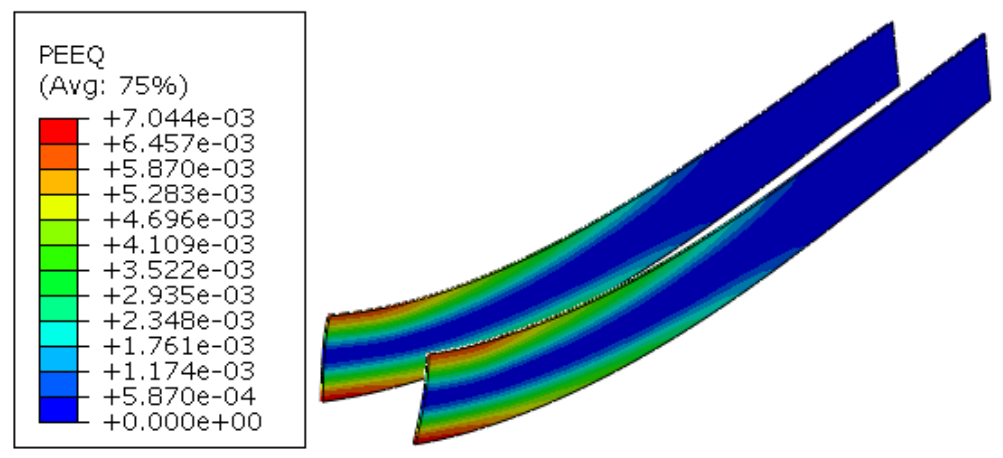

Figure 9-18. Plastic strain zones in the embedded steel plates in HWB beam

\subsubsection{HFB beam model}

The hybrid box-beam model with steel plates in the flanges was loaded centrally with a 16.8-kip load (failure load obtained experimentally). The load-deflection curve obtained from the model matched with the experimentally obtained curve with a maximum error of $14.7 \%$. The non-linear response was distinctly observed due to plastic deformation on the steel plates. The stiffer loaddeflection curve obtained from the FE analysis is due to an assumption of a perfect bond between steel plates and GFRP during simulation. 


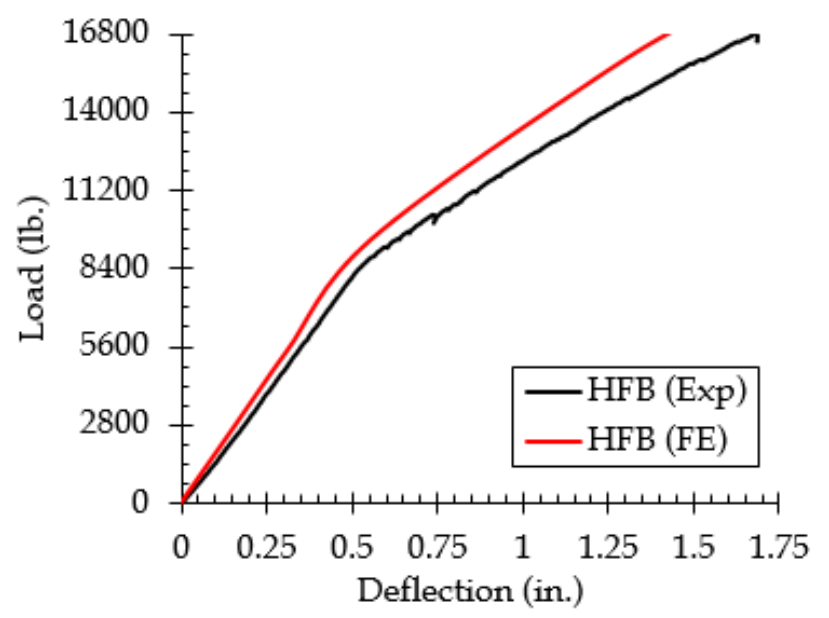

Figure 9-19. Load-deflection curves from FE and experiment for HFB beam at failure load

The maximum longitudinal bending strain and longitudinal bending stress are shown in Figs. 920a and 9-20b, respectively. The maximum stress of around $20.2 \mathrm{ksi}$ was observed in the compressive flange. Similarly, the transverse stress in the beam at the mid-span was around 16 ksi (Fig. 9-21). The compressive stress values indicate that the beam has not reached to its ultimate strength or strain to failure. However, when the failure was obtained at this load level during experimental investigation, it suggests that the beam failed though local effects, possibly due to debonding, delamination, and buckling.

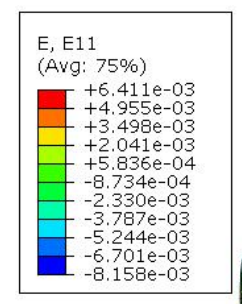

(a)

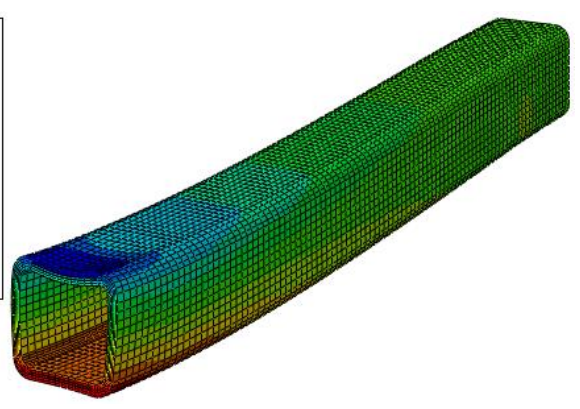

(b)

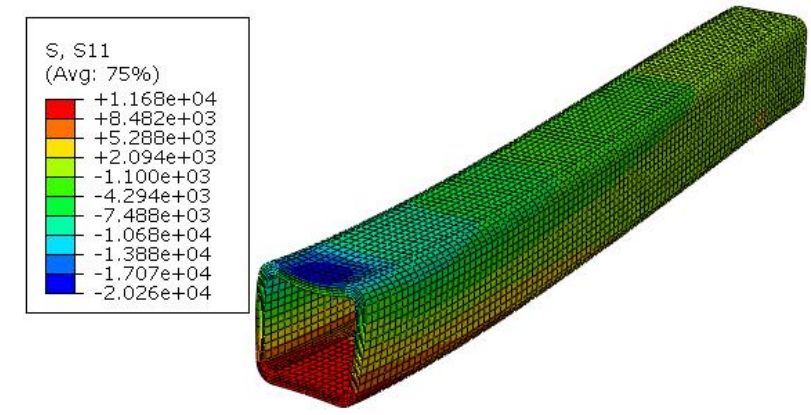

Figure 9-20. (a) Longitudinal bending strain, (b) longitudinal bending stress in HFB beam

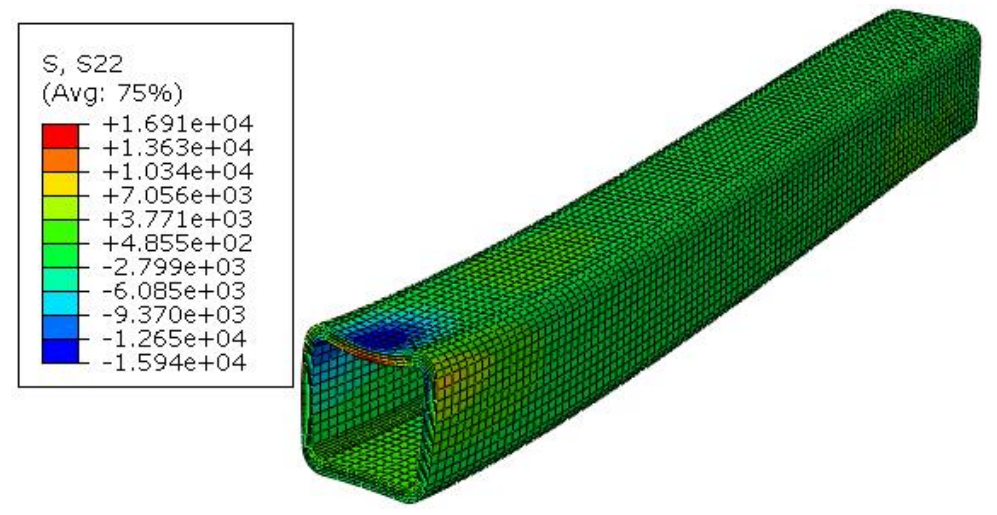

Figure 9-21. Transverse bending stress in HFB beam 
The bending strain and stress were observed in the embedded steel plates in the HFB beam model and are shown in Figs. 9-22a and 9-22b, respectively. The bending stress was around 43 ksi, beyond the yield strength of the steel plates.

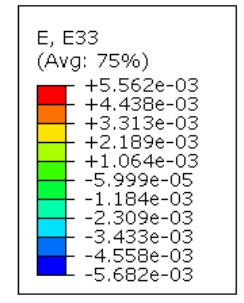

(a)

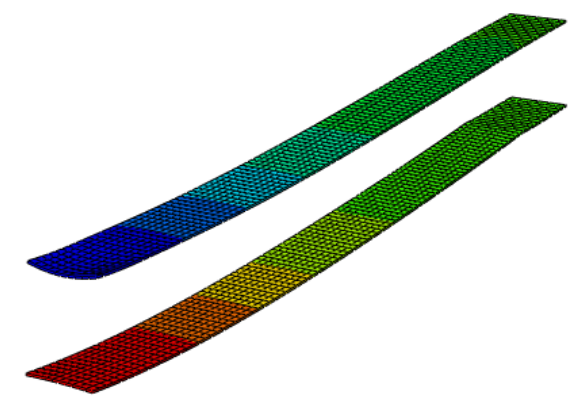

(b)

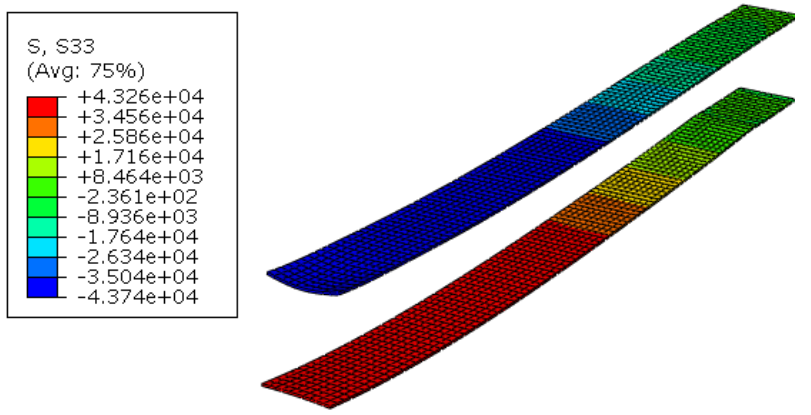

Figure 9-22. (a) Longitudinal bending strain, (b) longitudinal bending stress in steel plates

The Fig. 9-23 shows the equivalent plastic strain in the embedded steel plates at the failure load for HFB beam. Both top and bottom plates were under high plastic strains near the mid-span, which was the reason for the distinct non-linear or bilinear load-deflection curve (Fig. 9-19).

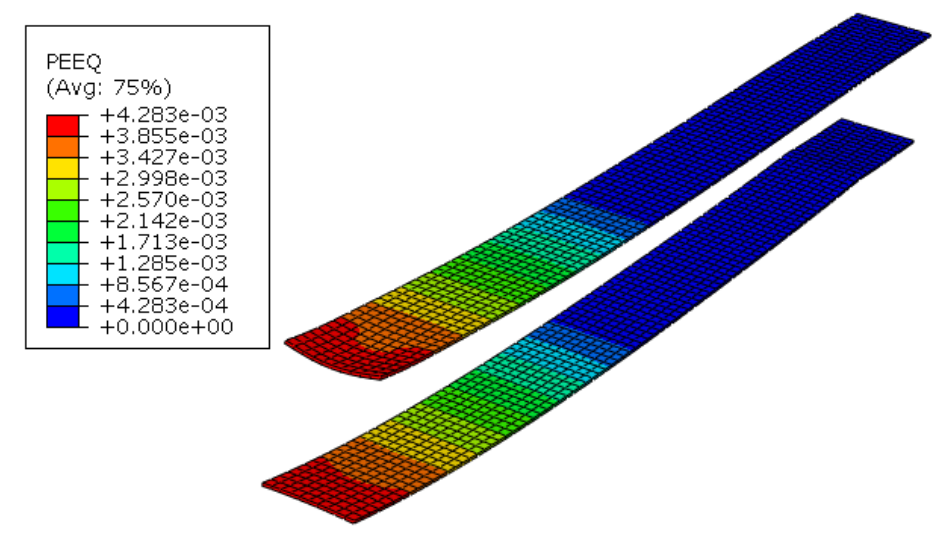

Figure 9-23. Plastic strain zones in the embedded steel plates in HFB beam

\subsubsection{HAB beam model}

The hybrid box-beam model with steel plates in both flanges and webs was loaded centrally with an 18.5-kip load (failure load obtained experimentally). The load-deflection curve obtained from the model matched closely with the experimentally obtained curve before the onset of steel yielding (Fig. 9-24). But after the plate yielding, the curve obtained from the FE model was stiffer with a maximum error of $32.3 \%$, suggesting that the debonding effects were dominant during experimental testing, while the model assumed a perfect bond between steel plates and GFRP during the analysis. 


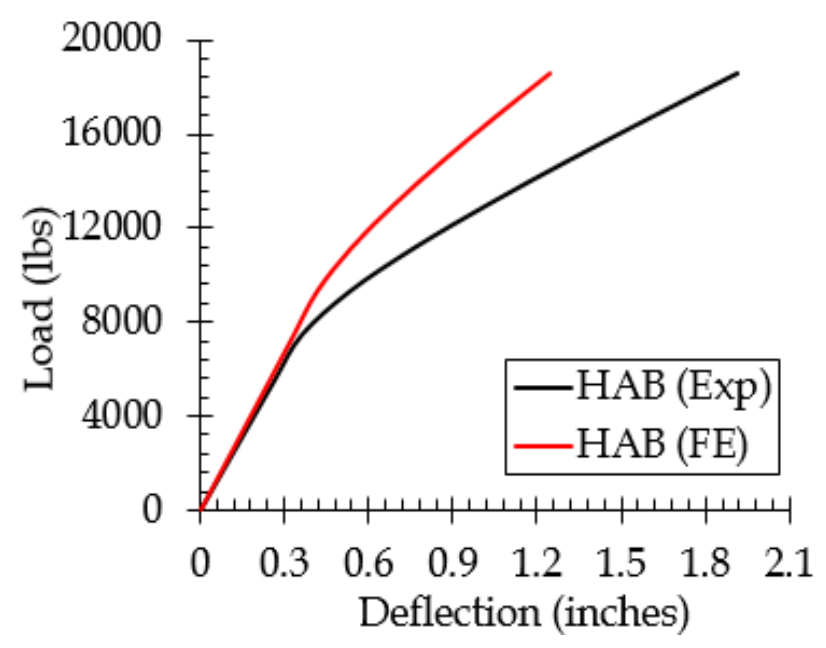

Figure 9-24. Load-deflection curves in HAB beam from FE and experiment

The maximum longitudinal bending strain and longitudinal bending stress are shown in Figs. 9$25 \mathrm{a}$ and 9-25b, respectively. The maximum stress of around $20.2 \mathrm{ksi}$ was observed in the compressive flange. Similarly, the transverse stress in the beam at the mid-span was around 20.8 ksi (Fig. 9-21). The compressive stress values indicate that the beam has not reached to its ultimate strength or strain to failure, suggesting the experimental beam failure due to local effects.

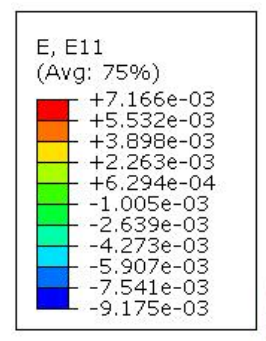

(a)

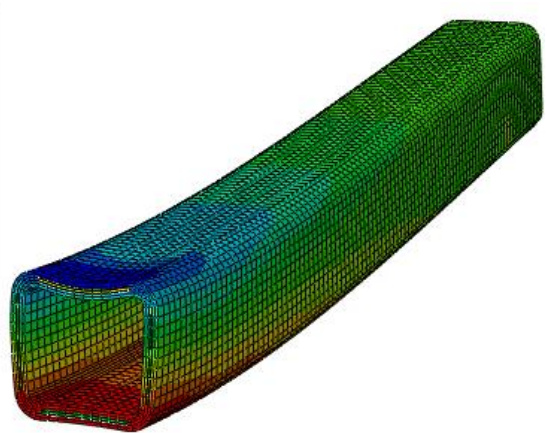

(b)
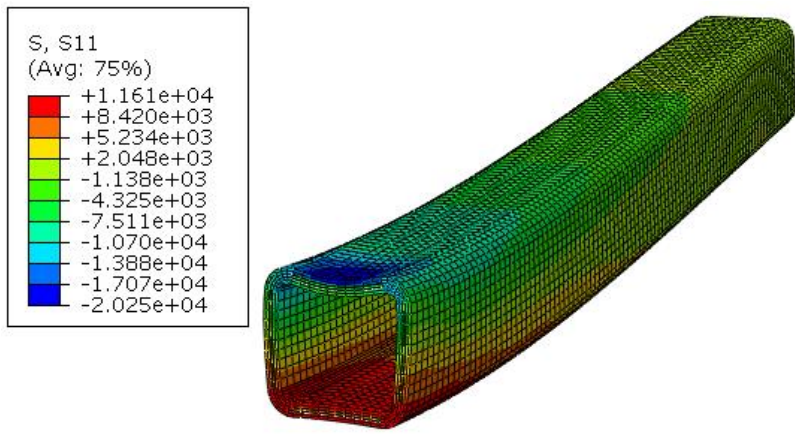

Figure 9-25. (a) Longitudinal bending strain, (b) longitudinal bending stress in HAB beam

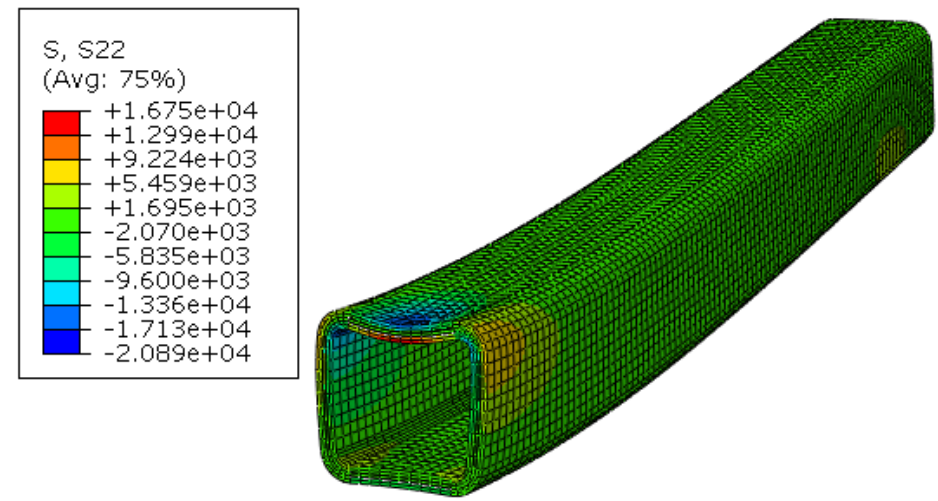

Figure 9-26. (a) Longitudinal bending strain, (b) longitudinal bending stress in HAB beam 
The bending strain-stress and shear strain-stress were observed in the embedded steel plates in the HAB beam model and are shown in Figs. 9-27 and 9-28, respectively. It is observed that the bending stresses are resisted by plates in the flanges (Fig. 9-27b) and similarly, shear stresses are resisted by plates in the webs (Fig. 9-28b).

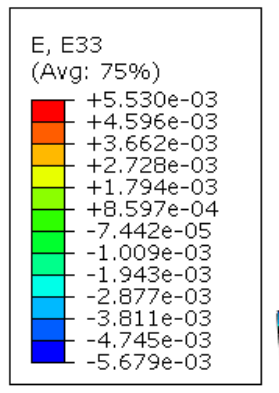

(a)

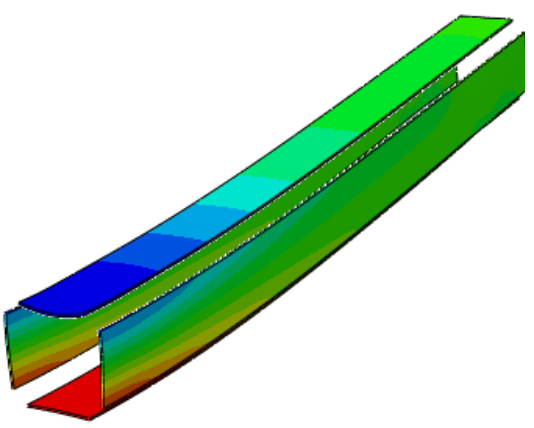

(b)

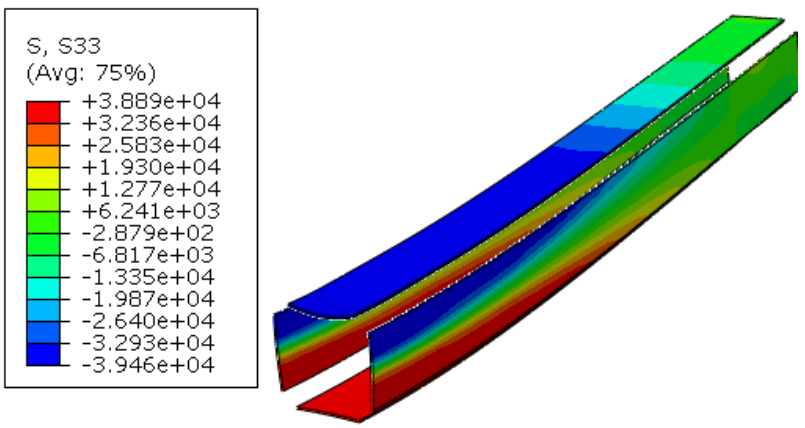

Figure 9-27. Longitudinal bending-(a) strain, (b) stress in embedded plates in HAB beam

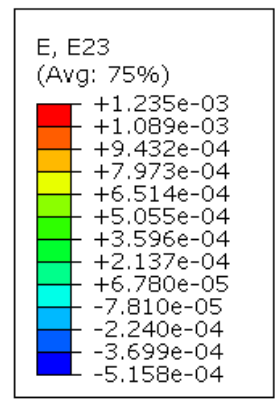

(a)
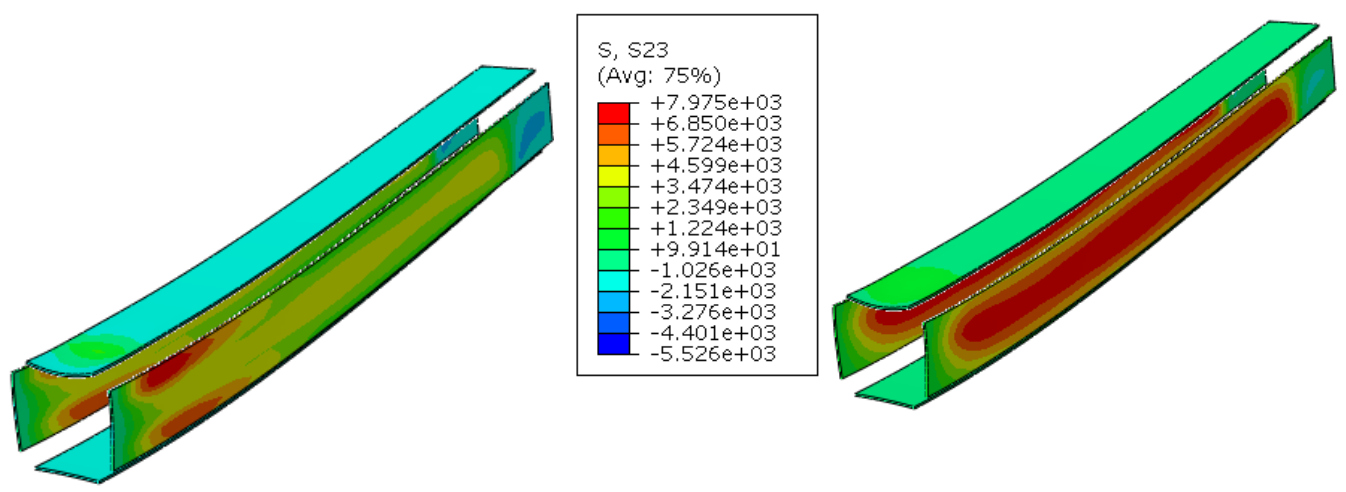

(b)

Figure 9-28. (a) Shear strain, (b) shear stress in embedded plates in HAB beam

The Fig. 9-29 shows the equivalent plastic strain in the embedded steel plates at the failure load for HAB beam. The plates in the flanges were under higher plastic strains near the mid-span, while the plates in the webs were not showing much plastic deformation.

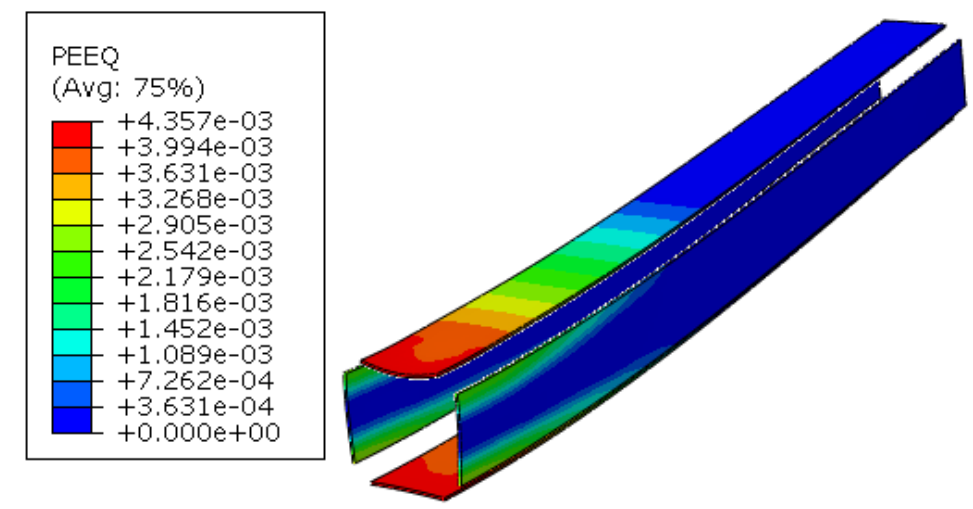

Figure 9-29. (a) Longitudinal bending strain, (b) longitudinal bending stress in HWB beam 


\subsection{Conclusions}

The structural behavior of GFRP and hybrid box-beams under bending and shear loads were successfully studied using finite element method. The following conclusions can be summarized.

1. The FE models for hybrid GFRP-steel box-beams developed by using 3D-solid elements (C3D20 and C3D20R) through this study showed results that correlated very well with the experimental values during the elastic stages. However, the FE and experimental values differed as much as by $32.3 \%$ during the plastic stages after the onset of steel yielding. The load-deflection and load-strain curves obtained from the FE models during all stages matched with the experimentally obtained curves with an error ranging from $2 \%$ to $32.3 \%$.

2. The bending and shear stresses in GFRP were lower in the hybrid section than that in the nonhybrid GFRP section at similar load levels. The hybrids showed higher bending stresses in the embedded steel plates than that in the surrounding GFRP section. The load was resisted more by the plates possibly due to its higher stiffness, thus acting as a stiffer member.

3. The bending strain-stress and shear strain-stress contours observed in the embedded steel plates of hybrid beams showed steel plates in the flanges were under higher bending stresses and steel plates in the webs under higher shear stresses.

4. The hybrid beams (HFB and HAB) showed higher bending capacity as the stresses in the GFRP section in HFB and HAB beams were lower compared to HWB beams. The embedded plates in flanges helped achieve higher moment of inertia. In HAB beams, the load was better distributed to all four steel plates.

5. The non-linear analysis on GFRP-steel hybrids at higher loads was performed. The bilinear load-deflection curves for the hybrid beams during plastic stages matched with the experimental curves with an error ranging from $6.5 \%$ to $32.3 \%$. The model predicted stiffer load-deflection curve after the onset of plastic deformation in steel plates due to an assumption of a perfect bonding between steel plates and GFRP during the analysis.

6. Under experimental failure load, the FE models showed higher bending compressive strains than tensile strains possibly due to the load applied at a smaller area on the top flange. The compressive strain values in the hybrid beams (HFB and HAB) were below their coupon-level ultimate failure strains, suggesting the failure was governed by local effects.

7. The plates in the flanges were under higher plastic strains near the mid-span for both hybrid beams (HFB and $\mathrm{HAB}$ ), while the plates in the webs exhibited very limited plastic deformation in beams (HWB and HAB). The bi-linear response of these hybrid beams was due to the plastic deformation of flange steel plates. The plastic deformation in web steel plates did not produce bi-linear beam response for HWB beam. 


\section{Chapter 10. Bolted Connections on GFRP and Hybrid members}

This chapter discusses the preparation of single and double bolted connection on GFRP and GFRP-steel hybrid laminates and presents the comparison of the experimental test results.

\subsection{Introduction}

Joints are often the weakest points in FRP composite structures as they do not possess ductility like metals and are incapable to redistribute local high stresses by yielding (Khashaba et al. 2013). At the same time, the bolted connection is one of the most common method of connecting structural members, mainly in civil infrastructure application, due to ease of assembly or disassembly, maintenance, and inspection processes. The bolted connection primarily transfers forces between structural components and is one of the most critical processes needed in either building or bridge constructions. The bolted connections are quite popular in construction industry mainly with steel and wood members. However, in FRP composites, bolted connections present some vulnerability, as holes drilled for bolts break the load carrying fibers and introduce high stress concentration zones, which is susceptible to fracture and cracking.

The understanding of the mechanical behavior of connections is very crucial to determine the capacity of the structure, which if often limited by the capacity of its connections. The objective in this chapter is to carry out experimental studies of single-row and double-row bolted connections in GFRP and GFRP-steel hybrid structural members under tensile loads as shown in Figs. 10-1 and 10-2. The study will highlight the comparison of the structural performance of the hybrid GFRP-steel members compared to all-GFRP members. The main objectives of the study presented in this chapter was to perform experimental evaluation of GFRP and GFRP-steel hybrid structural connections and analyze the ultimate failure load and failure mode on each connection.
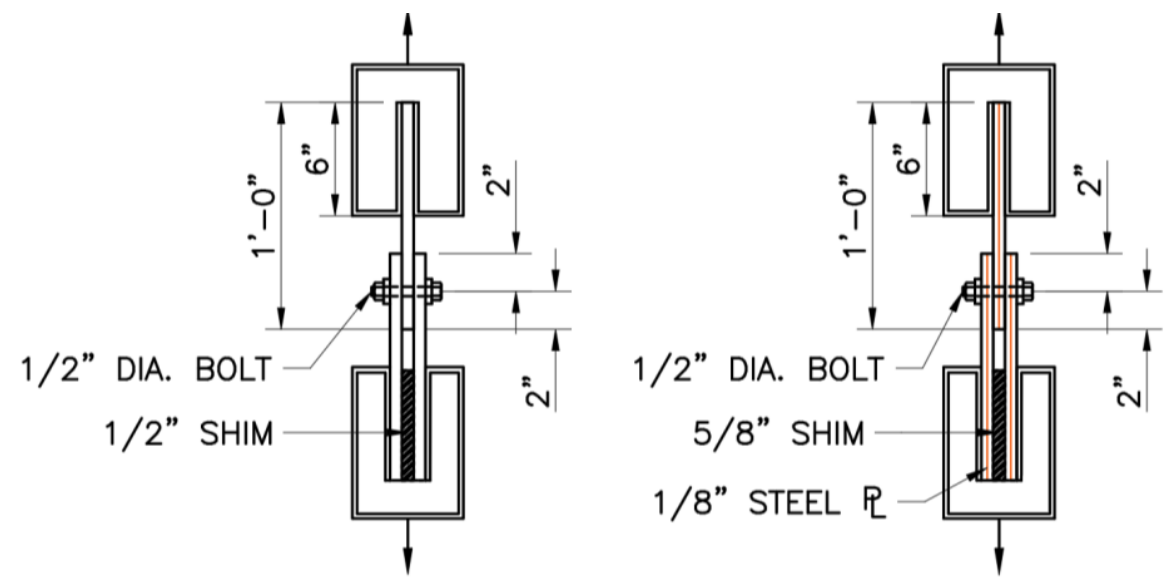

Figure 10-1. Single-row bolted connections in all-GFRP and hybrid members under tension 

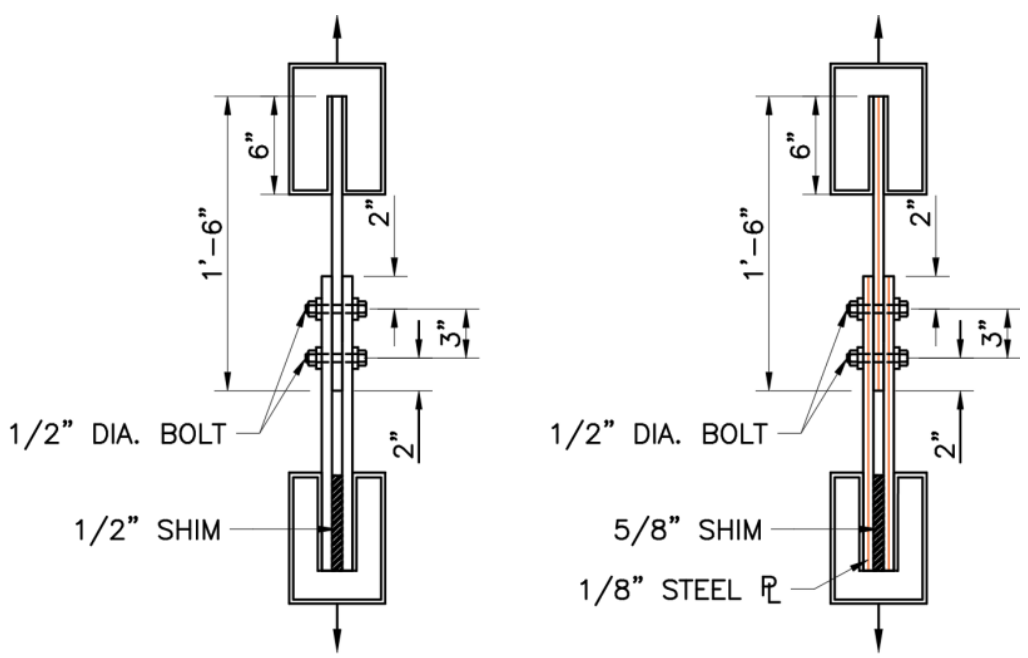

Figure 10-2. Double-row bolted connections in all-GFRP and hybrid members under tension

\subsection{Background on bolted connections}

Due to advances in capability of pultrusion and vacuum infusion technology, large and repetitive FRP composite parts are manufactured, which ultimately are looking for the place in structural applications (Bank, 2006, Mottram, 2009). The structural application of these mass manufactured composite members requires joining mechanism, and which have been derived mainly from steel connections. In civil engineering application, as stated earlier, bolted joints are the most practical connection despite having high stress concentrations due to drilling of holes (Thoppul et al. 2009). The holes reduce load-bearing capacity of FRP composite due to anisotropic, heterogeneous, and brittle nature of FRP, unlike ductile behavior of steel. There is also and bonded (adhesive) connection possibility in FRP, but the failure of bonded connection is sudden instead of gradual failure as observed in bolted connection and adhesive bonding is affected by environmental factors and the integrity of the connection during service life is very hard to quantify.

There are several parameters that affect bolted joint performance such as FRP laminate lay-up, ply orientation, stacking sequence, material properties, geometric dimensions, edge and pitch distances, number of bolts, bolt pattern, bolt torque, etc. (Pisano et al. 2013, Manalo 2012). The failure modes in FRP members under bolted connections are more complex than that observed in adhesively connected FRP members (Fig. 10-3). These failure modes are mainly true in FRP members loaded in transverse or longitudinal to their major axis of fiber orientation.

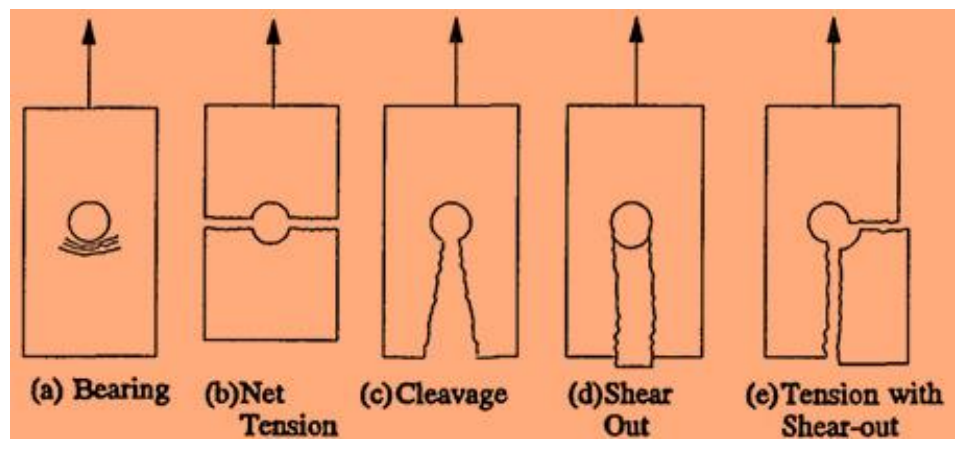

Figure 10-3. Failure modes on (a) bolted joints, (b) adhesive joint (Sotiropoulous et al. 1995) 
The bearing failure is the preferred failure mode in FRP connections and is more of a ductile in nature unlike net-tension and shear-out failures which are brittle (Abdelkerim et al. 2019). It typically occurs when the width of the member to the bolt diameter $(\mathrm{w} / \mathrm{d})$ is high and is caused by the bolt bearing on the member and inducing a compressive stress leading to local crushing and delamination of the FRP member (Bank, 2006, Clarke, 1996). The net tension failure and shear-out failure are brittle failures and are more likely to occur when the ratio of the member width to the bolt diameter $(\mathrm{w} / \mathrm{d})$ is low, or when the connection end distance is shorter, respectively. The crack forms due to large compressive or tensile stresses at the edges of the hole along a plane that is perpendicular to the direction of loading and between bolt holes or the bolt hole and the edge of the material. A block shear failure occurs when a connection is loaded to both shear and tensile loads. The shear failure in bolts occurs due to high shear stresses is not intended at all and occurs mainly in under-designed connections. The experimental study in this chapter was mainly performed to cause failure in members and study their failure modes.

\subsection{LRFD Pre-standard Bolted Connection Criteria}

The LRFD pre-standard published by ASCE provides recommendation on bolt size and type, and member geometric dimensions, etc. for bolted connections in structural members. The geometric dimension guidelines are shown in Table 10-1. In addition, the recommended geometries for lap joints that were determined through an extensive research database and published in Bank, 2006 are also shown in Table 10-1.

As per the guidelines, the recommended bolt sizes for FRP connections are $3 / 8$ " to 1 " in diameter. The recommended nominal drilled-hole diameter should be 1/16 in. larger than the nominal bolt diameter. However, Bank (2006) has stated that the holes should not be 1/16 in. larger than the bolt diameter as FRP connections are bearing connections, the oversized hole allows the connection to slip before it can bear on the connected member, causing added stress and deflections to the structure (Bank, 2006). It also recommends using at least one flat circular steel washer at the head of the bolt and at the nut having an outer diameter at least twice the nominal bolt diameter and with a thickness not less than 5/32 in.

Table 10-1. ASCE-LRFD Pre-standard minimum requirement for bolted connection geometries

\begin{tabular}{|l|c|c|c|}
\hline \multicolumn{2}{|l|}{ Item definition } & ASCE-LRFD Minimum & Bank, 2006 \\
\hline Plate width & $\mathrm{w}$ & - & $5 \mathrm{~d}$ \\
\hline End distance-1 row of bolts & \multirow{2}{*}{$\mathrm{e} 1$} & $4 \mathrm{~d}$ & $3 \mathrm{~d}$ \\
\cline { 1 - 4 } End distance-2 to 3 rows of bolts & & $2 \mathrm{~d}$ & - \\
\hline Edge distance & $\mathrm{e} 2$ & $1.5 \mathrm{~d}$ & $2 \mathrm{~d}$ \\
\hline Pitch spacing & $\mathrm{s}$ & $4 \mathrm{~d}$ & $4 \mathrm{~d}$ \\
\hline
\end{tabular}

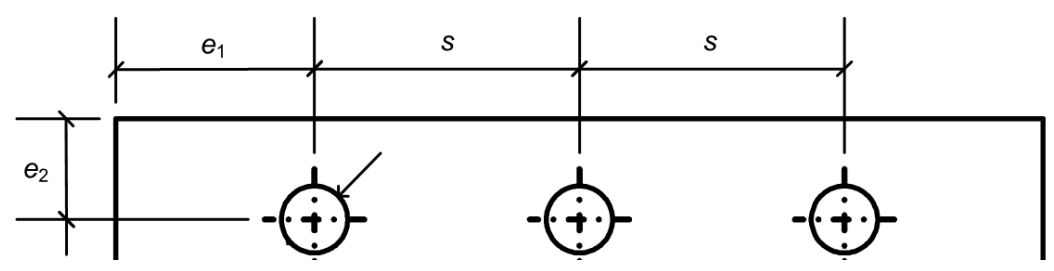

Figure 10-4. Edge, end and pitch distances in bolted connection (ASCE-LRFD, 2010) 


\subsection{Experimental methods}

First of all, GFRP and hybrid GFRP-steel laminates were cut from the flanges and webs of boxbeams using table saw and water-jet cutting methods, respectively. The 2 in-wide flat specimens were cut at a length of 12 " for testing with single bolted connection, and at a length of $18^{\prime \prime}$ for testing with double bolted connections.

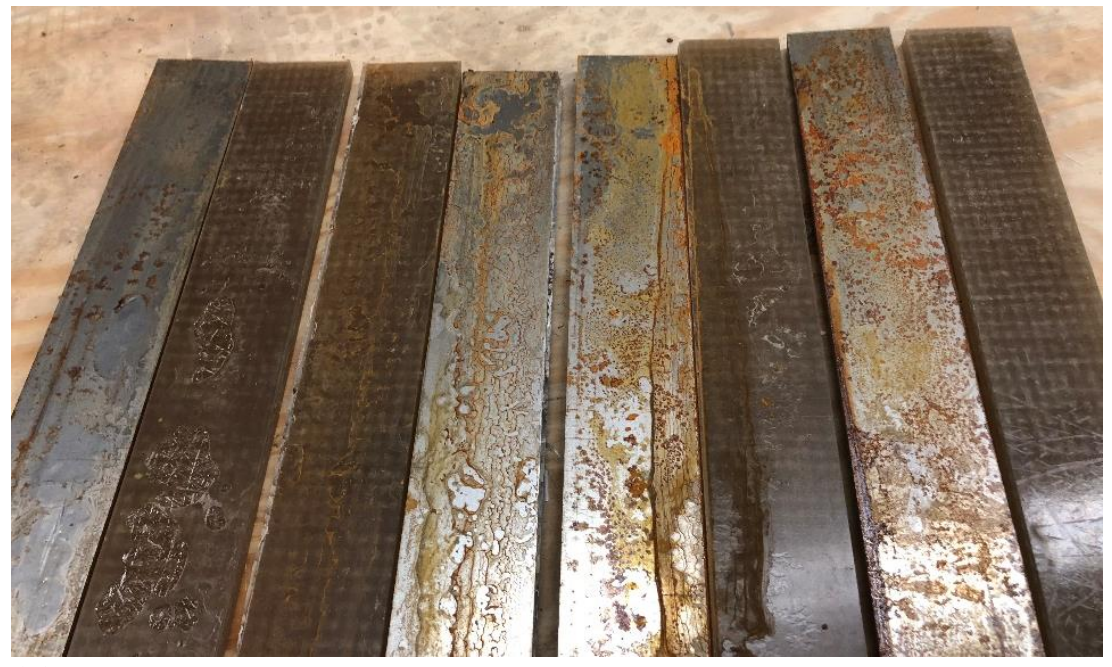

(a)

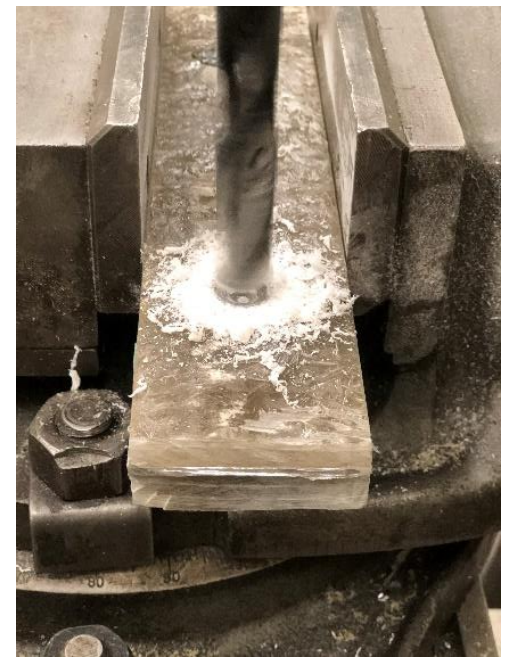

(b)

Figure 10-5. (a) Two-inch wide GFRP and steel specimens, (b) drilling a hole in the member

For GFRP-steel hybrid samples, as steel plates were separated during cutting process, they had to be bonded with an adhesive. The use of an adhesive needed some surface preparation of samples and a sequence of process that were followed in the laboratory are stated below.

- The steel plate surface was sanded with a regular medium-grit sandpaper.

- The GFRP laminate surface was minimally sanded with low-grit sand paper and was cleaned to remove dust and debris.

- The two-part polyurethane based adhesive "pliogrip" was mixed and applied over the bonded surface with a flat spatula.

- The steel plate was glued to GFRP laminate on both sides and the hybrid laminate was clamped with few clamps evenly spaced along the length.

- The excess adhesive flowing out of the hybrid laminate was wiped away and the laminate was left to cure for 24 hours in a room temperature.

- The clamps were removed after the adhesive was cured and the holes were drilled on the laminates as shown in the Fig. 10-5b.

A double-lap configuration testing as shown in Figs. 10-1 and 10-2 was selected for both singlebolted and double-bolted connection testing to eliminate secondary bending effects from load eccentricity, which is typically observed in single-lap joints. End tabs were not used during testing coupons under bolted connection, as the specimen was expected to fail in the vicinity of bolt hole. A spacer block of the same thickness was placed at the grip area to assure uniform, inplane loading as shown in Figs. 10-1 and 10-2. 
The bolts that were used in the experimental study were Grade- 5 Hex-bolts having a minimum yield strength of $92 \mathrm{ksi}$ and minimum tensile strength of $120 \mathrm{ksi}$. The two-size, one 3/8" diameter bolts and the other $1 / 2^{\prime \prime}$ diameter bolts were used in the study to observe different failure modes. The diameter for the bolt holes were 1/16" larger than the diameter of the bolts, as recommended by the AISC and ASCE-LRFD code standards. The bolts were snug-tightened which means they were installed in the manner as done while installing the lug nut on the wheel of a car, where each nut is turned to refusal according to American Institute of Steel Construction. However, the tightness of the bolts was checked with the torque wrench having a torque capacity of 50 lb.-ft.

The connected members were tested in tension in Instron 1000HDX by providing a grip length of 6 inches. The load and slip were recorded from the Instron in-built sensor and axial strains were recorded at the locations shown in Fig. 10-6. The test configuration was designed to cause failure on the member as shown in the Fig. 10-6.
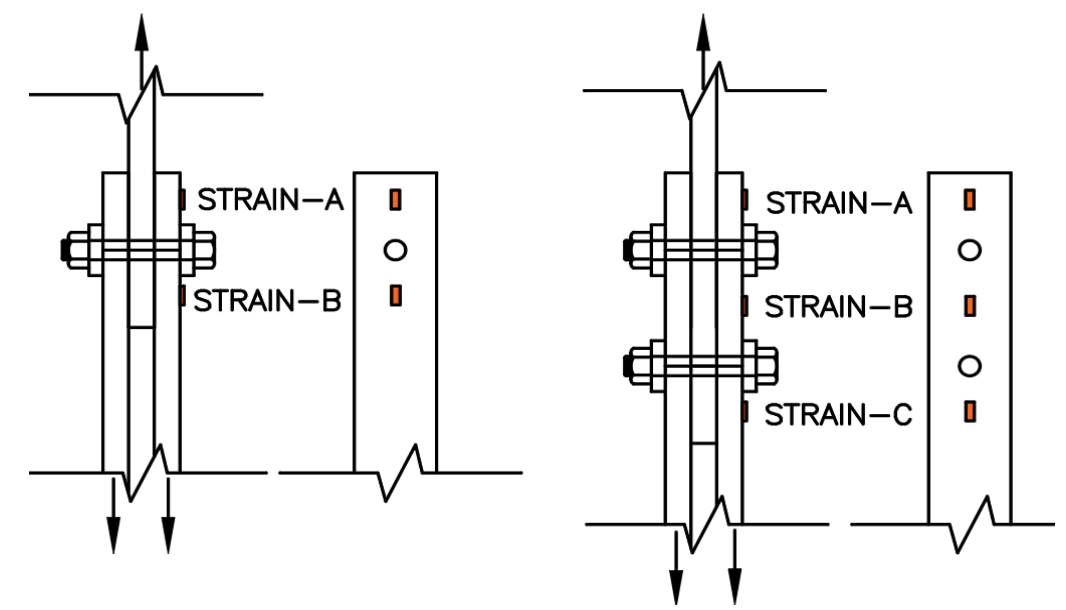

Figure 10-6. Location of strain gages in single- and double-row bolted connection

\subsection{Data interpretation}

The ultimate failure load and the slip in the joints were recorded from the data acquisition to compute the joint strength $\left(\sigma_{\text {ult }}{ }^{j}\right)$ as shown in Eqn. (10-1) (Sotiropoulos et al. 1995).

$$
\sigma_{\text {ult }}^{j}=\frac{P_{u l t}}{\left(w-d_{h}\right) t}
$$

Where, $P_{\text {ult }}$ is the ultimate load sustained by the joint, $\mathrm{w}$ is the width of the member, $\mathrm{d}_{\mathrm{h}}$ is the diameter of the hole, and $t$ is the thickness of the member. In addition to joint strength, the efficiency of the bolted connection, regardless of the failure mode, was computed as a fraction of the tensile strength of the member as given by Eqn. (10-2). Joint efficiency shows the magnitude of strength loss due to placement of joints in the member.

$$
\text { Joint efficiency }=\frac{\sigma_{\mathrm{ult}}{ }^{\mathrm{j}}}{\mathrm{F}_{\mathrm{t}}}
$$

Where, $F_{t}$ is the tensile strength of the member, which was obtained experimentally as $28.3 \mathrm{ksi}$ for GFRP and $27.0 \mathrm{ksi}$ for hybrid laminates as discussed in Chapter 6. The width to diameter of hole ratio (w/D) and edge distance ratio (e/D) were computed as shown in Eqns. (10-3 and 10-4) since test results and the failure modes are mostly dependent on these ratios. 


$$
\begin{aligned}
& \frac{\mathrm{w}}{\mathrm{D}}=\frac{\text { width of laminate across hole }}{\text { hole diameter }} \\
& \frac{\mathrm{e}}{\mathrm{D}}=\frac{\mathrm{g}+\mathrm{D} / 2}{\mathrm{D}}
\end{aligned}
$$

Where, $\mathrm{g}$ is the distance from hole edge to specimen end. The stresses in GFRP laminate under other failure modes such as bearing $\left(\sigma_{\mathrm{br}}\right)$, shear-out due to presence of the bolt having a diameter (d) are given by Eqns. (10-5) and (10-6), respectively.

$$
\begin{gathered}
\sigma_{\mathrm{br}}=\frac{\mathrm{P}}{\mathrm{dt}} \\
\tau_{\mathrm{v}}=\frac{\mathrm{P}}{2 \mathrm{et}}
\end{gathered}
$$

Where, $\mathrm{P}$ is the load on a single bolt, $\mathrm{e}$ is the end distance, and $\mathrm{t}$ is the thickness of the laminate.

\subsection{Experimental results}

The experimental test results on single- and double-bolted connection testing in GFRP and hybrid

\begin{tabular}{|c|c|c|c|}
\hline \multirow{2}{*}{\multicolumn{2}{|c|}{ Item }} & \multicolumn{2}{|c|}{ Values used in the experiment } \\
\hline & & For $\mathrm{d}=1 / 2 "$-dia. bolt & For $\mathrm{d}=3 / 8 \mathrm{~s}$-dia. bolt \\
\hline Plate width & W & $4 \mathrm{~d}$ & $5.3 \mathrm{~d}$ \\
\hline End distance- 1 or 2 row / s of bolt & E1 & $4 \mathrm{~d}$ & $3.3 \mathrm{~d}$ \\
\hline Edge distance & E2 & $2 d$ & $5.3 \mathrm{~d}$ \\
\hline Pitch spacing & S & $6 \mathrm{~d}$ & $8.0 \mathrm{~d}$ \\
\hline
\end{tabular}
GFRP-steel members are presented in this section. The geometric dimensions for the single-bolted and double-bolted connections based on the diameter of the bolt (d) are shown in Table 10-2.

Table 10-2. Bolted connection geometries for single-and double-bolted connections

\subsubsection{Single bolted connections}

For single-bolted connection testing, the GFRP laminate was 2 -in wide, $1 / 2$-in thick and 12 -in long. Similarly, hybrid GFRP-steel laminate was 2 -in wide, $5 / 8$-in thick and 12 -in long. The subsections are segregated based on $1 / 2^{\prime \prime}$ and $3 / 8^{\prime \prime}$ diameter bolts.

\subsubsection{With a 0.5 -in diameter bolt}

A typical load-displacement or load-slip curve obtained during the experimental testing of single bolted connection with $0.5^{\prime \prime}$-diameter bolt for GFRP and hybrid specimens are shown in Fig. 107. The curves for both GFRP and hybrid specimens are linear up to the maximum force, after which a sudden drop in load is observed in both curves, indicating a failure in the material. The ultimate failure load, connection strength and joint efficiencies for the single-bolted connection in GFRP and hybrid members are presented in Table 10-3. The joint in hybrid member showed higher joint strength and showed and efficiency of 0.96 . 
Table 10-3. Test results for GFRP and hybrid sections connected with one $0.5^{\prime \prime}$-diameter bolt

\begin{tabular}{|c|c|c|c|c|c|}
\hline Section & Failure load & $\sigma_{\text {ult }}{ }^{j}$ & Joint efficiency & Strain - A & Strain - B \\
\hline GFRP & 16,600 lbs. & $23.1 \mathrm{ksi}$ & 0.82 & -1507 & 2915 \\
\hline Hybrid & $23,200 \mathrm{lbs}$. & $25.9 \mathrm{ksi}$ & 0.96 & -3060 & 1430 \\
\hline
\end{tabular}

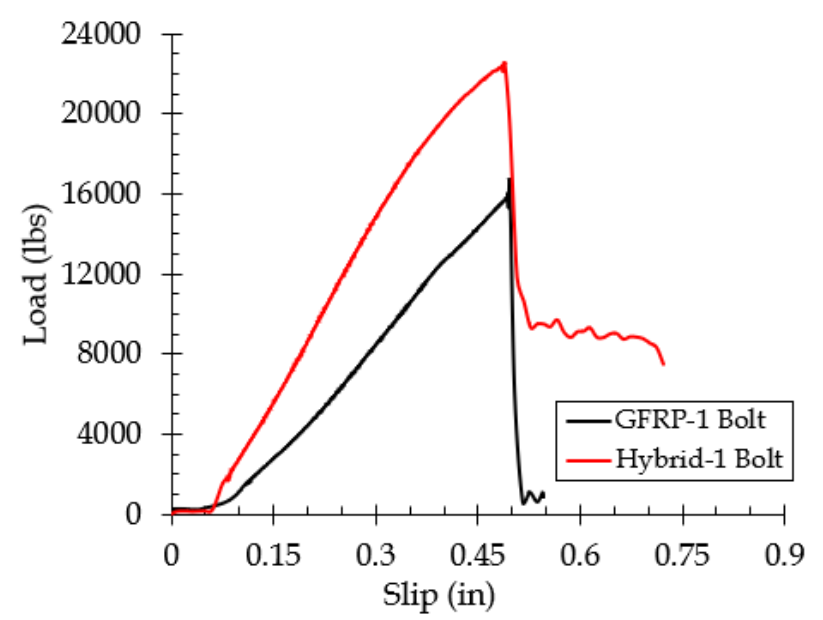

Figure 10-7. Load-slip plots for GFRP and hybrid sections with one 1/2"-dia bolted connection

For GFRP laminate, the failure occurred due to net-tensile crack formed at the edges of the hole along a plane that is perpendicular to the direction of loading at the was sudden and catastrophic as can be observed in Figs. 10.8a and 10-9a. The reason for the net-tensile crack is due to lower member width to the bolt diameter $(\mathrm{w} / \mathrm{d})$ ratio. For the hybrid laminate, the failure occurred at the outer GFRP laminates as indicated by the first drop in the load-slip plot in Fig. 10-6 due to net-tension failure. After the first failure, the load got transferred to the steel plate, which sustained the load at its yield-strength level. As can be noticed, the failure was not brittle, but ductile in nature due to yielding of the plates (Fig. 10-8b). The necking on the internal steel plate can be observed in the Fig. 10-9b. The load-slip curve indicate that the hybrid members can show some ductility before failure due to yielding of internal steel plates.

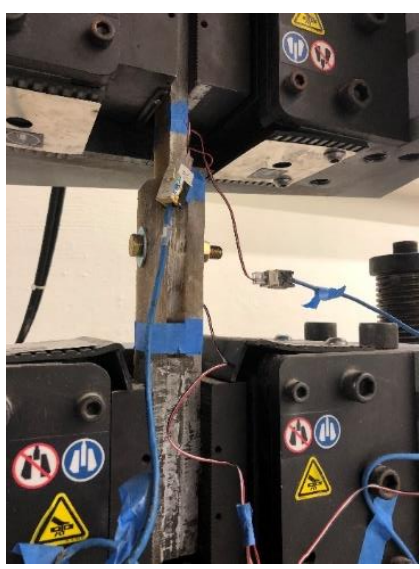

(a)

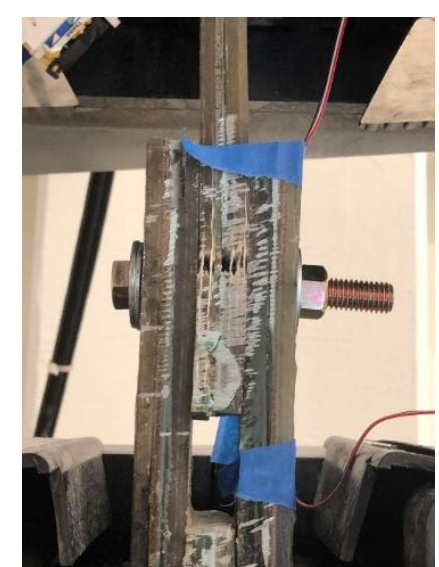

(b)

Figure 10-8. Failure under single-row bolted connection, (a) GFRP member, (b) hybrid member 
The axial strains were recorded at the locations as indicated in the Fig. 10-6. The load-strain plots for GFRP and hybrid members are shown in Fig. 10-10. The strain-A recorded compressive strains, while strain- $\mathrm{B}$ recorded tensile strains. The end regions above the bolt are under shear stresses and the end distance of $4 \mathrm{~d}$ (Table 10-2) was able to hold the stress to not let the member fail in shear-out failure.

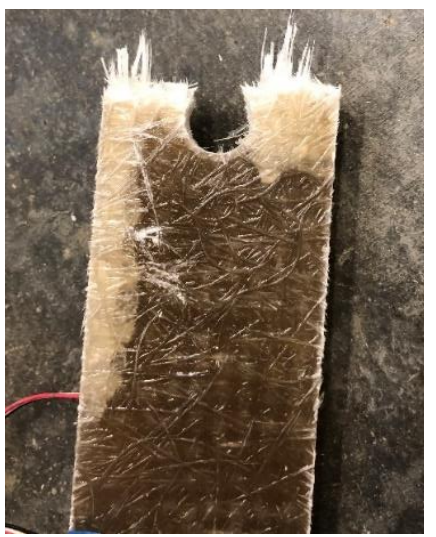

(a)

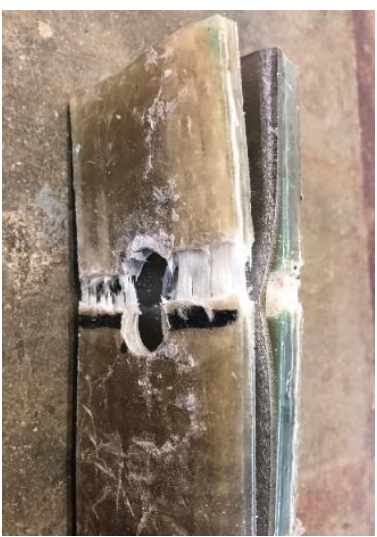

(b)

Figure 10-9. Net-tension failure on: (a) GFRP member, (b) hybrid member (necking on steel)

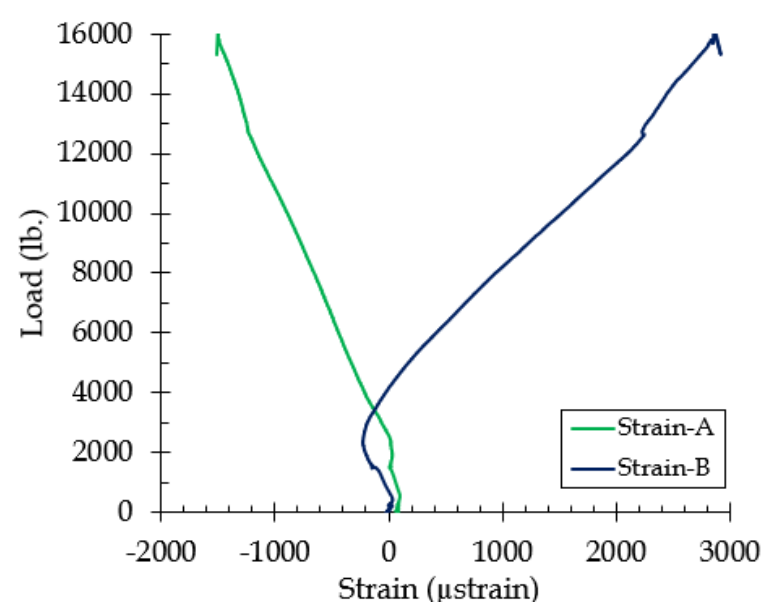

(a)

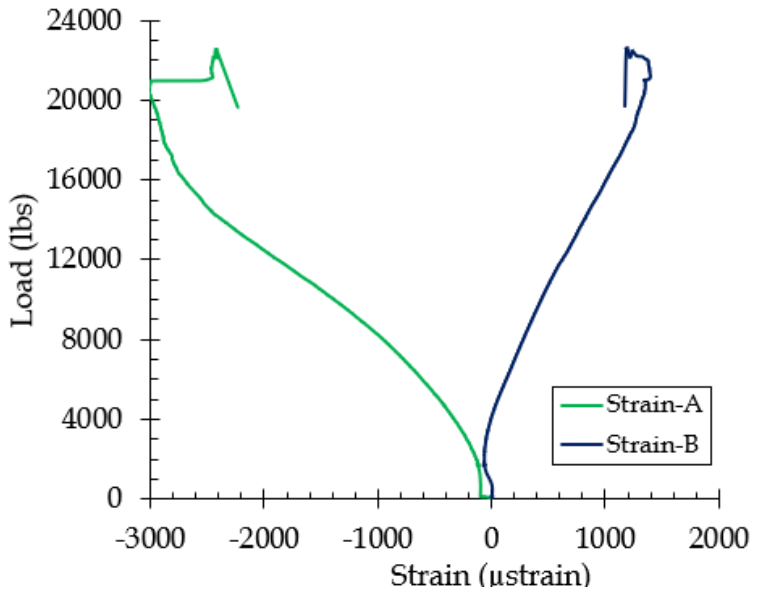

(b)

Figure 10-10. Load-strain plots for one $0.5^{\prime \prime}$-dia. bolt connection: (a) GFRP, (b) hybrid section

Since, the failure occurred due to net-tension, it is indicative that the member width to bolt diameter ratio is small, therfore, in order to change the failure mode, the diamter of the bolt and diameter of the hole was reduced to increase member width to diameter ratio.

\subsubsection{With a 0.375 -in diameter bolt}

By reducing the size of the bolt from $0.5^{\prime \prime}$ diameter to $0.375^{\prime \prime}$ diameter and the end distance from $4 \mathrm{~d}$ to $3.3 \mathrm{~d}$ (Table 10-2), the failure was not brittle and sudden but more progressive and ductile in nature with small drops in the load as indicated by the load-slip curves in Fig. 10-11. The ultimate failure load, joint strength and joint efficiencies for the single-bolted connection in GFRP and hybrid members with the use of $0.375^{\prime \prime}$ diameter bolts are presented in Table $10-4$. 
Table 10-4. Test results for GFRP and hybrid sections connected with one 3/8"-diameter bolt

\begin{tabular}{|c|c|c|c|c|c|}
\hline Section & Avg. failure load & $\sigma_{\text {ult }}{ }^{j}$ & Joint efficiency & Strain -A & Strain -B \\
\hline GFRP & $10,580 \mathrm{lbs}$. & $13.6 \mathrm{ksi}$ & 0.48 & -1225 & 570 \\
\hline Hybrid & $18,340 \mathrm{lbs}$. & $18.8 \mathrm{ksi}$ & 0.70 & -1270 & 1135 \\
\hline
\end{tabular}

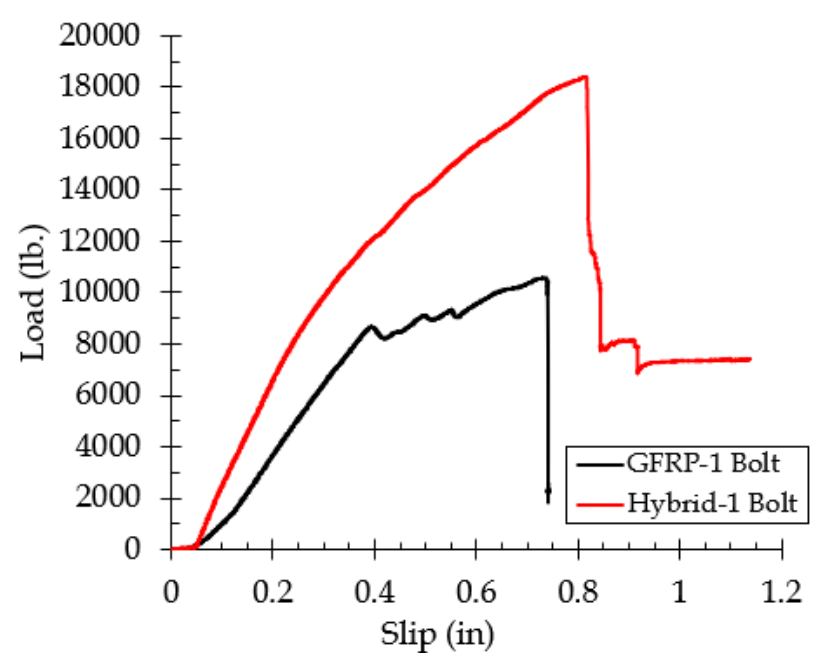

Figure 10-11. Load-slip plots for GFRP and hybrid sections with one 3/8"'-dia bolted connection

The failure in GFRP connected members started with a bearing failure but as the connection was continuously loaded, the connection started slipping with a final shear-out failure as can be seen in Fig. 10-12. The bolt was also yielded as can be seen in the Fig. 10-12. For hybrid member connection, it showed higher joint strength and showed and efficiency of 0.70 . The load-slip curve was non-linear in nature with a failure starting with a bearing failure in both GFRP and steel plate. As the connection was continuously loaded, the failure of the outer GFRP occurred with a shear-out failure and the large drop in the load was seen, however, the internal steel plates started taking the load at its yield strength level providing some ductility to the connection as can be seen in the Fig. 10-11 and 10-13.

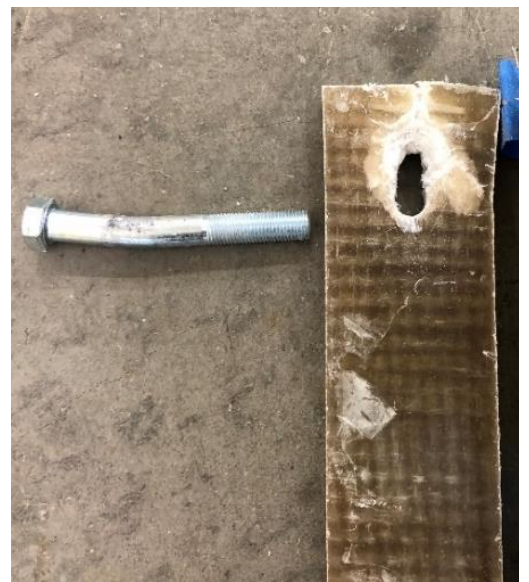

(a)

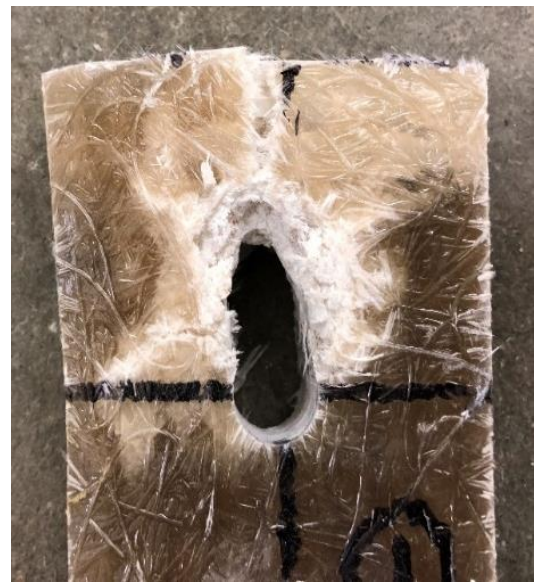

(b)

Figure 10-12. Failure on GFRP connected member, (a) bearing/shear-out, (b) failure (zoomed) 
The axial strains were recorded at the locations as indicated in the Fig. 10-6. The load-strain plots for GFRP and hybrid members are shown in Fig. 10-14. The strain-A recorded compressive strains, while strain- $\mathrm{B}$ recorded tensile strains. The end regions above the bolt are under shear stresses and the end distance of 3.3d (Table 10-2) was able to let the connection fail in bearing, which is more intended due to its ductile failure mode.

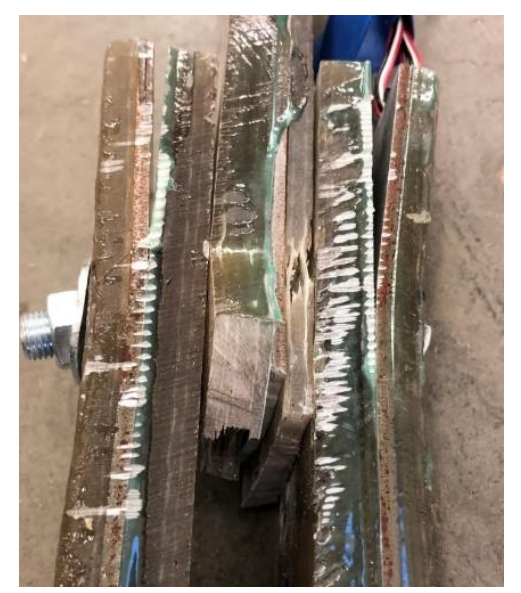

Figure 10-13. Failure in GFRP-steel hybrid member with single-row bolted connection

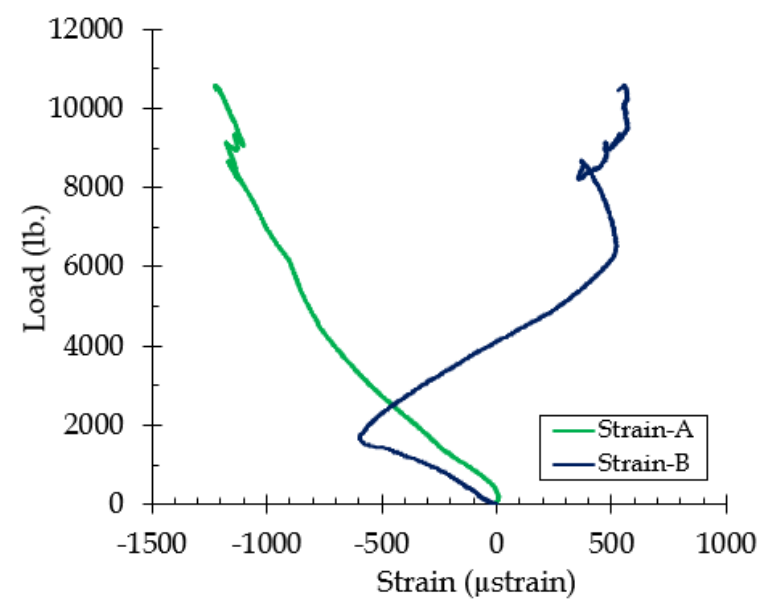

(a)

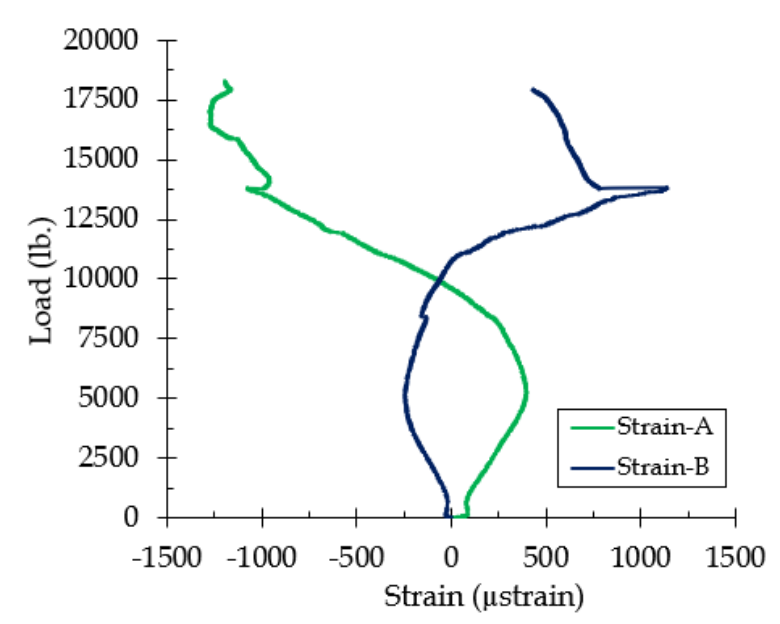

(b)

Figure 10-14. Load-strain plots for one $0.375^{\prime \prime}$-dia. bolt connection: (a) GFRP, (b) hybrid section

\subsubsection{Double bolted connections}

In FRP connections, load distribution is uneven between different rows of fasteners unlike steel connections, where load is transferred evenly among all of the bolts. The rows closest to the edge of the material, or those closest to the applied load carry more load than rows further from the edge or from the applied load (Bank, 2006, Clarke, 1996). However, for two rows-bolted, the distribution is equal, which will be studied through experimental results. For double-bolted connection, the GFRP and hybrid laminates were similar in width and thickness as discussed before, but the length was increased to 18 inches to accommodate two bolt rows. The geometric 
dimensions based on bolt-diameter (d) are shown in Table 10-2 and the sub-sections are divided based on $1 / 2$ " and 3/8" diameter bolts.

\subsubsection{With 0.5-in diameter bolts}

Similar to the single-bolted connection in GFRP members with 0.5-in diameter bolts, typical loadslip curves obtained during the experimental testing of double-bolted connection for GFRP and hybrid specimens with $0.5^{\prime \prime}$-diameter bolts are shown in Fig. 10-17. The curves for both GFRP and hybrid specimens are linear up to the maximum force, after which a sudden drop in load was observed, indicating a brittle failure in the material. The ultimate failure load, joint strength and joint efficiencies for GFRP and hybrid members are presented in Table 10-5. The joint connecting hybrid members showed slightly higher joint efficiency.

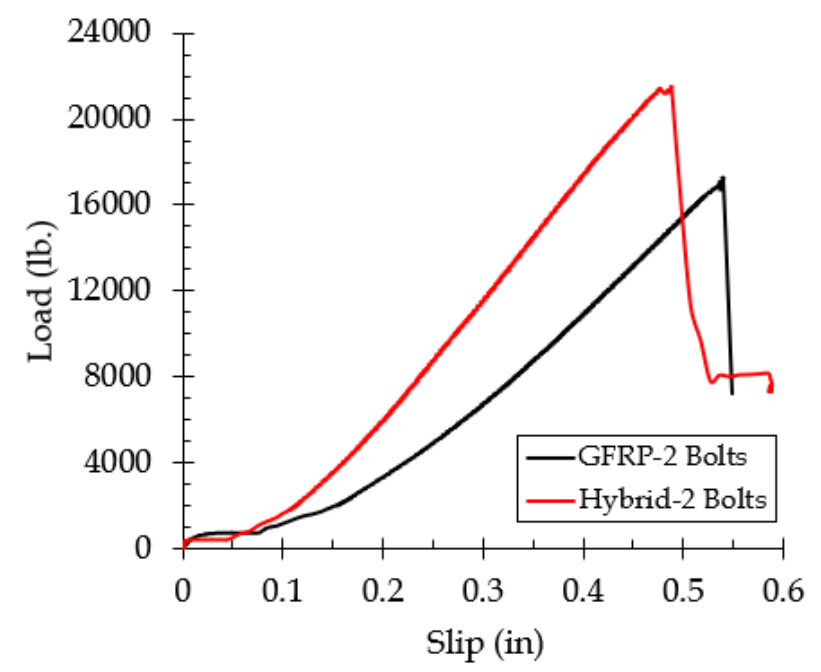

Figure 10-15. Load-slip plots for GFRP and hybrid sections with two $0.5^{\prime \prime}$-dia bolted connection

Table 10-5. Test results for GFRP and hybrid sections connected with two $0.5^{\prime \prime}$-diameter bolts

\begin{tabular}{|c|c|c|c|c|c|}
\hline Section & Avg. failure load & $\sigma_{\text {ult }}{ }^{j}$ & Joint efficiency & Strain -A & Strain -B \\
\hline GFRP & 17,240 lbs. & $21.2 \mathrm{ksi}$ & 0.75 & 3520 & 3550 \\
\hline Hybrid & $21,500 \mathrm{lbs}$. & $21.2 \mathrm{ksi}$ & 0.79 & 660 & 2000 \\
\hline
\end{tabular}

For GFRP laminate, the failure occurred due to net-tensile crack at the first hole closest to the applied load in perpendicular direction of loading (Figs. 10-16a, 10-17a). The failure was sudden and brittle. For the hybrid laminate, the failure occurred at the outer GFRP laminates as indicated by the first drop in the load-slip plot in Fig. 10-17 due to net-tension failure. After the first failure, the load got transferred to the internal steel plate, which sustained the load at its yield-strength level but got tensile failure within less than 0.1" slip (Figs. 10-15, 10-16b, 10-17b). 


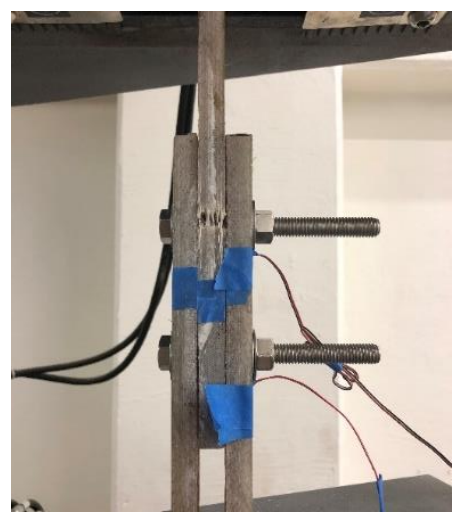

(a)

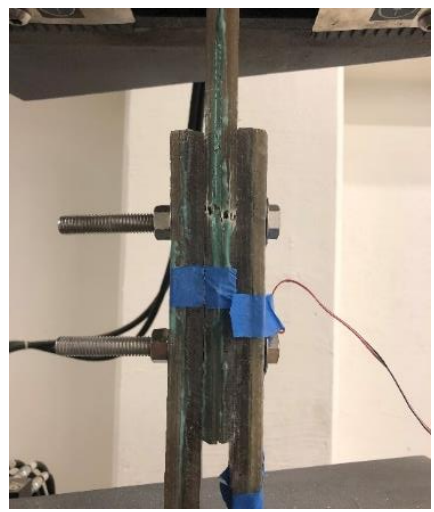

(b)

Figure 10-16. Net-tension failure on double-bolted connection on: (a) GFRP, (b) hybrid member

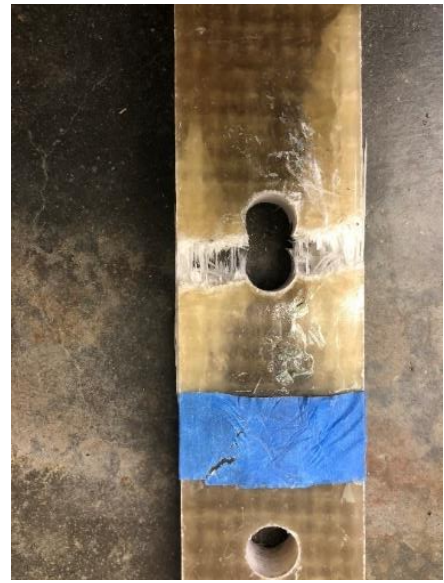

(a)

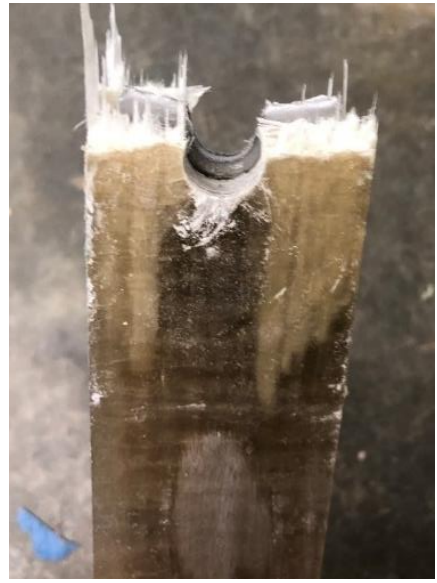

(b)

Figure 10-17. Net-tension failure on: (a) GFRP member, (b) hybrid member

The axial strains were recorded at the locations as indicated in the Fig. 10-6. The load-strain plots for GFRP and hybrid members are shown in Fig. 10-18. Both strain-A and -B recorded tensile strains. The end regions above the bolt were under shear stresses and the end distance of $4 \mathrm{~d}$ (Table 10-2) was long enough to not let the member fail in shear-out mode. However, due to lower width to diameter of bolt ratio, the net-tension failure occurred, which is not intended in the design. Therefore, by using smaller bolt and hole diameter, the change in the failure mode is discussed in the next section. 


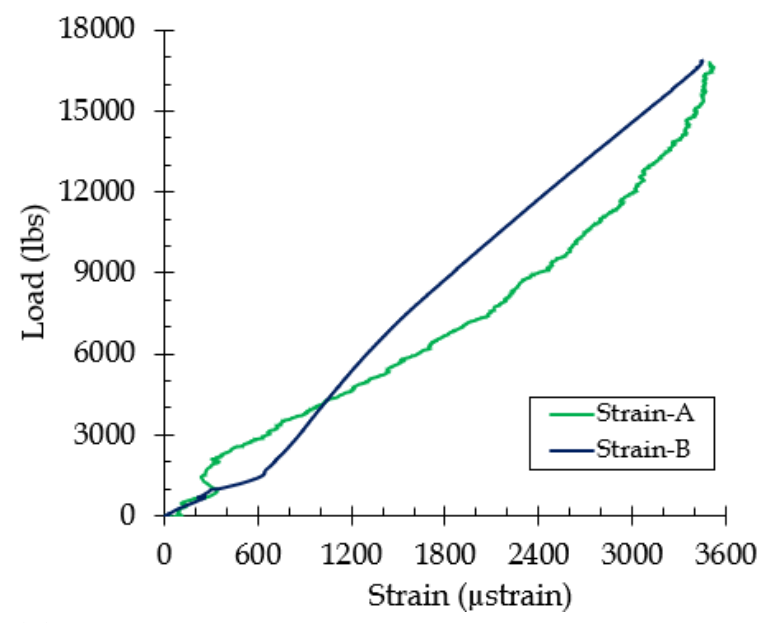

(a)

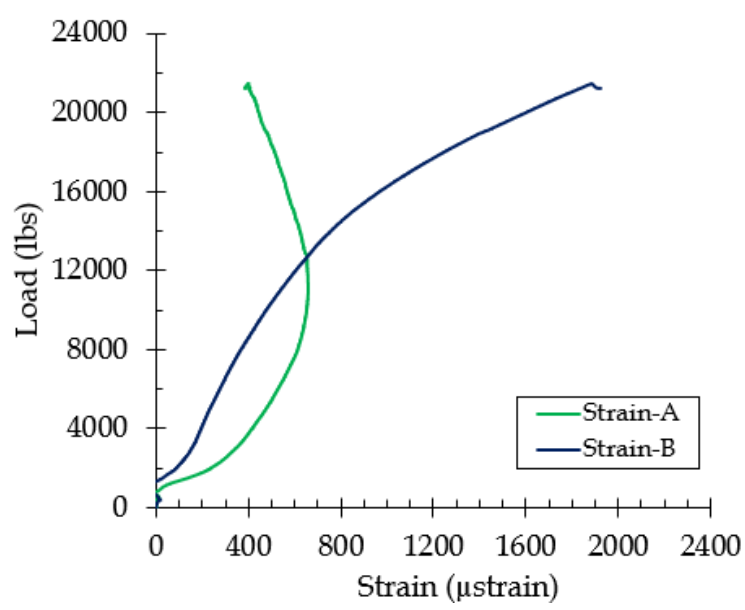

(b)

Figure 10-18. Load-strain plots under two 0.5"-dia. bolt connection: (a) GFRP, (b) hybrid section

\subsubsection{With 0.375-in diameter bolts}

The ultimate failure load, joint strength and joint efficiencies for the double-bolted connection in GFRP and hybrid members with the use of $0.375^{\prime \prime}$ diameter bolts are presented in Table 10-6. The joint strength and joint efficiency were slightly improved with the hybrid members. The failure modes in both GFRP and hybrid member connection were similar with net-tension failure occurring at the first hole closest to the load application. The stresses were not similar at two holes, the hole closest to the load application seems to have higher stresses even in two-bolted connection configuration. The hybrid member failed with the outer GFRP laminate failure in nettension, while the inner steel was not failed at the time when test got stopped (Fig. 10-21).

Table 10-6. Test results for GFRP and hybrid sections connected with two $0.375^{\prime \prime}$-diameter bolts

\begin{tabular}{|c|c|c|c|c|c|c|}
\hline Section & Failure load & $\sigma_{\text {ult }}{ }^{j}$ & Joint efficiency & Strain -A & Strain -B & Strain -C \\
\hline GFRP & 16,170 lbs. & $19.9 \mathrm{ksi}$ & 0.70 & -1072 & 1180 & 3120 \\
\hline Hybrid & $22,330 \mathrm{lbs}$. & $22.0 \mathrm{ksi}$ & 0.81 & -250 & 925 to -910 & 555 \\
\hline
\end{tabular}

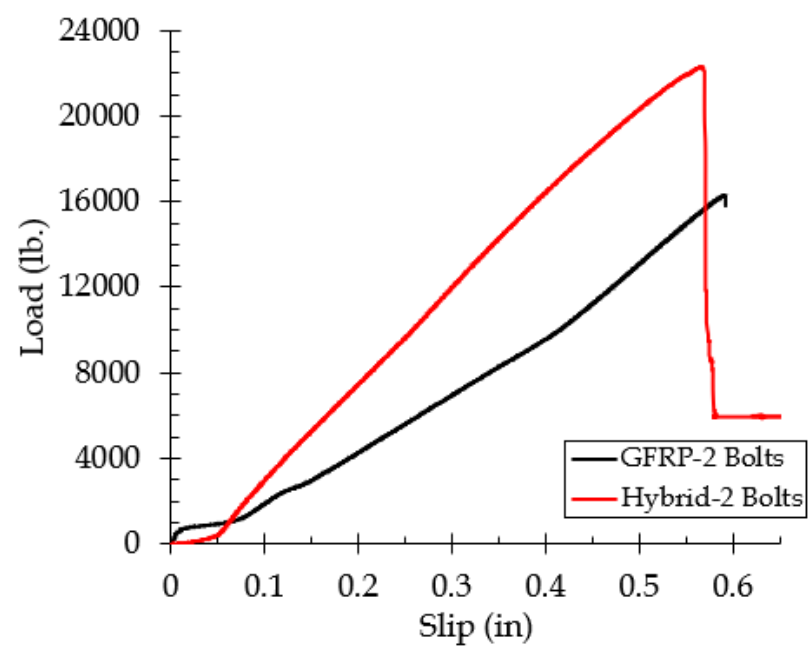

Figure 10-19. Load-slip plots for GFRP and hybrid sections with two 3/8"-dia bolted connection 
The strain distribution was not uniform across the locations where they were measured as can be seen in Fig. 10-20. The strain-A showed negative values, suggesting the end zone is in compression due to shear forces. The strain-B showed initial tensile strains but later showed compressive strain at the time of failure.

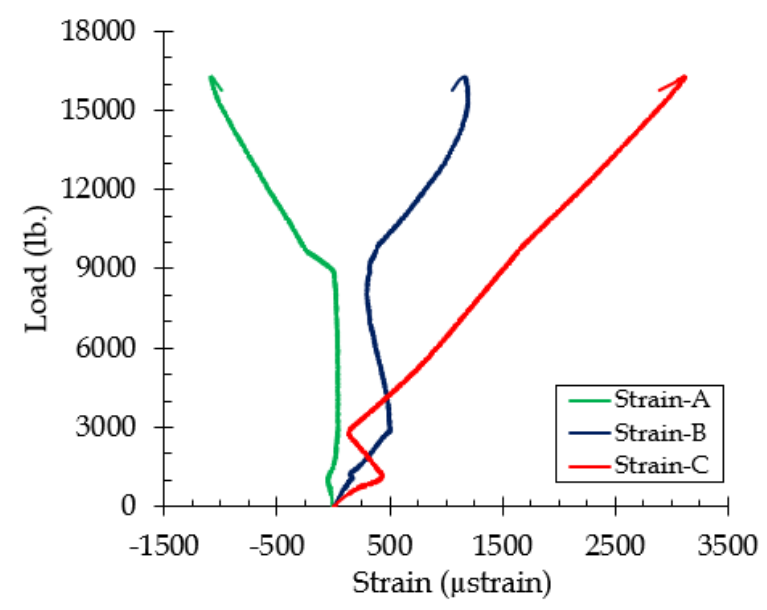

(a)

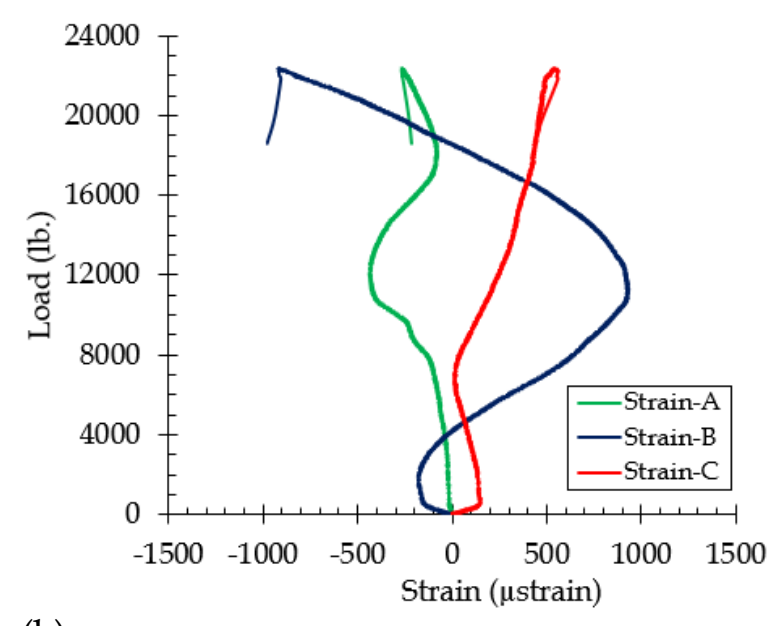

(b)

Figure 10-20. Load-strain plots for two $0.375^{\prime \prime}$-dia. bolt connection: (a) GFRP, (b) hybrid section

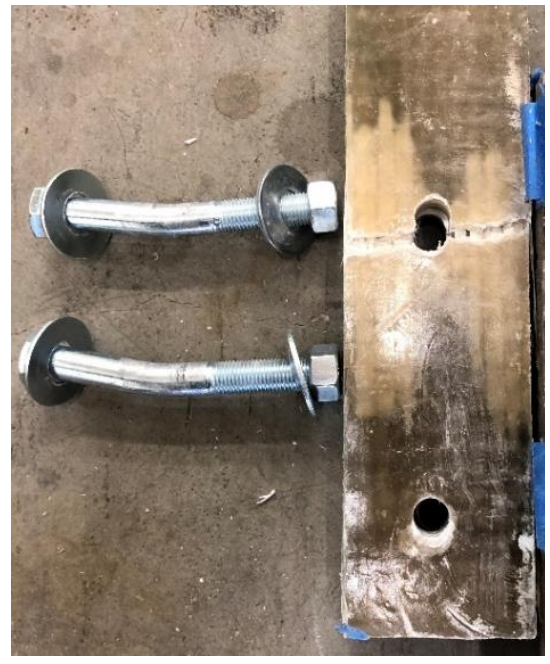

(a)

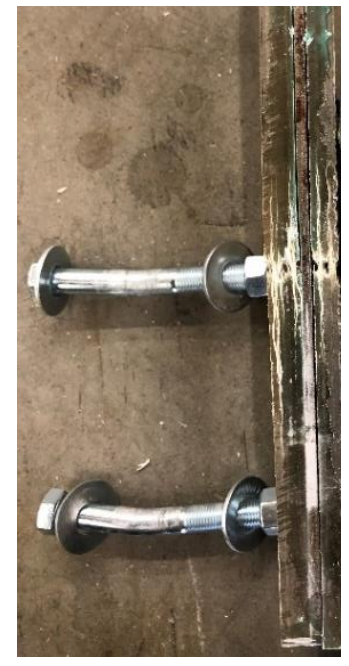

(b)

Figure 10-21. Net-tension failure on: (a) GFRP members, (b) hybrid members

\subsubsection{Summary of experimental results}

The bolted connection strength and connection (joint) efficiency for both single-and double-bolts in the GFRP-steel hybrid member were improved as compared to the GFRP members. The stiffness of the bolted connection (slope of the load-slip curve) was improved with the hybrid members. The members connected with single-row bolt by following the geometry guidelines of ASCE-LRFD pre-standard (4d for end distance) resulted in the net-tension failures. However, by increasing the member width to bolt-diameter ratio and by decreasing the end distance to bolt diameter ratio from $4 \mathrm{~d}$ to $3.3 \mathrm{~d}$, the failure shifted to bearing failure. 
Bank, 2006 actually recommends the member width to bolt-diameter ratio to be $5 \mathrm{~d}$ to obtain bearing failure mode and not allow net-tension failure in the member, which is more in-line with the experimental results obtained in this study. The ASCE-LRFD should also specify similar member width to bolt-diameter ratio, to obtain beating failure. The recommended end distance to bolt diameter ratio of $3 \mathrm{~d}$ by Bank, 2006 seems to be more appropriate, compared to ASCELRFD value of $4 \mathrm{~d}$, to obtain a bearing failure mode. Further, the members connected with tworow bolts do not seem to have equal load distribution among them. The end distance to boltdiameter ratio plays an important role in deciding the failure mode and providing more end distance than the recommended value of $2 \mathrm{~d}$, lead to the net-tension failure of the members, as was observed in the experimental study.

\subsection{Conclusions}

The conclusions obtained from the research presented in this chapter are summarized below.

1. The ultimate failure load, joint strength and joint efficiencies for the single-bolted and doublebolted connections in the GFRP-steel hybrid members were higher and improved compared to the non-hybrid GFRP members.

2. The failure in the hybrid GFRP-steel members connected through bolts consisted of an initial failure in outer GFRP laminates, but the load was sustained at the yield-strength level of the steel plates. The load-slip curve indicated that the hybrid members showed some ductility before failure due to yielding of internal steel plates. The failure was progressive and ductile due to internal steel plate yielding.

3. The recommended value of an end distance of 3d (3-times of bolt-diameter) in a single-row bolted connection by Bank, 2006 was found to result in a bearing failure than the ASCE-LRFD pre-standard recommended value of $4 \mathrm{~d}$ which led to undesirable tension rupture. The member width to bolt-diameter and end distance to bolt-diameter ratios were found to play an important role in deciding the failure mode of the bolt-connected members from nettension to more desirable ductile failure mode- bearing.

4. The load distribution on bolts in two-bolt connected members was not found to be equal for higher end distances of $4 \mathrm{~d}$ and $3.3 \mathrm{~d}$ and did not result in the intended bearing failure mode. Hence, the recommended value of an end distance of $2 \mathrm{~d}$ in multiple-rows of bolted connection by ASCE-LRFD pre-standard should be strictly followed to achieve equal distribution of load on bolts and a bearing failure mode.

5. Further study is needed to establish clear edge distances, end-distances and plate widths for optimizing failure modes in hybrids. 


\section{Chapter 11. \\ Conclusions and Recommendations}

This chapter summarizes conclusions obtained from this research study on GFRP-steel hybrid box-beams. In addition, the recommendations for the future work within the scope of this research work has been presented.

\subsection{Conclusions}

The following conclusions have been summarized from this research work.

\subsubsection{GFRP-steel panel (Wicket gate)}

1. Integrated GFRP wicket gate panel with GFRP-Steel hybridization was successfully developed as a replacement to the existing timber wicket gate consisting of an assembly of several timber leaves and support blocks held together by an assortment of steel plates and angles that are fastened with numerous bolts and welds.

2. Based on the non-destructive bending load tests, integrated GFRP-steel gate resisted an applied (desired) bending moment of $406.7 \mathrm{kN}-\mathrm{m}(300 \mathrm{k}-\mathrm{ft}$.) with maximum induced bending and shear strains of 3352 and 2230 micro-strains, respectively. These induced strains are about $1 / 4^{\text {th }}$ to $1 / 3^{\text {rd }}$ of the failure strains. The design factors of safety for the GFRP-steel wicket gate in bending, shear, and buckling are in the range of 4.3 to 16.4 .

3. The experimental and theoretical stiffness values (E) of the full-scale cellular hybrid wicket gate were found to be $27.2 \mathrm{GPa}(3.94 \mathrm{msi})$ and $26.8 \mathrm{GPa}(3.89 \mathrm{msi})$, respectively, showing an excellent correlation. The finite element analysis of the section also showed similar stiffness value within $1 \%$.

4. Based on the FE analysis, the addition of two steel plates within the GFRP section enhances the bending rigidity (EI) by $66 \%$ and reduces the deflection ( $\delta$ ) by $38 \%$.

5. Maximum theoretical deflection of the GFRP/steel wicket gate during operating position is 3 $\mathrm{mm}\left(0.12^{\prime \prime}\right)$ at the tip of the gate and corresponds to an acceptable ratio of L/660 for the cantilevered portion.

6. The failure bending moment for GFRP-steel wicket gate under 3-point bending setup from Hashin and Tsai-Wu failure criteria was 1,215 kN-m (897 kip-ft) and 1,129 kN-m (832.5 kip$\mathrm{ft})$, respectively.

7. The field implementation of the GFRP-steel wicket gates was successfully performed. These gates are monitored periodically to further evaluate their performance under actual field conditions consisting of turbulent water flow.

\subsubsection{GFRP/steel box-beam sections}

1. The bending and shear stiffnesses of control GFRP and hybrid box-beams were obtained through experimental testing and classical beam-deflection equations. Due to thin steel plate embedment around the web and flange locations, the bending stiffness values for hybrid sections (HWB, HFB, and HAB) were increased by $29.6 \%, 220.2 \%$ and $269.9 \%$, respectively 
compared to control GFRP (CB) box-beams, whereas, shear stiffness values were only improved for the hybrids with steel plate insertion in the webs (HWB, HAB).

2. The ultimate failure strengths of hybrid box-beams with steel plates embedded in the flanges $(\mathrm{HFB})$ or both in the flanges and webs $(\mathrm{HAB})$ were lower in comparison with the control boxbeams $(\mathrm{CB})$. The reason for lower failure load was primarily associated with the shift in the failure modes from global to local modes such as compression-flange junction rupture and punching shear underneath the loading point, which was validated by the lower compressive and tensile bending strains during the failure of those hybrid beams.

3. The fatigue testing on the hybrid beams within serviceability limits of L/180 (for a span of $84^{\prime \prime}$ ) or up to $54 \%$ of the failure load for 2 to 4 million cycles could not produce damages or reduction in stiffness values in both GFRP and hybrid box-beams. However, when fatigue load levels were increased beyond the yield-strain of steel plates, residual deflection and strains after removal of applied loads were observed to be as high as $10 \%$ for hybrid beams. The hybrid beam (HAB) fatigued at a load range of about $55-80 \%$ (i.e., lower and upper limit beyond steel yielding) of ultimate load produced a failure consisting of GFRP fracture at $0.625 \times 10^{6}$ load cycles. The results show that exceeding the yield strains significantly beyond steel yield strain level will result in very short fatigue life. A permanent deflection of about $5 \%$ was noticed in hybrid beams fatigued at higher loads at lower span of 27 inches.

4. At a span length of 84 in., the control (CB) box-beams showed brittle failure modes, with linear load-deflection curves until failure. On contrary, hybrid beams (HFB and HAB) showed nonlinear responses with distinct bilinear load-deflection and stress-strain curves. At lower spans of $27^{\prime \prime}$ and 36 ", all beams exhibited progressive failure with drops in $\mathrm{p}-\delta$ curves.

5. The local failure modes such as compression-flange junction cracking, compression flange buckling, transverse shear failure, and web-buckling/web-crushing were noticed in the hybrid beams for both longer (84") and shorter spans (36" and 27"). In addition to the above failure modes, the beams with shorter spans (36" and 27") exhibited transverse shear failure caused by high bearing and shear stresses over the roller supports.

6. The bending strains recorded in the hybrid beams during failure were lower by as much as $150 \%$ when compared to those recorded in the control GFRP beam, indicating tremendous reserve capacity in the section, provided the failure mode could be shifted from local to global modes by increasing the dimensions of vulnerable locations.

7. The design of GFRP composite structure is often governed by the serviceability deflection limits. For a given deflection limit, the maximum central load for hybrid (HAB) box-beam was 2.8-3.0 times higher than that obtained for the control GFRP (CB) box-beam. The addition of steel plates on flanges provided the most improvement in the bending stiffness (EI) of the hybrid section, resulting in greatest reduction in deflection values.

8. By limiting the strain on the embedded A36 steel plates within the elastic zone, the maximum central loads obtained for hybrid beams HFB and HAB with a span of 84 " were 5.88 kips and $6.25 \mathrm{kips}$, respectively. These values would increase to $9.5 \mathrm{kips}$ and $10.7 \mathrm{kips}$, respectively if A572 and Grade 60 steel plates were to be used.

9. The minimum surface preparation of a steel plate before embedding it in GFRP section was able to produce good bond with $\sim 95 \%$ effectiveness (compositeness). GFRP-steel hybrids helped overcome some of the major limitations of GFRP in terms of serviceability and energy- 
absorption related performance, thus providing a better and affordable alternative for future infrastructure construction.

\subsubsection{FE study}

1. The FE models for hybrid GFRP-steel box-beams developed by using 3D-solid elements (C3D20 and C3D20R) through this study showed results that correlated very well with the experimental values during the elastic stages. However, the FE and experimental values differed as much as by $32.3 \%$ during the plastic stages after the onset of steel yielding. The load-deflection and load-strain curves obtained from the FE models during all stages matched with the experimentally obtained curves with an error ranging from $2 \%$ to $32.3 \%$.

2. The bending and shear stresses in GFRP were lower in the hybrid section than that in the nonhybrid GFRP section at similar load levels. The hybrids showed higher bending stresses in the embedded steel plates than that in the surrounding GFRP section. The load was resisted more by the plates possibly due to its higher stiffness, thus acting as a stiffer member.

3. The bending strain-stress and shear strain-stress contours observed in the embedded steel plates of hybrid beams showed steel plates in the flanges were under higher bending stresses and steel plates in the webs under higher shear stresses.

4. The hybrid beams (HFB and HAB) showed higher bending capacity as the stresses in the GFRP section in HFB and HAB beams were lower compared to HWB beams. The embedded plates in flanges helped achieve higher moment of inertia. In HAB beams, the load was better distributed to all four steel plates.

5. The non-linear analysis on GFRP-steel hybrids at higher loads was performed. The bilinear load-deflection curves for the hybrid beams during plastic stages matched with the experimental curves with an error ranging from $6.5 \%$ to $32.3 \%$. The model predicted stiffer load-deflection curve after the onset of plastic deformation in steel plates due to an assumption of a perfect bonding between steel plates and GFRP during the analysis.

6. Under experimental failure load, the FE models showed higher bending compressive strains than tensile strains possibly due to the load applied at a smaller area on the top flange. The compressive strain values in the hybrid beams (HFB and HAB) were below their coupon-level ultimate failure strains, suggesting the failure was governed by local effects.

7. The plates in the flanges were under higher plastic strains near the mid-span for both hybrid beams (HFB and $\mathrm{HAB}$ ), while the plates in the webs exhibited very limited plastic deformation in beams (HWB and $\mathrm{HAB}$ ). The bi-linear response of these hybrid beams was due to the plastic deformation of flange steel plates. The plastic deformation in web steel plates did not produce bi-linear beam response for HWB beam.

\subsubsection{Bolted connection}

1. The ultimate failure load, joint strength and joint efficiencies for the single-bolted and doublebolted connections in the GFRP-steel hybrid members were higher and improved compared to the non-hybrid GFRP members.

2. The failure in the hybrid GFRP-steel members connected through bolts consisted of an initial failure in outer GFRP laminates, but the load was sustained at the yield-strength level of the 
steel plates. The load-slip curve indicated that the hybrid members showed some ductility before failure due to yielding of internal steel plates. The failure was progressive and ductile due to internal steel plate yielding.

3. The recommended value of an end distance of 3d (3-times of bolt-diameter) in a single-row bolted connection by Bank, 2006 was found to result in a bearing failure than the ASCE-LRFD pre-standard recommended value of $4 \mathrm{~d}$. The member width to bolt-diameter and end distance to bolt-diameter ratios were found to play an important role in deciding the failure modes of the bolt-connected members from net-tension to bearing.

4. The load distribution on bolts in two-bolt connected members was not found to be equal for higher end distances of $4 \mathrm{~d}$ and $3.3 \mathrm{~d}$ and did not result in the intended bearing failure mode. Hence, the recommended value of an end distance of $2 \mathrm{~d}$ in multiple-rows of bolted connection by ASCE-LRFD pre-standard should be strictly followed to achieve equal distribution of load on bolts and a bearing failure mode.

\subsubsection{Qualitative/quantitative interface evaluation}

1. The tap-hammer test for FRP composites was not able to distinguish between the intact and debonded GFRP-steel interface, possibly due to higher thickness $(0.25$ " in either side of the steel plates) of GFRP laminate than the range of the tap hammer.

2. The ultrasound non-destructive technique with direct transmission of waves was able to clearly distinguish between the intact and debonded GFRP-steel interface. On the intact hybrid sample with no defect, both $54 \mathrm{kHz}$ and $500 \mathrm{kHz}$ transducers showed similar pulse travel time of 7.2 to $7.4 \mu \mathrm{s}$. However, on the sample with delamination, the $500 \mathrm{kHz}$ transducer did not detect any signal during direct transmission of waves and the $54 \mathrm{kHz}$ transducer showed very longer travel time, indicating a presence of delamination (defect) within the samples.

3. The differential scanning calorimetry (DSC) tests on samples indicated that the resin from the GFRP-steel interface regions was better cured during the manufacturing process possibly due to exothermic curing reactions that produced heat and were absorbed by the steel plates causing secondary curing.

4. The hybrid GFRP-steel samples, cut from the beams that were failed under static loads, were observed under optical microscopy. The samples clearly showed loss of bond at the GFRPsteel interface of the failed specimens.

5. The SEM images of the GFRP-steel interface samples, cut from the fatigued hybrid beams, showed a resin rich layer at the interface between GFRP and steel plates. No interface cracks, debonding, pores or any interface defects were observed in the fatigued samples. However, few areas on the bond surface of GFRP were found to have few original defects such as airbubbles (voids) could be minimized during manufacturing processes through selective vacuum application.

6. The cost per unit stiffness of the GFRP-steel hybrid panel and box-beams (HWB, HFB, HAB) were found to significantly lower by as much as $71.9 \%$ than those for the similar non-hybrid GFRP panel and box-beams. 


\subsection{New and original contributions to the knowledge base}

With a goal of achieving higher stiffness on GFRP sections with an embedment of steel plates, the following specific findings from this research are the original contributions to this field.

1. Evaluating the feasibility and potential of GFRP-steel hybridization by manufacturing filedscale structural components by a combination and integration of brittle (GFRP) and ductile (steel) materials with differing stress-strain characteristics.

a. Design, development, and manufacturing of full-scale GFRP-steel hybrid structural components (box-section and multi-cellular section) for application in deformation critical structures by satisfying the strength requirements and enhancing bending stiffness by several folds.

b. Use of innovative manufacturing techniques (vacuum assisted resin transfer molding) to manufacture full scale hybrid GFRP-steel sections with the embedment of thin and thick steel plate elements $\left(1 / 8^{\prime \prime}-3 / 8^{\prime \prime}\right.$ thick) within the flange and web sections to significantly reduce the cost/unit stiffness (performance).

c. Conduct field-installation and observe the performance of hybrid GFRP-steel sections under realistic moisture exposure conditions over a period of few years.

2. Evaluating the improvements or reductions in bending and shear behavior of GFRP-steel hybrid sections for different $1 / \mathrm{d}$ ratios ranging from 4.5 to 14 under serviceability and ultimate failure conditions with due consideration to their failure modes.

a. Strategic embedment and hybridization of steel plates within the flange regions of GFRP box-sections to achieve higher bending stiffness and to increase stress carrying ability of flanges.

b. Strategic embedment and hybridization of steel plates within the web regions of GFRP box-sections to achieve higher shear stiffness and to eliminate/minimize web buckling/crushing failure modes through better stress distribution across the section.

3. Establishing the bending and shear failures in GFRP-steel hybrid structures including preand post- steel-yield performance and endurance levels under fatigue loads.

a. Establishing the potential failure modes in GFRP-steel hybrid structures with minimal steel surface preparation under static and fatigue loads at local and global levels.

b. Establishing the GFRP-steel interface integrity under steel-yield levels of loading and at failure through SEM and ultrasound techniques.

4. Understanding the improvements in load-deformation and failure behavior of GFRP-steel hybrid sections with bolt-connections typically used for such components.

5. Development of effective predictive tools using FE modeling of the GFRP-steel hybrid sections for pre- and post- steel-yield loading conditions.

\subsection{Recommendations for future study}

The following studies are recommended to expand the findings of this study in the future. 
1. Study of other shapes and structural components: The insertion of steel plates in flanges and webs can be extended to the corners of the box-sections or edge angle sections to reduce stress concentrations along with the establishment of hybrid structures with different shapes such as I-sections, channel sections, pipes and others. These studies can evaluate various bending, shear and deformation characteristic for varying $1 / \mathrm{d}$ ratios under static and fatigue loads.

2. Creep behavior: Study of reduction in creep due to the embedment of thin steel plates inside GFRP composite beams. The study of creep behavior of GFRP-steel hybrid beams can further lead to the development of serviceability-based creep-coefficients for use in code specifications.

3. Durability: The durability and aging-related issues under natural and artificial environments can be established on the steel plate-embedded GFRP sections with and without access to moisture. Though, it is anticipated that any steel incorporated into the section would be lesssusceptible to corrosion as it is completely embedded inside of GFRP. However, studying the effect of moisture diffusion within GFRP on the embedded steel plates and rate of corrosion should be studied.

4. Manufacturing: Pultrusion and other manufacturing techniques should be investigated for modular hybrid-section production at a reduced cost and time.

5. Field implementation and monitoring: The hybrid structures should be field implemented and instrumented to evaluate their performance over a long-term period of 5 to 25 years. 


\section{References}

Abdelkerim, D. S., Wang, X., Ibrahim, H. A., \& Wu, Z. (2019). Static and fatigue behavior of pultruded FRP multi-bolted joints with basalt FRP and hybrid steel-FRP bolts. Composite Structures.

ACI (2015): Report on “Airport Capital Development Needs.” Airports Council International.

Aero: Available on http://www.aerospaceengineeringblog.com

Akkerman, R. (2005). Laminate mechanics for balanced woven fabrics. Composites Part B: Engineering, 37(2-3), 108-116.

Aliancys. Available on https://aliancys.com/en/cases/aliancys-resins-used-for-worlds-largestcomposite-lock-gates/

Aly, M. F., Goda, I. G. M., \& Hassan, G. A. (2010). Experimental investigation of the dynamic characteristics of laminated composite beams. International Journal of Mechanical \& Mechatronics, 10, 59-67.

ASCE (2012). Report on Failure to act - The economic impact of current investment trends in airports, inland waterways and marine ports infrastructure.

ASCE. (2017): “Report Card for America's Infrastructure.” American Society of Civil Engineers.

AWC (2005). American Wood Council. National Design Specification (NDS) Supplement. Design values for wood construction. 2005

Bakis, C. E., Bank, L. C., Brown, V., Cosenza, E., Davalos, J. F., Lesko, J. J., ... \& Triantafillou, T. C. (2002). Fiber-reinforced polymer composites for construction-State-of-the-art review. Journal of composites for construction, 6(2), 73-87.

Bank, L. C. (2006). Composites for construction: Structural design with FRP materials. John Wiley \& Sons.

Bank, L. C. (2006). Composites for construction: structural design with FRP materials. John Wiley \& Sons.

Barbero, E. J. (2013). Finite element analysis of composite materials using Abaqus. CRC press.

Barbero, E. J. (2017). Introduction to composite materials design. CRC press.

Bedon, C. (2016). Review on the use of FRP composites for façades and building skins. American Journal of Engineering and Applied Sciences, FRP Structures Special Issue, in print.

Béjar LAD, Hall RL. Forces on edge-hinged panels in gradually varied flow. Journal of Hydraulic Engineering. 1998; 124.8: 813-821.

Belarbi, A., \& Acun, B. (2013). FRP systems in shear strengthening of reinforced concrete structures. Procedia Engineering, 57, 2-8.

Bhagwat, P. M., Ramachandran, M., \& Raichurkar, P. (2017). Mechanical Properties of Hybrid Glass/Carbon Fiber Reinforced Epoxy Composites. Materials Today: Proceedings, 4(8), 7375-7380. 
Boscato, G. (2017). Comparative study on dynamic parameters and seismic demand of pultruded FRP members and structures. Composite Structures, 174, 399-419.

Bunsell, A. R., \& Harris, B. (1974). Hybrid carbon and glass fibre composites. Composites, 5(4), 157-164.

Burgoyne, C. (2009). Fibre reinforced polymers-strengths, weaknesses, opportunities and threats. In Proceedings of the 9th international symposium on fiber reinforced polymer reinforcement for concrete structures (FRPRCS-9), Sydney, Australia (pp. 13-15).

Camanho, P. P., \& Matthews, F. L. (2000). Bonded inserts for CFRP bolted joints. European Space Agency-Publications-ESA SP, 468, 207-212.

Chowdhury et al. (1998a). Flow-induced structural response of a 1:5-scale Olmsted wicket model (No. WES-SL-98-2). Army Engineer Waterways Experiment Station. 1998.

Chowdhury et al. (1998b). Experimental results for full-scale composite and steel wickets at Smithland facility. Journal of Composites for Construction. 1998; 2.2:69-77

Chowdhury MR, Davis WG. Olmsted horse wicket experiment in 1: 5-scale hydraulic flume model (No. ERDC-TR-01-11). Engineer research and development center. Vicksburg. MS. 2001.

Chowdhury MR, Hall RL. Dynamic performance evaluation of gate vibration. Journal of Structural Engineering. 1999; 125.4:445-52.

Clarke, J. L. (1996). Structural design of polymer composites: Eurocomp design code and background document. London: Spon Press.

Cusen AR, Pama RP. Bridge deck analysis. John Wiley \& Sons. 1975.

Czél, G., \& Wisnom, M. R. (2013). Demonstration of pseudo-ductility in high performance glass/epoxy composites by hybridisation with thin-ply carbon prepreg. Composites Part A: Applied Science and Manufacturing, 52, 23-30.

Dong, C., \& Davies, I. J. (2014). Flexural and tensile moduli of unidirectional hybrid epoxy composites reinforced by S-2 glass and T700S carbon fibres. Materials \& Design (1980-2015), 54, 893-899.

Dorigato, A., \& Pegoretti, A. (2014). Flexural and impact behaviour of carbon/basalt fibers hybrid laminates. Journal of Composite Materials, 48(9), 1121-1130.

Eamon, C. D., Jensen, E. A., Grace, N. F., \& Shi, X. (2012). Life-cycle cost analysis of alternative reinforcement materials for bridge superstructures considering cost and maintenance uncertainties. Journal of Materials in Civil Engineering, 24(4), 373-380.

Fiberline. Available on https:/ / fiberline.com/fiberline-bridge-kolding

Gan, Y. (2009). Effect of interface structure on mechanical properties of advanced composite materials. International journal of molecular sciences, 10(12), 5115-5134.

GangaRao HVS, Vijay PV. Feasibility review of FRP materials for structural applications. Report submitted to US Army Corps of Engineers. 2010. 
Gomez ICP. Dynamic behavior of large hydraulic structures in FRP. MS thesis. TU Delft. Delft University of Technology. 2014.

GVR, 2017. Available on http://www.grandviewresearch.com/press-release/global-fiberreinforced-polymer-frp-composites-market

Haghani, R., \& Olsson, E. (2018). Falcon-A Multi-Disciplinary Effort to Promote FRP bridges in Sweden.

Hai, N. D., Mutsuyoshi, H., Asamoto, S., \& Matsui, T. (2010). Structural behavior of hybrid FRP composite I-beam. Construction and Building Materials, 24(6), 956-969.

Hensher, D. A. (2016). Fiber-reinforced-plastic (FRP) reinforcement for concrete structures: properties and applications (Vol. 42). Elsevier.

Hollaway, L. C. (2010). A review of the present and future utilization of FRP composites in the civil infrastructure with reference to their important in-service properties. Construction and Building Materials, 24(12), 2419-2445.

Iqbal MA. Fatigue life of pultruded and hand lay-up GFRP exposed to different environmental conditions. MS thesis. University of Maine. 2001.

Ji, H. S., Byun, J. K., Lee, C. S., Son, B. J., \& Ma, Z. J. (2011). Structural performance of composite sandwich bridge decks with hybrid GFRP-steel core. Composite Structures, 93(2), 430-442.

Karbhari VM, Zhao L. Use of composites for 21st century civil infrastructure. Computer methods in applied mechanics and engineering 2000; 185.2:433-454.

Karbhari, V. M., Chin, J., Hunston, D., Benmokrane, B., Juska, T., Morgan, R., \& Reynaud, A. D. (2003). Durability gap analysis for fiber-reinforced polymer composites in civil infrastructure. Journal of composites for Construction, 7(3), 238-247.

Kelkar AD. Behavior of low cost manufactured thick FRP woven composite laminates under cyclic loading. In FRP Composites in Civil Engineering. Proceedings of the International Conference on FRP composites in Civil Engineering. 2001; 1:235-243.

Keller, T. (2001). Recent all-composite and hybrid fiber-reinforced polymer bridges and buildings. Progress in Structural Engineering and Materials, 3(2), 132-140.

Keller, T., Tracy, C., \& Hugi, E. (2006). Fire endurance of loaded and liquid-cooled GFRP slabs for construction. Composites Part A: Applied Science and Manufacturing, 37(7), 1055-1067.

Khashaba, U. A., Sebaey, T. A., Mahmoud, F. F., Selmy, A. I., \& Hamouda, R. M. (2013). Experimental and numerical analysis of pinned-joints composite laminates: Effects of stacking sequences. Journal of Composite Materials, 47(27), 3353-3366.

Kim, H. Y., \& Lee, S. Y. (2012). A steel-reinforced hybrid GFRP deck panel for temporary bridges. Construction and Building Materials, 34, 192-200.

Kolesnikov, B., Herbeck, L., \& Fink, A. (2008). CFRP/titanium hybrid material for improving composite bolted joints. Composite Structures, 83(4), 368-380

Krabbe JPV. World's largest FRP composite miter gates for a new lock in the Netherlands. Paper 11. Smart Rivers. Buenos Aires, Argentina. 2015. 
Kretsis, G. (1987). A review of the tensile, compressive, flexural and shear properties of hybrid fibre-reinforced plastics. Composites, 18(1), 13-23.

Kulkarni, R. R., Chawla, K. K., Vaidya, U. K., Koopman, M. C., \& Eberhardt, A. W. (2008). Characterization of long fiber thermoplastic/metal laminates. Journal of Materials Science, 43(13), 4391-4398.

Lampo RG, Marshall OS, Dutta PK. Use of FRP composites in civil works structures. Application of composites in infrastructure renewal and economic development. Polymer Composites II. CRC press. 2001; 235-244.

Lampo, R., Nosker, T., Bamo, D., Busel, J., \& Maher, A. (1998). Development and Demonstration of FRP Composite Fender Loadbearing, and Sheet Piling Systems (No. CERL-TR-98/123). Construction Engineering Research Lab (ARMY), Champaign, IL.

Lampo, RG, Nosker T, Bamo D, Busel J, Maher A. Development and demonstration of FRP composite fender loadbearing, and sheet piling systems (No. CERL-TR-98/123). Construction engineering research lab (army) Champaign IL. 1998.

Lau KT, Zhou LM. Mechanical performance of composite-strengthened concrete structures. Composites Part B: Engineering 2001; 32.1:21-31.

Li, Y., Wang, Y., \& Ou, J. (2014). Mechanical behavior of BFRP-steel composite plate under axial tension. Polymers, 6(6), 1862-1876.

Lombardi, N. J., \& Liu, J. (2011). Glass fiber-reinforced polymer/steel hybrid honeycomb sandwich concept for bridge deck applications. Composite structures, 93(4), 1275-1283.

Lu, Y., Li, W., Li, S., Li, X., \& Zhu, T. (2015). Study of the tensile properties of CFRP strengthened steel plates. Polymers, 7(12), 2595-2610.

Manders, P. W., \& Bader, M. G. (1981). The strength of hybrid glass/carbon fibre composites. Journal of materials science, 16(8), 2246-2256.

Mara, V., Haghani, R., \& Al-Emrani, M. (2016). Improving the performance of bolted joints in composite structures using metal inserts. Journal of Composite Materials, 50(21), 3001-3018.

Mara, V., Haghani, R., \& Harryson, P. (2014). Bridge decks of fibre reinforced polymer (FRP): a sustainable solution. Construction and Building Materials, 50, 190-199.

March TA, \& Elder RA. (1992). Review of the 1:25 scale hydraulic model Olmsted Wicket Dam. US Army Engineer Division. Ohio River. Contract\# DACW55-92-0187. Cincinnati. OH.1992.

Mathieson H, \& Fam A. (2011). GFRP polyurethane sandwich panels under reversed bending fatigue. In Advances in FRP Composites in Civil Engineering. Springer Berlin Heidelberg. 2011;164-167.

Matsuzaki, R., Shibata, M., \& Todoroki, A. (2008). Improving performance of GFRP/aluminum single lap joints using bolted/co-cured hybrid method. Composites Part A: applied science and manufacturing, 39(2), 154-163.

Micelli, F., \& Nanni, A. (2004). Durability of FRP rods for concrete structures. Construction and Building materials, 18(7), 491-503. 
Miguel, J.C., \& Diaz. M.A. (2015). Fiber reinforced polymer (FRP): A new material used in facades of tall buildings. Council on Tall Buildings and Urban Habitat, Paper-2519.

Motoc, D. L., Ivens, J., \& Dadirlat, N. (2013). Coefficient of thermal expansion evolution for cryogenic preconditioned hybrid carbon fiber/glass fiber-reinforced polymeric composite materials. Journal of thermal analysis and calorimetry, 112(3), 1245-1251.

Mottram, J. T. (2009). Design guidance for bolted connections in structures of pultruded shapes: Gaps in knowledge. In Proceedings of the 17th International Conference on Composite Materials (ICCM17) (No. Paper A1: 6, pp. 1-10). IOM Communications.

Mouritz AP, Gellert E, Burchill P, Challis K. Review of advanced composite structures for naval ships and submarines. Composite structures 2001; 53.1:21-42.

O'Connor, J. S. (2013). Composite bridge decking: Final project report (FHWA-HIF-13-029).

Ostapiuk, M., Surowska, B., \& Bieniaś, J. (2014). Interface analysis of fiber metal laminates. Composite Interfaces, 21(4), 309-318.

Pandya, K. S., Veerraju, C., \& Naik, N. K. (2011). Hybrid composites made of carbon and glass woven fabrics under quasi-static loading. Materials \& Design, 32(7), 4094-4099.

Park, K. T., Kim, H. Y., You, Y. J., Lee, S. Y., \& Seo, D. W. (2013). Hybrid FRP Reinforcing Bars for Concrete Structures. In 4th Asia-Pacific Conference on FRP in Structures, December, Melbourne, Australia.

Prusty, R. K., Rathore, D. K., Singh, B. P., Mohanty, S. C., Mahato, K. K., \& Ray, B. C. (2016). "Experimental optimization of flexural behavior through inter-ply fiber hybridization in FRP composite". Construction \& Building Materials, 118, 327-336.

Prusty, R. K., Rathore, D. K., Singh, B. P., Mohanty, S. C., Mahato, K. K., \& Ray, B. C. (2016). Experimental optimization of flexural behaviour through inter-ply fibre hybridization in FRP composite. Construction and Building Materials, 118, 327-336.

Qureshi, J., \& Mottram, J. T. (2015). Moment-rotation response of nominally pinned beam-tocolumn joints for frames of pultruded fiber reinforced polymer. Construction and Building Materials, 77, 396-403.

Robert, M., \& Benmokrane, B. (2013). Combined effects of saline solution and moist concrete on long-term durability of GFRP reinforcing bars. Construction and Building Materials, 38, 274-284.

Rossum SV. Road toward a standardized lock gate. MS thesis. TU Delft. Delft University of Technology. 2015.

Seica MV, Packer JA. FRP materials for the rehabilitation of tubular steel structures, for underwater applications. Composite Structures 2007; 80.3:440-450.

Shenoi RA, Wellicome JF. Composite materials in maritime structures: Volume 1, Fundamental Aspects. Cambridge University Press 1993.

Smits, J. (2016). Fiber-Reinforced Polymer Bridge Design in the Netherlands: Architectural Challenges toward Innovative, Sustainable, and Durable Bridges. Engineering, 2(4), 518527. 
Smits, J. (2016). Fiber-Reinforced Polymer Bridge Design in the Netherlands: Architectural Challenges toward Innovative, Sustainable, and Durable Bridges. Engineering, 2(4), 518527.

Soma. http:/ / www.soma-rchitecture.com/index.php?page=theme_pavilion\&parent=2

Sonnenschein, R., Gajdosova, K., \& Holly, I. (2016). FRP composites and their using in the construction of bridges. Procedia engineering, 161, 477-482.

Soti PR. Advanced composites for design and rehabilitation of hydraulic structures. MS thesis. West Virginia University, 2014.

Sridharan S, Zureick AH, Muzzy, JD. Effect of hot-wet environments on E-glass/vinylester composites. In technical papers of the annual technical conference-society of plastics engineers incorporated. Society of Plastics Engineers Inc. 1998; 2:2255-2261.

Stevanović, M. M., \& Stecenko, T. B. (1992). Mechanical behaviour of carbon and glass hybrid fibre reinforced polyester composites. Journal of materials science, 27(4), 941-946.

Summerscales, J., \& Short, D. (1978). Carbon fibre and glass fibre hybrid reinforced plastics. Composites, 9(3), 157-166.

Swolfs, Y., Gorbatikh, L., \& Verpoest, I. (2014). Fibre hybridisation in polymer composites: a review. Composites Part A: Applied Science and Manufacturing, 67, 181-200.

Swolfs, Y., McMeeking, R. M., Verpoest, I., \& Gorbatikh, L. (2015). The effect of fibre dispersion on initial failure strain and cluster development in unidirectional carbon/glass hybrid composites. Composites Part A: Applied Science and Manufacturing, 69, 279-287.

Thoppul, S. D., Finegan, J., \& Gibson, R. F. (2009). Mechanics of mechanically fastened joints in polymer-matrix composite structures-a review. Composites Science and Technology, 69(34), 301-329.

Tomiyama T, Nishizaki I. Applicability of fiber reinforced plastics to hydraulic gates. In Third International Conference on FRP Composites in Civil Engineering. 2006; 13-15).

Torabizadeh, M. A. (2013). Tensile, compressive and shear properties of unidirectional glass/epoxy composites subjected to mechanical loading and low temperature services.

Tripi JM. The applicability of advanced composite structural members, Doctoral dissertation, Massachusetts Institute of Technology. 1999.

Turvey, G. J., \& Cooper, C. (2004). Review of tests on bolted joints between pultruded GRP profiles. Proceedings of the Institution of Civil Engineers-Structures and Buildings, 157(3), 211-233.

Turvey, G. J., \& Zhang, Y. (2006). Shear failure strength of web-flange junctions in pultruded GRP WF profiles. Construction and Building Materials, 20(1-2), 81-89.

TWH. (2014): “An Economic Analysis of Transportation Infrastructure Investment", National Economic Council.

USACE. (2015): Report on “Technologies to Extend the Life of Existing Infrastructure." US Army Corps of Engineers. Navigation Infrastructure, Vol. 1. 
Van Den Einde L, Zhao L, Seible F. Use of FRP composites in civil structural applications. Construction and building materials 2003; 17.6:389-403.

Vijay, P. V., Soti, P. R., GangaRao, H. V., Lampo, R. G., \& Clarkson, J. D. (2016). Design and evaluation of an integrated FRP composite wicket gate. Composite Structures, 145, 149-161.

Williams JG. Developments in composite structures for the offshore oil industry. In Offshore Technology Conference. Offshore Technology Conference. 1991.

Wu, G., Wu, Z. S., Luo, Y. B., Sun, Z. Y., \& Hu, X. Q. (2010). Mechanical properties of steel-FRP composite bar under uniaxial and cyclic tensile loads. Journal of materials in civil engineering, 22(10), 1056-1066.

Yazdanbakhsh, A., \& Bank, L. C. (2014). A critical review of research on reuse of mechanically recycled FRP production and end-of-life waste for construction. Polymers, 6(6), 1810-1826.

Yu, H., Longana, M. L., Jalalvand, M., Wisnom, M. R., \& Potter, K. D. (2015). Pseudo-ductility in intermingled carbon/glass hybrid composites with highly aligned discontinuous fibres. Composites Part A: Applied Science and Manufacturing, 73, 35-44.

Zaman, A., Gutub, S. A., \& Wafa, M. A. (2013). A review on FRP composites applications and durability concerns in the construction sector. Journal of Reinforced Plastics and Composites, 32(24), 1966-1988.

Zellcomp. Available on http://www.zellcomp.com/highway_bridge_instal.html

Zorgdrager, A. Feasibility study on the application of fiber-reinforced polymers in large lock gates. PhD diss. TU Delft, Delft University of Technology, 2014.

Zweben, C. (1977). Tensile strength of hybrid composites. Journal of materials science, 12(7), 13251337. 


\section{Appendix A. GFRP-steel hybrid panel (wicket gate) supplementary data}

The computation of the center of gravity, composite moment of inertias and the weight of the GFRP-steel hybrid gate is presented here.

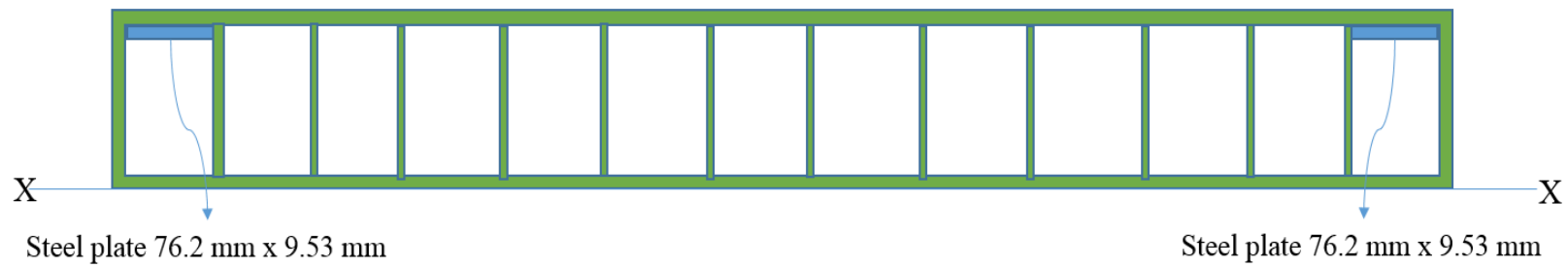

Figure A-1. Cross-section of GFRP-steel hybrid wicket gate

Table A-1. Center of gravity of the FRP wicket gate with two embedded steel plates

\begin{tabular}{|c|c|c|c|c|c|}
\hline \multicolumn{2}{|c|}{ Items } & $\begin{array}{l}\text { Dimension } \\
\text { mm (in) }\end{array}$ & $\begin{array}{l}\text { Areas } \\
\mathrm{mm}^{2}\end{array}$ & $\begin{array}{l}\text { Areas in terms } \\
\text { of GFRP }\end{array}$ & $\begin{array}{c}\text { CG from } x-x, \\
\text { mm (in) }\end{array}$ \\
\hline \multirow{2}{*}{$\begin{array}{l}\text { Two embedded } \\
\text { steel plates }\end{array}$} & width & $76.2(3)$ & \multirow{2}{*}{$\begin{array}{l}1452 \\
(2.25)\end{array}$} & \multirow{2}{*}{$11177.4(17.33)$} & \multirow{2}{*}{$198(7.79)$} \\
\hline & depth & $9.53(0.375)$ & & & \\
\hline \multirow{5}{*}{ GFRP section } & width & $1168(46)$ & \multirow{5}{*}{$\begin{array}{l}57484 \\
(89.1)\end{array}$} & \multirow{5}{*}{$57484(89.1)$} & \multirow{5}{*}{$108(4.25)$} \\
\hline & flange thickness & $13.28(0.523)$ & & & \\
\hline & no. of webs & 14 & & & \\
\hline & web thickness & $10.16(0.4)$ & & & \\
\hline & depth & $215.5(8.5)$ & & & \\
\hline \multicolumn{5}{|c|}{ Center of gravity of cellular FRP gate from bottom X-X (Fig. 14) } & $134.1(5.28)$ \\
\hline
\end{tabular}

Table A-2. Composite moment of inertia of FRP gate section with two embedded steel plates

\begin{tabular}{|c|c|c|}
\hline Components of a hybrid section & $\begin{array}{l}\text { Moment of Inertia } \\
\mathrm{mm}^{4}\left(\mathrm{in}^{4}\right)\end{array}$ & $\begin{array}{l}\text { Transformed moment of } \\
\text { inertia } \mathrm{mm}^{4}\left(\mathrm{in}^{4}\right)\end{array}$ \\
\hline Two embedded steel plates & $5.91 \times 10^{6}(14.2)$ & $42 \times 10^{6}(100.8)$ \\
\hline GFRP section & $439.1 \times 10^{6}(1055)$ & $439.1 \times 10^{6}(1055)$ \\
\hline \multicolumn{2}{|r|}{ Composite moment of inertia } & $481.1 \times 10^{6}(1155.8)$ \\
\hline
\end{tabular}

The weight of a hybrid section (wicket gate) was computed to be 3525 lbs., including embedded steel plates. 


\section{Appendix B. Non-destructive testing}

This chapter discusses the use of non-destructive methods such as tap hammer and ultrasound testing to detect the presence of debonding between outer GFRP and embedded steel plate.

\section{B.1. Introduction}

The bonding between the GFRP and embedded steel plates is very crucial for proper functioning of a GFRP-steel hybrid structure. The debonding of GFRP-steel interface in field-implemented hybrids, if detected using non-destructive testing, can be fixed using resin injection prior to their failure. It is crucial for maintenance and inspection of hybrid structures.

\section{B.2. Digital tap hammer}

The feasibility of using digital tap hammer developed by Boeing/Wichitech group in detecting the debond between GFRP and embedded steel plate was studied. The digital tap hammer consists of an accelerometer in the hammer head, which translates the force-time pulse at each tap into a voltage pulse, whose amplitude and pulse width is computed by the logical array and displays a number on the screen (Georgeson et al. 1996). During tapping, the readings on intact and delaminated portions of the hybrid section were very close which varied between 1100 to 1160 and showed no specific distinction. The thickness of an outer GFRP laminate of the test section measured quarter inch, and presence of debond was after the outer 0.25 " thick GFRP laminate. Typically, the use of tap hammer is effective in detecting delamination present in thin FRP sections less than $6 \mathrm{~mm}\left(0.25^{\prime \prime}\right)$. When the delamination is deeper, it falls outside the measurement range of this particular tap hammer device.

\section{B.3. Ultrasound Observation}

Pundit PL 200 ultrasonic testing device (Fig. B.1a) was used to detect debond in the GFRP-steel hybrids (Figs. B.1b and B.1c). The test device had a range of 0.1 to 7930 microseconds and a bandwidth of 20 to $500 \mathrm{kHz}$, with three different measurement modes where transmission time, distance between transducers, and pulse velocity can be obtained. Usually, the Pundit Lab ultrasonic tester is used to detect cracks, voids and other imperfections in concrete, and to determine and monitor the strength and deterioration of concrete.

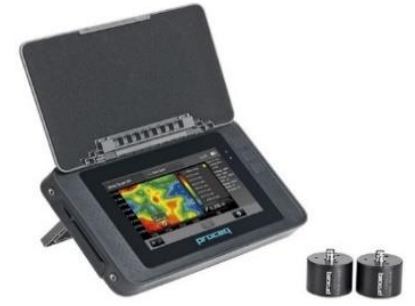

(a)

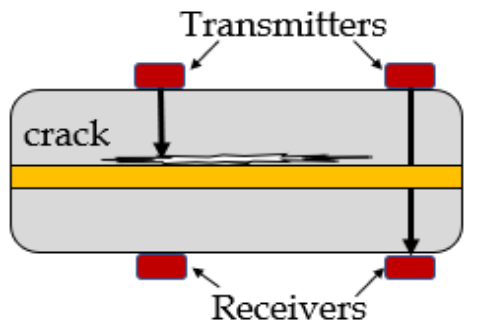

(b)

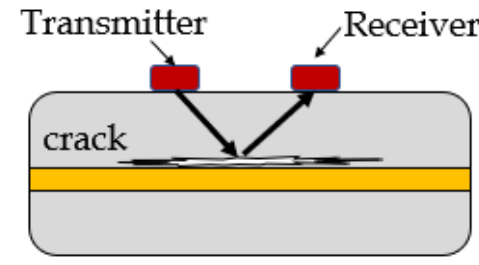

(c)

Figure B-1. (a) Pundit PL 200 ultrasonic pulse velocity test machine, (b) Direct transmission, (c) Indirect transmission of ultrasonic signals 


\section{B.3.1. Test principle}

During testing, a pulse of longitudinal vibrations is produced by an electro-acoustical transducer, which is held in contact with one surface of the material (Fig. B-1b). When the pulse is generated from the transmitting transducer, it undergoes multiple reflections at the boundaries of the different material phases within the test section. The longitudinal stress waves propagate through the material and the first wave to reach the receiving transducer are converted into an electrical signal. The ultrasonic pulse velocity testing can measure the time of flight, which is the time of arrival of an ultrasonic pulse from one transducer to another through a solid medium. Finally, the ultrasonic pulse velocity (UPV) is calculated by dividing the distance between the transducers by the time of arrival. During wave transmission, it is reflected in boundary of defects resulting in higher travel time. Thus, higher transmission time is obtained in poor quality material with more defects and lower transmission time in good quality material with fewer defects.

\section{B.3.2. Defect description and test procedure}

The GFRP-steel hybrid laminate was cut from the bottom flange of the failed hybrid box-beams. The laminate was $0.625^{\prime \prime}$ thick and consisted $0.125^{\prime \prime}$ thick steel plate inside the section. Some areas had a debond between steel plate and surrounding GFRP, whereas other areas were intact with a proper bond. The ultrasound observations were targeted in both good and bad areas for comparison purposes. The GFRP test surface was cleaned properly and a thin layer of petroleumbased couplant was applied on the surface to reduce air pockets between the transducer and material and also to achieve full contact of transducers with the material surface for transmitting maximum amount of energy. The transducers with two different frequencies of $54 \mathrm{kHz}$ and 500 $\mathrm{kHz}$ in both direct and indirect signal transmission were used (Figs. A-1b and A-1c).

\section{B.3.3. Direct transmission of waves}

The transducers when used in direct transmission of signals showed a clear difference between the debonded and intact portions (Fig. B-2). On the intact portion with no defect, both transducers showed the travel time of around 7.2 to $7.4 \mu$ s for the pulse as shown in the graphs between amplitude of signal detection over time (Figs. B-3 and B-4). On the sample with a debond, the signal was not detected with the use of $500 \mathrm{kHz}$ transducers (Fig. B-5). The energy loss (attenuation) for higher frequency waves is greater, resulting in lower penetration, especially in the presence of a defect. With the use of lower frequency transducers ( $54 \mathrm{kHz}$ ), the receiver was able to detect some signal, but the travel time of pulse was longer and measured $45 \mu$ s (Fig. B-6), suggesting a presence of a defect in the direct route of a wave.

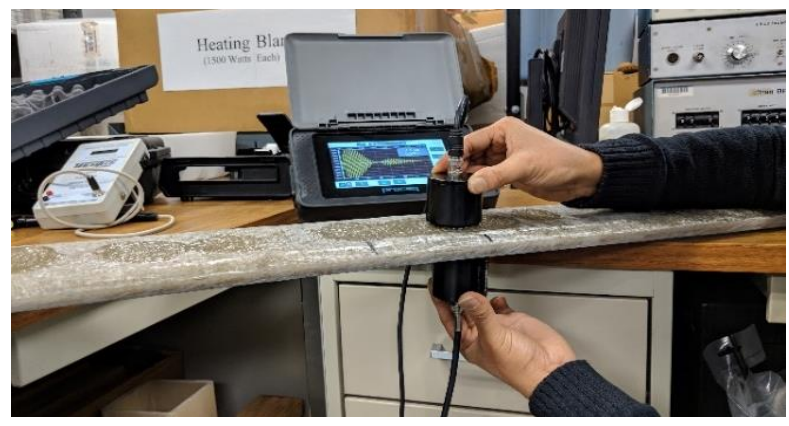

Figure B-2. Ultrasound testing on hybrid GFRP-steel laminate via direct transmission 


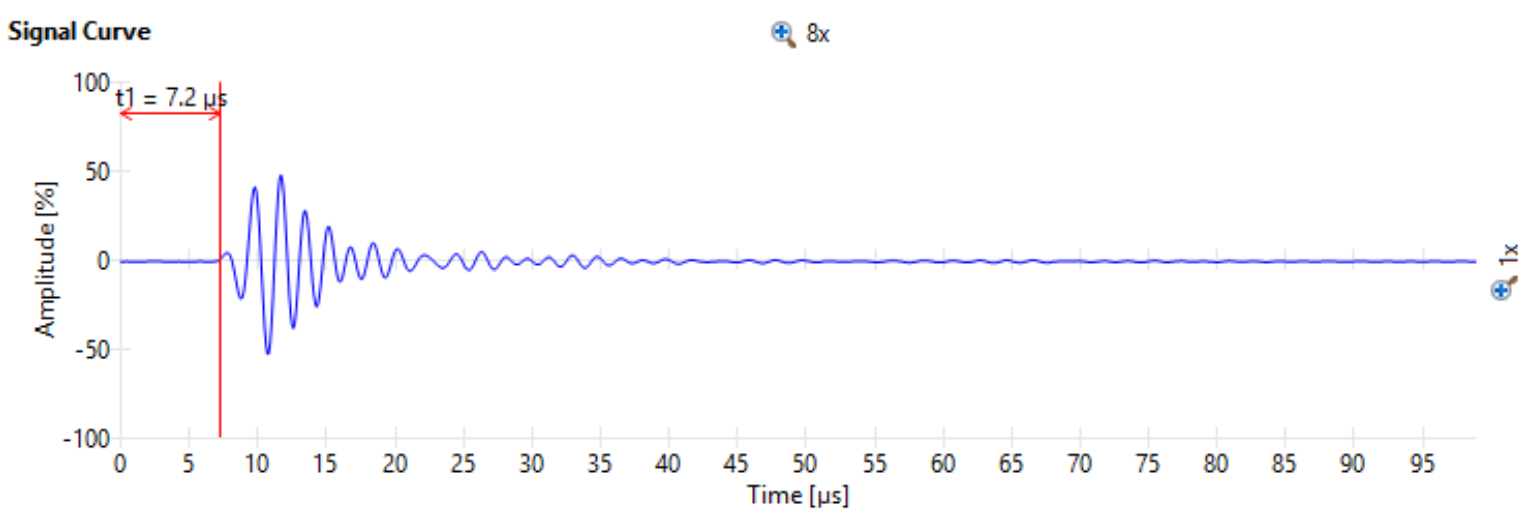

Figure B-3. Ultrasound waves with $500 \mathrm{kHz}$ transducers under direct transmission for GFRP laminate without any defect

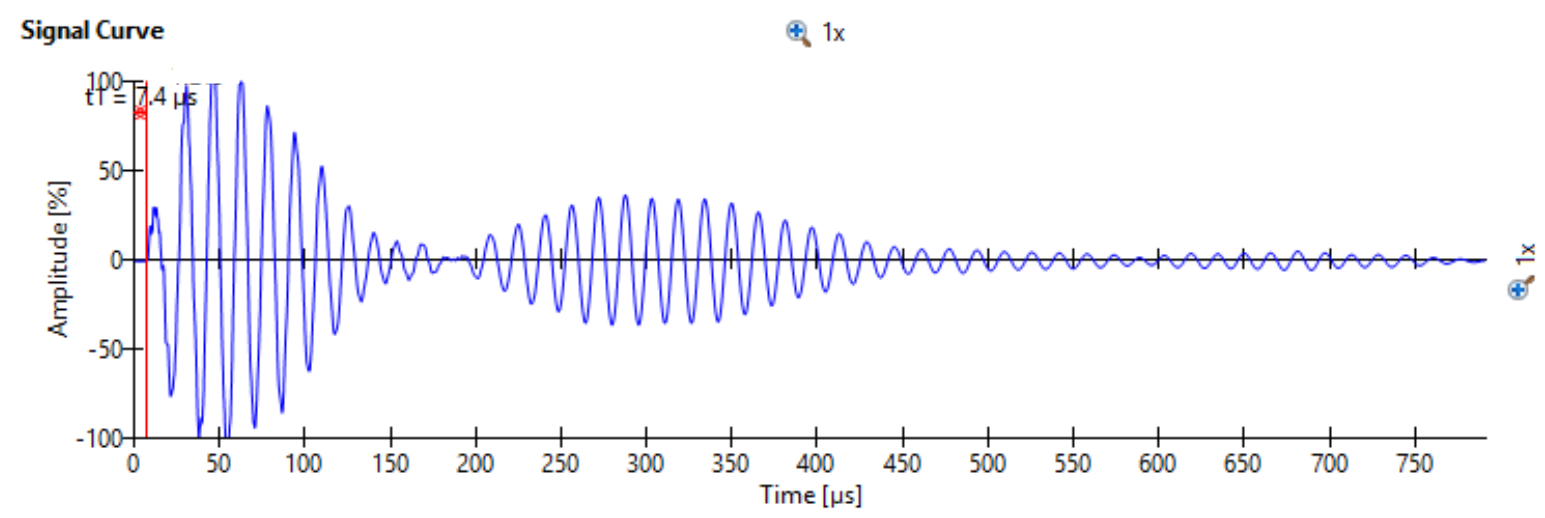

Figure B-4. Ultrasound waves with $54 \mathrm{kHz}$ transducers under direct transmission for GFRP laminate without any defect

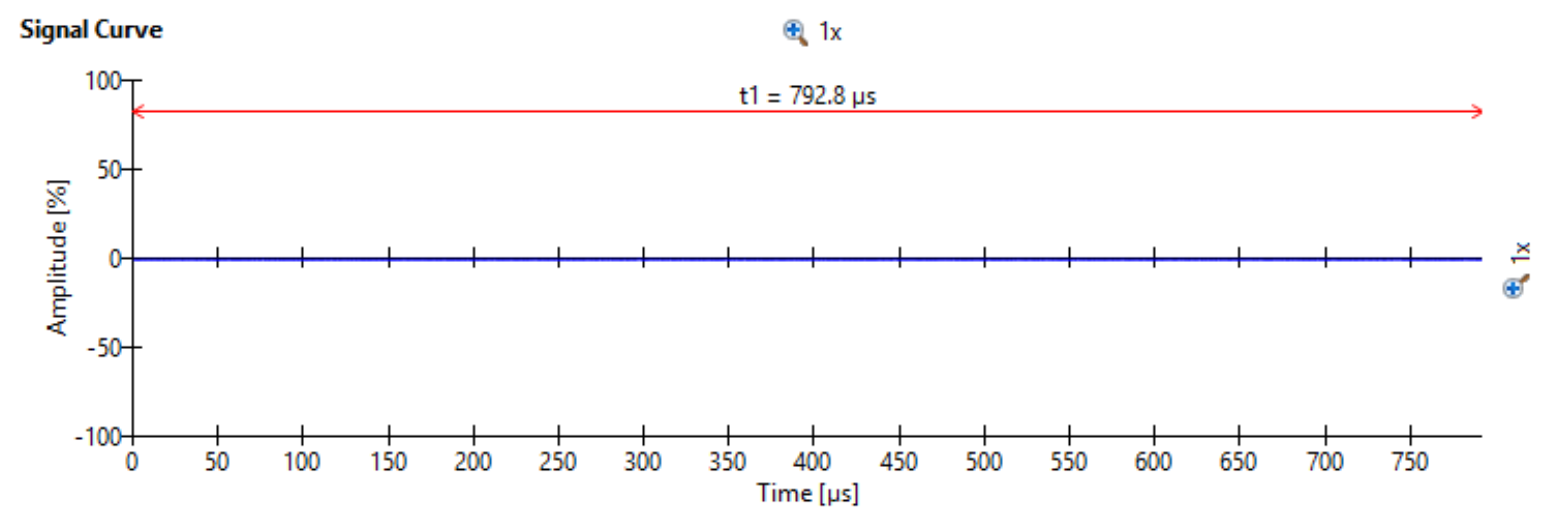

Figure B-5. Ultrasound waves with $500 \mathrm{kHz}$ transducers under direct transmission for GFRP laminate with a defect 


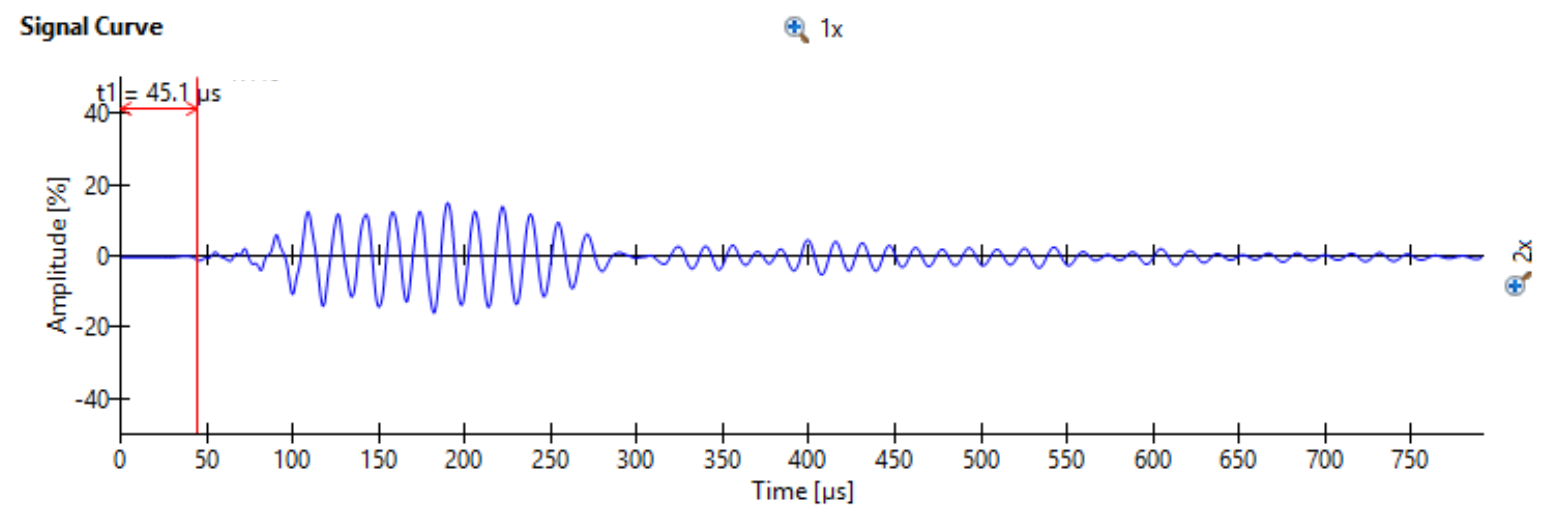

Figure B-6. Ultrasound waves with $54 \mathrm{kHz}$ transducers under direct transmission for GFRP laminate with a defect

\section{B.3.4. Indirect transmission of waves}

When transducers were used with indirect transmission (Fig. B-7), the time travel obtained for the pulse was slightly higher with both 500 and $54 \mathrm{kHz}$ transducers in good areas (Figs. B-8 and B-9) than the values obtained in the bad areas (Figs. B-10 and B-11). The presence of debond between outer GFRP laminate and embedded steel plate shifted the interface upward for the reflection of signals, resulting in lower travel distance and lower time travel for the signals.

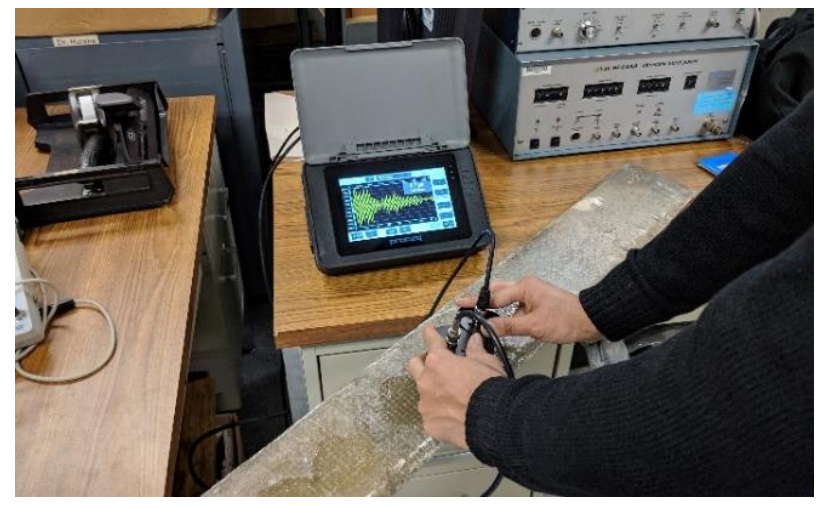

Figure B-7. Ultrasound testing on hybrid GFRP-steel laminate via indirect transmission

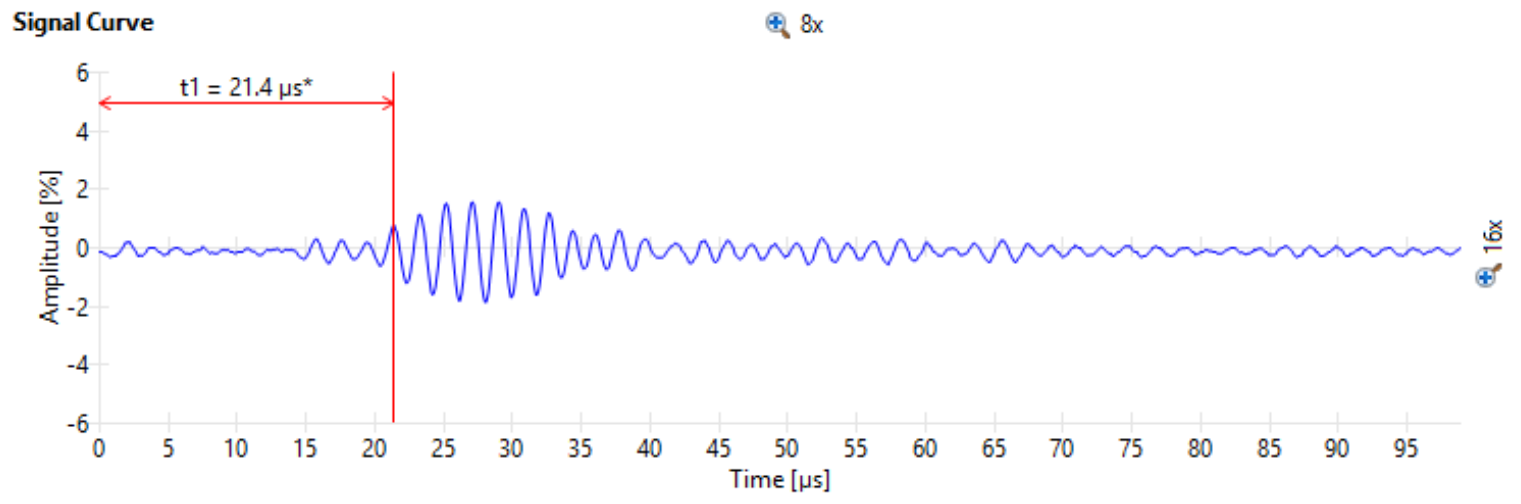

Figure B-8. Ultrasound waves with $500 \mathrm{kHz}$ transducers under indirect transmission for GFRP laminate without any defect 


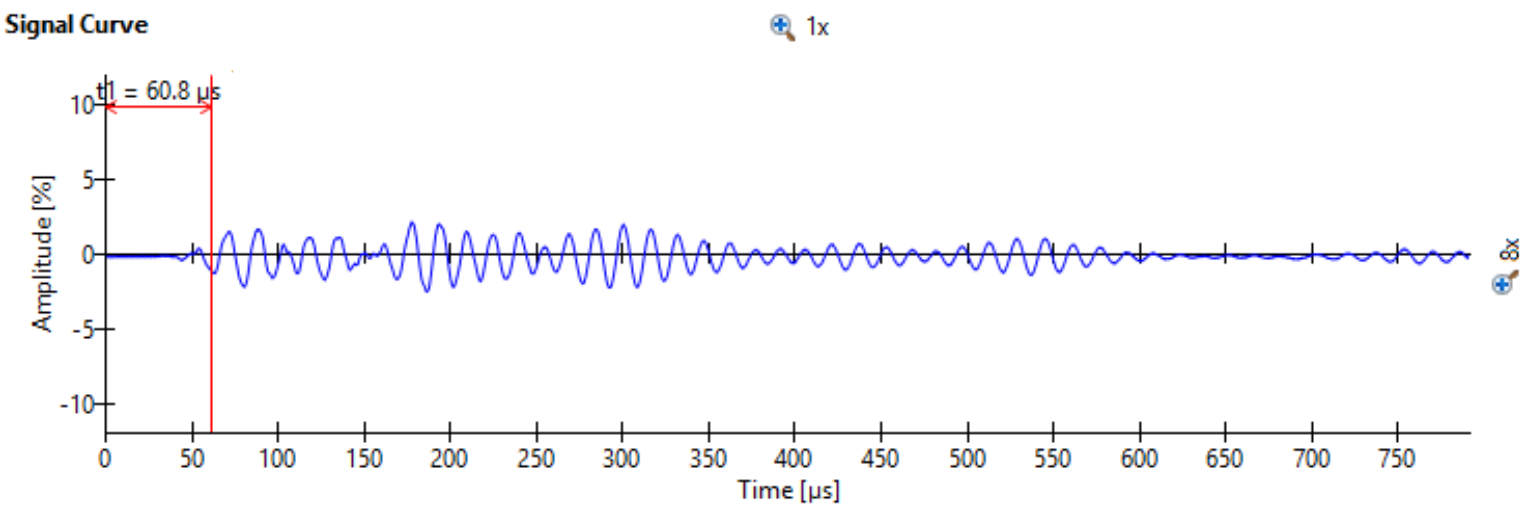

Figure B-9. Ultrasound waves with $54 \mathrm{kHz}$ transducers under indirect transmission for GFRP laminate without any defect

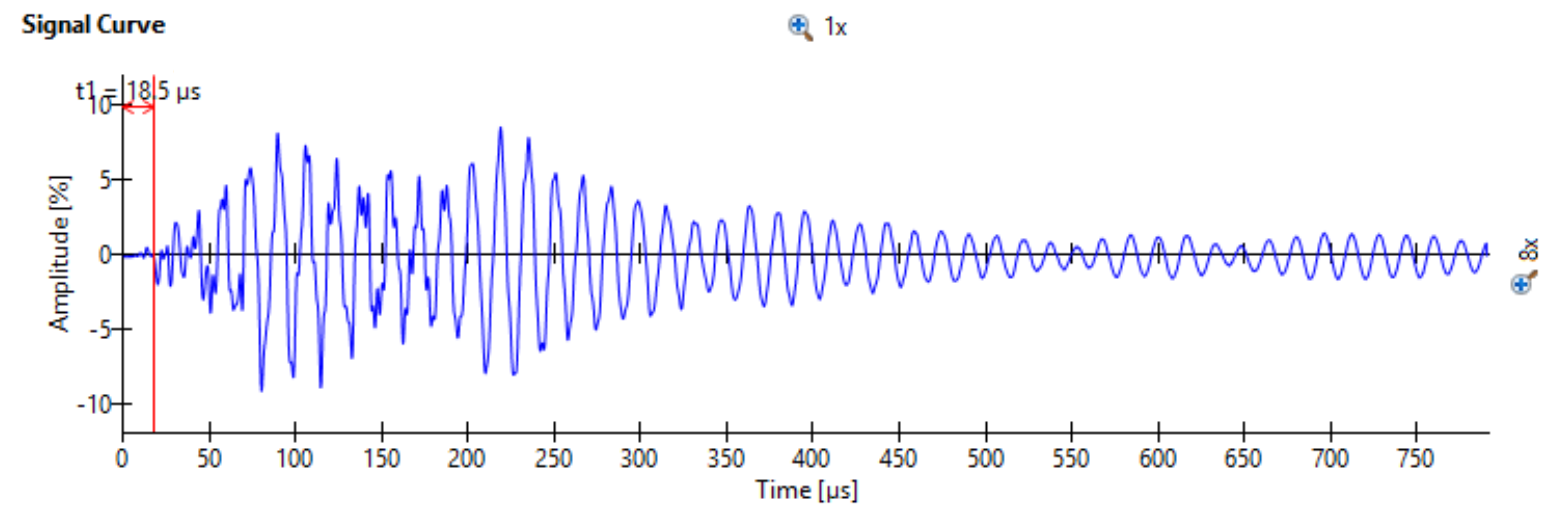

Figure B-10. Ultrasound waves with $500 \mathrm{kHz}$ transducers under indirect transmission for GFRP laminate with a defect

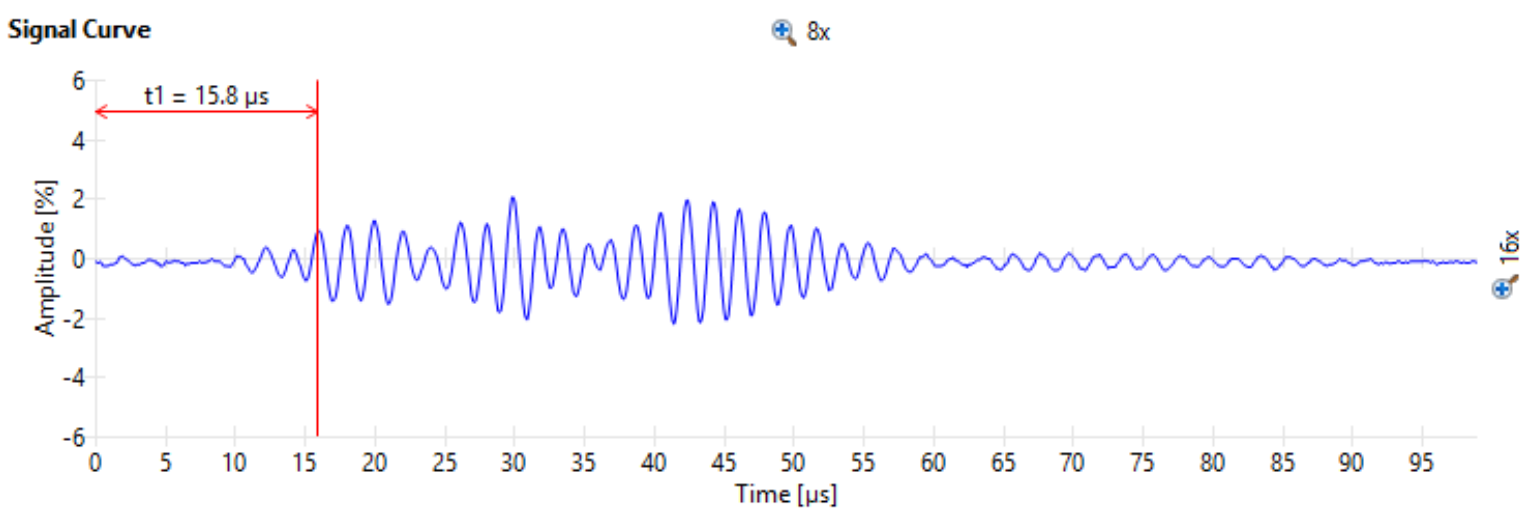

Figure B-11. Ultrasound waves with $54 \mathrm{kHz}$ transducers under indirect transmission for GFRP laminate with a defect 


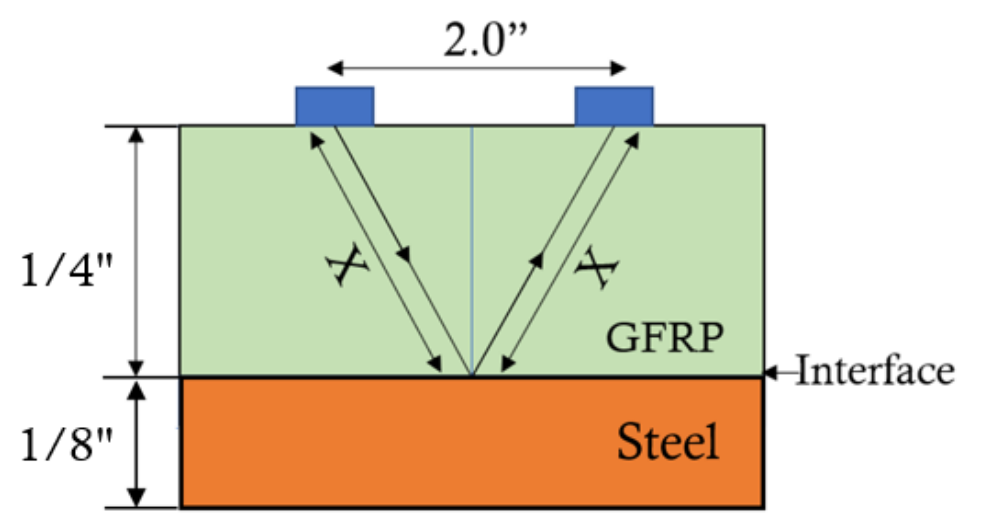

Figure B-12. Ultrasound wave travel under indirect transmission

Based on the geometry computation of the wave travel (Fig. B-12), the travel time for the distance $(2 \mathrm{X})$ is computed by assuming the wave velocity $(\mathrm{v})$ as obtained from the direct transmission of waves using Eqn. (B-1).

$$
\mathrm{v}=\frac{\mathrm{d}}{\mathrm{t}}=\frac{0.625^{\prime \prime}}{7.2 \mu \mathrm{s}}=86805.6 \mathrm{in} / \mathrm{s}
$$

During ultrasound testing, the distance between two transducers on the surface was 2 inches. Therefore, the theoretical time travel for the waves was found to be $23.7 \mu \mathrm{s}$, which is close to the readings obtained through the device as can be seen in Figs. B-8, B-10, and B-11. However, the velocity of the wave in the longitudinal direction of fibers in FRP composite is significantly higher than that in the perpendicular direction, where wave propagation is greatly influenced by the low-modulus resin. The diagonal velocity is in between the velocities in longitudinal and perpendicar directions, and therefore, the time travel obtained through tests were lower than the theoretical value. The travel time detected by $54 \mathrm{kHz}$ transducers in intact sample as shown in Fig. B-9 is erroneous data.

\section{B.4. Conclusions}

The following conclusions can be drawn from the study.

1. Use of ultrasound testing with direct (through) transmission of signals was able to distinguish the areas of debond with no detection of signal using higher frequency $(500 \mathrm{kHz})$ transducers, and with longer time travel using lower frequency $(54 \mathrm{kHz})$ transducers.

2. Use of ultrasound testing with indirect transmission of signals was able to distinguish the areas of debond with slightly lower travel time for the debonded areas than that obtained for the intact areas due to shift in the boundary of signal reflections using $500 \mathrm{kHz}$ transducers. However, the shift in the boundary of reflection is dependent on the defect thickness.

3. In the field, detection of debond in the direct (through) transmission can be difficult since it requires access to two opposite sides of the member. In such cases, the indirect transmission mode can be used. 


\section{Appendix C. Qualitative observations of GFRP-steel interface}

This chapter discusses the qualitative observations of the GFRP-steel interface regions of the hybrids using differential scanning calorimetry (DSC), optical microscopy, and Scanning Electron Microscopy (SEM).

\section{C.1. Introduction}

During manufacturing of the hybrid members via. vacuum infusion, there might be a possibility of resin rich areas and uncured resin at the interface (Fig. C-1), which can be susceptible to environmental factors that may initiate debonding, thus degree of resin cure was studied through differential scanning calorimetry (DSC) tests to confirm on the resin curing stage. Since, the weakest link in hybrid GFRP-steel bonded composites is the steel/GFRP interface region, where failure occurs mainly by interface debonding. The qualitative observation of the GFRP-steel interface was performed on the intact specimens and the specimens cut from the failed hybrid box-beams under optical microscopy. Further, the samples cut from the fatigued hybrid beam for 1 million cycles were observed through scanning electron microscopy to study the GFRP-steel bond integrity, to answer some of the questions such as, if sand-blasting on steel plates were adequate for obtaining good bonding within the GFRP and embedded steel plates.

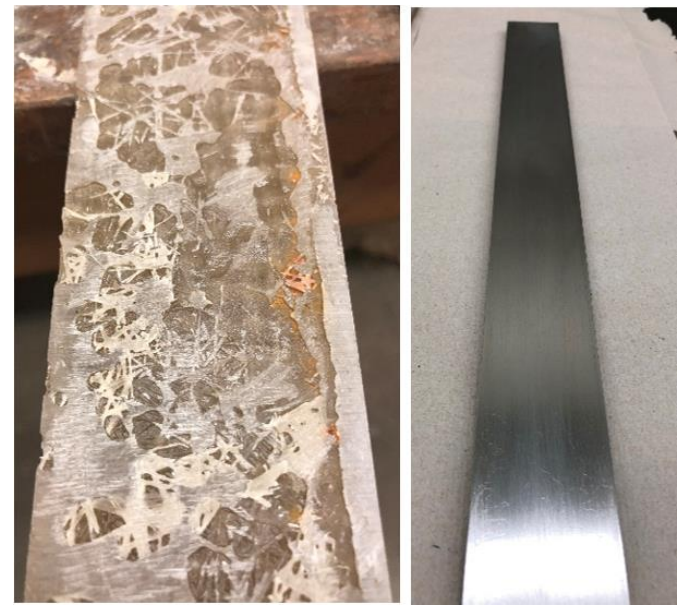

Figure C-1. Separated GFRP-steel bonded surfaces

\section{C.2. DSC tests}

Differential scanning calorimetry (DSC) tests were performed on specimens cut from hybrid boxbeams to evaluate the glass transition temperature and degree of resin cure (Fig. 11-13). DSC is a thermal analysis technique that measures the temperatures and heat flows associated with transitions in materials as a function of time and temperature. Degree of cure and glass transition temperature of a composite provide an indication on the thermal and oxidative stability of the resin system. A highly under cured specimen poses long-term durability problems and DSC test is a good way of looking at a degree of resin cure within the sample. 
Two tests were conducted using DSC Q Series Model Q100, TA Instruments Inc (Fig.C-2). Two samples were cut from the GFRP-steel plate interface and from the outer layers of GFRP section. During DSC testing, heat-vs-temp data were recorded for each sample which was first heated to $250{ }^{\circ} \mathrm{C}$ and then cooled down to $10^{\circ} \mathrm{C}$ and again heated to $250^{\circ} \mathrm{C}$. Each sample was subjected to two cycles of heating and cooling.

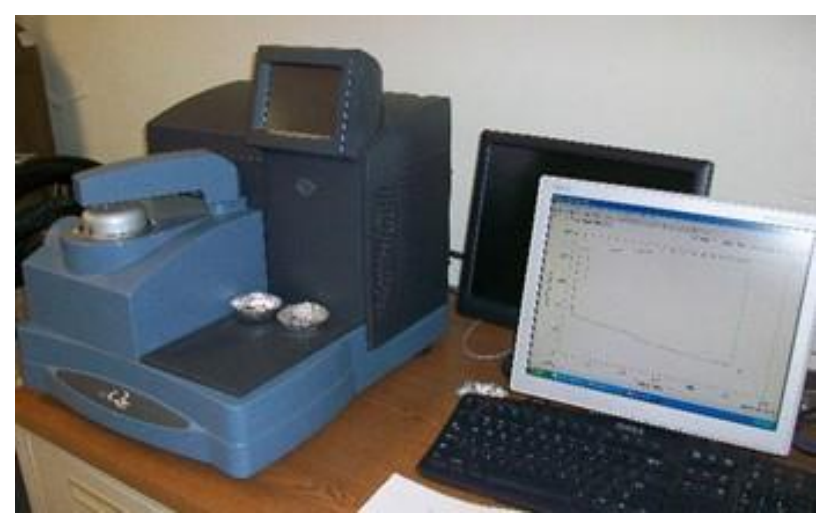

Figure C-2. DSC test equipment

Samples taken from the surface layers of the beam showed an initial glass transition temperature of around $108.9^{\circ} \mathrm{C}$ (Fig. C-3). Samples exhibited noticeable exothermic process while heating, indicating that the resin in not cured fully. In second round of scan, a glass transition temperature was observed at around $120.5^{\circ} \mathrm{C}$ (Fig. C-4).

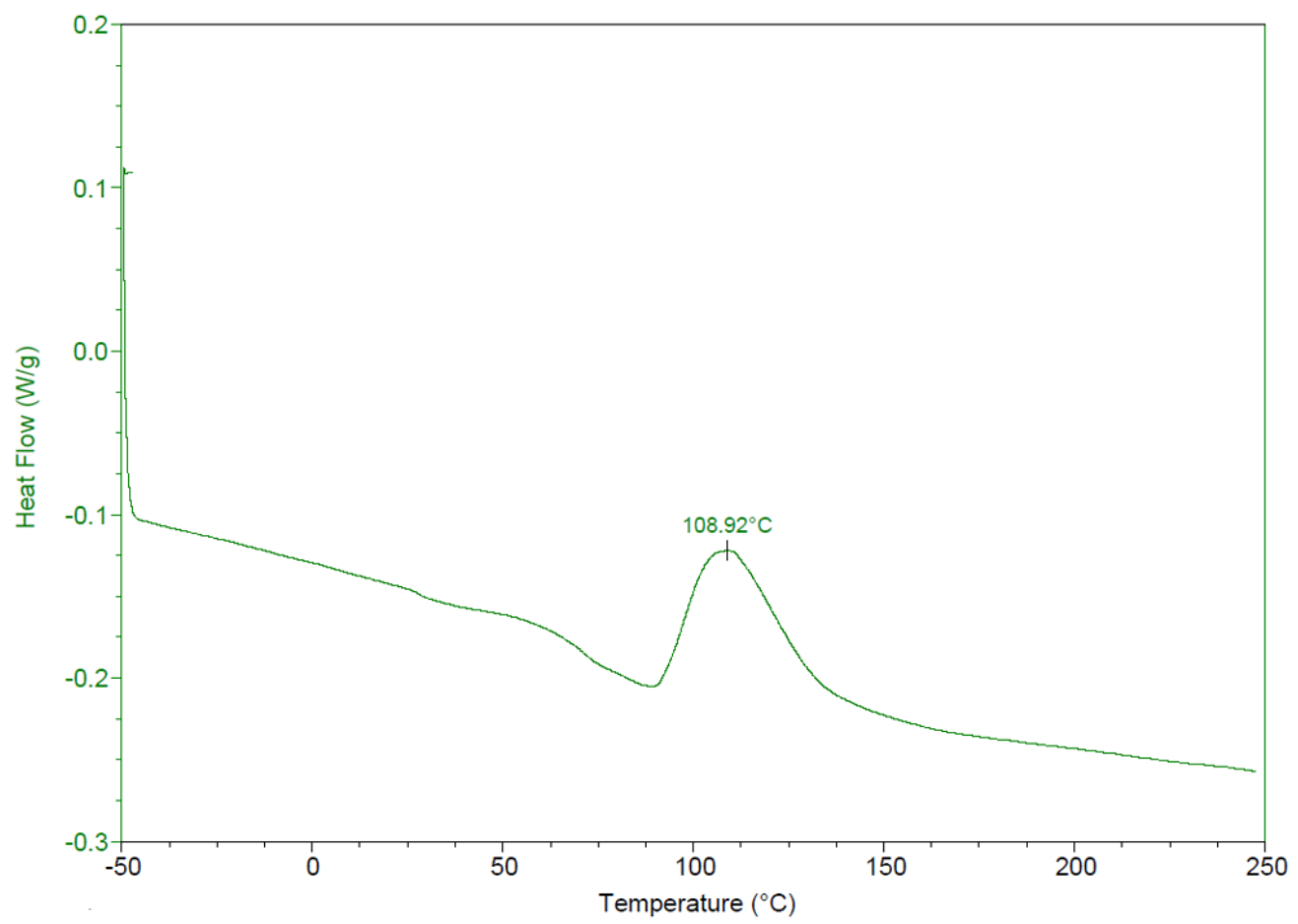

Figure C-3. DSC curve of a sample from surface GFRP layers (first heating cycle) 


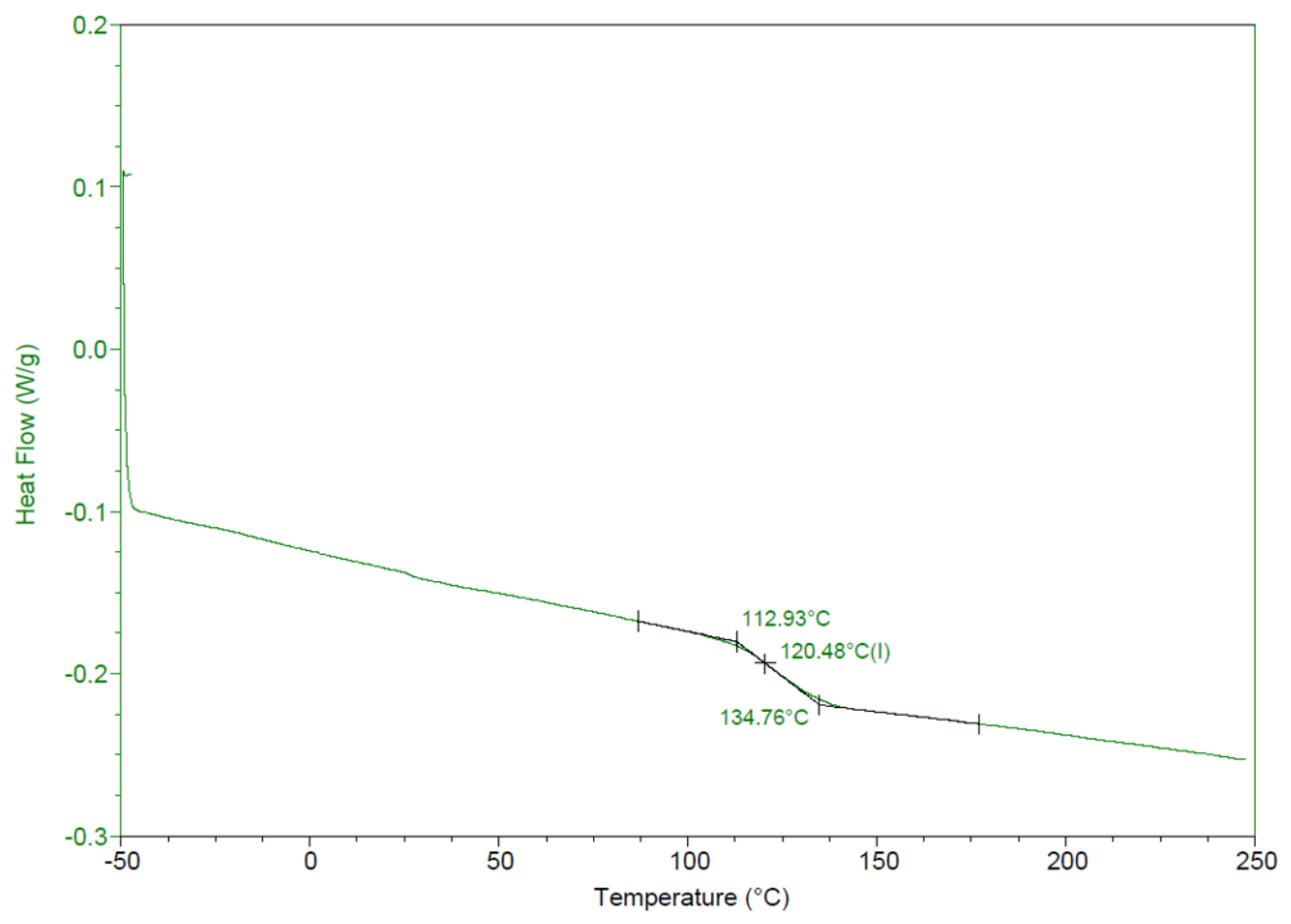

Figure C-4. DSC curve of a sample from surface GFRP layers (second heating cycle)

For samples taken from the GFRP-steel interface regions, an initial glass transition temperature of $117.2^{\circ} \mathrm{C}$ was observed along with a small exothermic process between $100-140{ }^{\circ} \mathrm{C}$, indicating a small amount of heat release from curing reaction of the uncured resin (Fig. C-5). In the second round of scan, a glass transition temperature was observed at around $128.7^{\circ} \mathrm{C}$ (Fig. C-6).

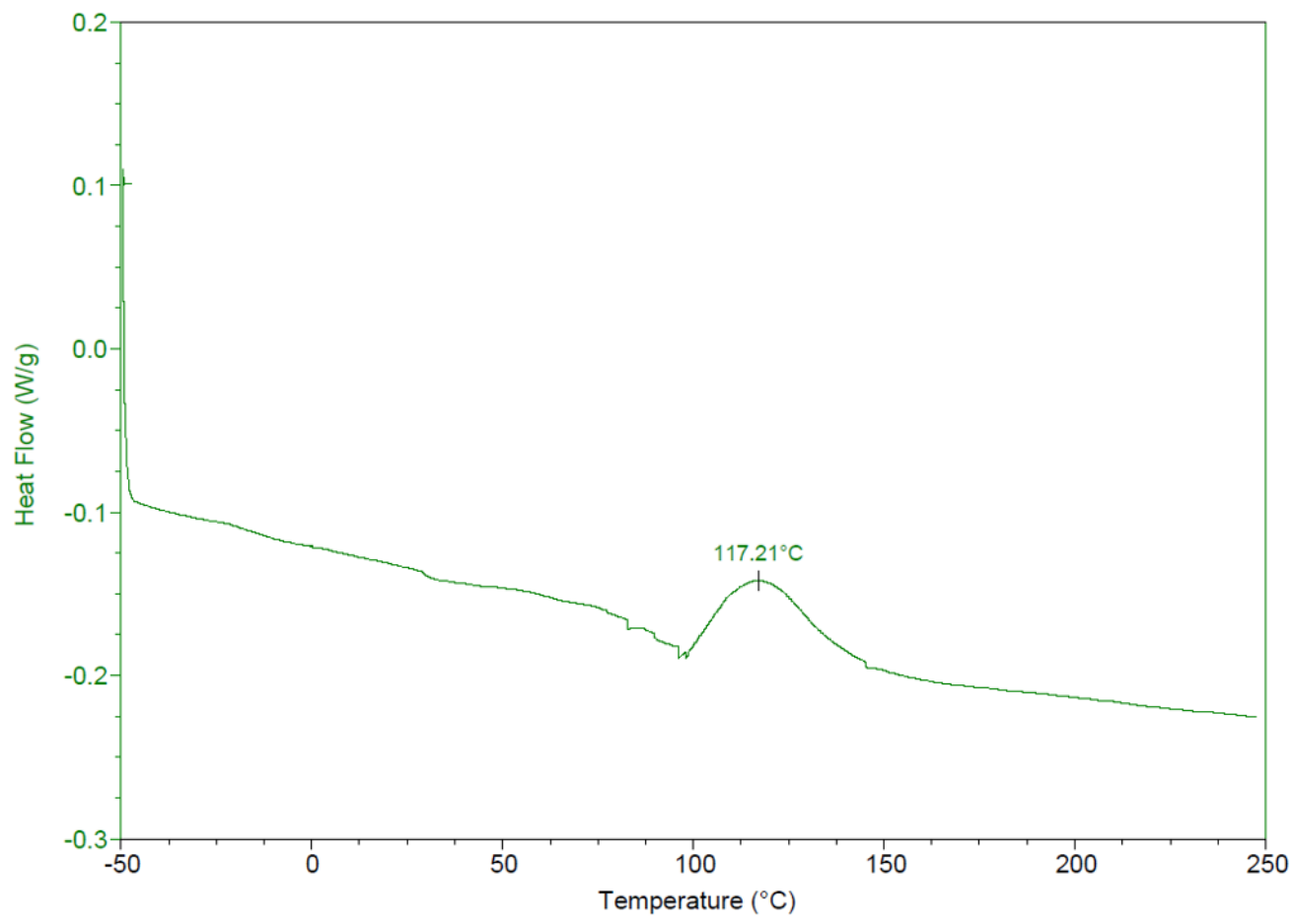

Figure C-5. DSC curve of a sample from GFRP-steel interface (first heating cycle) 


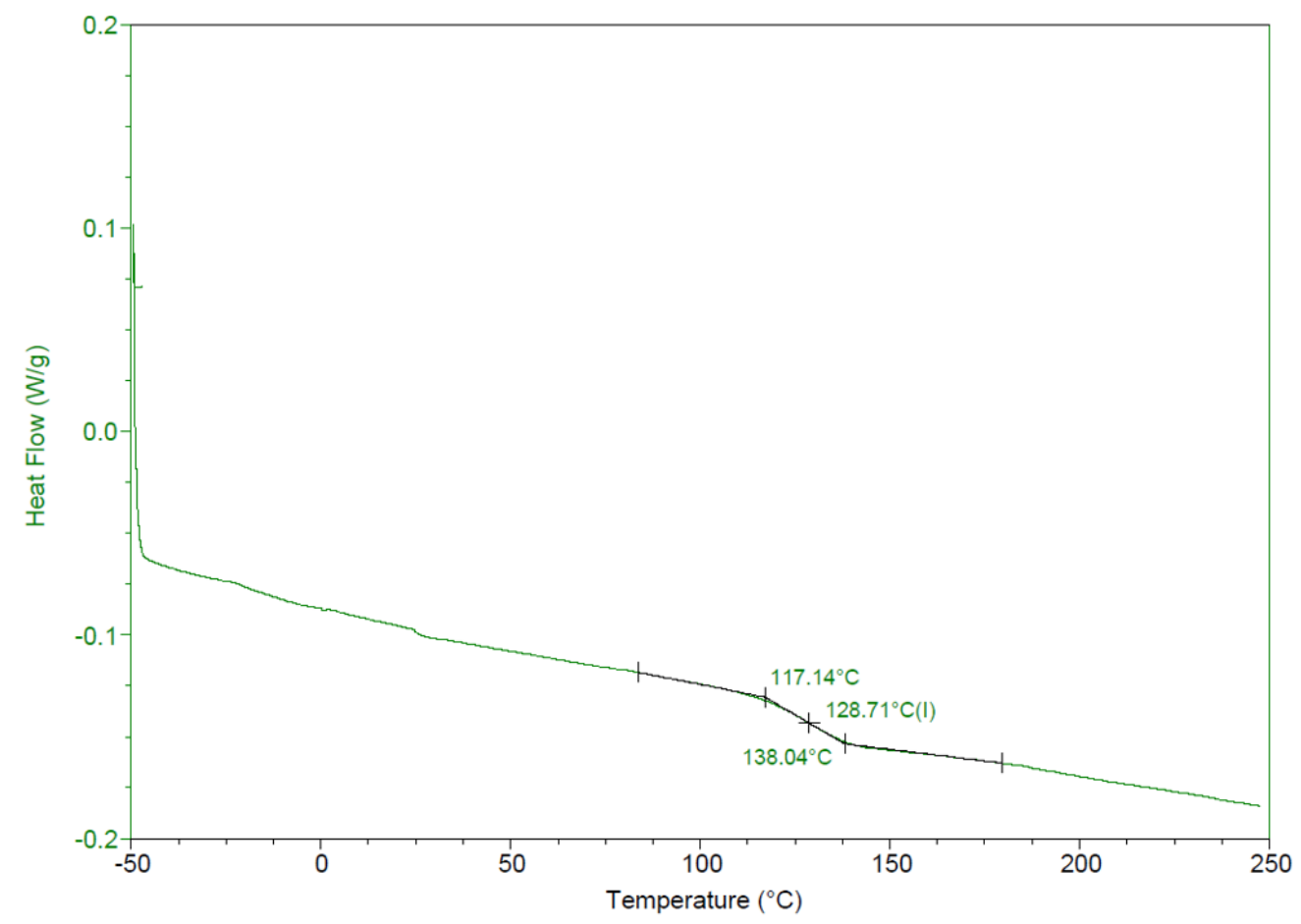

Figure C-6. DSC curve of a sample from GFRP-steel interface (second heating cycle)

The results from two different samples indicate that the resin from the GFRP-steel interface was better cured during the manufacturing process possibly due to more heat absorbed or drawn by the steel plate and dissipating the heat to the surrounding resin. The samples from surface layers were found to have slightly less cured resin, possibly due to distribution of more heat towards the central steel plates. However, the results showed that the embedment of steel plates does not adversely affect the curing of resin.

\section{C.3. Optical microscopic observation}

The samples cut from the intact and failure suspected regions of GFRP-steel hybrid beams failed under static loads as discussed in Chapter 7, were looked under optical microscope to observe the bond integrity between GFRP and steel plates. The intact GFRP-steel hybrid regions did not show any debonding or cracking (Fig. C-7a). In failure suspected regions, it was anticipated that the failure would be in the bond between GFRP and steel plates and the optical microscopy clearly showed the damages in the GFRP-steel interface (Figs. C-7b, C-8a). In addition, a crack originating from the interface region was observed in one of the samples, which can be attributed to the presence of higher stress concentrations near the corners of the box-beam (Fig. C-8b). 


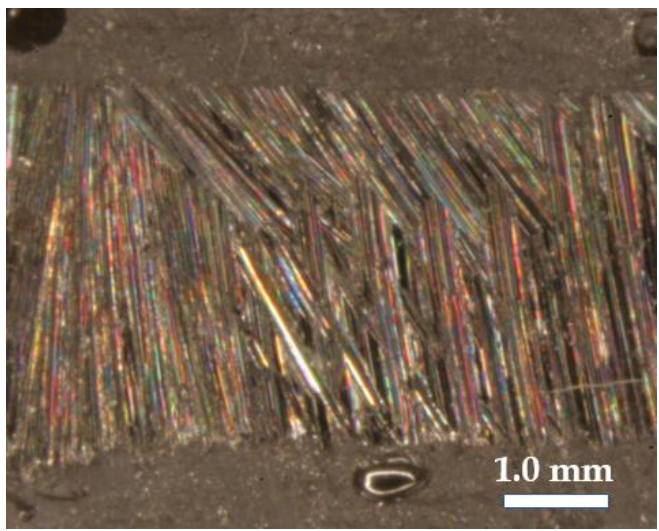

(a)

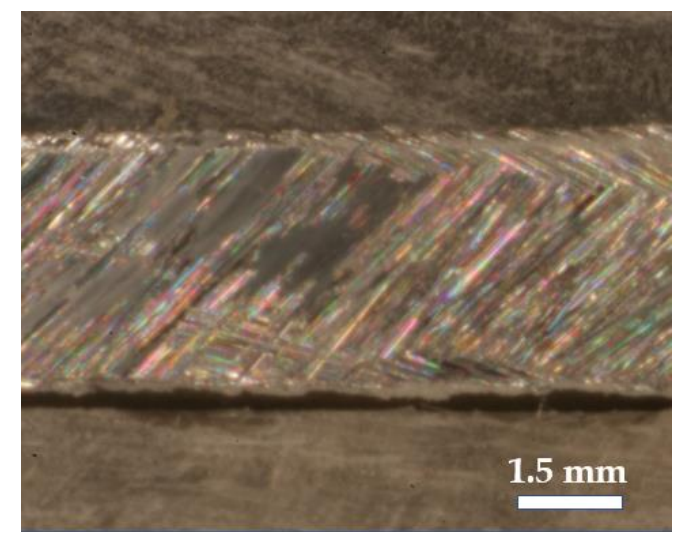

(b)

Figure C-7. GFRP-steel interfacial bond failures: (a) sample-1, (b) sample-2

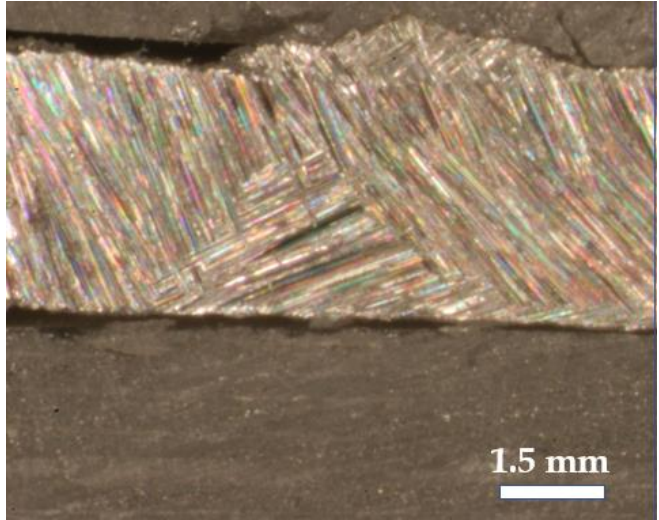

(a)

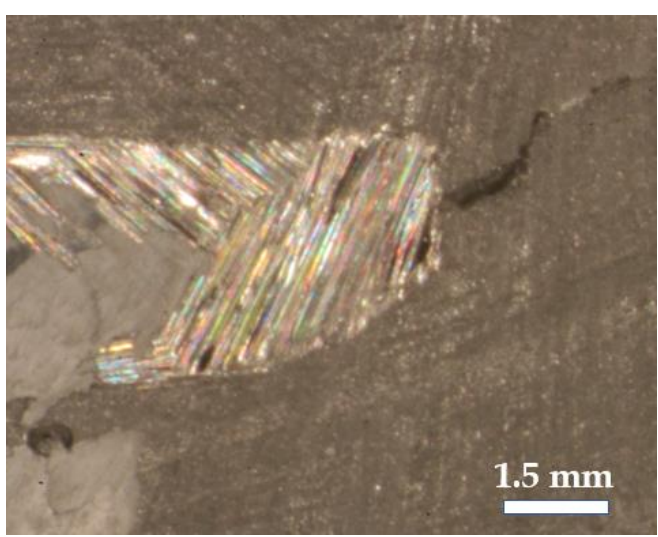

(b)

Figure C-8. (a) Crack observed at the ends of the steel plate, (b) intact bond

\section{C.4. SEM observations}

The bond integrity between GFRP and embedded steel plates of the hybrid box-beam (HFB) that went through 2 million cycles of fatigue with higher load range equivalent to $50 \%$ of the static failure load were looked at using scanning electron microcopy (SEM). The hybrid beams in service undergo repetitive loading and unloading cycles for example in bridge, and it is very necessary for these beams to maintain the bond between the GFRP and embedded steel plates during their service life. The GFRP-steel interface as well as bond surfaces of GFRP were observed and the findings are discussed within this section.

The interface region between GFRP and steel plates were found to be filled with resin rich areas (Figs. C-9a, C-10a). The formation of this resin rich adhesive layer between the GFRP and steel plate is crucial in establishing good bond, as was found from other studies (Ostapiuk et al. 2014, Gan, 2009). The interface regions were also filled with a lot of debris, probably deposited on the surface due to abrasive cutting of the blade during sample preparation (Fig. C-9b). However, the SEM images did not reveal any interface cracks and debonding suggesting the fatigue loaded hybrid section still maintain the bond integrity between GFRP and embedded steel plates. 


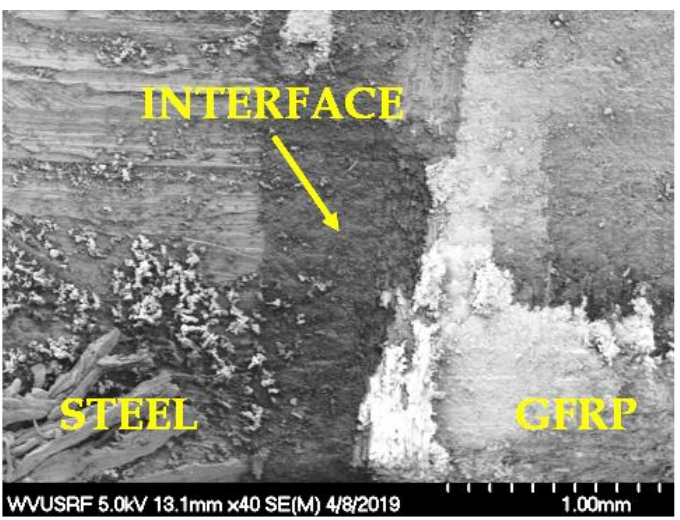

(a)

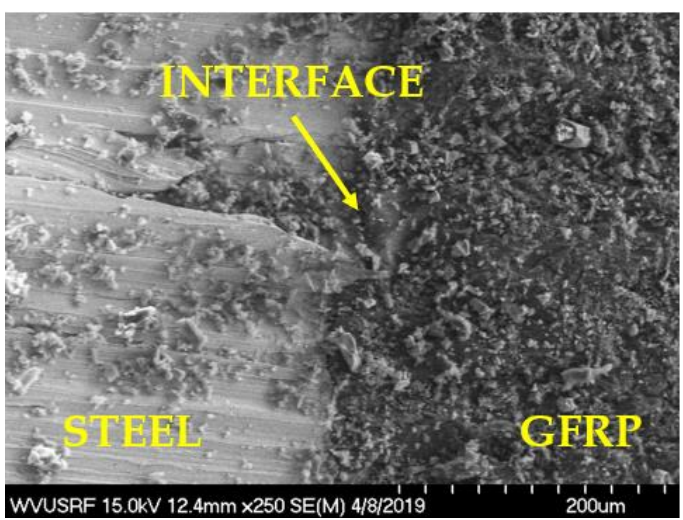

(b)

Figure C-9. GFRP-steel interface under SEM, (a) resin-rich interface, (b) surface with debris

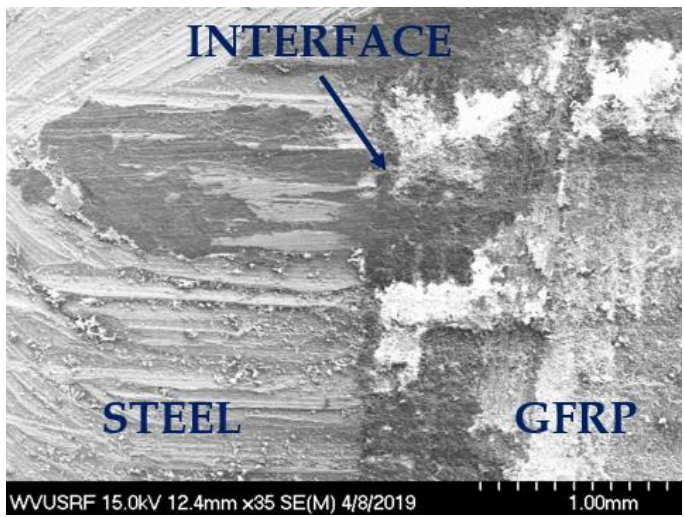

(a)

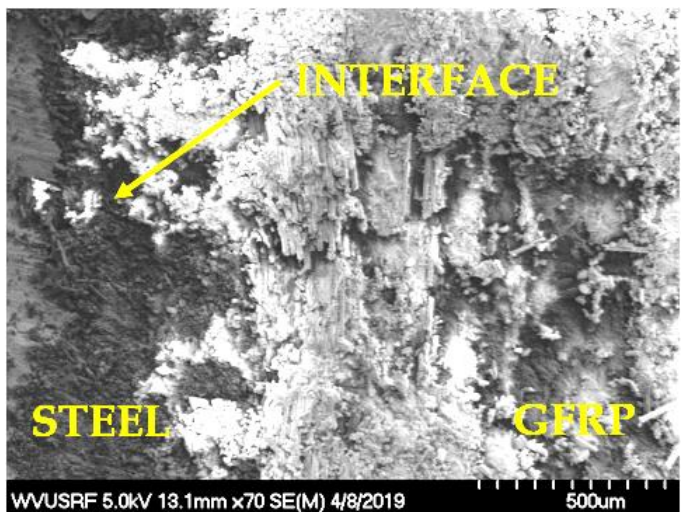

(b)

Figure C-10. GFRP-steel interface under SEM, (a) sample-1, (b) sample-2

The bond surfaces of GFRP were also observed under SEM. The images revealed the formation of depressions caused by the chopped fiber strands (Fig. C-11), The low-density glass fiber strands probably helps in strengthening the resin layer to transfer stresses within the interface. However, few defects such as air voids, resin pockets and resin scaling were also detected in the interface regions (Figs. 11-23 and 11-24).

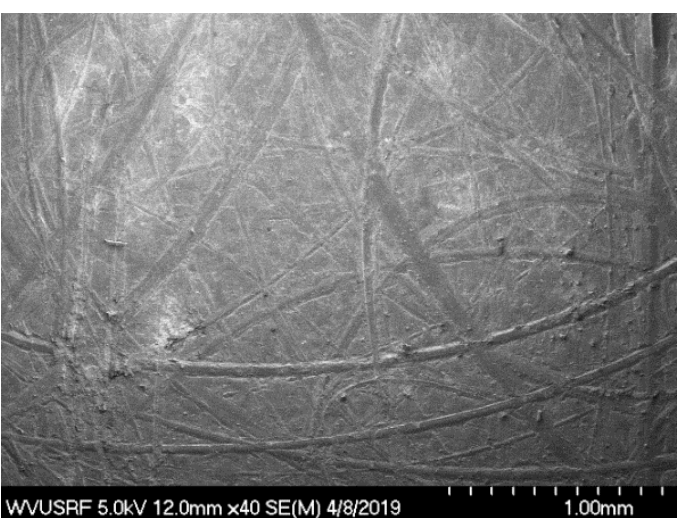

(a)

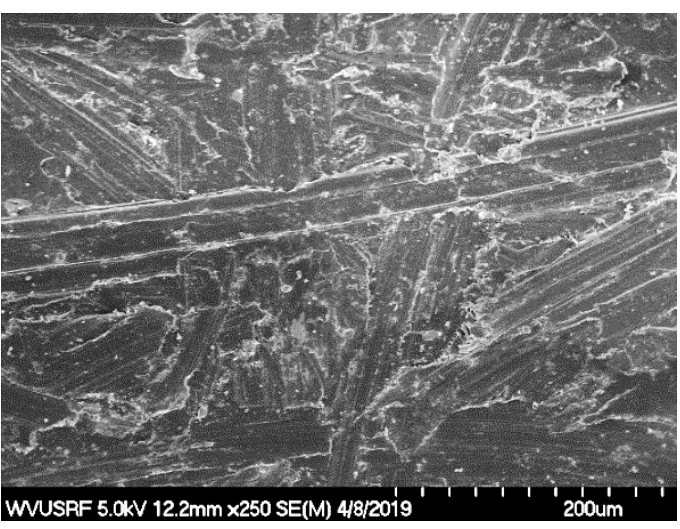

(b)

Figure C-11. GFRP surface under SEM: (a) chopped strands, (b) depression marks from fibers 


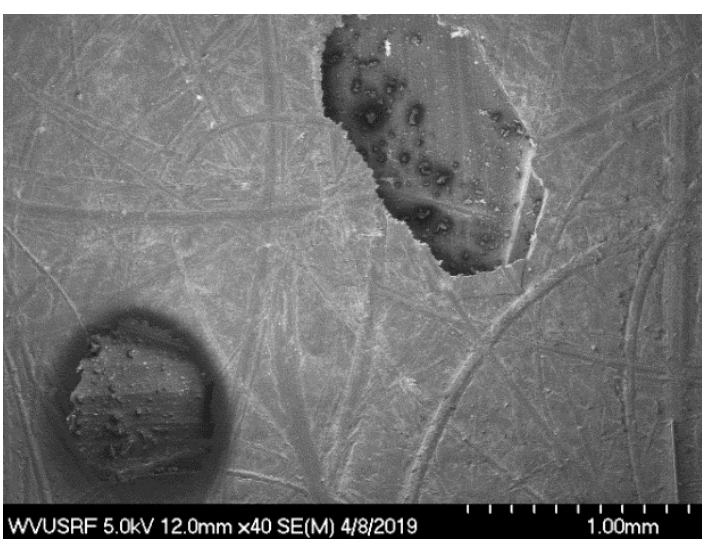

(a)

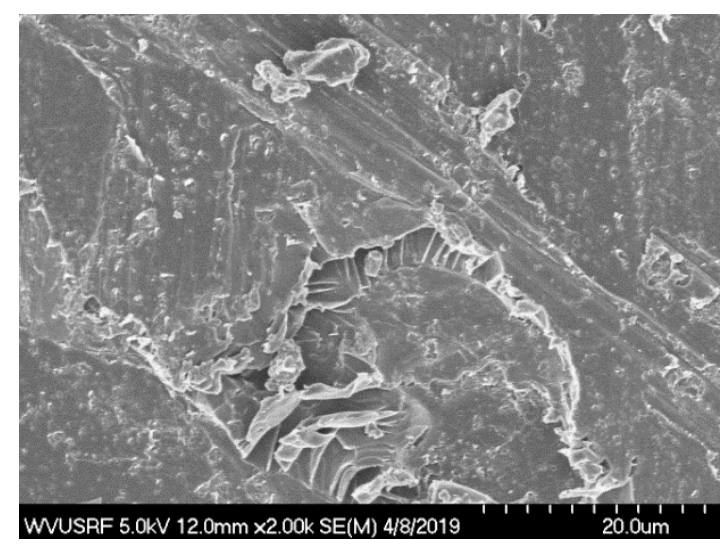

(b)

Figure C-12. GFRP surface under SEM: (a) air voids, (b) resin scaling

\section{C.5. Conclusions}

The following conclusions can be drawn from the study.

1. The samples cut from the GFRP-steel hybrid beams failed under static loads, were observed under optical microscopy, which clearly revealed the separation of bond between GFRP and embedded steel plates, suggesting the bond separates during failure of the beam.

2. The SEM images of the GFRP-steel interface samples, cut from the hybrid beams fatigued for 2 million cycles, did not reveal any debonding between GFRP and embedded steel plates, suggesting that the bond integrity between GFRP and steel plates in the hybrid beam is maintained even after 2 million cycles of fatigue loads.

3. The minimum surface preparation of steel plates (medium-grit sanding) before embedding them within the GFRP section helped in creating a good bond between GFRP and steel plates.

4. The GFRP-steel interface regions were found to have a resin rich layer with few original defects such as air-bubbles (voids) and resin scales, which could be minimized during manufacturing processes through selective vacuum application. 


\section{Appendix D. \\ Cost comparison}

The manufacturing cost of the multi-cellular panel and box-beams were obtained from the respective manufacturers. Based on the manufacturer, the cost of labor for both non-hybrid and hybrid sections were same. The cost of surface preparation of steel plates and insertion into the mold was negligible. The additional cost for hybrid sections were the addition of the cost of the steel plates used within the section. The manufacturing cost of the GFRP and hybrid sections in terms of their stiffness values are computed and are shown in Tables D-1 and D-2, respectively.

Table D-1. Cost comparison between GFRP and hybrid multi-cellular panel (Chapter-5)

\begin{tabular}{|c|c|c|c|c|}
\hline Section & Dimension & $\begin{array}{c}\text { Manufacturing } \\
\text { Cost }\end{array}$ & $\begin{array}{c}\text { Bending Stiffness } \\
\left(\text { kip-in }{ }^{2}\right.\end{array}$ & Cost/stiffness \\
\hline GFRP & $46^{\prime \prime} \times 8.5^{\prime \prime} \times 16.5^{\prime}$ & $\$ 11,000$ & $2.73 \times 10^{6}$ & 0.40 cents \\
\hline Hybrid & $46^{\prime \prime} \times 8.5^{\prime \prime} \times 16.5^{\prime}$ & $\$ 11,300$ & $4.55 \times 10^{6}$ & 0.25 cents \\
\hline
\end{tabular}

Table D-2. Cost comparison between GFRP and hybrid box-beams (Chapter-7)

\begin{tabular}{|c|c|c|c|c|}
\hline Section & Dimension & $\begin{array}{c}\text { Manufacturing } \\
\text { Cost }\end{array}$ & $\begin{array}{c}\text { Bending Stiffness } \\
\left(\text { kip-in }{ }^{2}\right.\end{array}$ & Cost/stiffness \\
\hline CB & 6 6" $\times 6 " \times 1 / 2^{\prime \prime}$ & $\$ 1,500$ & $0.98 \times 10^{5}$ & 1.53 cents \\
\hline HWB & $6 " \times 6 " \times 5 / 8^{\prime \prime}$ & $\$ 1,530$ & $1.27 \times 10^{5}$ & 1.20 cents \\
\hline HFB & $6 " \times 6 " \times 5 / 8^{\prime \prime}$ & $\$ 1,530$ & $3.14 \times 10^{5}$ & 0.49 cents \\
\hline HAB & $6 " \times 6 " \times 5 / 8^{\prime \prime}$ & $\$ 1,560$ & $3.63 \times 10^{5}$ & 0.43 cents \\
\hline
\end{tabular}

Note: These representative costs could reduce further for mass-manufactured members and may depend on the specific manufacturing techniques and design approaches.

\section{D.1. GFRP-steel panel (wicket gate)}

The cost of the GFRP-steel hybrid panel (wicket gate) was $\$ 11,300$. The cost per unit stiffness of the GFRP-steel hybrid panel was found to be 37.5\% cheaper than the non-hybrid panel. An equivalent stiffness GFRP section that could provide similar bending stiffness that of the hybrid would cost $\$ 18,200$, which is $61 \%$ more than that of hybrid panel.

\section{D.2. GFRP-steel box-beams}

The cost of hybrid box-beams (HWB, HFB, HAB) were found to be $21.6 \%, 68.0 \%$, and $71.9 \%$ cheaper than the non-hybrid box-beam, respectively. An equivalent stiffness GFRP box-beam (CB) that could provide similar bending stiffness that of GFRP-steel hybrid box-beam (HAB) would cost $\$ 5,500$, which is $252 \%$ more than that of hybrid beam.

\section{D.3. Conclusions}

GFRP-steel hybrids can satisfy added serviceability limits at a lower cost in comparison to nonhybrid GFRP section. Thus, hybridization provides cost-effective performance. 